\title{
ANÁLISIS PALEOAMBIENTAL Y DIAGENÉTICO DE LA FORMACIÓN CALABOZO (JURÁSICO MEDIO A SUPERIOR) Y SU LÍMITE BASAL CON LA FORMACIÓN LAJAS (JURÁSICO MEDIO) EN EL SECTOR NOROCCIDENTAL DE LA CUENCA NEUQUINA, MENDOZA, ARGENTINA
}

Tesis Doctoral 2019

Licenciada Ailen Borya

Directores:

Dr. Sergio Daniel Matheos Dra. María Sol Raigemborn

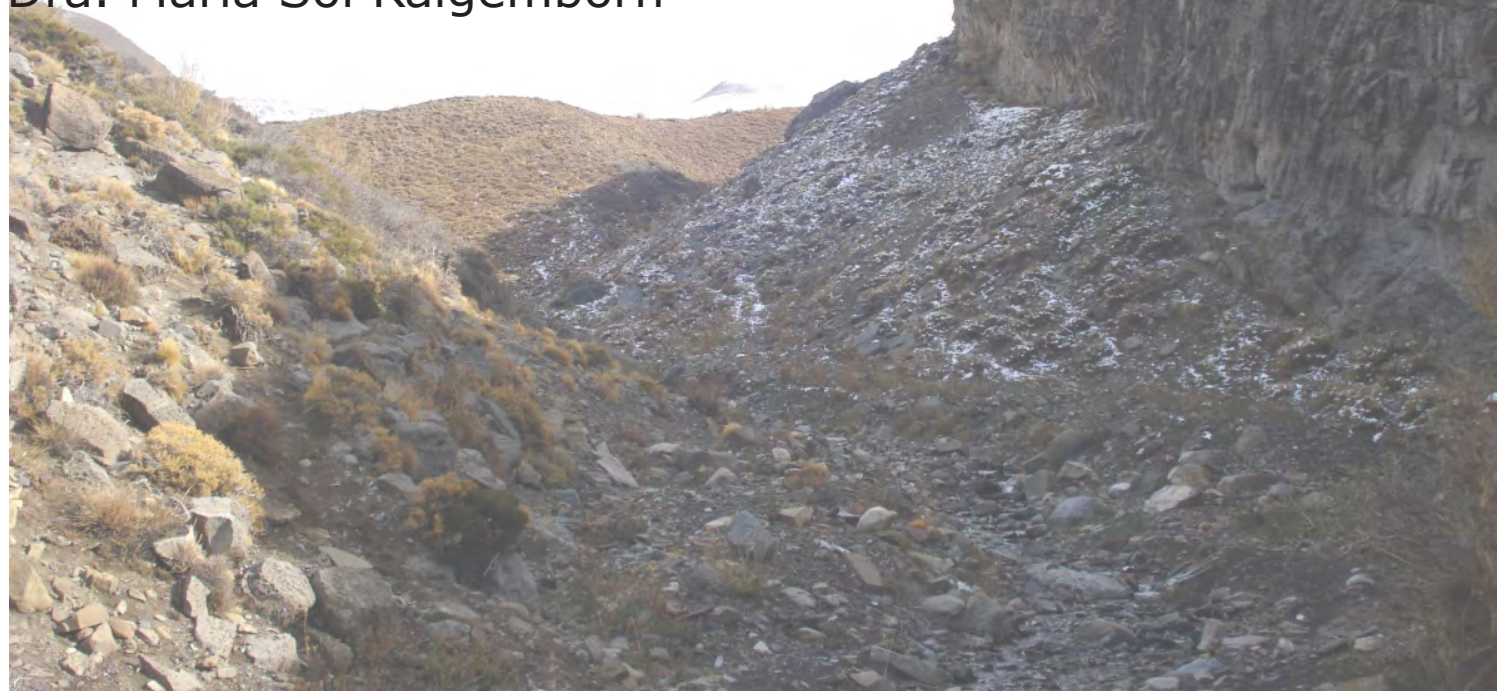




\author{
Universidad Nacional de La Plata \\ Facultad de Ciencias Naturales y Museo
}

Tesis doctoral

"Análisis paleoambiental y diagenético de la Formación Calabozo (Jurásico medio a superior) y su límite basal con la Formación Lajas (Jurásico medio) en el sector noroccidental de la Cuenca Neuquina, Mendoza, Argentina"

Lic. Ailen Borya

Directores: Dr. Sergio Daniel Matheos

Dra. María Sol Raigemborn

Diciembre de 2019

La Plata, Argentina 
A mis viejos, Ambar y Gero

"Tal vez camine lento, pero nunca caminaré hacia atrás" 


\section{ÍNDICE}

\section{RESUMEN}

ABSTRACT

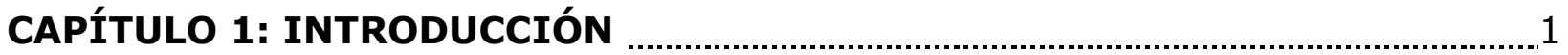

CAPÍTULO 2: METODOLOGÍA

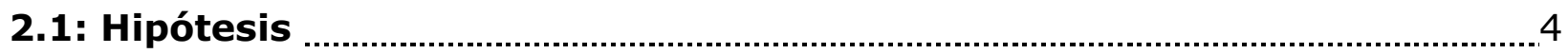

2.2: Revisión y análisis de la información bibliográfica y cartográfica............. 5

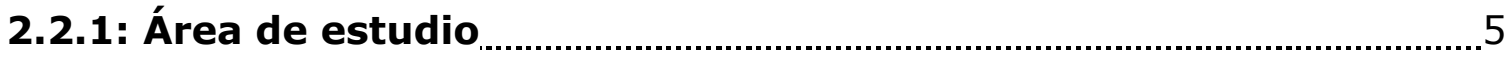

2.3: Tareas de campo

2.3.1: Relevamiento de perfiles sedimentológicos ....................................6

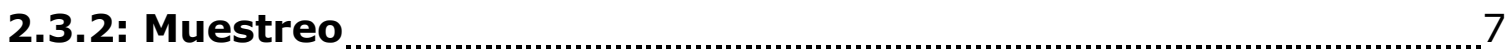

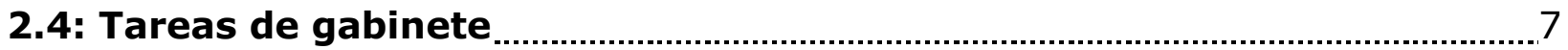

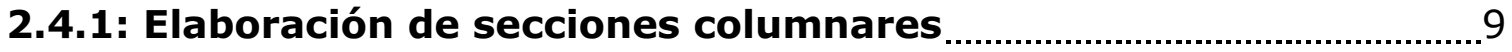

2.4.2: Definición de facies y asociaciones de facies ..................................

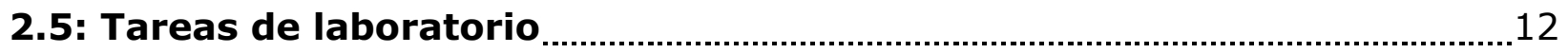

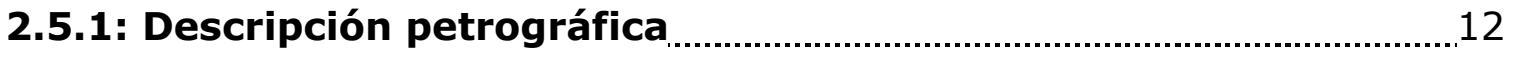

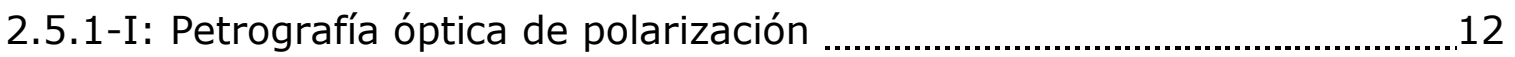

2.5.1-II: Petrografía no convencional (cátodoluminiscencia en frío) .................14

2.5.2: Análisis composicional por difractometría de rayos $X \ldots \ldots \ldots \ldots \ldots . . . .16$

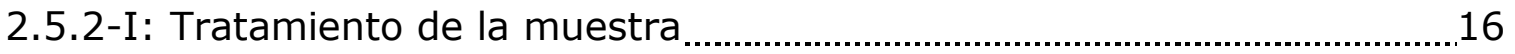

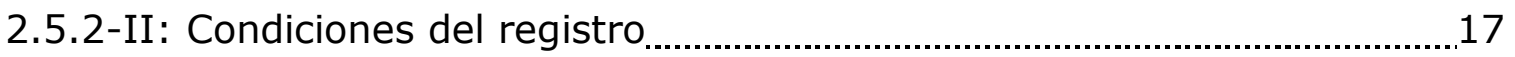

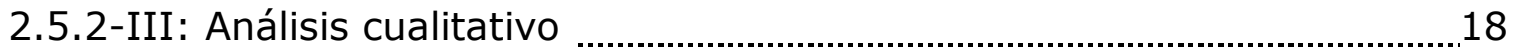

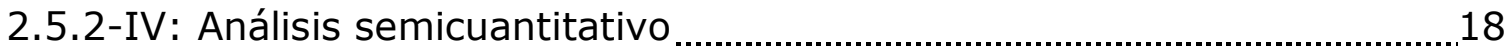

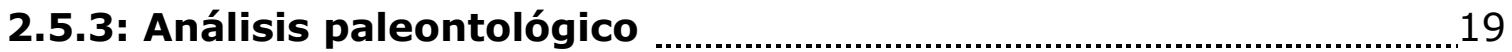


2.6: Elaboración intelectual de la información obtenida

CAPÍtULO 3: ÁMBITO GEOLÓGICO, ESTRATIGRAFÍA Y ANTECEDENTES $\ldots . . . .21$

3.1: La Cuenca Neuquina

3.2: Contexto tectonoestratigráfico de la Cuenca Neuquina ………..................23

3.3: El relleno sedimentario de la Cuenca Neuquina ............................................ 27

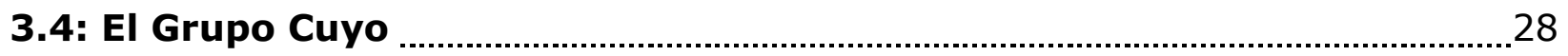

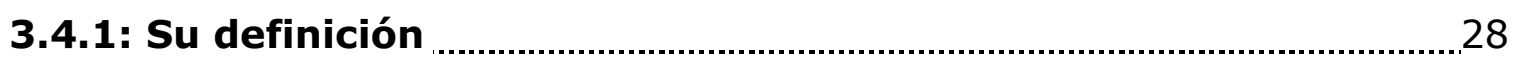

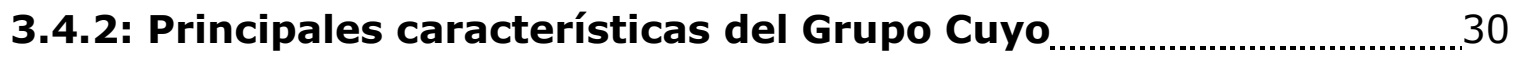

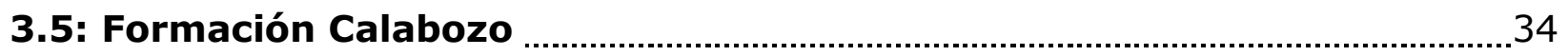

3.5.1: Su definición ............................................................................................. 34

3.5.2: Alcance actual de la unidad ............................................................... 38

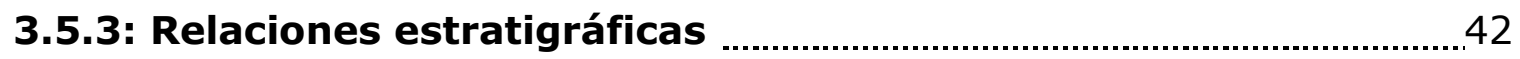

3.5.3-I: Límite inferior ............................................................................................ 42

3.5.3-I: Límite superior ........................................................................................... 43

3.5.4: Litofacies y contenido fosilífero

3.5.5: Espesor

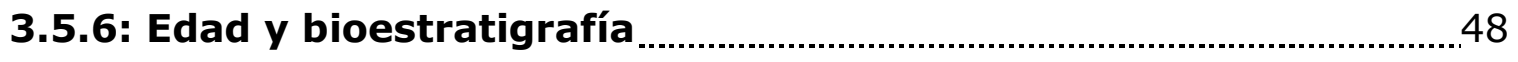

3.5.7: Sistema de acumulación ..............................................................................4

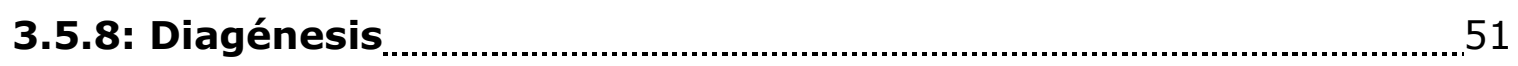

3.6: Resumen del análisis bibliográfico

CAPÍTULO 4: CARACTERIZACIÓN DE LA ZONA DE ESTUDIO ...............................54

4.1: Introducción

4.2: Geografía del área

4.3: Estructura

4. 3.1: Faja plegada y corrida de la Cordillera Principal mendocina ...56 
4. 3.2: Faja plegada y corrida de Malargüe ……..........................................5

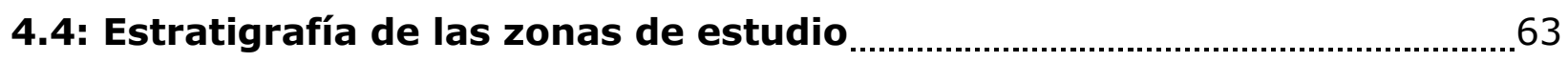

4.5: Perfiles sedimentológicos relevados

4.5.1: Introducción

4.5.2: Ubicación y características de las secciones......................................67

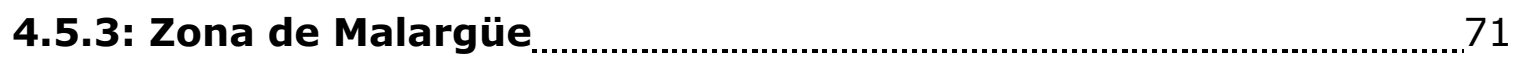

4.5.4: Zona de Bardas Blancas....................................................................... 78

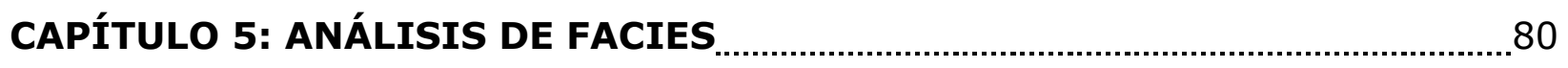

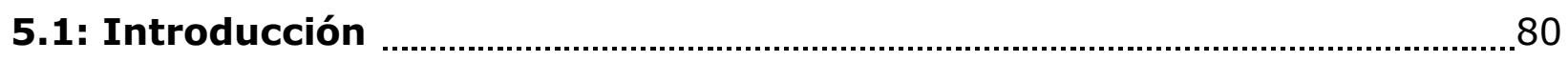

5.2: Caracterización general de las sedimentitas …….......................................... 81

5.2.1: Petrografía de las sedimentitas carbonáticas ...................................83

5.2.1-I: Componentes principales del entramado ...................................................83

5.2.1-II: Componentes menores del entramado ................................................100

5.2.2: Petrografía de las areniscas …………………........................................ 104

5.2.2-I: Componentes principales del entramado ...............................................107

5.2.2-II: Componentes menores del entramado

5.2.2-III: Clasificación de las areniscas ...........................................................117

5.2.3: Análisis de argilominerales en calizas y areniscas ......................122

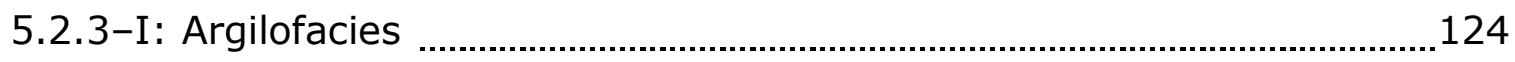

5.2.3-II: Consideraciones acerca del contenido de argilominerales ..............129

5.3- Identificación e interpretación de las litofacies.....................................131

5.3.1: Litofacies carbonáticas

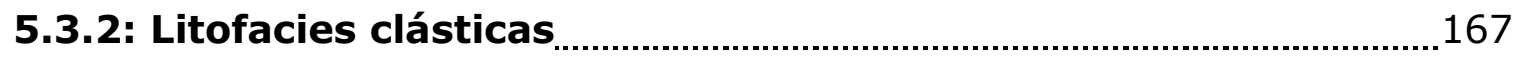

5.3.2-I: Litofacies psefíticas ................................................................................. 167

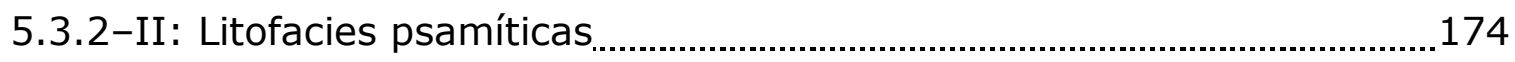


6.2: Asociaciones de facies de sistema de acumulación marino abierto carbonático (C)

6.2.1: Subambiente de rampa media. 189

6.2.1-I: Foreshoal dominado por eventos de tormenta (C1) 189

6.2.1-II: Foreshoal con bioconstrucción (C2) 192

6.2.2: Subambiente de rampa interna 199

6.2.2-I: Shoal (C3) 200

6.2.2-II: Intershoal (C4) 203

6.2.2-III: Albufera (C5) 206

6.2.2-IV: Llanura de marea (C6) 208

6.3: Asociaciones de facies de sistema de acumulación marino abierto clástico (M)

6.3.1: Subambiente de shoreface inferior (M1). 212

6.3.2: Subambiente de shoreface inferior a superior con bioconstrucción (M2) 216

6.3.3: Subambiente de shoreface superior (M3). 218

6.3.4: Barra de tormenta (M4). 221

6.3.5: Subambiente de foreshore-shoreface superior (M5). 222

6.3.6: Barra de desembocadura (M6)

6.4: Consideraciones finales ........................................................................22

CAPÍTULO 7: DIAGÉNESIS DE LA SUCESIÓN CARBONÁTICA ……....................230

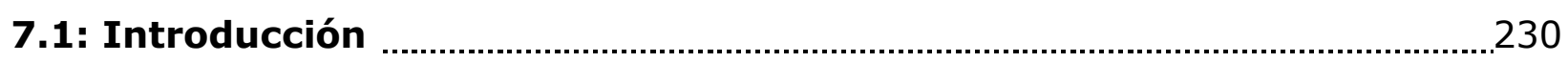

7.2: Diagénesis de las sedimentitas carbonáticas ...............................................2. 231 


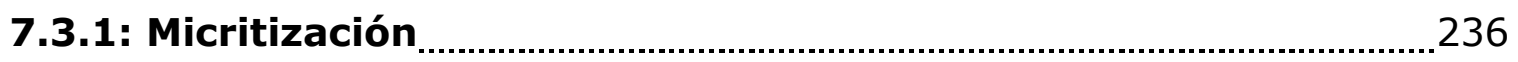

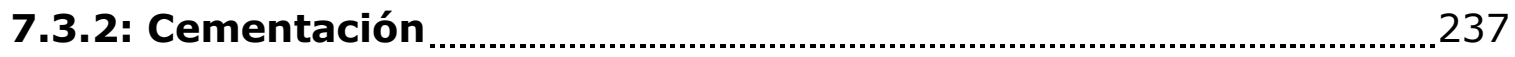

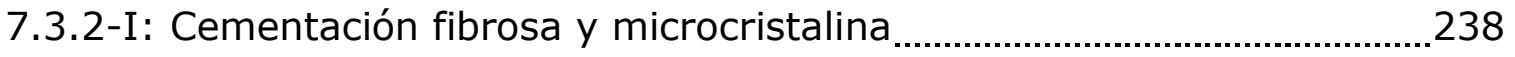

7.3.2-II: Cementación ecuante o esparítica.......................................................221

7.3.2-III: Cementación en venas ........................................................................243

7.3.2-IV: Cementación silícea y de feldespato autigénico................................246

7.3.3: Autigénesis de arcillas .......................................................................... 247

7.3.4: Neomorfismo

7.3.4-I: Calcitización ............................................................................................ 248

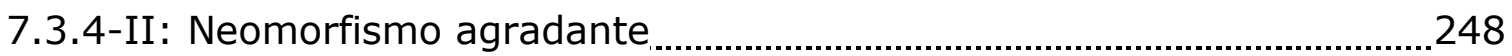

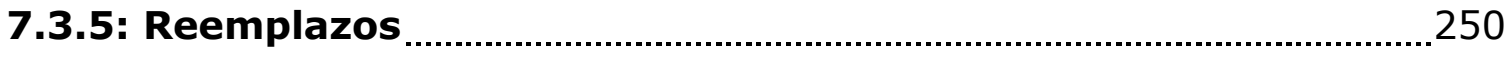

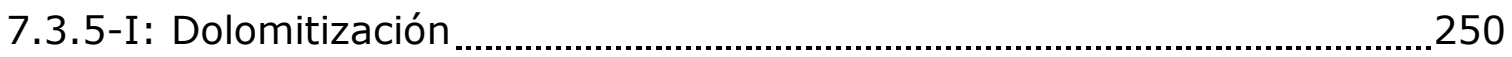

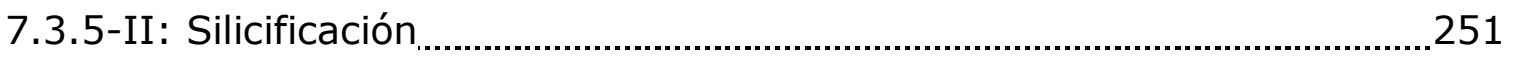

7.3.5-III: Reemplazo por cristales de evaporitas ..............................................2 252

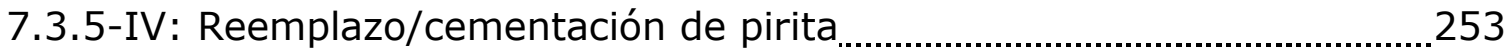

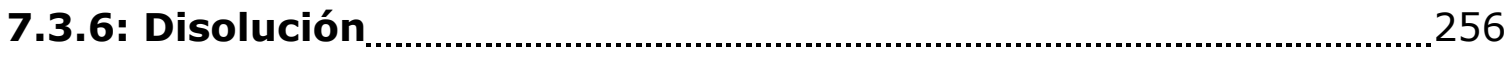

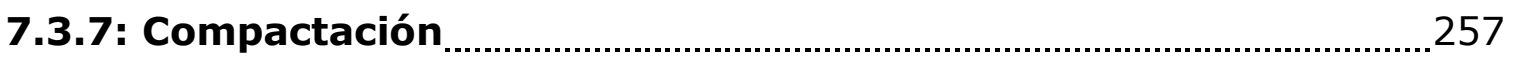

7.3.7-I: Compactación mecánica...........................................................................225

7.3.7-II: Compactación química...........................................................................2258

7.4: Historia diagenética 259

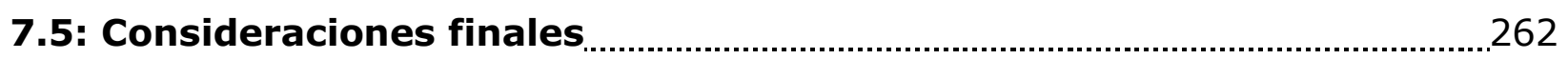

CAPÍTULO 8: PALEOAMBIENTE DE SEDIMENTACIÓN ……………………...........24

8.1: Introducción

8.2: Sistema de rampa carbonática

8.2.1: Distribución espacial de las asociaciones de facies ....................265

8.2.1-I: Consideraciones sobre la distribución espacial.....................................268

8.2.2: Composición del sistema de rampa carbonática ............................271

8.2.2-I: Consideraciones sobre la composición del sistema ............................272 
8.2.3: Dinámica del sistema de rampa carbonática ……………...............277

8.2.4: Consideraciones finales $\ldots$

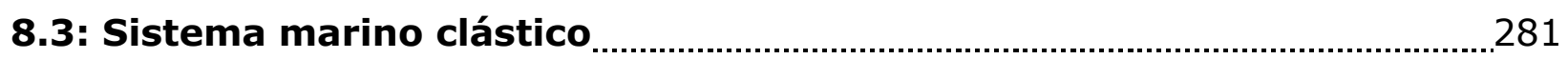

8.3.1: Distribución espacial de las asociaciones de facies ...................281

8.3.1-I: Consideraciones sobre la distribución espacial ...................................286

8.3.2: Dinámica del sistema marino clástico .............................................287

8.3.2-I: Consideraciones sobre la dinámica del sistema …................................289

8.3.3: Consideraciones finales ..................................................................... 289

8.4: Paleoambiente de sedimentación del intervalo estratigráfico en estudio ........................................................................................................................2 291

8.5: Definición de la base de la Formación Calabozo

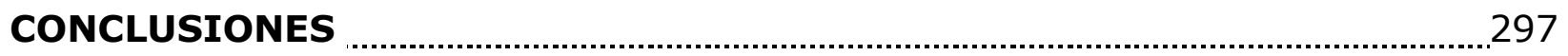

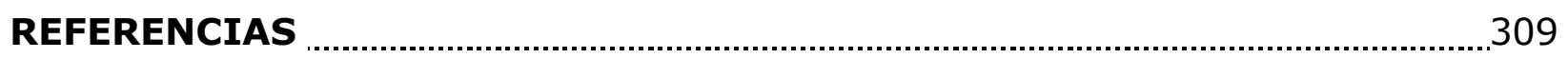

AGRADECIMIENTOS

ANEXOS

ANEXO I: Perfiles sedimentológicos relevados

Ia: Zona de Malargüe

Ib: Zona de Bardas Blancas

ANEXO II: Muestras obtenidas en el campo y los análisis realizados

ANEXO III: Taxones identificados en este trabajo

IIIa: Dentro de las facies definidas y su forma de preservación

IIIb: Dentro de las asociaciones de facies definidas

ANEXO IV: Perfiles sedimentológicos según sus asociaciones de facies

IVa: Zona de Malargüe

IVb: Zona de Bardas Blancas 


\section{RESUMEN}

El objetivo principal de este trabajo de Tesis Doctoral consistió en caracterizar desde el punto de vista paleoambiental y diagenético a las sedimentitas de la Formación Calabozo (Calloviano), y de forma secundaria, caracterizar paleoambientalmente a su unidad infrayacente la Formación Lajas (Bathoniano-Calloviano), aflorantes en el sector noroccidental de la Cuenca Neuquina, Provincia de Mendoza. A partir de este estudio se pretendió explicar los cambios acontecidos y las relaciones estratigráficas entre ambas unidades para este sector de la Cuenca Neuquina. En este contexto, se propuso la utilización de diversas herramientas aplicadas al análisis composicional y sedimentológico de sucesiones marinas carbonáticas y clásticas, que permitieran reconstruir el paleoambiente de sedimentación de los depósitos atribuidos a las formaciones Lajas y Calabozo. Asimismo, se plantearon metodologías aplicadas al análisis diagenético de depósitos carbonáticos, para determinar los cambios postdepositacionales que afectaron a la Formación Calabozo.

Luego de la recopilación bibliográfica y cartográfica, se dividió al intervalo estratigráfico bajo estudio, de base a techo, en una sucesión terrígena-mixta que incluye a la Formación Lajas y a los depósitos clásticos basales de la Formación Calabozo, cubierta por una sucesión carbonática que incluye a las calizas de la Formación Calabozo. De forma posterior, se definieron dos áreas principales de afloramientos para el desarrollo de esta investigación: una zona norte o de Malargüe y una zona sur o de Bardas Blancas. En estos sitios se relevaron once perfiles sedimentológicos de detalle (escala 1:50), donde se identificaron las principales litologías, estructuras sedimentarias primarias, contenido fosilífero, relaciones y geometrías estratales y toda característica relevante a escala de campo.

Sobre la base de los datos obtenidos en afloramientos y la construcción de mapas geológicos de detalle, se determinó la distribución de las sucesiones analizadas dentro del área de estudio y su litología dominante. La sucesión terrígena-mixta fue identificada sólo en la zona de Malargüe, con una marcada disminución de su potencia desde el sudeste hacia el noreste, mientras que la sucesión carbonática se reconoció en ambos sectores, con 
sus mayores espesores hacia el centro de la zona de Malargüe. Litológicamente, en la sucesión carbonática dominan las calizas con subordinadas areniscas (tramo inferior a medio), mientras que la sucesión terrígena-mixta resulta arenosa, con psefitas y calizas subordinadas.

Una vez reconocidas las principales litologías, se seleccionaron muestras de roca, de ejemplares y trazas fósiles para los diferentes análisis de laboratorio, conducentes a establecer la composición de las sedimentitas, su contenido fosilífero e implicancias paleoambientales asociadas, el área de aporte de las mismas y los principales eventos diagenéticos en la sucesión carbonática. Para este fin se utilizaron una serie de herramientas complementarias entre sí como la petrografía convencional y por catodoluminiscencia y la difractometría de rayos $\mathrm{X}$.

Así, a partir de los estudios petrográficos las calizas de ambas sucesiones fueron caracterizadas, en términos generales, como no esqueletales. Las variedades peloidales-oolíticas (tramo inferior a medio) y oolíticasoncolíticas (tramo medio a superior) dominaron en la sucesión carbonática, mientras que las calizas peloidales e intraclásticas (tramo superior) dominaron en la sucesión terrígena-mixta. Sus modas detrítica (líticos volcánicos y feldespatos) resultan menores al 15\% del total y en la sucesión carbonática sólo se identificaron en las calizas del tramo inferior a medio.

Por su parte, dentro de las areniscas se identificaron variedades terrígenas (en ambas sucesiones) y mixtas (sólo en la sucesión terrígena-mixta), clasificadas como litoarenitas feldespáticas $\left(Q_{17-30 \%} ; F_{26-40 \%} ; L_{38-52 \%}\right)$ y feldearenitas líticas $\left(Q_{15-34 \%} ; F_{35-60 \%} ; L_{20-35 \%}\right)$, con una tendencia general en sentido estratigráfico al aumento de estas últimas. Estas areniscas en la sucesión terrígena-mixta provendrían de un ambiente de arco volcánico de composición ácida a intermedia, que evolucionó desde un arco transicional hacia un arco disectado. Esta zona de aporte es asimilada a las vulcanitas ácidas a intermedias del Grupo Choiyoi y/o del Ciclo Precuyano, las cuales afloran en el sud-sudeste de la zona Malargüe y en Bardas Blancas.

Los análisis difractométricos demostraron que la illita y el interestratificado illita/esmectita resultan ser los argilominerales predominantes en las calizas y areniscas, especialmente de la sucesión terrígena-mixta y del tramo inferior a medio de la sucesión carbonática. Su abundancia disminuye hacia 
el tope de la sucesión carbonática (tramo medio a superior) donde la caolinita resulta significativa. Dichos minerales se habrían originado a través de la alteración de líticos volcánico y feldespatos presentes en las litologías analizadas durante una etapa de eogénesis temprana a mesogénesis.

Sobre la base de las litologías presentes, sus rasgos microscópicos (litologías carbonáticas) y los tipos y escala de estructuras sedimentarias primarias reconocidas en el campo, se definieron dieciséis litofacies carbonáticas y once clásticas, en las que se identificaron los procesos dinámicos elementales que dieron lugar a los depósitos en estudio. Las litofacies de packstone con subordinados framestone y areniscas masivas caracterizaron al tramo inferior a medio de la sucesión carbonática, mientras que los grainstone, floatstone y packstone al sector medio a superior. Por su parte, en la sucesión terrígena-mixta dominaron areniscas estratificadas o masivas y conglomerados masivos, con una tendencia en sentido estratigráfico al aumento de las primeras. Litofacies de framestone (tramo medio) y floatstone (tramo superior) resultaron subordinadas.

De forma posterior, se agruparon las facies en doce asociaciones de facies marinas, representando dos sistemas: uno carbonático (sucesión carbonática) y otro clástico (sucesión terrígena-mixta). Dentro del primero, se reconoció un subambiente de rampa media (tramo inferior a medio) y otro de rampa interna (tramo medio a superior) integrado por zonas de shoal (externo e interno), intershoal, albúfera y llanura de marea. Por su parte, en el sistema clástico se identificaron subambientes de foreshoreshoreface superior (tramo inferior) y de foreshore a shoreface inferior (sectores medio y superior).

A partir del análisis petrográfico de los subambientes de rampa se caracterizaron diferentes procesos diagenéticos, considerando el ambiente y el estadio diagenético en el cual tuvieron lugar, conducentes a delinear la evolución diagenética de la sucesión carbonática. Durante la eogénesis temprana en el medio marino, la micritización afectó de forma generalizada a estos subambientes de rampa, seguida por un evento localizado de cementación marina. Hacia la llanura de marea la mezcla de aguas porales marinas y meteóricas en esta etapa generarían el neomorfismo agradante, dolomitización y reemplazo por evaporitas. Luego de una leve compactación 
mecánica (eogénesis temprana), dichos subambientes fueron afectados localmente por un evento meteórico vadoso, seguido por un período generalizado de diagénesis freática de mezcla de aguas porales marinas y meteóricas que se prolongaría hasta un soterramiento muy somero de la sucesión (eogénesis temprana-tardía). De forma posterior se registrarían cambios locales en el pH del medio (eogénesis tardía-mesogénesis temprana), para culminar con una moderada compactación química de la sucesión durante su soterramiento (mesogénesis temprana-moderada).

Acto seguido, mediante la integración de los subambientes definidos y los principales aspectos diagenéticos (subambientes carbonáticos) se estableció un sistema de rampa peloidal homoclinal (sucesión carbonática) que cubre a otro, marino somero clástico, dominado por olas y con influencia fluvial o deltaica (sucesión terrígena-mixta). Dentro del primero, las variaciones de salinidad y turbidez de sus aguas condicionaron el asentamiento de la fauna bentónica, en especial de bioconstrucciones discretas que colonizaron la rampa media proximal (zona de Malargüe). A lo largo de rampa, las olas de buen tiempo y tormenta habrían transportado el material intracuencal y extracuencal, este último suministrado a la rampa media desde el sistema clástico subyacente (zona de Malargüe) o un área fuente no identificada (zona de Bardas Blancas).

A partir de las relaciones espaciales de los sistemas de acumulación, se estableció el paleoambiente de sedimentación para el intervalo estratigráfico en estudio, cuya evolución sería controlada principalmente por las variaciones relativas del nivel del mar y los efectos de estructuraciones locales. A modo de conclusión, se establecieron las relaciones estratigráficas entre ambos sistemas de acumulación y se propuso denominar a la rampa peloidal homoclinal como Formación Calabozo. La misma cubre mediante un contacto neto a transicional, en la zona de Malargüe, al sistema marino clástico propuesto como Formación Lajas. Hacia la zona de Bardas Blancas, esta unidad se apoya mediante un contacto neto sobre la Formación Tres Esquinas dado que la Formación Lajas no se preservó o acumuló. 


\section{ABSTRACT}

The aim of this PhD thesis was mainly to characterize the deposits of the Calabozo Formation (Calloviano) from a paleoenviroment and diagenetic perspective, and secondarily to paleoenvironmentally characterize the underlying unit known as Lajas Formación (Bathoniano-Calloviano), whose outcrops are located at the northwestern of the Neuquén basin, Mendoza, Argentina. This study focused on trying to elucidate the geological changes that occurred, as well as the stratigraphic relation between the units at this area of the Neuquén basin. Several tools were applied for the composition and sedimentological analysis of carbonate and siliciclastic marine successions to reconstruct the paleoenvironment of these deposits, which have been attributed to the Lajas and Calabozo Formation. Likewise, to the purpose of determining the post-depositional changes that affected the Calabozo Formation, the required methodologies for the diagenetic analysis of carbonate deposits were defined in detail.

Following bibliographic and cartographic data collection, the stratigraphic unit under study was divided, from base to top, into a mixed siliciclasticcarbonate succession including the Lajas Formation and a basal siliciclastic deposits of the Calabozo Formation, the latter being covered by a carbonate succession (limestones) of the same unit. Two main areas of outcrops were then defined for this study: a northern area (or Malargüe) and a southern area (or Bardas Blancas). Eleven detailed sedimentological profile (scale 1:50) were measured for each area, and the main lithologies, sedimentary structures, fossiliferous content, geometry and relation between strata were identified, as well as other relevant features at the outcrop scale.

Based on the collected data at the outcrops and the reconstruction of detailed geological maps, the distribution of the successions within the area of study as well as the dominant lithology were determined. The mixed siliciclastic-carbonate succession was only found at the Malargüe area, displaying a conspicuous decrease of its thickness from southeast to northeast, while the carbonate succession was identified at both areas with its greatest thickness towards the center of the Malargüe area. Regarding 
the lithology, the carbonate succession is found to be dominated by limestones with subordinate sandstones (lower to middle interval), while the mixed siliciclastic-carbonate succession is mainly composed of sandstones with subordinate conglomerates and limestones.

After the lithology analysis, rock, fossils, and trace fossils samples were then selected for various laboratory analyses to establish rock composition, fossiliferous content and related paleoenvironment implications, as well as the source area and the principal diagenetic events within the carbonate succession. In this regard, several tools such as optical petrography, cathodoluminescence petrography, and x-ray diffractometry were applied complementary.

Based on the findings of petrographic analyses, limestones of both successions were characterized mainly as non-skeletals. The peloidal-oolitic (lower to middle interval) and the oolitic-oncolitic (middle to upper level) limestones dominate the carbonate succession, while peloidal and intraclastic limestones (upper interval) dominate the mixed siliciclasticcarbonate succession. The detrital mode (volcanic lithoclasts and feldspar) of these limestones are less than $15 \%$ of the total, and were only identified at the lower to middle interval of the carbonate succession.

On the other hand, terrigenous (both successions) and mixed (only in the mixed siliciclastic-carbonate) sandstones were identified and classified as feldespathic litoarenites $\left(\mathrm{Q}_{17-30 \%} ; \mathrm{F}_{26-40 \%} ; \mathrm{L}_{38-52 \%}\right)$ and lithic feldarenites $\left(Q_{15-34 \%} ; F_{35-60 \%} ; L_{20-35 \%}\right)$, the latter having a general tendency to increase its proportion from base to top. These sandstones would have come from a volcanic arc environment of acid to intermediate composition, which evolved from a transitional arc to a dissected arc for the mixed siliciclastic-carbonate sucession. The acid to intermediate vulcanites of the Choyoi Group and/or Precuyano cycle are considered as the source rock, which are exposed in the south-southeast of the Malargüe and Bardas Blancas areas.

X-ray measurements showed that illite and illite/smectite mixed-layers are the predominant clay minerals in the limestones and sandstones, especially in the mixed siliciclastic-carbonate succession and the lower to middle interval of the carbonate succession. The illite and illite/smectite mixedlayers abundance decreases towards the top of the carbonate succession 
(middle to upper interval) where the kaolinite becomes more significant. These minerals would have originated from the alteration of volcanic lithoclasts and feldspars, both present in the analyzed lithologies, during an early eogenetic to mesogenetic stages.

Based on the lithologies, microscopic features (carbonate lithologies), the types and the scale of the primary sedimentary structures identified in the field, sixteen carbonate and eleven siliciclastic lithofacies were defined, thus allowing to identify the elemental dynamic processes that led to the accumulation of the deposits. Packstones lithofacies with subordinate framestone and massive sandstones characterize the lower to middle interval of the carbonate succession, while grainstones, floatstones and packstones characterize the middle to upper interval. On the other hand, stratified or massive sandstones and massive conglomerates dominate the mixed siliciclastic-carbonate succession, the former having a general tendency to increase its proportion from base to top. Framestone (middle interval) and floatstone lithofacies (upper interval) are defined as subordinate.

Sedimentary facies were grouped in twelve marine facies associations, representing two systems: a carbonate system (carbonate succession) and a siliciclastic system (mixed siliciclastic-carbonate succession). In the first system, two subenvironments were recognized: a middle ramp subenvironment (lower to middle interval) and an inner ramp (middle to upper interval) integrated by shoal zones (outer and inner), intershoal, lagoon and tidal flat. In the siliciclastic system, foreshore-upper shoreface (lower interval) and foreshore to lower shoreface (middle to upper interval) were identified.

In order to outline the diagenetic evolution of the carbonate succession, several diagenetic processes were characterized based on the petrographic analysis of ramp subenvironments, taking into consideration the environment and diagenetic stage. During the early eogenesis in the marine environment, the analysis suggests that micritization would first have affected these ramp subenvironments, followed by a localized event of marine cementation. At this stage, the mix of poral marine water and meteoric-water in the tidal flat would have 
generated aggrading neomorphism, dolomitization and replacement by evaporites. After the initial mechanic compaction (early eogenesis), such subenvironments were locally affected by a vadose meteoric event, followed by a generalized period of phreatic diagenesis of mixed marine poral and meteoric water, which would extend to a very shallow burial of the succession (early-late eogenesis). In a later stage, local changes in the surrounding $\mathrm{pH}$ would have been manifested (late eogenesis-early mesogenesis), to culminate with a moderate chemistry compaction of the succession during the burial (early-moderate mesogenesis).

Via the integration of these subenvironments and the principal diagenetic aspects (carbonate subenvironments), results suggest that a peloidal homoclinal ramp system was established (carbonate succession) which overlies a wave dominated shallow marine siliciclastic system with fluvial or deltaic influence (mixed siliciclastic-carbonate succession). Within the ramp system, the water salinity and turbidity variations conditioned the settlement of the benthic fauna, especially the discrete bioconstructions that colonized the proximal mid-ramp (Malargüe area). Along the ramp, fair weather and storms waves would have transported the intra- and extrabasin materials, the latter supplied to the mid-ramp from either the overlying siliciclastic system (Malargüe area) or from an yet unidentified source area (Bardas Blancas area).

Based on the spatial relations of the accumulation systems, the sedimentary paleoenvironment was established for the stratigraphic interval under study, and its evolution would have been controlled mainly by relative variations of sea level and the effects of local structuring. Finally, the stratigraphic relations between both accumulation systems were established, and it was proposed to assign Calabozo Formation to the peloidal homoclinal ramp. The Calabozo Formation overlies the siliciclastic marine system, proposed as the Lajas Formation, through a net to transitional contact in the Malargüe area. In contrast, towards the Bardas Blancas area, this unit overlies the Tres Esquinas Formation through a net contact, given that the Lajas Formation was not preserved nor accumulated. 


\section{CAPÍTULO 1: INTRODUCCIÓN}

La Formación Calabozo (Dessanti, 1973) es una de las unidades jurásicas marinas con menor distribución areal dentro del ámbito de la Cuenca Neuquina (figura 1.1), una de las razones por la cual ha sido mencionada por unos pocos autores (Legarreta et al., 1993; Gulisano y Gutiérrez Pleimling, 1994; Cabaleri et al., 2001; Palma et al., 2007a; Armella et al., 2013) dentro de una de las mayores cuencas productoras de hidrocarburos de la República Argentina. Sedimentológicamente está conformada por calizas con un abundante contenido de fauna marina normal, asociadas con areniscas y conglomerados hacia la base de la unidad. Sus depósitos fueron reconocidos en el sudoeste de la provincia de Mendoza (Armella et al., 2005a; Cabaleri et al., 2003; Palma et al., 2005; figura 1.1), mientras que hacia el centro y sur de Neuquén no han sido acumulados (Gulisano y Gutiérrez Pleimling, 1994). Estratigráficamente se distingue con claridad de la infrayacente Formación Lajas, silicoclástica y de ambiente marino somero a deltaico, a través de un cambio marcado en las condiciones depositacionales (Armella et al., 2005a; Palma et al., 2007a). Asimismo, el contraste de facies de la Formación Calabozo resulta marcado con las evaporitas de la Formación Tábanos suprayacentes, que registran una fuerte restricción de la Cuenca Neuquina, coetánea con una caída global del nivel del mar (Riccardi et al., 2000).

Desde los primeros estudios realizados en la Formación Calabozo, la unidad fue abordada de manera integrada con las formaciones infrayacente y suprayacentes, en trabajos sedimentológicos de índole regional (Gulisano et al., 1984; Legarreta y Uliana, 1996, entre otros), no obstante, no se registran estudios que expliquen en un contexto paleoambiental los cambios acontecidos dentro de este intervalo estratigráfico. Consideraciones paleoambientales de la Formación Calabozo han sido abarcados en menor medida (Armella et al., 2005b, 2013; Cabaleri et al., 2001; Palma et al., 2007a), mientras que, los aportes de Palma et al. (2000b, 2007) dan a conocer las únicas contribuciones que mencionan aspectos diagenéticos de la unidad. Esta situación generó un vacio de conocimiento desde el punto de vista paleoambiental y diagenético dentro de los depósitos jurásicos del norte de la 
Cuenca Neuquina. En este contexto es que la presente tesis aportará nueva información para solucionar la presente problemática.

La acumulación de los depósitos de la Formación Calabozo tuvo lugar durante el Calloviano temprano en el norte de la Cuenca Neuquina, durante un período de subsidencia termal lenta combinada con fenómenos localizados de inversión tectónica (Spalletti et al., 2012). En este ámbito para el Bathoniano a Calloviano temprano el área de acumulación se reducía como consecuencia de una regresión general de los mares (Legarreta y Uliana, 1996). Esta tendencia decreciente del espacio de acomodación se reviertió durante un episodio de inundación en tiempos del Calloviano temprano que es precedida por una fuerte restricción de la Cuenca Neuquina hacia fines del Calloviano temprano a medio (Legarreta y Uliana, 1996).

De acuerdo a lo expuesto, la asociación de los factores de índole tectónico y las variaciones del nivel del mar durante y de forma posterior a la depositación de la Formación Calabozo, con seguridad condicionaron el desarrollo y la distribución de la unidad, y podrían incidir en los proceso diagenéticos que la modificaron. Estos factores deben ser tenidos en cuenta a la hora de analizar la depositación de la unidad y los cambios postdepositacionales que la afectan. Con el objetivo principal de comprender cómo afectaron el ambiente en que se acumularon los depósitos de la Formación Calabozo y su evolución, es que la presente tesis plantea elaborar un modelo paleoambiental completo y delinear la evolución diagenética de dicha unidad. A partir de este modelo y con el análisis conjunto con la Formación Lajas se pretende explicar lo acontecido entre ambas unidades.

De esta forma, los objetivos particulares de este estudio fueron:

1. caracterizar los atributos composicionales y texturales de las formaciones Calabozo y Lajas,

2. definir las facies y a partir de su asociación los subambientes de acumulación para dicho intervalo estratigráfico,

3. analizar los procesos diagenéticos que afectaron a la Formación Calabozo y delinear su evolución temporal dentro de la unidad,

4. establecer los sistemas de acumulación para ambas unidades a partir de las relaciones horizontales y verticales de los diferentes subambientes, 
5. definir el paleoambiente de sedimentación para dicho intervalo estratigráfico dentro de la Cuenca Neuquina,

6. discutir los cambios acontecidos y controles que tuvieron lugar durante la acumulación de cada unidad,

7. a partir del análisis de los resultados, establecer el alcance de la Formación Calabozo y su límite basal con la Formación Lajas.

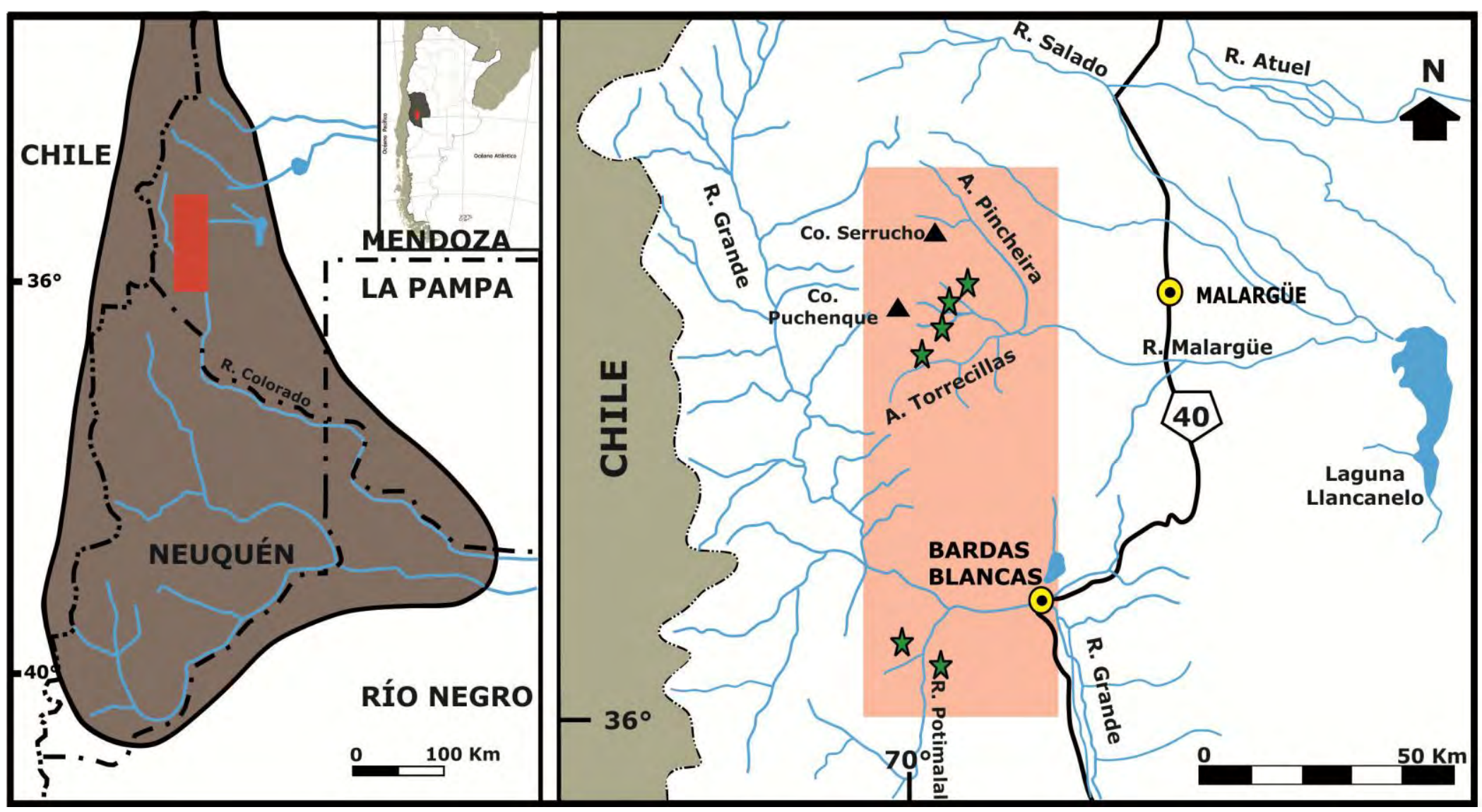

Figura 1.1: Mapa de localización de la Cuenca Neuquina modificado de Legarreta y Gulisano (1989). El rectángulo rojo indica el área donde se realizó el estudio, las estrellas indican los sectores donde se relevaron los perfiles sedimentológicos. 


\section{CAPÍTULO 2: METODOLOGÍA}

En el trabajo de tesis doctoral se desarrollaron las sucesivas etapas que involucran al método científico. En primera instancia se planteó la hipótesis y se determinaron las condiciones generales del problema a abordar. Luego se elaboró una recopilación bibliográfica del objeto de estudio con la finalidad de aproximarse a dicha problemática. A continuación se llevo adelante la etapa de observación y toma de medidas, con la recolección de datos en el campo y diversos análisis en laboratorio. Por último, mediante la integración y análisis de toda la información se elaboraron intelectualmente los resultados.

\section{1: Hipótesis}

La Formación Calabozo (Calloviano) representa una sucesión sedimentaria conformada por sedimentitas predominantemente carbonáticas de origen marino. Su contraste con las unidades marinas infrayecentes (Formación Lajas) y suprayacente (Formación Tábanos), de carácter silicoclástico y evaporítico respectivamente resulta marcado. Cambios significativos dentro del paleoambiente de sedimentación y en los controles de los procesos de acumulación deberían haberse registrado para generar este brusco cambio de litologías, especialmente entre las formaciones Lajas y Calabozo. En este contexto se considera que asociado con el pasaje hacia la Formación Tábanos procesos diagenéticos pudieron haber modificado las texturas depositacionales de la Formación Calabozo, dando inicio a su alteración.

En este trabajo de tesis doctoral se propone la utilización de diversas herramientas aplicables al análisis sedimentológico de sucesiones marinas carbonáticas y clásticas, propicias para elaborar el paleombiente de sedimentación de los depósitos atribuidos a las formaciones Calabozo y Lajas, así como también explicar la naturaleza de los cambios acontecidos entre ambas unidades. Asimismo, se plantea el uso de metodologías aplicadas al estudio diagenético de depósitos carbonáticos, 
para determinar los cambios postdepositacionales que afectaron a la Formación Calabozo, en especial los relacionados con su pasaje hacia la Formación Tábanos.

\section{2: Revisión y análisis de la información bibliográfica y cartográfica existente}

Se llevaron a cabo las tareas de recopilación y lectura del material bibliográfico correspondiente a la Formación Calabozo, a unidades equivalentes y a unidades infra y suprayacentes, especialmente lo referido a la Formación Lajas. También se tuvieron en cuenta los antecedentes respecto a la historia tectónica y estratigráfica de toda la Cuenca Neuquina. Además se analizaron e interpretaron las cartas geológicas e imágenes satelitales disponibles de los afloramientos del Jurásico Medio a Superior en la Cuenca Neuquina, especialmente los de las formaciones Calabozo y Lajas en el sudoeste mendocino. A partir de estos datos se pudo establecer el estado actual de conocimiento sobre dicho intervalo estratigráfico y definir el alcance del área de estudio. Una vez establecida la zona de tesis se seleccionaron los potenciales lugares para la realización de los perfiles sedimentológicos de detalle.

En forma paralela se intensificó la lectura bibliográfica de trabajos sedimentológicos específicos, que permitió adquirir las herramientas teóricas fundamentales para el estudio de las sedimentitas en cuestión.

\subsection{1: Área de estudio}

Los afloramientos de las formaciones Calabozo y Lajas sobre los que se realizó esta investigación se localizan en el sudoeste de la provincia de Mendoza, coincidente con el sector noroccidental de la Cuenca Neuquina (ver figura 1.1). La región en estudio está comprendida entre los $35^{\circ} 24^{\prime}$ y $36^{\circ} 00^{\prime}$ LS y entre los $69^{\circ} 47^{\prime}$ y $70^{\circ} 03^{\prime}$ LW (figura 2.1). Se extiende a lo largo de unos $67 \mathrm{~km}$ por $25 \mathrm{~km}$ de ancho máximo (aproximadamente $1.610 \mathrm{~km}^{2}$ ), donde se incluyen territorios del departamento 
provincial de Malargüe, ubicados en los distritos de Ciudad de Malargüe y Río Grande.

En virtud de la distribución y extensión de los afloramientos dentro del área de estudio, se optó por dividir a la región en dos zonas. En este contexto, la zona septentrional o de Malargüe se sitúa a $30 \mathrm{Km}$ al oeste de la ciudad homónima, entre los $35^{\circ} 24^{\prime} y 35^{\circ} 34^{\prime}$ LS y entre los $69^{\circ} 47^{\prime}$ y $70^{\circ} 03^{\prime}$ LW (figura 2.2 ). Incluye los afloramientos delimitados al norte por el arroyo Serrucho y al sur por el arroyo Torrecillas (figura 2.2). Por su parte, la zona austral o de Bardas Blancas, se localiza en las cercanías de la localidad de Bardas Blancas, entre los $35^{\circ} 51^{\prime}$ y $36^{\circ} 00^{\prime}$ LS y entre los $69^{\circ} 47^{\prime}$ y $70^{\circ} 03^{\prime}$ LW. Esta zona comprende los afloramientos ubicados al sur del río Grande (figura 2.2).

Entre ambas zonas se encuentra una región de aproximadamente $760 \mathrm{~km}^{2}$ donde no se registran afloramientos del intervalo estratigráfico analizado.

\section{3: Tareas de campo}

Durante el período comprendido entre los meses de abril de 2012 y abril del 2015 se desarrollaron las tareas de campo al área de tesis (figura 2.1), que constaron de tres viajes de veinte días de duración cada uno. En primera instancia, mediante el relevamiento general del área de estudio, se corroboraron los potenciales lugares para la realización de perfiles sedimentológicos sobre la base del análisis bibliográfico y cartográfico inicial. De esta forma, se establecieron los sectores en los cuales las unidades se encontraban con las mejores y más completas exposiciones y por lo tanto resultaban óptimas para su estudio. Posteriormente, en el transcurso de estos viajes se relevaron y muestrearon los perfiles sedimentológicos de detalle en los sectores de interés dentro del área de estudio.

\subsection{1: Relevamiento de perfiles sedimentológicos}

En los lugares definidos previamente dentro de las zonas de Malargüe y de Bardas Blancas se relevaron once secciones sedimentológicas de detalle (escala 1:50). Nueve corresponden a la zona de Malargüe, siendo de norte a sur, Arroyo Serrucho (ASE), Arroyo Negro (ANE), Arroyo Calabozo Norte (ACN), Arroyo Calabozo Sur 
(ACS), Plomo Norte (PLN), Plomo Oeste (PLW), Plomo Este (PLE), Arroyo Plomo Sur (APS) y Arroyo Torrecillas Oeste (ATW), y dos pertenecen a la zona de Bardas Blancas, siendo de sudeste a noroeste, Río Potimalal (PCH) y Arroyo La Vaina (ALV) (figura 2.2). Asimismo, se realizaron observaciones complementarias en zonas aledañas a los perfiles, con el relevamiento de secciones parciales que fueron tomadas como puntos de control. Tales datos se usaron para lograr una interpretación más acabada de la zona de estudio.

Durante las actividades de campo se puso especial énfasis en la descripción del contacto entre unidades, la medida de espesores, descripción de las litologías presentes, estructuras sedimentarias, bioturbación, contenido fósil, relaciones y geometrías estratales. Al mismo tiempo se realizó la medición de datos de paleocorrientes sobre los estratos que así lo permitiesen y se identificaron los rasgos diagenéticos observables a escala macroscópica.

\subsection{2: Muestreo}

En los sitios donde se relevaron los perfiles sedimentológicos se realizó un muestreo sistemático de los diferentes litosomas que conforman la unidad. Esta tarea tuvo como objetivo el posterior análisis de laboratorio sobre las muestras seleccionadas, tanto de índole composicional como diagenético. Asimismo, en la mayoría de las localidades se realizó un muestreo no sistemático de macrofósiles y trazas fósiles de la Formación Calabozo, con el fin de determinar los cambios durante la evolución ambiental de dicha unidad.

\section{4: Tareas de gabinete}

Se realizó el procesamiento y análisis de la información obtenida durante la recolección de datos en el campo. Las tareas desarrolladas incluyeron la elaboración de secciones columnares y la definición de facies sedimentarias y asociaciones de facies. 


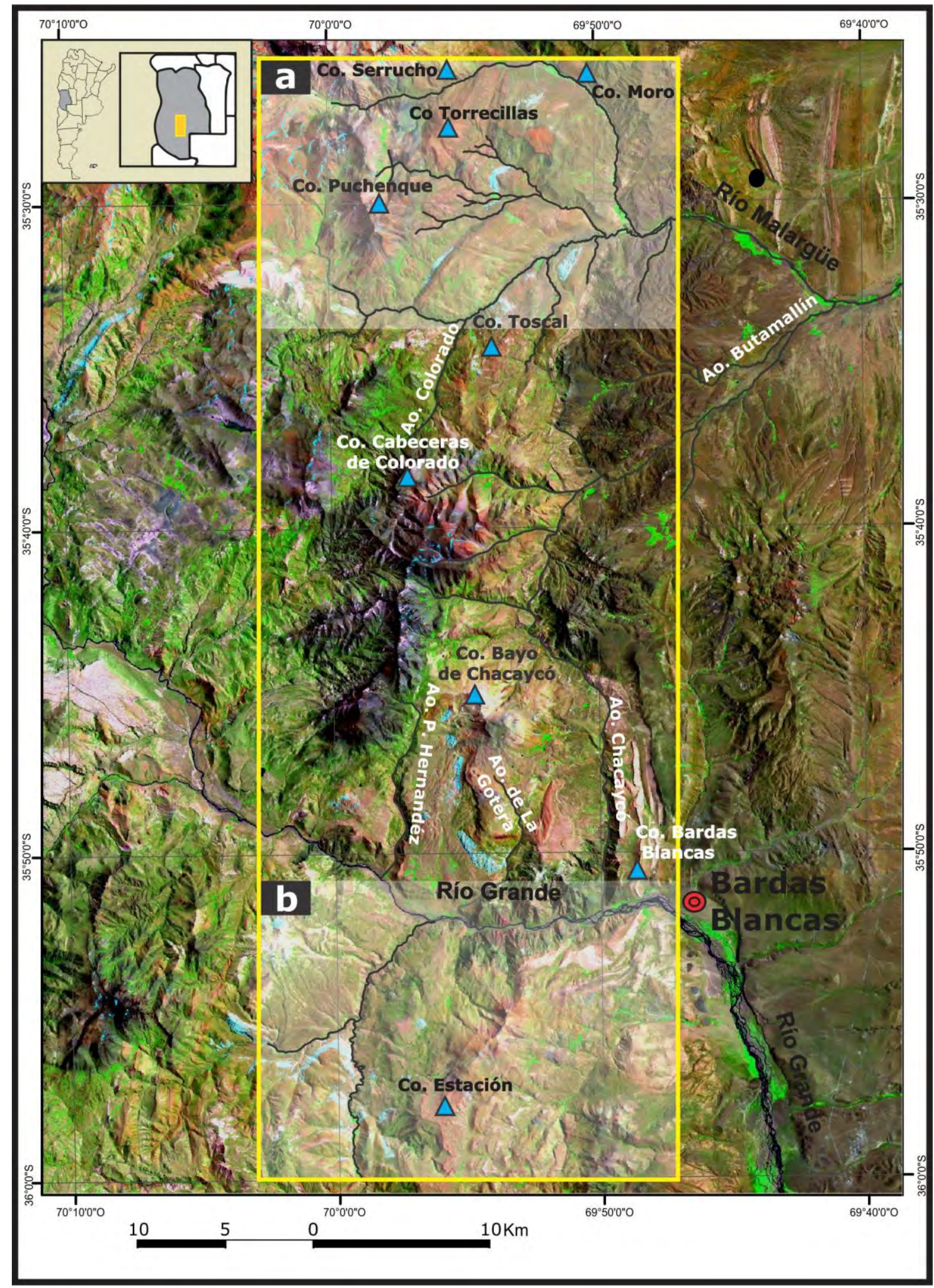

Figura 2.1: Ubicación geográfica y extensión del área de estudio en el sudoeste de la provincia de Mendoza. Los recuadros en blanco representan las zonas de trabajo: a) zona septentrional o de Malargüe, b) zona austral o de Bardas Blancas. 


\subsection{1: Elaboración de secciones columnares}

Se graficaron las columnas sedimentarias a escala de detalle (1:50) en donde se volcó la información referida a litología, espesores, tipos de contactos, estructuras sedimentarias primarias, estructuras sedimentarias orgánicas, datos de paleocorrientes, contenido fosilífero y todo rasgo descriptivo de relevancia (Anexo Ia-Ib). Los gráficos fueron elaborados en formato digital a partir de la utilización del programa de dibujo Corel Draw. Esta actividad permitió visualizar de manera sinóptica toda la información relevada en el campo. Además, el procesamiento digital facilitó el manejo de la información a distintas escalas.

\subsection{2: Definición de facies y asociaciones de facies}

A efectos de comprender los procesos sedimentarios acontecidos, los controles que tuvieron lugar en la sedimentación y el paleoambiente resultante de las unidades en estudio de esta tesis, se ha utilizado la metodología descriptiva acorde con Reading y Levell (1996). El análisis de facies provee una de las herramientas más importantes para esclarecer estos elementos, y su utilidad en el estudio de sucesiones antiguas y modernas fue establecida en innumerables trabajos científicos y recopilados en diversos libros de textos sobre el tema (Walker y James, 1992; Reading, 1996; entro otros).

La mayoría de los estudios de facies clásicos se basan en la evaluación cualitativa de los aspectos litológicos, estructuras sedimentarias y trazas fósiles características (Williams y Rust, 1969; Wilson, 1975; Cant y Walker, 1976; Scholle et al., 1983; Walker, 1983). Sin embargo, existe un consenso entre los investigadores que en ciertas litologías resulta necesaria la cuantificación de los parámetros descriptivos para una correcta definición de las facies (Imbrie y Purdy, 1962; Harbaugh y Demirmen, 1964; Klovan, 1964; Harbaugh y Merriam, 1968).

En esta tesis, para la identificación de las facies carbonáticas y clásticas se consideró la textura, el tipo de estructura sedimentaria y su escala, la geometría de los cuerpos, el grado de bioturbación y el contenido fosilífero. En el caso particular de las sedimentitas carbonáticas con atributos litológicos similares a escala de 
campo y escasas estructuras sedimentarias, se utilizaron además las características texturales microscópicas siguiendo los criterios expuestos por Colombié y Strasser (2005), Bádenas y Aurell (2010), Benyoucef y Meister (2015), entre otros. Los atributos texturales considerados fueron la granulometría, la composición de los componentes principales (esqueleto y matriz), y el contenido de partículas carbonáticas aloquímicas, esqueletales y terrígenos.

Una vez definidas las facies se especificó un código apropiado para la denominación de las litofacies carbonáticas y otro para las clásticas. Luego, mediante el análisis de los atributos macroscópicos y microscópicos se interpretaron las condiciones de sedimentación bajo las cuales se formaron cada facies.

De forma posterior se definieron las asociaciones de facies a partir del agrupamiento de las facies reconocidas. Para establecer cada asociación se consideraron las relaciones entre facies, la geometría y escala de los litosomas intervinientes (definida en los afloramientos) y la composición en el caso del grupo de facies carbonáticas. En este sentido, las diferentes asociaciones de facies fueron descriptas en términos de la distribución espacial de las facies presentes, de la geometría externa (tabular, irregular, cuneiformes) y dimensiones (espesor y extensión lateral).

Figura 2.2: Ubicación de las zonas de estudio dentro del área de trabajo. a) Zona septentrional o de Malargüe. b) Zona austral o de Bardas Blancas. Los círculos amarillos indican los perfiles sedimentológicos relevados en cada zona. ASE: Arroyo Serrucho; ANE: Arroyo Negro; ACN: Arroyo Calabozo Norte; ACS: Arroyo Calabozo Sur; PLN: Plomo Norte; PLE: Plomo Este; PLW: Plomo Oeste; APS: Arroyo Plomo Sur; ATW: Arroyo Torrecillas Oeste; ALV: Arroyo La Vaina; PCH: Río Potimalal. 


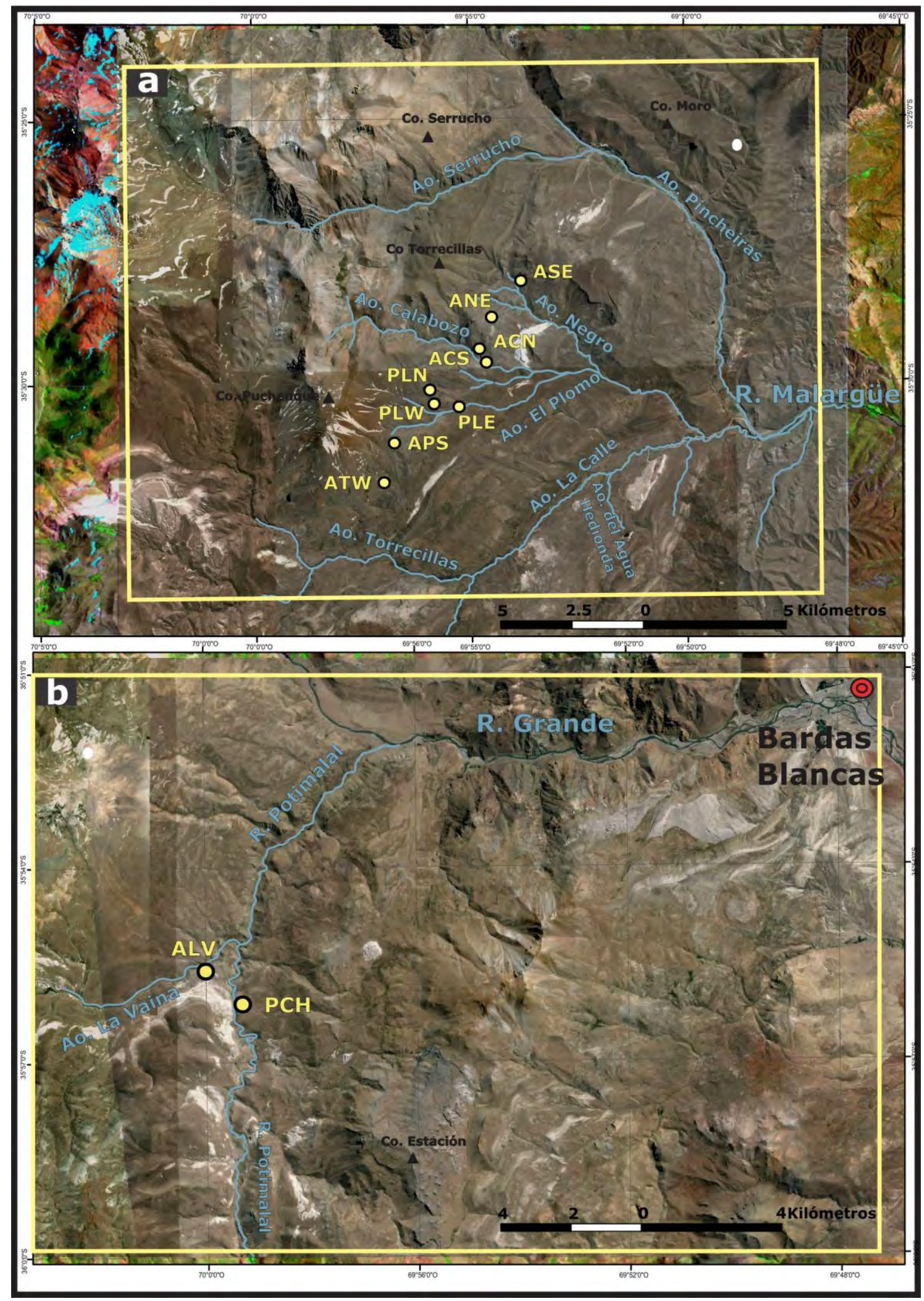




\section{5: Tareas de laboratorio}

Las actividades de laboratorio consistieron en la descripción petrográfica, el análisis composicional por difractometría de rayos $\mathrm{X}, \mathrm{y}$ el estudio paleontológico de microfósiles y macrofósiles. En el Anexo II puede consultarse un índice de las muestras obtenidas en el campo sobre las que se realizaron dichos estudios.

\subsection{1: Descripción petrográfica}

Se efectuaron estudios petrográficos bajo microscopio óptico de polarización y, en determinados casos bajo microscopio de catodoluminiscencia en frío, sobre doscientas veinticinco secciones delgadas de calizas y areniscas (Anexo II). Estos análisis de detalle se llevaron a cabo mediante una descripción exhaustiva de las láminas delgadas, acompañada por la captura de imágenes en los sectores de interés dentro de las láminas y su posterior procesamiento a través del uso de software específico. Además se realizó el conteo de modas detríticas sobre determinadas secciones delgadas. Luego esta información se analizó en gabinete con el objetivo de obtener una clasificación y caracterización diagenética del material en estudio.

\subsection{1-I: Petrografía óptica de polarización}

El análisis composicional y diagenético se realizó sobre ciento setenta y cuatro secciones delgadas de calizas y areniscas (Anexo II), presentando en general escaso grado de alteración, a fin de facilitar el reconocimiento óptico de las especies minerales. Además se estudió la composición de cinco secciones delgadas pertenecientes al relleno de trazas fósiles.

\section{Condiciones operativas}

Las secciones delgadas fueron pulidas hasta obtener un espesor de $30 \mu \mathrm{m}$ en el Taller de Cortes Delgados y en el Laboratorio de Mesoscopía ubicados en las 
instalaciones del Centro de Investigaciones Geológicas. Posteriormente, los cortes delgados fueron analizados en el Laboratorio de Microscopía del Centro de Investigaciones Geológicas mediante un microscopio óptico de polarización Nikon Eclipse E-200. Para la toma de fotografías se utilizó una cámara digital para microscopio LEICA FC290HD y para el procesamiento de las imágenes capturadas se usó el software Leica Application Suite (LAS) 3.7. Por su parte, el conteo de las modas detríticas se llevó a cabo mediante un contador de puntos Swift model $F$ adosado a un microscopio óptico de polarización Leitz Laborlux 12 POL.

\section{Análisis de las secciones delgadas}

En cuanto a las características litológicas de las calizas y areniscas, la descripción de las secciones delgadas bajo petrografía convencional permitió ajustar las modas granulométricas descriptas en el campo. Sobre las secciones delgadas de calizas se realizó la descripción y caracterización de los principales componentes (partículas carbonáticas, fracción terrígena, matriz y cemento), se determinaron parámetros texturales y se llevo a cabo un análisis semicuantitativo empleando tablas de comparación (Flügel, 1982). Los parámetros texturales considerados fueron el tamaño de las partículas, su forma, el grado de preservación, y el contenido relativo de los granos respecto al de la matriz. Las sedimentitas carbonáticas fueron denominadas según sus texturas depositacionales (Dunham, 1962; modificada por Embry y Klovan, 1971) acompañada por un adjetivo calificativo basado en el componente mejor representado.

Respecto a la litología de las psamitas, la descripción de las láminas delgadas permitió determinar en forma particular el tamaño, redondez, selección y composición de los detritos. Además, a través de la cartilla de cuantificación por comparación visual (Terry y Chilingar, 1955) se estimó inicialmente la composición modal de los minerales detríticos.

Asimismo se realizaron conteos de modas detríticas siguiendo el método GazziDickinson (Ingersoll et al., 1984; Zuffa, 1985), en muestras representativas de las distintas texturas psamíticas. Sobre las secciones delgadas se realizó el conteo de 
trescientos clastos con el objeto de efectuar el análisis modal y definir la procedencia de las areniscas. Los criterios utilizados para la identificación de los granos del entramado se basaron en aquellos propuestos por Dickinson (1970), Dickinson y Suczek, (1979) y Dickinson et al. (1983). Los resultados del análisis composicional y de procedencia se volcaron en diagramas triangulares (Dott, 1964 modificado por Pettijhon et al., 1972; Folk et al., 1970; Dickinson et al., 1983).

En forma paralela al análisis composicional de las calizas, se identificaron en las secciones delgadas los productos diagenéticos y posteriormente se definieron los procesos diagenéticos. Se puso especial énfasis en la descripción de la fábrica de los cementos carbonáticos y su posición dentro de la cavidad poral, lo que permitió distinguir diferentes generaciones de cementos. Para la caracterización de la fábrica de los cementos se tuvo en cuenta su textura y composición.

\subsection{1-II: Petrografía no convencional (catodoluminiscencia en frío)}

El estudio diagenético de detalle se llevo a cabo sobre cincuenta y uno (51) láminas delgadas de calizas (Anexo II) con abundantes generaciones de cemento carbonático, con el objetivo de identificar los rasgos diagenéticos no reconocidos bajo petrografía estándar, especialmente los referidos a las variaciones texturales y composicionales de las fases cementantes.

\section{Condiciones operativas}

Las secciones delgadas efectuadas fueron pulidas hasta obtener un espesor de $15 \mu$, apropiado para ser examinado bajo un microscopio Nikon Eclipse con equipo de catodoluminiscencia en frío CITL MkIII, localizado en el Centro de Investigaciones Geológicas. Un grupo de laminas delgadas fueron observadas mediante un microscopio Nikon Eclipse $\mathrm{Ci}$ con equipo de catodoluminiscencia por cátodo en frío marca CITL Mk5-2, ubicado en las instalaciones de la University of Liverpool, Reino Unido. Sus condiciones operativas fueron mantenidas a 10-12 Kv (corriente 
utilizada), 300 a $500 \mu \mathrm{A}$ (tensión apropiada) y 0.04-0.07 mbar (vacio sostenido). Para la toma de fotografías se utilizó una cámara digital para microscopio Nikon DS Fi1C, mientras que su procesamiento se llevo a cabo a través del uso del software NiSElements F4.00.06.

Ésta técnica se basa en que la generación de catodoluminiscencia en un cristal está relacionada con la presencia de centros de luminiscencia, correspondientes a impurezas o defectos estructurales dentro del cristal que absorben energía y emiten un fotón de luz (Tarashchan y Waychunas, 1995). En los minerales la luminiscencia comúnmente es controlada por iones que actúan como impurezas en la estructura cristalina, dentro de los que se puede diferenciar a los elementos que se comportan como activadores de la luminiscencia de aquellos que lo hacen como inhibidores. Para el estudio de los minerales carbonáticos se considera como elemento índice activador al $\mathrm{Mn}^{+2}$ y como elemento inhibidor al Fe ${ }^{+2}$ (Marshall, 1988).

\section{Análisis de las secciones delgadas}

A partir del análisis bajo catodoluminiscencia ( $C L$ ) de las secciones delgadas de calizas se revelaron rasgos de pequeña escala presentes en la roca, como también aspectos texturales de las fases cementantes no diferenciables bajo petrografía convencional. Las características de pequeña escala identificadas fueron el crecimiento de minerales neoformados remplazando o desplazando la textura previa, la presencia de microfracturas, y las texturas de reemplazo en los clastos terrígenos. Por otra parte, en el caso particular de las fases cementantes se diferenciaron generaciones de cementos no luminiscentes de otras luminiscentes. Dentro de las fases luminiscentes se distinguieron patrones de luminiscencia zonados, y se identificó el contenido máximo y mínimo de zonas dentro de cada uno de los patrones. Asimismo, se pudo reconocer con mayor precisión la porosidad inicial de la roca y como fue su evolución en el tiempo a través de la secuencia de crecimiento de las fases cementantes dentro de las cavidades porales. 


\subsection{2: Análisis composicional por difractometría de rayos $X$}

Mediante difractometría de rayos $X$ fueron analizadas un total de veintiséis muestras en el laboratorio de Difracción de Rayos $X$ del Centro de Investigaciones Geológicas; cinco de ellas corresponden a psamitas y veintiuna a calizas (Anexo II). El objetivo de este estudio consistió en obtener tanto la composición mineralógica esencial de las rocas (diagrama de roca total) como las proporciones relativas de los argilominerales presentes la matriz de cada una de ellas (diagramas de arcillas).

\subsection{2-I: Tratamiento de la muestra}

Se molieron entre 10 y 20 gramos de las muestras seleccionadas en un mortero de porcelana hasta obtener un polvo muy fino impalpable. Una fracción de este polvo fue colocada en un portamuestra de aluminio, compactando el polvo uniformemente hasta obtener una superficie lisa y regular para ser expuesta a los Rayos X. La muestra así preparada se denomina muestra total, ya que a partir de su diagrama se puede establecer la mineralogía general de la roca.

En el caso particular de las muestras de calizas y areniscas carbonáticas, antes de determinar la composición de la fracción arcillosa, se trató a estas muestras con una solución buffer de acetato sódico y ácido acético glacial (solución de Morgan) según el método descripto por Hein et al. (1976). El objetivo de este pretratamiento es remover el material carbonático de la muestra con el fin de analizar la fracción fina contenida en el residuo sólido insoluble.

Para determinar de manera precisa la composición de los minerales arcillosos se prepararon tres muestras orientadas. El polvo impalpable de la muestra se coloca en un vaso precipitado y se lo completa con agua destilada. La mezcla de sedimento y agua se deja reposar por veinte minutos y posteriormente se extrae una porción de la suspensión mediante una pipeta y se la monta en un portaobjeto. Este procedimiento se repite hasta obtener las tres muestras. Se dejan secar, permitiendo que las arcillas sedimenten lentamente, adquiriendo una orientación 
preferencial según el plano (001) (Moore y Reynolds, 1989). El primero de los preparados (muestra natural) fue analizado directamente a fin de obtener un difractograma base con las reflexiones de los distintos minerales presentes. La segunda muestra orientada, denominada muestra glicolada, fue colocada en una campana de vacío sometida a los vapores de etilenglicol durante dos horas. Este compuesto químico fue utilizado para identificar de manera rápida a las arcillas del grupo de la esmectita, debido a que éstas aumentan su espaciado basal en forma muy evidente al absorber las moléculas de gran tamaño del etilenglicol. La última muestra montada, Ilamada muestra calcinada, fue colocada en una mufla a $550^{\circ}$ C durante dos horas. Este tipo de tratamiento, denominado calcinación, genera diferentes efectos según el tipo de argilomineral presente. En los minerales del grupo de la caolinita produce la destrucción de su estructura cristalina, con lo cual su registro no aparece en los difractogramas. En el caso de las esmectitas, al ser eliminada el agua de las capas internas, el espaciado basal se contrae de $15 \AA$ (para la muestra natural) a $10 \AA$, adquiriendo de esta forma la estructura cristalina de la illita. Por otra parte, este proceso no modifica la estructura de la illita ni de la clorita, conservándose su espaciado de $10 \AA$ y $14 \AA$ respectivamente.

\subsection{2-II: Condiciones del registro}

Para la lectura de las muestras se empleó un Difractómetro PANalitical Xpert Pro, con radiación de CuK ade $1,54 \AA$ con filtro de $\mathrm{Ni}$, un voltaje de $40 \mathrm{Kv}$. y una intensidad de corriente de $40 \mathrm{~mA}$. La velocidad de registro se fijó en $2^{\circ} 2 \theta / \mathrm{min}$., con una constante de tiempo de 5 segundos y el intervalo de registro se fijó entre:

$3^{\circ}$ y $37^{\circ} 2 \theta$ para la muestra total

$2^{\circ}$ y $32^{\circ} 2 \theta$ para la muestra natural

$2^{\circ}$ y $27^{\circ} 2 \theta$ para la muestra glicolada

$3^{\circ}$ y $15^{\circ} 2 \theta$ para la muestra calcinada.

Los diagramas de difracción de rayos $X$ obtenidos se procesaron digitalmente mediante programas de tratamiento de datos (Origin) y de dibujo (Corel Draw). 


\subsection{2-III: Análisis cualitativo}

Con el objetivo de identificar las diferentes especies minerales presentes en las muestras se convirtieron los valores de los picos del difractograma a los correspondientes espaciados $\boldsymbol{d}$ de los planos que generan las reflexiones, según lo expresado en la Ley de Bragg. En la Ley de Bragg $\boldsymbol{n}$ es un número entero, $\boldsymbol{\lambda}$ es la longitud de onda de los rayos $X, \boldsymbol{d}$ es el espaciado entre la familia de planos equivalentes (medido en Amstrongs) y $\boldsymbol{\theta}$ es el ángulo de difracción.

\section{$\mathbf{N} \lambda=\mathbf{2 d} \operatorname{sen} \theta$}

Luego se procedió a la lectura de este gráfico, para lo cual se le asignó a cada pico una especie mineral de acuerdo con los patrones estándar establecidos (Brown y Brindley, 1980), tanto para conocer la mineralogía general de las rocas (sobre muestra total), como para determinar la composición de los argilominerales (sobre muestras orientadas).

\subsection{2-IV: Análisis semicuantitativo}

En el difractograma de la muestra total se realizó una estimación de las proporciones de los componentes a partir de la intensidad del pico principal de cada mineral. La estimación de los componentes minerales se clasificó de acuerdo a su abundancia en: traza (tr: $<1 \%$ ); muy escaso (me: 1-5\%); escaso (e: 5-15\%); moderado ( $\boldsymbol{m}:$ 15-25\%); abundante (a: $25-50 \%$ ) y muy abundante (ma: $>50 \%$ ), según los trabajos de Raigemborn et al. (2014) y Varela et al. (2013).

Mediante esta técnica se reconocieron las principales asociaciones mineralógicas.

Para estimar las proporciones semicuantitativas de los argilominerales, se procedió a la medición de las áreas encerradas bajo los picos de las reflexiones (001) para la illita, la caolinita y la esmectita y (002) para la clorita (Biscaye, 1965), sobre el patrón de la preparación glicolada. De esta forma fueron determinados los porcentajes relativos de cada argilomineral dividiendo los valores de las áreas por un factor empírico, establecido por Biscaye (1965) como 1 para la illita, 2 para la caolinita y la clorita, y 4 para la esmectita. 


\subsection{3: Análisis paleontológico}

La identificación taxonómica de los fósiles recolectados en el campo, especialmente ostras y braquiópodos (Anexo III), estuvo a cargo del Lic. Aron Siccardi (UNLPCONICET) y el Dr. Leandro M. Pérez (UNLP-CONICET). Por otra parte, un total de quince muestras de caliza de textura wackestone, packstone y floatstone perteneciente a seis perfiles sedimentológicos (Anexo II), fueron tratadas para la recuperación de microfósiles y nanofósiles, analizadas por el Dr. Juan Pérez Panera (CONICET, Y-TEC), la Lic. Diana Ronchi (Y-TEC) y la Lic. Luciana Hiriart (Y-TEC). Dicho trabajo constituye el primer estudio de estas características en la Formación Calabozo y se realizó con la finalidad de reconocer la signatura paleoambiental de algunas sucesiones portadoras de escasa diversidad de macrofósiles.

Esta información, detallada en el Anexo III, resulto de importancia para caracterizar la fauna presente en las formaciones Calabozo y Lajas y sus resultados más importantes se encuentran insertos en la identificación e interpretación de las facies carbonáticas y las asociaciones de facies del intervalo estratigráfico en estudio.

Finalmente, en cuanto al análisis de las trazas fósiles, si bien la mayor parte fueron identificadas en el campo, en gabinete se realizo la asignación icnotaxonómica de aquellas que a escala de campo resultaron dudosas (Anexo II). Para las tareas de identificación, descripción e interpretación de las icnitas se contó con la colaboración del Dr. Sebastián Richiano (UNLP-CONICET) y del Lic. Aron Siccardi (UNLP-CONICET). Los datos obtenidos a través de este estudio contribuyeron a las interpretaciones paleoambientales.

\section{6: Elaboración intelectual de la información obtenida}

Sobre la base del análisis conjunto de las características macroscópicas y microscópicas del intervalo estratigráfico analizado se identificaron e interpretaron las facies sedimentarias carbonáticas y clásticas. Para la denominación e interpretación dinámica de las diferentes litofacies se especificó un código de facies. Una vez definidas se agruparon según su íntima relación en sentido vertical y sus 
relaciones estratales, obteniendo las asociaciones de facies que representan los diferentes subambientes de acumulación. En particular en los subambientes carbonáticos se definieron los procesos diagenéticos que modificaron a los mismos, y a partir de su interpretación se elaboró un modelo evolutivo diagenético. Posteriormente, mediante el análisis de esta información y de las relaciones laterales y verticales de los diferentes subambientes, se logró la interpretación de los sistemas de acumulación, estableciendo el paleoambiente de sedimentación para el intervalo estratigráfico estudiado. De esta forma se alcanzó un esquema general de evolución temporal y espacial para este intervalo estratigráfico en la región sudoccidental de la provincia de Mendoza. Dicho esquema permite explicar los factores que controlaron la acumulación de los depósitos de las formaciones Calabozo y Lajas y los cambios que tuvieron lugar en el pasaje entre ambas unidades y entre las formaciones Calabozo y Tábanos, dentro del ámbito de la Cuenca Neuquina. 


\section{CAPÍTULO 3: ÁMBITO GEOLÓGICO, ESTRATIGRAFÍA Y ANTECEDENTES}

\section{1: La Cuenca Neuquina}

La Cuenca Neuquina se ubica en la región centro-oeste de Argentina y este de Chile, entre los $34^{\circ}$ y $41^{\circ}$ LS y los $66^{\circ}$ y $71^{\circ}$ LW (figura 3.1). Esta cubeta comprende un área de $120.000 \mathrm{~km}^{2}$ (Yrigoyen, 1991) que en el territorio argentino abarca casi la totalidad de la provincia de Neuquén, el sur de la provincia de Mendoza, sudoeste de la provincia de La Pampa y noroeste de la provincia de Río Negro (Digregorio, 1972; Digregorio y Uliana, 1979) (figura 1.1). Hacia el norte se extiende a lo largo del eje de la Cordillera de los Andes hasta los $31^{\circ}$ LS en la provincia de San Juan, donde se la denomina Cuenca de Aconcagua o Sector Aconcagüino (Gulisano y Gutiérrez Pleimling, 1994; figura 3.1).

Durante la mayor parte de su historia, la Cuenca Neuquina estuvo limitada al noreste y al sudeste por regiones tectónicamente estables del Bloque de la Sierra Pintada y del Macizo Nordpatagónico, respectivamente. Por el contario, su borde occidental fue determinado por la presencia de un arco magmático desarrollado en el margen activo de la placa Sudamericana (Legarreta y Gulisano, 1989; Howell et al., 2005) (figura 3.1).

En términos generales, la cuenca presenta una marcada geometría triangular, constituida entre los $34^{\circ}$ y $37^{\circ}$ LS por una zona estrecha y alargada en sentido norte-sur, mientras que al sur de los $37^{\circ}$ LS se extiende hacia el este en los dominios extraandinos, conformando el Engolfamiento Neuquino (Gulisano y Gutiérrez Pleimling, 1994; figura 3.1). 


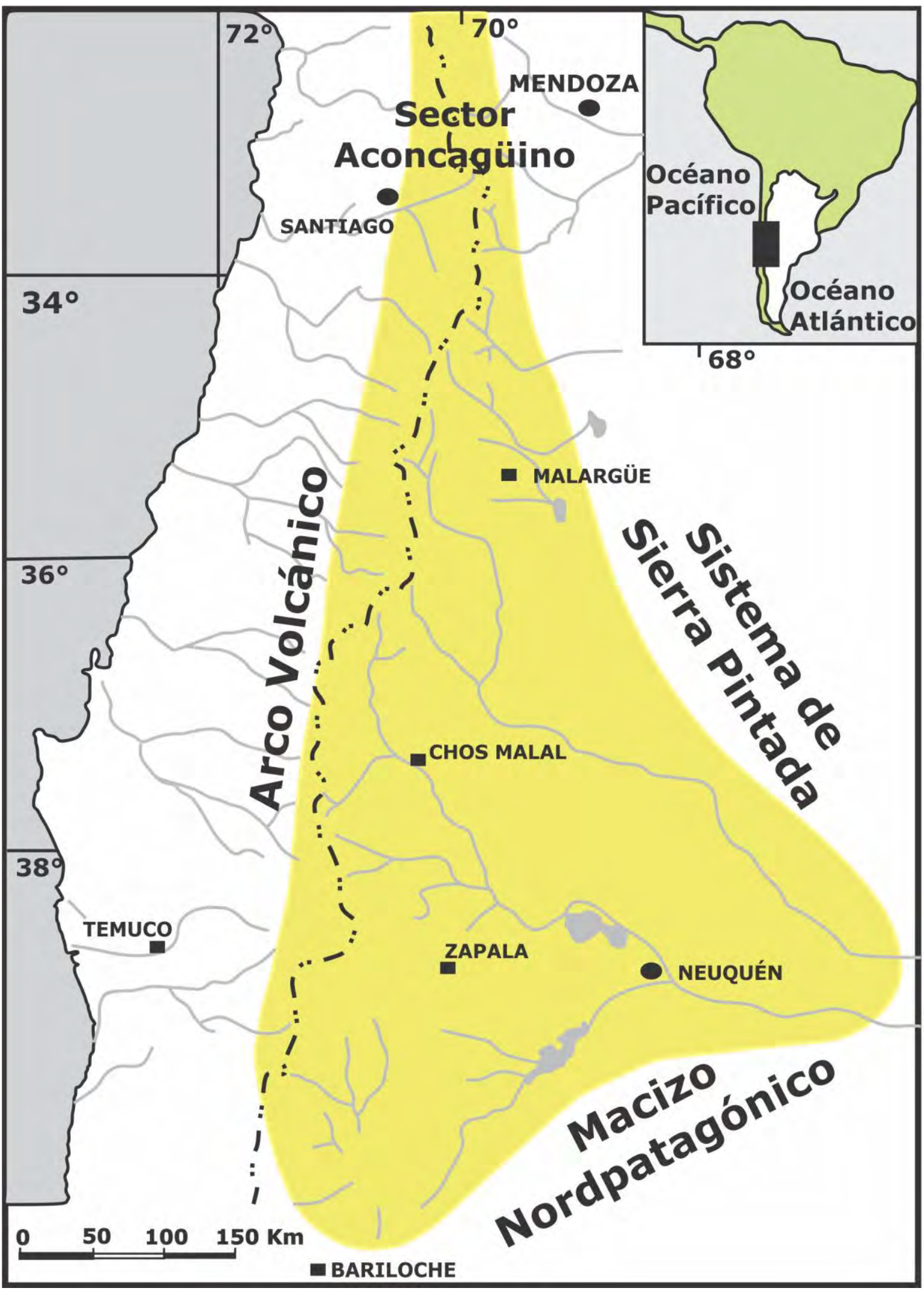

Figura 3.1: Contexto geológico de la Cuenca Neuquina y su extensión hasta el Sector Aconcagüino (modificado de Howell et al., 2005) 
Desde el punto de vista geológico, la Cuenca Neuquina constituye una depresión formada entre el Triásico Superior-Jurásico Inferior y el Paleoceno, en la cual se acumularon más de $6000 \mathrm{~m}$ de rocas sedimentarias marinas y continentales (Legarreta y Gulisano, 1989; Gulisano y Gutiérrez Pleimling, 1994). Esta cubeta subandina se asocia a un margen de placas convergentes, en donde una de las placas, de naturaleza oceánica, formó parte del proto-Oceáno Pacífico y la otra, conformada por corteza continental, constituyó el límite sudoccidental de Gondwana (Arregui et al., 2011).

\section{2: Contexto tectonoestratigráfico de la Cuenca Neuquina}

La historia tectonoestratigráfica de la Cuenca Neuquina (figura 3.2) muestra que esta cubeta ha tenido una evolución muy compleja y registra al menos 200 Ma de subsidencia cuencal (Vergani et al., 1995). Durante el Paleozoico, en tiempos previos a la generación de la cuenca, el área estuvo afectada por la convergencia, colisión y acreción de diferentes terrenos de corteza continental representados por los terrenos de Cuyania, amalgamado en el Ordovícico medio-tardío (Astini, 1996), Chilenia (Ramos et al., 1986) que colisionó durante el Devónico tardío, y finalmente el terreno Patagonia (Ramos, 1984) integrado al resto durante el Carbonífero tardío o Pérmico temprano (Rapalini et al., 2010). La acreción de este último terreno habría dado lugar a la formación de un frente de deformación adosado en el sudoeste de Gondwana (Arregui et al., 2011).

En el Carbonífero tardío (330-280 Ma), y como consecuencia de la convergencia de una placa oceánica por debajo del margen occidental de Gondwana, se generó en la región un arco magmático (Franzese y Spalletti, 2001; Llambias, 2001). Según estos autores hacia el Pérmico más alto a Triásico temprano (280 a $240 \mathrm{Ma}$ ) una anomalía astenosférica relacionada con el cese de la subducción habría generado un fenómeno extensional regional y magmatismo bimodal en zonas periféricas de la actual Cuenca Neuquina (Provincia Magmática Choiyoi cf. Llambías, 2001). Bajo estas condiciones de corteza engrosada y con temperatura anómala, la región de Gondwana adyacente al margen proto-Pacífico entre los $30^{\circ}$ y $40^{\circ}$ LS se habría debilitado y colapsado, generando la fase de rift inicial de la cuenca (estadio de 
sinrift). Este período abarcó del Triásico más alto al Jurásico temprano y se caracterizó por la generación de hemigrábenes aislados controlados por una fuerte subsidencia mecánica (figura 3.3). Los mismos se rellenaron con depósitos clásticos y volcaniclásticos asociados con flujos de lava e intrusivos de composición bimodal (Franzese y Spalletti, 2001). Posteriormente se instaló una etapa de post-rift con dominio de subsidencia de tipo termal (Jurásico temprano a medio) acompañado por el inicio de la subducción a lo largo del margen occidental de Gondwana (Franzese et al., 2003; figura 3.3). Bajo este contexto se posibilitó una transgresión marina generalizada desde el océano proto-Pacífico y la unificación de todos los pequeños depocentros en una sola entidad geodinámica (Franzese y Spalletti, 2001). A partir de este momento, la subsidencia regional coexistió con el crecimiento y desarrollo al oeste de un arco magmático durante el Mesozoico. Es de notar que durante ese estadío se produjeron diversos períodos de inversión tectónica debido a movimientos tectónicos relacionados con el desarrollo de los Andes (Uliana y Legarreta, 1993; Vergani et al., 1995). En el transcurso de este período, que abarca del Jurásico temprano al Cretácico temprano, se suceden una serie de ciclos sedimentarios conformados por alternancias de sedimentación marina y continental, de diferente distribución paleogeográfica y espesor.

Hacia el Cretácico tardío finaliza la etapa de subsidencia termal y comienza el alzamiento de la cordillera de los Andes que clausura definitivamente la conexión de la cuenca con el océano Pacífico (Arregui et al., 2011). De esta forma se implanta en la cuenca el domino de la subsidencia flexural, adquiriendo un comportamiento de cuenca de tipo antepaís, que alcanza su máxima fase de deformación en el Neógeno (figura 3.3). Esta fase tectónica compresiva, con clímax en el Mioceno y Plioceno, es la responsable de la generación de relieves montañosos importantes, así como también de la configuración final de deformación de la Cuenca Neuquina. 


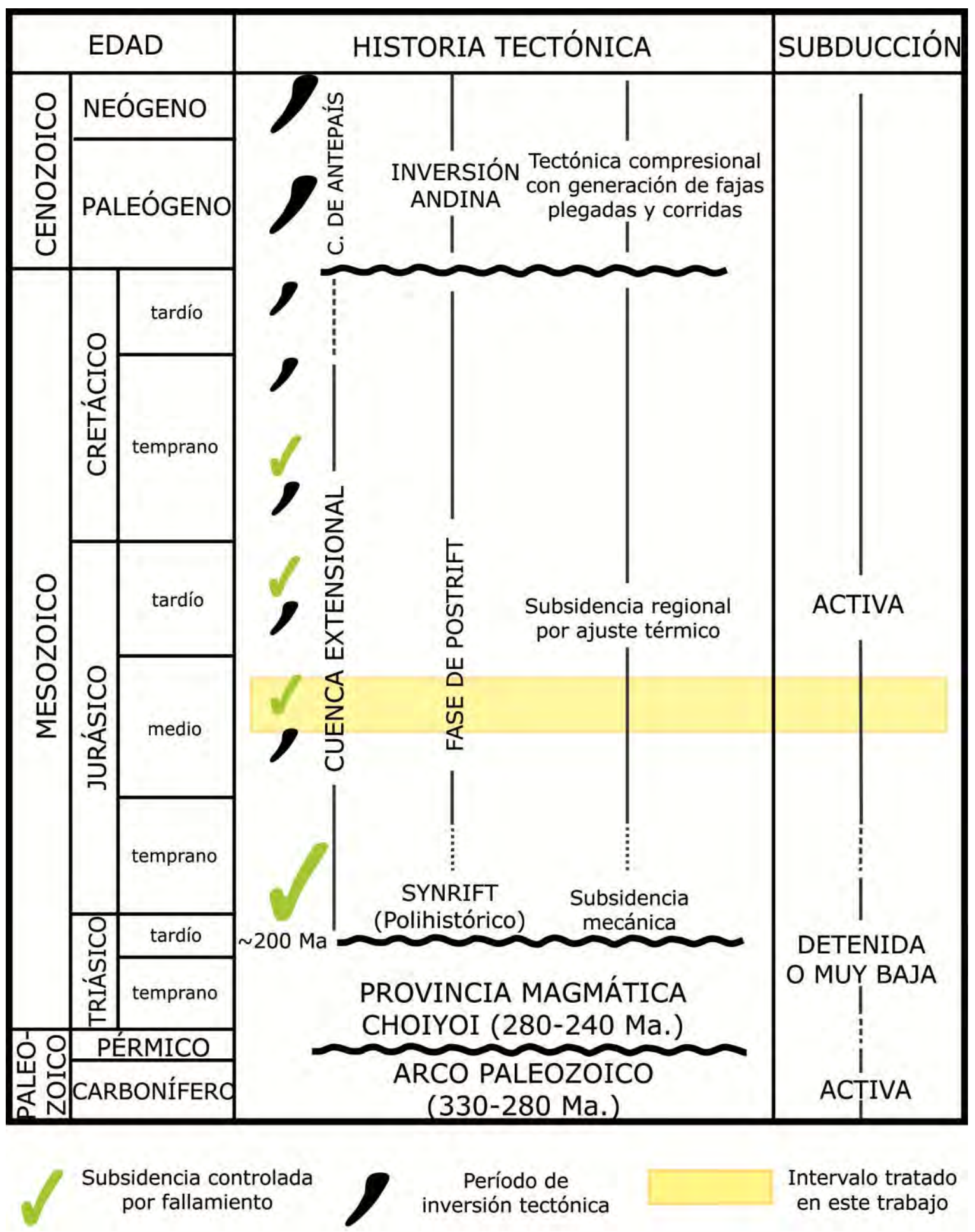

Figura 3.2: Historia tectonoestratigráfica de la Cuenca Neuquina y eventos relacionados (modificado de Schwarz, 2003). La subducción se desarrolla en el margen proto-Pacífico de Gondwana. 


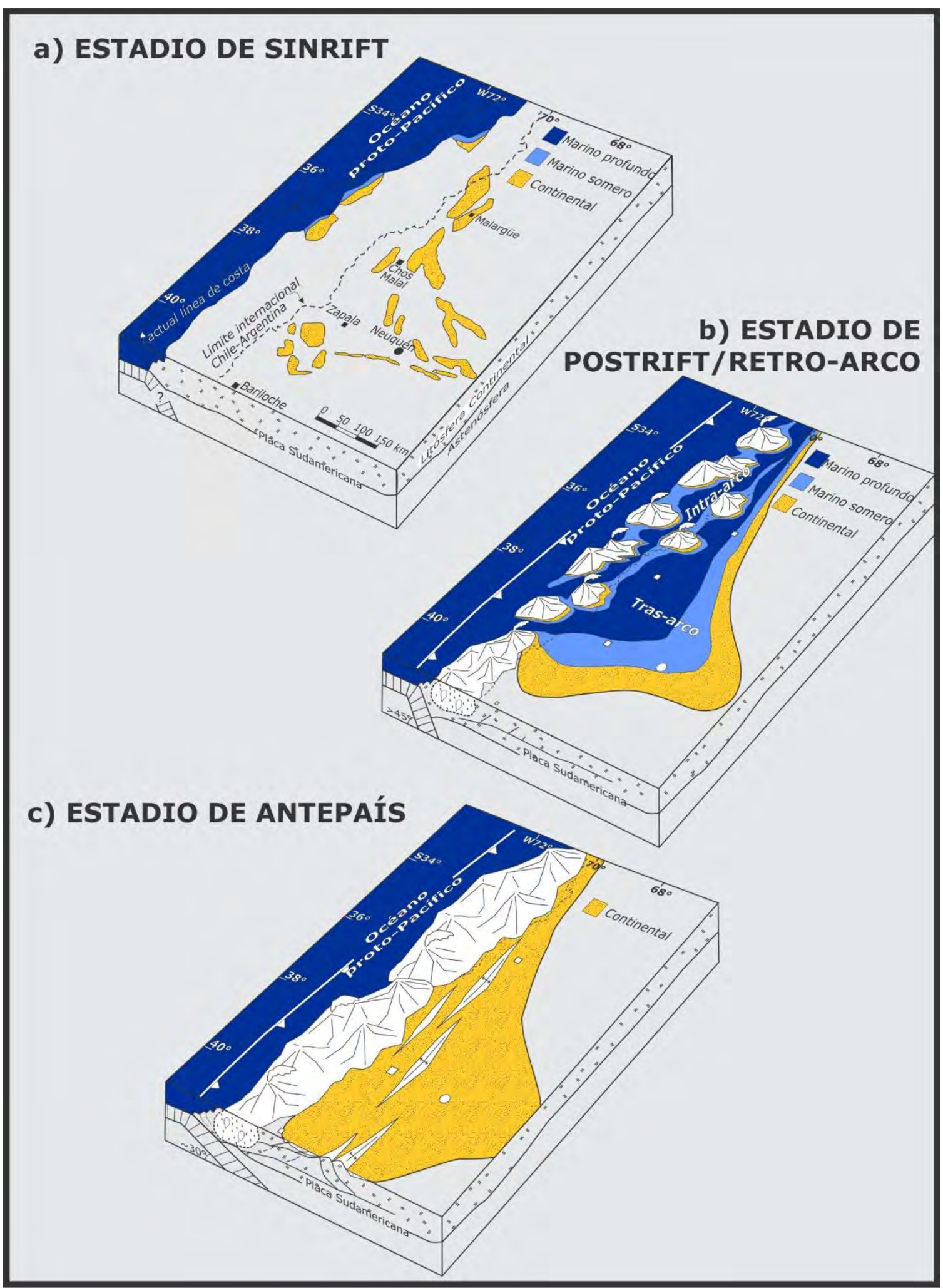

Figura 3.3: Representación esquemática de los estadios de evolución de la Cuenca Neuquina (modificado de Howell et al., 2005). 


\section{3: El relleno sedimentario de la Cuenca Neuquina}

La sucesión sedimentaria de la Cuenca Neuquina abarca desde el Triásico tardío hasta el Paleoceno y está integrada por rocas clásticas, carbonáticas, evaporíticas, piroclásticas y, en menor proporción, depósitos volcánicos, de ambiente marino hasta continental (Gulisano y Gutiérrez Pleimling, 1994). Este conjunto sedimentario se apoya sobre un basamento formado por rocas metamórficas de edad paleozoica inferior (formaciones Piedra Santa, Guaraco Norte y Colohuincul; Cingolani et al., 2011); rocas volcánicas, sedimentitas marinas y volcaniclásticas del Carbonífero Superior (Grupo Andacollo; Llambías et al., 2007) y rocas plutónicas y volcánicas incluidas dentro del Grupo Choiyoi de edad paleozoica superior a triásica inferior (Llambías y Sato, 2011).

Los estudios iniciales de carácter regional en la Cuenca Neuquina fueron realizados a partir del siglo XIX, entre los que se destacan los aportes de Bodenbender (1892), Burckhart (1900), Schiller (1912), Groeber (1918), Gerth (1925, 1931), Jaworski (1926), Lahee (1927), y Weaver (1931). No obstante, el primer análisis estratigráfico completo del relleno sedimentario fue elaborado por Groeber (1929, 1933, 1946), quien realizó extensos estudios en la Cuenca Neuquina. Este autor definió tres ciclos de sedimentación de mayor escala a los que denominó "Jurásico", Ándico y Riográndico (Groeber, 1946), basado en el reconocimiento de discordancias mayores e interrupciones en la sedimentación. Dentro de ellos también identificó ciclos de menor orden o subciclos (Cuyano, LotenianoChacayano, Mendociano, Rayociano, Neuqueniano y Malahueyano) que interpretó, en parte, como generados por la existencia de repetitivas transgresiones $y$ regresiones marinas. Los lineamientos propuestos por este autor aún hoy revisten significativa importancia.

Numerosos trabajos de Stipanicic (1966, 1969, entre otros) denotan un constante y exitoso esfuerzo por refinar el modelo original de Groeber mediante la documentación y valoración cronológica de las discontinuidades dentro del registro sedimentario del depocentro neuquino. Revisiones posteriores acerca del relleno de la cuenca fueron efectuadas por Digregorio (1972), Digregorio y Uliana (1979), 
Legarreta y Gulisano (1989) y Legarreta y Uliana (1999), entre otros. Sobre la base de estos aportes, se ha podido establecer el cuadro general de la figura 3.4.

Los estudios con enfoque estratigráfico-secuencial han permitido reagrupar parcialmente a las unidades litoestratigráficas correspondientes a la Megasecuencia Neuquina (Legarreta y Gulisano, 1989; Legarreta et al., 1993). Estos autores han diferenciado secuencias deposicionales o Supersecuencias, que a su vez se dividen en Mesosecuencias y por último en Secuencias. Se destaca que las Supersecuencias y Mesosecuencias se correlacionan en parte con los ciclos y subciclos de Groeber (1946). Estos estudios secuenciales han considerado que los cambios eustáticos de escala global y local han controlado de manera primordial el desarrollo de dichas secuencias de distinta escala. Sin embargo, investigaciones posteriores han mostrado una fuerte influencia de la tectónica en la génesis de algunas sucesiones del Mesozoico de la Cuenca Neuquina (Vergani et al., 1995).

\section{4: El Grupo Cuyo}

\subsection{1: Su definición}

El Subciclo Cuyano fue definido por Groeber (1946) como "facies marinas que varían en trechos cortos de arenosas a calcáreas y arcillosas a esquistosas", ubicadas en la sección inferior del Jurásico Andino. Su edad comprendía desde el "Hettangense" hasta el "Bajocense" medio a superior, y en ocasiones se extendía hasta el "Batonense". Más tarde, Groeber et al. (1953) diferenciaron dentro del Subciclo Cuyano un intervalo basal que abarca prácticamente todo el Liásico (Jurásico Inferior) conformado por lutitas, areniscas con conglomerados, tobas y mantos de carbón al cual denominaron Cuyano Inferior. A su vez, estos autores designaron como Cuyano Superior al intervalo "que comienza con la Zona de Leioceras opalinum y termina con la de Witchellia romani", correspondiente al Jurásico Medio basal, compuesto por lutitas, areniscas y areniscas conglomerádicas. Con posterioridad, el Subciclo Cuyano fue elevado a la categoría de "ciclo" al mismo tiempo que el Cuyano Inferior y Cuyano Superior fueron considerados como 
"subciclos" (Stipanicic, 1969). Asimismo, este autor delimitó el alcance de este ciclo al intervalo comprendido entre las discontinuidades asignadas a las fases diastróficas Río Atuel (Triásico Superior) y Sierra de Reyes (Bajociano superior). De igual modo, el límite entre los Subciclos Cuyano Inferior y Superior fue ubicado en la discontinuidad Charahuilla acaecida a fines del Pliensbaquiano (Stipanicic y Rodrigo, 1970).

El término Grupo Cuyo fue utilizado por primera vez por Stipanicic (1966) como una expresión equivalente al Subciclo Cuyano de Groeber (1946) para las provincias de San Juan, Mendoza y Neuquén, y posteriormente fue adoptado por Volkheimer (1978) para la región del río Atuel, provincia de Mendoza. Digregorio (1978) y Digregorio y Uliana (1980) también hicieron uso de esta denominación como equivalente al Subciclo Cuyano de Groeber (1946) o Ciclo Cuyano de Stipanicic (1969).

Dellape et al. (1978) propusieron denominar Grupo Cuyo al ciclo sedimentario restringido a tiempos del Liásico-Calloviano inferior, delimitado en su tope mediante una importante discontinuidad de carácter regional a la que denominaron discordancia Intracalloviana. Posteriormente, Gulisano (1981) definió el límite inferior de este grupo a través de la discontinuidad Intraliásica acaecida en el Hettangiano inferior. De esta manera, siguiendo el criterio de estos autores, el Grupo Cuyo quedó definido como un conjunto sedimentario limitado en su base y techo por las discordancias Intraliásica e Intracalloviana, respectivamente. Finalmente, sobre la base de muy diversos y exhaustivos trabajos paleontológicos, se ha determinado que esta secuencia evolutiva comprende el lapso Hettangiano a Calloviano medio (Riccardi y Gulisano, 1990).

Los aportes de Gulisano et al. (1984), Legarreta y Gulisano (1989), Gulisano y Gutiérrez Pleimling (1994), Limeres (1996) y posteriormente Legarreta y Uliana (1996) han contribuido a dividir este intervalo estratigráfico en unidades de diferente rango jerárquico basándose en los principios de la estratigrafía secuencial. Aspectos generales estratigráficos, bioestratigráficos y sedimentológicos del Grupo Cuyo, o de partes de él, fueron profusamente estudiados desde la década de los 70 
hasta la actualidad, tanto por sus potenciales como rocas generadoras y reservorio de hidrocarburos, como por su interés científico (Ballent, 1987; Zavala, 1993; Spalletti, 1995; Veiga, 1998; Riccardi et al., 1999; Gomez Omil et al., 2002; Ballent, 2004; McIlroy et al., 2005; Palma et al., 2005; Cabaleri et al., 2007; Riccardi, 2008; Spalletti et al., 2012; Armella et al., 2013a; Bressan et al., 2013; Veiga et al., 2013, entre otros).

\subsection{2: Principales características del Grupo Cuyo}

El Grupo Cuyo comprende la primera ingresión marina que cubre la cubeta neuquina y que a través de sucesivas oscilaciones de la línea de costa depositó un espeso intervalo de pelitas, areniscas, conglomerados, calizas y evaporitas de ambiente marino profundo hasta continental. Este ciclo sedimentario abarca un lapso de tiempo desde el Hettangiano-Sinemuriano, en el sur de la provincia de Mendoza, y el Pliensbachiano-Toarciano en la provincia del Neuquén, hasta el Calloviano medio (Gulisano y Gutiérrez Pleimling, 1994). La unidad tal como fue definida posee dos importantes discontinuidades en su base y techo: la discordancia basal determinada por la fase Rioatuélica (Intraliásica) que marca el hiatus sobre el que avanza la transgresión marina inicial sobre el sustrato, formado por depósitos piroclásticos y volcánicos del Ciclo Precuyano ,y en ocasiones, por las rocas ígneas del Grupo Choiyoi (Gulisano, 1981); y la discordancia Intracalloviana (Loténica) (Dellapé et al., 1978) ubicada en el tope de este ciclo, la cual indica una fuerte restricción de la Cuenca Neuquina en estos tiempos, coetánea con una caída global del nivel del mar (Riccardi et al., 2000). Mediante este límite se establece una clara diferenciación sedimentaria en el centro de la cubeta, consistente en un pasaje sin transición litológica desde depósitos distales de circulación restringida (evaporitas de la Formación Tábanos) pertenecientes a la cúspide del Grupo Cuyo, a niveles proximales de textura areno-conglomerádica propios de un ambiente de energía elevada y circulación abierta (base del Grupo Lotena; Dellapé et al., 1978). 


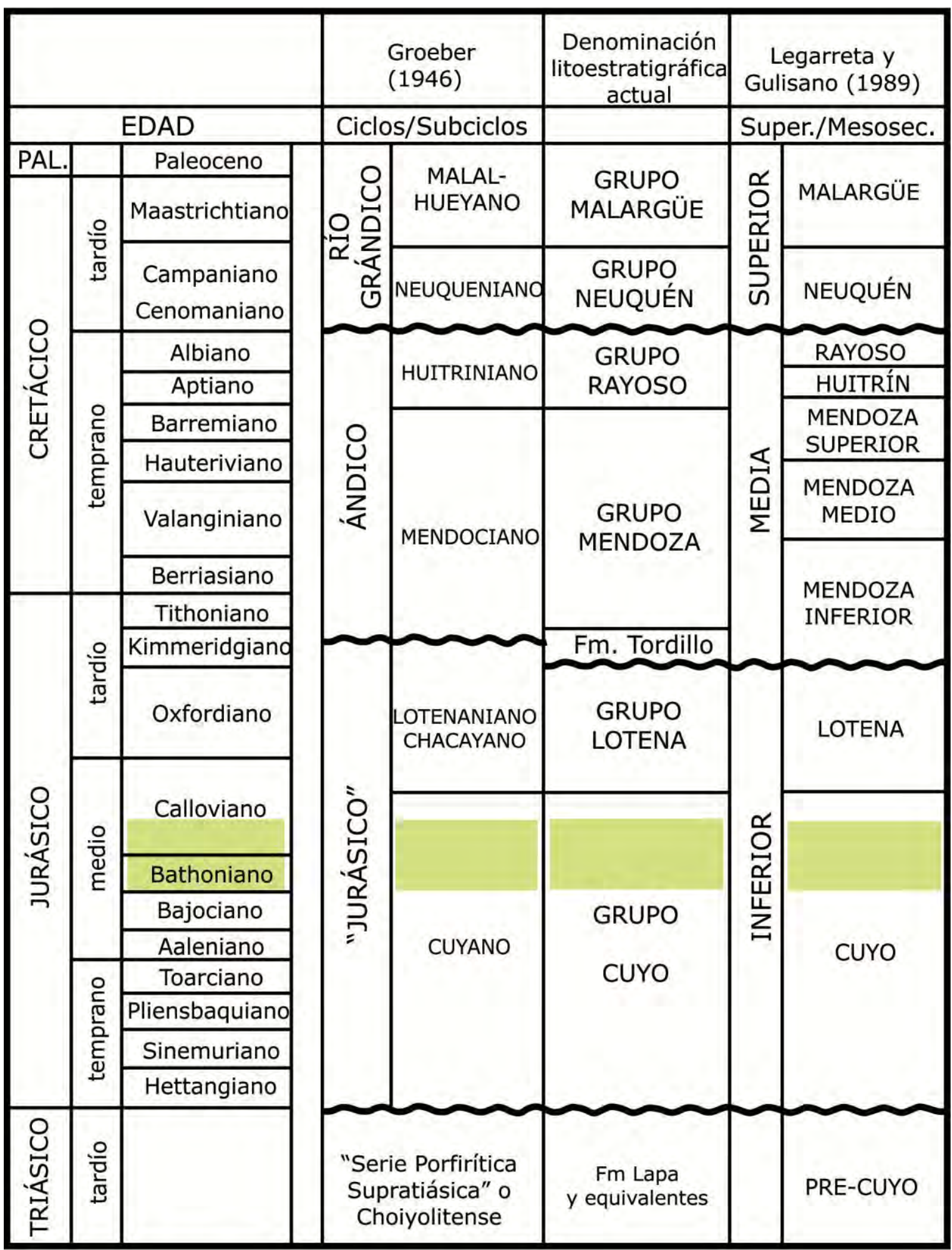

Figura 3.4: Cuadro estratigráfico del relleno de la Cuenca Neuquina (compilado de Groeber, 1946; Digregorio, 1972; Legarreta y Gulisano, 1989; Legarreta y Uliana, 1999). Super.: Supersecuencia; Mesosec.: Mesosecuencia; Pal.: Paleógeno. La zona sombreada de verde identifica el intervalo tratado en este trabajo. 
Desde el punto de vista secuencial, este conjunto sedimentario ha sido denominado Mesosecuencia Cuyo correspondiente a un ciclo de sedimentación de segundo orden de acuerdo a los criterios definidos por Haq et al. (1987). Este conjunto se dividió en siete unidades genéticas (secuencias de tercer orden) separadas por discordancias y sus concordancias correlativas en el sur de la provincia de Mendoza, y seis en el territorio de Neuquén (figura 3.5; Legarreta y Gulisano, 1989).

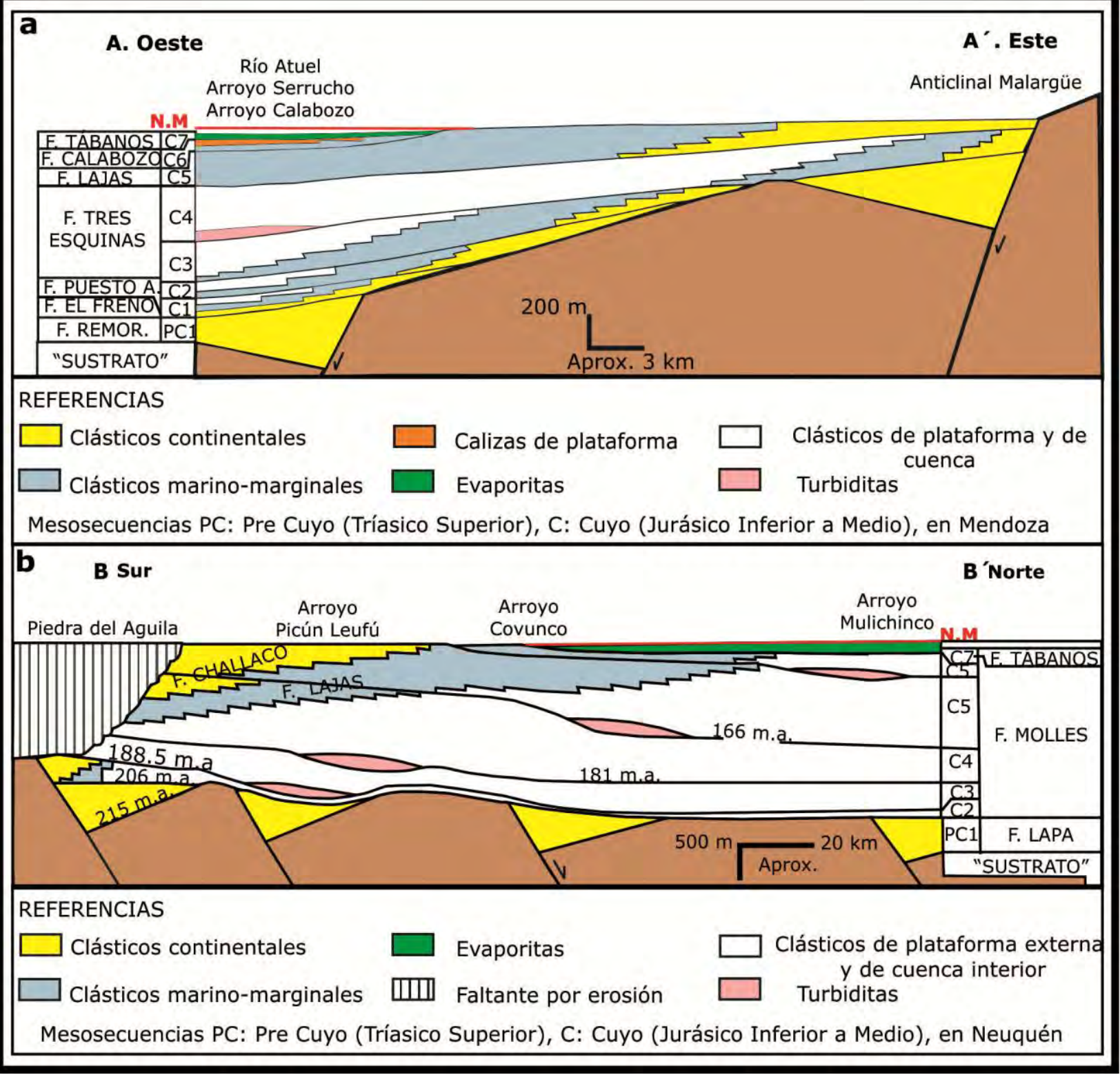

Figura 3.5: Esquema estratigráfico para la Mesosecuencia Cuyo: a) en la provincia de Mendoza, b) en la provincia de Neuquén (modificado de Legarreta y Gulisano, 1989). 
En tiempos del Retiano-Sinemuriano, mediante una subsidencia localizada en la región del río Atuel provincia de Mendoza, se produjo la primera ingresión marina a la Cuenca Neuquina a través de un corredor marítimo denominado "Estrecho de Curepto" (Vicente, 2005). A partir de ese momento comenzó la depositación de la Mesosecuencia Cuyo en el norte del depocentro neuquino representada por facies de lutitas negras finamente estratificadas atribuidas a la Formación Tres Esquinas, desarrollada en ambiente marino de plataforma externa a centro de cuenca (Volkheimer, 1978; Legarreta y Gulisano, 1989). Lateralmente esta unidad es reemplazada por depósitos arenosos de ambiente marino (Formación Puesto Araya) y hacia el antepaís, por conglomerados de ambiente fluvial hasta abanicos aluviales conocidos como la Formación El Freno (Gulisano y Gutiérrez Pleimling, 1994). Durante el Pliensbachiano al Toarciano, el mar se expandió rápidamente hacia el sur y el este de la cuenca, en una etapa de transición entre la subsidencia mecánica localizada ( $r i f t$ ) y de tipo térmica (sag). En este período se inició la depositación del Grupo Cuyo en el centro y suroeste de la provincia de Neuquén representada por la Formación Los Molles, integrada mayormente por pelitas oscuras de ambiente marino (plataforma costa afuera hasta interior de cuenca), que alternan con areniscas finas hasta gruesas y conglomerados de ambiente litoral hasta fluvial (Legarreta y Gulisano, 1989).

En el trascurso del Aaleniano al Bajociano, coincidente con la máxima expansión del área depositacional, se produjo un incremento del aporte clástico procedente del antepaís. Bajo estas condiciones en el sur y sudeste de la Cuenca Neuquina se establecieron sistemas progradantes de ambiente deltaico (Formación Lajas) acompañado por facies de capas rojas de origen fluvial (formaciones Challacó y Punta Rosada; Legarreta y Uliana, 1996). Por el contrario, hacia el sector mendocino de la cuenca un influjo reducido de sedimentos, acompañado por una baja tasa de subsidencia, produjo una sucesión con arreglo retrogradante de facies donde los clásticos acarreados por los ríos fueron retrabajados por acción de olas y tormentas (Formación Bardas Blancas) (Legarreta et al., 1993; Legarreta y Uliana, 1996).

En tiempos del Bathoniano a Calloviano temprano el área de acumulación del depocentro neuquino se redujo como consecuencia de una regresión general de los 
mares (Legarreta y Uliana, 1996). Durante este estadio, caracterizado por una marcada progradación de las facies de aguas someras, se depositó en el sudoeste de Mendoza la Formación Lajas conformada por areniscas y conglomerados finos hasta muy gruesos acumulados en condiciones marino-marginales a plataforma, acompañada por los términos terrígenos basales de la Formación Calabozo. Posteriormente, en el curso del Calloviano temprano, la tendencia decreciente del espacio de acomodación se revirtió momentáneamente durante un episodio de inundación que indujo la depositación de los niveles calcáreos de la Formación Calabozo (Legarreta et al., 1993). El perímetro de acumulación de esta unidad, desarrollada en un ambiente marino de plataforma somera, estuvo fuertemente controlado por la topografía heredada del sistema depositacional precedente (Legarreta y Uliana, 1996). Hacia la culminación del Calloviano temprano o bien en el comienzo del Calloviano medio tuvo lugar la acumulación de las evaporitas de la Formación Tábanos, las cuales se hayan restringidas a la depresión central de la cubeta (Legarreta y Gulisano, 1989). En este período la Cuenca Neuquina permaneció aislada del Océano Pacífico y bajo condiciones de acumulación hipersalina, muy posiblemente por un efecto de umbral morfológico ejercido por el arco magmático situado al oeste (Legarreta y Uliana, 1996; Armella et al., 2013).

\section{5: Formación Calabozo}

\subsection{1: Su definición}

Antes de que la Formación Calabozo fuera definida como tal por Dessanti (1973) en el sudoeste de la provincia de Mendoza, numerosos autores se ocuparon de la estratigrafía de la región, entre los que se destacan Bodenbender (1982), Burckhardt (1900, 1903), Gerth (1925), Jaworski (1926), Groeber (1953) y Stipanicic (1966), entre otros. En el trabajo "Sobre el terreno Jurásico y Cretáceo en los Andes Argentinos entre el río Diamante y el río Limay", Bodenbender (1982) describió la estratigrafía del oeste de la localidad de Malargüe en donde menciona los afloramientos del arroyo Negro y de los alrededores del arroyo Calabozo (figura 
2.2). Posteriormente, Gerth (1925) analizó con más detalle la estratigrafía de esta zona y realizó una serie de secciones columnares en las que identifica aspectos litológicos y paleontológicos de los niveles presentes. En el perfil relevado en la zona del arroyo Calabozo y el arroyo Negro (figura 3.6) Gerth (1925) reconoció bancos de calizas grises de carácter brechiforme y dolomítico, y niveles de calizas oscuras, correspondientes a la actual Formación Calabozo, que se apoyan sobre esquistos margosos y arenosos, asignados actualmente a la Formación Lajas. En su trabajo "Sedimentos mesozoicos de los Andes Argentinos" se lee: "En la pendiente hacia el arroyo Calabozo asoman debajo de las calizas, de carácter brechiforme y dolomítico, algunos bancos de caliza oscura con restos de fósiles silicificados no determinables (Rhynchonella, espina de Cidaris, etc.). Más abajo se hayan esquistos margosos, arenosos, con Gryphaeas y Sphaerocerates hinchados de mala conservación".

Por otro parte, el autor destacó que los bancos de caliza gris expuestos al sur del arroyo Calabozo, ubicados en el extremo austral del Cerro Puchenque (figura 2.2), presentan intercalaciones margosas que son rellenadas con colonias de corales Isastraca jawoskiii nov. sp. y Latimaeandra cf. Caraolensis steinm. Como se ha dicho, Gerth (1925) caracterizó a estos niveles carbonáticos desde el punto de vista litológico y paleontológico, pero en sus descripciones no definió sus límites estratigráficos ni su potencia.

Luego Groeber et al. (1953) mediante los datos de Bodenbender (1982), Burckhardt (1900), Gerth (1925) y Jaworski (1926), confeccionaron una sección columnar de la zona del Cerro Puchenque. En sus descripciones el autor le adjudicó una potencia de $40 \mathrm{~m}$ a los niveles de calcáreo dolomítico portadores de un banco de Isastrea jaworskii Gerth y Latimeandra sp., y $70 \mathrm{~m}$ a las lutitas oscuras con fósiles silicificados. Además, Groeber et al. (1953) le asignaron tentativamente una edad calloviana-oxfordiana a este paquete sedimentario que subyace a las evaporitas del Auquilcoense. Años más tarde, Stipanicic (1966) consideró que los niveles calcáreos expuestos en la zona del Cerro Puchenque pertenecen a la Formación La Manga y les adjudicó una edad oxfordiana. Asimismo, Stipanicic (1966) indicó que esta unidad subyace a la Formación Auquilco, yesífera, y se apoya sobre las areniscas del Calloviano inferior. Este autor basó sus 
interpretaciones en las similitudes litológicas que esta unidad presenta con las sedimentitas de la Formación La Manga expuestas en las Sierras de Reyes y de Bardas Blancas, y en los arroyos Blanco, La Manga y Santa Elena, localizados en provincia de Mendoza.

Fig. 7. - Perfil IX.-Seguida de los estratos del Lias y Dogger, según nfloramientos en In pendiente sud.poniente del Cerro Puchen y en los arroyos $\mathrm{Ca}$ lavoso y Negro.

1.- Yeso.

2.- Caliza dolomitica, brechiforme; interposicloues margosas con corales.

3.- Colizas negrns con restos de fósiles silicificados.

4.- Esquistos arenosos y bancos de caliza con Sphnerocerns $y$ Gryphanens.

5. - Esquistos margosos y bancos calcareos interpuestos. Banco con Phyllocerns.

6.-Banco de caliza margosn, arenosa, Heno de Pseudomonotis substrintr, $\mathrm{Du}$ mortieria, Paremileia. Localidad D 22

7.-Bancos de callza arenosa, en el arroyo Calavoso, llenos de Pleuromyn lin$\operatorname{sina} y$ Pseudogrammoceras quadratum. D 23.

8.- Calizas duras, azuladas. Spiriferinn rostruta, Terebratula, Rhynchonellas, Harpocerns ef. exaratum. L. 5.

9.- Calizas sillceas y areniscas tobácens.

10.-- Equivalente de 7, Lins superior; en el extremo austral del cerro Puchen. D 24 .

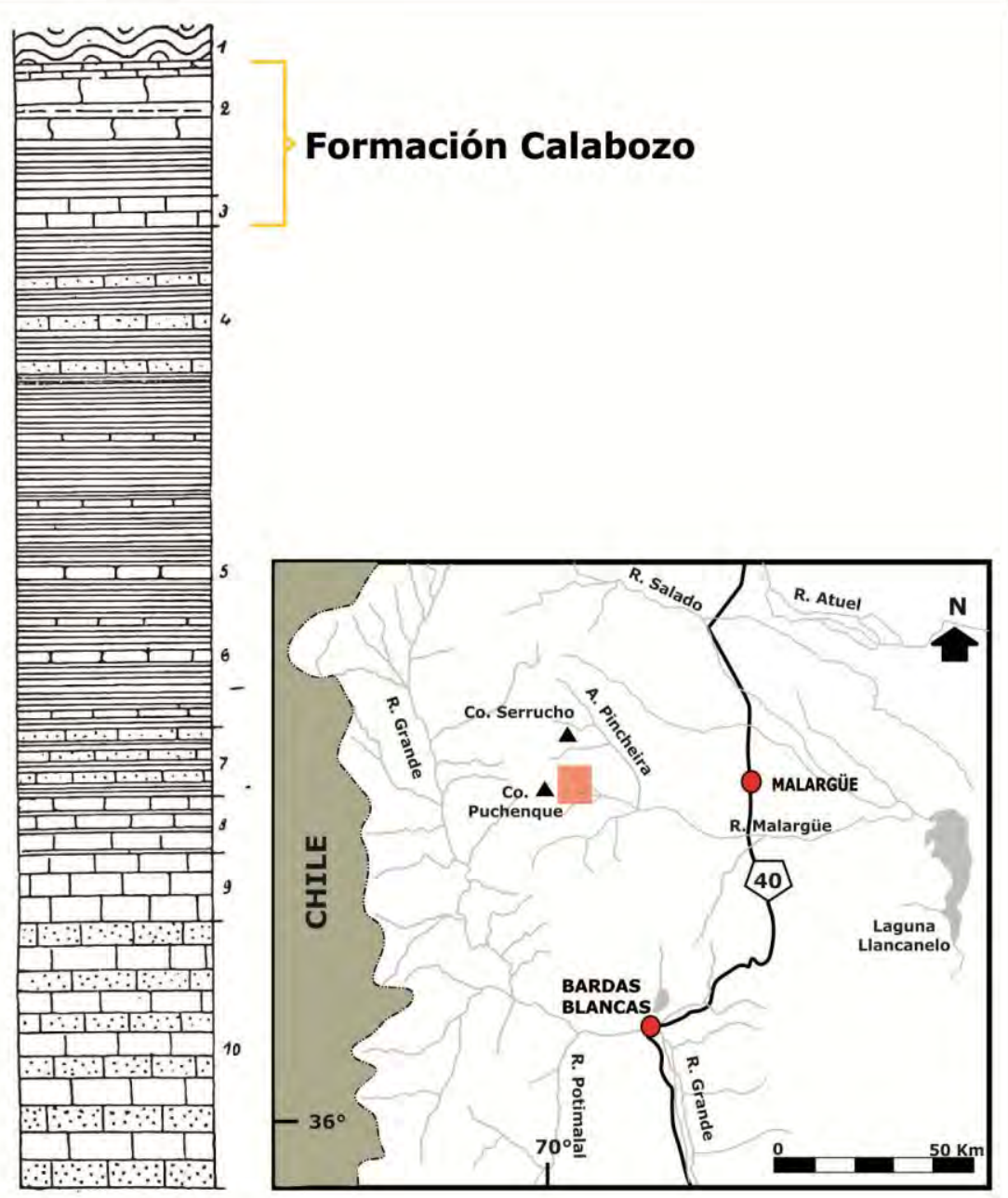

Figura 3.6: Perfil original relevado en la zona del arroyo Calabozo y el arroyo Negro extraído del trabajo de Gerth (1925) y su ubicación en la provincia de Mendoza.

Finalmente Dessanti (1973), en sus descripciones geológicas sobre la región de Bardas Blancas, provincia de Mendoza, definió formalmente a la Formación Calabozo. En el arroyo homónimo el autor describió a esta unidad como: "...gruesos bancos de calizas dolomíticas de color gris azulado, compactas y duras, con restos 
fragmentarios de bivalvos y braquiópodos entre los que distingue una pequeña ostra que viene siendo clasificada como Gryphea calceola Quens". Asimismo, Dessanti (1973) complementó que dentro de la Formación Calabozo incluye "...una caliza brechiforme que encierra trozos angulosos de la misma caliza en cemento calcáreo", con las que se asocian areniscas calcáreas y conglomerados. Según la definición de este autor la unidad presenta una potencia de $150 \mathrm{~m}$ y descansa, a través de una fina camada de conglomerados poligénicos, sobre las areniscas calcáreas del Calloviano (actualmente denominadas Formación Lajas). Dessanti (1978) agregó que con discontinuidad bien notable, pero sin discordancia, los estratos basales de la Formación Calabozo se apoyan sobre las areniscas calcáreas del Calloviano.

Dessanti (1973) reconoció otros afloramientos de la misma unidad calcárea al sur de la localidad tipo, en los Cerros del Toscal y de las Bardas Blancas y en la Sierra Azul (figura 3.7). Haciendo alusión a los afloramientos de la Sierra Azul, el autor escribió: "En discordancia bien notable descansan sobre las areniscas y conglomerados del Dogger calizas dolomíticas de color gris azulado con Gryphea calceola Quens y calizas arenosas de color gris blanquecino. A veces se presentan separaciones arcillosas entre los bancos de calizas gris azulados que encierran corales que forman colonias esferoidales".

Como punto sobresaliente de su trabajo, Dessanti $(1973,1978)$ expuso que: "La formación de calizas arenosas y dolomíticas ha sido equiparada por sus características litológicas con el Oxfordiano de los arroyos Blanco y de La Manga que contiene amonites estudiados por Stipanicic (1951)", adjudicándole una edad oxfordiana a la Formación Calabozo.

Con lo expuesto hasta aquí se aprecia que Dessanti $(1973,1978)$ difirió de las ideas de Stipanicic (1966) en incluir a los niveles calcáreos del Cerro Puchenque y de los alrededores de Bardas Blancas dentro de la Formación La Manga. Sin embargo, ambos autores coincidieron en atribuirle una edad oxfordiana a esta unidad. 


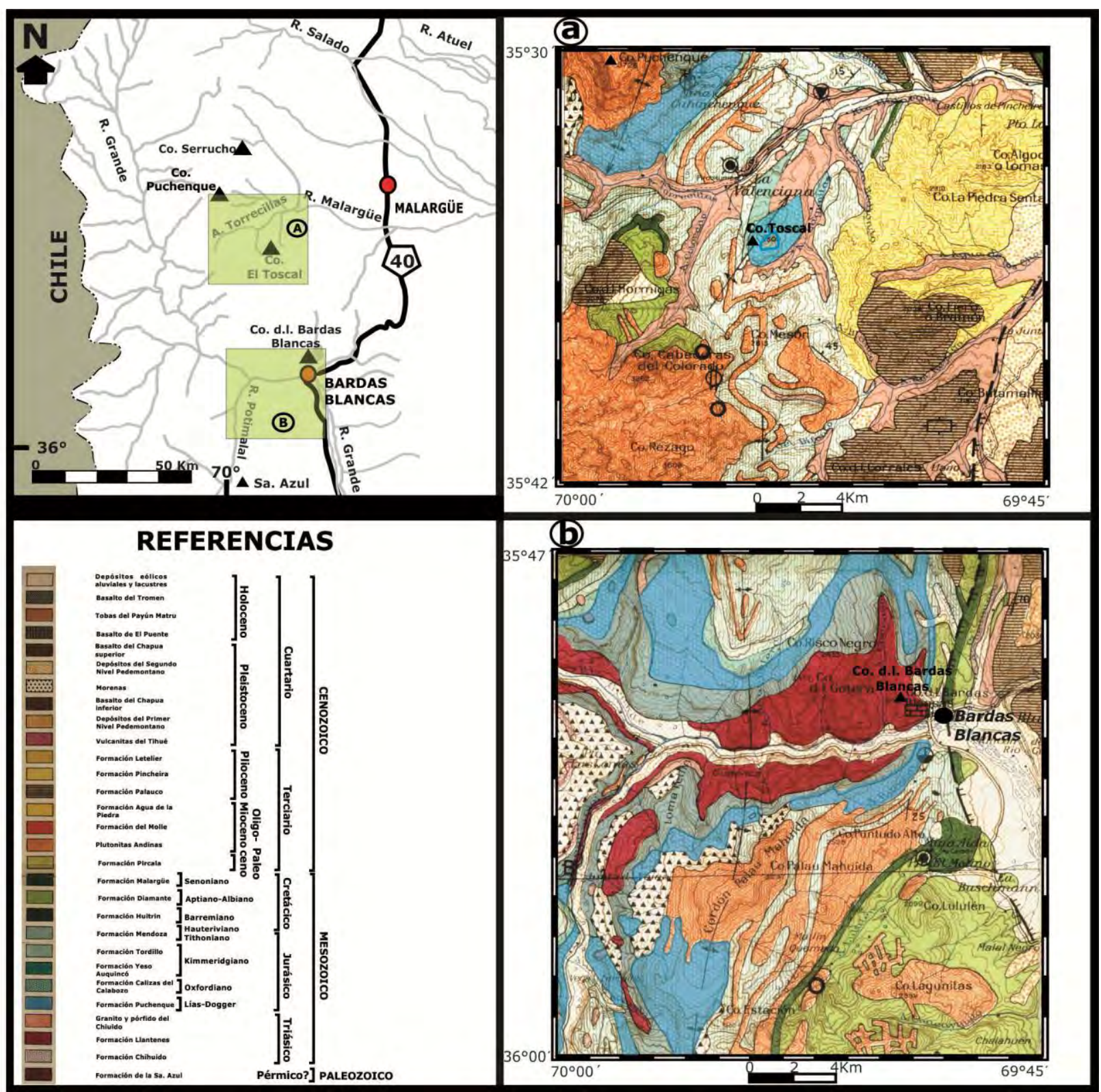

Figura 3.7: Hoja geológica de Bardas Blancas publicada por Dessanti (1973), donde se muestra los sectores donde aflora lo que el autor definió como Formación Calabozo (modificado de Dessanti, 1973). Se encuentra acompañado de un mapa de ubicación en la provincia de Mendoza.

\subsection{2: Alcance actual de la unidad}

Posteriormente a los trabajos de Dessanti $(1973,1978)$, varios autores abordaron el estudio de la Formación Calabozo de manera integrada con las formaciones infrayacentes y suprayacentes, en trabajos de índole regional (Gulisano et al., 
1984; Legarreta y Gulisano, 1989; Westermann y Riccardi 1991; Legarreta et al., 1993; Gulisano y Gutiérrez Pleimling, 1994; Legarreta y Uliana, 1996).

Gulisano et al. (1984) indicaron que la Formación Calabozo no está presente en el sector centro y sur de la Cuenca Neuquina, posiblemente debido a la acción de los procesos erosivos (discordancia intra-Calloviana) posteriores a la depositación de la unidad.

Legarreta y Gulisano (1989) en su contribución "Análisis estratigráfico secuencial de la Cuenca Neuquina (Triásico Superior-Terciario Inferior)" incluyeron a la Formación Calabozo dentro de la secuencia depositacional C6 ubicada en el tramo superior de la Mesosecuencia Cuyo del sur mendocino. Estos autores indicaron que esta entidad carbonática subyace a la secuencia depositacional C7 conformada por las evaporitas de la Formación Tábanos.

Años más tarde, Westermann y Riccardi (1991) describieron una serie de perfiles junto a su contenido fosilífero en el sudoeste de la provincia de Mendoza. En el perfil relevado en el Cerro Puchenque mencionaron que la Formación Calabozo está compuesta por calizas negras a grises y areniscas que subyacen a los niveles evaporíticos de la Formación Tábanos y suprayacen a las lutitas calcáreas gris oscuras a negras de la Formación Tres Esquinas. En su contribución dichos autores incluyeron dentro de la Formación Calabozo a los niveles arenosos de la unidad subyacente (Formación Lajas). A su vez, Westermann y Riccardi (1991) describieron en la sección relevada en las inmediaciones del arroyo La Vaina (localidad de Bardas Blancas) bancos de lutitas y calizas que por su posición estratigráfica y litología actualmente se asignan a la Formación Calabozo.

Posteriormente, Gulisano (1993) indicó que las capas calcáreas que se encuentran expuestas en los alrededores de las Sierras de Bardas Blancas y Azul, corresponden al Manguense sensu Groeber (1951) o a su equivalente, la Formación La Manga (Stipanicic, 1966). De esta forma, el autor excluyó a las citadas calizas de la Formación Calabozo y restringe el término "Caliza Calabozo" a la entidad carbonática que aflora en los alrededores del cerro Puchenque, incluida dentro de la parte alta del Grupo Cuyo (figura 3.8). 
Luego, Gulisano y Gutiérrez Pleimling (1994) en su trabajo "The Jurassic of the Neuquen Basin" destacaron que la Formación Calabozo se encuentra expuesta desde la zona del río Atuel hasta el sur de Bardas Blancas, sudoeste de la provincia de Mendoza (figura 3.8). Además, conforme con otros autores (Gulisano et al., 1984; Legarreta y Uliana, 1996), Gulisano y Gutiérrez Pleimling (1994) indicaron que en el noroeste de la provincia de Neuquén se registran niveles carbonáticos de poco espesor ubicados en la Sierra de la Vaca Muerta y en el sur del Cerro Domuyo, los cuales podrían asignarse tentativamente a la Formación Calabozo. Asimismo, Gulisano y Gutiérrez Pleimling (1994) destacaron que tanto los depósitos de la Formación Calabozo, como los de la unidad que la suprayace (Formación Tábanos), están ausentes en el centro y el sur de Neuquén y en el sur de Mendoza, debido a que no han sido depositados.

Trabajos posteriores focalizados en el análisis de facies y paleoambiental de la unidad restringieron la distribución de la Formación Calabozo al sudoeste de la provincia de Mendoza (Armella et al., 2005a, 2013; Cabaleri et al., 2003, 2007; Palma et al., 2005, 2007; Valencio et al., 2003). Palma et al. (2005, 2007a) limitaron la distribución de la unidad a los afloramientos ubicados en los alrededores del Cerro Puchenque. Por su parte, Cabaleri et al. (2003), Valencio et al. (2003) y Armella et al. (2005a, 2013) delimitaron la extensión norte de la unidad hasta las inmediaciones del río Salado, en el área de Las Leñas, y aportaron datos del área de Malargüe y Bardas Blancas (figura 3.8).

De lo anteriormente citado, se puede concluir que existen disparidades entre los diferentes autores acerca de la distribución de la Formación Calabozo en lo que concierne al área de la Cuenca Neuquina y, especialmente, en lo referido al suroeste mendocino. En el presente trabajo de tesis doctoral se consideran solo los afloramientos del sudoeste de la provincia de Mendoza, ubicados desde el sur del valle del arroyo Pincheiras (zona de Malargüe) hasta el sur de la localidad de Bardas Blancas (zona de Bardas Blancas) (figura. 3.8), donde se encuentran los mejores y más completos registros de la unidad. A continuación se presenta una síntesis bibliográfica sobre las principales características estratigráficas, de litofacies, paleontológicas, ambientales y diagenéticas de la unidad en esta región. 


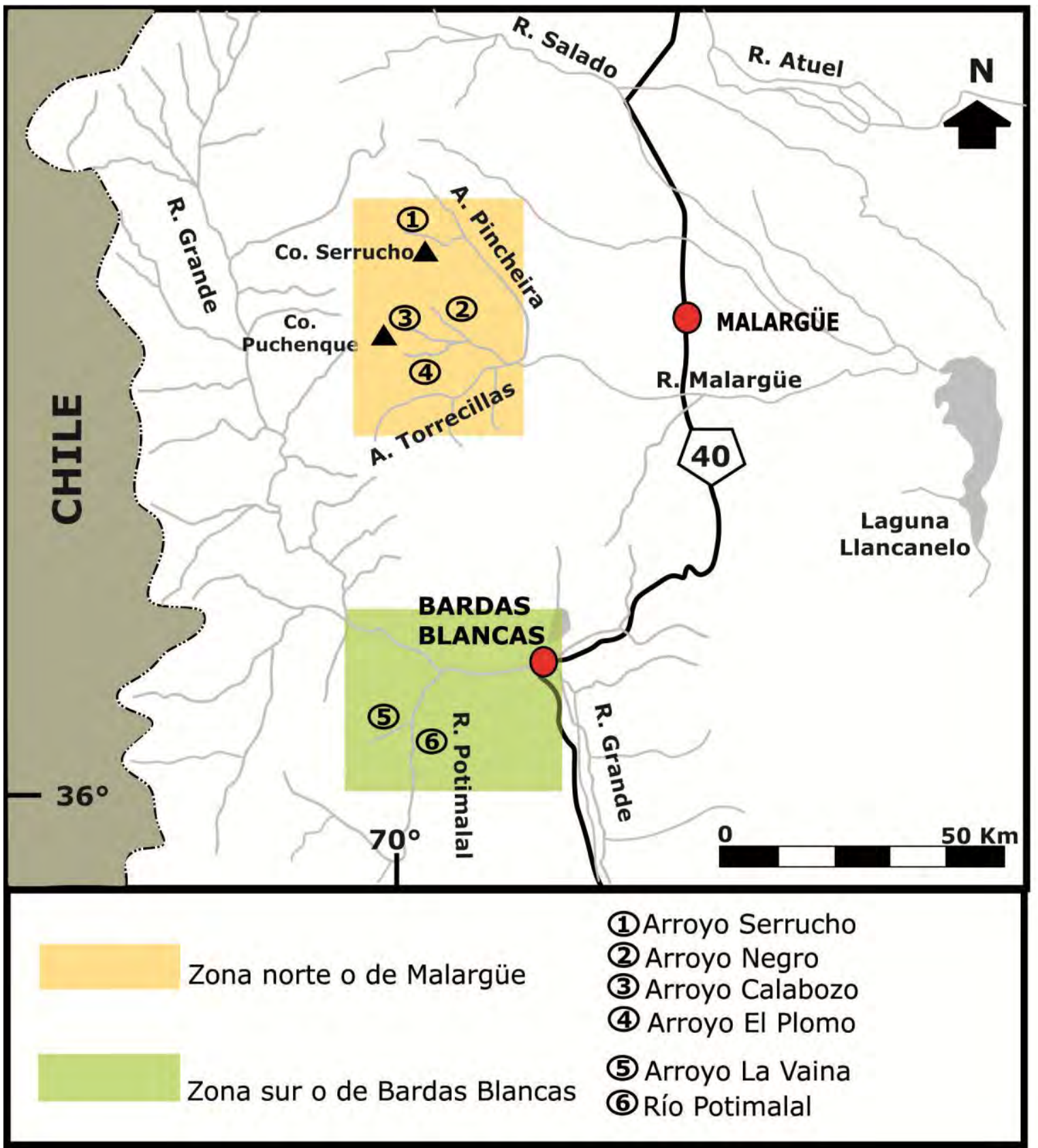

Figura 3.8: Extensión areal de las sedimentitas de la Formación Calabozo. 


\subsection{3: Relaciones estratigráficas}

\subsection{3-I: Límite inferior}

Los autores que estudiaron el intervalo Bathoniano-Calloviano coincidieron en señalar que la Formación Calabozo se distingue claramente de las infrayacentes por un abrupto cambio de facies (Dessanti, 1973, 1978; Legarreta et al., 1993; Gulisano y Gutiérrez Pleimling, 1994; Cabaleri et al., 2001, 2003; Palma et al., 2005, 2007a; Armella et al., 2013). De esta forma, en el sector norte de la zona de los afloramientos (figura 3.8) se estableció un contacto erosivo e irregular entre los depósitos marinos de composición predominantemente carbonática de la unidad analizada, y la Formación Lajas silicoclástica subyacente. De acuerdo con Legarreta et al. (1993) y Gulisano y Gutiérrez Pleimling (1994) esta última unidad está conformada por areniscas, conglomerados y pelitas subordinadas de ambiente marino a marino marginal (deltaico, estuarino). Asimismo, Legarreta et al. (1993) mencionaron areniscas calcáreas dentro de estos depósitos. Por su parte, en esta zona la Formación Calabozo se inicia con una delgada capa de conglomerados poligénicos o rudstones arenosos, que se asocia localmente a fenómenos de incisión y redepositación de la Formación Lajas (Dessanti, 1973, 1978; Legarreta et al., 1993; Gulisano y Gutiérrez Pleimling, 1994; Palma et al., 2005, 2007a; Armella et al., 2013). Este nivel de alta energía es cubierto abruptamente por las facies carbonáticas de la Formación Calabozo (Palma et al., 2005, 2007a).

Hacia el sector sur de los afloramientos (figura 3.8) la Formación Calabozo yace a través de un contacto erosivo sobre las facies arenosas marinas de la Formación Bardas Blancas o bien sobre las lutitas marino profundas de la Formación Tres Esquinas o de las areniscas de ambiente marino-marginal de la Formación Lajas (Cabaleri et al., 2003, 2001; Nullo et al., 2005; Armella et al., 2013). Por encima de este contacto en el arroyo La Vaina, se presenta un nivel poco espeso de floatstone bioclástico-intraclástico que refleja la influencia de un evento de alta energía en la remoción y redepositación de las partículas pertenecientes a la Formación Lajas (Cabaleri et al., 2001). No obstante, en los alrededores del río 
Potimalal el pasaje entre la Formación Lajas y la entidad carbonática es gradual, mediante facies de packstone bio-silicoclástico ubicadas en la base de la Formación Calabozo (Armella et al., 2005a).

Por su parte, Gulisano y Gutiérrez Pleimling (1994) expusieron que en los afloramientos localizados en las inmediaciones de los arroyos Serrucho y Calabozo (zona de Malargüe; ver figura 3.8), el contacto neto e irregular que separa los niveles basales de la Formación Calabozo de las sedimentitas silicoclásticas de la Formación Lajas representa un límite de secuencia. Además se destaca que Gulisano y Gutiérrez Pleimling (1994) reconocieron la presencia del mismo límite en los alrededores del arroyo La Vaina (zona de Bardas Blancas; ver figura 3.8) donde expusieron que los niveles basales pelítico-calcáreo de la Formación Calabozo se apoyan a través de un contacto neto sobre las areniscas de la Formación Lajas.

\subsection{3-II: Límite superior}

En cuanto al límite superior, entre la Formación Calabozo y las evaporitas de la Formación Tábanos, algunos autores afirmaron que dicho límite es gradual y concordante (Cabaleri et al. 2001, 2003; Armella et al., 2005a, 2013; Cagnoni et al., 2006), mientras que otros autores indicaron que el pasaje es a través de un contacto neto y concordante (Gulisano y Gutiérrez Pleimling, 1994; Palma et al., 2005, 2007a).

Hacia el sector norte de los afloramientos (figura 3.8) los niveles superiores de la Formación Calabozo se encuentran representados por facies de grainstone a packstone y capas poco espesas de estromatolitos estratiformes (Cabaleri et al., 2003; Palma et al., 2005, 2007a; Cagnoni et al., 2006; Armella et al., 2013). Según Cabaleri et al. (2003) y Armella et al. (2013) el pasaje de esta unidad hacia la Formación Tábanos es gradual y está evidenciado por la aparición de niveles de yeso intercalados con facies de caliza estromatolítica. Por otra parte, Palma et al. 
(2005, 2007a) indicaron que el contacto de la Formación Calabozo con la unidad evaporítica suprayacente es neto y concordante.

En la zona sur de los afloramientos (figura 3.8), Armella et al. (2005a, 2013) indicaron que los niveles superiores de la Formación Calabozo están conformados por facies de packstones/grainstones oobioclásticos asociadas a niveles de pelitas con anhidrita y facies de boundstones estromatolíticos. El pasaje de esta unidad hacia la Formación Tábanos, de carácter evaporítico, es transicional y está indicado por la aparición de niveles de yeso intercalados con facies de caliza estromatolítica (Armella et al., 2005a, 2013). En esta misma región, otros autores (Gulisano y Gutiérrez Pleimling, 1994; Cabaleri et al., 2001; Cagnoni et al., 2006) ubicaron la base de la Formación Tábanos en el comienzo de los niveles de calizas estromatolíticas e indicaron que las mismas gradan verticalmente hacia las capas de evaporitas. Asimismo, Gulisano y Gutiérrez Pleimling (1994) consignaron que el pasaje de la Formación Calabozo hacia la entidad evaporítica es a través de un contacto neto que representa un límite de secuencia.

\subsection{4: Litofacies y contenido fosilífero}

Los niveles carbonáticos de la Formación Calabozo descriptos por Dessanti (1973, 1978) en su localidad tipo son portadores de restos fragmentarios de bivalvos y braquiópodos entre los que distingue una pequeña ostra clasificada como Gryphea calceola Quens. En esta zona, Westermann y Riccardi (1991) señalaron que la unidad está representada por depósitos de coloración verde a gris azulada conformados por areniscas a limos con presencia de niveles de conglomerados intercalados cerca de la base, y que hacia la parte superior pasan a niveles de calizas negras a grises. Las litofacies calcáreas están mayormente representadas por texturas wackestone, aunque en la base y el techo menciona facies de packstones y boundstones, respectivamente. En lo que se refiere a su contenido fosilífero, estos autores citaron la presencia de equinodermos, corales, estromatolitos y amonites. En su contribución Westermann y Riccardi (1991) 
incluyeron dentro de la Formación Calabozo a los niveles clásticos que subyacen a la unidad (Formación Lajas).

En las inmediaciones de los arroyos Calabozo y Serrucho (zona de Malargüe) Legarreta et al. (1993), Gulisano y Gutiérrez Pleimling (1994) y Legarreta y Uliana (1996) describieron a la Formación Calabozo conformada por capas de conglomerados y areniscas ubicadas en la base de la unidad, seguidas por niveles de grainstones oolíticos-bioclásticos, framestones coralinos y calizas con tapices algales. Gulisano y Gutiérrez Pleimling (1994) indicaron que la fauna de bivalvos es dominante en la unidad, aunque también destacan la presencia ocasional de los amonites Perisphinctidae sp., Choffatia sp. y Grossouvria sp., cerca de la base.

Asimismo, Gulisano y Gutiérrez Pleimling (1994) reconocieron que la Formación Calabozo en las cercanías del arroyo La Vaina, área de Bardas Blancas (figura 3.8), se compone de facies basales pelíticas-calcáreas a las que denominan Sección I, cubiertas por calizas esqueletales con abundantes fragmentos de bivalvos, gasterópodos, corales, equinodermos y amonites Eurycephalites rofundus, correspondientes a la Sección II. Años más tarde, Cabaleri et al. (2001) y Cagnoni et al. (2006) realizaron la descripción e interpretación de las litofacies y microfacies de la Formación Calabozo en esta zona. Estos autores mencionaron que la entidad está conformada por un nivel basal de floatstone poco potente con base erosiva compuesto por intraclastos y restos de bivalvos, con presencia de estratificación entrecruzada hummocky. Por encima del nivel basal, reconocieron dos asociaciones de facies (inferior y superior) que se encuentran separadas por depósitos de floatstones y areniscas calcáreas con estratificación entrecruzada hummocky/swaley y ondulas simétricas hacia el tope. Según estos autores la asociación de facies inferior está integrada por las microfacies de wackestone peloidal, packstone peloidal y grainstone intraclástico y la superior, de leve tendencia regresiva, por microfacies de grainstone/packstone ooidal y wackestone bioclástico. Cabaleri et al. (2001) expusieron que en esta zona solo se encuentra representada la Sección II de Gulisano y Gutiérrez Pleimling (1994). Sin embargo, en las inmediaciones del río Potimalal (figura 3.8) ambas secciones se encuentran presentes. 
En la zona del río Potimalal, Armella et al. (2005a, 2013) indicaron que la Formación Calabozo se inicia con facies de calizas bioclásticas interestratificadas con lutitas negras ricas en materia orgánica, que representan las facies transicionales con la formación subyacente (Formación Lajas). Por encima se presentan facies de mudstone, wackestone y packstone con presencia de bioclastos y peloides, que hacia los niveles superiores gradan a facies de packstone y grainstone acompañados por niveles micríticos con abundantes fenestras irregulares y moldes de cristales de anhidrita. Además agregaron que la unidad es portadora de bivalvos (Pholadomya sp. y Ostrea), equinodermos, braquiópodos, algas dasicladáceas y codiáceas (Halimeda), briozoos, foraminíferos, gasterópodos (Nerineidos) y trazas fósiles asignadas a las icnofacies de Cruziana, Skolitos y Glossifungites.

Como se presentara en el apartado 3.5.3, en el sector norte de los afloramientos (figura 3.8) la Formación Calabozo se inicia con una delgada capa de conglomerados o rudstones arenosos que es cubierta por las facies carbonáticas de la unidad (Dessanti, 1973, 1978; Legarreta et al., 1993; Gulisano y Gutiérrez Pleimling, 1994; Palma et al., 2005, 2007a; Armella et al., 2013). En este sentido, Palma et al. (2005, 2007a) describieron a la unidad en las márgenes del arroyo Calabozo compuesta por una amplia variedad de rocas carbonáticas en las que incluyen wackestones-packstones bioclásticos-peloidales, packstones-grainstones oolíticos, framestones coralígenos y estromatolitos laminares hacia el tope. Estas facies se encuentran asociadas con un menor contenido de niveles silicoclásticos ubicados en la base y representados por conglomerado líticos y areniscas finas. A su vez, indicaron que la Formación Calabozo presenta una abundante fauna marina que incluye principalmente bivalvos, equinodermos, corales escleractínidos (Actinastrea sp.), foraminíferos (miliólidos), especies de algas dasicladáceas Salpingoporella annulata, Cylindroporella sp. y Heteroporella sp.) y cianobacterias calcáreas (Cayeuxia (Rivularia) piae, y Cayeuxia (Rivularia) kurdistanensis).

Cagnoni et al. (2006) mencionaron que al noreste de la localidad tipo, en el arroyo Serrucho (figura 3.8), la Formación Calabozo comienza con una alternancia de 
facies de mudstone y margas sin disturbar, con altos contenidos de materia orgánica (filamentos de algas y cianobacterias). Agregaron que estos niveles gradan hacia el tope de la unidad a facies de wackestone, packstone y grainstone con un mayor contenido fosilífero representado éste por cefalópodos, pelecípodos, gasterópodos, briozoos, equinodermos y algas. Por su parte, Armella et al. (2013) indicaron que en esta zona y en los alrededores del arroyo El Plomo (figura 3.8), la Formación Calabozo se inicia con un nivel de rudstone intraclástico-arenoso. Estos autores, junto con Cabaleri et al. (2003), destacaron que en el arroyo El Plomo este nivel es cubierto por facies de wackestone, packstone y floatstone con ooides, intraclastos y bioclastos, finalizando con depósitos de grainstones intraclásticos-ooidales y boundstones estromatolíticos. En lo que respecta al contenido fosilífero Cabaleri et al. (2003) reconocieron restos de amonites, bivalvos (Weyla sp.), braquiópodos, foraminíferos, corales y algas dasicladáceas, acompañados por trazas fósiles asignadas a la icnofacies de Cruziana.

\subsection{5: Espesor}

Varios autores (Groeber et al., 1953; Dessanti 1973, 1978) le asignaron un espesor mayor a los $100 \mathrm{~m}$ a la Formación Calabozo en su localidad tipo (véase apartado 3.5.1), posiblemente debido a que en sus descripciones incluyeron dentro de esta unidad niveles correspondientes a la Formación Lajas o la Formación La Manga. Trabajos posteriores de Riccardi y Westermann (1991) en esta misma zona, citaron espesores de $260 \mathrm{~m}$ para la Formación Calabozo dado que en sus contribuciones incorporaron dentro de esta formación $225 \mathrm{~m}$ pertenecientes a la unidad subyacente, actualmente denominada Formación Lajas. Asimismo, estos autores destacaron que en el área de Bardas Blancas (figura 3.8), esta unidad presenta $9 \mathrm{~m}$ de potencia.

Años más tarde, Gulisano y Gutiérrez Pleimling (1994) mencionaron que en la zona de Malargüe (área del arroyo Serrucho-arroyo Calabozo) (figura 3.8) la Formación Calabozo alcanza espesores variables entre los 10 a $35 \mathrm{~m}$. A su vez, estos autores 
indicaron que en el área sur de los afloramientos (figura 3.8) la potencia de esta unidad oscila entre los 5 y los $9 \mathrm{~m}$.

Varios autores que abordaron el estudio de la unidad de forma posterior (Cabaleri et al., 2001, 2003; Valencio et al., 2003; Armella et al., 2005a ,2013; Cagnoni et al., 2006) coincidieron en caracterizar a la Formación Calabozo como una sucesión sedimentaria poco potente, con espesores variables entre 4 y $16 \mathrm{~m}$. Estos autores citaron espesores de 4 a $8 \mathrm{~m}$ para la unidad en el área de Malargüe y espesores variables entre 4 y $16 \mathrm{~m}$ en la zona de Bardas Blancas. No obstante, Palma et al. (2005; 2007a) mencionaron espesores de 30 m para la Formación Calabozo en su localidad tipo (zona de Malargüe).

\subsection{6: Edad y bioestratigrafía}

Desde los orígenes del estudio de la Cuenca Neuquina, la bioestratigrafía basada en el análisis de las faunas de amonites ha sido un tema de mucho interés (Buckhardt, 1903; Gerth, 1925; Weaver, 1931; Leanza, 1945; Groeber, 1946; 1952). En este sentido, varios autores han utilizado el contenido amonitífero de la Formación Calabozo para atribuirle un rango temporal a dicha entidad carbonática (Riccardi, 1985 inedt.; Riccardi y Westermann, 1991; Legarreta et al., 1993; Gulisano y Gutiérrez Pleimling, 1994).

Como se ha mencionado, en su definición Dessanti (1973) consideró a la Formación Calabozo formada en tiempos del Oxfordiano por correlación con niveles carbonáticos de esa edad aflorantes en los arroyos Blanco y La Manga, portadores de amonites de la Zona de Cordatum-Plicatilis estudiados por Stipanicic (1951). Años más tarde, Riccardi (1985) y Riccardi y Westermann (1991) le asignaron una edad batoniana superior a calloviana inferior a esta unidad carbonática, sobre la base de las determinaciones realizadas en la fauna de amonites recolectadas en su localidad tipo. Estos autores le atribuyeron dicho rango temporal a la Formación Calabozo debido a que incluyeron dentro de ésta a los niveles arenosos de la Formación Lajas, portadores de amonites de las Zonas Estándar de Steinmanni y Bodenbenderi, correspondientes al Bathoniano superior y Calloviano inferior 
respectivamente. Asimismo, Riccardi y Westermann (1991) describieron en las inmediaciones del arroyo La Vaina (zona de Bardas Blancas) una unidad compuesta por lutitas y calizas que subyace a la Formación Tábanos y que a su vez se apoya sobre los depósitos de lutitas gris oscuro de la Formación Tres Esquinas. Estos afloramientos, actualmente asignados a la Formación Calabozo, presentan cerca de su tope fauna de Eurycephalithes rotundus y Gryphaea santiaguensis (HUPE), correspondientes a la Zona de Bodenbenderi.

Legarreta et al. (1993) indicaron la presencia de Rehmannia sp., Choffatia sp. y Grossovira sp. en la Formación Calabozo y le asignan una edad calloviana inferior. En su contribución "Las secuencias sedimentarias Jurásico-Cretácicas", estos autores destacaron que las determinaciones fueron realizadas por A. Riccardi, pero no especifican en qué año ni en que localidad fueron llevadas a cabo. Posteriormente, esta edad fue confirmada por Gulisano y Gutiérrez Pleimling (1994) en los afloramientos de la localidad de Bardas Blancas y del Cerro Puchenque. Estos autores indicaron la presencia de fauna de amonites incluida dentro de la Zona Estándar de Bodenbenderi (Riccardi et al., 1989) representada por Eurycephalithes rotundus y Perisphinctidae sp., Choffatia sp.? y Grossouvira sp.

A partir de los estudios citados previamente, se ha determinado que la fauna de amonites de la Formación Calabozo comprende elementos de la Zona Estándar de Bodendenderi, lo que permite asignarle a dicha unidad una edad calloviana inferior.

\subsection{7: Sistema de acumulación}

Como se puede apreciar en el apartado 3.5.1, desde su definición Dessanti (1973) consideró a la Formación Calabozo como desarrollada en un ambiente marino. Años más tarde, los autores que estudiaron a la unidad coincidieron en señalar que se habría depositado en un ambiente marino somero de plataforma (Legarreta y Gulisano, 1989; Legarreta et al., 1993; Gulisano y Gutiérrez Pleimling, 1994; Legarreta y Uliana, 1996) o de rampa carbonática homoclinal con tendencia 
regresiva (Cabaleri et al., 2001, 2003; Valencio et al., 2003; Palma et al., 2000a, 2005, 2007a; Armella et al., 2005a, 2005b, 2013; Cagnoni et al., 2006). De esta manera en el norte de la zona de estudio, específicamente en los alrededores de los arroyos El Plomo y Calabozo (figura 3.8), algunos autores interpretaron un sistema marino somero de energía moderada a alta representado por los subambientes de rampa media e interna (Palma et al., 2000 a, 2005, 2007a; Cabaleri et al., 2003; Valencio et al., 2003; Armella et al., 2005b, 2013; Cagnoni et al., 2006). Dentro de estos subambientes reconocieron numerosos ciclos somerizantes de escala métrica, conformados completamente por facies submareales (ciclos submareales) o por facies submareales a intermareales someras hacia el tope (ciclos perimareales). Palma et al. (2005) indicaron que estos ciclos disminuyen su espesor hacia el tope de la unidad lo que podría evidenciar una disminución gradual del espacio de acomodación relacionada a un posible descenso del nivel relativo del mar.

Asimismo, Palma et al. (2007a) sobre la base de las asociaciones de partículas esqueletales y no esquetales presentes en la unidad (algas verdes, corales, ooides y peloides) consideraron que la producción de carbonatos en su localidad tipo fue controlada por una asociación de tipo Photozoan, desarrollada bajo condiciones climáticas subtropicales. Estos autores además agregaron que en este ambiente de aguas someras y cálidas el desarrollo de los arrecifes en parche es escaso debido al abundante contenido de nutrientes en las aguas superficiales (nutrificación), que estaría reflejado en la disminución de los corales y en el incremento de algas, cianobacterias y bioerosión.

De acuerdo con Cagnoni et al. (2006) y Armella et al. (2005b), los depósitos de la Formación Calabozo en el arroyo Serrucho (figura 3.8) se habrían acumulado inicialmente en un ambiente de baja energía, por debajo de las olas de tormenta (rampa externa), que es cubierto por intervalos más someros ubicados en posiciones de rampa media a interna. Por el contrario, Armella et al. (2013) interpretaron para esta zona un sistema de rampa media a interna, de moderada a alta energía, controlado por la acción de las olas y las mareas. 
Hacia el sector sur de los afloramientos, en las inmediaciones del río Potimalal (figura 3.8), Armella et al. (2005a, 2005b, 2013) establecieron que la Formación Calabozo comienza con un ambiente de rampa externa y culmina con uno de rampa interna con características perimareales. Asimismo destacaron que tanto en el subambiente de rampa externa como en el de rampa media la sedimentación ocurre en un medio de baja energía, con buena oxigenación y escaso aporte detrítico, apto para el desarrollo de la fauna bentónica y de las algas dasicladáceas. Estas condiciones cambiarían hacia los niveles superiores de la rampa donde el incremento en la evaporación y la salinidad del medio habrían originado condiciones extremas, aptas para la proliferación de las comunidades microbianas bentónicas. Por su parte, al oeste del río Potimalal en los alrededores del arroyo La Vaina (figura 3.8), Cabaleri et al. (2001) y Armella et al. (2013) interpretaron que la unidad se habría depositado en un sistema de rampa media a interna, de moderada a alta energía, dominado por la acción de las olas de buen tiempo y tormenta.

\subsection{8: Diagénesis}

Los aportes de Palma et al. (2000b, 2007a) son las únicas contribuciones acerca de los aspectos diagenéticos de la Formación Calabozo. El primero de ellos (Palma et al., 2000b) resulta de carácter cualitativo y localizado, y es referido a la diagénesis de los corales escleractínidos Araucanastrea sp. presentes en la unidad. Estos autores mediante el uso de petrografía estándar y de catodoluminiscencia y el análisis de isotopos estables $(\mathrm{C}, \mathrm{O})$ definieron el grado de preservación de las colonias de corales, acompañado por la descripción de las fases cementantes meteórico freáticas ubicadas en el interior de las mismas.

Por su parte, Palma et al. (2007a) mediante técnicas de petrografía de polarización, catodoluminiscencia y EDAX (Energy Dispersive Analysis of X-rays) describieron en la localidad tipo de la unidad diferentes estadíos de cementación carbonática, conjuntamente con eventos de diagénesis marina sinsedimentaria y de diagénesis meteórica freática. Además indicaron la presencia de aspectos diagenéticos generados por el soterramiento de la Formación Calabozo. 
Otros autores mencionaron someramente aspectos diagenéticos de la Formación Calabozo pero en forma general en trabajos focalizados al estudio paleoambiental a través del análisis geoquímico $(\mathrm{Mn}, \mathrm{Sr}, \mathrm{Fe})$ e isotópico $\left(\delta^{18} \mathrm{O}-\delta^{13} \mathrm{C}\right)$ de la unidad (Cabaleri et al., 2001; Valencio et al., 2003; Cagnoni et al., 2006; Armella et al., 2013).

\section{6: Resumen del análisis bibliográfico}

Del análisis bibliográfico se han podido extraer las siguientes consideraciones como principales atributos de la Formación Calabozo:

1) Se utiliza la denominación Formación Calabozo para referirse a los sedimentos predominantemente carbonáticos de origen marino, que se disponen entre los depósitos clásticos (arenosos y conglomerádicos) marinos a marino marginal de la Formación Lajas y las evaporitas marinas de la Formación Tábanos.

2) Los afloramientos considerados de la unidad se encuentran en el sudoeste de la provincia de Mendoza, desde el sur del arroyo Pincheiras en la localidad de Malargüe (zona de Malargüe), hasta el sur de Bardas Blancas (zona de Bardas Blancas, figura 3.8).

3) La base de la unidad está marcada por un contacto erosivo e irregular sobre las unidades subyacentes. En el caso de la zona de Malargüe sobre la Formación Lajas, mientras que hacia el área de Bardas Blancas cubre indistintamente a los depósitos marinos de las formaciones Tres Esquinas, Bardas Blancas o Lajas.

4) El tope de la unidad es concordante con las evaporitas de la Formación Tábanos, pudiendo ser dicho límite neto o gradual.

5) Desde el punto de vista litológico la entidad se compone de rocas calcáreas con texturas wackestones, packstones, grainstones con abundante contenido de peloides, ooides y fragmentos esqueletales, framestones coralinos, y 
estromatolitos laminares hacia el tope de la unidad. Estas facies se encuentran asociadas con un menor contenido de niveles silicoclásticos ubicados en la base, representados por conglomerados, areniscas y lutitas.

6) En lo que respecta a su contenido fosilífero presenta una abundante fauna marina, que incluye principalmente bivalvos, equinodermos, corales escleractínidos, foraminíferos, algas dasicladáceas, cianobacterias calcáreas, gasterópodos, braquiópodos y amonites.

7) El espesor de la Formación Calabozo en el área de Bardas Blancas varía entre 4 y $16 \mathrm{~m}$, y en la zona de Malargüe entre los 4 y $8 \mathrm{~m}$. No obstante en su localidad tipo la Formación Calabozo presenta potencias de $30 \mathrm{~m}$.

8) La Formación Calabozo contiene fauna de amonites correspondiente a la Zona Estándar de Bodendenderi que permiten asignarle una edad calloviana inferior.

9) Estos depósitos representan un sistema de rampa carbonática homoclinal con clara tendencia regresiva, donde se encuentran presentes los subambientes de rampa externa, media e interna.

Conforme a lo expresado acerca de la Formación Calabozo, en este trabajo de tesis doctoral será analizado el intervalo estratigráfico que abarca a dicha unidad y a la Formación Lajas subyacente dentro del área de estudio. Será dividido en una sucesión inferior terrígena-mixta que comprende los niveles arenosos, conglomerádicos de la Formación Lajas, acompañados por los depósitos clásticos basales de la Formación Calabozo. Cubierta por una sucesión superior carbonática que incluye a los niveles de calizas de la Formación Calabozo. Dichas consideraciones sirven de punto de partida para este trabajo de tesis doctoral. 


\section{CAPÍTULO 4: CARACTERIZACIÓN DE LA ZONA DE ESTUDIO}

\section{1: Introducción}

Las sucesiones terrígena-mixta y carbonática se encuentran expuesta en el sudoeste de la provincia de Mendoza (figura. 3.7). Esta región presenta una profusa deformación tectónica que afecta la calidad y continuidad de los afloramientos de de la sucesión carbonática y principalmente de la Formación Tábanos que la suprayace.

En este capítulo se expondrán los límites geográficos y los principales lineamientos geológicos y estructurales del área de estudio. Además, se realizará una breve descripción del ámbito geográfico y geológico de cada una de las secciones sedimentológicas relevadas durante este trabajo de tesis.

\section{2: Geografía del área}

El área de estudio se localiza en el sudoeste de la provincia de Mendoza, dentro de los distritos de Ciudad de Malargüe y Río Grande (véase capítulo 2 apartado 2.2.1 y figura 2.1), siendo las localidades y parajes más importantes Malargüe y Bardas Blancas, La Valenciana y Minacar, respectivamente (figura 4.1). Fue dividida de acuerdo con este trabajo de investigación en dos zonas, la zona septentrional o de Malargüe y la austral o de Bardas Blancas (figura 2.2) descriptas de forma detallada en el capítulo 2, apartado 2.2.1.

Desde la ciudad de San Rafael se accede a la zona de estudio a través de las rutas nacionales $N^{\circ} 144$ y 40 en dirección suroeste-sur. Mediante esta última ruta, que bordea longitudinalmente el extremo oriental del área de estudio, se llega hasta la zona norte y sur (figura 4.1).

Este sector del territorio argentino está ubicado en la provincia geológica Cordillera Principal, abarcando un terreno montañoso formado por una sucesión de elevaciones de rumbo generalmente meridional, cuyas alturas absolutas crecen 
hacia el oeste. Estos cordones serranos, compuestos por sedimentitas y vulcanitas mesozoicas, no tienen una gran extensión y están cortados casi transversalmente por los grandes colectores de la red de drenaje como son el río Malargüe y Grande. En esta región dominan de preferencia los cerros con altitudes entre los 1900 y los 3800 m, entre los que se destacan de norte a sur: el Cerro Serrucho (3561 m), Puchenque (3726 m), Toscal (2500 m), Cabeceras del Colorado (3262 m), de Bardas Blancas (1979 m) y Estación (2600 m; figura 2.1). En tanto hacia el este, fuera del área de estudio, la zona presenta un relieve volcánico del Cuaternario que establece la transición entre la montaña y la altiplanicie.

En cuanto a la red hidrográfica, los ríos más importantes son el Malargüe, ubicado en el extremo superior derecho, y el Grande, que atraviesa con rumbo casi esteoeste la zona sur del área (figura 2.1). El río Malargüe, formado por la confluencia de los arroyos Torrecillas y Colorado, recibe las aguas de los arroyos Pincheira, Negro, Calabozo y El Plomo desde el norte, y de los arroyos de las Agua Hedionda y Butamallín desde el sur (figuras 2.1 y 2.2). Por su parte, en el río Grande, vierten sus aguas los arroyos Piedra Hernandéz, de la Gotera y Chacaycó en la margen izquierda del río, y los arroyos La Vaina y Ranquil y el río Potimalal en su margen derecha (figuras 2.1 y 2.2). Numerosos arroyos surcan esta región, siendo más abundantes los cursos de agua permanentes hacia la zona montañosa, y estacionales o efímeros hacia el sector oriental.

\section{3: Estructura}

Mediante los estudios pioneros de Gerth (1931) y Groeber (1933, 1947a, b, c), y con posterioridad de Yrigoyen (1972), Ramos (1985) y Kozlowski et al. (1993), se establecieron los lineamientos generales de la estructura de la Cordillera Principal a escala regional. En ese marco, la región aquí considerada se encuentra dentro de la faja plegada y corrida de Malargüe (figura 4.2) que abarca el segmento austral de la faja plegada y corrida de la Cordillera Principal mendocina (Kozlowski et al., 1993). Así definida, el área queda ubicada en el sector sur de la faja plegada y 
corrida de Malargüe, limitada al este por el retrocorrimiento La Brea-Doña Juana (figura 4.3).

\subsection{1: Faja plegada y corrida de la Cordillera Principal mendocina}

La faja plegada y corrida de la Cordillera Principal de Mendoza es una de las principales expresiones de la tectónica compresiva andina, desarrollada en el norte de la Cuenca Neuquina entre el Cretácico tardío y el Cenozoico. Este período de deformación, que constituye el último ciclo importante de la evolución de la cuenca (figura 3.2), permite disponer en la actualidad de excelentes afloramientos de la secuencia sedimentaria mesozoica en el área de estudio.

La Cordillera Principal puede ser dividida en dos segmentos de diferente comportamiento estructural (figura 4.2), el sector norte o faja plegada y corrida del Aconcagua (Ramos, 1988) y el sector sur denominado faja plegada y corrida de Malargüe (Kozlowski et al., 1993). El sector norte se corresponde con un orógeno de piel fina que comienza en el sur de la provincia de San Juan ( $\left.32^{\circ} \mathrm{LS}\right)$ y se extiende hasta la latitud de la caldera del Maipo ( 34 $\left.{ }^{\circ} \mathrm{LS}\right)$ en territorio mendocino. Por su parte, la faja plegada y corrida de Malargüe se prolonga desde el sur de la caldera del Maipo hasta la provincia de Neuquén y está caracterizada por un estilo estructural de piel gruesa, es decir que el basamento pre-Jurásico volcánico (Grupo Choiyoi) se encuentra involucrado en la deformación (Kozlowski et al., 1993). Según Manceda y Figueroa (1995) estas fallas de basamento estarían relacionadas a la inversión tectónica de fallas normales lístricas que controlaron la sedimentación durante el estadio de rift triásico-jurásico de la Cuenca Neuquina. 


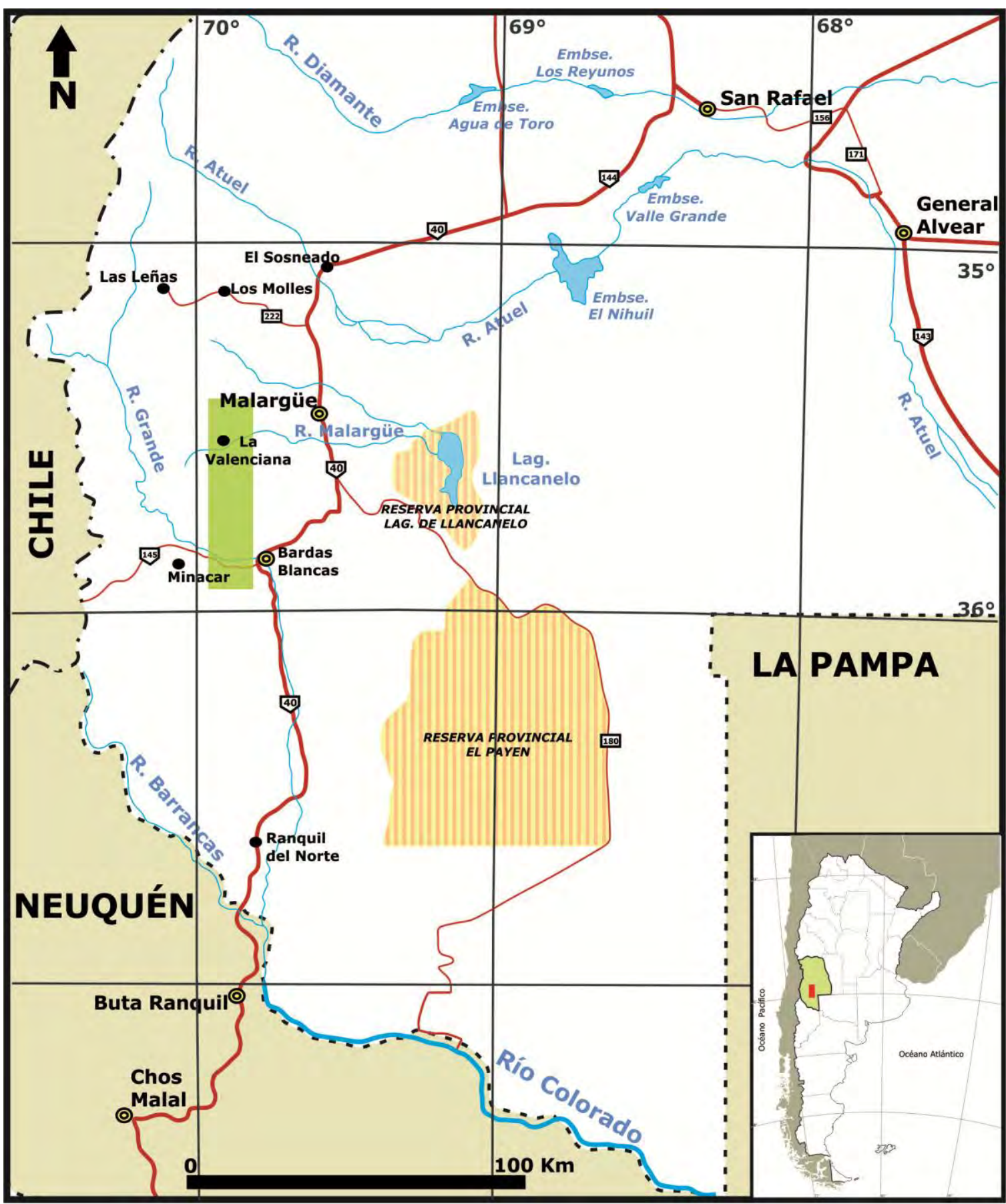

Figura 4.1: Ubicación geográfica y extensión del área de estudio en la provincia de Mendoza. El recuadro verde delimita el área de estudio. 


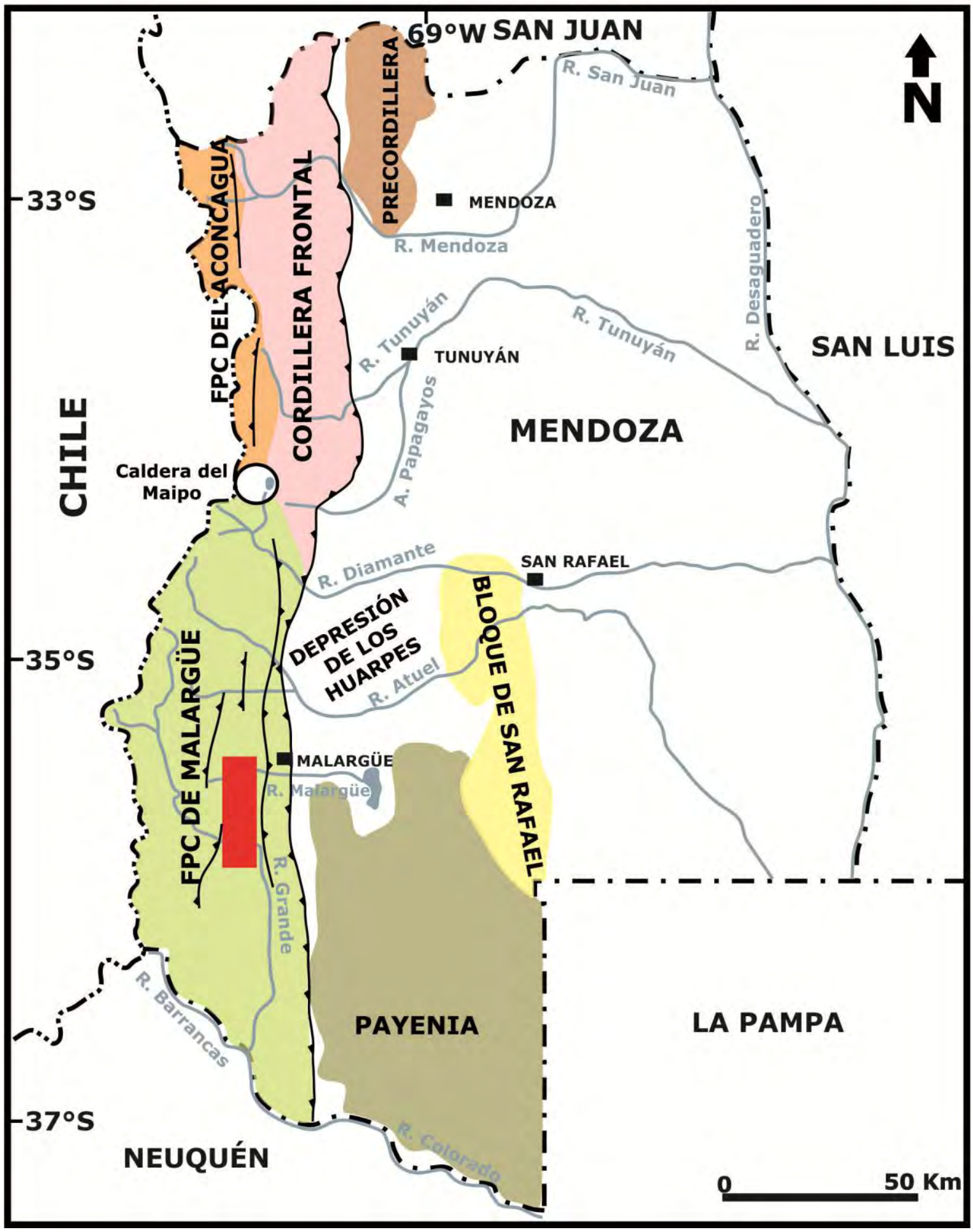

Figura 4.2: Principales unidades morfo-estructurales de la provincia de Mendoza. Las fajas plegadas y corridas del Aconcagua y Malargüe conforman la Cordillera principal (modificado de Kozlowski et al., 1993). El recuadro rojo indica la ubicación del área de estudio. 


\subsection{2: Faja plegada y corrida de Malargüe}

La faja plegada y corrida de Malargüe está conformada por corrimientos y retrocorrimientos con predominio de vergencia oriental y rumbo $\mathrm{N}$ a $\mathrm{NNE}$, y fallas inversas de alto ángulo con la misma vergencia y rumbo NO a NNO, generados entre el Mioceno Medio y el Plioceno (Kozlowski 1984; Manceda y Figueroa, 1995; Silvestre y Kraemer, 2005; Giambiagi et al., 2008a, 2009a). Tradicionalmente se interpretó a esta faja como el resultado de la inversión de fallas normales mesozoicas durante la deformación compresiva andina (Manceda y Figueroa, 1995; Uliana et al., 1995; Kley et al., 1999; Giambiagi et al., 2005a, 2008a). Sin embargo, Turienzo (2010) indica que la estructuración tuvo lugar mediante la generación de corrimientos de bajo ángulo durante la orogenia andina, descartando completamente la inversión tectónica. Una versión intermedia para esta región es propuesta por Giambiagi et al. (2009a), quienes postulan la existencia tanto de estructuras pre-existentes invertidas como corrimientos andinos.

Como se aprecia en la figura 4.4 la faja plegada y corrida de Malargüe se puede dividir en dos sectores de distinto comportamiento estructural ubicados al norte y al sur del río Atuel. El sector norte presenta una región con basamento involucrado en la deformación (Kozlowski et al., 1993; Manceda y Figueroa, 1995; Turienzo et al., 2005; Fortunatti y Dimieri, 2005) y otra región, ubicada al este de la anterior, de comportamiento de piel fina (Kozlowski, 1984; Kozlowski et al., 1989, 1990; Manceda y Figueroa, 1995; Ramos, 2002; Pereira y Broens, 2005; Kim et al., 2005). Por el contrario, el sector sur posee un comportamiento de piel gruesa a lo ancho de toda la faja y está caracterizado por una serie de bloques de basamento que limitan zonas internas de deformación de piel fina (Manceda y Figueroa, 1995; Zapata et al., 1999; Rojas y Radic, 2002).

El área de estudio, ubicada en el sector sur de la faja plegada y corrida de Malargüe, comprende una región sobre elevada tanto topográfica como estructuralmente. En esta zona las estructuras están representadas por pliegues asimétricos y corrimientos, ambos con predominio de vergencia oriental. El estilo 
de plegamiento consiste en pliegues abiertos con grandes estructuras anticlinales (10-50 km de longitud) y sinclinales asociados (Kozlowski et al., 1993; Arcila Gallego, 2010). En la región norte del área de estudio se presentan anticlinales y sinclinales-de rumbo NE con sus núcleos resueltos en las sedimentitas del Grupo Cuyo o del Grupo Mendoza. Entre las estructuras más importantes se destacan los anticlinales de Torrecillas y La Valenciana y el sinclinal de La Valenciana ubicado entre los anteriores (figura 4.3). En cuanto a su origen, Arcila Gallego (2010) sugiere que dichas estructuras conforman un sistema de plegamiento por propagación de falla producido por la interacción entre fallas del basamento y la cobertura sedimentaria. El nivel de despegue es profundo y estaría relacionado a la inversión tectónica de fallas extensionales previas que afectaron al basamento (Silvestre y Kraemer, 2005; Giampaolli et al., 2005; Arcila Gallego, 2010). Por el contrario, en la zona sur del área de estudio los pliegues consisten en anticlinales de ejes meridionales, con sus núcleos conformados por las vulcanitas del Grupo Choiyoi. Hacia sus flancos se encuentran representadas las sedimentitas jurásicascretácicas del Grupo Cuyo, Lotena y Mendoza (Kozlowski et al., 1993; Dicarlo y Cristallini, 2007). El estilo de plegamiento está caracterizado por pliegues por propagación de falla que se encuentran asociados a sistemas de retrocorrimientos imbricados generados en las rocas del Grupo Choiyoi (Dimieri, 1997; Silvestre y Kraemer, 2005). Estas estructuras se corresponden con los anticlinales de PalaoMahuida, Ventana y Potimalal, y el braquianticlinal de Bardas Blancas (figura 4.3). Este último está vinculado a la prolongación de un tren de estructuras anticlinales de basamento como las de Sierra Azul, Palauco, Malargüe, Cara Cura, Sierra de Reyes y Las Yeseras-Pampa Tril, entre otras (Di Carlo y Cristallini, 2007; Giambiagi et al., 2009b). 


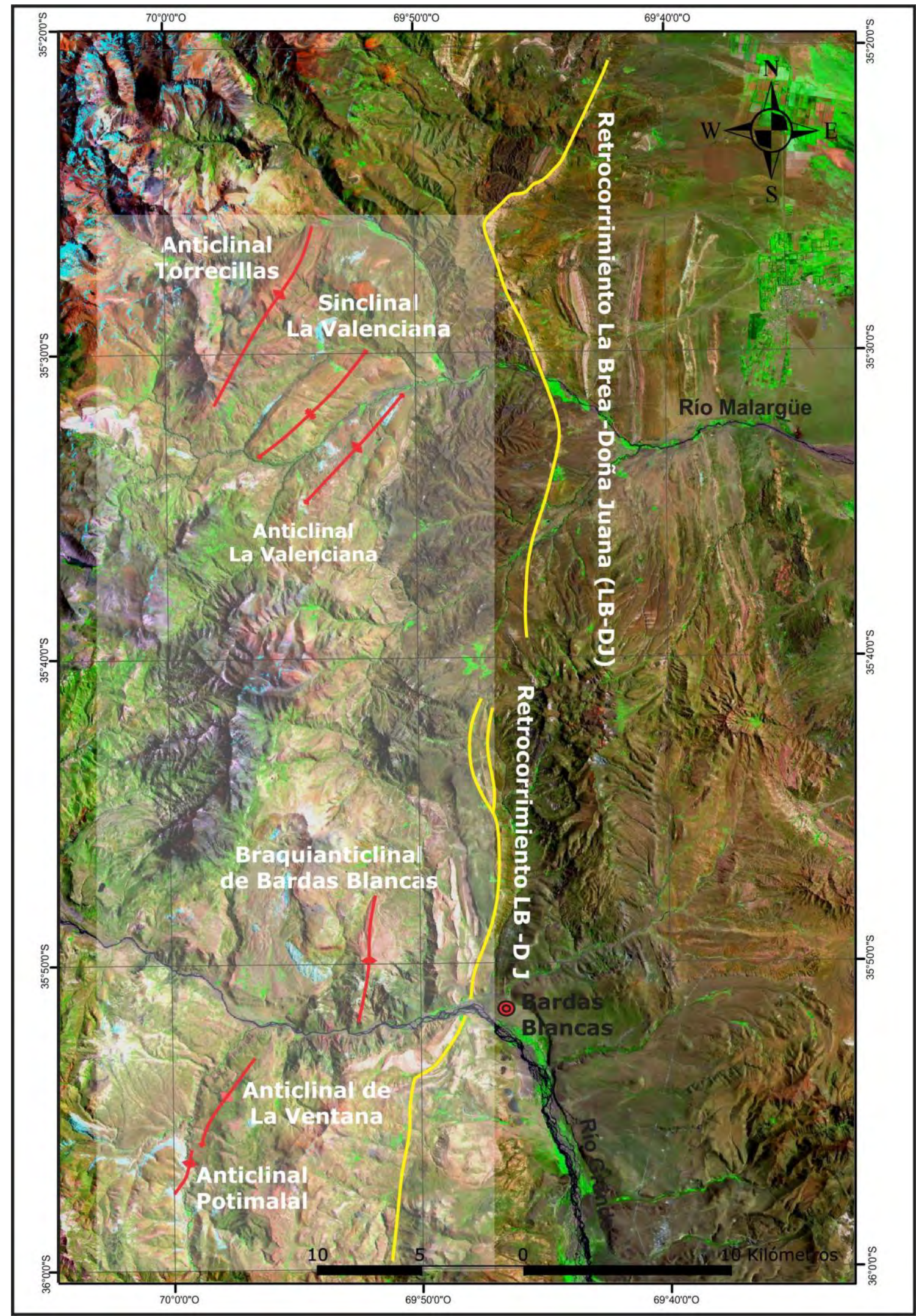

Figura 4.3: Ubicación de las principales estructuras dentro del área de estudio. El recuadro blanco marca la extensión del área de estudio. 


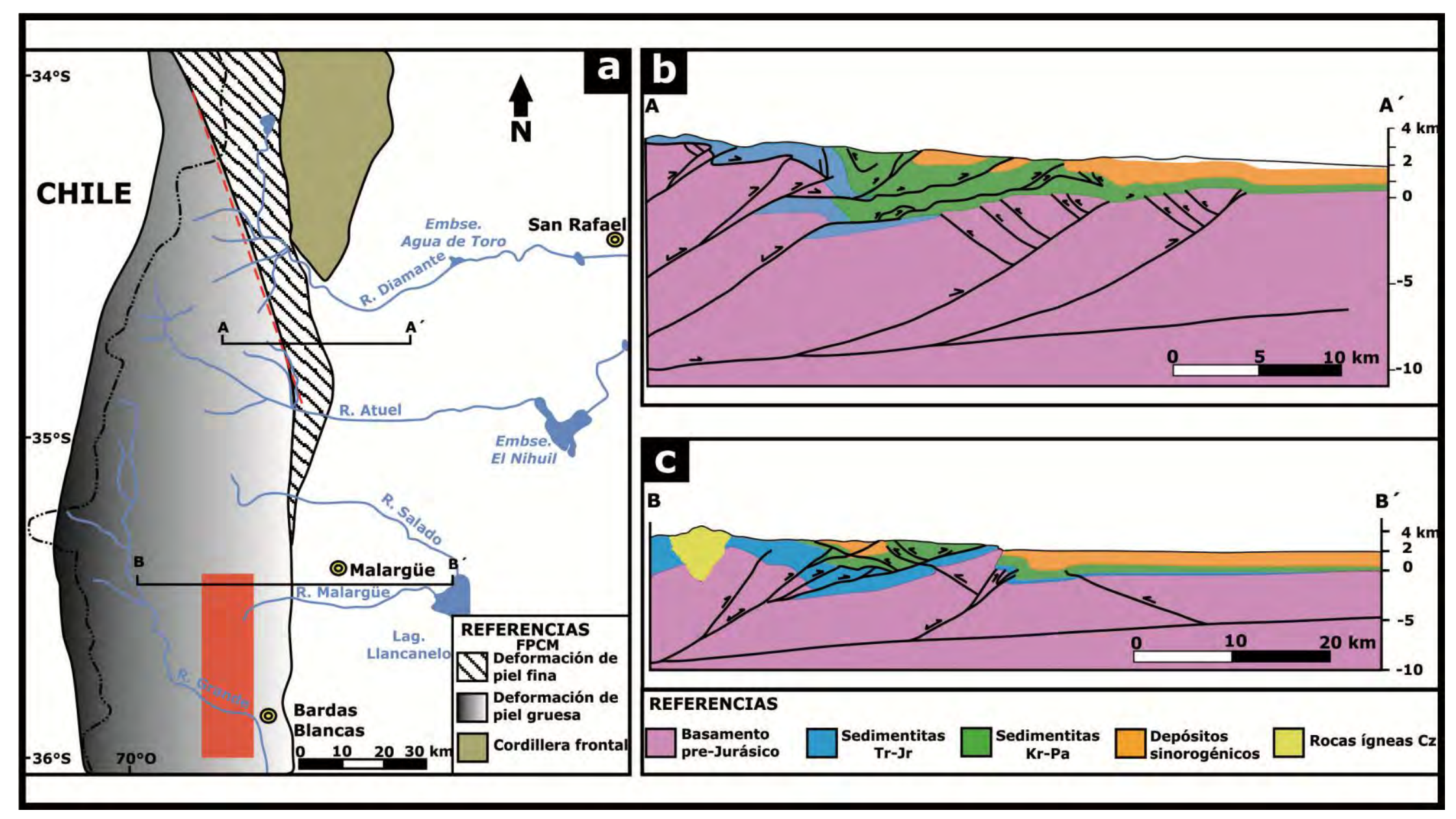

Figura 4.4:a) Estilos estructurales de la faja plegada y corrida de Malargüe (FPCM) al norte y al sur del río Atuel (modificado de Mescua y Giambiagi, 2012). El recuadro rojo indica el área de estudio. b) Perfil estructural en el sector norte de la FPCM (modificada de Turienzo, 2010). c) Perfil estructural en el sector sur de la FPCM (modificada de Giambiagi et al., 2009b) 


\section{4: Estratigrafía de las zonas de estudio}

Para describir la estratigrafía general del área de trabajo se utilizó la información bibliográfica y cartográfica disponible, junto con los mapas geológicos de la región presente en otras publicaciones (Gulisano y Gutiérrez Pleimling, 1994; Arcila Gallego, 2010). Por su parte, para describir los afloramientos del intervalo estratigráfico analizado dentro de las zonas de estudio fue necesario generar una base geológica propia de detalle. Esta síntesis fue confeccionada sobre la base de un mosaico de dos imágenes satelitales LANDSAT $7+$ (p232r084 y p232r085) en falso color compuesta (figura 4.3). En ella se volcó la información geológica disponible (Hojas Geológicas del SEGEMAR publicadas a escala 1:250.000 y $1: 200.000)$, a la que se sumó la de mapas geológicos de detalle presentes en otras publicaciones (Gulisano y Gutiérrez Pleimling, 1994; Arcila Gallego, 2010). También se utilizó un mosaico de imágenes Google Earth Pro y observaciones de campo para ajustar el mapeo realizado sobre la imagen satelital. Tanto el mapeo vectorial como el procesamiento digital de las imágenes fueron realizados con el programa ArcGis $\checkmark 10$ del Centro de Investigaciones Geológicas.

Con toda esta información cartográfica y la compilación de la bibliografía existente, más las tareas de campo, se lograron los mapas que se muestran en las figuras 4.5 y 4.6. Estos mapas constituyen una síntesis de las unidades litoestratigráficas que afloran en la zona norte y sur del área de estudio y por lo tanto poseen ciertas simplificaciones. Cabe aclarar que en los mismos la sucesión terrígena-mixta comprende a Formación Lajas, junto a los depósitos clásticos basales de la Formación Calabozo, mientras que la sucesión carbonática abarca a las calizas de la Formación Calabozo (ver capítulo 3, apartado 3.6).

Teniendo en cuenta el relleno general presentado para la Cuenca Neuquina (figura 3.4), en el área de estudio la secuencia sedimentaria comienza con los depósitos del Ciclo Precuyano (Triásico Superior a Jurásico Inferior) expuestos en la zona de Bardas Blancas. Estos depósitos se hallan en el núcleo del anticlinal de Potimalal y un sinclinal asociado, representados por la Formación Remoredo (figura 4.6). 
Las sedimentitas del Grupo Cuyo se encuentran expuestas en el sector noroccidental de la zona de Malargüe, dentro del anticlinal Torrecillas, y en la región de Bardas Blancas en el anticlinal de Potimalal y sinclinales asociados (figuras 4.5 y 4.6). Asimismo, en el sector noroccidental Kozlowski et al. (1993) indican la existencia de un gran espesor del Grupo Cuyo en el anticlinal de La Valenciana, probada por un sondeo ubicado en la culminación de la estructura que atravesó más de 2000 m de sedimentos. Debido a que parte de las unidades que conforman al Grupo Cuyo (figura 3.5) son las que revisten mayor interés para este estudio, fueron revisadas y mapeadas con mayor detalle. En la zona de Malargüe, el núcleo del anticlinal Torrecillas está conformado por la Formación El Freno, por encima se ubica la Formación Puesto Araya expuesta en ambos flancos. Hacia el flanco oriental se ubican la Formación Tres Esquinas, la sucesión terrígena-mixta, el intervalo carbonático, la Formación Tábanos y el Grupo Lotena integrado por la Formación Auquilco de carácter evaporítico (figura 4.5). En esta estructura los afloramientos de la sucesión carbonática y la Formación Tábanos carecen de continuidad estructural, con exposiciones saltuarias y espesores variables y las unidades basales del Grupo Lotena no se encuentran expuestas (formaciones Lotena y La Manga) (figura 4.5). Un hecho similar fue observado por Kozlowski et al. (1993) para el mismo intervalo estratigráfico en el anticlinal del río Atuel, ubicado al norte fuera del área de estudio. Estos autores consideran que dicho fenómeno se genera por la existencia de un desacople estructural entre las formaciones Tres Esquinas y Tordillo.

En la región de Bardas Blancas el Grupo Cuyo se encuentra expuesto en ambos flancos del anticlinal de Potimalal y de un sinclinal asociado (figura 4.6). En estas estructuras aparece representado por las formaciones Bardas Blancas, Tres Esquinas, la sucesión carbonática y la Formación Tábanos (figura 4.6). Estas dos últimas unidades presentan afloramientos muy discontinuos y con espesores variables, faltando en la región asiduamente (figuras 4.7a-b). Por encima suprayace el Grupo Lotena conformado por las formaciones La Manga y Auquilco. Tanto en esta región como en la de Malargüe las evaporitas de la Formación Auquilco presentan afloramientos distintivos con excelentes exposiciones en los 


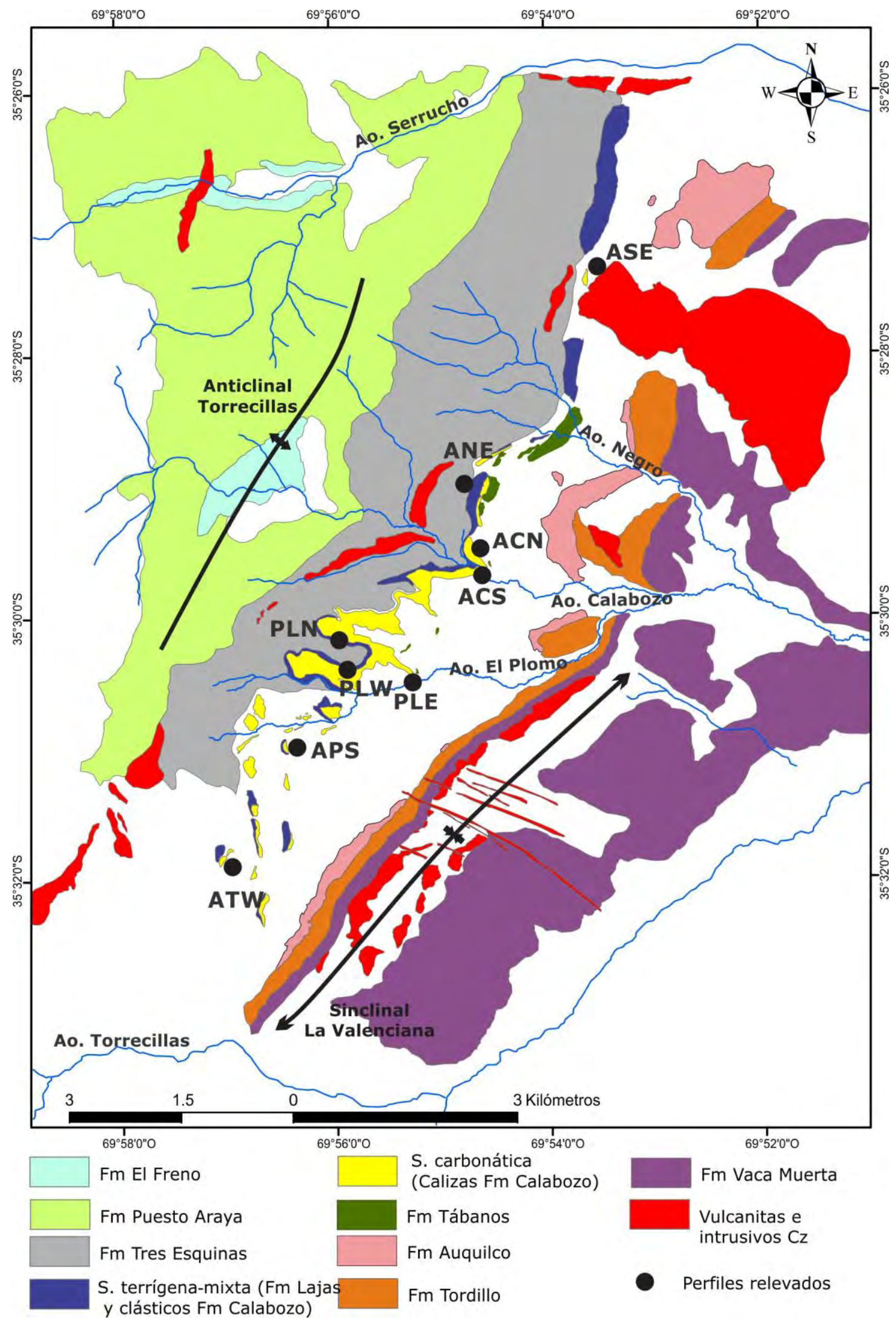

Figura 4.5: Mapa de afloramientos de la zona de Malargüe. 
cortes de arroyos y carreteras con espesores variables debido a su comportamiento plástico durante la orogenia andina (Narciso et al., 2001; Arcila Gallego, 2010).

En el área de Malargüe y Bardas Blancas apoyados sobe las sedimentitas del Grupo Lotena se presentan la Formación Tordillo y El Grupo Mendoza representado por la Formación Vaca Muerta. En la zona de Malargüe afloran de preferencia hacia el sector oriental del área de estudio en una franja continua en sentido norestesudoeste formando parte del sinclinal La Valenciana (figura 4.5). Mientras que, en el área de Bardas Blancas se presentan en el núcleo de un sinclinal asociado con el anticlinal de Potimalal (figura 4.6). Finalmente las unidades más jóvenes del relleno de la Cuenca Neuquina, Grupos Rayoso, Neuquén y Malargüe, se encuentran expuestas al este, fuera de ambas zonas de estudio. Las unidades más modernas presentes se corresponden con el vulcanismo cenozoico (Neógeno-Cuaternario) que afecto a la región. Estas rocas volcánicas e intrusivas están expuestas de norte a sur tanto en la región de Malargüe como en la de Bardas Blancas y fueron carteadas como una sola unidad (figuras 4.5 y 4.6 ).

\section{5: Perfiles sedimentológicos relevados}

\subsection{1: Introducción}

La confección de los mapas geológicos, junto a la recopilación bibliográfica disponible, resultaron imprescindibles para decidir la ubicación de los lugares donde se efectuaron los perfiles sedimentológicos. La decisión sobre la ubicación de estas secciones también requirió de viajes de campo para verificar la información disponible, al tiempo que permitió reconocer otras alternativas.

Dentro del intervalo estratigráfico analizado, el sector carbonático está compuesto por calizas de coloración gris azulada que resaltan claramente en afloramiento ante el tramo clástico infrayacente de tonalidad castaña a gris. Lo mismo sucede con las unidades infrayacente, cuando la sucesión terrígena-mixta no está representada, y suprayacente, conformadas por sedimentitas clásticas de tonalidad negra y evaporitas blanquecinas, respectivamente. Este fuerte contraste litológico y de 
coloración que presentan las sucesiones analizadas en afloramientos facilitó su identificación. Además, dicho intervalo estratigráfico aparece por lo general en los flancos de las estructuras deformadas elongadas en sentido NE-SW o N-S, por lo que muestra exposiciones extensas, generalmente discontinuas, debido al comportamiento plástico de la entidad carbonática ante la deformación tectónica imperante en la región.

Como se observa en las figuras 4.5, 4.6 y 4.7, mediante la descripción y medición en 11 sectores del área de estudio, se logra una buena cobertura del área de afloramiento del intervalo estratigráfico analizado. En buena parte, esto se vio favorecido por el hecho de que existen rutas nacionales y numerosos caminos rurales que cruzan la región uniendo las distintas localidades y parajes que permiten acceder a gran parte del área de trabajo.

\subsection{2: Ubicación y características de las secciones}

Para esta tesis se relevaron once perfiles del intervalo estratigráfico analizado. Una lista de todas las localidades con su ubicación por posicionador satelital (GPS Garmin eTrex Vista HCx) y los espesores medidos de cada unidad se muestran en la tabla 1. Por su parte en el Anexo Ia y Anexo Ib se encuentran los perfiles columnares dibujados a escala 1:50.

A continuación se presentan las principales características de los lugares donde fueron relevadas las secciones sedimentológicas dentro de cada zona de estudio, descriptas de noreste a sudoeste en la región septentrional y de noroeste a sudeste en la región austral. Esta caracterización fue realizada con efectos informativos y también con la finalidad de que dichas localidades puedan ser encontradas por otras personas y utilizadas en trabajos posteriores. 


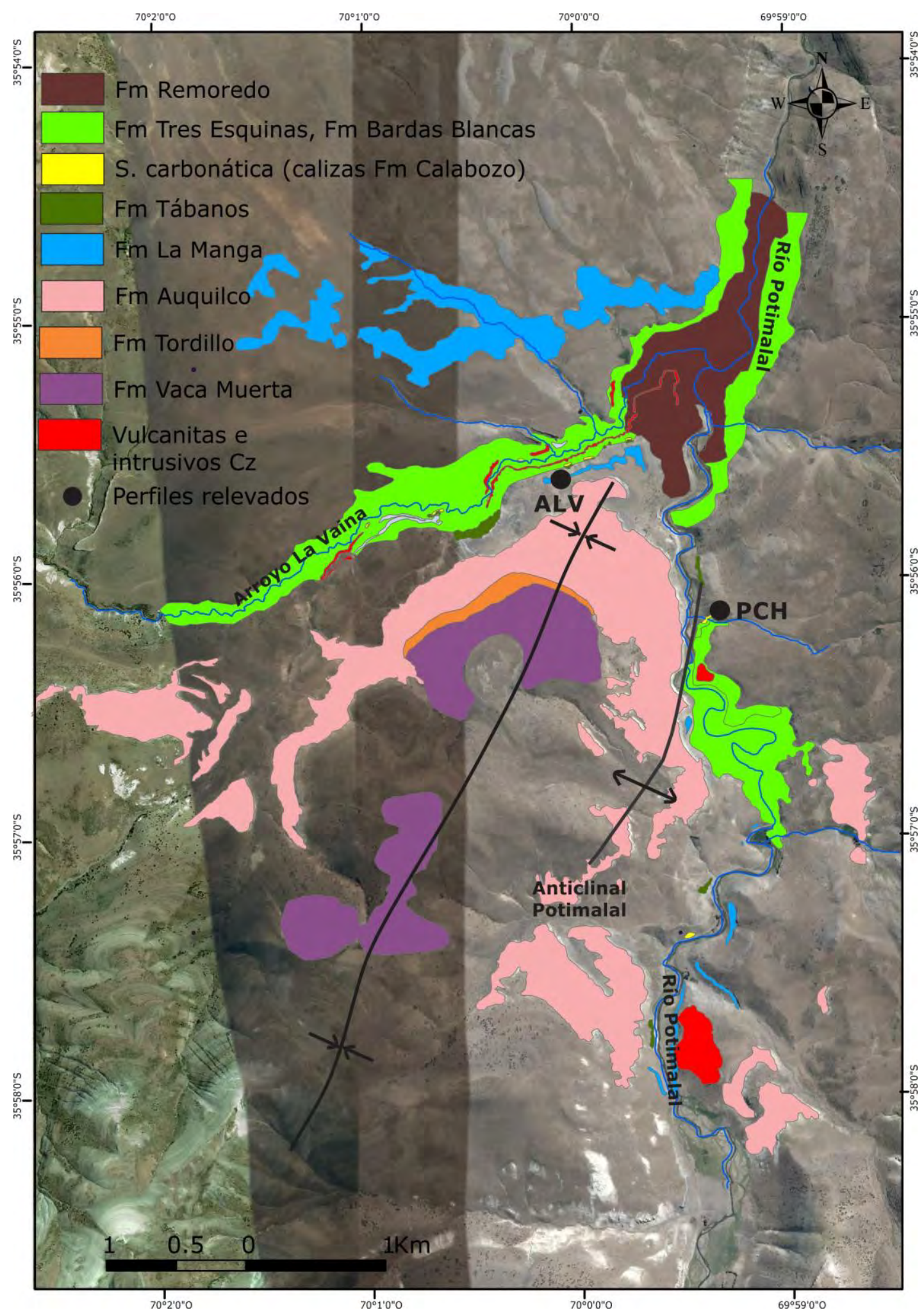

Figura 4.6: Mapa de afloramientos de la zona de Bardas Blancas. 


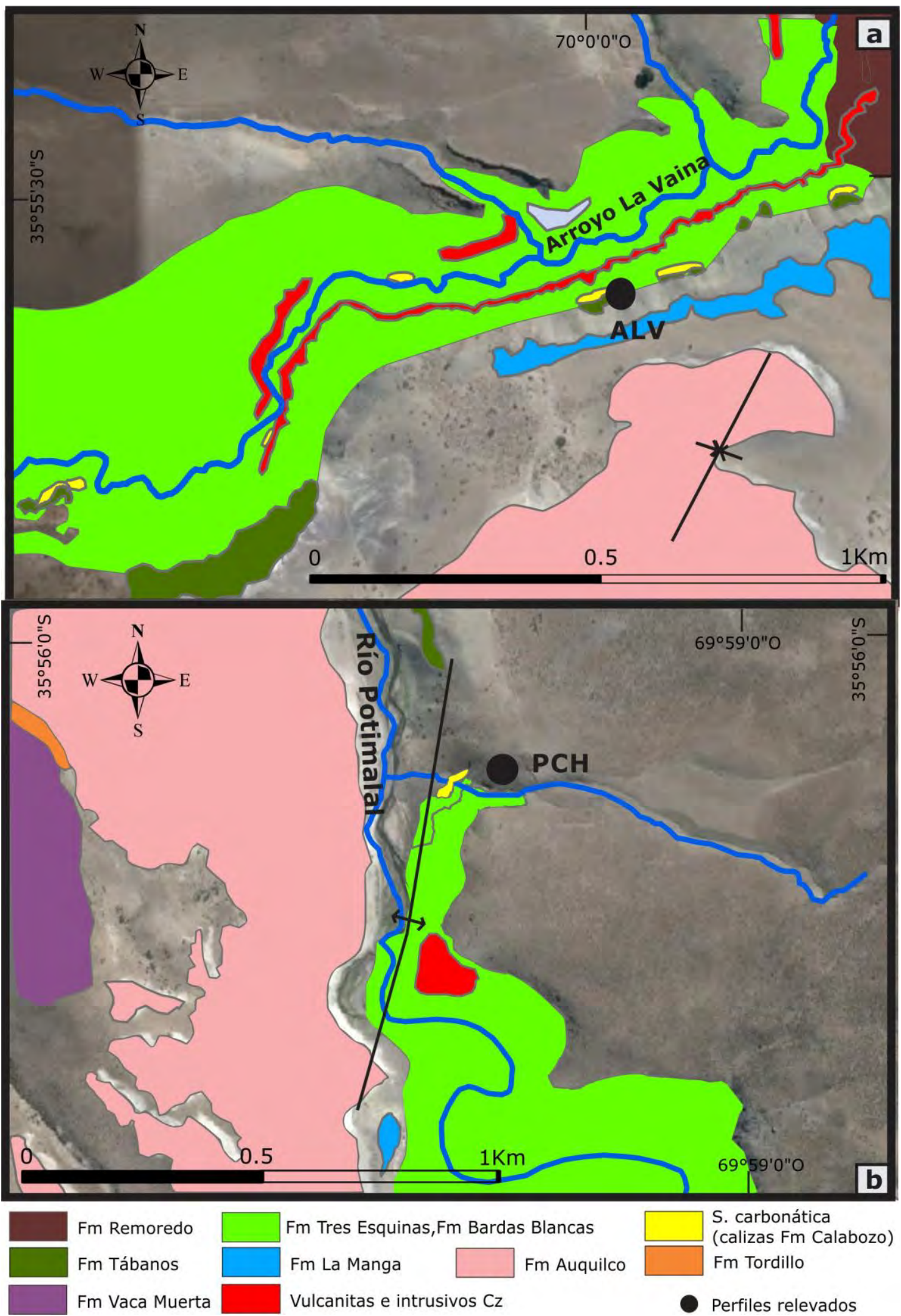

Figura 4.7: Detalle de los afloramientos en los alrededores de la secciones a) Arroyo La Vaina (ALV) y b) Río Potimalal (PCH). 


\begin{tabular}{|c|c|c|c|c|c|c|}
\hline PERFIL & Abrev. & $\begin{array}{c}\text { Lat. Sur } \\
\text { Long. Oeste }\end{array}$ & $\begin{array}{l}\text { Espesor } \\
\text { S.t-m/TE }\end{array}$ & $\begin{array}{c}\text { Espesor } \\
\text { S.carb. }\end{array}$ & $\begin{array}{c}\text { Espesor } \\
\text { Tab. }\end{array}$ & $\begin{array}{c}\text { Espesor } \\
\text { total }\end{array}$ \\
\hline $\begin{array}{l}\text { Arroyo } \\
\text { Serrucho }\end{array}$ & ASE & $\begin{array}{l}35^{\circ} 27^{\prime} 18^{\prime \prime} \\
69^{\circ} 53^{\prime} 38^{\prime \prime}\end{array}$ & 4.00 & 21.00 & 0 & *26.8 \\
\hline $\begin{array}{l}\text { Arroyo } \\
\text { Negro }\end{array}$ & ANE & $\begin{array}{c}35^{\circ} 28^{\prime} 46.5^{\prime \prime} \\
69^{\circ} 54^{\prime} 29^{\prime \prime}\end{array}$ & 6.80 & 2.75 & 0 & 9.55 \\
\hline $\begin{array}{l}\text { Arroyo } \\
\text { Calabozo } \\
\text { Norte }\end{array}$ & $A C N$ & $\begin{array}{c}35^{\circ} 29^{\prime} 26^{\prime \prime} \\
69^{\circ} 54^{\prime} 45.8^{\prime \prime}\end{array}$ & 11.70 & 4.50 & 0 & 16.20 \\
\hline $\begin{array}{l}\text { Arroyo } \\
\text { Calabozo } \\
\text { Sur }\end{array}$ & ACS & $\begin{array}{l}35^{\circ} 29^{\prime} 37.8^{\prime \prime} \\
69^{\circ} 54^{\prime} 36.7^{\prime \prime}\end{array}$ & 7.20 & 18.20 & 1.50 & 26.90 \\
\hline $\begin{array}{l}\text { Arroyo } \\
\text { Plomo Norte }\end{array}$ & PLN & $\begin{array}{l}35^{\circ} 30^{\prime} 8.8^{\prime \prime} \\
69^{\circ} 55^{\prime} 55.7^{\prime \prime}\end{array}$ & 14.60 & 14.20 & 0 & 28.80 \\
\hline $\begin{array}{l}\text { Arroyo } \\
\text { Plomo Oeste }\end{array}$ & PLW & $\begin{array}{c}35^{\circ} 30^{\prime} 24.5^{\prime \prime} \\
69^{\circ} 55^{\prime} 50^{\prime \prime}\end{array}$ & 2.00 & 5.10 & 0 & 7.10 \\
\hline $\begin{array}{l}\text { Arroyo } \\
\text { Plomo Este }\end{array}$ & PLE & $\begin{array}{c}35^{\circ} 30^{\prime} 28^{\prime \prime} \\
69^{\circ} 55^{\prime} 15.5^{\prime \prime} \\
\end{array}$ & 8.45 & 6.35 & 1 & 15.80 \\
\hline $\begin{array}{l}\text { Arroyo } \\
\text { Plomo Sur }\end{array}$ & APS & $\begin{array}{c}35^{\circ} 31^{\prime} 10.4^{\prime \prime} \\
69^{\circ} 56^{\prime} 45^{\prime \prime}\end{array}$ & 15.00 & 6.10 & 0 & 21.10 \\
\hline $\begin{array}{l}\text { Arroyo } \\
\text { Torrecillas } \\
\text { Oeste }\end{array}$ & ATW & $\begin{array}{c}35^{\circ} 31^{\prime} 52^{\prime \prime} \\
69^{\circ} 57^{\prime} 2^{\prime \prime}\end{array}$ & 34.00 & 3.55 & 0 & 37.55 \\
\hline $\begin{array}{l}\text { Río } \\
\text { Potimalal }\end{array}$ & PCH & $\begin{array}{c}35^{\circ} 56^{\prime} 9^{\prime \prime} \\
69^{\circ} 59^{\prime} 21.7 "\end{array}$ & 3.55 & 6.15 & 0 & 9.70 \\
\hline $\begin{array}{l}\text { Arroyo La } \\
\text { Vaina }\end{array}$ & ALV & $\begin{array}{c}35^{\circ} 55^{\prime} 33^{\prime \prime} \\
70^{\circ} 0^{\prime} 2^{\prime \prime}\end{array}$ & 4.00 & 5.60 & 1.20 & 10.80 \\
\hline
\end{tabular}

Tabla 1: Principales características de los perfiles sedimentológicos relevados en esta investigación. Espesores en metros. Abrev.: abreviatura o código del perfil; Lat.: Latitud; Long.: Longitud; S. t-m: sucesión terrígena-mixta; TE: Formación Tres Esquinas; S. carb.: sucesión carbonática; Tab.: Formación Tábanos. *entre ambas sucesiones se presenta $1.80 \mathrm{~m}$ cubiertos. Las secciones sombreadas fueron utilizadas como base estratigráfica porque poseen la sucesión completa o gran parte del intervalo estratigráfico estudiado. 


\subsection{3: Zona de Malargüe}

En esta región los afloramientos de la sucesión terrígena-mixta y carbonática se encuentran en el flanco oriental del anticlinal de Torrecillas, ubicado en las inmediaciones de los cerros Serrucho y Puchenque. Se corresponde con un anticlinal asimétrico de $10 \mathrm{~km}$ de longitud de onda con eje de rumbo $\mathrm{N} 40^{\circ} \mathrm{E}$ y limbos occidental-oriental que inclinan $12^{\circ}$ y $42^{\circ}$, respectivamente (Arcila Gallego, 2010). En el núcleo se encuentran aflorando las unidades basales del Grupo Cuyo y en los flancos se exponen las sedimentitas de los Grupos Cuyo, Lotena y Mendoza. Gran parte del pliegue está cubierto por diferentes pulsos de flujos volcánicos cenozoicos de composición basáltica a andesítica.

A esta zona se accede fácilmente desde la localidad de Malargüe, de la que dista unos $30 \mathrm{~km}$, por el camino que une a esta localidad con el atractivo turístico de Los Castillos de Pincheira. Además, se utilizaron para llegar hasta los afloramientos los caminos secundarios a las canteras de yeso explotadas en la zona y algunas cortas huellas que parten desde los puestos presentes en el área.

Dentro de esta zona fueron relevadas 9 secciones columnares que se describen a continuación:

1) Arroyo Serrucho (ASE). En esta zona la estructura es compleja debido a la presencia de pliegues y fallas menores desarrolladas en el flanco oriental del anticlinal Torrecillas. Por este motivo no se pudo hallar una sección completa del intervalo estratigráfico estudiado, igualmente se relevó un perfil sedimentológico integrado donde se volcó la información de tres secciones separadas por sectores cubiertos. Se ubica al este del cerro Torrecillas, entre los arroyos Pincheira y Negro. Aquí las sucesiones terrígena-mixta y carbonática presentan una potencia de 4 y $21 \mathrm{~m}$, respectivamente (tabla 1 ). El contacto entre ambas no se encuentra expuesto, están separadas por un sector de $2 \mathrm{~m}$ de derrubios. 
2) Arroyo Negro (ANE). Dicha sección está localizada en los alrededores del cerro Torrecillas, entre los arroyos Negro y Calabozo. El intervalo estratigráfico a estudiar se encuentra completo, la sucesión terrígena-mixta muestra un espesor de $7 \mathrm{~m}$, mientras que la carbonática una potencia de $2.7 \mathrm{~m}$ (tabla 1). En esta sección se puede apreciar claramente el contacto entre ambas sucesiones (figura 4.8).

3) Arroyo Calabozo Norte (ACN). Se encuentra muy próxima a la localidad tipo de la Formación Calabozo (sección ACS), aproximadamente a $0.5 \mathrm{~km}$ al noroeste. A pesar de su cercanía con la sección ACS se decidió relevar un perfil sedimentológico en este sector debido a las diferencias litofaciales observadas entre ellos. Este perfil se levantó en la margen izquierda del arroyo Calabozo, donde el intervalo estratigráfico estudiado presenta $16 \mathrm{~m}$ de espesor y el contacto entre ambas sucesiones se encuentra expuesto (figura 4.9a). La sucesión terrígena-mixta tiene potencias de $12 \mathrm{~m}$, mientras que la carbonática presenta espesores de $4 \mathrm{~m}$ (figura $4.9 \mathrm{~b}$, tabla 1 ).

4) Arroyo Calabozo Sur (ACS). Este sector se corresponde con el área tipo de la Formación Calabozo definida por Dessanti (1973) donde la unidad se apoya sobre el intervalo II de la Formación Lajas descripto por Gulisano y Gutiérrez Pleimling (1994). Aquí los afloramientos de este intervalo estratigráfico se encuentran en ambas márgenes del arroyo homónimo, valle que se ubica al sur del arroyo Negro. Sin embargo, las mejores exposiciones se encuentran en la margen izquierda de este arroyo, donde fue relevado el perfil sedimentológico ACS (figura 4.10a). En dicha sección la sucesión carbonática alcanza unos $18 \mathrm{~m}$ de potencia y se encuentra completa. La relación de este tramo con la infrayacente sucesión terrígena-mixta de $7 \mathrm{~m}$ de potencia se aprecia de forma clara, no ocurre lo mismo con la Formación Tábanos (suprayacente) cuyo contacto se encuentra cubierto (figura 4.10 b; tabla 1 ).

5) Arroyo Plomo Norte (PLN). Dicha sección está localizada en las inmediaciones del cerro Puchenque entre los arroyos Calabozo y El Plomo. El intervalo 


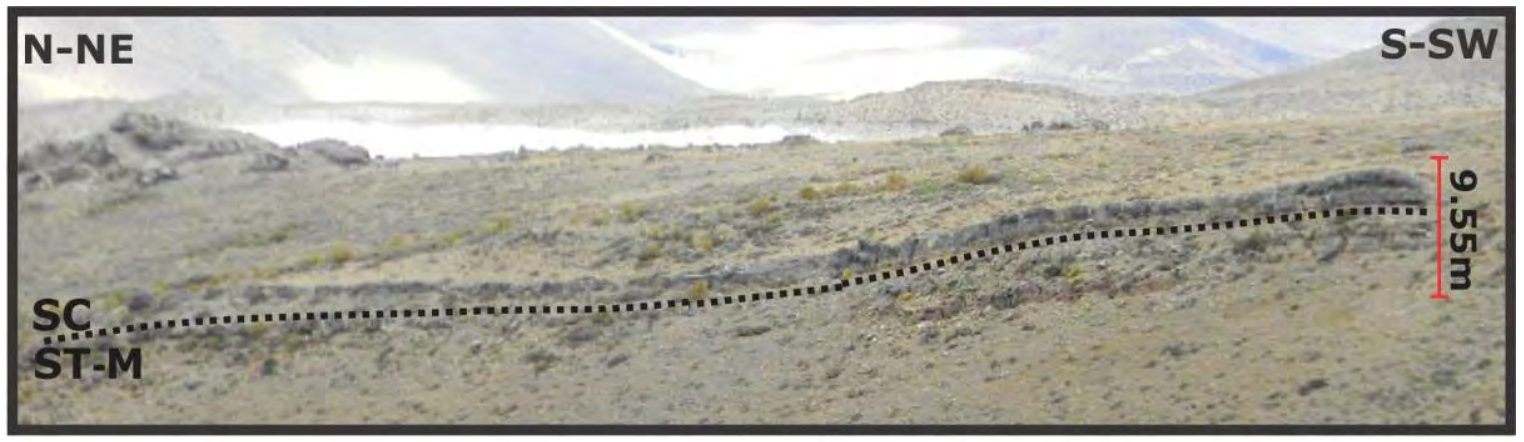

Figura 4.8: Sucesión terrígena-mixta (ST-M) y carbonática (SC) en la sección Arroyo Negro (ANE). La línea negra marca el contacto entre ambas sucesiones.

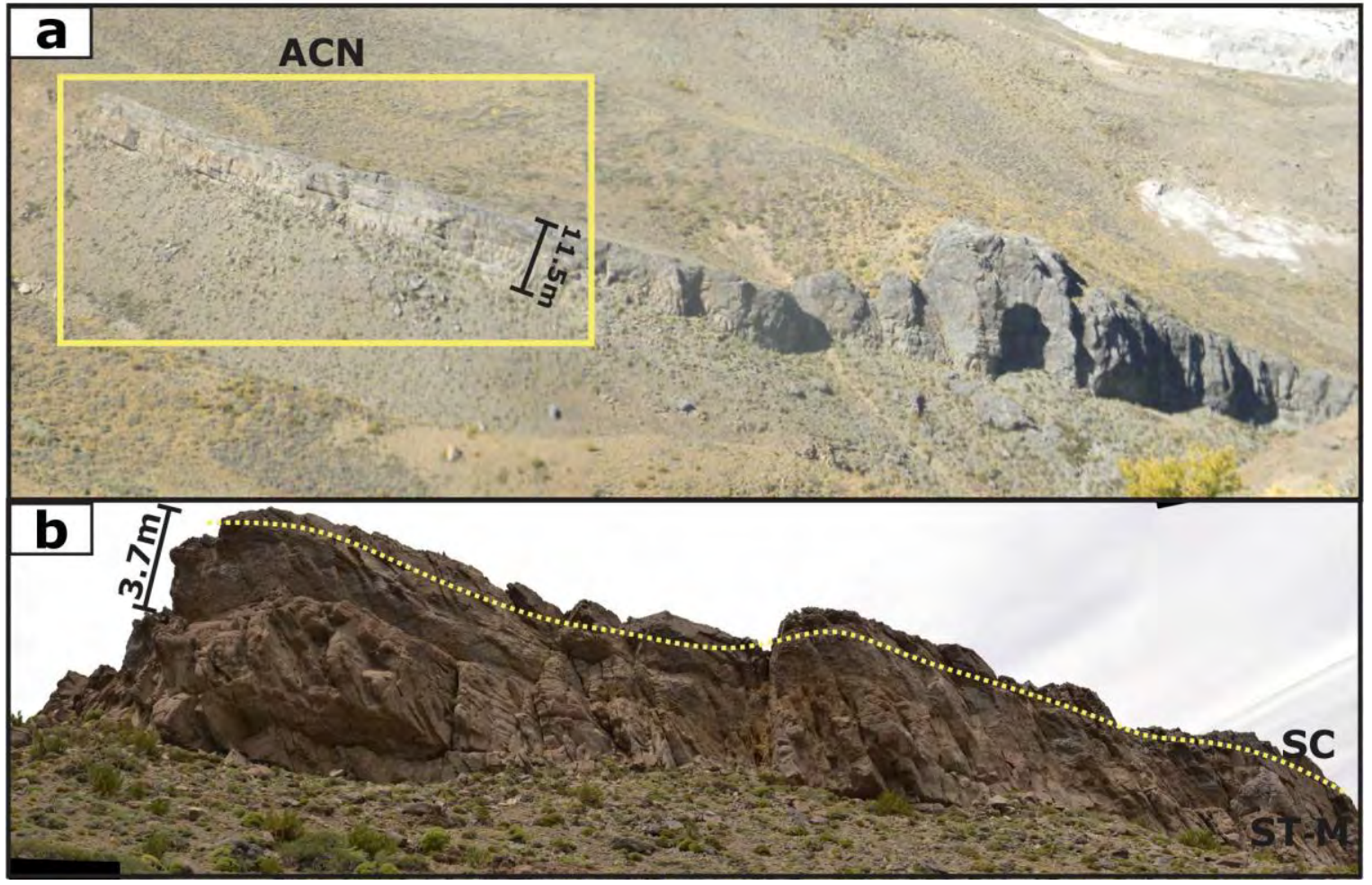

Figura4.9a): Las sucesiones terrígena-mixta y carbonática en la margen izquierda del arroyo Calabozo (vista al nordeste). El recuadro amarillo marca la ubicación de la sección columnar ACN (Arroyo Calabozo Norte). b): Detalle de los afloramientos de la sucesión terrígena-mixta (ST-M) y carbonática (SC) en la sección ACN. 


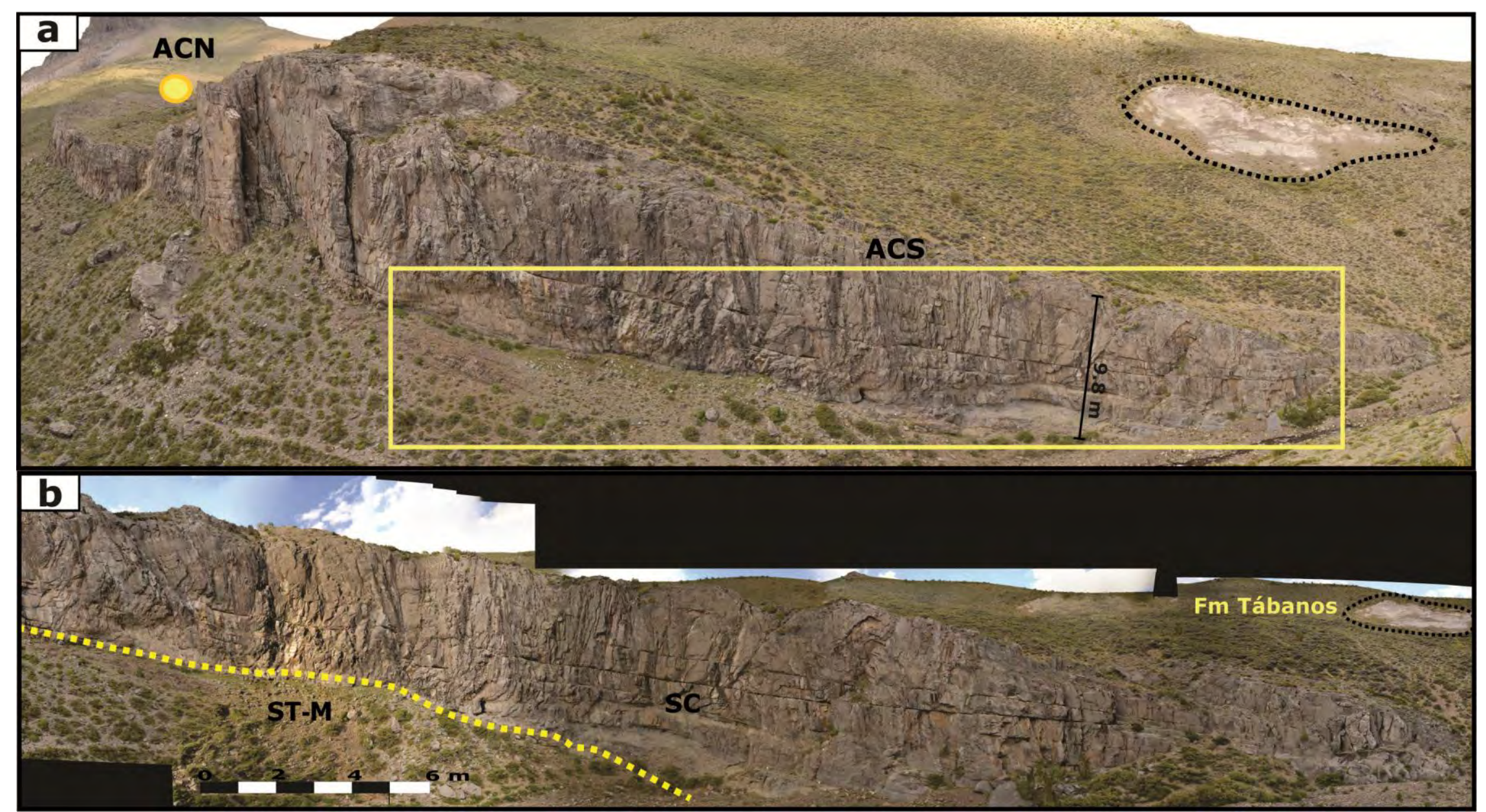

Figura 4.10: Vista al norte de las sucesiones terrígena-mixta (ST-M) y carbonática (SC) en las inmediaciones del arroyo Calabozo. a) Ubicación de los perfiles sedimentológicos relevados en la zona (ACN, ACS); la línea punteada indica los afloramientos de la Formación Tábanos. b) Detalle de los afloramientos en la sección ACS. La línea punteada amarilla indica el contacto entre ambas sucesiones y la línea punteada negra marca los afloramientos de la Formación Tábanos. 
analizado está parcialmente completo, solo falta parte del tramo superior de la sucesión carbonática. El espesor medido es de 29 m, dentro de los cuales ambas sucesiones presentan potencias similares (figura 4.11a; tabla 1 ).

6) Arroyo Plomo Oeste (PLW). Se presenta al este del cerro Puchenque sobre la margen izquierda del arroyo El Plomo. La sucesión terrígena-mixta y carbonática se encuentran con una potencia de $7 \mathrm{~m}$, menor respecto al perfil PLN (tabla 1). Ambas están incompletas, solo aflora el tramo superior de la sucesión terrígenamixta y el inferior a medio del sector carbonático. No obstante, el contacto entre ambas sucesiones está expuesto (figura 4.11b).

De forma complementaría se relevó una sección columnar al noroeste del perfil PLW de $3 \mathrm{~m}$ de espesor debido a las diferencias litológicas encontradas en la sucesión carbonática. A los fines prácticos, la información relevada en esta sección será graficada de forma conjunta con la obtenida en la sección columnar PLW, dado el bajo espesor que presenta y las similitudes litológicas de la sucesión terrígena-mixta en ambas secciones.

7) Arroyo Plomo Este (PLE). Este perfil se ubica sobre la margen izquierda del arroyo El Plomo, aproximadamente a un km al este de la sección anterior. Aquí el intervalo estratigráfico se encuentra completo, presenta una potencia de $16 \mathrm{~m}$ y ambas sucesiones se encuentran en contacto (figuras $4.12 a$ y $b$; tabla 1 ). No sucede lo mismo con la Formación Tábanos suprayacente, cuyo contacto no está expuesto.

8) Arroyo Plomo Sur (APS). En este sector la estructura es compleja debido a la presencia de pliegues y fallas menores presentes en el flanco oriental del anticlinal Torrecillas que afectan la calidad y continuidad de los afloramientos del intervalo estratigráfico analizado. A pesar de esto se pudo relevar una sección columnar entre los arroyos El Plomo y Torrecillas, donde la sucesión terrígenamixta presenta $15 \mathrm{~m}$ de potencia y el sector carbonático $6 \mathrm{~m}$ (tabla 1). De esta última no se preserva su tramo superior al igual que su contacto con la Formación Tábanos suprayacente. 


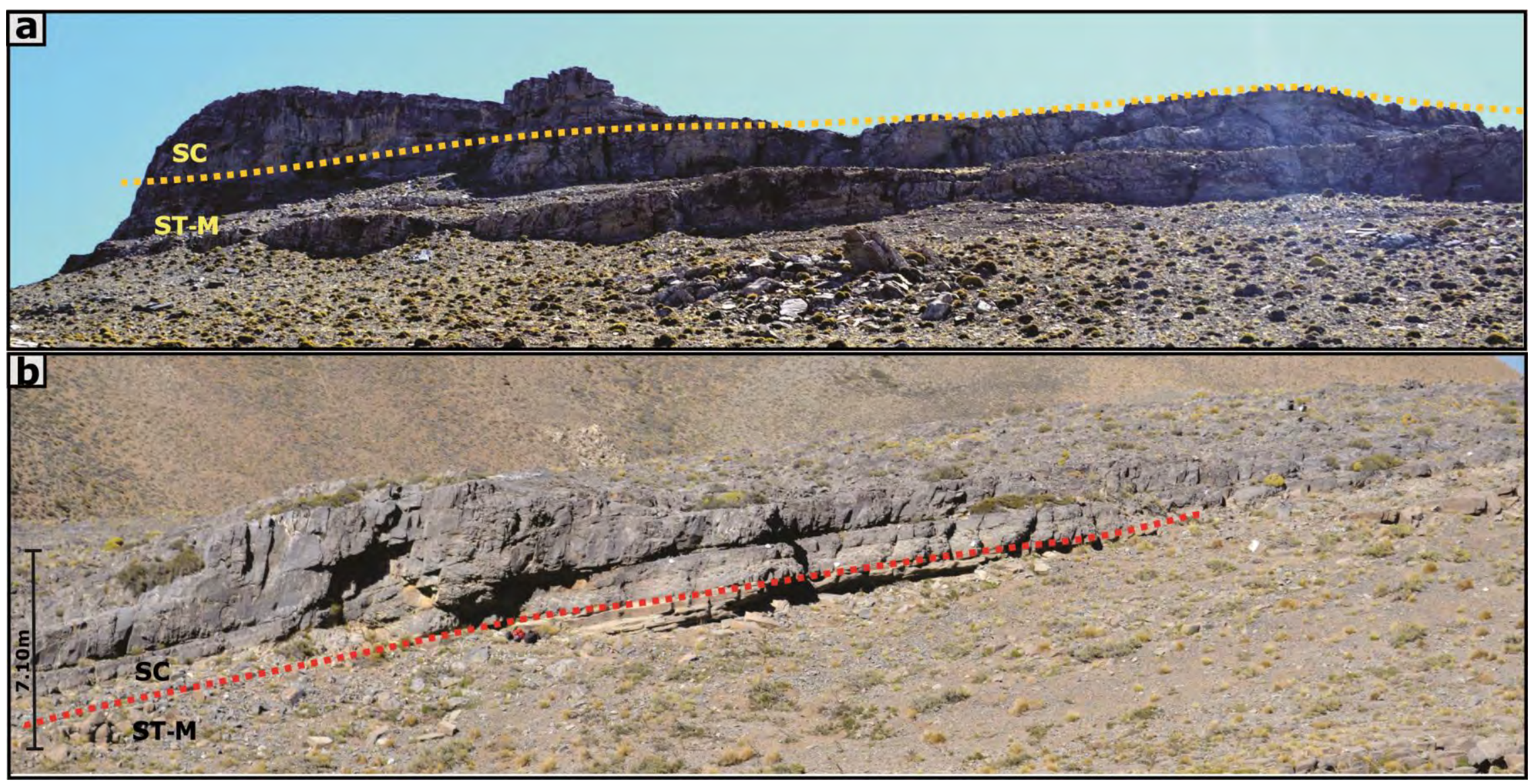

Figura 4.11: Afloramientos de la sucesión terrígena-mixta (ST-M) y carbonática (SC) en los alrededores del arroyo El Plomo. a) Vista al noreste del intervalo estratigráfico analizado en el perfil PLN (Arroyo Plomo Norte). La línea amarilla punteada marca el contacto entre la sucesión terrígena-mixta infrayacente y el intervalo carbonático suprayacente. b) Vista al sudeste de la las sucesiones terrígena-mixta y carbonática en la sección Plomo Oeste (PLW). La línea roja punteada marca el contacto entre ambas sucesiones. 
9) Arroyo Torrecillas Oeste (ATW). Dicho perfil está ubicado al norte del arroyo Torrecillas, a $1.5 \mathrm{~km}$ al sur de la sección anterior. En este sector la sucesión terrígena-mixta presenta su mayor potencia (34 m), no obstante su base no se encuentra expuesta. No sucede lo mismo con la sucesión carbonática la cual resulta poco espesa (3.5 m) y falta su tramo superior (ver tabla 1). Ambas sucesiones se encuentran en contacto.

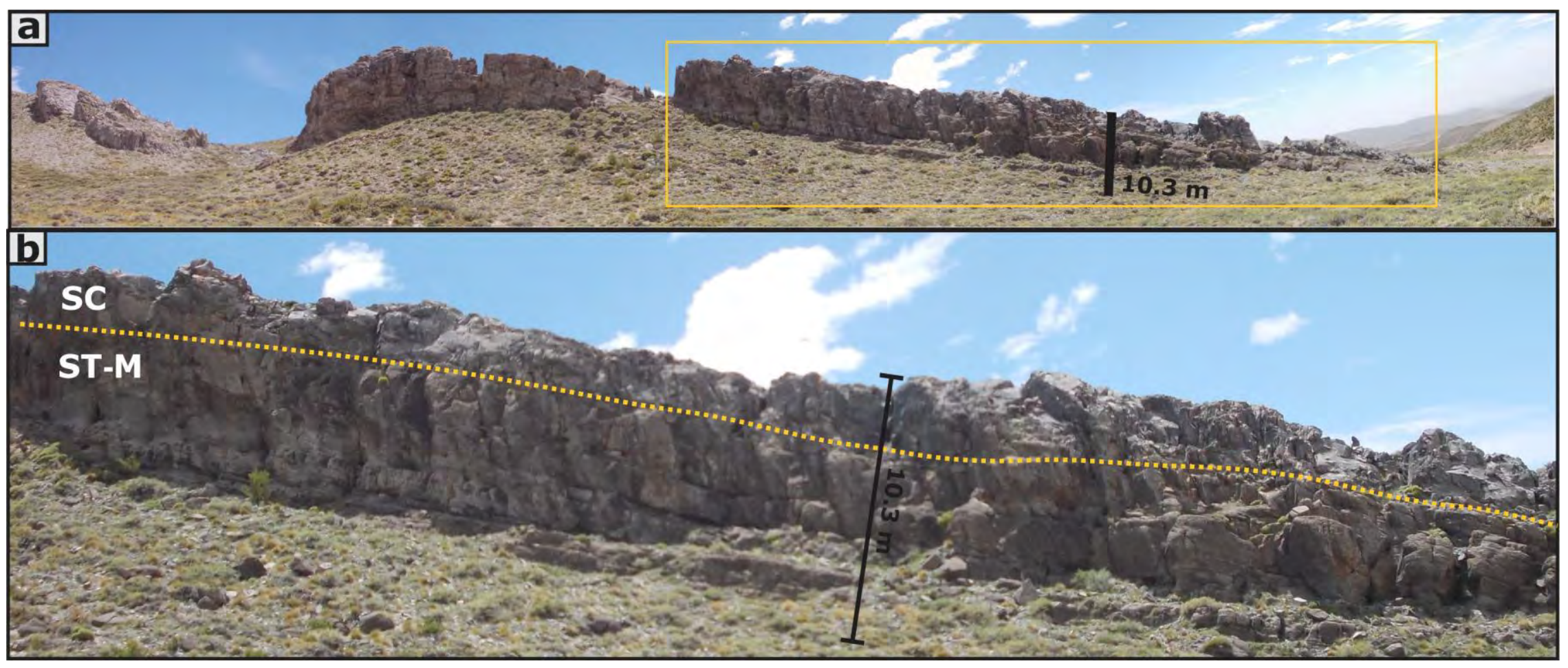

Figura 4.12: La sucesión terrígena-mixta (ST-M) y carbonática (SC) en los alrededores del arroyo El Plomo. a) Vista al norte de ambas sucesiones en el perfil PLE (Plomo Este). El rectángulo en amarillo indica la ubicación del perfil PLE. b) Detalle de los afloramientos en la sección PLE. La línea amarilla punteada marca el contacto entre la sucesión terrígena-mixta infrayacente y el intervalo carbonático suprayacente. 


\subsection{4: Zona de Bardas Blancas}

En esta zona solo se presentan los afloramientos de la sucesión carbonática los cuales se disponen en ambos flancos del anticlinal Potimalal localizado sobre el río homónimo y al sur de su unión con el arroyo La Vaina. Como se describiera en el apartado 4.4, en esta estructura los afloramientos de la sucesión carbonatica son discontinuos y generalmente se encuentran disturbados. Este pliegue se corresponde con un anticlinal asimétrico de $250 \mathrm{~m}$ de longitud de onda con eje de dirección $\mathrm{N} 40^{\circ} \mathrm{E}$ y limbos occidental-oriental que inclinan $50^{\circ}-90^{\circ}$ y $10^{\circ}-20^{\circ}$, respectivamente (Dimieri, 1992). En dicha estructura se encuentran expuestas las sedimentitas del Grupo Cuyo, Lotena y Mendoza.

A esta región se llega desde la localidad de Bardas Blancas, ubicada a $22 \mathrm{~km}$ al noreste, a través de la ruta internacional $N^{\circ} 145$ y los caminos secundarios que van desde esta ruta hasta los puestos presentes en la zona.

Dentro de esta zona fueron relevados 2 perfiles sedimentológicos que se describen a continuación:

9) Arroyo La Vaina (ALV). Dicho perfil se ubica en la margen derecha del arroyo La Vaina, sobre el flanco occidental del anticlinal Potimalal. En este caso la sucesión carbonática está completa, pero a diferencia de las secciones relevadas en la zona de Malargüe, sus exposiciones no son tan buenas (figura 4.13a). El espesor medido alcanza los $6 \mathrm{~m}$ (tabla 1) y su contacto con la Formación Tres Esquinas infrayacente es concordante. Además el contacto neto con la unidad que la suprayace (Formación Tábanos) se encuentra expuesto (figuras 4.13a-b).

10) Río Potimalal (PCH). Esta sección está localizada aproximadamente a 10 $\mathrm{km}$ al sur del río Grande, sobre la margen derecha del río Potimalal. La misma fue relevada sobre el flanco oriental del anticlinal Potimalal, donde se encuentra representada la sucesión carbonática casi en su totalidad, solo faltan algunos niveles del tramo superior. La unidad presenta una potencia de $6 \mathrm{~m}$ (tabla 1) y su contacto es concordante con la Formación Tres Esquinas infrayacente (figura 4.14). 


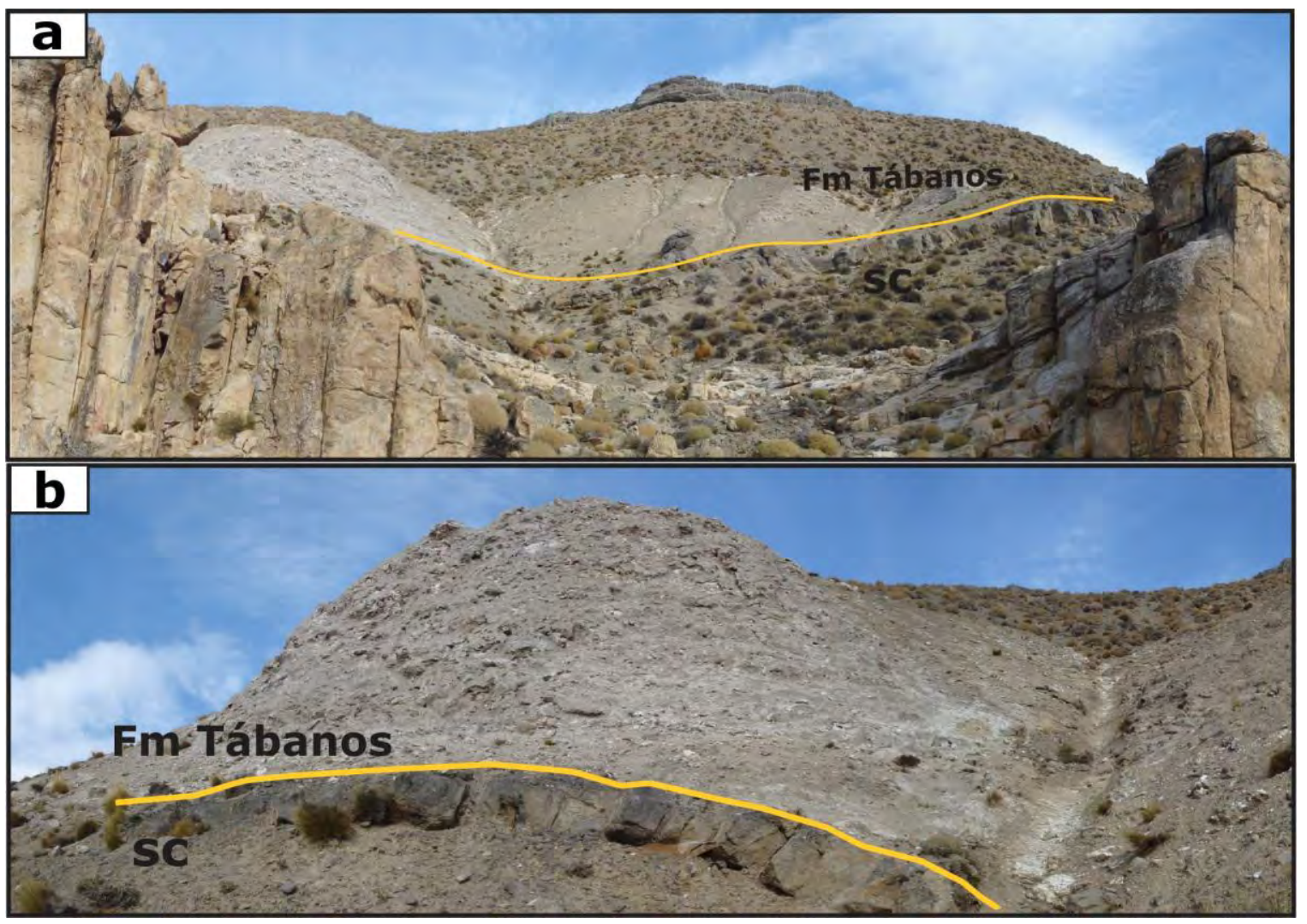

Figura 4.13a: Vista al sudeste de la sucesión carbonática (SC) en la margen izquierda del arroyo La Vaina, perfil sedimentológico ALV (Arroyo La Vaina). La línea amarilla indica el contacto entre la SC y la Formación Tábanos. b) Detalle del contacto neto con la Formación Tábanos.

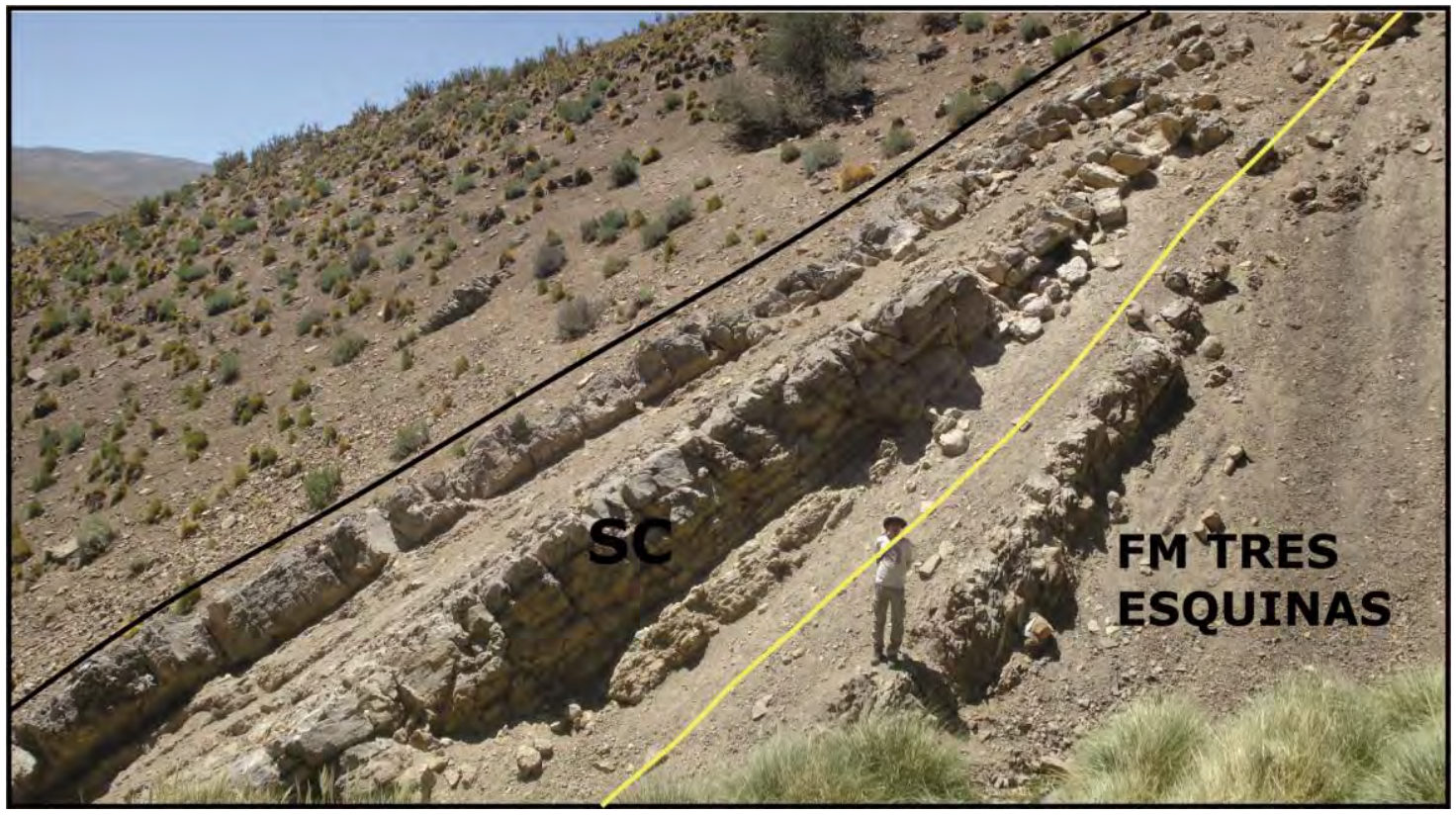

Figura 4.14: La sucesión carbonática (SC) expuesta en la sección Río Potimalal (vista al noroeste). La línea amarilla marca el contacto con la Formación Tres Esquinas y la línea negra indica el tope de la sección. La persona utilizada como escala mide $1.70 \mathrm{~m}$. 


\section{CAPÍTULO 5: ANÁLISIS DE FACIES}

\section{1: Introducción}

A los efectos de dilucidar los procesos sedimentarios, modelos de sedimentación y factores de control que tuvieron lugar durante la generación de la sucesiones carbonática y terrígena-mixta se desarrolla el análisis de facies del intervalo estratigráfico en estudio. De acuerdo con Pirrie (1998), el análisis de facies posee cinco etapas principales: 1) descripción detallada del intervalo estratigráfico estudiado; 2) subdivisión en un número determinado de facies descriptivas y cuantificación semicuantitativa; 3) interpretación de las facies en términos de procesos depositacionales; 4) agrupamiento de las facies individuales en asociaciones de facies; 5) comparación de las asociaciones de facies con modelos de facies preexistentes para lograr una interpretación paleoambiental. En este capítulo, y en total concordancia con lo antedicho, se abordarán los aspectos concernientes a las tres primeras etapas, en tanto que las dos últimas serán presentadas en los siguientes capítulos.

En este contexto, en primera instancia se desarrollará la caracterización general de las sedimentitas del intervalo estratigráfico estudiado, acompañado por el análisis composicional de calizas y areniscas. En esta etapa, mediante un análisis petrográfico detallado, se realizará la descripción de los componentes principales y menores que conforman a estas sedimentitas, y el estudio cuantitativo en areniscas. Además, mediante difractometría de rayos $\mathrm{X}$, se analizará el contenido de argilominerales en ambas litologías. Luego, se llevará a cabo la subdivisión del intervalo estratigráfico en estudio en un número determinado de facies carbonáticas y clásticas las cuales se interpretarán en término de los procesos depositacionales que las formaron. 


\section{2: Caracterización general de las sedimentitas}

La mayor parte de las sedimentitas reconocidas en este trabajo están conformadas por granos carbonáticos intracuencales, o provienen de la destrucción de los mismos, con un mínimo transporte en un medio subácueo hasta su depositación en la cuenca sedimentaria. Las mismas pueden presentar un contenido variable de detritos terrígenos derivados de la fragmentación de rocas previas, conformando rocas sedimentarias mixtas. Además, se registran otras sedimentitas calcáreas formadas in situ, donde los componentes resultan ligados orgánicamente durante la depositación (boundstone). En menor proporción se presentan sedimentitas clásticas que provienen de la erosión y transporte de detritos terrígenos en un medio subaéreo a subácueo, hasta su posterior acumulación en la cubeta sedimentaria. Este nivel de diferenciación será considerado para el esquema de facies, incluyendo en las sedimentitas clásticas a las rocas sedimentarias mixtas.

Los siguientes parámetros a considerar en las sedimentitas carbonáticas son la granulometría, el contenido de fango carbonático y la textura (matriz o clasto sostén), para el primer grupo, y el modo como los organismos ligan el material para los boundstone, según la clasificación de Dunham (1962) modificada por Embry y Klovan (1971). En las sucesiones carbonática y terrígena-mixta se diferenciaron wackestone (menos de $10 \%$ de granos $>2 \mathrm{~mm}$, matriz sostén), packstone (menos del $10 \%$ de granos $>2 \mathrm{~mm}$, clasto sostén y presencia de fango carbonático), grainstone (menos del $10 \%$ de granos $>2 \mathrm{~mm}$, clasto sostén, sin fango carbonático) y floatstone (más de $10 \%$ de granos $>2 \mathrm{~mm}$, fango sostén). Además, se identificaron boundstone formados por comunidades microbianas bentónicas que entrampan e incrustan material (bindstone o estromatolitos), y aquellos conformados por organismos que construyen una estructura rígida (framestone). Dentro de la sucesión carbonática los grupos de packstone, grainstone y floatstone resultan ser los más abundantes.

En lo que respecta a las litologías clásticas, la granulometría de los fragmentos presentes resulta ser el parámetro descriptivo a considerar. En las unidades estudiadas se identificaron rocas psefíticas (significativa proporción de clastos mayores a $2 \mathrm{~mm}$ ) y rocas psamíticas (detritos en su mayoría entre 0.062 y $2 \mathrm{~mm}$ ), 
siendo las psamitas más abundante. Este segundo nivel de diferenciación será tenido en cuenta para el esquema de las litofacies carbonáticas y clásticas.

Desde el punto de vista genético-composicional en las sedimentitas carbonáticas se distingue el predominio de las partículas carbonáticas intracuencales (fragmentos esqueletales y granos carbonáticos no esqueletales) respecto a los fragmentos extracuencales no carbonáticos o terrígenos (cuarzo, feldespatos y líticos principalmente). En general, estos últimos se encuentran representados en bajas proporciones en la parte inferior a media de la sucesión carbonática, ubicada en los tramos medio a superior de las secciones. En lo que respecta a las sedimentitas clásticas se aprecian considerables variaciones en el origen de los detritos. Los terrígenos, son los más importantes volumétricamente en los materiales mayores a $2 \mathrm{~mm}$ y en areniscas finas a gruesas. En las psefitas se reconocieron además fragmentos derivados del sustrato sedimentario infrayacente (intraformacionales), consolidados y contemporáneos (litoclastos arenosos). Asimismo, se identificaron componentes carbonáticos intracuencales como bioclastos, ooides e intraclastos carbonáticos en baja proporción. Estos componentes resultan muy abundantes en psamitas finas a gruesas de la región sur de la zona de Malargüe, ubicadas en los tramos inferiores a medio de las secciones PLN, PLE, PLW, APS y ATW (Anexo Ia).

Sobre la base del análisis composicional puede alcanzarse un tercer grado de diferenciación de los tipos litológicos. De esta forma se identificaron: rocas carbonáticas o mixtas en las que predominan los materiales carbonáticos intracuencales o con similar participación de detritos carbonáticos y terrígenos, y rocas silicoclásticas dominadas por componentes extracuencales no carbonáticos.

A continuación se presenta la descripción de los componentes principales y menores que conforman a las sedimentitas carbonáticas y a las areniscas de la sucesión carbonática y de la sucesión terrígena-mixta. En primer término, mediante el uso de técnicas de petrografía estándar de polarización se han identificado los principales componentes que constituyen a estas rocas. A continuación se expone la clasificación de los diferentes tipos de psamitas, y por último, a través del análisis por difracción de rayos $X$, se identifican los argilominerales presentes en ambas litologías. 


\subsection{1: Petrografía de las sedimentitas carbonáticas}

A partir de las descripciones de ciento treinta y cuatro secciones delgadas (ver Anexo II) se distinguieron los componentes principales y minoritarios que conforman a la sucesión carbonática y a algunos niveles de calizas presentes en la sucesión terrígena-mixta.

Las muestras analizadas están representadas por texturas wackestone, packstone, grainstone y floatstone poco alteradas. Los componentes principales que constituyen a estas calizas se pueden dividir en tres grupos: a) granos no esqueletales carbonáticos, b) granos esqueletales o bioclastos y c) detritos silicoclásticos o terrígenos. Dentro de los componentes menores se diferencian dos grupos: d) la micrita y e) el cemento.

\subsection{1-I: Componentes principales del entramado}

\section{a) Granos no esqueletales carbonáticos:}

\section{$\underline{\text { Ooides }}$}

Están conformados por ooides micríticos, generalmente simples, que presentan una corteza laminar poco espesa respecto al diámetro del núcleo, cuya relación entre el núcleo y la corteza varía entre 10:1 a 3:1 (figura 5.1a). Raramente se distinguen formas con una corteza de igual o mayor espesor que el núcleo. La estructura interna de la corteza está conformada por una a cuatro láminas micríticas concéntricas poco definidas debido a la intensa micritización que presentan estas partículas. Dentro de estos ooides se distinguen ooides micríticos superficiales (figura 5.1b), cuya corteza está conformada por una o dos láminas concéntricas (Flügel, 2010).

De acuerdo a las características que presentan estos componentes no esqueletales se los designa como ooides Tipo 1 según la clasificación de Strasser (1986). Conforme a esta clasificación, los ooides micríticos normales son frecuentes en 
ambientes de alta energía, mientras que los superficiales son característicos de ambientes de moderada a baja energía. Estas partículas se presentan en proporciones muy variadas desde 20 a $80 \%$ de la roca. En general se distribuyen en el sector superior de la sucesión carbonática, sin embargo los ooides superficiales son comunes en el tramo inferior a medio.

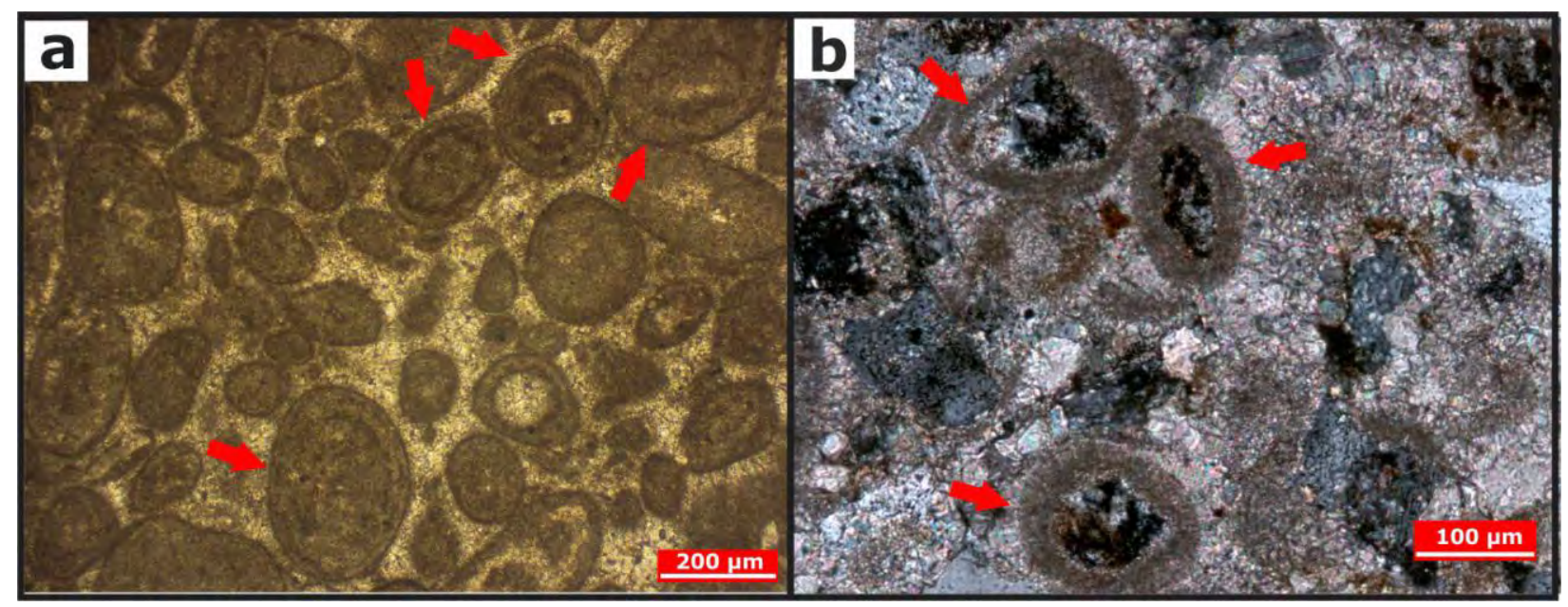

Figura 5.1a [NX,10X]: Ooides micríticos con laminación concéntrica difusa conformada por una a tres laminas (flechas). Niveles superiores de la sucesión carbonática en el perfil Plomo Este (PLE). Figura 5.1b [NX,10X]: Ooides micríticos superficiales (flechas). Niveles inferiores de la sucesión carbonática del perfil PLE.

\section{Peloides}

Grupo poligenético de partículas conformadas por carbonato micro a criptocristalino, redondeadas, sin estructura interna (McKee y Gutschick, 1969). Sus formas varían desde esféricas, ovoidales hasta irregulares y en general presentan tamaños entre los 62 a $500 \mu \mathrm{m}$ (figuras $5.2 \mathrm{a}$ y b).

Dentro de este grupo se distinguen peloides de origen fecal o pellets (Flügel, 2010) constituidos por partículas micríticas con detritos tamaño limo en su interior, o con una estructura interna conformada por cavidades regularmente espacias rellenas de esparita (figuras $5.3 a$ y b). Presentan formas esféricas, ovoidales a irregulares y tamaños uniformes que varían entre los 200 a $1000 \mu \mathrm{m}$. 
Los peloides se distribuyen en proporciones muy variadas dentro de toda la sucesión carbonática (20 a 80\% del total de la roca), siendo abundantes en el tramo inferior a medio. Mientras que los pellets son poco frecuentes dentro del tramo superior de la sucesión carbonática. En los niveles de calizas del sector terrígeno-mixto los peloides conforman el 10 a $40 \%$ del total.

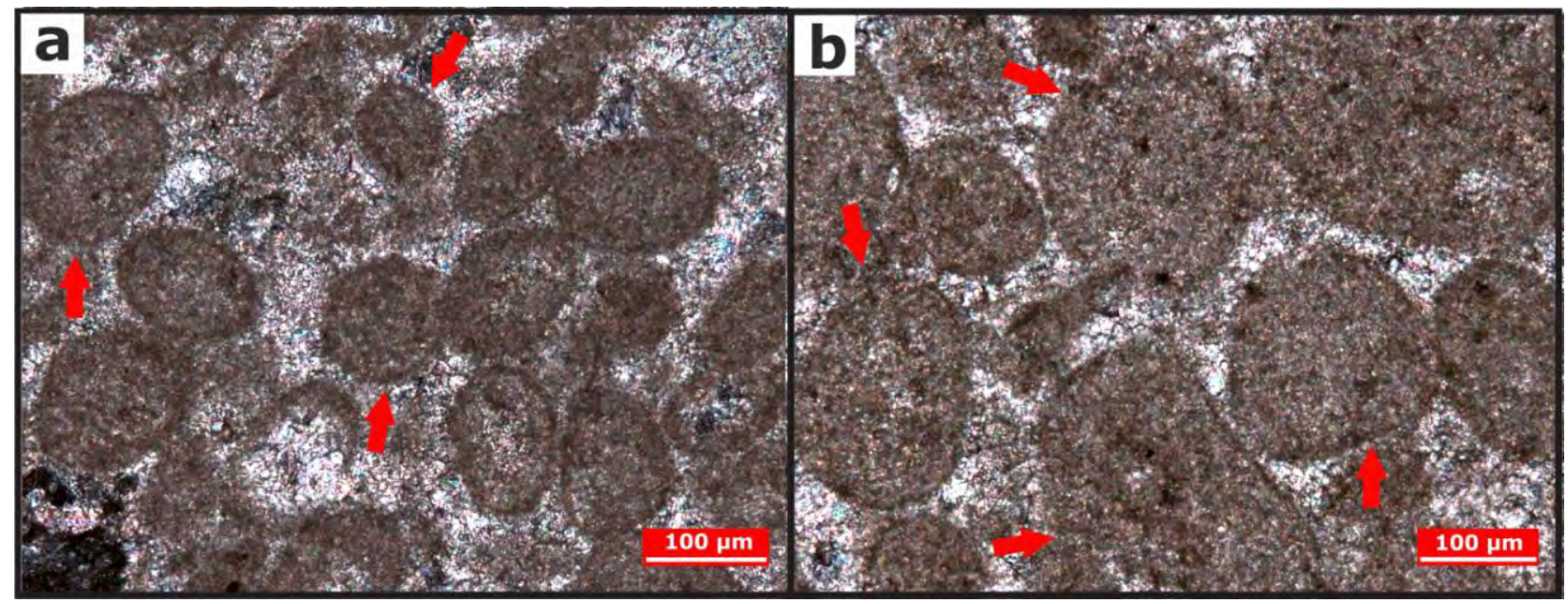

Figura 5.2a [NX,10X]: Peloides de formas esféricas (flechas). Niveles inferiores de la sucesión carbonática en el perfil PLW (muestra PLW4C). Figura 5.2b [NX,10X]: Peloides de formas esféricas y ovoidales (flechas). Niveles superiores de la sucesión carbonática en el perfil PLW (muestra PLW6A).

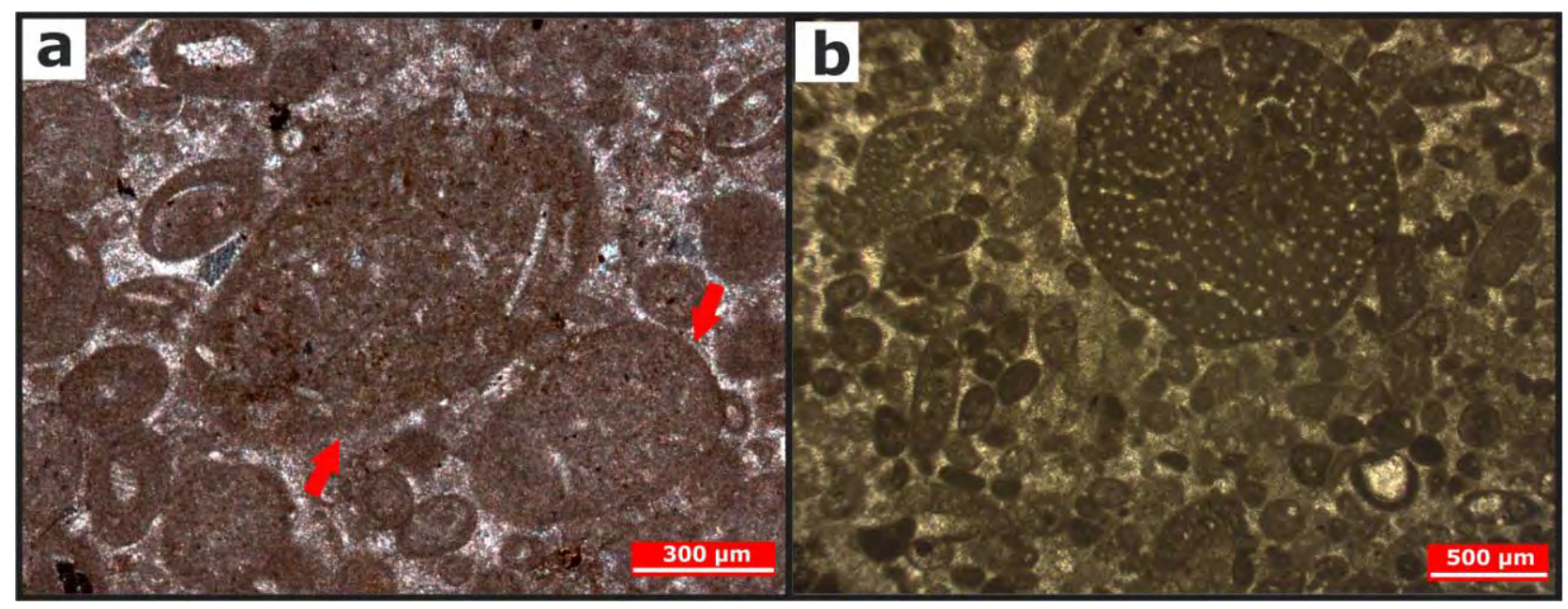

Figura $5.3[\mathrm{NX}, 4 \mathrm{X}]$ : Variedades de pellets identificados dentro de la sucesión carbonática. a) Con presencia de detritos tamaño limo en su interior, conformando el núcleo de ooides micríticos (flechas). Bancos superiores de la sucesión carbonática en el perfil ASE (muestra ASE7). b) Con estructura interna formada por cavidades regularmente espacias rellenas de esparita. Niveles superiores de la sucesión carbonática en el perfil ALV (muestra ALV 10). 


\section{Oncoides}

Están caracterizados por presentar un núcleo definido (formas simples) rodeado por una estructura de láminas irregulares concéntricas a no concéntricas (figuras 5.4a y b), en menor medida se reconocen formas con dos o más núcleos denominadas formas compuestas. También se identifican oncoides cuya envoltura presenta una laminación difusa hasta ausente (figuras 5.4c, d). La envoltura de los oncoides puede estar conformada por láminas de micrita homogénea con presencia de filamentos algales, o láminas de micrita grumosa compuesta de peloides y micrita. De acuerdo con la relación entre el espesor de la estructura laminar respecto al núcleo, se observan tanto formas con un mayor espesor, como oncoides con una potencia menor a igual que la del núcleo. Dentro de los oncoides laminados se pueden distinguir diferentes formas según el patrón de crecimiento de las láminas. Conforme a la clasificación de Logan et al. (1964) modificada por Flügel (2004), se identifican oncoides tipo $\mathrm{C}$ de formas esféricas a elípticas con patrones de crecimiento concéntrico (figura 5.4a) y oncoides tipo $\mathrm{R}$ de formas elípticas y crecimiento aleatorio de láminas semiesféricas (figura 5.4b). Los oncoides tipo C indican que el crecimiento de esta partícula se produjo en un ambiente con constante agitación de las aguas, mientras que los oncoides tipo $\mathrm{R}$ evidencian corrientes intermitentes donde se produce el rolido y acreción de partículas sobre la superficie del oncoide, seguidos por períodos sin movimiento (Logan et al., 1964).

En general los oncoides presentan un núcleo conformado por valvas articuladas a desarticuladas de braquiópodos, o fragmentos angulosos a redondeados de otros bioclastos. Igualmente se reconocen escasas formas sin núcleo. La forma de los oncoides varía de esférica, elíptica a irregular, con contornos lisos a ondulados. Sus tamaños oscilan entre los 1.5 a 30 mm. Estos componentes no esqueletales se distribuyen en el tramo medio a superior de la sucesión carbonática, en proporciones variables del 10 a $80 \%$ de la roca. 


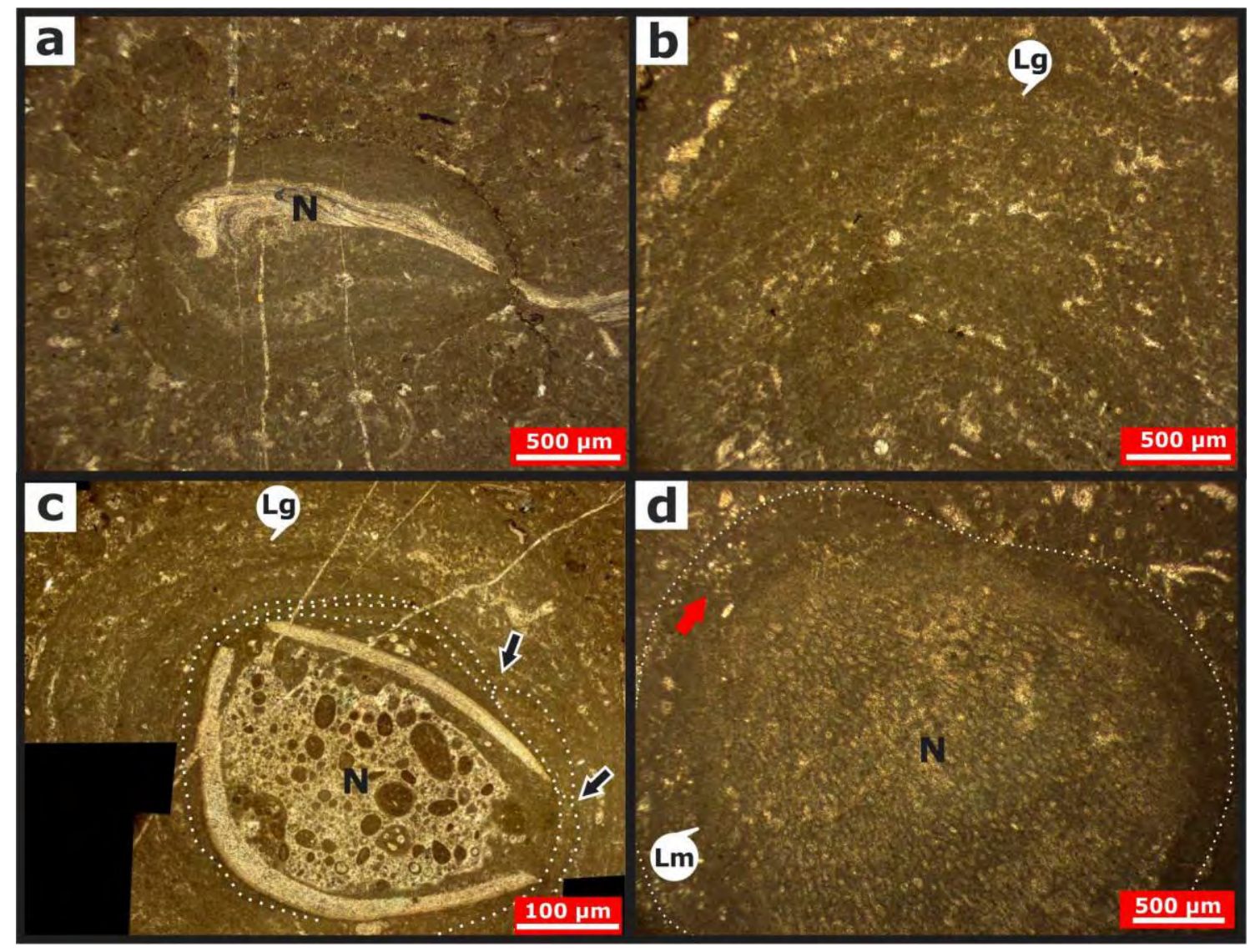

Figura 5.4a $[\mathrm{NX}, 4 \mathrm{X}]$ : Oncoide tipo $\mathrm{C}$ con núcleo de braquiópodo rhynchonellido (N). Niveles inferiores de la sucesión carbonática en el perfil ANE (muestra ANE2B). Figura 5.4b [4X]: Detalle de la envoltura de un oncoide tipo $\mathrm{C}$ conformado por láminas concéntricas de micrita grumosa (Lg). Muestra ANE2B. Figura 5.4C $[N X, 4 X]$ :Oncoide tipo $\mathrm{R}$ con un núcleo de braquiópodo telebratúlido (N),rodeado por láminas semiesféricas de micrita grumosa (Lg). Las líneas punteadas marcan la distribución de las láminas y las flechas indican el solapamiento. Muestra ANE2B. Figura 5.4d [4X]: Oncoide con laminación difusa a ausente y un núcleo de cianobacteria $(\mathrm{N})$. La envoltura es de micrita homogénea $(\mathrm{Lm})$ y presenta filamentos algales en su interior (flechas rojas). La línea punteada indica el contorno del oncoide. Niveles medios a superiores del perfil PLN (muestra PLN8A). 


\section{Agregados e intraclastos}

Los agregados de partículas están conformados por un conjunto de granos carbonáticos, esqueletales y no esqueletales, unidos entre sí a través de cemento microcristalino o micrita (Tucker, 1991). Presentan formas esféricas a irregulares, con bordes redondeados a angulosos y tamaños que oscilan entre 100 y $3000 \mu \mathrm{m}$ (figura 5.5a). Estos agregados son frecuentes en ambientes depositacionales de baja energía, donde las partículas se encuentran poco cementadas, con períodos intermitentes de alta energía donde se produce la erosión y formación de los agregados (Scholle y Ulmer-Scholle, 2003). Se presentan en el tramo superior de la sucesión carbonática en proporciones que varían de 10 a 40\%.

Los intraclastos se corresponden con fragmentos de sedimento carbonático contemporáneo, parciamente litificados a litificados, que fueron erosionados y redepositados dentro de la misma secuencia depositacional donde se formaron (Folk, 1959; 1962). Están representados por fragmentos de textura packstone, de formas irregulares, bordes subangulosos a subredondeados y tamaños que varían entre 20 y 120 mm (figura 5.5b). Estos componentes son comunes en el sector superior de la sucesión terrígena-mixta (70\% de la roca) y poco frecuentes en el tramo medio a superior (30-10\% del total) de la sucesión carbonática.

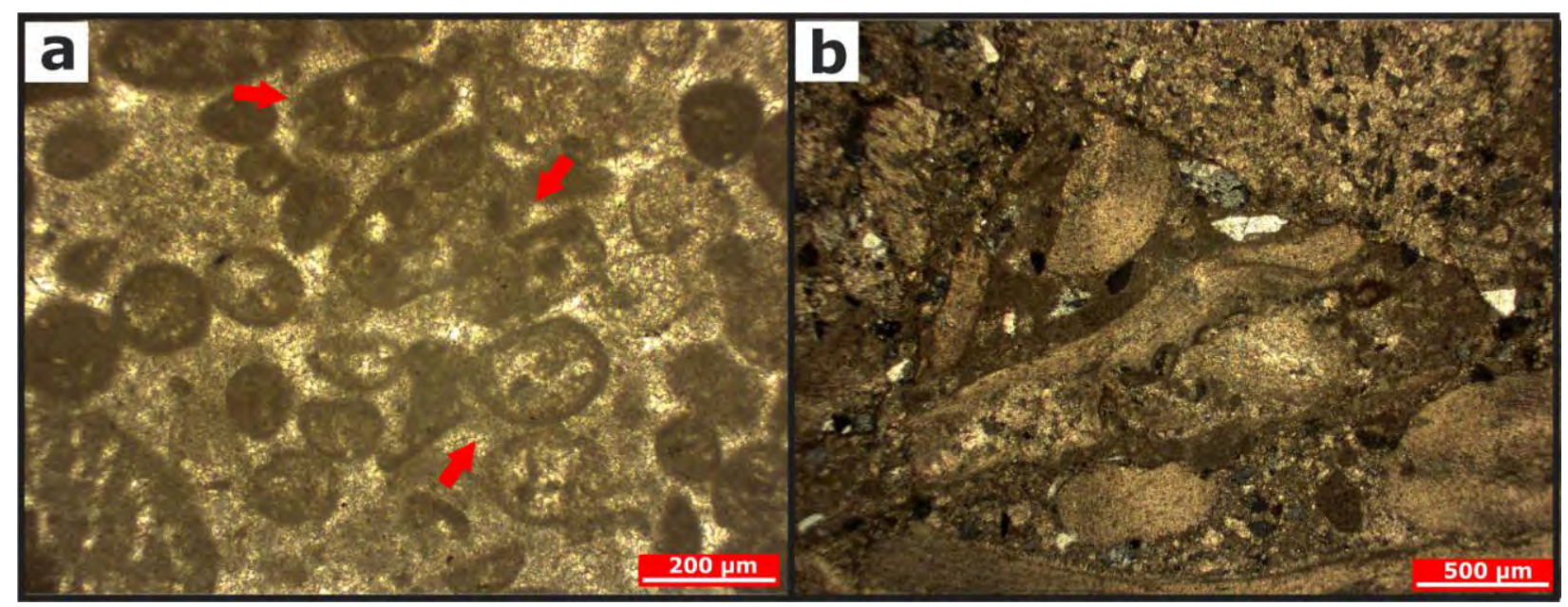

Figura 5.5a [NX,10X]: Agregado de partículas carbonáticas no esqueletales de formas esféricas (flechas rojas). Niveles superiores de la sucesión carbonática en el perfil Arroyo La Vaina (muestra ALV10). Figura 5.4b [NX,4X]: Intraclasto carbonático con textura packstone. Tramo inferior de la sucesión en el perfil Arroyo Calabozo Sur (muestra ACS1A). 


\section{b) Granos esqueletales:}

Dentro de este grupo se describen los restos esqueletales de macro, micro y nanofósiles, así como también los fragmentos de algas y cianobacterias. Los representantes más importantes son:

Moluscos (Mollusca)

Están representados por fragmentos de bivalvos conformados por ostras ("Ceratostreon" sp., Ostreidae indet.) y bivalvos no ostreidos (Pholadomya sp. y Bivalvia indet.), acompañados por gasterópodos identificados como Nerinea sp. (cf. Palma et al., 2007a; figuras 5.6; 5.7). Su esqueleto puede estar conformado por aragonita, calcita de bajo contenido en magnesio o una combinación de ambos minerales (Tucker y Wright, 1991). Las formas aragoníticas no preservan su estructura interna, se presentan como moldes rodeados por una envoltura micrítica, rellenos con cemento carbonático (figuras $5.6 a ; 5.7$ ). Por el contrario los moluscos compuestos por calcita de bajo contenido en magnesio, como es el caso de las ostras, conservan su estructura original (figura 5.6b). Presentan una textura laminar compuesta por finos cristales de calcita dispuestos de forma oblicua a paralela respecto a la superficie de la valva, acompañada por una textura porosa de microcristales de calcita (textura chalky). En los gasterópodos las cavidades internas de la conchilla suelen encontrarse rellenas por partículas carbonáticas acompañadas por micrita (figura $5.7 \mathrm{~b}$ ).

Los moluscos se presentan tanto como formas completas de valvas articuladas a desarticuladas y conchillas enteras, así como restos de valvas y conchillas de formas prismáticas a irregulares y bordes redondeados a angulosos. Sus tamaños varían entre 300 y $2000 \mu \mathrm{m}$, aunque algunos bivalvos y gasterópodos presentan tamaños mayores a $2000 \mu \mathrm{m}$. Se distribuyen en variables proporciones (10 a 50\%) a lo largo de toda la sucesión carbonática y en los niveles de calizas de la sucesión terrígena-mixta. 


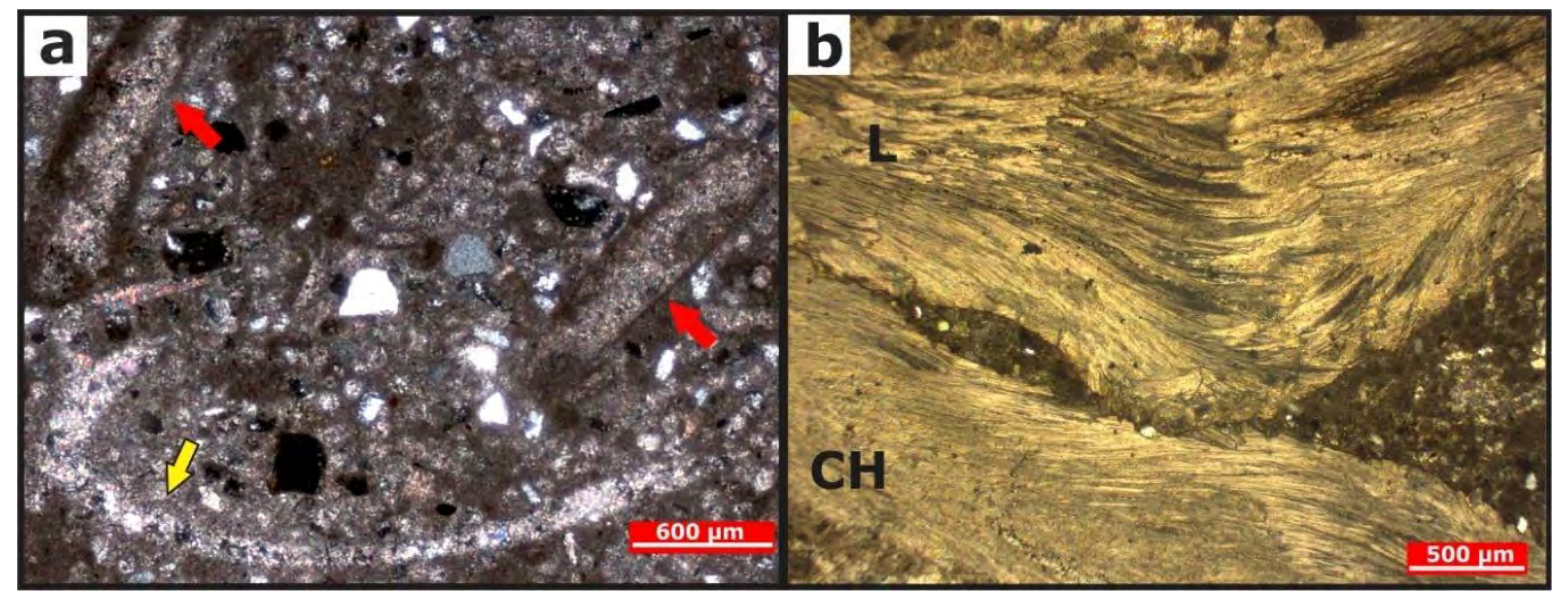

Figura $5.6[\mathrm{NX}, 2 \mathrm{X}]$ : Variedades de restos de bivalvos presentes en la sucesión carbonática. a) Bivalvia indet. (flechas rojas), acompañado por Pholadomya sp. (flecha amarilla). Ambos ejemplares se presentan como moldes rellenos de cemento carbonático. Capas inferiores de la sucesión carbonática en el perfil PCH (muestra $\mathrm{PCH} 4$ ). b) Ostras con su estructura interna conformada por las texturas laminar $(\mathrm{L})$ y chalky $(\mathrm{CH})$. Niveles inferiores medios de la sucesión carbonática del perfil ACS (muestra ACS5A).

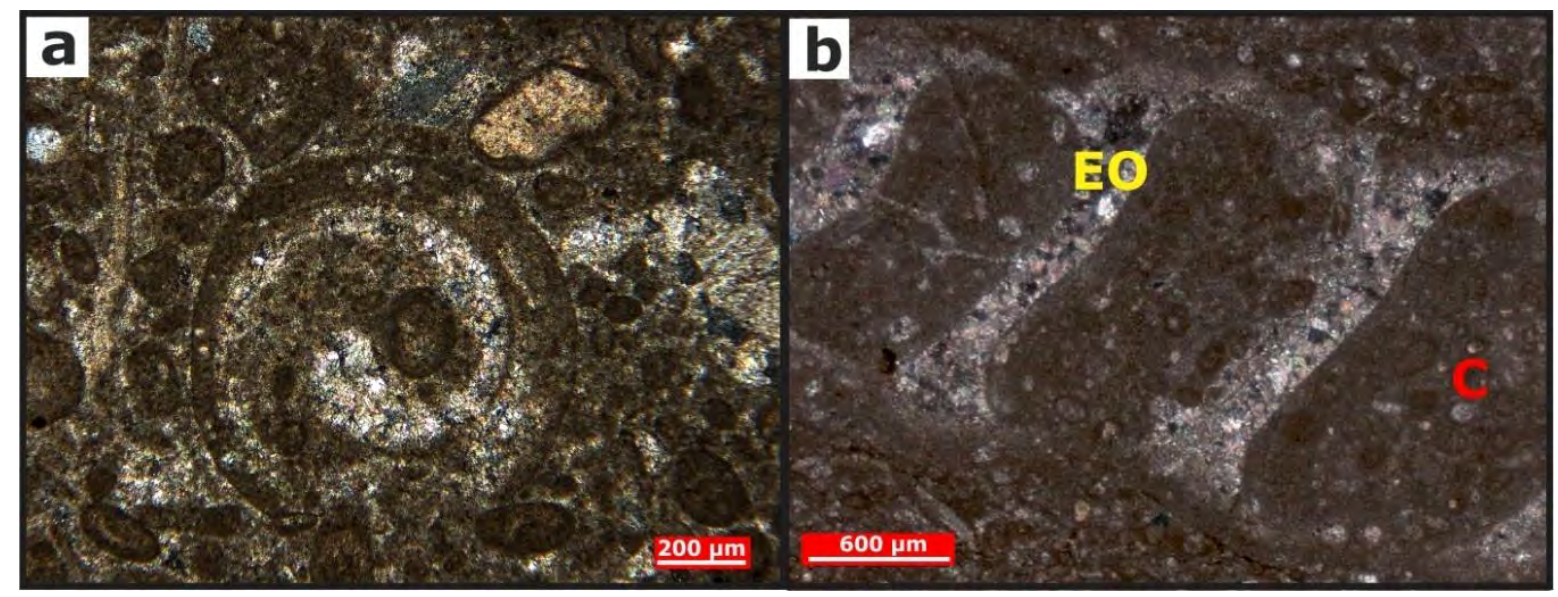

Figura 5.7a [NX,4X]: Sección transversal de la conchilla de un gasterópodo. Niveles medios de la sucesión carbonática en el perfil PLW (muestra PLW5A). Figura 5.7b [NX, 2X]: Sección longitudinal de la espira de una conchillas de gasterópodo. La estructura original de la conchilla (EO) se encuentra reemplazada por cemento carbonático, mientras que sus cavidades (C) están rellenas por peloides, calciesferas y micrita. Niveles medios de la sucesión carbonática del perfil $\mathrm{PCH}$ (muestra PCH9). 


\section{Braquiópodos (Brachiopoda)}

Los braquiópodos están integrados por ejemplares de rhynchonellidos (?Torquirhynchia sp. y Rhynchonelloidela sp.; figura 5.8a) y de telebratúlidos (?Loboidothyris sp. y Telebratulida indet.; figura 5.8b), siendo el primer grupo el más abundante. Su esqueleto está compuesto por calcita con bajo contenido en magnesio y en general presenta su estructura interna preservada. Está conformada por una capa externa poco espesa de fibras de calcita dispuestas de forma normal a la superficie de la valva, acompañada por una capa interna de mayor espesor de cristales de calcita oblicuos respecto a la superficie de la valva (Tucker, 1991; figura 5.8a). Además dentro de las valvas de los braquiópodos telebratúlidos se distingue la presencia de puntuaciones (figura 5.8b), característica que permite diferenciarlos de los braquiópodos rhynchonellidos (Tucker, 1991).

Estos organismos se identifican en general como formas completas de valvas articuladas a desarticuladas o fragmentos de bordes angulosos. También pueden conformar el núcleo de oncoides laminados y con laminación difusa a ausente (figuras 5.4a y c). Su tamaño varía entre 1.5 y $10 \mathrm{~mm}$. En general los braquiópodos aparecen en bajas proporciones (10\%) dentro de la sucesión carbonática, raramente representan un 30 a $80 \%$ del total.

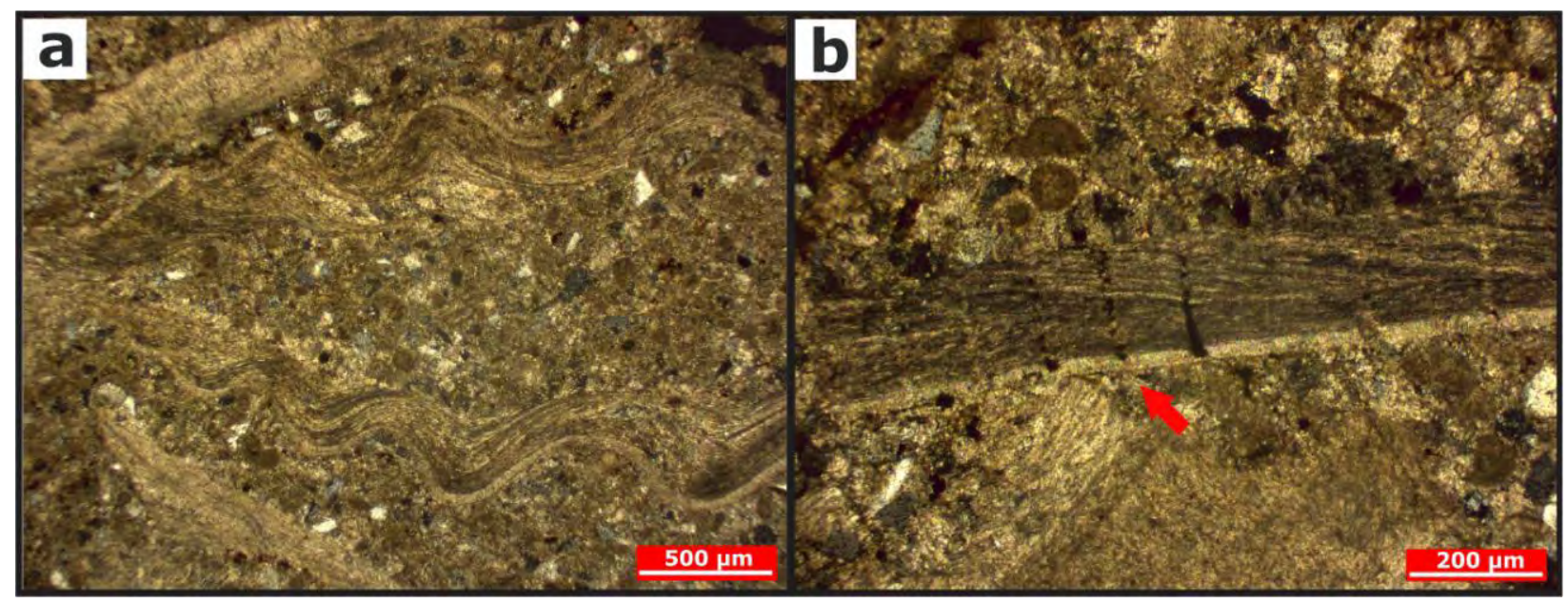

Figura 5.8: Valvas de braquiópodos. a) [NX,4X]: rhynchonellido. b) [NX,10X]: telebratúlido donde se observa las puntuaciones dentro de la valva (flecha roja). Niveles inferiores de la sucesión carbonática del perfil ACN (muestra ACN6A). 


\section{Equinodermos (Echinodermata)}

Comprenden restos esqueletales de equinoideos (Euechinoidea indet.) y crinoideos (Isocrinida indet.) conformados por un único cristal de calcita con alto contenido en magnesio, lo que le otorga una sola extinción a estos bioclastos (Tucker, 1991; Scholle y Ulmer-Scholle, 2003). Tienen una estructura interna porosa que en la mayoría de los casos se encuentra parcialmente rellena con micrita lo que le confiere una apariencia sucia (figura 5.9a). En general se presentan como secciones transversales o longitudinales de espinas y placas de equinoideos (figura 5.9a), y de artejos y placas de crinoideos (figura 5.9b). Raramente se observan fragmentos de estos bioclastos. Sus tamaños varían entre 500 y $2000 \mu \mathrm{m}$. Se encuentran distribuidos en bajas proporciones (10 a 15\%) a lo largo de toda la sucesión carbonática y en los niveles de calizas del sector terrígeno-mixto, siendo en algunas secciones de la sucesión carbonática el bioclasto predominante (perfil Arroyo Serrucho; ver Anexo Ia).

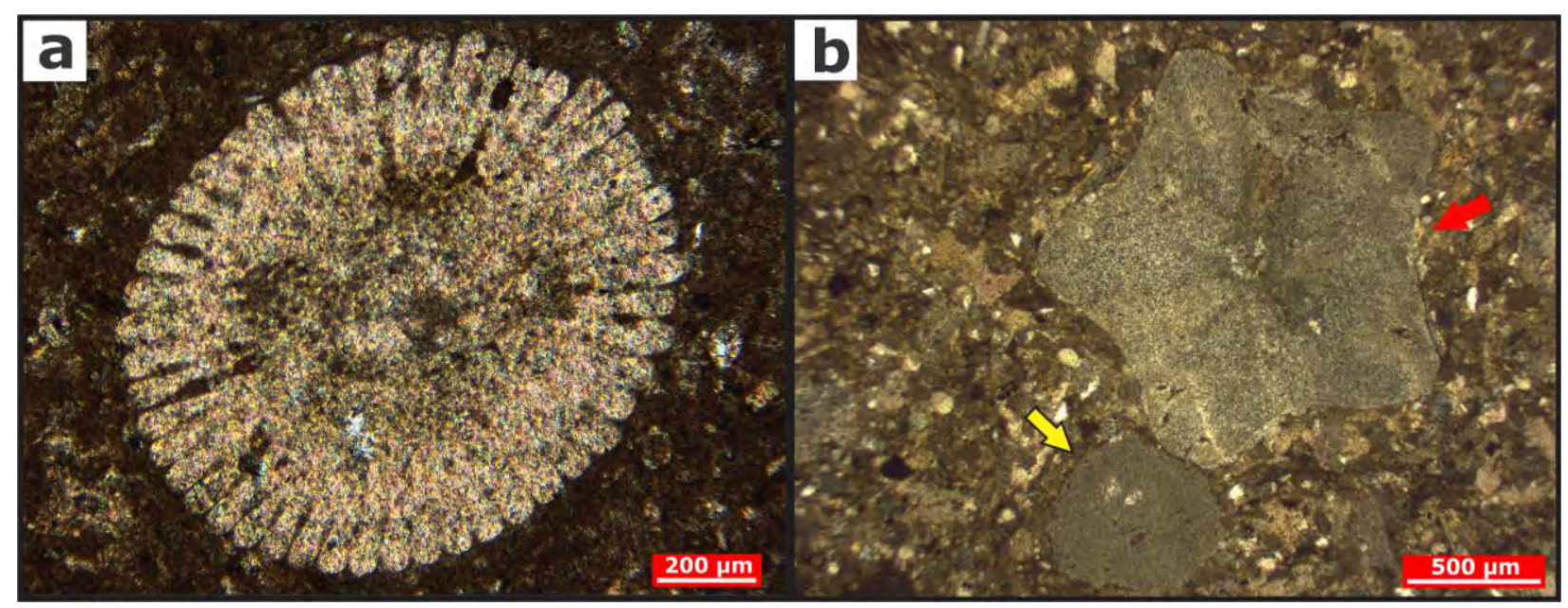

Figura 5.9: Fragmentos esqueletales de equinodermos presentes en la sucesión carbonática. a) [NX,10X] Sección transversal de una espina de equinoideo. Niveles medios de la sucesión carbonática (muestra ACN9B). b) [NX,4X] Sección transversal de un artejo (flecha roja) y placa de crinoideo (flecha amarilla). Niveles inferiores a medios de la sección carbonática (muestra ASE5). 


\section{Cnidarios (Cnidaria)}

Están conformados por colonias de corales escleractínidos identificadas como Araucanastrea sp. y Actinastrea sp. (cf. Palma et al., 2000b, 2007a). Su composición original es de aragonita y presentan una baja preservación de la estructura interna. En la mayoría de los casos la colonia se encuentra rodeada por una fina a moderada envoltura micrítica que también puede bordear las cavidades de la colonia. Su estructura original se encuentra disuelta, con la cavidad de disolución rellena con cemento carbonático (figura 5.10a). Además, contienen material externo dentro de las cavidades del coral representado por partículas carbonáticas y micrita (figura 5.10a).

Las corales aparecen como fragmentos de colonia, raramente se identifican formas completas en las secciones delgadas. Sus tamaños oscilan entre 0.4 y $20 \mathrm{~mm}$. Estos bioclastos conforman entre el 10 y el 30\% del total de la roca, encontrándose mejor representadas en el tramo inferior a medio de la sucesión carbonática. Mientras que en los niveles de calizas del sector terrígeno-mixto se presentan en bajas proporciones (10 a $20 \%$ ).

Anélidos (Annelida)

Este grupo está compuesto por anélidos Polychaeta o serpúlidos, que secretan una conchilla calcárea (Scholle y Ulmer-Scholle, 2003). El esqueleto de los serpúlidos está compuesto de calcita con alto contenido en magnesio, aragonita o una combinación de ambos minerales (Scholle y Ulmer-Scholle, 2003; Flügel, 2010). En general las formas aragoníticas muestran una baja preservación de su estructura original, encontrándose rellenas por cemento carbonático o reemplazadas por cemento silíceo o carbonático (figura 5.10b). Por el contrario, las formas calcíticas preservan su estructura interna conformada por láminas concéntricas de escaso espesor. Las cavidades de las conchillas se encuentran rellenas por cemento carbonático acompañada en algunos casos por granos no esqueletales. La conchilla varía su forma de esféricas a ovaladas, y su diámetro oscila entre 500 y $2000 \mu \mathrm{m}$. 
Se presentan como restos esqueletales, formas aisladas libres o adosadas a valvas de bivalvos o braquiópodos. También aparecen como formas coloniales adosados a valvas de ostras. Su representación dentro de la sucesión carbonática es baja ( 5 a $10 \%$ del total), mientras que en los niveles de calizas del sector terrígeno-mixto comprende un $40 \%$ del total hasta encontrarse ausentes.

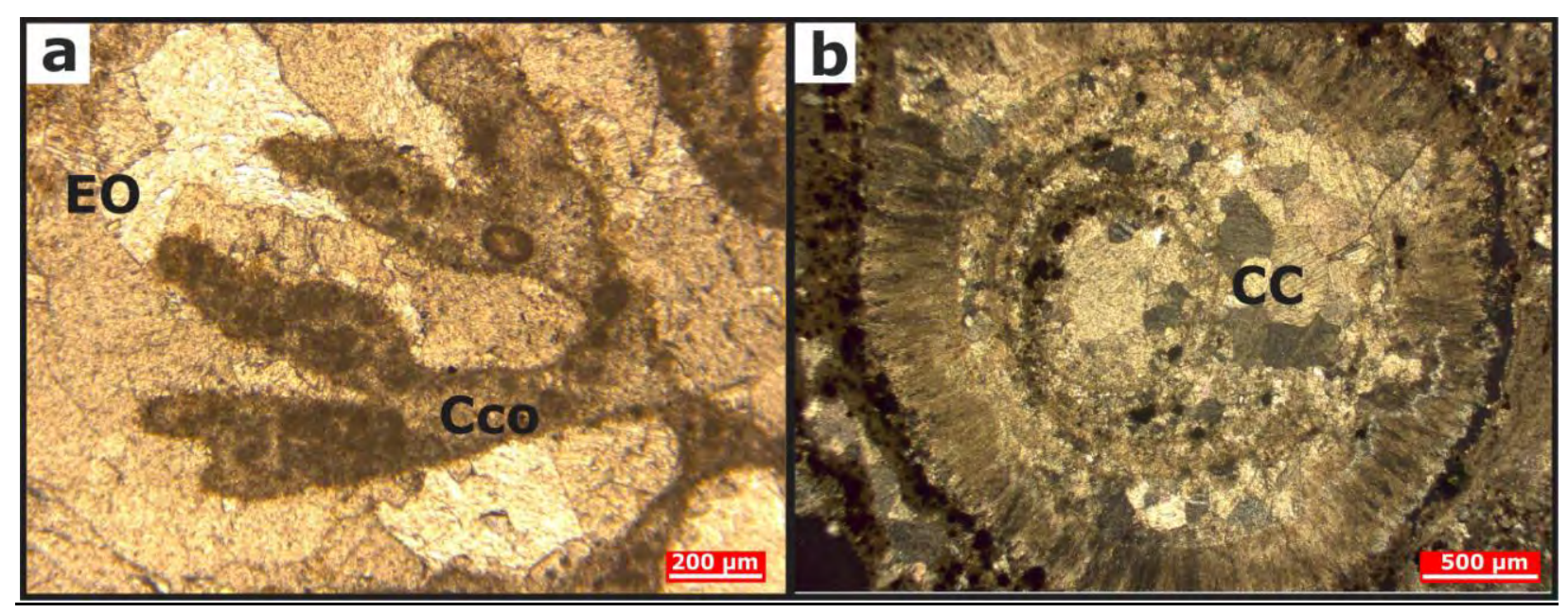

Figura 5.10a [4X]: Sección transversal de una colonia de corales escleractínidos. Se distingue la estructura original (EO) de la colonia rellena por cemento carbonático y sus cavidades (Cco) rellenas con peloides y micrita. Niveles medios de la sucesión carbonática del perfil ACS (muestra ACS7b). Figura 5.10b [NX, 4X]: Sección transversal de una colonia de serpúlidos reemplazada parcialmente por cemento carbonático y silíceo. Su cavidad central (CC) está rellena con cemento carbonático. Niveles inferiores de la sucesión terrígena-mixta del perfil PLN (muestra PLN2A).

\section{Algas (Chlorophyta) y cianobacterias (Cyanobacteria)}

Comprenden algas Dasycladales como Cylindroporella sp. (cf. Palma et al., 2005) y ejemplares de cianobacterias Caulerpales como Cayeuxia (Rivularia) piae y Cayeuxia (Rivularia) kurdistanensis (cf. Palma et al., 2005; figura 5.11). Dado que su esqueleto está compuesto de aragonita, estos organismos están representados por moldes rellenos con cemento carbonático. Las algas Dasycladales se distinguen por presentar una cavidad central rellena de esparita, rodeada por una zona externa que muestra cavidades de distribución radial rellenas con micrita (figura 5.11a). Por su parte las cianobacterias se diferencian por poseer una estructura filamentosa, con los moldes de los filamentos rellenos con cemento carbonático (figura 5.11b). 


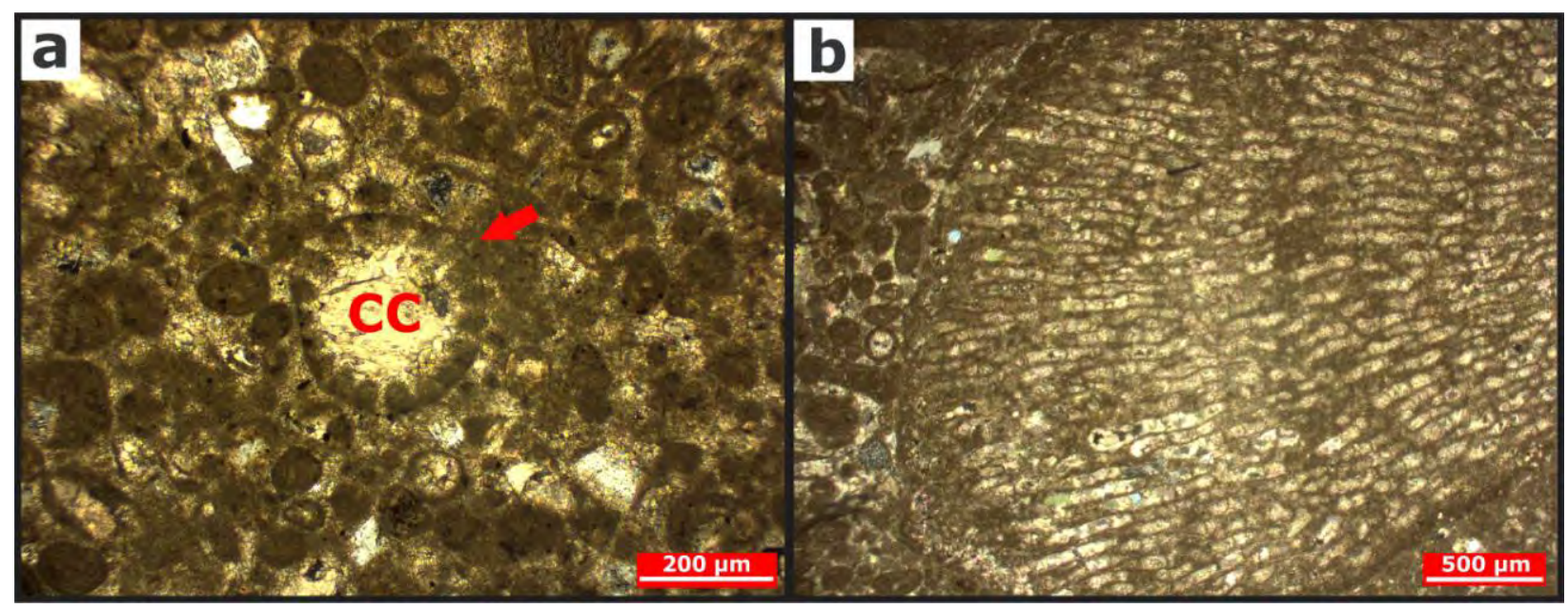

Figura 5.11a [NX,10X]:Sección transversal de alga Dasycladales Cylindroporella sp. Se distingue la cavidad central (CC) y zona externa (flecha roja) del alga. Niveles inferiores de la sucesión carbonática en el perfil ACS (muestra ACS3A). b) [NX,4X]: Estructura filamentosa de cianobacterias Caulerpales. Niveles superiores de la sucesión carbonática en el perfil PLW (muestra PLW7A).

Las algas Dasycladales aparecen como secciones transversales de formas esféricas y tamaños que varían entre 200 y $400 \mu \mathrm{m}$. Por el contrario, las cianobacterias se identifican como fragmentos de estructura filamentosa, con formas irregulares y bordes redondeados a angulosos, cuyos tamaños varían entre 700 y $8000 \mu \mathrm{m}$. También se observan cianobacterias formando parte del núcleo de oncoides con laminación difusa a ausente (figura 5.4d). Las algas Dasycladales se distribuyen en el tramo inferior de la sucesión carbonática, mientras que las cianobacterias están presentes en la parte media a superior de la sucesión.

Dentro de los niveles carbonáticos de la sucesión terrígena-mixta se distingue la presencia de ¿algas rojas? compuestas por calcita con alto contenido en magnesio y una estructura filamentosa conformada por un fino reticulado (Scholle y Ulmer-Scholle, 2003). Aparecen como secciones transversales y longitudinales, o restos de bordes redondeados, con tamaños variables entre los 700 a $3000 \mu \mathrm{m}$, distribuidas en el tramo medio de esta sucesión. 


\section{Microfósiles (Retaria) y nanofósiles (Haptophyta)}

De las quince muestras de calizas analizadas para determinar su contenido en microfósiles y nanofósiles se obtuvo solo una muestra fértil con presencia de nanofósiles (ver Anexo II). Por este motivo, la identificación de los géneros de foraminíferos se realizó únicamente por análisis petrográfico bajo luz transmitida y polarizada en sección delgada. Los microfósiles comprenden foraminíferos uniseriados (Nodosaria sp., Marginulina sp.) y foraminíferos indet. con enroscamiento polymorphinido (foraminíferos indet.) o planoespiral como Astacolus sp. (figura 5.12). Estos microfósiles pueden estar compuestos de calcita con bajo contenido en magnesio o calcita con alto contenido en magnesio, raramente se presentan formas aragoníticas (Tucker, 1991). En los foraminíferos uniseriados, los ejemplares con enroscamiento planoespiral y pocos con enroscamiento polymorphinido, se distingue la estructura interna de la conchilla conformada por finos cristales de calcita que se orientan de forma normal a la superficie de la conchilla (figuras 5.12a-d). Por su parte, la mayoría de los ejemplares con enroscamiento polymorphinido presentan su conchilla micritizada o con impregnaciones de óxidos de hierro y sus cámaras están rellenas con cemento carbonático (figura $5.12 \mathrm{e}$ ). Sus tamaños varían entre 50 y $300 \mu \mathrm{m}$ y en general se presentan como formas completas dispersos dentro de la matriz de la roca. Los foraminíferos con enroscamiento polymorphinido son frecuentes en el tramo superior de la sucesión carbonática, mientras que los foraminíferos uniseriados y con enroscamiento plano espiral son comunes en el sector inferior (sección Arroyo Serrucho, ver Anexo Ia).

En lo que respecta a los nanofósiles, se identificaron algas unicelulares calcáreas (Coccolithophyacea) correspondientes a Watznaueria británica y Watznaueria barnesae (figura 5.12f). Su exoesqueleto está compuesto por calcita con bajo contenido en magnesio (Scholle y Ulmer-Scholle, 2003) y sus tamaños oscilan entre 4 y $8 \mu \mathrm{m}$. Estos organismos se encuentran representados en escasa proporción dispersos en la matriz de la roca. Se ubican en el tramo superior de la sucesión carbonática en la sección Arroyo Negro. 


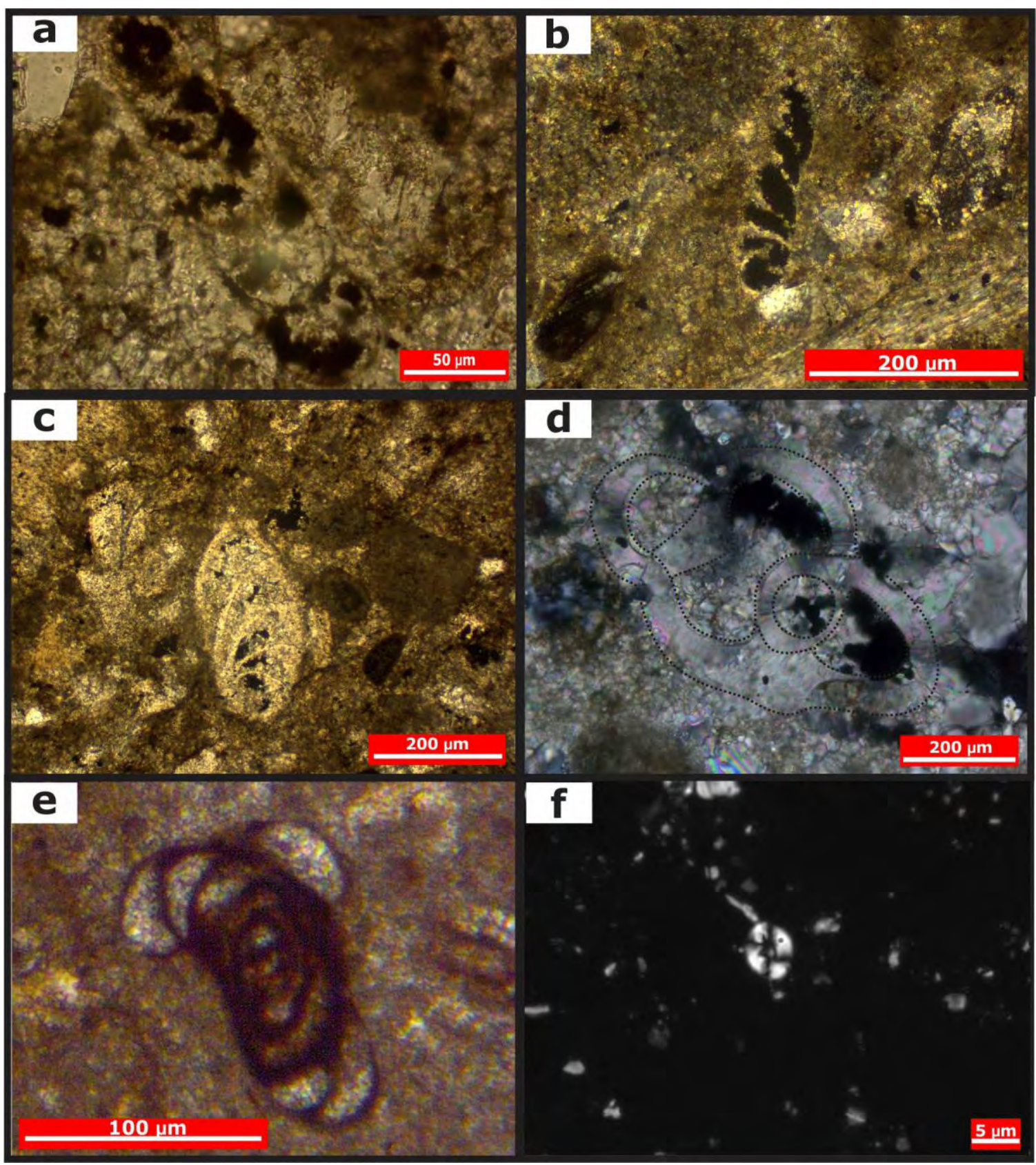

Figura 5.12: Microfósiles y nanofósiles presentes en la sucesión carbonática. a) y b)[40X], [NX,10X]: Foraminíferos uniseriados correspondiente a Nodosaria sp. y Marginulina sp.; c) [NX,10X]: foraminífero con enroscamiento planoespiral (Astacolus sp.); d) [NX,20X] y e) $[\mathrm{NX}, 10 \mathrm{X}]$ : foraminífero con enroscamiento polymorphinido (foraminífero indet.) con diferente preservación de la estructura interna de la conchilla. En el ejemplar de la figura d se distingue la estructura interna de la conchilla (marcada por una línea punteada), mientras que en el espécimen de la figura e la conchilla se distingue por la presencia de impregnaciones de óxidos. f) $[N X, 100 X]$ : Alga unicelular referida a Watznaueria británica. Las figuras a-d se corresponden con el sector inferior a medio de la sucesión carbonática en la sección ASE (muestras ASE3, ASE6A). La figura e se presenta en el tramo superior de la sucesión carbonática en el perfil ACN (muestra ACN10B), mientras que la figura $f$ se corresponde con la sección superior de la sucesión en el perfil ANE (muestra ANE 3). 


\section{Calciesferas}

Las calciesferas son pequeñas partículas carbonáticas de hasta $0.5 \mathrm{~mm}$ de diámetro que presentan una cavidad central rodeada por una corteza fina, que puede contener perforaciones o aperturas (Tucker, 1991; Scholle y Ulmer-Scholle, 2003). Estos granos carbonáticos están compuestos de calcita o aragonita, y en la mayoría de los casos su corteza está conformada por una a dos láminas micríticas sin perforaciones ni aperturas, que rodean una cavidad central rellena con cemento carbonático (figura 5.13a). En algunas calciesferas la envoltura externa micrítica puede estar ausente. Sus formas varían de esféricas, ovoidales a reniformes y presentan tamaños uniformes entre 80 y $100 \mu \mathrm{m}$. El origen de estas partículas carbonáticas es incierto, algunos autores les atribuyen un origen algal (Tucker, 1991; Scholle y Ulmer-Scholle, 2003), aunque otros como Afşar et al. (2014) asignan como espículas de esponjas a las formas esféricas a reniformes con pared micrítica y sin perforaciones ni aperturas. Es por éste motivo que las calciesferas se describen dentro de los granos esqueletales. Las calciesferas se encuentran representadas en bajas a moderadas proporciones dentro de la sucesión carbonática (10 a 40\%).

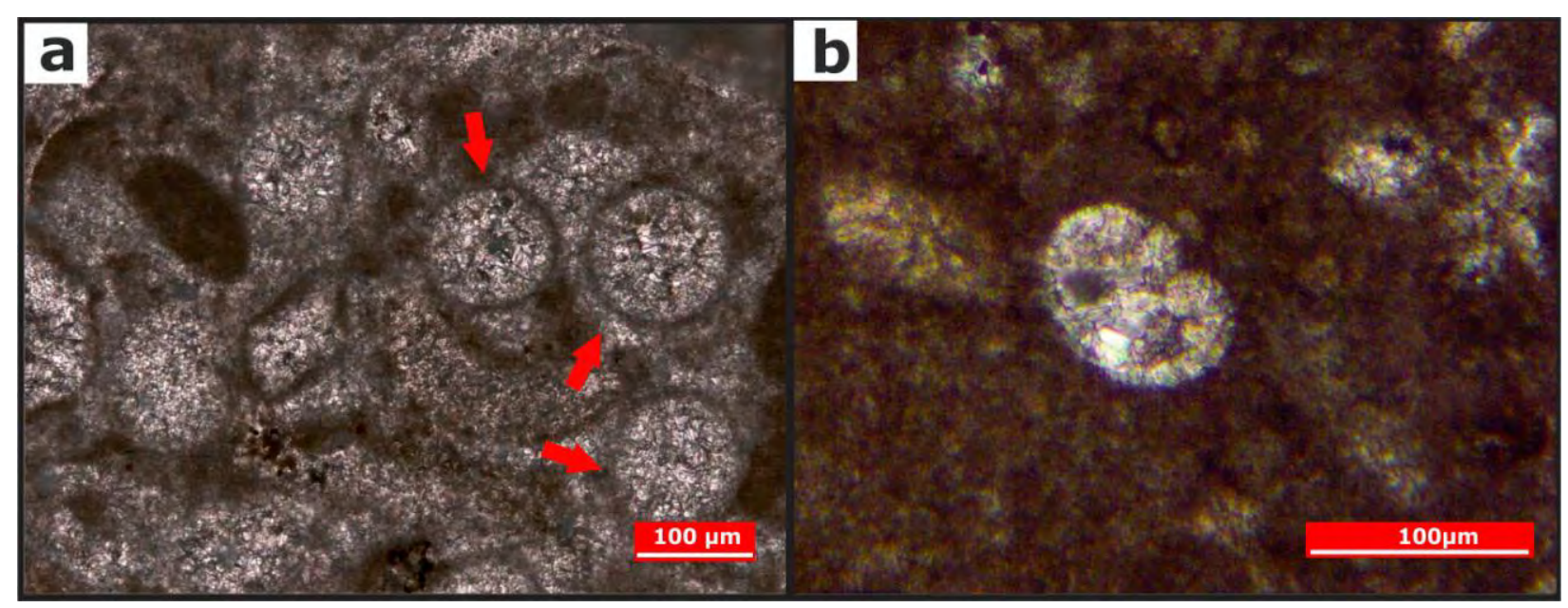

Figura 5.13: Variedades de calciesferas. a) [NX,10X]: Con paredes micríticas y formas esféricas a ovoidales (flechas). b) [10X]: Sin paredes micríticas con formas reniformes. Tramo medio a superior de la sucesión carbonática en el perfil ACN (muestras ACN8B y ACN10B). 


\section{c) Terrígenos:}

Comprenden cristales de cuarzo monocristalino, feldespatos y líticos volcánicos. El cuarzo monocristalino se caracteriza por su aspecto límpido con bajo contenido de inclusiones, formas prismáticas a esféricas con bordes angulosos a redondeados, y extinción recta (figuras $5.14 \mathrm{a}$ y b). En general los cristales de feldespato tienen un aspecto poco fresco, muestran alteraciones a minerales arcillosos y en algunos casos presentan un núcleo poco alterado rodeado por un sobrecrecimiento inalterado de bordes rectos (figura 5.14a). Es poco común la presencia de cristales con aspecto límpido donde se reconoce el maclado polisintético y de Carlsbad, siendo el primero el mejor representado (figura 5.14b). El hábito de los feldespatos es tabular, con bordes subangulosos a angulosos.

En lo que respecta a los líticos volcánicos están representados en su mayoría por pastas afaníticas con textura felsítica y en menor proporción pilotáxica, ambos parcialmente alterados. La textura felsítica está compuesta por un mosaico microcristalino de cristales anhedrales de cuarzo y feldespatos y caracteriza a composiciones de rocas volcánicas ácidas (figuras $5.14 \mathrm{a}$ y b). Por su parte, los líticos volcánicos pilotáxicos contienen cristales subhedrales a euhedrales de feldespato de forma tabular (generalmente plagioclasas), los cuales se ubican dentro de una pasta afanítica de vidrio volcánico sin una distribución definida. Dichos líticos se corresponden con composiciones de rocas volcánicas intermedias. Ambos líticos volcánicos presentan formas prismáticas a subprismáticas de bordes subangulosos a subredondeados, con tamaños que varían entre 80 y $300 \mu \mathrm{m}$.

Los terrígenos se distribuyen en baja proporción ( $<15 \%$ del total de la roca) en las calizas de ambas sucesiones. En la sucesión carbonática se ubican dentro del tramo inferior a medio, mientras que en las calizas de la sucesión terrígena-mixta es común a lo largo de la sucesión. En todos los casos los feldespatos con maclado polisintético y los líticos volcánicos ácidos a intermedios son los terrígenos más frecuentes. 


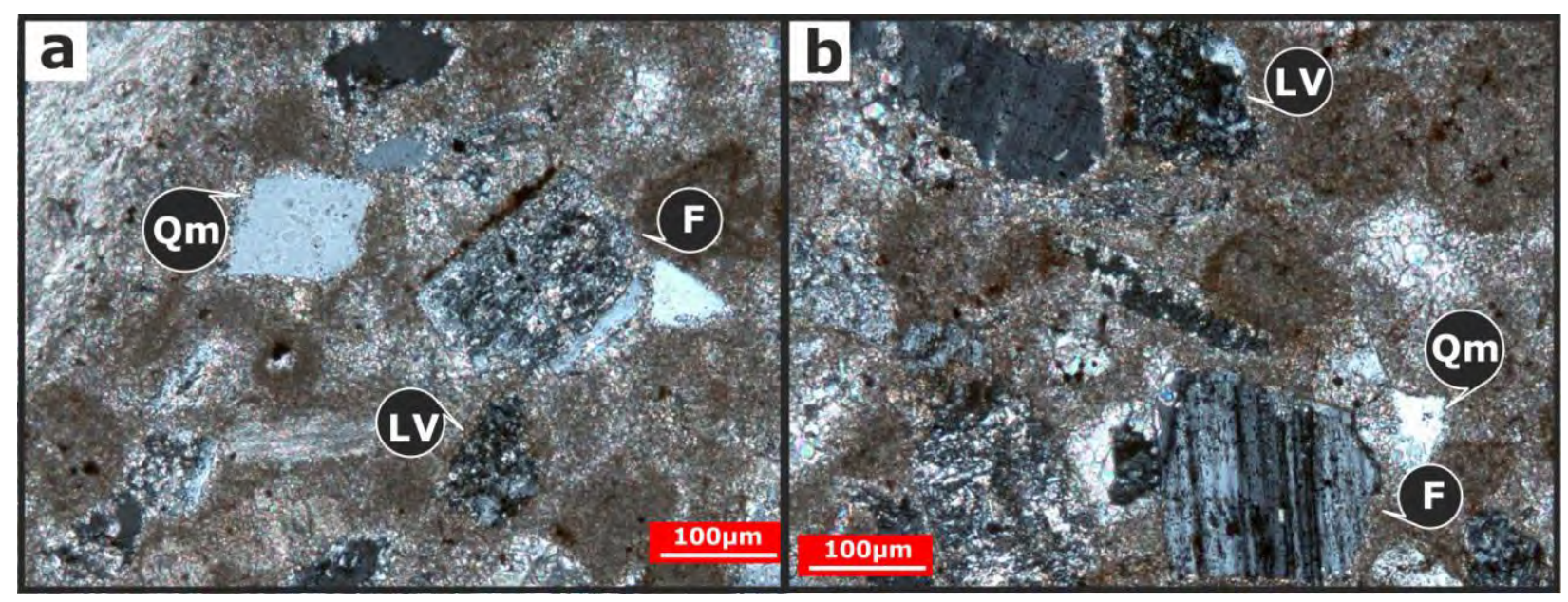

Figura 5.14: Terrígenos presentes en la sucesión carbonática. a) [NX,10X]: Cristales de cuarzo monocristalino $(\mathrm{Qm})$ con formas prismáticas, acompañados por cristales de feldespato de aspecto turbio conformado por un núcleo alterado rodeado por un sobrecrecimiento inalterado ( $F)$ y líticos volcánicos de textura felsítica parcialmente alterados (LV). Capas inferiores a medias de la sucesión en el perfil ANE (muestra ANE2A). Figura 5.14b [NX,10X]: Clastos de Qm de aspecto límpido, prismáticos, con bordes angulosos a subangulosos junto con $\mathrm{F}$ de aspecto límpido con macla polisintética, y clastos de líticos volcánicos con textura felsítica (LV). Niveles inferiores de la sucesión en el perfil ANE (muestra ANE2A).

\subsection{1-II: Componentes menores del entramado}

Se distinguen dentro de los componentes menores de las sedimentitas carbonáticas la micrita, o fango carbonático, y el cemento. La micrita está conformada por calcita microcristalina con un tamaño de grano menor a $4 \mu \mathrm{m}$. Aunque su composición es calcítica, muchos fangos carbonáticos pueden presentar una composición original de aragonita que es reemplazada por calcita durante la diagenésis (Tucker, 1991). Puede presentar textura homogénea cuando se encuentra conformada totalmente por micrita, o grumosa cuando está constituida por peloides de bordes indistinguibles acompañada por fango carbonático (Horowitz y Potter, 1971). En esta última fábrica es común el pasaje gradual entre las partículas carbonáticas totalmente micritizadas y la micrita homogénea (figura 5.15a). El origen de la micrita es variado, puede derivar de la desintegración de restos algales, esqueletales o peloides, precipitar inorgánicamente desde aguas marinas sobresaturadas respecto a aragonita o calcita, o que su precipitación sea inducida por la actividad de algas o microorganismos fotosintéticos (Tucker, 1991; Horowitz y Potter, 1971). 
El fango carbonático se presenta rellenando parcial a totalmente el espacio poral entre los granos (porosidad intergranular) u ocupando las cavidades internas de partículas carbonáticas esqueletales y no esqueletales (porosidad intragranular; figuras 5.7, 5.10a). Su contenido dentro de las calizas es variable, desde escaso a bajo en texturas grainstone a packstone, hasta moderado a abundante en fábricas floatstone y wackestone. En el caso de los boundstone la micrita puede ser el componente principal de las sedimentitas en estromatolitos, o encontrarse en baja a abundante proporción dentro de las cavidades porales en los framestone.

En lo que respecta a los cementos, el principal agente cementante dentro de las sedimentitas carbonáticas es el carbonato de calcio. En forma minoritaria aparece representado el cemento silíceo (figura 5.15b). En los precipitados carbonáticos de acuerdo con la morfología de los cristales se pueden distinguir cementos fibrosos y ecuantes (Tucker, 1991). Dentro de los cementos fibrosos se distinguen precipitados en halo isopáquico, compuestos por cristales de hábito alargado e igual longitud (7-18 $\mu \mathrm{m}$ de espesor) que se ubican en la periferia de los granos rodeando completamente a los mismos (figura 5.15c). Además se presentan cementos fibrosos asimétricos, constituidos por cristales aciculares orientados al azar que rodean a los granos con fábrica pendant o microestalactítica. Este precipitado en forma de gota, ubicado entre granos adyacentes, forma una fina envoltura menor a los $50 \mu \mathrm{m}$ de espesor. Ambos constituyen los primeros precipitados en rellenar la cavidad poral de las sedimentitas carbonáticas. Cuando éstos faltan, los cementos ecuantes ocupan su lugar. Los precipitados ecuantes o esparíticos se caracterizan por estar conformados por un mosaico de cristales equidimensionales de bordes intercristalinos planos que según su tamaño de grano se pueden clasificar en microesparíticos (4-15 $\mu \mathrm{m}$ de largo), esparíticos (15-100 $\mu \mathrm{m}$ de largo) y macroesparíticos (100-700 $\mu \mathrm{m}$ de largo). Asimismo, de acuerdo con su textura se reconocen cementos granulares (cementos esparíticos) o en mosaico (cementos macroesparíticos) conformados por cristales de igual tamaño, texturas drusiformes donde se observa un incremento del tamaño de grano a medida que crecen los cristales y sintaxial donde un solo cristal crece en continuidad óptica sobre un fragmento de bioclasto, generalmente de equinodermo (figuras 5.15d, e, f). En general los cementos esparíticos se presentan indistintamente como un relleno 
homogéneo, que oblitera parcial a totalmente las cavidades intergranulares, intragranulares y móldicas (moldes de bioclastos, cavidades generadas por disolución), o como parches que abarcan parte de las sedimentitas. Los cementos carbonáticos se presentan en escasa a baja proporción dentro de las texturas wackestone, packstone y floatstone, y en moderada a abundante proporción dentro de las texturas grainstone y boundstone. En el capítulo 7 referido a la diagenésis de la sucesión carbonática, la cementación carbonática será analizada mediante petrografía no convencional (catodoluminiscencia).

En lo que se refiere al cemento silíceo, éste se encuentra en escasa proporción respecto a los precipitados carbonáticos, distribuido en el interior de las cavidades intercristalinas de los cementos carbonáticos (figura 5.15b). Está representado por calcedonia zebraica conformada por un haz de cristales fibrosos de disposición radial que aumentan su tamaño de grano hacia el interior de la cavidad gradando a cristales de megacuarzo ( $>20 \mu \mathrm{m}$ de longitud; Folk y Pittman, 1971). Por otro lado, el cemento de feldespato autigénico se presenta como un sobrecrecimiento de bordes rectos que crece en continuidad óptica sobre clastos de feldespato alterados a argilominerales (figura 5.14a). Su aspecto es límpido respecto al núcleo de feldespato y sus bordes rectos se encuentran encastrados con los granos que lo rodean, característica que evidencia su origen autigénico (Scholle, 1979). Este tipo de cementación es común en el tramo inferior a medio de la sucesión carbonática, donde los terrígenos se encuentran en baja proporción. 


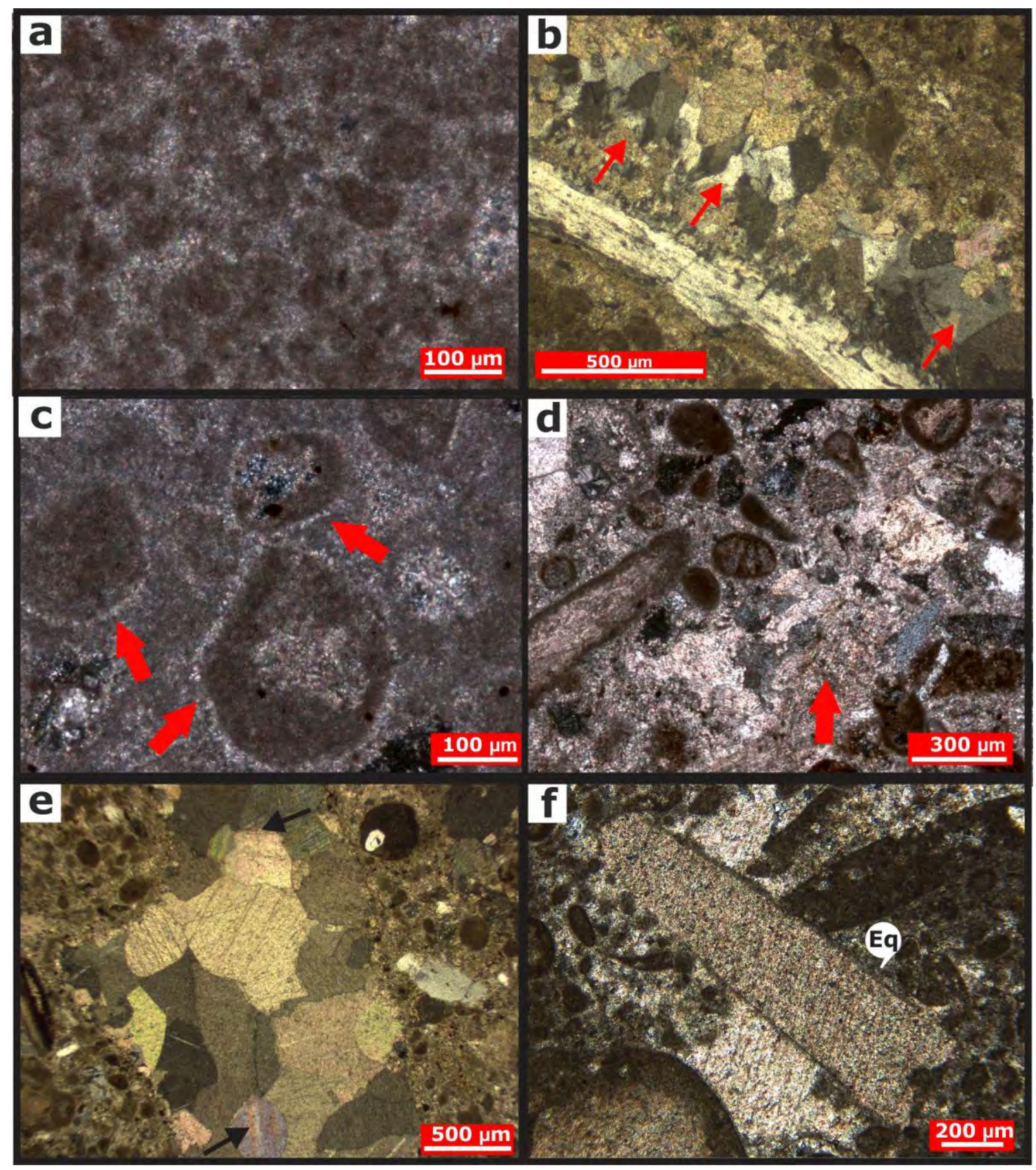

Figura 5.15a [NX,10X]: Fango carbonático con textura grumosa donde se observa el pasaje gradual entre los peloides y la micrita homogénea. Niveles superiores de la sucesión carbonática en el perfil ANE (muestra ANE3). b) [NX,4X]: Cemento silíceo rellenando la porosidad intercristalina del precipitado carbonático. Las flechas rojas indican el pasaje gradual de la calcedonia zebraica a cristales de cuarzo hacia el interior de la cavidad. Niveles inferiores de la sucesión carbonática en la sección ASE (muestra ASE4). c) [NX,10X]: Cemento fibroso en halo isopáquico (flechas rojas). Tramo inferior de la sucesión en la sección ACS (muestra ACS2A). d) [NX,4X]: Cemento esparítico granular (flecha roja). Muestra ASE2. e) [NX,4X]: Cemento macroesparítico drusiforme rellenando la cavidad de disolución de un bioclasto. Las flechas negras indican el aumento del tamaño de los cristales hacia el interior de la cavidad. Muestra ASE4. f) $[N X, 4 X]$ : Cemento sintaxial que crece en continuidad óptica con un fragmento de equinodermo (Eq). Tramo inferior a medio de la sucesión en el perfil PLW (muestra PLW5A). 


\subsection{2: Petrografía de las areniscas}

Sobre la base de la descripción de treinta y tres secciones delgadas de areniscas (ver Anexo II) se determinaron los componentes principales y menores. Además, se ajustaron las modas granulométricas de las distintas facies y se reconocieron cualitativamente areniscas terrígenas y mixtas. A partir de todas estas observaciones se seleccionó un grupo de muestras representativas para los análisis cuantitativos que se sintetizan en las tablas 2 y 3.

Las muestras analizadas corresponden a areniscas finas a gruesas, poco alteradas y en la mayoría de los casos con un porcentaje de matriz menor al $15 \%$. Dicho contenido de matriz delimita el campo entre las areniscas y los vaques (Pettijhon et al., 1987). Los componentes reconocidos dentro de las psamitas se dividen en dos grupos: componentes principales conformados por granos extracuencales (cuarzo, feldespato y líticos) e intracuencales (bioclastos y partículas carbonáticas no esqueletales) y componentes menores representados por la matriz y el cemento. De acuerdo con el contenido de componentes intracuencales respecto a los extracuencales se distinguen psamitas terrígenas, con un contenido de componentes intracuencales menor al $15 \%$ y areniscas mixtas con un contenido mayor al 15\% del total según criterios propuestos por Olivo (2016).

Para la caracterización de las areniscas se seleccionaron cuatro muestras de psamitas terrígenas y once de areniscas mixtas representativas de las diferentes texturas presentes. Se contabilizaron diez y ocho modas detríticas respectivamente, utilizando el método de Gazzi-Dickinson (Ingersoll et al., 1984; Zuffa, 1985) (Tablas $2 a \quad y \quad b)$. Durante su determinación se reconocieron componentes extracuencales (CE) e intracuencales (CI) y dentro de estos últimos se diferenciaron granos esqueletales de no esqueletales (ooides, peloides e intraclastos carbonáticos). La mayoría de las muestras de areniscas analizadas pertenecen a la sucesión terrígena-mixta, aflorante en la zona de Malargüe. En menor cantidad se distinguen ejemplares del tramo inferior a medio de la sucesión carbonática, localizados en la zona de Bardas Blancas (figura 2.2). 


\begin{tabular}{|c|c|c|c|c|c|c|c|c|c|c|c|c|c|c|c|c|c|c|c|c|c|}
\hline \multicolumn{5}{|c|}{ TABLA 2a } & \multicolumn{9}{|c|}{$\overline{C E}$} & \multicolumn{2}{|r|}{$\mathrm{CI}$} & \multicolumn{6}{|c|}{ VR } \\
\hline Muestra & Grim. & \%Clast. & \%Mtz. & $\%$ Cto. & Qm & Qp & $\mathbf{F}$ & LVf & LVp & LVT & LP & LT & Ac & NE & $\mathbf{E}$ & Qm & Qp & QT & $\mathbf{F}$ & LT & $\mid L T+Q p$ \\
\hline ALV5A & $\mathrm{Vf}$ & 57,33 & 17,00 & 25,67 & 16,86 & 2,33 & 30,81 & 35,47 & 0,00 & 35,47 & 0 & 35,47 & 11,05 & 3,49 & 0,00 & 19,73 & 2,72 & 22,45 & 36,05 & 41,50 & \begin{tabular}{|l|l|}
50 & 44,22 \\
\end{tabular} \\
\hline PLE2D & $V m$ & 69,67 & 17,67 & 12,67 & \begin{tabular}{|l|}
9,57 \\
\end{tabular} & 5,26 & 34,45 & 33,49 & 3,35 & 36,84 & 0 & 36,84 & 5,74 & 2,87 & 5,26 & 11,11 & 6,11 & 17,22 & \begin{tabular}{l|l}
22 & 40,0
\end{tabular} & 42,78 & \begin{tabular}{|l|l|}
8 & 48,89 \\
\end{tabular} \\
\hline ACN5 & $\mathrm{Ag}$ & 77,33 & 4,67 & 18,00 & 16,38 & 7,33 & 25,86 & 38,36 & 2,16 & 40,52 & 0 & 40,52 & 0,43 & 6,90 & 2,59 & 18,18 & 8,13 & 26,32 & \begin{tabular}{l|l|}
32 & 28,7 \\
\end{tabular} & 44,98 & \begin{tabular}{|l|l|}
8 & 53,11 \\
\end{tabular} \\
\hline CS2 & Af & 85,33 & 5,67 & 9,00 & 24,61 & 1,56 & 30,08 & 41,02 & 0,00 & 41,02 & 0 & 41,02 & 2,73 & 0,00 & 0,00 & 25,30 & 1,61 & $\begin{array}{ll}31 & 26,9 \\
1\end{array}$ & \begin{tabular}{l|l}
91 & 30,9 \\
\end{tabular} & \begin{tabular}{|l|l}
2,17 \\
2,17
\end{tabular} & \begin{tabular}{|l|l|}
17 & 43,78 \\
\end{tabular} \\
\hline \multicolumn{5}{|c|}{ TABLA 2b } & \multicolumn{6}{|c|}{$\mathrm{CE}$} & \multicolumn{2}{|c|}{$\overline{C I}$} & & & & \multicolumn{6}{|c|}{ VR } \\
\hline Muestra & GrIm. & \%Clast. & \%Mtz. & \begin{tabular}{|l|}
$\%$ Cto. \\
\end{tabular} & Om & Op & $\mathbf{F}$ & LVT & LP & Ac & NE & E & CEt & CIt & Clase & Om & Op & OT & $\mathbf{F}$ & LT & $L T+0 p$ \\
\hline APS2 & $\mathrm{Ag}$ & 75,33 & 8,67 & 15,67 & 12,39 & 0,88 & 15,04 & 17,70 & 0,00 & 0,44 & 20,35 & 33,19 & 46,46 & 53,54 & Mixta & 26,92 & 1,92 & 28,85 & 32,69 & 38,46 & 40,38 \\
\hline ATW6 & $\mathrm{Ag}$ & 77,33 & 9,33 & 13,33 & 5,60 & 0,00 & 18,10 & 6,03 & 0,43 & 1,29 & 32,76 & 35,78 & 31,47 & 68,53 & Mixta & 18,57 & 0,00 & \begin{tabular}{|l|}
18,57 \\
\end{tabular} & 60,00 & 21,43 & 21,43 \\
\hline PLN3 & $\mathrm{Vm}$ & 73,33 & 15,67 & 11,00 & 10,00 & 0,00 & 26,36 & 12,27 & 1,36 & 0,91 & 24,55 & 24,55 & 50,91 & 49,09 & Mixta & 20,00 & 0,00 & 20,00 & 52,73 & 27,27 & 27,27 \\
\hline \begin{tabular}{|l} 
PLE4A \\
\end{tabular} & $\mathrm{Am}$ & 72,00 & 9,67 & 18,33 & 20,37 & 3,24 & 25,00 & 18,06 & \begin{tabular}{l|}
1,85 \\
\end{tabular} & 0,00 & 21,76 & 9,72 & 68,52 & 31,48 & Mixta & 29,73 & 4,73 & \begin{tabular}{|l|}
34,46 \\
\end{tabular} & 36,49 & 29,05 & 33,78 \\
\hline PLW3 & $\mathrm{Am}$ & 57,00 & 3,33 & 39,67 & 8,19 & 1,75 & 32,16 & 20,47 & 0,58 & 2,34 & 17,54 & 16,96 & 65,50 & 34,50 & Mixta & 12,96 & 2,78 & \begin{tabular}{|l|}
15,74 \\
\end{tabular} & \begin{tabular}{|l|}
50,93 \\
\end{tabular} & 33,33 & 36,11 \\
\hline \begin{tabular}{|l} 
APS3 \\
\end{tabular} & $\mathrm{Am}$ & 81,67 & 1,33 & 17,00 & 20,82 & 1,22 & 39,18 & 20,00 & 0,82 & 0,41 & 11,43 & 6,12 & 82,45 & 17,55 & Mixta & 25,37 & 1,49 & \begin{tabular}{|l|}
26,87 \\
\end{tabular} & \begin{tabular}{|l|}
47,76 \\
\end{tabular} & 25,37 & 26,87 \\
\hline ATW1 & Am & 79,33 & 4,33 & 16,33 & 11,76 & 1,26 & 27,31 & 19,75 & 0,00 & 0,42 & 8,82 & 30,67 & 60,50 & 39,50 & Mixta & 19,58 & 2,10 & 21,68 & 45,45 & 32,87 & 34,97 \\
\hline PLE2A & Am & 84,00 & 8,00 & 8,00 & 11,90 & 1,19 & 21,43 & 36,51 & 0,40 & 1,19 & 3,17 & 24,21 & 72,62 & 27,38 & Mixta & 16,67 & 1,67 & \begin{tabular}{|l|}
18,33 \\
\end{tabular} & 30,00 & 51,67 & 53,33 \\
\hline PLE2C & Am & 84,33 & 2,33 & 11,67 & 16,67 & 2,71 & 17,05 & 27,13 & 1,55 & 1,16 & 4,26 & 27,52 & 66,28 & 31,78 & Mixta & 25,60 & 4,17 & 29,76 & 26,19 & 44,05 & 48,21 \\
\hline PLE2F & Am & 83,00 & 4,67 & 12,33 & 7,23 & 2,01 & 11,24 & 16,47 & 1,20 & 0,00 & 20,48 & 41,37 & 38,15 & 61,85 & Mixta & 18,95 & 5,26 & 24,21 & \begin{tabular}{|l|}
29,47 \\
\end{tabular} & 46,32 & 51,58 \\
\hline \begin{tabular}{|l|} 
PLE3B \\
\end{tabular} & Am & \begin{tabular}{|c|}
74,67 \\
\end{tabular} & 4,67 & $\frac{2,107}{20,67}$ & \begin{tabular}{|l|}
7,14 \\
\end{tabular} & $\frac{2,70}{1,79}$ & \begin{tabular}{l|l}
12,95 \\
1,2
\end{tabular} & \begin{tabular}{|l|}
16,07 \\
\end{tabular} & o, & 0,45 & \begin{tabular}{|l|}
16,07 \\
\end{tabular} & 44,64 & 39,29 & 60,71 & Mixta & \begin{tabular}{|l|}
18,39 \\
\end{tabular} & 4,60 & \begin{tabular}{|l|}
22,99 \\
\end{tabular} & 33,33 & \begin{tabular}{|l|}
43,68 \\
\end{tabular} & 48,28 \\
\hline quel & . & . & Af & fin & If. & . & , dies & (Int) & +1 & 25 & ; & $\mathrm{COI}$ & her & int & dencal & tale & VE- & VR & alore & rec & $\begin{array}{l}\text { icos); } \\
\text { culados }\end{array}$ \\
\hline
\end{tabular}

Tabla 2a: Parámetros contabilizados en las areniscas terrígenas recalculados al $100 \%$ del total de la roca. Tabla 2b: Parámetros contabilizados en las psamitas mixtas recalculados al $100 \%$ del total de la roca. El sombreado indica las muestras utilizadas en los diagramas clasificatorios de Dickinson et al. (1983). 


\begin{tabular}{|c|c|c|c|c|c|c|c|}
\hline \multicolumn{8}{|c|}{ TABLA $3 \mathbf{a}$} \\
\hline Muestra & $\mathbf{Q}$ & $\mathbf{F}$ & L & $F / L$ & Q/F & $\begin{array}{c}\text { Pettijhon et al. (1972) } \\
\text { (19) }\end{array}$ & Clasificación de Folk et al. (1970) \\
\hline ALV5A & 22,45 & 36,05 & 41,50 & 0,87 & 0,62 & VAQUE LÍTICO & - \\
\hline PLE2D & 17,22 & 40,00 & 42,78 & 0,94 & 0,43 & VAQUE LÍTICO & - \\
\hline ACN5 & 26,32 & 28,71 & 44,98 & 0,64 & 0,92 & ARENITA LÍTICA & LITOARENITA FELDESPÁTICA \\
\hline CS2 & 26,91 & 30,92 & 42,17 & 0,73 & 0,87 & ARENITA LÍTICA & LITOARENITA FELDESPÁTICA \\
\hline \multicolumn{8}{|c|}{ TABLA 3b-I } \\
\hline Muestra & $\mathbf{Q}$ & $\mathbf{F}$ & $\mathbf{L}$ & $\mathbf{F} / \mathbf{L}$ & Q/F & $\begin{array}{c}\text { Clasificación de Dott (1964) modificada por } \\
\text { Pettijhon et al. (1972) }\end{array}$ & Clasificación de Folk et al. (1970) \\
\hline APS2 & 28,85 & 32,69 & 38,46 & 0,85 & 0,88 & ARENITA LÍTICA & LITOARENITA FELDESPÁTICA \\
\hline PLE2A & 18,33 & 30,00 & 51,67 & 0,58 & 0,61 & ARENITA LÍTICA & LITOARENITA FELDESPÁTICA \\
\hline PLE2C & 29,76 & 26,19 & 44,05 & 0,59 & 1,14 & ARENITA LÍTICA & LITOARENITA FELDESPÁTICA \\
\hline PLE2F & 24,21 & 29,47 & 46,32 & 0,64 & 0,82 & ARENITA LÍTICA & LITOARENITA FELDESPÁTICA \\
\hline PLE3B & 22,99 & 33,33 & 43,68 & 0,76 & 0,69 & ARENITA LÍTICA & LITOARENITA FELDESPÁTICA \\
\hline \multicolumn{8}{|l|}{ II } \\
\hline Muestra & $\mathbf{Q}$ & $\mathbf{F}$ & $\mathbf{L}$ & F/L & Q/F & $\begin{array}{c}\text { Clasificación de Dott (1964) modificada por } \\
\text { Pettijhon et al. (1972) }\end{array}$ & Clasificación de Folk et al. (1970) \\
\hline ATW6 & 18,57 & 60,00 & 21,43 & 2,80 & 0,31 & ARENITA ARCOSICA & FELDARENITA LÍTICA \\
\hline PLN3 & 20,00 & 52,73 & 27,27 & 1,93 & 0,38 & VAQUE FELDESPÁTICO & - \\
\hline PLE4A & 34,46 & 36,49 & 29,05 & 1,26 & 0,94 & ARENITA ARCÓSICA & FELDARENITA LÍTICA \\
\hline PLW3 & 15,74 & 50,93 & 33,33 & 1,53 & 0,31 & ARENITA ARCÓSICA & FELDARENITA LÍTICA \\
\hline ATW1 & 21,68 & 45,45 & 32,87 & 1,38 & 0,48 & ARENITA ARCÓSICA & FELDARENITA LÍTICA \\
\hline APS3 & 26,87 & 47,76 & 25,37 & 1,88 & 0,56 & ARENITA ARCOSICA & FELDARENITA LÍTICA \\
\hline
\end{tabular}

Tabla 3: Diferenciación de las areniscas terrígenas y mixtas de acuerdo con el contenido de cuarzo, feldespato y líticos y las relaciones entre estos componentes. Tabla 3a: Areniscas terrígenas con una relación F/L menor a 1. Tabla 3b-I: Psamitas mixtas con una relación F/L menor a 1. Tabla 3b-II: areniscas con una relación F/L mayor a 1. 


\subsection{2-I: Componentes principales del entramado}

\section{a) Componentes extracuencales:}

\section{Cuarzo}

El cuarzo se presenta en sus variedades de cuarzo monocristalino y policristalino. Los cristales de cuarzo monocristalino $(\mathrm{Qm})$ se caracterizan por su aspecto límpido, con bajo contenido de inclusiones y extinción recta o relámpago. Dentro de ellos se distinguen cristales con formas prismáticas a esféricas, bordes angulosos a subredondeados y tamaños que oscilan entre 100 y $500 \mu \mathrm{m}$ (figura 5.16a). También se observan cristales de formas esféricas a subprismáticas, bordes subredondeados con engolfamientos, bahías y vacuolas, indicando su origen volcánico. Dichos cristales presentan tamaños que varían entre 400 y $1000 \mu \mathrm{m}$ (figura 5.16a). Ambos tipos de cuarzo se presentan en bajas proporciones dentro de las areniscas, con valores que varían entre 10 y $25 \%$ del total de las areniscas terrígenas y entre 5 y $20 \%$ del total de las psamitas mixtas (tablas $2 a$ y b).

En lo que se refiere a los cristales de cuarzo policristalino (Qp), se identifican como formas subprismáticas a esféricas con bordes bien redondeados, conformadas por subcristales de cuarzo que presentan orientación variable del eje c. En general dichos subcristales presentan formas equidimensionales a elongadas con bordes rectos (figura 5.16b), característica que denota su origen metamórfico de alto grado (Scholle, 1979). Asimismo, se reconoce una menor proporción de cristales de cuarzo policristalino conformado por individuos de formas alargadas, con bordes irregulares y crenulados. Ambas variedades de cuarzo policristalino poseen tamaños variables entre 400 y $800 \mu \mathrm{m}$. Los mismos representan una escasa proporción del total de las areniscas terrígenas ( 2 a $7 \%$ ) y de las mixtas ( 2 a $5 \%$; tablas 2 y 3 ). 


\section{Feldespatos}

Los feldespatos (F) se reconocen como cristales de aspecto turbio debido a la alteración a minerales arcillosos que presentan (figura 5.17a). Muestran hábito tabular, predominantemente largo, y bordes subangulosos a angulosos; raramente se identifican cristales con bordes subredondeados. En algunos casos los feldespatos presentan un núcleo poco alterado rodeado por un sobrecrecimiento inalterado de bordes rectos (figura 5.17b). La presencia de las maclas polisintética y de Carlsbad es poco frecuente en los fragmentos de feldespato, siendo la primera la más representada. De acuerdo al hábito que predomina en los cristales, la abundancia de maclas polisintéticas respecto a la de Carlsbad y el análisis petrográfico realizado, podría considerarse que el feldespato más abundante es la plagioclasa. Dado el alto grado de alteración de estos cristales no fue posible determinar el tipo de plagioclasas por el método óptico de Michel-Levy. El tamaño de los cristales oscila entre 100 y $1000 \mu \mathrm{m}$.

En las areniscas analizadas los feldespatos se encuentran desde moderadas a altas proporciones, llegando a ser junto con los líticos volcánicos los componentes principales de la psamitas terrígenas (25 a 40\% del total) y los componentes extracuencales más abundantes en las mixtas (10 a 30\% del total; tablas 2 a y b).

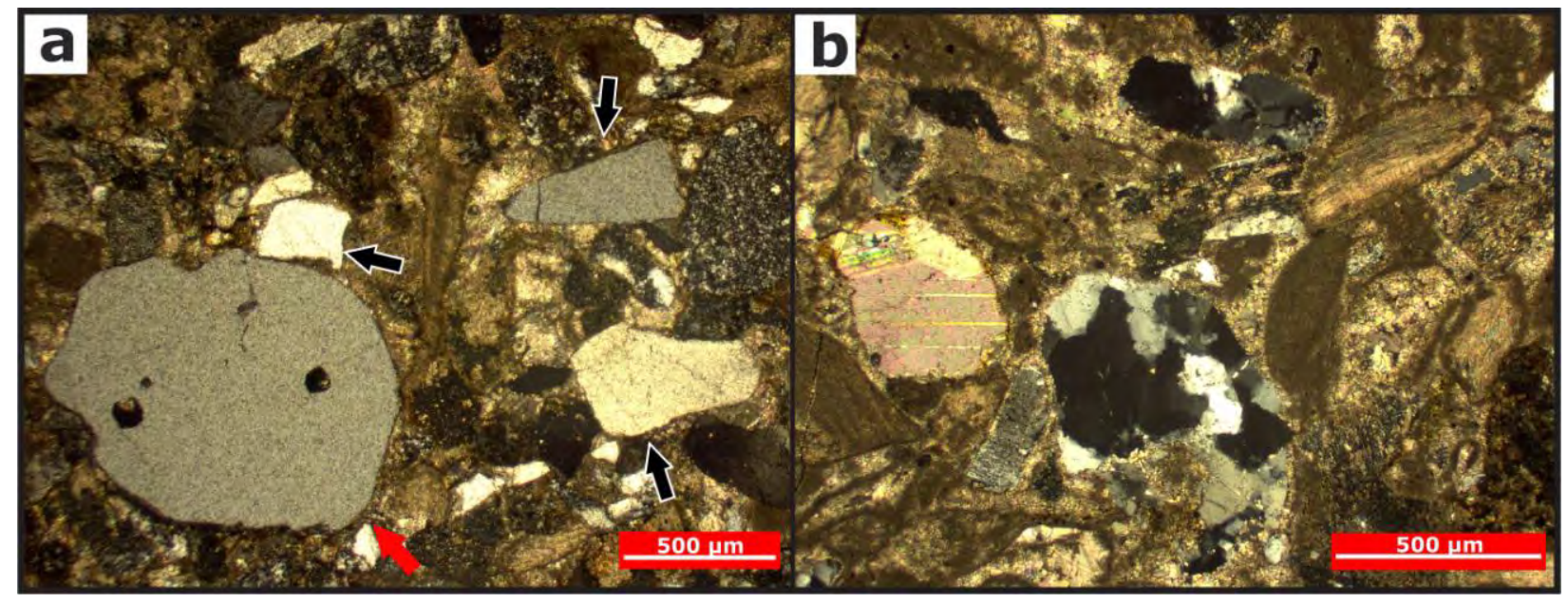

Figura 5.16 [NX,4X]: Variedades de cuarzo. a): Monocristalino con bordes subangulosos a subredondeados y formas esféricas a prismáticas (flechas negras). Además se distinguen cristales de cuarzo con bordes subredondeados y presencia de bahías y vacuolas (flecha roja). Niveles inferiores de la sucesión terrígena-mixta en el perfil ATW (muestra ATW2). b) Policristalino con subcristales equidimensionales a alargados de bordes rectos. Tramo medio a superior de la sucesión terrígenamixta en el perfil ATW (muestra ATW5). 


\section{Fragmentos líticos}

Incluyen líticos volcánicos felsíticos, líticos volcánicos pilotáxicos y líticos plutónicos. Dentro de los líticos volcánicos felsíticos (LVf) se distinguen clastos con textura porfírica y pasta afanítica felsítica (figuras $5.18 \mathrm{a}$ y b) y fragmentos conformados en su totalidad por pasta afanítica felsítica (figuras $5.18 \mathrm{c}$ y d). Las texturas porfíricas presentan fenocristales de cuarzo límpido y feldespato de aspecto turbio, ambos con formas subhedrales a anhedrales y en ocasiones con bordes engolfados. La pasta que rodea a los fenocristales, descripta en el apartado 5.2.1.I, se corresponde con composiciones de rocas volcánicas ácidas. Los líticos volcánicos felsíticos tienen formas prismáticas a esféricas con bordes subredondeados a redondeados y tamaños que varían entre 100 y $800 \mu \mathrm{m}$ para los fragmentos conformados por pasta afanítica y entre 700 y $3000 \mu \mathrm{m}$ para las texturas porfíricas. Se presentan en moderadas proporciones dentro de las psamitas terrígenas (10 a $40 \%$ ) y mixtas (6 a 35\%), siendo el lítico volcánico más frecuente.

En lo que respecta a los líticos volcánicos pilotáxicos (LVp) se caracterizan por contener cristales subhedrales a euhedrales de feldespato de forma tabular, generalmente plagioclasas, los cuales se ubican dentro de una pasta afanítica de vidrio volcánico sin una distribución definida (figuras $5.18 \mathrm{e}$ y $\mathrm{f}$ ). Algunos clastos pueden presentar fenocristales de cuarzo límpido y feldespato de aspecto turbio de forma subhedral a anhedral. Este tipo de textura se corresponde con lavas de composición intermedia. Dichos fragmentos tienen formas prismáticas a subprismáticas con bordes subredondeados a redondeados y tamaños que varían entre 100 y $800 \mu \mathrm{m}$ para los fragmentos compuestos por pasta afanítica, y entre 700 y $2000 \mu \mathrm{m}$ para las texturas porfíricas. Se encuentran representados en escasa proporción dentro de las psamitas terrígenas y mixtas (menos del $5 \%$ del total).

En general las pastas de los fragmentos líticos volcánicos se encuentran parcialmente alteradas evidenciado por su recristalización a agregados de cuarzo y feldespato de mayor tamaño de grano y por el aspecto turbio que presentan, del mismo modo que ocurre con los fenocristales de feldespatos incluidos en ellas (figuras 5.18a-d). En menor proporción de identifican pastas de líticos volcánicos con un menor grado de alteración (figuras 5.18e-f). Además, los clastos de líticos 
volcánicos presentan formas de bordes redondeados a subredondeados y su tamaño de grano es similar al de los fragmentos no volcánicos que lo acompañan. De acuerdo con Zuffa (1985) y Critelli e Ingersoll (1995), estos caracteres se vinculan con un vulcanismo anterior a la sedimentación, denominándolos de esta forma fragmentos paleovolcánicos.

Los líticos de origen plutónicos (LP) están representados por texturas gráficas correspondientes a un intercrecimiento de cristales de cuarzo y feldespato alcalino de hábito cuneiforme. Sus formas varían desde prismáticas a esféricas, con bordes subredondeados a redondeados y tamaños que oscilan entre 200 y $800 \mu \mathrm{m}$. Se presentan en proporciones muy escasas, con valores promedio del $0.8 \%$ en las areniscas mixtas, hasta ausentes en las psamitas terrígenas (tablas $2 a$ y $2 b$ ).

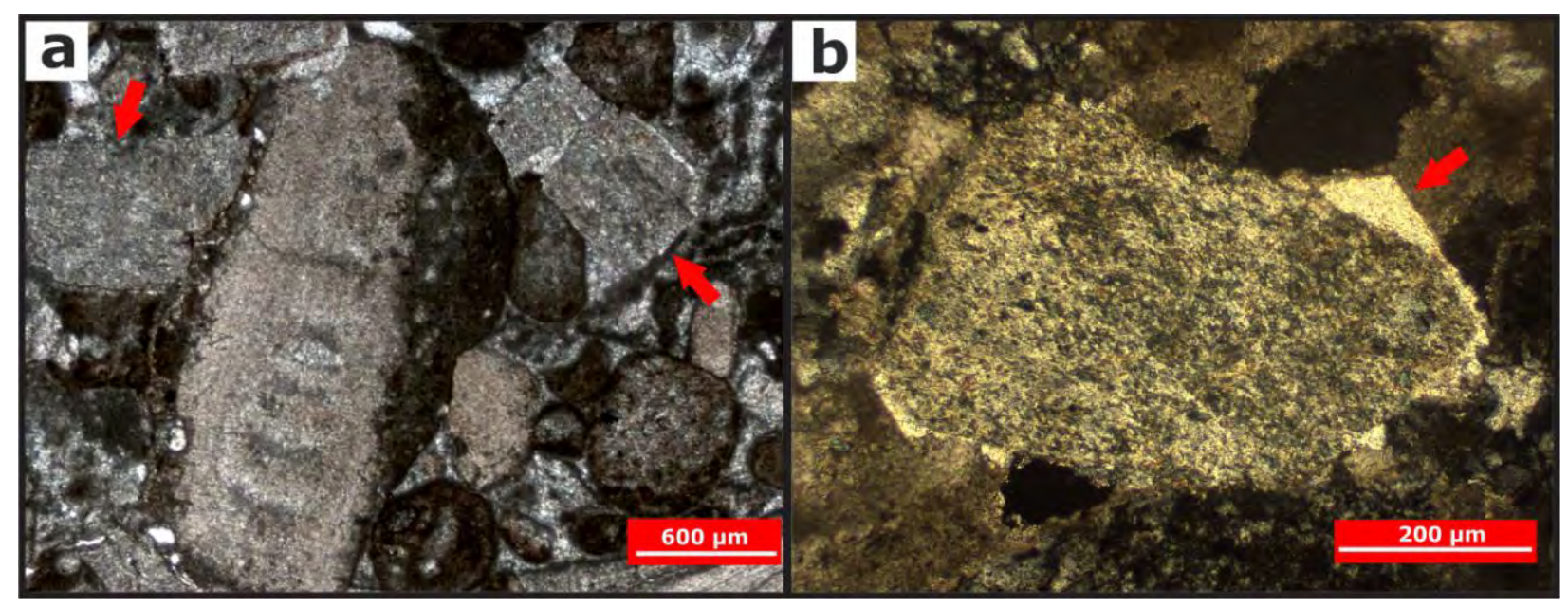

Figura 5.17a [NX,2X]: Cristales de feldespato de aspecto turbio (flechas rojas) que rodean a un intraclasto carbonático. Tramo medio a superior de la sucesión terrígena-mixta en el perfil ATW (muestra ATW6). Figura 5.17b [NX,10X]: Cristal de feldespato de aspecto turbio rodeado por un sobrecrecimiento inalterado de bordes rectos (flecha roja). Sector inferior de la sucesión terrígenamixta en el perfil PLE (muestra PLE2B). 


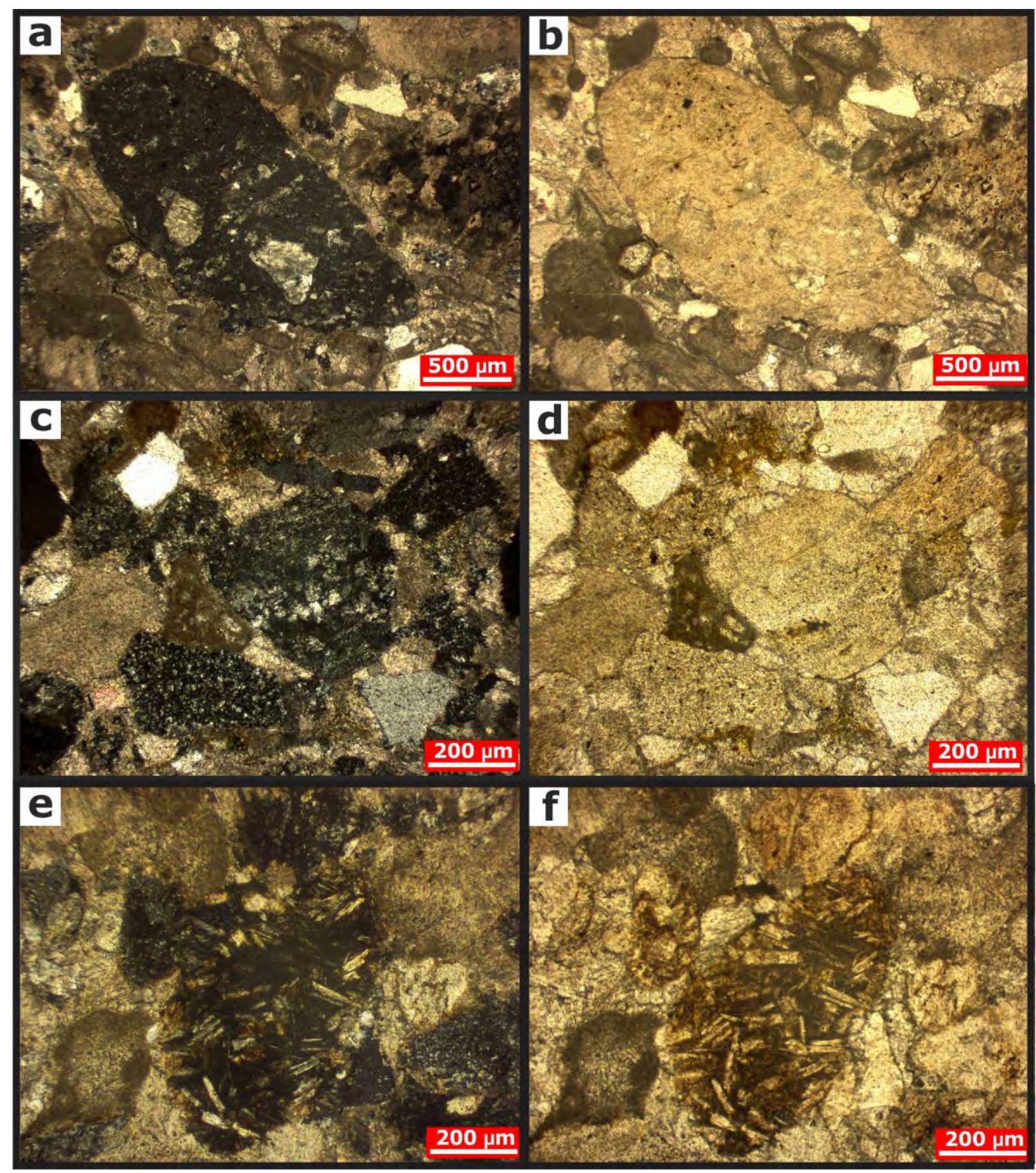

Figura 5.18a [NX,4X] y b[4X]: Fragmento de lítico volcánico con fenocristales de feldespato parcialmente alterados y pasta afanítica felsítica. Muestra PLE3B. c) [NX,10X] y d [10X]: Líticos volcánicos conformados por pasta felsítica parcialmente alterada. Muestra PLE2A. e) [NX,10X] y f [10X]:fragmento de lítico volcánico compuesto por pasta afanítica pilotáxica. Muestra PLE2C. Niveles inferiores de la sucesión terrígena-mixta en el perfil PLE. 


\section{b) Componentes intracuencales:}

\section{Granos esqueletales (CNE)}

Comprenden ¿algas rojas?, bivalvos (Bivalvia indet., Ostreidae indet.), equinoideos (Euechinoidea indet.) y escasos braquiópodos rhynchonellidos (Rhynchonellida indet., ?Torquirhynchia sp.; figura 5.19). Las ¿algas rojas? están compuestas por calcita con alto contenido en magnesio y presentan una estructura filamentosa conformada por un fino reticulado (Scholle y Ulmer-Scholle, 2003). Se puede distinguir una región interna de otra externa a través del patrón de reticulado que presentan (figura 5.19a). Estos bioclastos pueden tener rasgos de bioerosión y en general se presentan como secciones transversales, longitudinales o como fragmentos de bordes redondeados a angulosos. En lo que respecta a los bivalvos, están conformados por aragonita (Bivalvia indet.) o calcita de bajo contenido en magnesio (Ostreidae indet.). Las formas aragoníticas no preservan su estructura interna, se observan como moldes rodeados por una fina a espesa envoltura micrítica, rellenos con cemento carbonático. Por el contrario, las ostras conservan su estructura original característica (figuras 5.6b; 5.19b). La mayoría de los bivalvos se identifican como restos de formas prismáticas a irregulares con bordes redondeados.

Los equinoideos están compuestos por calcita con alto contenido de magnesio y presentan su estructura interna preservada (figura 5.19b). La mayoría se reconocen como secciones transversales o longitudinales de placas y espinas, raramente se observan fragmentos de estos bioclastos. Por último los braquiópodos están constituidos por calcita con bajo contenido en magnesio y presentan su estructura foliada característica (figura 5.8a). Aparecen como valvas completas desarticuladas a articuladas.

Los granos esqueletales presentan tamaños que varían entre 300 y $2000 \mu \mathrm{m}$. Se distribuyen en proporciones escasas hasta ausentes dentro de las psamitas terrígenas (menos del 6\%) y con valores que oscilan entre 10 y $45 \%$ del total de las areniscas mixtas (tablas $2 a$ y b). 


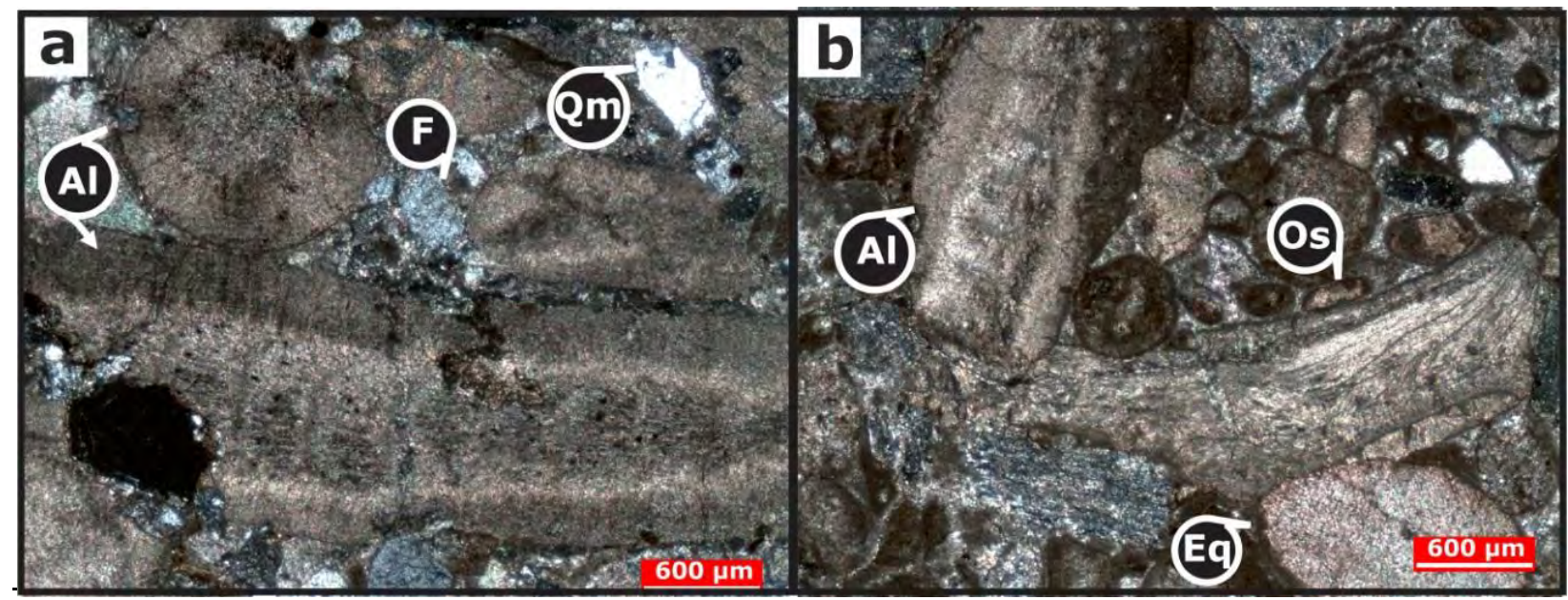

Figura 5.19: Componentes esqueletales presentes en las areniscas terrígenas y mixtas. a) [NX,2X]: Secciones transversales y longitudinales de ¿algas rojas? (Al) acompañadas por fragmentos de feldespato (F) y cuarzo monocristalino (Qm). b) [NX,2X]:Restos de ostra (Os), equinoideos (Eq) y ¿algas rojas? $(\mathrm{Al})$ junto con intraclastos carbonáticos, peloides y clastos de feldespato. Tramo inferior a medio de la sucesión carbonática en la sección ATW (muestra ATW1, ATW6).

\section{Granos no esqueletales (CE)}

Incluyen peloides, intraclastos carbonáticos y ooides. Los peloides se presentan como partículas micríticas redondeadas sin estructura interna, de formas prismáticas a irregulares y tamaños que varían entre 200 y $700 \mu \mathrm{m}$ (figura 5.20a). En las areniscas mixtas se observa la transición entre estas formas de peloides y los fragmentos de bivalvos parcialmente micritizados. En menor proporción se identifican peloides de formas esféricas a ovoidales cuyo tamaño varía entre 100 y $300 \mu \mathrm{m}$. En lo que se refiere a los intraclastos carbonáticos, éstos están conformados por fragmentos de wackestone a packstone, con formas irregulares, bordes subredondeados a redondeados y tamaños que varían entre 300 y $2000 \mu \mathrm{m}$ (figura 5.20b). Por su parte, los ooides están representados por ooides micríticos Tipo 1 (Strasser, 1986), simples, con una corteza conformada por láminas concéntricas poco definidas debido a la intensa micritización que presentan estas partículas. En general se distinguen ooides micríticos superficiales (Flügel, 2010), raramente se diferencian formas con una corteza conformada por tres láminas (figura 5.20a). El núcleo está constituido por clastos terrígenos de líticos volcánicos, feldespatos o cuarzo monocristalino. Los ooides presentan formas variables desde esféricas hasta irregulares y tamaños que se encuentran entre los 100 y $500 \mu \mathrm{m}$. 
Los componentes no esqueletales se presentan en bajas proporciones (menos del $12 \%$ del total) hasta ausentes en las areniscas terrígenas (tabla 2a). Sin embargo, en las psamitas mixtas representan 3 a 25\% del total (tabla 2b), siendo los peloides la partícula más representada en ambas areniscas.

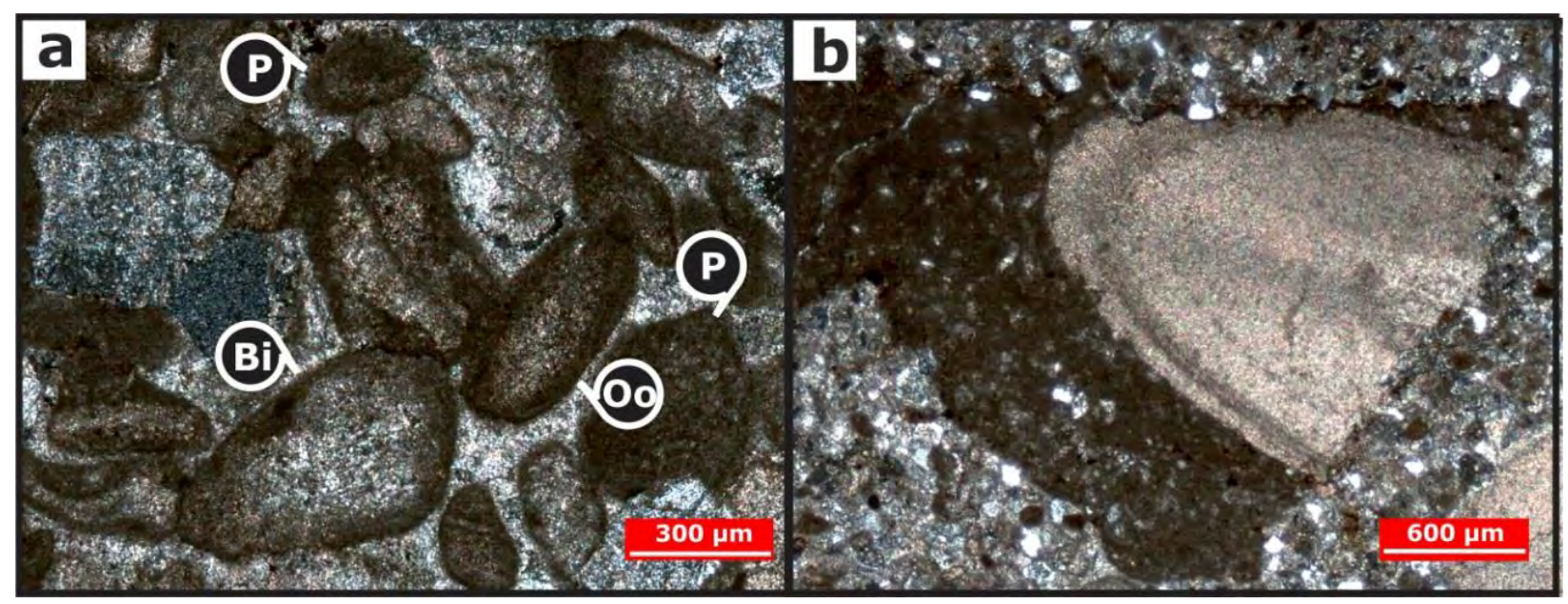

Figura 5.20: Componentes no esqueletales presentes en las areniscas terrígenas y mixtas. a) [NX,4X]: Peloides $(P)$ de formas esféricas a prismáticas, en estos últimos se puede distinguir la transición con los restos de bioclastos indeterminado (Bi).Además se observan ooides micríticos superficiales. b) [NX,2X]: Intraclasto carbonático con textura wackestone, forma irregular y bordes subredondeados. Tramo medio a superior de la sucesión mixta terrígena en la sección Arroyo Torrecillas Oeste (muestras ATW4b, ATW6).

\subsection{2-II: Componentes menores del entramado}

\section{Matriz}

De acuerdo con Folk et al. (1970), se considera matriz a todo el material detrítico con tamaño de grano menor a los $30 \mu \mathrm{m}$ que se deposita junto con los clastos mayores. Esta matriz clástica representa valores menores al 15\% de la muestra, aunque en algunos casos la proporción puede ser algo mayor (15-18\%). En general la matriz de las psamitas se compone de un conjunto de argilominerales, fragmentos de feldespatos y cuarzo que son depositados simultáneamente con las partículas tamaño arena. En el caso de las areniscas mixtas también se identifica micrita homogénea y restos de partículas esqueletales y no esqueletales. En las areniscas analizadas también se reconoció la presencia de pseudomatriz, relacionada con un origen diagenético, formada por la deformación y alteración de 
clastos inestables que conducen al crecimiento autigénico de arcillas (Dickinson, 1970; Garzanti, 2017).

\section{Cemento}

El principal agente cementante en las areniscas terrígenas y mixtas es el carbonato de calcio. En forma minoritaria aparecen los cementos de feldespato autigénico y de argilominerales. Este último sólo se presenta en escasa proporción dentro de las psamitas terrígenas de grano fino de la zona de Bardas Blancas. Los precipitados carbonáticos están representados por cementos fibrosos y esparíticos. Los primeros están conformados por cristales de 10 a $50 \mu \mathrm{m}$ de espesor que se ubican en la periferia de las partículas carbonáticas con fábricas microestalactíticas o pendant. Dicho precipitado es poco frecuente dentro de las areniscas mixtas y cuando está presente constituye la primera generación de cementos de estas psamitas. Por su parte, los cemento ecuantes están representados por microesparita (5 a $15 \mu \mathrm{m}$ ), esparita granular $(15$ a $70 \mu \mathrm{m})$ y macroesparita $(100$ a $400 \mu \mathrm{m})$ con textura en bloque, drusiforme y sintaxial (figuras 5.21a-c). Estos precipitados son abundantes en ambas areniscas, se encuentran obliterando total a parcialmente la porosidad intergranular e intragranular representada por moldes de bioclastos y cavidades generadas por disolución. Raramente están en la periferia de los granos formando un halo alrededor de los mismos. Son los segundos precipitados en aparecer dentro de las psamitas, de forma posterior a los fibrosos. En general los precipitados carbonáticos se encuentran en baja a moderada proporción dentro de las areniscas; raramente se presentan en abundante cantidad (ver tablas 2a y b).

En lo que refiere al cemento de feldespato autigénico, aparece como un sobrecrecimiento de aspecto límpido y bordes rectos que crece en continuidad óptica sobre clastos de feldespato alterados a minerales de arcilla (figura 5.17). Las formas minerales comunes son la albita y la ortosa, desarrolladas en areniscas con concentraciones de sílice, alúmina y de iones $\mathrm{Na}^{+}$y $\mathrm{K}^{+}$adecuadas para su formación, generalmente derivados de la alteración y/o disolución de feldespatos detríticos y líticos volcánicos (De Ros et al., 1994; Rossi et al., 2002). 
Este tipo de cemento es frecuente dentro de las psamitas terrígenas y mixtas de la sucesión terrígena-mixta y en las mismas representa uno de los primeros precipitados junto con los cementos fibrosos. Además, en las areniscas se reconoce escaso cemento arcilloso homogéneo, conformado por argilominerales de color amarillo y alta birrefringencia, posiblemente illita y/o interestratificado illitaesmectita, que ocluyen totalmente la cavidad poral (figura 5.21d).

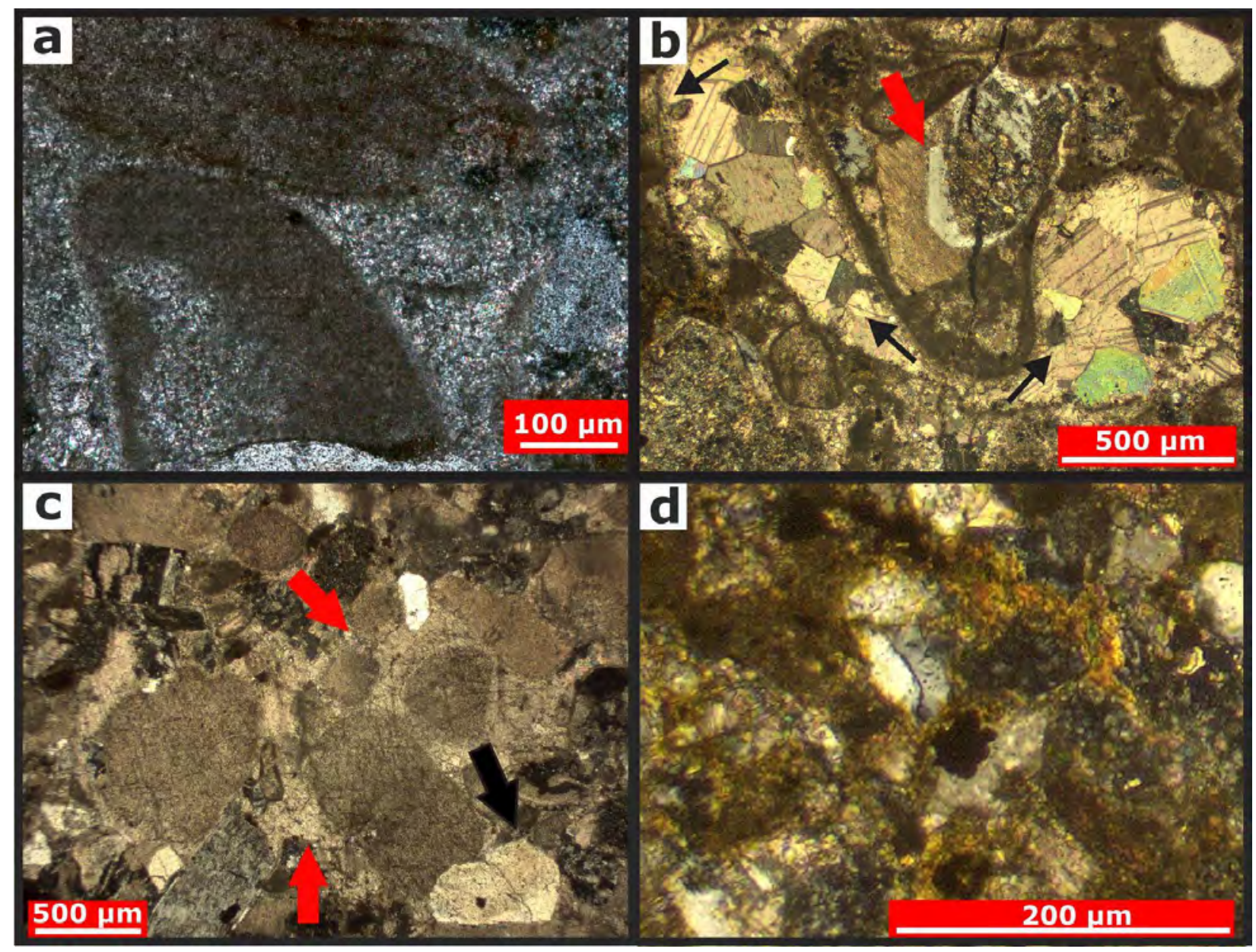

Figura 5.21a [NX,10X]: Cemento microesparítico obliterando la porosidad intergranular. Sector inferior de la sucesión terrígena-mixta en la sección APS (muestra APS2). b) [NX,4X]: Cemento macroesparítico drusiforme obliterando totalmente la porosidad móldica. Las flechas negras indican el incremento del tamaño de los cristales dentro del precipitado. Nótese la presencia de cemento de feldespato autigénico creciendo en continuidad óptica sobre un clasto de feldespato (flechas rojas). Tramo medio a superior de la sucesión en la sección ATW (muestra ATW5). c) Cemento macroesparítico con textura sintaxial (flechas rojas), acompañado por cemento de feldespato autigénico (flecha negra). Muestra PLE2C. d) [NX,4X]: Cemento de argilomineral ocluyendo la porosidad intergranular. Tramo inferior de la sucesión carbonática del perfil ALV (muestra ALV5B). 


\subsection{2-III: Clasificación de las areniscas}

De acuerdo con los criterios propuestos por Folk et al. (1970), las areniscas terrígenas de la sucesión terrígena-mixta y de la sucesión carbonática se caracterizan por presentar una relación feldespatos/líticos $(F / L)<$ a 1 (tabla 3a y figura 5.22). Abarcan a las psamitas de los tramo medio a superior de la sucesión terrígena-mixta y del sector inferior a medio de la sucesión carbonática. En todos los casos las areniscas están enriquecidas en fragmentos líticos volcánicos provenientes de volcanitas ácidas, el feldespato (plagioclasa > feldespato potásico) es más abundante que el cuarzo, y ambos se encuentran en menor proporción que los fragmentos líticos (Q: 17-26\%; F: 28-40\%; L: 41-45\%). Según Dott (1964) modificado por Pettijhon et al. (1972) estas psamitas se corresponden a arenisca y vaque lítico, mientras que para Folk et al. (1970) a litoarenitas feldespáticas. De acuerdo con Scasso y Limarino (1997), las litoarenitas feldespáticas se originan debido a la disgregación mecánica de los fragmentos líticos y a la eliminación de los clastos de mayor inestabilidad química. Dentro del espectro de areniscas líticas volcánicas este grupo posee una madurez mineralógica intermedia, dado su contenido de cuarzo y feldespato y la nula participación de líticos altamente inestables (e.g. piroclastos).

En lo que respecta a las areniscas con alto contenido de elementos intracuencales, del análisis de las muestras de la tabla 3b puede indicarse que en la sucesión terrígena-mixta existen psamitas mixtas con rangos variables de componentes intracuencales (CI) cuyos valores límites se sitúan entre 17 y 65\%. En la mayoría de los casos se observa un predominio de los fragmentos esqueletales sobre los no esqueletales, siendo los bioclastos más representados los restos de bivalvos y ¿algas rojas? (tabla 2b y figura 5.19a). Solo en una baja proporción de areniscas se identifica un mayor contenido de componentes no esqueletales respecto a los esqueletales, siendo los peloides los más frecuentes (tabla 2 b y figura $5.20 a$ ).

En lo que respecta al contenido de componentes extracuencales (CE), se identifican dos grupos, uno cuya relación de $F / L$ es $<$ a 1 , y otro grupo con una relación $F / L>$ a 1 (tabla 3b y figura 5.22). En las areniscas del primer grupo se encuentran las psamitas de los tramos medio a superior del sector terrígeno-mixto, con la misma 
tendencia composicional que su contraparte terrígena (Q: 17-30\%; F: 26-33\%; L: 38-52\%). De acuerdo con el contenido de CE las mismas se ubicarían dentro del campo de las arenisca y vaques líticos, según Dott (1964) modificado por Pettijhon et al. (1972), y en el campo de las litoarenitas feldespáticas de acuerdo con Folk et al. (1970; tabla 3b-I y figura 5.22).

El segundo grupo de areniscas cuya relación $\mathrm{F} / \mathrm{L}$ es $>$ a 1 se distribuye en el tramo inferior a superior de la sucesión terrígena-mixta. Estas areniscas presenta abundante contenido de feldespatos (plagioclasa> feldespato potásico), fragmentos líticos volcánicos, entre los que predominan los derivados de volcanitas ácidas, y relaciones Q/F < a 1 (Q: 15-34\%; F: 35-60\%; L: 20-35\%). Teniendo en cuenta solamente el contenido de CE estas psamitas se ubicarían en los campos de arenitas arcósicas y vaque feldespático de acuerdo con Dott (1964) modificado por Pettijhon et al. (1972), y según Folk et al. (1970) en el campo de las feldarenitas líticas (tabla 3b-II y figura 5.22).

En lo que respecta al área de aporte, se volcaron en los diagramas QtFLi y QmFLt de Dickinson et al. (1983) todas las muestras de psamitas con un contenido de matriz+cemento $<25 \%$, correspondientes a la sucesión terrígena-mixta (figura 5.23, ver tabla 2). A partir de los datos ploteados en el diagrama QtFLi de Dickinson et al. (1983) se observa que las areniscas terrígenas y mixtas se ubican dentro del campo de arco magmático (figura 5.23a). Las mismas se distribuyen de preferencia dentro del campo de arco magmático transicional y en mucha menor medida en el campo de arco disectado. En este sentido la mayoría de las arenitas líticas, correspondientes al tramo medio a superior de la sucesión terrígena-mixta se ubican dentro del ámbito de arco transicional. La excepción la cumplen dos ejemplares que se ubican en el límite entre ambos campos (muestras APS2 y PLE2C, ver tabla 3a-II). Aparecen acompañados por la mayor parte de las arenitas feldespáticas correspondientes al sector inferior a superior de la sucesión terrígenamixta. Mientras que solo una muestra de arenita arcósica del tramo superior se encuentran en el sector de arco disectado (muestra APS3, ver tabla 3b-II). 
Por otra parte, cuando las modas detríticas son volcadas en el diagrama QmFLt Dickinson et al. (1983) (figura 5.23b) se percibe que las muestras continúan ubicándose en los campos de arco transicional y disectado, pero en este caso con una mayor participación en el sector de arco disectado y en el límite entre ambos campos. De esta forma se distingue un mayor contenido de arenitas líticas y arcósicas dentro del campo de arco disectado (muestras APS2 y APS3) y en el límite entre ambos campos (muestras PLE2C, ATW6, CS2, ver tablas 3a-I, 3b-I y II), todos correspondientes al sector medio a superior de la sucesión terrígenamixta.

A partir de la composición, clasificación y procedencia de las areniscas se sugiere que el aporte de material extracuencal fue desde un arco magmático ácido a intermedio, anterior a la sedimentación de la sucesión terrígena-mixta (véase apartado 5.2.2.I). En primera instancia el suministro fue desde un arco magmático transicional (tramo inferior a medio) para luego evolucionar de forma gradual a un arco disectado hacia el sector medio a superior (secciones PLN, PLE, APS y ATW). 


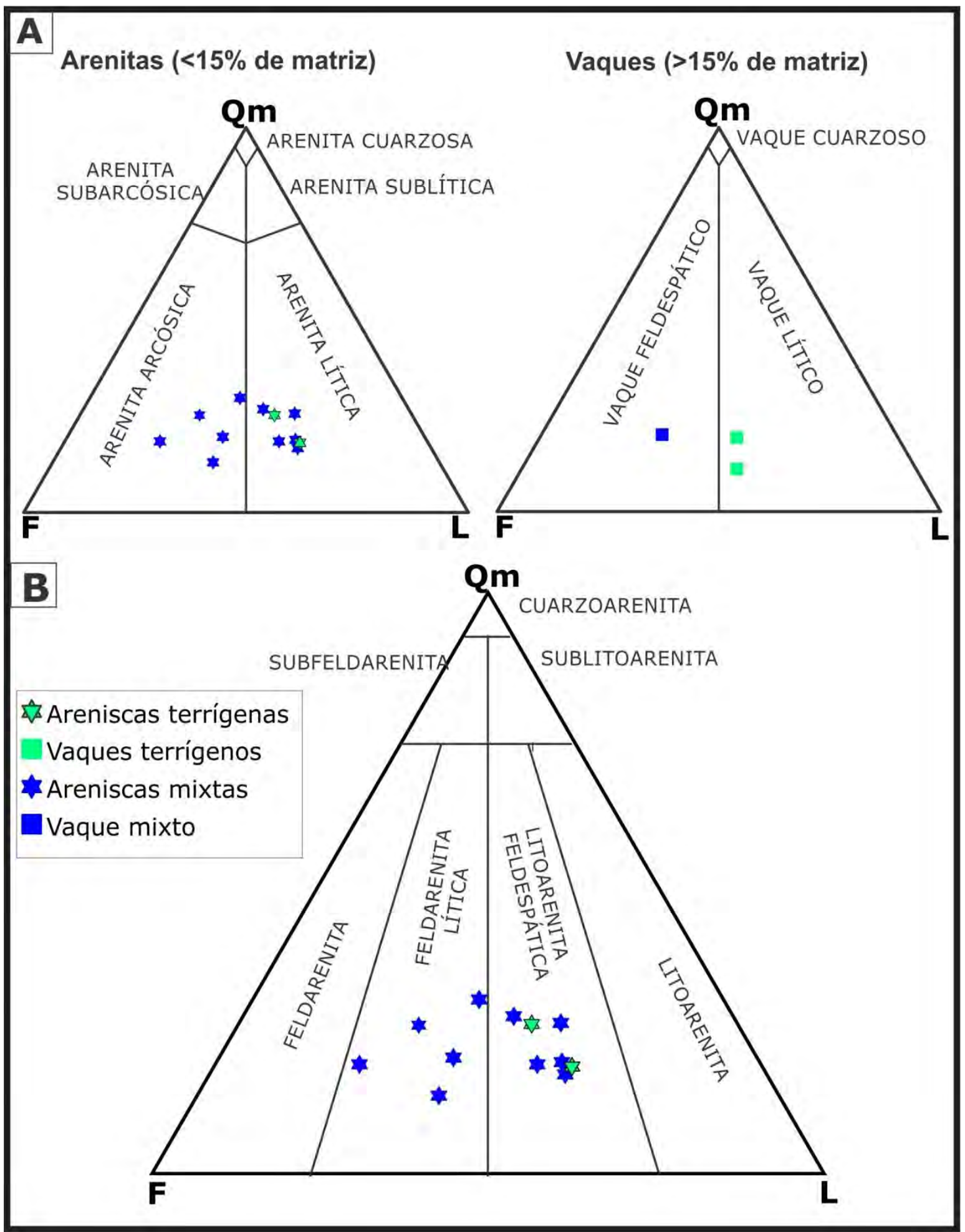

Figura 5.22a: Diagrama clasificatorio QFL de Dott (1964) modificado por Pettijhon et al. (1972). Qm: cuarzo monocristalino, F: feldespato total, L: líticos totales+ cuarzo policristalino. Figura 5.22b: Diagrama clasificatorio QmFL de Folk et al. (1970). Qm: cuarzo monocristalino, F: feldespato total, L: líticos totales+ cuarzo policristalino. 


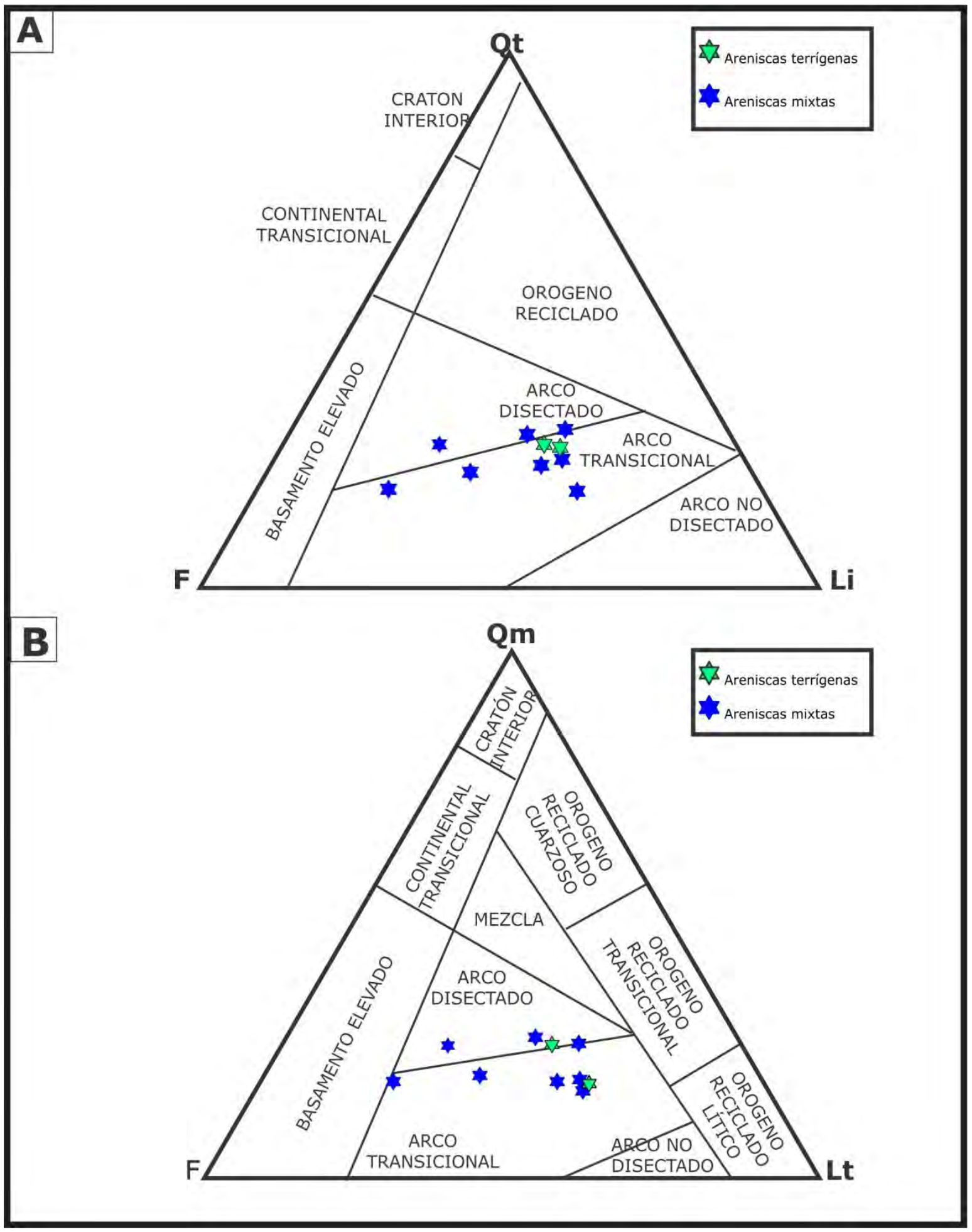

Figura 5.23a: Diagrama QtFLi de discriminación del ambiente tectónico en el área de aporte tomado de Dickinson et al. (1983). Qt: cuarzo monocristalino (Qm)+cuarzo policristalino (Qp); F: feldespato total; Li: líticos totales. Figura 5.23b: Diagrama QmFLt de discriminación del ambiente tectónico del área de aporte tomado de Dickinson et al. (1983). Qm: cuarzo monocristalino; F: feldespato total; Li: líticos totales+ Qp. 


\subsection{3: Análisis de argilominerales en calizas y areniscas}

Al igual que el análisis petrográfico sobre calizas y areniscas, el estudio del contenido de argilominerales brinda mayor información acerca de la constitución de las sedimentitas de la sucesión carbonática y de la sucesión terrígena-mixta. Si bien esta información de la fracción fina no es fundamental para la definición de las litofacies, es de importancia para establecer la composición de los minerales arcillosos presentes en su matriz y cemento, así como también de los argilominerales a los cuales se alteran los clastos lábiles (feldespatos y líticos volcánicos).

Para este análisis se realizaron estudios difractométricos de rayos $X$ en un total de veintiséis muestras pertenecientes a ambas sucesiones, veintiuno de ellas corresponden a calizas y cinco a areniscas mixtas y terrígenas (ver Anexo II). Dentro de cada perfil sedimentológico se muestrearon niveles correspondientes al tramo inferior a superior de la sucesión carbonática y otros del sector inferior a superior de la sucesión terrígena-mixta (tablas 4a-b).

La metodología llevada a cabo para la preparación de la muestra, las condiciones del registro, el análisis cualitativo y semicuantitativo se detallan en el apartado 2.5.2. Para la identificación de los componentes mineralógicos se realizaron difractogramas sobre muestras totales de polvos no orientados. Las especies minerales encontradas han sido, en orden de abundancia decreciente, calcita, cuarzo, plagioclasa, feldespato potásico, argilominerales y otros minerales en los que se incluye dolomita (tabla 4).

Como se describiera en el apartado 5.2.1 la calcita se presenta en proporciones muy abundantes dentro de la sucesión carbonática (tabla 4a). El cuarzo prosigue con contenidos que varían entre abundantes y muy escasos en el tramo inferior a medio de la sucesión, a escasos a traza hacia el tramo medio a superior (tabla 4a). Esta abundante proporción de cuarzo en el sector inferior a medio podría estar reflejando el contenido de líticos volcánicos junto con el de las variedades de cuarzo presentes (ver apartado 5.2.1-1, c-terrígenos). En orden decreciente suceden en este sector los feldespatos con proporciones escasas a traza, raramente se 
presentan en el tramo medio a superior. En todos los casos, la plagioclasa domina respecto al feldespato potásico (tabla 4a). Por su parte, los argilominerales aparecen con contenidos que oscilan entre muy escasos a ausentes a lo largo de la sucesión (tabla 4a).

Del total de las muestras analizadas se seleccionaron 9 ejemplares del tramo inferior a medio y uno del sector medio a superior de la sucesión, en las que se determinó la presencia de las siguientes especies de argilominerales: illita (I), interestratificado illita-esmectita (I/S), caolinita (K), clorita (C), esmectita (S) e interestratificado caolinita-esmectita $(\mathrm{K} / \mathrm{S})$, en orden decreciente de abundancia (tabla 4a). En líneas generales la illita y el I/S son los minerales de arcilla más abundantes y en conjunto conforman el 58 a $99 \%$ del total de las muestras analizadas. Le siguen la caolinita y la clorita con contenidos del $10 \%$ hasta traza, aunque excepcionalmente la caolinita puede representar el $28 \%$ del total en el tramo medio a superior de la sucesión (ACN9b, ver tabla 4a). Luego aparece la esmectita con una baja participación en toda la sucesión (contenidos del $5 \%$-ausente). Por último, se presenta el interestratificado caolinita-esmectita (K/S) con valores del $2 \%$ hacia el sector medio a superior de la sucesión (tabla $4 a$ ).

En lo que respecta a la sucesión terrígena-mixta se analizaron areniscas y vaques terrígenos líticos (muestras PLE 2D, APS1 y ATW2, ver tabla 4b) y areniscas mixtas arcósicas (muestras PLE4B y PLW1, ver tabla 4b). A diferencia de lo observado mediante petrografía en el análisis de polvos no orientados el componente mayoritario en estas litologías resulta ser la calcita, con valores muy abundantes a abundantes (contenidos mayores al 50\% hasta el 25\% del total), seguido por el cuarzo con abundante participación (contenidos del 25 al 50\%, tabla 4b). Estos elevados contenidos de calcita, tanto en psamitas terrígenas como mixtas, podrían ser atribuidos al aporte de carbonato de calcio por parte de las partículas esqueletales y no esqueletales, las proporciones de cementos carbonático presentes en estas psamitas (ver tablas 2a-b) y el contenido de fango carbonático. Por su parte, la abundante participación de cuarzo dentro de estas areniscas podría estar relacionada con el contenido de sílice aportado por los líticos volcánicos y por las variedades de cuarzo presente en las mismas. En orden decreciente de abundancia prosiguen los feldespatos en moderada a muy escasa cantidad (raramente 
ausentes), siendo en todos los casos la plagioclasa predominante sobre el feldespato potásico (tabla 4b). Por último, los argilominerales se encuentran en muy escasa cantidad en toda la sucesión y sólo en dos muestras (PLE2D y ATW2) se identificaron trazas de dolomita (tabla 4b).

En general, en las psamitas terrígenas y mixtas los minerales arcillosos más abundantes son la illita y el interestratificado illita-esmectita y en conjunto conforman el 68 al $90 \%$ del total (tabla 4b). Solo en un ejemplar del tramo inferior de la sucesión el I/S no está presente (muestra APS1, ver tabla 4b). Le siguen en abundancia la clorita y la caolinita con valores del 15 al $2 \%$ y por último la esmectita con contenidos del 5 al 2\%, raramente $10 \%$ (tabla 4b).

\subsection{3-I: Argilofacies}

Sobre la base de la presencia, tipo y cantidad relativa de argilominerales en las muestras analizadas, fueron definidas tres argilofacies o asociaciones de minerales de arcillas. Su codificación se estableció de acuerdo a las proporciones relativas con las que se presentan cada uno de los argilominerales mejor representados dentro de la unidad y cómo éstos se asocian entre sí. En la argilofacies A1, la illita resulta la especie más abundante respecto a I/S, caolinita o esmectita (ILL>I/S, O K O S). Se encuentra dividida en tres subargilofacies, S1, S2 y S3. Por su parte, la argilofacies A2 presenta iguales proporciones de illita respecto a I/S (ILL=I/S); y A3 contenidos de illita menores a los de I/S (ILL<I/S; tabla 4c). 


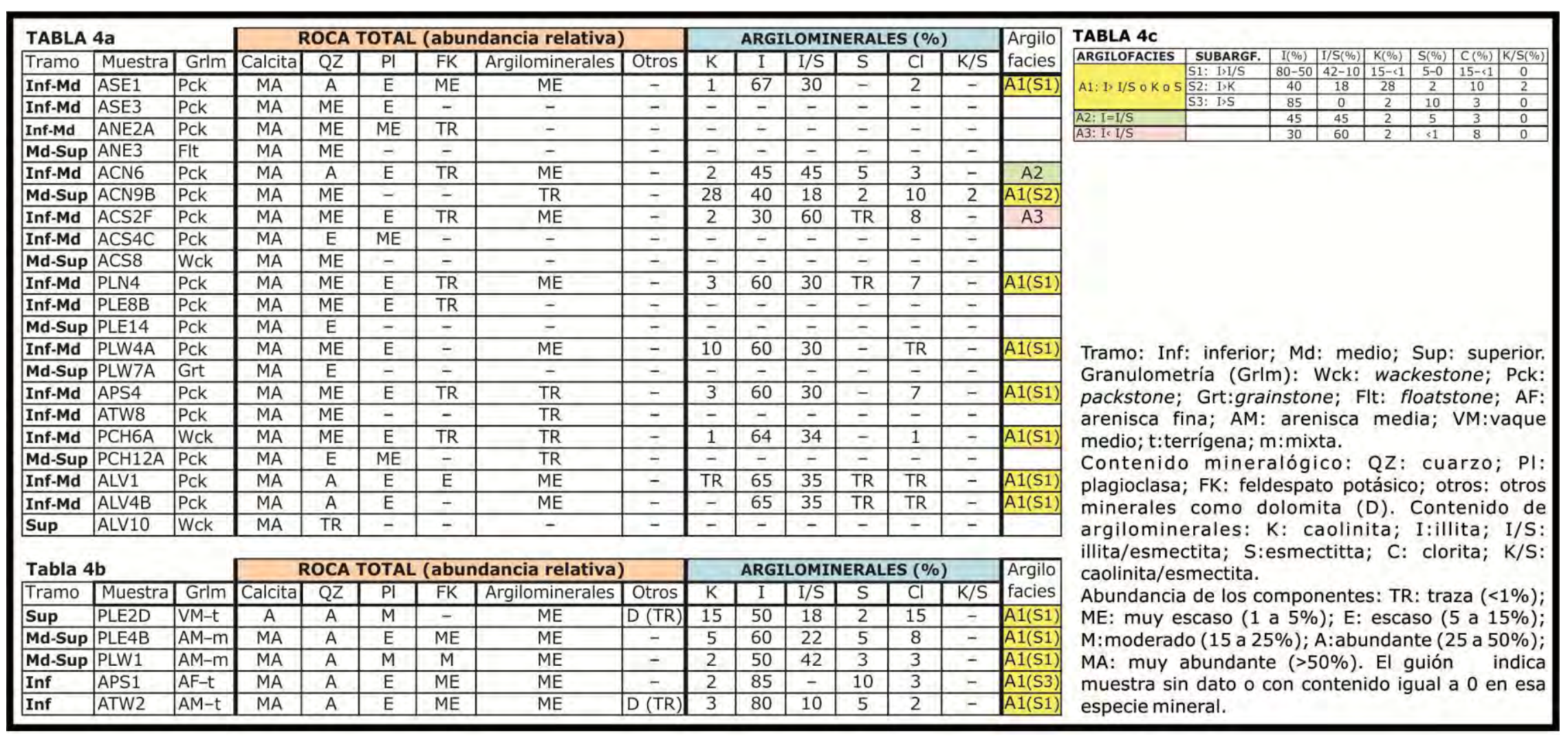

Tabla 4a: Composición mineralógica de las calizas de la sucesión carbonática determinada mediante el análisis por difracción de rayos X, acompañada por las argilofacies reconocidas dentro de esta sucesión carbonática. Tabla 4b: Composición mineralógicas de las psamitas terrígenas y mixtas obtenida mediante el análisis por difracción de rayos $\mathrm{X}$, acompañada por las argilofacies reconocidas dentro de esta sucesión terrígena-mixta. Tabla 4c: Proporciones mineralógicas de las argilofacies y subargilofacies (subargf.) identificadas. 


\section{Argilofacies A1-Subargilofacies S1}

Esta subargilofacies está integrada por illita como componente mayoritario (80$50 \%$ ), junto a cantidades menores de I/S (42-10\%), valores discretos de caolinita y clorita (15\%-traza) y muy bajos de esmectita ( $\leq 5 \%$; tabla 4 c y figura $24 a$ ). La misma muestra una amplia distribución en la zona de estudio tanto dentro de la sucesión carbonática como en el sector terrígeno-mixto. En la primera se presenta en el tramo inferior a medio de la sucesión (tabla 4a), mientras que en el sector terrígeno-mixto aparece desde el tramo inferior al superior (tabla 4b).

\section{Argilofacies A1-Subfacies 52}

Dicha asociación se caracteriza por presentar a la illita como el componente mejor representado (40\%), acompañado por valores menores de caolinita (28\%), junto con contenidos discretos de I/S y Cl (<20\%) y escasa participación de esmectita y K/S ( $<5 \%$; tabla 4c). Esta subargilofacies solo se encuentra en el sector medio a superior de la sucesión carbonática dentro del perfil ACN (tabla 4a).

\section{Argilofacies A1-Subfacies S3}

Esta subargilofacies se caracteriza por presentar los mayores valores de illita (85\%), acompañados por un bajo contenido de esmectita (10\%) y escasa cantidad de clorita y caolinita ( $\langle 5 \%$; tabla $4 c$ y figura $5.24 b$ ). Se presenta solo en una sección dentro del sector inferior de la sucesión terrígena-mixta (tabla 4b). 


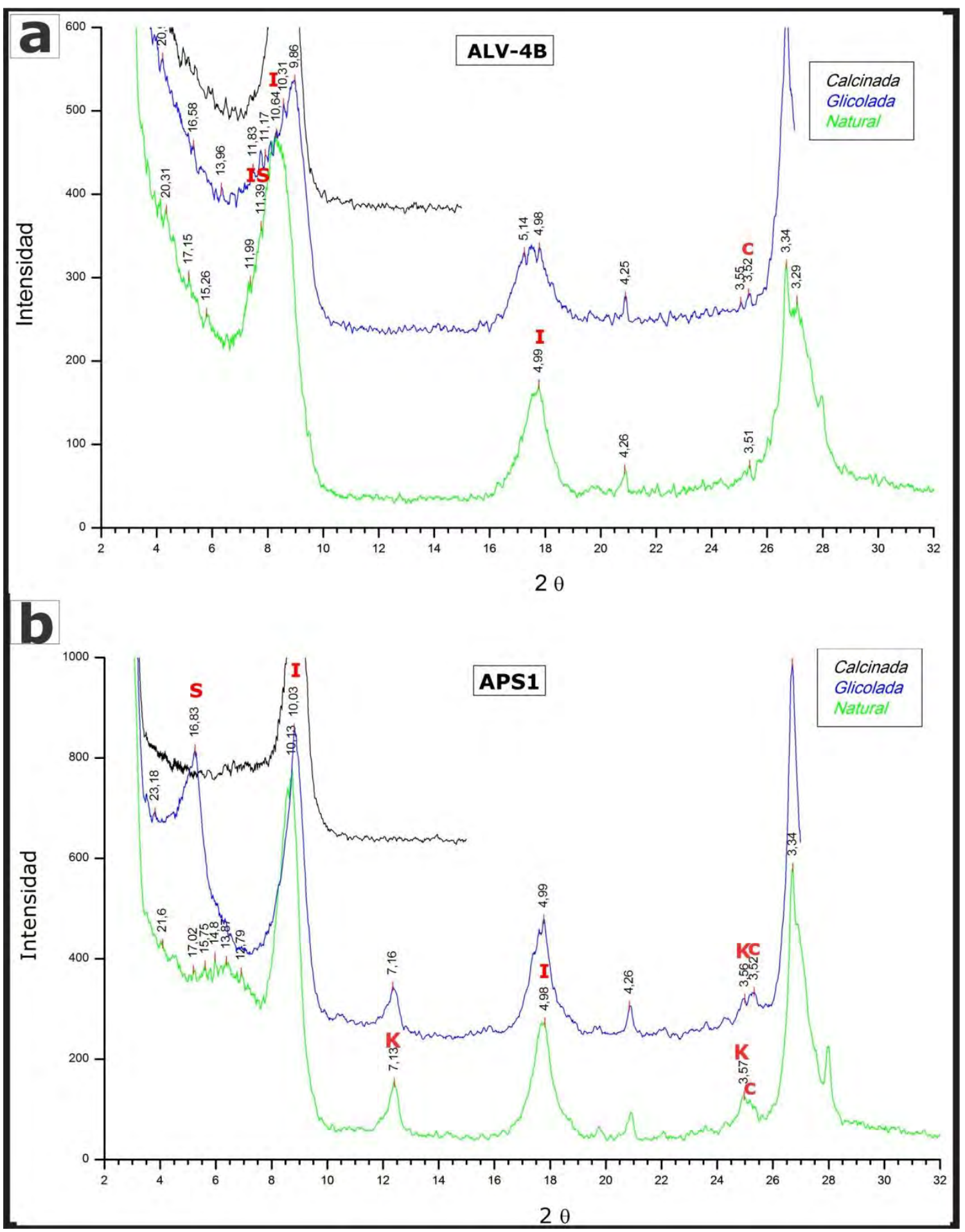

Figura 5.24: Argilofacies A1. a) Difractograma de la subargilofacies S1, compuesta principalmente por illita (I), interestratificado illita-esmectita (IS) y clorita (C). Muestra de la sucesión carbonática. b) Difractograma típico de la subargilofacies S3, conformada principalmente por illita (I), esmectita (S), clorita (C) y caolinita (K). Muestra de la sucesión terrígena-mixta. 


\section{Argilofacies A2}

En esta argilofacies las proporciones de illita e I/S son iguales (45\%) y se encuentran acompañadas por escaso contenido de caolinita, clorita, y esmectita (<10\%; tabla 4c y figura 5.25). Se distribuye únicamente en el tramo inferior a medio de la sucesión carbonática dentro de la sección ACN (tabla 4a).

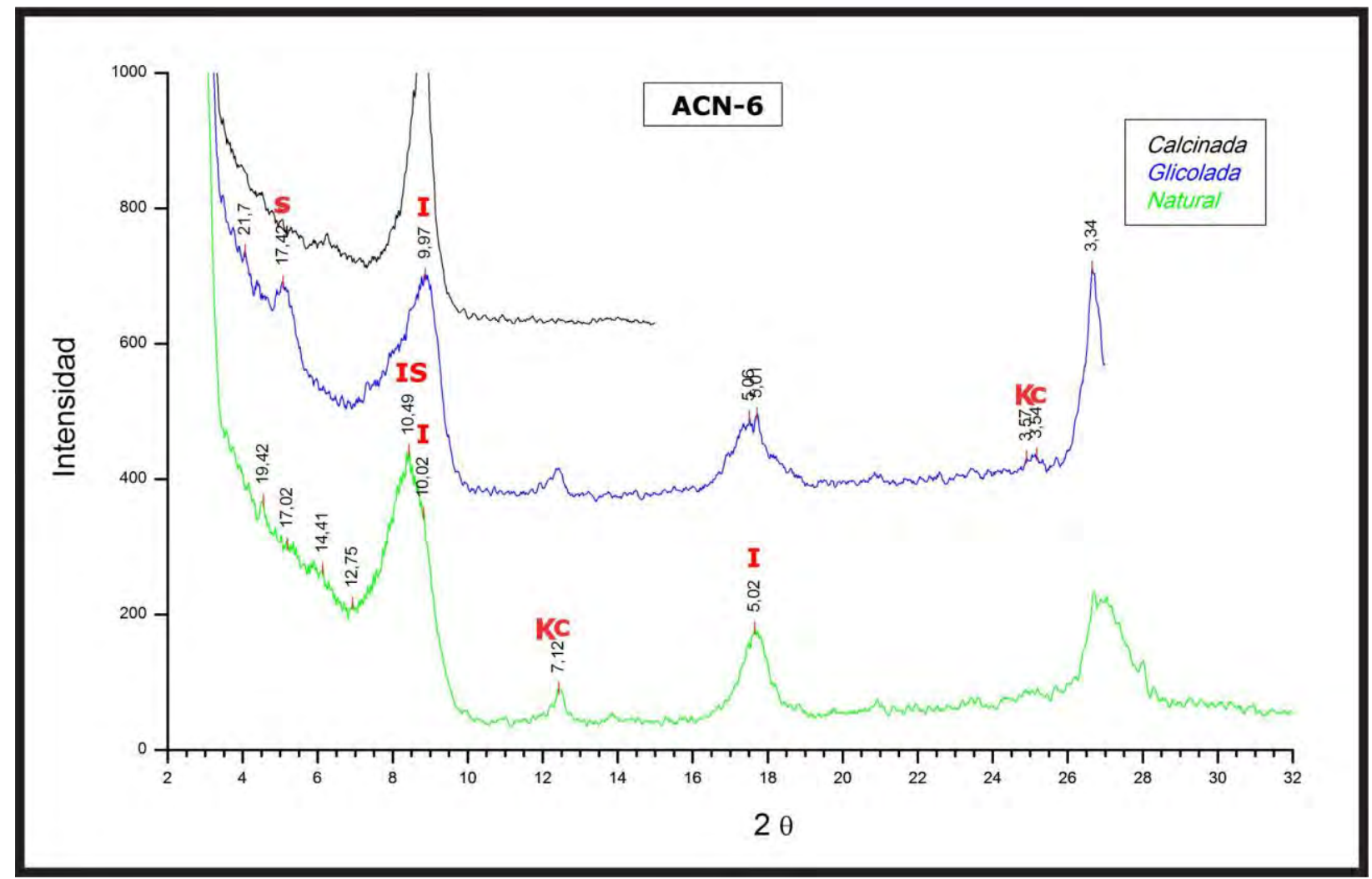

Figura 5.25: Difractograma típico de la argilofacies A2, conformada principalmente por illita (I), interestratificado illita-esmectita (IS), clorita (C), caolinita (K) y esmectita (S). Muestra de la sucesión carbonática.

\section{Argilofacies A3}

Esta asociación mineral se caracteriza por presentar al interestratificado illita-esmectita como componente mayoritario (60\%), acompañado por contenidos menores de illita (30\%) y baja participación de clorita, caolinita y esmectita $(<10 \%)$. Se encuentra solo en el tramo inferior a medio de la sucesión carbonática, en el perfil ACS (tabla 4a). 


\subsection{3-II: Consideraciones acerca del contenido de argilominerales en calizas y areniscas}

De acuerdo con la distribución de las argilofacies analizadas, puede observarse un predominio de la argilofacies A1 a lo largo de las sucesiones carbonática y terrígena-mixta, denotando una abundante proporción de illita respecto a los otros argilominerales. Se puede apreciar que las subargilofacies S1 y S3, con contenidos de illita del 85 a 50\%, se relacionan con el tramo inferior a medio de la sucesión carbonática y toda la sucesión terrígena-mixta en las secciones analizadas. Una excepción ocurre en el tramo inferior a medio de la sucesión carbonática donde las argilofacies A3 y A2 aparecen de forma localizada. En las mismas el contenido de illita disminuye discretamente con el incremento de I/S, siendo mayor las proporciones de I/S en la argilofacies A3. Finalmente, hacia el tramo medio a superior de la sucesión carbonática aparece la subargilofacies S2, donde la illita resulta el componente mayoritario pero con un contenido menor (40\%). En esta asociación la caolinita toma un papel preponderante por sobre el I/S.

Los minerales arcillosos presentes en una cuenca sedimentaria pueden tener dos orígenes: detrítico o autigénico. Los argilominerales detríticos se originan en un área externa a la cuenca sedimentaria y son transportados hacia la misma con leves modificaciones. Mientras que los minerales autigénicos se generan in situ por la neoformación o transformación de minerales preexistentes (Wilson y Pittman, 1977). Con lo expresado anteriormente se podría inferir que el dominio de illita a lo largo de la unidad junto con el abundante contenido de interestratificado I/S y la escasez de esmectita en toda la secuencia analizada podría estar relacionado con un origen diagenético de dichos argilominerales. Esta deducción se basa en que durante la diagénesis a medida que las condiciones de soterramiento aumentan (eogénesis tardía-mesogénesis) el agua contenida en el cristal de esmectita es removida $\mathrm{y}$ en su lugar se incorporan iones $\mathrm{K}^{+}$convirtiendo a este mineral primeramente en interestratificados de illita/esmectita y luego en illita (Tucker, 1991; Egger et al., 2002; Suresh et al., 2004, entre otros). De este modo podría considerarse que los líticos volcánicos parcialmente alterados presentes dentro de 
la sucesión terrígena-mixta y del sector carbonático (tramo inferior a medio) serían la posible fuente de esmectita del sistema (ver apartado 5.2.1-1, c-terrígenos; apartado 5.2.2-1, a-componentes extracuencales). Dicho supuesto radica en que el vidrio volcánico es inestables en condiciones superficiales o durante los primeros estadios diagenéticos (eogénesis temprana) por lo que tiende a ser alterado a argilominerales como la esmectita (Chamley, 1989; Tomita, 1993). Asimismo, el detrimento de las proporciones de illita hacia el tope de la unidad estaría en consonancia con el origen diagenético de este mineral. No obstante, la presencia de feldespatos alterados a argilominerales en las muestras analizadas junto con el escaso contenido de caolinita presente en la mayoría de las muestras, podrían indicar que parte de la illita proviene de la alteración de estos tectosilicatos.

Con respecto al elevado contenido de I/S presente en el tramo inferior a medio de la sucesión carbonática (argilofacies A2 y A3), el mismo también podría tener un origen diagenético derivado de la alteración de líticos volcánicos presentes en baja proporción dentro de estas calizas o en los niveles clásticos subyacentes de la sucesión terrígena-mixta (muestra CS2, ver tablas 2a y 3a-I, y Anexo Ia). Además, el bajo contenido de illita presente en este sector respecto a lo esperado para los niveles del tramo inferior de la sucesión carbonática, avala este supuesto. Asimismo, un posible origen detrítico se estipula para el contenido anómalo de caolinita presente en el tramo medio a superior de la sucesión carbonática (argilofacies S2), un sector con muy escaso contenido de cuarzo y argilominerales solo detectado por difracción de rayos X (ver tabla 4a). 


\section{3: Identificación e interpretación de las litofacies}

En esta tesis se definen e interpretan las facies sedimentarias de acuerdo al concepto de Reading y Levell (1966). Según estos autores, cada unidad litológica es asignada a una facies sobre la base de una observación objetiva. Los atributos esenciales para la identificación de las facies son la textura, a los que se le agregan el tipo de estructura sedimentaria y su escala, la geometría, el grado de bioturbación y el contenido fosilífero. En el caso particular de las sedimentitas carbonáticas con atributos litológicos similares a escala de campo y escasas estructuras sedimentarias, se utilizaron además las características texturales microscópicas siguiendo los criterios expuestos por Colombié y Strasser (2005), Bádenas y Aurell (2010), Benyoucef y Meister (2015), entre otros. Los atributos texturales considerados fueron la granulometría, la composición de los componentes principales (esqueleto y matriz), y el contenido de partículas carbonáticas aloquímicas, esqueletales y terrígenos.

Desde un punto de vista interpretativo, se asume que cada facies ha sido formada bajo determinadas condiciones de sedimentación, reflejando en cada caso un proceso particular (características de un flujo, su régimen, etc.).

De esta forma se puede alcanzar la interpretación de todas las rocas presentes en la sucesión carbonática y en el sector terrígeno-mixto, que corresponderían a litofacies (Reading y Levell, 1966). Entre las facies se incluye las rocas carbonáticas, silicoclásticas y mixtas con estructuras mecánicas. La diferenciación composicional entre rocas carbonáticas y terrígenas se registra en el análisis de facies no solo para comprender los procesos sedimentarios, sino también por su diferente significado en reconstrucciones paleoambientales y paleogeográficas (Zuffa, 1980; 1985).

Como último paso, se debe aclarar que el esquema de facies que se utilice puede resultar arbitrario, puesto que éste debe ser lo suficientemente manejable en cantidad de facies, pero por otro lado debe reflejar en forma completa las variaciones de la sucesión estudiada (Pirrie, 1988). La variabilidad que muestran las sedimentitas del intervalo estudiado hizo dificultoso arribar a un esquema general 
que involucre todos los parámetros considerados en forma completamente satisfactoria; de esta manera se establece que el esquema que aquí se propone para el mismo y cuya síntesis se encuentra en las figuras $5.26 a$ y b no resulta único ni está agotado. En el mismo se describen 27 litofacies y 6 subfacies, 16 de ellas se corresponden con facies carbonáticas, acompañadas por 3 subfacies, y 11 comprenden litofacies clásticas junto con 3 subfacies. Dentro de estas litofacies se incluyen los taxones identificados en el Anexo IIIa.

En primer lugar se describen las litofacies de las rocas carbonáticas conformadas por componentes aloquímicos, ordenadas según su granulometría decreciente y posteriormente las bioconstruídas (boundstone; figura 5.26a). De esta manera se identifican litofacies de floatstone (F), grainstone (GR), packstone (P), wackestone (W), estromatolitos (B) y framestone (FR). Para su codificación se utiliza la letra o las letras iniciales de la textura carbonática (W, P, GR, F, B, FR) acompañada por un adjetivo calificativo en el caso de las texturas aloquímicas, según el componente mejor representado dentro de la roca (Folk, 1962). De esta forma cuando el componente frecuente es un bioclasto se le agrega el adjetivo bioclástico, y cuando la partícula común es un peloide, ooide o intraclasto se utilizan los términos peloidal, oolítico e intraclástico, respectivamente. Las litofacies carbonáticas identificadas son: floatstone algal-oncolítico (Fa-on), floatstone bioclástico (Fb), floatstone intraclástico (Fi), floatstone oncolítico (Fon), grainstone bioclástico (GRb), grainstone a packstone oolítico (GRo), packstone a grainstone peloidal con ostras (Pp-oy), packstone bioclástico ( $\mathrm{Pb})$, packstone peloidal (Pp), packstone peloidal-bioclástico (Pp-b) dividida en subfacies 1 (Pp-b SF1) y subfacies 2 (Pp-b $\mathrm{SF2}$ ), packstone peloidal-bioclástico-intraclástico (Pp-b-i), packstone peloidal bioturbado (Pp-bi), wackestone a packstone con pellets (W-Ppe), wackestone bioclástico $(\mathrm{Wb})$, estromatolito planar $(\mathrm{BI})$ y framestone coralígeno (FRc) dividido en subfacies 1 (FRc-SF1).

Finalmente se describe e interpreta el segundo grupo de litofacies correspondiente a las rocas clásticas, listadas según su granulometría decreciente. De esta forma se reconocen litofacies psefíticas que incluyen a psefitas conglomerádicas (G), litofacies psamíticas (s) donde se encuentran areniscas y psamitas mixtas gruesas 
a finas. Nótese que para las facies clásticas se utiliza un estilo distinto de letra para su rápida identificación. Luego las diferentes litofacies aparecen descriptas según las estructuras mecánicas. El código utilizado para denominar a las estructuras responde al utilizado por Miall (1996). De esta forma las litofacies clásticas identificadas son: conglomerado con estratificación entrecruzada en artesa (Gt), conglomerado con estratificación entrecruzada planar $(\mathbf{G} \mathbf{p})$, conglomerado con estratificación horizontal (Gh), conglomerado masivo clasto sostén (Gmc), conglomerado masivo matriz sostén $(\mathbf{G m m})$, areniscas con estratificación entrecruzada en artesa (St), subfacies de areniscas conglomerádicas con estratificación entrecruzada en artesa (SGt), arenisca con estratificación entrecruzada monticular (Sx), arenisca con estratificación entrecruzada de bajo ángulo (S1), arenisca con estratificación horizontal ( $\mathbf{S h}$ ), subfacies de arenisca con laminación horizontal (Shl), arenisca y arenisca conglomerádica masiva ( $\mathbf{S m}$, SGm), subfacies de arenisca masiva con ondulas simétricas ( $\mathbf{S m w})$.

\subsection{1: Litofacies carbonáticas}

En este grupo se incluye a la mayor cantidad de litofacies reconocidas en la sucesión carbonática y con mayor distribución areal (Anexo I); siendo subordinada la presencia de las mismas en la sucesión terrígena-mixta. Las litofacies en cuestión se describen teniendo en cuenta en primer lugar sus caracteres megascópicos y luego sus atributos microscópicos (figura 5.26a). En general como veremos en las litofacies de wackestone, packstone y grainstone con pocos rasgos texturales megascópicos y escasas estructuras mecánicas y orgánicas, su definición se realiza mediante sus atributos microscópicos, siendo la caracterización a escala de campo acotada. Sin embargo, en las litofacies con abundantes rasgos texturales megascópicos y/o con presencia de estructuras mecánicas y orgánicas la descripción a escala de campo resulta detallada. 


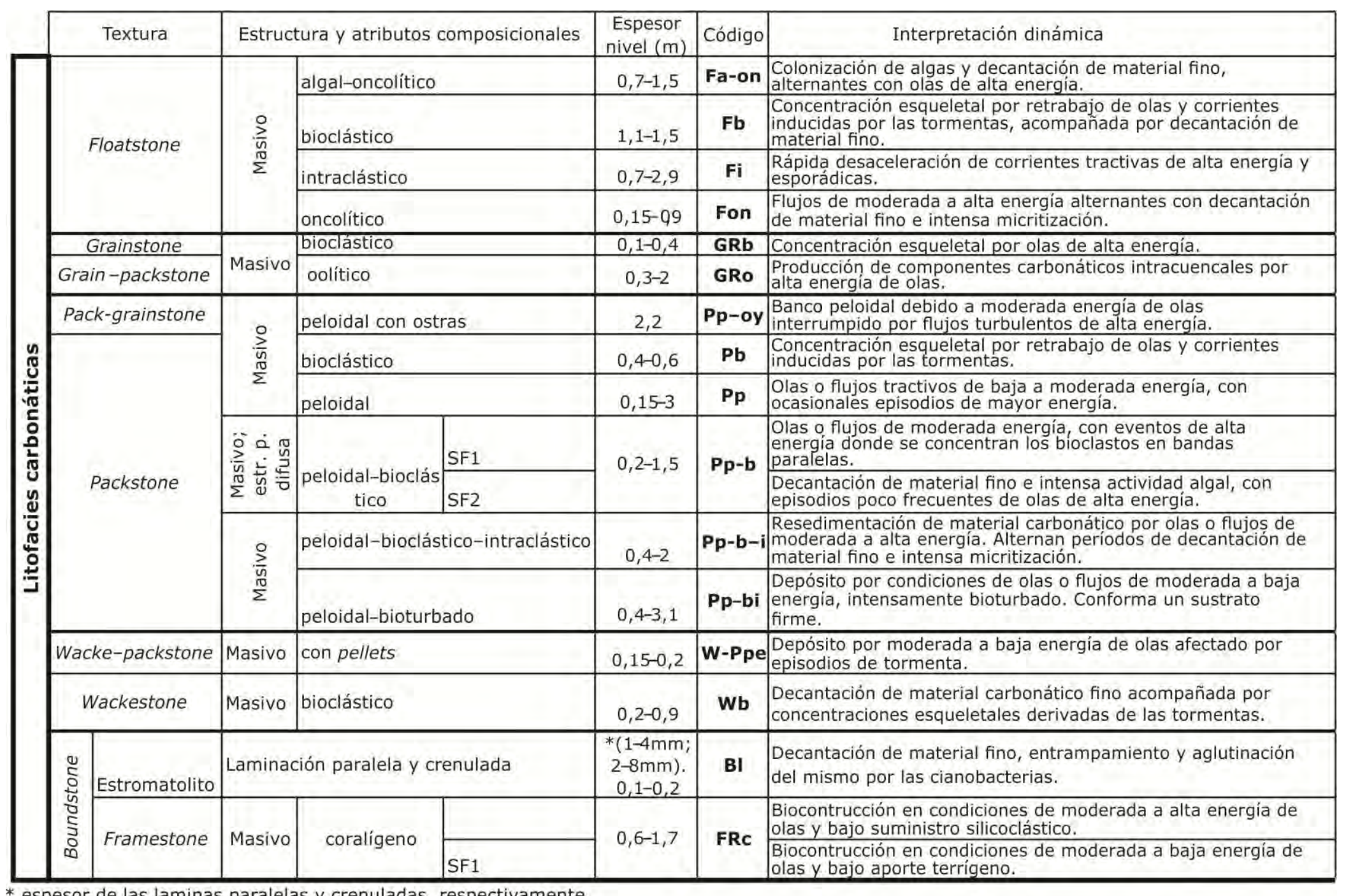

* espesor de las laminas paralelas y crenuladas, respectivamente.

Figura 5.26a: Facies carbonáticas de la sucesión carbonática y de la sucesión terrígena-mixta identificadas e interpretadas en este trabajo (estr.: estratificación; p.: paralela). 


\begin{tabular}{|c|c|c|c|c|c|c|c|c|c|c|c|}
\hline & \multicolumn{2}{|r|}{ Textura } & \multicolumn{3}{|c|}{ Estructura } & \begin{tabular}{|l|} 
Espesor set \\
estruc. $(\mathrm{cm})$
\end{tabular} & \begin{tabular}{|l} 
Espesor \\
nivel $(m)$
\end{tabular} & Geometría & $\begin{array}{l}\text { Otras } \\
\text { caract. }\end{array}$ & Código & Interpretación dinámica \\
\hline & \multirow{5}{*}{ 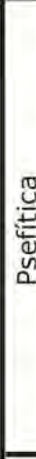 } & \multirow{5}{*}{ Conglomerado } & \multirow{2}{*}{$\begin{array}{l}\text { Estratificación } \\
\text { entrecruzada }\end{array}$} & \multicolumn{2}{|l|}{ en artesa } & 20 & $0,15-0,4$ & Cuña & - & Gt & $\begin{array}{l}\text { Migración de dunas gravo-arenosas 3D } \\
\text { en condiciones de tormenta. }\end{array}$ \\
\hline & & & & \multicolumn{2}{|l|}{ planar } & $40-110$ & $0,4-2$ & Tabular & - & $\boldsymbol{G}_{\mathbf{P}}$ & $\begin{array}{l}\text { Migración de dunas 2D gravosa por } \\
\text { corrientes inducidas por olas de alta } \\
\text { energía. }\end{array}$ \\
\hline & & & \multicolumn{3}{|c|}{ Estratificación horizontal } & $* 1-4$ & 0,6 & Tabular & $\begin{array}{l}\text { Fósiles } \\
\text { marinos } \\
\text { (FM) }\end{array}$ & Gh & $\begin{array}{l}\text { Depósito por flujos de alta descarga y } \\
\text { baja profundidad inducidos por las olas. }\end{array}$ \\
\hline & & & \multirow[b]{2}{*}{ Masiva } & \multicolumn{2}{|c|}{ clasto sostén } & - & $0,5-0,7$ & Tabular & - & Gmc & Depósitos por alta energía de olas. \\
\hline & & & & \multicolumn{2}{|c|}{ matriz sostén } & - & $0,8-1,75$ & $\begin{array}{l}\text { Lenticular } \\
\text { a irregular }\end{array}$ & \begin{tabular}{|c|}
$\begin{array}{c}\text { Flutes e } \\
\text { intraclastos } \\
\text { (base). FM }\end{array}$ \\
\end{tabular} & $G \operatorname{man}$ & $\begin{array}{l}\text { Depósito debido a la súbita } \\
\text { desaceleración de un flujo confinado. }\end{array}$ \\
\hline \multirow{9}{*}{ 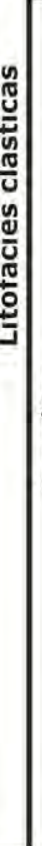 } & \multirow{9}{*}{ 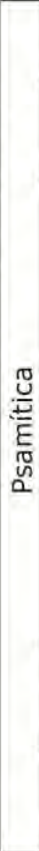 } & \multirow{7}{*}{ Arenisca } & \multirow{5}{*}{$\begin{array}{l}\text { Estratificación } \\
\text { entrecruzada }\end{array}$} & \multirow{2}{*}{ en artesa } & & $20-2$ & $0,1-0,5$ & \begin{tabular}{|l|}
$\begin{array}{c}\text { Tabular a } \\
\text { irregular }\end{array}$ \\
\end{tabular} & - & st & $\begin{array}{l}\text { Migración de ondulas a dunas 3D en } \\
\text { condiciones de buen tiempo o tormenta. }\end{array}$ \\
\hline & & & & & SF1 & $10-20$ & 0,4 & Cuña & - & SGt & $\begin{array}{l}\text { Migración de dunas gravo-arenosas 3D } \\
\text { generadas bajo condiciones de tormenta. }\end{array}$ \\
\hline & & & & monticul & & $10-60$ & $0,3-0,6$ & Tabular & - & $\mathbf{S x}$ & $\begin{array}{l}\text { Forma de lecho debido a flujos } \\
\text { oscilatorios puros o combinados en } \\
\text { condiciones de tormenta. }\end{array}$ \\
\hline & & & & planar & & $15-60$ & $0,4-1,1$ & $\begin{array}{l}\text { Tabular a } \\
\text { irregular }\end{array}$ & $\begin{array}{l}\text { Fósiles } \\
\text { marinos }\end{array}$ & Sp & $\begin{array}{l}\text { Migración de ondulas a dunas 2D } \\
\text { arenosas por olas o corrientes inducidas } \\
\text { por las mismas. }\end{array}$ \\
\hline & & & & $\begin{array}{l}\text { de bajo } \\
\text { ángulo }\end{array}$ & & $40-60$ & 2,3 & Irregular & Flutes & si & $\begin{array}{l}\text { Depósito debido a corrientes erosivas de } \\
\text { alta descarga y baja profundidad. }\end{array}$ \\
\hline & & & Estratifica & ación & & $* 1-4$ & $0,3-0,7$ & $\begin{array}{l}\text { Tabular a } \\
\text { irregular }\end{array}$ & $\begin{array}{l}\text { Fósiles } \\
\text { marinos }\end{array}$ & Sh & $\begin{array}{l}\text { Depósito debido a condiciones acueas de } \\
\text { alta descarga y baja profundidad. }\end{array}$ \\
\hline & & & & & SF1 & ${ }^{*} 0,1-0,2$ & 0,15 & Tabular & - & Shl & $\begin{array}{l}\text { Depósito por flujo de densidad inducido } \\
\text { por las tormentas. }\end{array}$ \\
\hline & & $\begin{array}{l}\text { Arenisca/ } \\
\text { arenisca cgl. }\end{array}$ & Masiva & & & - & $0,2-1,60$ & \begin{tabular}{|l} 
Tabular \\
irregular, \\
lenticular.
\end{tabular} & $\begin{array}{l}\text { Fósiles } \\
\text { marinos }\end{array}$ & $\begin{array}{c}\mathbf{S m} / \\
\mathbf{S G m}\end{array}$ & $\begin{array}{l}\text { Depósito por flujo de alta densidad o por } \\
\text { retrabajo biogénico post-depositación. }\end{array}$ \\
\hline & & Arenisca & $\begin{array}{l}\text { Masiva. Ocasic } \\
\text { ondulas simét } \\
\text { laminacion pa }\end{array}$ & $\begin{array}{l}\text { onales } \\
\text { ricas y } \\
\text { iralela }\end{array}$ & SF1 & - & $0,1-1,10$ & $\begin{array}{l}\text { Tabular, } \\
\text { irregular. }\end{array}$ & \begin{tabular}{|c|} 
Briznas \\
vegetales y \\
FM.
\end{tabular} & Smw & $\begin{array}{l}\text { Depósito por baja velocidad de olas y/o } \\
\text { flujos bidireccionales, homogeinizado por } \\
\text { bioturbación. }\end{array}$ \\
\hline
\end{tabular}

Figura 5.26b: Facies clásticas de la sucesión carbonática y de la sucesión terrígena-mixta identificadas e interpretadas en este trabajo (estruc.: estructura; caract.: características). 


\section{Floatstone:}

\section{Floatstone algal-oncolítico (Fa-on)}

Se compone de floatstone masivo con abundantes fragmentos algales, oncoides y escasos restos de gasterópodos y ostras. Los oncoides presentan envolturas con laminación difusa a nula cuyo espesor es menor al diámetro del núcleo (figura 5.27a). Los tamaños de estas partículas oscilan entre los 5 a $20 \mathrm{~mm}$. Las capas varían sus espesores entre los 0.7 a $1.50 \mathrm{~m}$ y poseen geometrías tabulares. El contacto con las facies inferiores es transicional y neto con las superiores. Lateralmente pasa hacia facies de packstone peloidal con ostras (Pp-oy). Esta facies caracteriza a la sección media y superior de la sucesión carbonática en el perfil PLN (Anexo Ia).

Petrografía: floatstone con restos de cianobacterias (Caulerpales) de bordes redondeados y oncoides con laminación difusa y núcleo de bioclasto (figura 5.4d). En menor medida se distinguen espinas y placas de equinoideo, restos de gasterópodos, ostras y bivalvos no ostreidos. Estos fragmentos esqueletales presentan bordes redondeados y suelen estar rodeados por marcadas envolturas micríticas (figura 5.27b). La matriz está constituida por abundantes partículas carbonáticas totalmente micritizadas que gradan a micrita homogénea, acompañada por calciesferas y escaso cemento microesparítico.

Interpretación dinámica: se infiere un fondo colonizado por algas que recubren los restos esqueletales alóctonos, bajo condiciones de sedimentación tranquila (Bádenas et al., 1993), acompañado por la decantación de material carbonático fino. Sustentan estas condiciones, el contenido de micrita homogénea presente en la facies y la micritización intensa de las partículas carbonáticas producto de la actividad algal (Tucker y Bathurst, 1990; Bádenas y Aurell, 2010). A su vez, la presencia de bioclastos con marcada abrasión señalaría la alternancia con olas de alta energía que transportan dichos restos hasta este sector y dan lugar al retrabajo de las cubiertas oncolíticas previas (Wright y Burchette, 1996). 


\section{Floatstone bioclástico (Fb)}

Está conformado por floatstone masivo con abundante fauna de serpúlidos coloniales (figura 5.27c) y valvas articuladas a desarticuladas de ostras (10 a 150 $\mathrm{mm}$ de largo). Las ostras de mayor tamaño presentan colonias de serpúlidos y ostras pequeñas adheridas. También se observan braquiópodos rhynchonellidos, espinas de equinoideos y colonia de corales dómicas en posición de vida con evidencias de bioerosión, o representadas como fragmentos. Los niveles presentan espesores que varían los 1.10 a $1.50 \mathrm{~m}$, geometrías tabulares a irregulares y un contacto neto y plano con la facies subyacente (arenisca masiva-Sm). El contacto con las facies superiores varía desde neto de morfología irregular a transicional, con las facies de arenisca masiva y framestone coralígeno (FRc), respectivamente. Esta litofacies solo se presenta en el tramo inferior a medio de la sucesión terrígenamixta en la sección PLN (Anexo Ia).

Petrografía: floatstone con valvas de ostras completas o como restos de bordes angulosos, y colonias de serpúlidos (figuras $5.10 \mathrm{~b}$ y $5.27 \mathrm{~d}$ ). Las valvas de ostras pueden presentar organismos incrustantes como cianobacterias (Caulerpales) o briozoos. En menor medida se identifican fragmentos de bordes angulosos de equinoideos y colonias de corales. La matriz está conformada por abundante micrita homogénea acompañada por un bajo contenido de feldespatos, líticos volcánicos y cuarzo monocristalino, junto con peloides y escasa microesparita.

Interpretación dinámica: el origen de esta facies estaría vinculado con eventos de tormenta en un ambiente de moderada a baja energía, por debajo del nivel de olas de buen tiempo. La presencia de ostras y serpúlidos adaptados a un modo de vida en sustrato duros a firmes (Bastida-Zavala y Salazar-Vallejo, 2000) permite suponer que esta fauna fue retrabajada por olas de tormenta en zonas costeras y depositada rápidamente en este ambiente por corrientes de retorno (Tucker y Wright, 1991). A medida que la intensidad de la tormenta disminuye el material carbonático fino decanta de la suspensión en los concentrados bioclásticos. Estas condiciones se sustentan con la ausencia de abrasión que presentan los bioclastos, la presencia de valvas articuladas a desarticuladas y el abundante contenido de 
micrita dentro del depósito (Kreisa y Bambach, 1982; Fürsich y Oschmann, 1993). A su vez la presencia de colonias de corales in situ indican que el mismo se encuentra dentro de la zona fótica (Wilson, 2005).

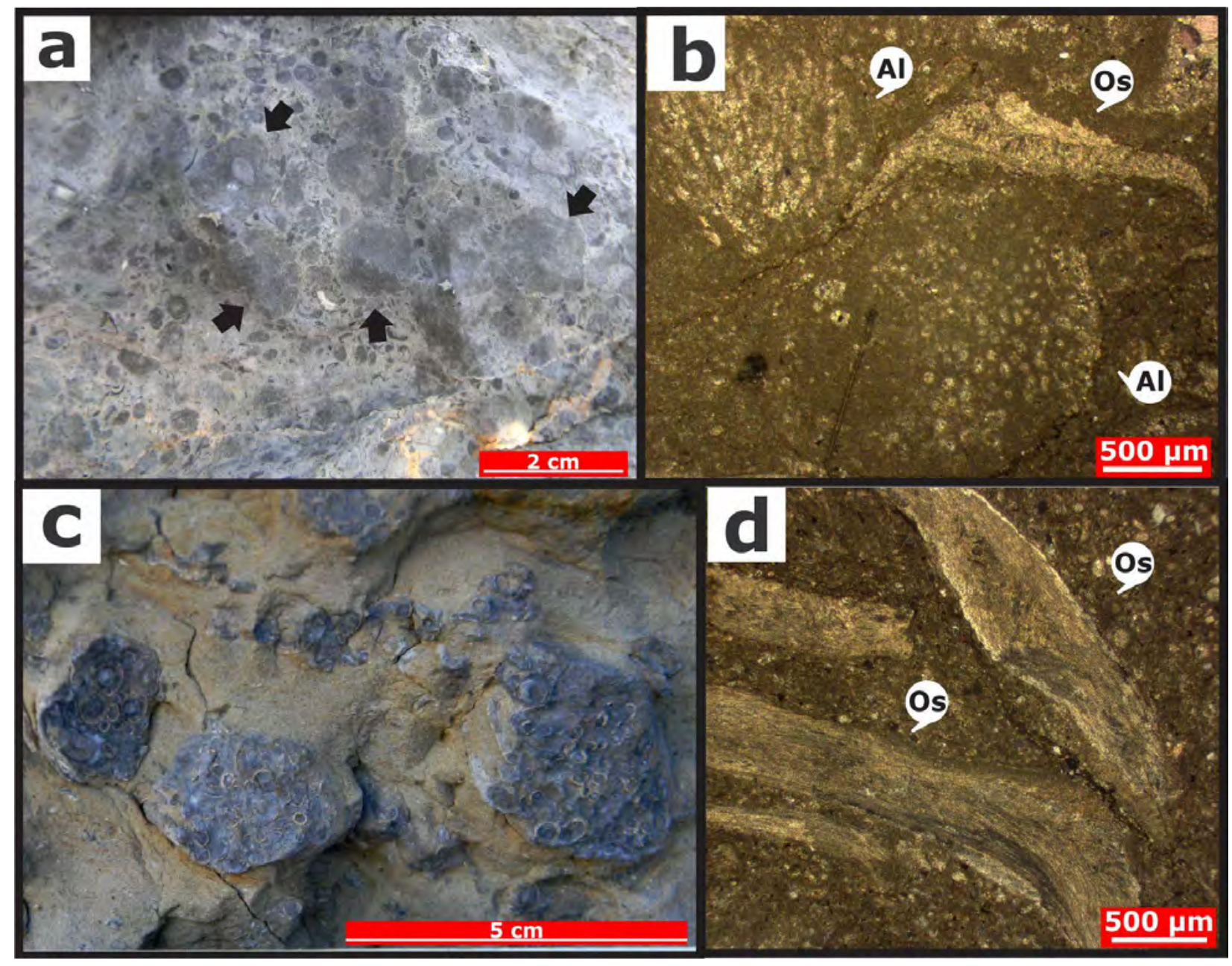

Figura 5.27: Litofacies de floatstone. a) Algal-oncolítico (Fa-o). Las flechas negras identifican los oncoides con laminación difusa a nula. b) $[\mathrm{NX}, 4 \mathrm{X}]$ : Restos de cianobacterias (Al) y ostras (Os) de la facies Fa-o. Nótese la marcada micritización que presentan las partículas. c) Colonias de serpúlidos en la facies de floatstone bioclástico (Fb). d) [NX,4X]: Restos angulosos de Os en la facies $\mathrm{Fb}$. Imágenes tomadas de la sección Arroyo Plomo Norte. 


\section{Floatstone intraclástico (Fi)}

Esta litofacies presenta una amplia distribución en el noreste de la zona de Malargüe, con notable disminución en importancia y espesor hacia el sudoeste (perfiles ASE a PLW-sección complementaria, ver apartado 4.5.3 del capítulo 4 y Anexo Ia). Se distribuye en el tramo inferior a medio de la sucesión carbonática y superior de la sucesión terrígena-mixta. Consta de floatstone masivo con intraclastos carbonáticos y en menor proporción de areniscas, subangulosos a subredondeados, de 0.3 a $80 \mathrm{~cm}$ de tamaño (son raros los intraclastos de $2 \mathrm{~m}$ de largo). En general los intraclastos carbonáticos provienen de las facies de packstone peloidal bioturbado ( $\mathrm{Pp}-\mathrm{bi})$, packstone peloidal con ostras (Pp-oy), packstone peloidal-bioclástico-intraclástico ( $\mathrm{Pp}-\mathrm{b}-\mathrm{i})$, floatstone bioclástico (Fb), framestone coralígeno (FRc) y otras litofacies de packstone no identificadas. En la sección PLW predominan los intraclastos de las litofacies Pp-b-i y Pp-bi, mientras que en las secciones ASE a PLN dominan los de las facies Fb y FRc. No obstante, los perfiles ASE y ACN pueden contener intraclastos de Pp-b-i y Pp-oy. En ambos casos se reconocen junto con intraclastos de areniscas. Están acompañados por restos de bivalvos, colonia de corales, de serpúlidos, amonites y clastos subredondeados a redondeados de líticos volcánicos y cuarzo de 5 a $30 \mathrm{~mm}$ (figuras 5.28a-b). Presenta pobre a muy pobre selección (figura 5.28c). Las capas tienen potencias de 0.70 a $2.90 \mathrm{~m}$, geometrías lenticulares a irregulares y contactos basales erosivos (figura $5.28 \mathrm{~d}$ ). En general se presentan junto con la facies de conglomerado matriz sostén masivo (Gmm).

Petrografía: floatstone masivo con intraclastos carbonáticos (figura 5.5b), acompañado por peloides, calciesferas, restos esqueletales redondeados (¿algas rojas?, ostras, equinodermos, gasterópodos, serpúlidos, y bioclastos indeterminados), ooides micríticos superficiales y clastos terrígenos (líticos volcánicos ácidos, feldespato y cuarzo monocristalino). Estos últimos pueden alcanzar mayores proporciones dentro de la facies, conformando un 20 a 30\% de la roca. El contenido de micrita homogénea y cemento microesparítico, esparítico granular y macroesparítico sintaxial oscila entre escaso a moderado (figura 5.28e). 


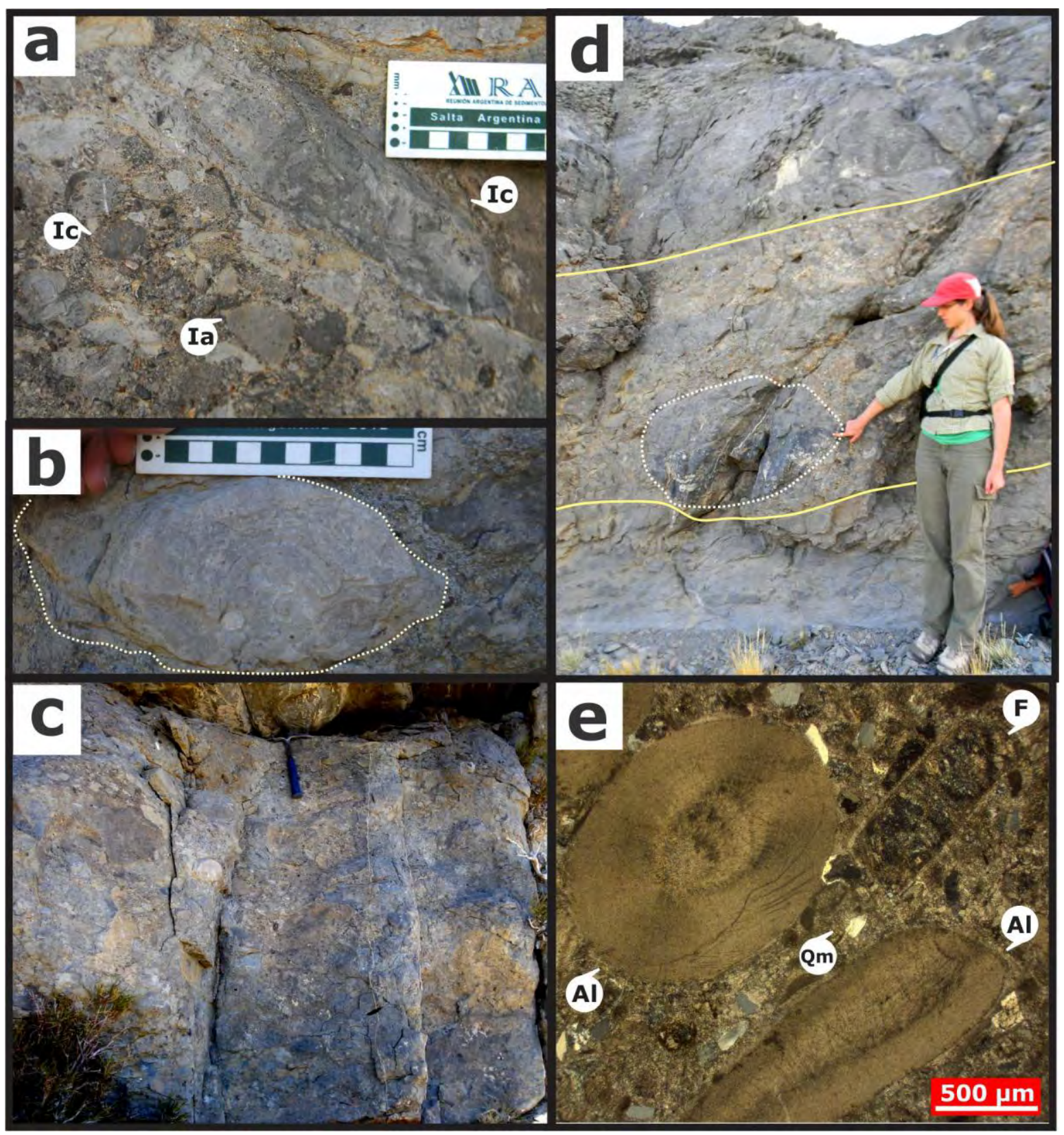

Figura 5.28: Litofacies de floatstone intraclástico (Fi). a) Intraclastos carbonáticos (Ic) y de areniscas (Ia), subangulosos a subredondeados. b) Intraclasto de la litofacies FRc. c) Pobre a muy pobre selección en la facies Fi (la piqueta mide $35 \mathrm{~cm}$ ). d) Contacto basal erosivo con la facies subyacente, se destaca la presencia de un Ic de la facies Pp-bi de $75 \mathrm{~cm}$ de largo (línea punteada).Las líneas amarillas marcan la base y el tope de la facies ( $\mathrm{Fi}$ ) respectivamente (la persona de escala mide $1.68 \mathrm{~m}$ ). e) [NX,4X]: Restos de calgas rojas? (Al), clastos de feldespato $(\mathrm{F})$, cuarzo monocristalino $(\mathrm{Qm})$ en Fi. Se destaca el moderado contenido de cemento microesparítico y esparítico y la escasa presencia de micrita homogénea. Los ejemplos de las figuras a, b y c son de la sección Arroyo Calabozo Norte, mientras que los de la figura d y e se corresponden a los perfiles Arroyo El Plomo Oeste y Arroyo Negro, respectivamente. 
Interpretación dinámica: se considera un origen relacionado a la rápida desaceleración de corrientes tractivas de alta energía y esporádicas, correspondientes a episodios de tormentas o flujos de gravedad (e.g. Bádenas et al., 1993; Aurell et al., 2009). Sustentan esta interpretación parámetros tales como su granulometría, selección, abundante contenido de matriz y la ausencia de una estructura sedimentaria. Asimismo, las características de los intraclastos indican que su resedimentación se produce en un sitio muy cercano al de depositación original de las facies (Pp-bi, Pp-b-i, Pp-oy, Fb y FRc). En este sentido, podrían derivar de la erosión y retrabajo de corrientes de alta energía sobre litofacies previas en ambientes someros (Flügel, 2010), o bien estar relacionados a la fracturación de dichas facies y posterior deslizamiento de sus fragmentos hacia zonas más profundas (Aurell et al., 2009).

\section{Floatstone oncolítico (Fon)}

Se trata de floatstone oncolítico masivo. Los oncoides están representados mayormente por formas simples, con envolturas laminadas y un núcleo conformado por valvas articuladas a desarticuladas de braquiópodos rhynchonellidos y telebratúlidos de tamaños variados (figura 5.29a). En menor cantidad se identifican formas compuestas con envolturas laminadas y dos o más núcleos de oncoides o valvas de braquiópodos. Tanto en las formas simples como compuestas la envoltura presenta un mayor espesor respecto al diámetro del núcleo. Los tamaños de estas partículas varían entre 10 a $80 \mathrm{~mm}$. Esta facies presenta espesores que oscilan entre los 0.15 a $0.90 \mathrm{~m}$ y geometrías que varían de tabulares a irregulares. El contacto con la facies subyacente es transicional y con la facies suprayacente es neto de morfología plana. Esta facies se encuentra en el tramo medio a superior de la sucesión carbonática dentro del perfil ANE (Anexo Ia).

Petrografía: floatstone masivo con abundantes oncoides tipo $\mathrm{C}$ y en menor cantidad tipo R (ver apartado 5.2.1-I y figuras 5.4a-c). También se identifican restos de braquiópodos y equinoideos de formas angulosas. La matriz está constituida por 
abundantes peloides que gradan a micrita homogénea a grumosa junto con foraminíferos con enroscamiento polymorphinido y escasa microesparita a esparita (figura 5.29b).

Interpretación dinámica: de acuerdo con el dominio de oncoides tipo C y la fauna presente se infiere un depósito generado por el retrabajo de flujos de alta a moderada energía en un ambiente marino somero (Logan et al., 1964; Brandano y Ronca, 2014). Asimismo, la intensa micritización que afecta a las partículas carbonáticas, junto con el abundante contenido de micrita indican la alternancia con períodos de sedimentación tranquila donde decanta el material carbonático fino (Tucker y Bathurst, 1990).

Grainstone:

\section{Grainstone bioclástico (GRb)}

Se trata de grainstone masivo con abundantes restos de ostras de tamaños que varían entre los 5 y $50 \mathrm{~mm}$, distribuidos sin una orientación preferencial (figuras 5.29 c y d). Además, contiene escasos clastos de líticos volcánicos, subredondeados a redondeados, cuyos tamaños oscilan entre los 5 a $20 \mathrm{~mm}$. Las capas son poco potentes $(0.10$ a $0.40 \mathrm{~m})$, con geometrías irregulares y contactos erosivos con las facies inferiores. Esta facies que resulta poco frecuente se presenta en el tramo inferior de la sucesión carbonática en la zona de Malargüe (perfil ASE, ver Anexo Ia), mientras que, en la zona de Bardas Blancas se ubica en el sector medio de la sucesión (sección ALV, ver Anexo Ib). 
Petrografía: grainstone con restos de ostras, equinodermos, gasterópodos y cianobacterias (Caulerpales) de formas subredondeadas a redondeadas. Están acompañados por peloides, ooides micríticos superficiales (Tipo 1; Strasser, 1986), intraclastos carbonáticos derivados de las facies subyacentes, y un bajo contenido de líticos volcánicos ácidos, feldespato y cuarzo. La presencia de micrita homogénea es escasa a nula, no obstante el contenido de microesparita, esparita granular y macroesparita sintaxial es moderado a abundante (figura 5.29e). Además se identifica escaso cemento silíceo.

Interpretación dinámica: comprende concentraciones esqueletales generadas por condiciones de alta energía de olas o flujos de alta energía. Evidencian esta afirmación su textura clasto soportada y la marcada abrasión de los restos esqueletales, asociada con el escaso contenido de micrita del depósito (Fürsich y Oschmann, 1993; Zeller et al., 2015).

\section{Grainstone a packstone oolítico (GRo)}

En esta facies de grainstone a packstone masivo la presencia de ooides se reconoce solamente mediante petrografía. No obstante tanto a escala megascópica como microscópica se distingue un bajo contenido de restos de gasterópodos, ostras, bivalvos no ostreidos, escasas espinas de equinoideos y fragmentos de colonias de corales. Los bancos tienen espesores que varían los 0.30 a $2.00 \mathrm{~m}$ y geometrías tabulares a irregulares. Posee contacto neto con la facies infrayacente. En el techo de algunos niveles se reconocieron trazas fósiles correspondientes a Thalassinoides paradoxidus. Esta facies se presenta en el tramo medio a superior de la sucesión carbonática en las secciones de la zona de Malargüe y de Bardas Blancas (ver Anexos Ia-Ib). En la zona de Malargüe se identifica una disminución del desarrollo de esta facies desde el sudeste hacia el noroeste. 
Petrografía: grainstone a packstone con abundantes ooides micríticos (Tipo 1; Strasser, 1986) normales y escasos superficiales (figuras 5.1a-b). En menor medida aparecen peloides, fragmentos de bioclastos, agregados de partículas carbonáticas, escasos oncoides con laminación difusa y pellets (figura 5.29f). Los bioclastos comprenden gasterópodos, bivalvos, cianobacterias (Caulerpales), espinas y placas de equinoideos. En la zona de Bardas Blancas se presentan de forma subordinada clastos de líticos volcánicos ácidos e intermedios, feldespato y cuarzo. El contenido de micrita homogénea es escaso a bajo y puede estar acompañada por foraminíferos con enroscamiento polimorphynido. Mientras que, los cementos fibroso isopáquico, microesparítico y esparítico granular se presentan en baja a moderada proporción.

Interpretación dinámica: se la interpreta como un banco carbonático desarrollado por la producción de componentes carbonáticos intracuencales bajo condiciones de alta energía de olas, en un ambiente marino por encima o en las cercanías del nivel de olas de buen tiempo (Pomar et al., 2002; Bádenas y Aurell, 2010). Sustentan esta interpretación la abundancia de ooides micríticos normales, la variedad de partículas esqueletales y no esqueletales presentes, acompañado por el bajo contenido de micrita en la facies y su textura clasto soportada (Strasser, 1986; Bádenas y Aurell, 2010).

\section{Packstone:}

\section{Packstone a grainstone peloidal con ostras (Pp-oy)}

Está constituida por packstone a grainstone masivo, con abundantes valvas de Ostras de gran tamaño(100 a $150 \mathrm{~mm}$ ), junto con fragmentos de colonias de corales, escasas espinas y formas completas de equinoideos, restos de gasterópodos y bivalvos no ostreidos. Las ostras están representadas por valvas completas desarticuladas y en menor medida articuladas, distribuidas sin una orientación preferencial, que pueden tener evidencias de bioerosión. Se observan dos concentraciones de bioclastos, una cercana a la base de la capa y otra a la parte media a superior de la misma. Los niveles comúnmente presentan espesores 
de $2.20 \mathrm{~m}$, geometrías tabulares y contactos plano y neto con las facies infrayacentes y transicional con las facies suprayacentes (figuras 5.30a-b). Esta facies se encuentra en el sector medio de la sucesión carbonática en el centro de la zona de Malargüe (secciones ACS y PLN, ver Anexo Ia).

Petrografía: packstone a grainstone de buena a moderada selección con abundantes peloides y restos esqueletales subredondeados a subangulosos. Están acompañados por ooides micríticos superficiales y normales, bajo contenido de clastos terrígenos y escasos intraclastos carbonáticos y calciesferas (figura 5.30c). Los bioclastos están representados por ostras, espinas y placas de equinoideos, fragmentos de colonias de corales, bivalvos no ostreidos, cianobacterias (Caulerpales), gasterópodos y restos indeterminados. Los terrígenos comprenden clastos de cuarzo monocristalino, feldespatos y líticos volcánicos ácidos. La matriz está compuesta por un bajo contenido de micrita homogénea acompañada por escaso cemento microesparítico y esparítico granular.

Interpretación dinámica: de acuerdo con su textura packstone a grainstone, grado de selección, abundante contenido de peloides, bioclastos con variable abrasión y ooides superficiales y normales que la integran, se infiere el desarrollo de un banco peloidal bajo moderada energía de olas dentro de un ambiente marino por encima o en las cercanías del nivel de las olas de buen tiempo (Bádenas y Aurell, 2010; Amour et al., 2013). Asimismo la presencia de concentraciones esqueletales, principalmente de valvas sin una orientación preferencial, refleja una depositación turbulenta de las valvas en suspensión en la base y parte media del depósito, observada en depósitos de tormenta (Kidwell y Bosence, 1991). Estos eventos de mayor energía interrumpen las condiciones de sedimentación del banco peloidal. 


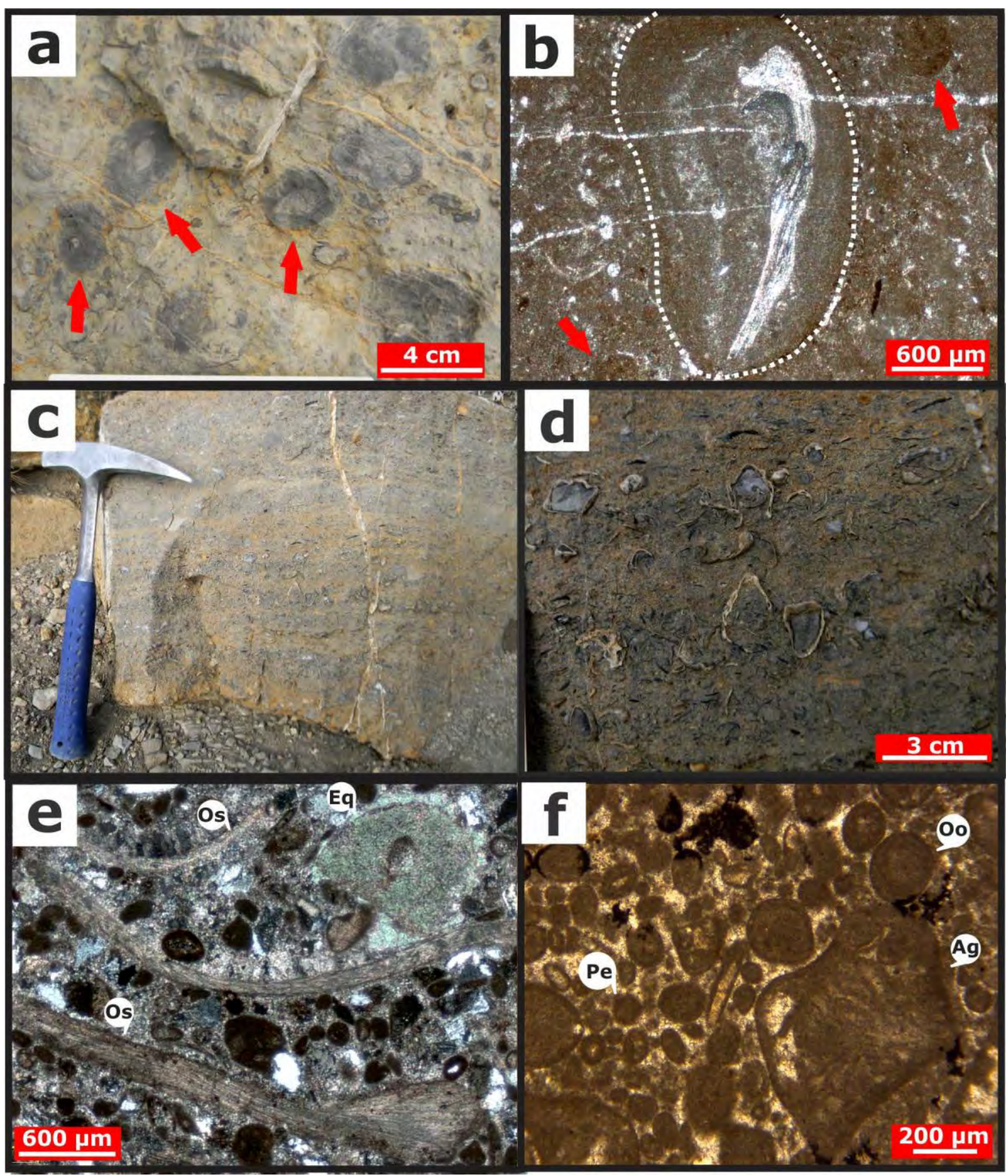

Figura 5.29a: Litofacies de floatstone oncoidal (Fo) con oncoides laminados cuyo núcleo está conformado por valvas articuladas de braquiópodo (flechas). b) [NX,2X]: Marcada micritización de las partículas que conforman la matriz (flechas). La línea punteada indica el contorno del oncoide. Perfil Arroyo Negro. c) Textura general de grainstone bioclástico (GRb) (la piqueta mide $35 \mathrm{~cm})$. d) Litofacies de GRb donde se distinguen fragmentos de bioclastos indeterminados acompañados por valvas de ostras. e) [NX,2X]: Restos de ostras (Os), equinodermos (Eq), peloides y terrígenos en GRb, acompañado por abundante contenido de cemento microesparítico y esparítico. Sección Arroyo Serrucho. f) [NX,4X]: Grainstone oolítico con presencia de ooides micríticos (Oo), peloides (Pe), agregados de partículas carbonáticas ( $\mathrm{Ag}$ ) y escasos bioclastos. Ejemplo tomado del perfil Arroyo Calabozo Sur. 

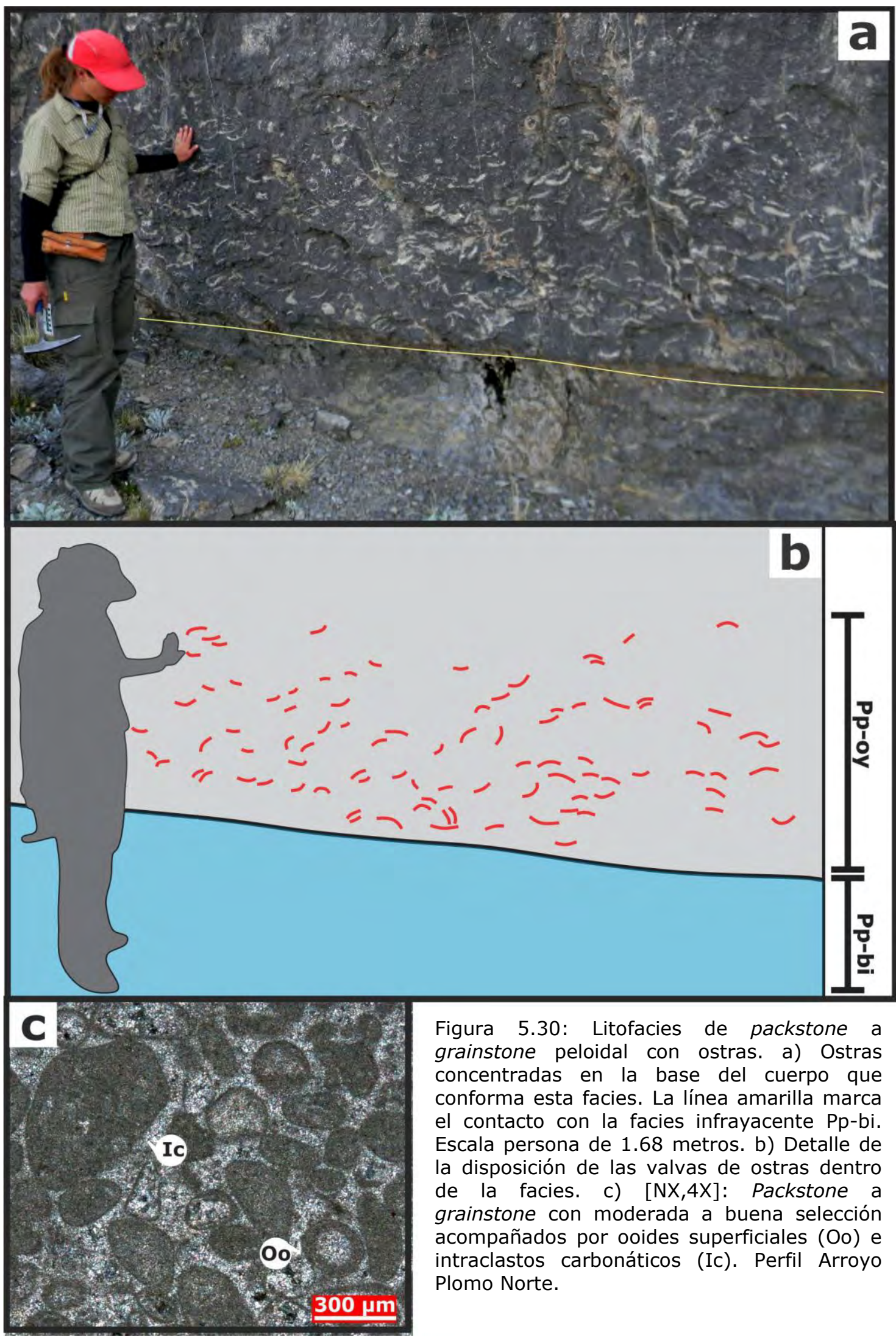

Figura 5.30: Litofacies de packstone a grainstone peloidal con ostras. a) Ostras concentradas en la base del cuerpo que conforma esta facies. La línea amarilla marca el contacto con la facies infrayacente Pp-bi. Escala persona de 1.68 metros. b) Detalle de la disposición de las valvas de ostras dentro de la facies. c) [NX,4X]: Packstone a grainstone con moderada a buena selección acompañados por ooides superficiales (Oo) e intraclastos carbonáticos (Ic). Perfil Arroyo Plomo Norte. 


\section{Packstone bioclástico $(\mathrm{Pb})$}

Está constituida por un packstone masivo con restos de valvas y moldes de bivalvos no ostreidos, aunque también aparecen equinoideos regulares completos (figuras 5.31a-b). Las capas tienen espesores que oscilan entre los 0.40 a $0.50 \mathrm{~m}$, geometrías irregulares y contactos neto y plano con la facies inferior y transicional con la superior. Esta facies solo se representa en la base de la sucesión carbonática en la sección PCH, ubicada en la zona de Bardas Blancas (ver Anexo Ib).

Petrografía: packstone con abundantes fragmentos esqueletales no diferenciables, y en menor proporción clastos de feldespato, cuarzo monocristalino y líticos volcánicos ácidos, todos de forma angulosa. Además, contiene valvas desarticuladas de pelecípodos no ostreidos y restos de equinoideos y gasterópodos (figura 5.31c). La matriz está constituida por un bajo a moderado contenido de micrita homogénea, acompañada por escaso cemento microesparítico.

Interpretación dinámica: a juzgar por el contenido de restos esqueletales y clastos terrígenos, su proporción de matriz micrítica y contacto basal neto y plano, se habrían originado por flujos tractivos de moderada a alta energía dentro de un ambiente marino de sedimentación tranquila (Kreisa y Bambach, 1982 ; Flügel, 2010). En este sentido, su contacto basal indica el retrabajo de las facies subyacentes por olas de moderada a alta energía, seguido por el rápido transporte del material retrabajado (Flügel, 2010). Se destaca que el excelente estado de preservación de los equinoideos y los bivalvos derivados de zonas costera, evidencian un mínimo transporte de estas partículas previo a su rápido enterramiento (Kreisa y Bambach, 1982; Tucker y Wright, 1991).

\section{Packstone peloidal (Pp)}

Está constituida por packstone a wackestone subordinado, masivo, con escasos fragmentos de colonias de corales masivas y ramosas, valvas de ostras desarticuladas a articuladas, restos de bivalvos no ostreidos, gasterópodos y 
braquiópodos rhynchonellidos. Los niveles tienen espesores de 0.15 a $3 \mathrm{~m}$, geometrías irregulares a cuneiforme y contacto neto e irregular con la facies inferior y superior y en ocasiones transicional con las superior. Esta facies de amplia distribución regional, se ubica en el tramo inferior a medio de la sucesión carbonática en la zona de Malargüe (perfiles ASE y ACS, ver Anexo Ia) y de Bardas Blancas (secciones PCH y ALV, ver Anexo Ib). También se presenta en el tramo superior de la sucesión terrígena-mixta (perfil ATW, ver Anexo Ia).

Petrografía: packstone a wackestone subordinado con peloides, asociados con ooides micríticos superficiales (Tipo 1; Strasser, 1986) y clastos de feldespato, cuarzo monocristalino y líticos volcánicos ácidos en baja proporción (figuras 5.1b y 5.31d). En menor proporción se identifican restos esqueletales, calciesferas y oncoides con laminación difusa. Los bioclastos están conformados por colonias de corales, restos de equinoideos, crinoideos, ostras, bivalvos no ostreidos, algas (Dasycladales), cianobacterias (Caulerpales), gasterópodos y braquiópodos, de formas subangulosas a subredondeadas. La matriz está compuesta por un bajo a moderado contenido de micrita homogénea, acompañada por foraminíferos uniseriados o con enroscamiento planoespiral dispersos, y escaso cemento microesparítico y en halo.

Interpretación dinámica: considerando su textura, el abundante contenido de peloides y ooides micríticos superficiales característicos de aguas tranquilas (Strasser, 1986) y la fauna presente, se asume que este depósito podría haber sido generado por condiciones marinas de baja a moderada energía de olas o flujos tractivos. Asimismo, la presencia de restos esqueletales con variable grado de abrasión asociada con el contenido de micrita dentro de la facies, indican ocasionales períodos de mayor energía donde se produce el retrabajo de los bioclastos y el lavado de material fino por acción de corrientes u oleaje (Flügel, 2010). 


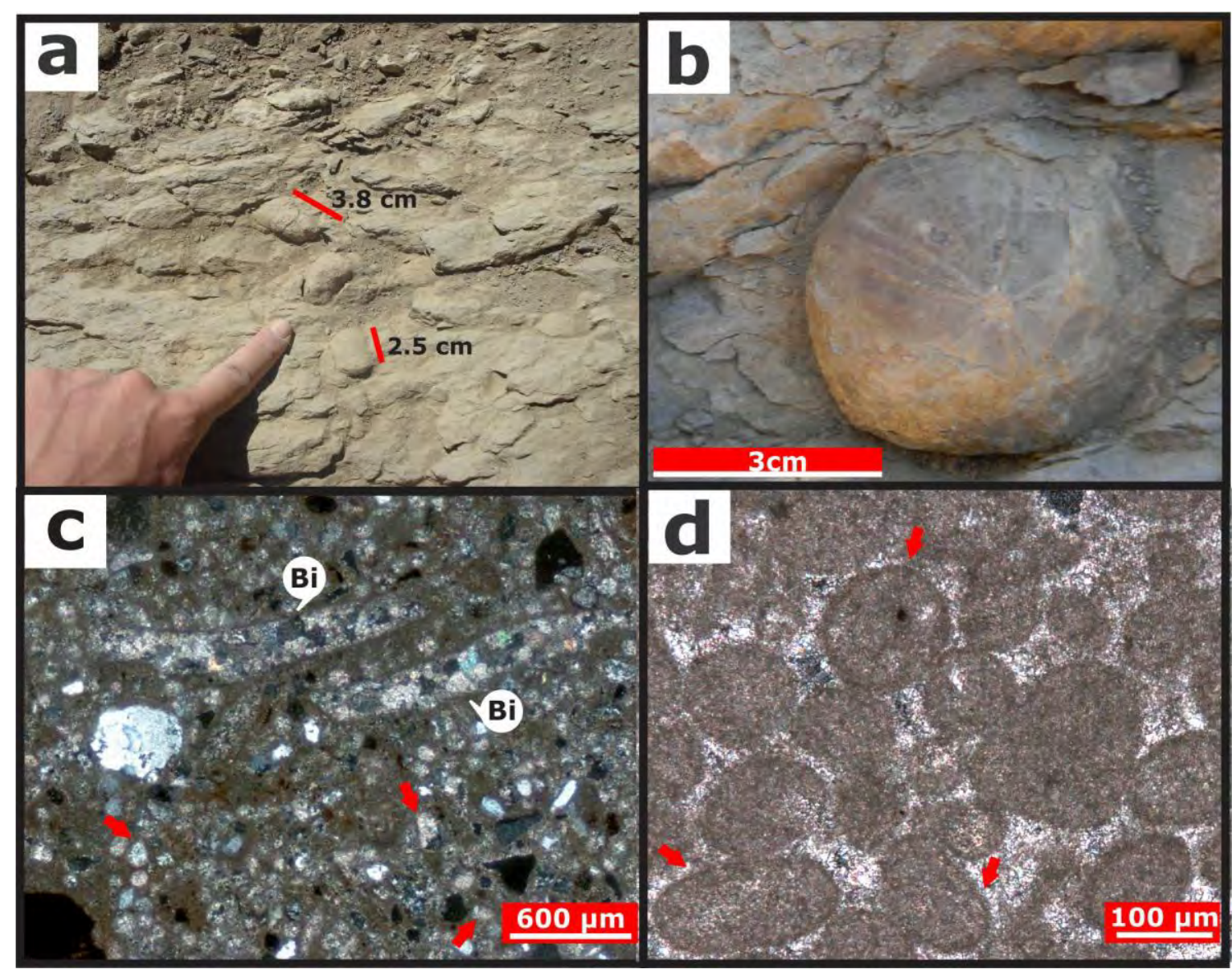

Figura 5.31: Litofacies de packstone. a) Moldes de bivalvos dentro de la facies de packstone bioclástico $(\mathrm{Pb})$. Se señala la posición de los bivalvos no ostreidos. b) Equinoideos regulares completos en $\mathrm{Pb}$. c) $[\mathrm{NX}, 2 \mathrm{X}]$ : Detalle de la textura de la facies $\mathrm{Pb}$ donde se reconocen fragmentos de bioclastos indiferenciables (flechas rojas) acompañados por restos de bivalvos no ostreidos (Bi), cristales de feldespato y cuarzo monocristalino. d) [NX,10X]: Facies de packstone peloidal donde se identifican abundantes peloides de formas esféricas a ovoidales (flechas). Los ejemplos de las figuras a, b y c son de la sección Río Potimalal, mientras que el de la figura d fue tomado del perfil Arroyo Plomo Oeste. 


\section{Packstone peloidal-bioclástico (Pp-b)}

Esta facies de notoria distribución regional, está conformada por packstone masivo con abundantes restos esqueletales carentes de una orientación preferencial distribuidos a lo largo de la facies o concentrados en bandas paralelas (figuras 5.32a-b). En este último conforman una estratificación difusa de bandas paralelas con abundantes bioclastos intercaladas con otras con restos esqueletales escasos a ausentes (figura 5.32c). Hacia el noreste de la zona de Malargüe en las secciones ASE, ANE y ACN (ver Anexo Ia) la fauna está representada por fragmentos de equinodermos o de braquiópodos rhynchonellidos y telebratúlidos, mientras que hacia el sudoeste (perfil ATW, ver Anexo Ia) predominan los restos de ¿algas rojas? (figuras 5.32a, b y d). Por su parte, en la zona de Bardas Blancas (perfil ALV, ver Anexo Ib), los bivalvos denotan ser la fauna predominante. En el caso de los niveles con braquiópodos se puede distinguir un pasaje gradual desde la base, constituida por restos de valvas, hacia el tope conformado por valvas completas y articuladas. Los bancos tienen espesores variables entre los 0.20 a $1.50 \mathrm{~m}$, geometrías que oscilan entre irregulares, tabulares o forma de cuña y contacto transicional a neto con la facies subyacente. Esta facies se distribuye a lo largo de la sucesión carbonática en las zonas de Malargüe y Bardas Blancas. En el sudoeste de Malargüe (perfil ATW) está en el tramo medio de la sucesión terrígena-mixta.

Sobre la base al análisis petrográfico esta facies se dividió en dos subfacies:

Subfacies 1 (Pp-b SF1): packstone masivo a estratificado con peloides y restos esqueletales subangulosos a subredondeados con escaso a nulo desarrollo de la envoltura micrítica. En menor proporción presenta clastos de líticos volcánicos ácidos, feldespato y cuarzo monocristalino, calciesferas y ooides micríticos superficiales y normales (figuras $5.32 \mathrm{e}-\mathrm{f}$ ). La matriz está constituida por bajo contenido de micrita homogénea junto con escaso cemento microesparítico, esparítico y macroesparítico sintaxial. Esta subfacies se presenta en las secciones ASE, ANE, ATW y ALV (ver Anexos Ia y Ib). 
Interpretación dinámica: en relación con su textura, contenido de peloides y restos esqueletales con moderada abrasión y su proporción de matriz micrítica, se infiere un depósito generado por flujos u olas bajo condiciones de moderada energía. Asimismo, la concentración de bioclastos en bandas paralelas, indica flujos tractivos de alta energía que depositan rápidamente los restos esqueletales inhibiendo su retrabajo posterior. En el caso de los niveles con abundantes braquiópodos, se distingue una disminución progresiva de la energía desde la base al techo del depósito.

Subfacies 2 (Pp-b SF2): packstone a wackestone masivo con peloides y fragmentos de bioclastos, generalmente braquiópodos, que suelen conformar el núcleo de oncoides. Los mismos contienen envolturas con laminación difusa a nula, en general con un espesor menor a igual respecto al diámetro del núcleo (figura $5.32 \mathrm{~g}$ ). La matriz está conformada por un moderado contenido de micrita homogénea acompañada por calciesferas, foraminíferos con enroscamiento polimorphynido y escasa microesparita. Es frecuente el pasaje gradual de peloides a matriz micrítica. Dicha subfacies se encuentra en el perfil ACN (ver Anexo Ia).

Interpretación dinámica: de acuerdo con su textura, el moderado contenido de matriz micrítica que presenta y la intensa micritización que afecta a las partículas carbonáticas, se infiere un depósito generado por la decantación de material carbonático fino, afectado por una intensa actividad algal. El mismo se generaría bajo condiciones de sedimentación tranquila en un medio marino somero protegido (Tucker y Bathurst, 1990; Bádenas y Aurell, 2010). No obstante, las características de los oncoides descriptos, sugieren episodios poco frecuentes de flujos de mayor energía donde se produce el crecimiento de estas partículas.

Figura 5.32: Litofacies de packstone peloidal-bioclástico (Pp-b). a) Restos de braquiópodos sin una orientación preferencial dispersos a lo largo de la capa. b) Bandas paralelas con bioclastos concentrados que intercalan con niveles con escasos restos esqueletales. c) Estratificación paralela difusa. d) Pp-b con abundantes restos de ¿algas rojas?. e y f) [NX,4X]: Subfacies 1 compuesta de peloides, restos esqueletales subangulosos de equinodermos ( $\mathrm{Eq})$ y braquiópodos $(\mathrm{Br})$, y terrígenos. g) $[N X, 4 X]$ : Subfacies 2 con peloides y fragmentos de bioclastos que conforman el núcleo de oncoides (On). La línea punteada marca su contorno. Los ejemplos de las figuras a, b, c y g fueron tomados de la sección Arroyo Calabozo Norte, mientras que las imágenes d, e y $f$ son de los perfiles Arroyo Torrecillas, Arroyo Negro y Arroyo Serrucho, respectivamente. 


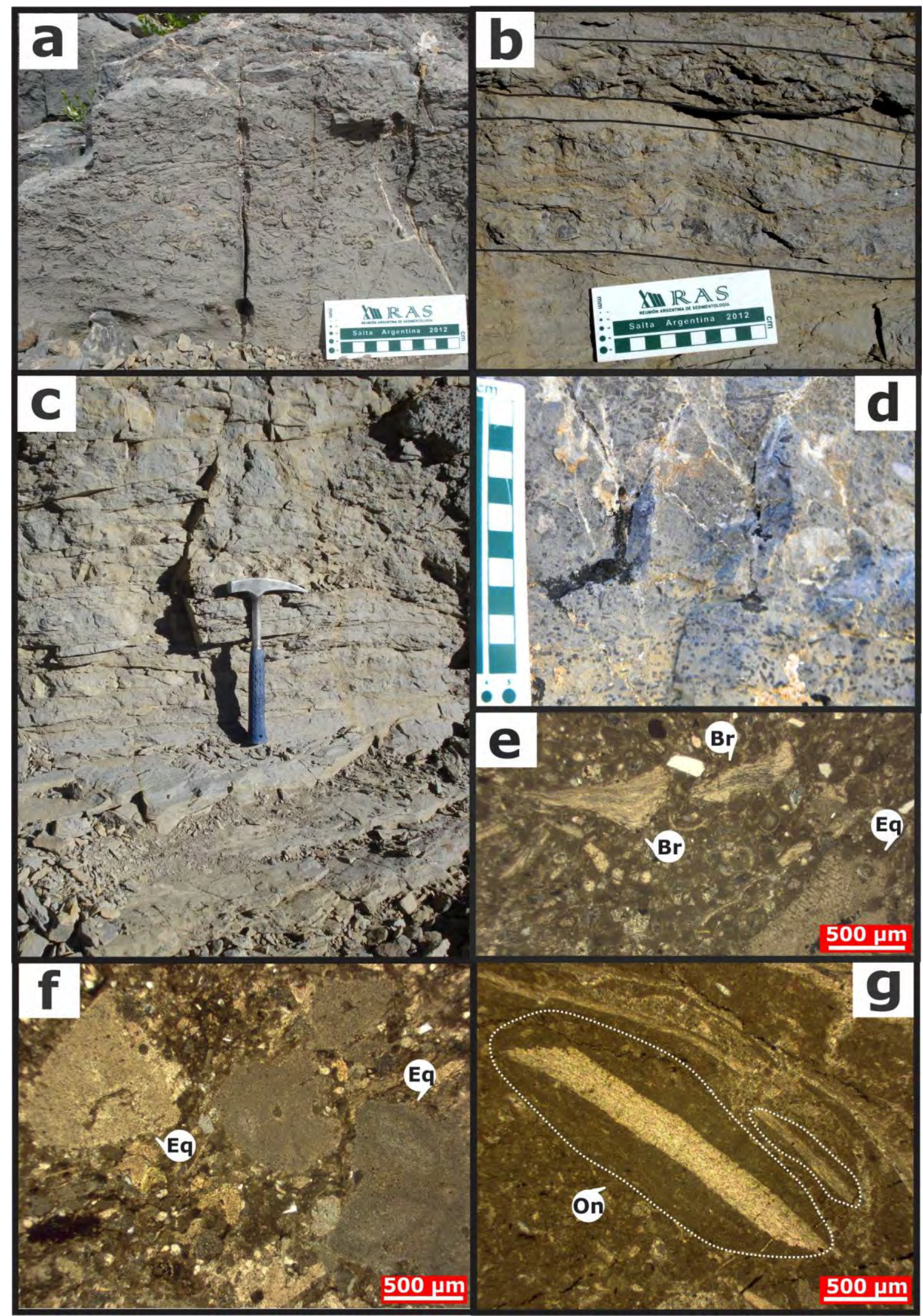




\section{Packstone peloidal-bioclástico-intraclástico (Pp-b-i)}

Se trata de packstone a floatstone subordinado masivo, con fragmentos de bioclastos indeterminados junto con restos de colonias de corales (dómicas y ramosas), valvas desarticuladas de ostras, equinoideos, gasterópodos, restos de bivalvos no ostreidos y oncoides con laminación difusa. Los fragmentos de corales y las ostras tienen evidencias de bioerosión y en algunos casos los corales presentan organismos incrustantes (figura 5.33a). Los bioclastos pueden encontrarse dispersos dentro de la facies o formando concentraciones cerca de la base (figura 5.33b). Las capas comúnmente tienen espesores entre los 0.40 a $2 \mathrm{~m}$ y geometrías tabulares, irregulares o cuneiformes. Cerca de la base puede presentar trazas fósiles asignadas a Skolithos isp. y Arenicolites isp. El contacto con la facies inferior y superior varía entre neto, de morfología plana a irregular, a transicional. Esta facies de notoria distribución regional, se presenta en el sector medio a superior de la sucesión carbonática en la zona de Malargüe y de Bardas Blancas (ver Anexos Ia y b). En el área de Malargüe esta facies frecuentemente suprayace a la facies de packestone peloidal-bioturbado (Pp-bi; figura 5.33b).

Petrografía: packstone de moderada a pobre selección con abundantes peloides de tamaños variables, acompañados por fragmentos esqueletales e intraclastos (de las litofacies $\mathrm{Fa}-\mathrm{O}, \mathrm{Pp}$ y $\mathrm{Pp}-\mathrm{bi}$ ) de bordes redondeados a subredondeados. Los bioclastos suelen estar rodeados por marcadas envolturas micríticas o finas coberturas algales (figura 5.33c). En menor proporción se presentan ooides micríticos superficiales y normales, oncoides con laminación difusa, calciesferas y escasos clastos terrígenos comunes en las secciones de Bardas Blancas. La matriz está compuesta por un bajo a moderado contenido de micrita homogénea, asociada a una baja a moderada proporción de microesparita, esparita granular y macroesparita (en mosaico, drusiforme). 


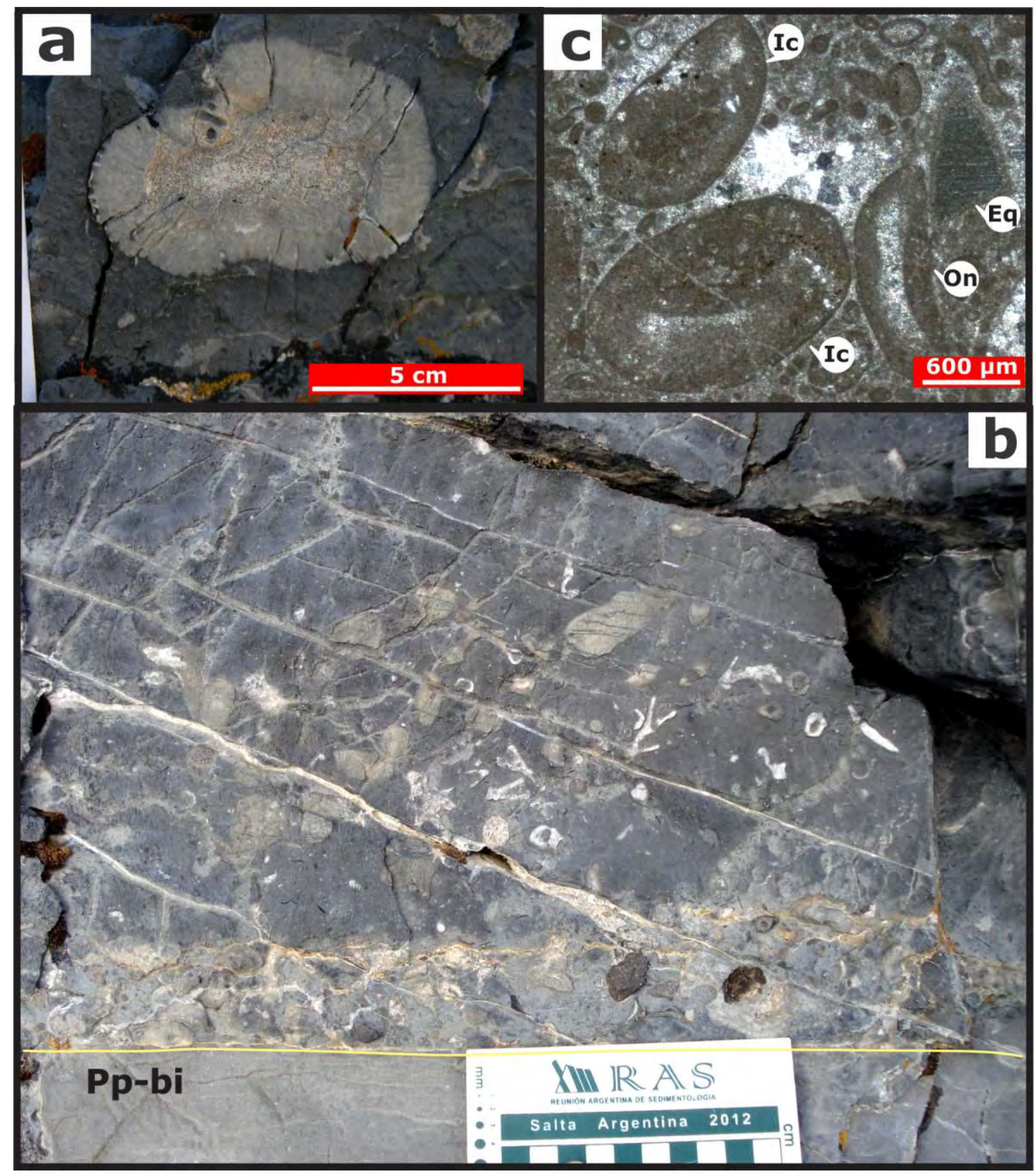

Figura 5.33: Litofacies de packstone peloidal-bioclástico-intraclástico (Pp-b-i). a) Fragmento de colonia de coral dómica en Pp-b-i. b) Concentración de bioclastos en la base de la capa que conforma esta facies. La línea amarilla marca el contacto basal con packstone peloidal bioturbado (Pp-bi). c) [NX,2X] Peloides de tamaños variados acompañados por restos de equinodermos (Eq), oncoides (On) e intraclastos carbonáticos (Ic) en Pp-b-i. Obsérvese la marcada micritización que presentan las partículas. Los ejemplos de las figuras $a, b$ y $c$ fueron tomados de los perfiles ACN, ATW y PLE respectivamente. 
Interpretación dinámica: a juzgar por la marcada abrasión de las partículas carbonáticas se infiere un depósito formado bajo condiciones de moderada a alta energía de olas, en un ambiente marino somero. La moderada a pobre selección del depósito, junto con la diversidad de componentes que presenta (peloides, intraclastos, bioclastos, ooides y oncoides), sugieren una re-sedimentación del material carbonático generada por corrientes de alta energía (Brigaud et al., 2009a). No obstante, las proporciones de fango carbonático que presenta el depósito, asociadas con el grado de micritización de las partículas carbonáticas, indican períodos de menor energía donde la decantación del fango carbonático es común y la actividad de microorganismos resulta intensa (Morad et al., 2016).

\section{Packstone peloidal bioturbado (Pp-bi)}

Está conformada por packstone intensamente bioturbados con trazas fósiles caracterizadas por galerías tridimensionales con uniones en " $Y$ " y secciones circulares de 0.6 a $4 \mathrm{~cm}$ de diámetro asignadas a Thalassinoides paradoxidus (Borya et al., 2015; figura 5.34a). Asimismo, hacia el tope del nivel que contiene a esta facies pueden aparecer escasas estructuras habitacionales con forma general de gota o lágrima referidas a Gastrochaenolites isp., cuyo diámetro basal ronda entre los 0.2 a $1 \mathrm{~cm}$ y su largo máximo llega a los $2 \mathrm{~cm}$ (Borya et al., 2015; figura 5.34b). Tanto Thalassinoides isp. como Gastrochaenolites isp. presentan una superficie externa lisa y un contacto neto con la roca hospedante, además, se encuentran rellenas pasivamente por la facies suprayacente (figuras 5.34a-b). En menor medida se identifican trazas asignadas a Arenicolites isp. y Planolites isp y fragmentos de colonias de corales, ostras, bivalvos no ostreidos, gasterópodos y equinoideos. Los niveles presentan potencias que varían entre 0.40 y $3.10 \mathrm{~m}$ de las cuales 0.25 a $3.10 \mathrm{~m}$ se encuentran bioturbados (figura 5.34c). Su geometría varía de tabular a cuneiforme. El contacto con las facies inferiores es neto y plano y con las superiores es neto, plano a irregular. En este último caso es común el truncamiento de las trazas ubicadas cerca del tope. Esta facies se presenta dentro del tramo inferior a medio de la sucesión carbonática en el centro a sudoeste de la 
zona de Malargüe (secciones PLN a ATW, ver Anexo Ia). Se distingue una disminución de la representación de la facies en este sentido.

Petrografía: packstone con importante participación de peloides junto con ooides micríticos superficiales (Tipo 1; Strasser, 1986). En forma subordinada participan terrígenos, calciesferas y escasos restos de ostras, equinoideos, braquiópodos. Los terrígenos comprenden clastos de cuarzo monocristalino, feldespato y líticos volcánicos. Presenta Thalassinoides rellenas pasivamente con la facies subrayacente (figura 5.34d). La matriz está constituida por un bajo contenido de micrita homogénea junto a escasa a baja proporción de microesparita a esparita.

Interpretación dinámica: de acuerdo con su textura y el contenido de peloides y ooides micríticos superficiales presentes en la facies, característicos de ambientes de aguas tranquilas (Strasser, 1986), se infiere un depósito formado bajo condiciones de moderada a baja energía e intensamente bioturbado. En este sentido, las características que presenta la asociación de Thalassinoides y Gastrochaenolites preservada en la facies como su contacto liso y neto con la roca hospedante, y su relleno pasivo con la facies que la cubre, permite interpretarlas como perteneciente a la icnofacies de Glossifungites (Christ et al., 2012; Schwarz y Buatois, 2012). Dicha icnofacies es propia de sustratos estables y cohesivos, firmground, desarrollados en ambientes marinos someros (Buatois y Mángano, 2011; Christ et al., 2012). 


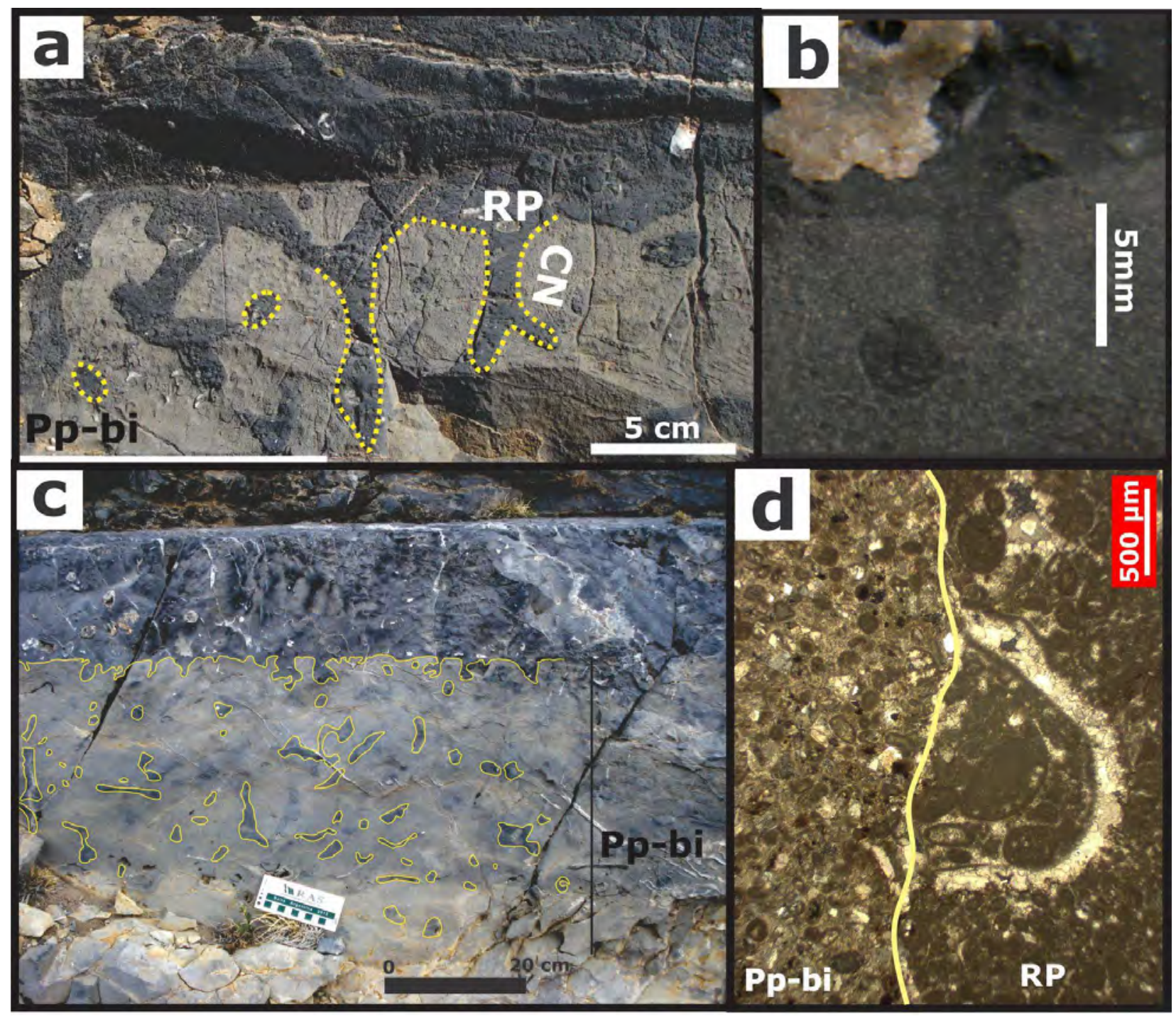

Figura 5.34: Litofacies de packstone peloidal bioturbado (Pp-bi). a) Thalassinoides paradoxidus con galerías tridimensionales con uniones en " $\mathrm{Y}$ " y secciones circulares. Presenta contacto neto (CN) con la roca hospedante y relleno pasivo (RP) derivado de la facies suprayacente. b) Gastrochaenolites isp. rellena pasivamente con la facies suprayacente. c) Nivel completamente bioturbado. d) [NX,4X]: Relleno pasivo de Thalassinoides paradoxidus en contacto neto con la facies Pp-bi (línea amarilla). Los ejemplos de las figuras a, b y c fueron tomados de la sección Arroyo Plomo Oeste, mientras que el de la figura d fue sacado del perfil Arroyo Plomo Este. 


\section{Wackestone:}

\section{Wackestone a packstone con pellets (W-Ppe)}

Wackestone masivo conformando niveles poco potentes $(0.15$ a $0.20 \mathrm{~m}$ de espesor), con geometrías tabulares a irregulares (figura 5.35a). Es poco frecuente la presencia de moldes de cristales de evaporitas dentro de la capa y de porosidad fenestral parcialmente rellena (estructura bird eyes) hacia el tope (figura 5.35b). El contacto con las facies subyacentes y suprayacentes varía de transicional a neto. Es común el pasaje vertical hacia facies de estromatolito laminar ( $\mathrm{Bl}$; figura 5.35a). Esta facies se presenta tanto en la zona de Malargüe como en la de Bardas Blancas, dentro del tramo superior de la sucesión carbonática (secciones ANE, ACN y PLE y ALV, ver Anexos Ia y Ib).

Petrografía: wackestone a packstone masivo con abundantes pellets (figuras 5.3ab), agregados de partículas carbonáticas (figura 5.5b), escasos oncoides Tipo C (Logan et al., 1964; modificado por Flügel, 2010) y con laminación difusa a ausente y fragmentos redondeados a angulosos de bioclastos (bivalvos no ostreidos, gasterópodos y equinoideos). La matriz está conformada por bajo a moderado contenido de micrita homogénea junto con foraminíferos con enroscamiento polymorphinido y escasa microesparita. Se observa la presencia de moldes de evaporitas vacíos reemplazando a las partículas carbonáticas y a la matriz.

Interpretación dinámica: considerando la presencia de pellets y el contenido de micrita en la facies, se infiere un depósito generado por la decantación de material carbonático fino en un ambiente marino con olas de moderada a baja energía (Pierre et al., 2010). Asimismo, la presencia de agregados de partículas carbonáticas producto de la acción de corriente erosivas sobre sustratos poco cementados (Scholle y Ulmer-Scholle, 2003), indican la actividad intermitente de olas de mayor energía. Sustentan esta interpretación los oncoides presentes y los restos esqueletales redondeados a angulosos llevados hacia este sector por olas de mayor energía. 


\section{Wackestone bioclástico (Wb)}

Se trata de un wackestone masivo con restos de bioclastos indeterminados sin una orientación preferencial (figura 5.35d). También se encuentran valvas articuladas de pelecípodos, mayormente ostras y en menor medida bivalvos no ostreidos (figura 5.35e). Las capas varían su espesor entre 0.20 y $0.90 \mathrm{~m}$ y presentan geometrías irregulares. El contacto con la facies subyacente varía de neto e irregular a transicional, y con la facies suprayacente es neto y plano. Se representa sólo en la zona de Bardas Blancas, dentro del sector inferior a medio de la sucesión carbonática (ver Anexo Ib).

Petrografía: wackestone portador de restos fragmentarios de bordes angulosos a subangulosos de ostras y en menor medida de equinodermos, con bajo a nulo desarrollo de la envoltura micrítica (figura 5.35f). Además, presenta peloides, calciesferas y un bajo contenido de clastos angulosos de feldespato y cuarzo monocristalino. La matriz está constituida por moderada a abundante micrita homogénea, acompañada por escaso cemento microesparítico.

Interpretación dinámica: se infiere un depósito generado por la decantación de material carbonático fino en un medio tranquilo, por debajo del nivel de olas de tormenta, acompañado por acumulaciones de restos esqueletales con un grado variable de retrabajo y evidencias de rápido soterramiento (Bádenas et al., 1993; Benyoucef y Meister, 2015). Esta interpretación se basa en la presencia de bioclastos con un variado grado de fragmentación, escasa abrasión y baja a nula micritización, y el moderado a abundante contenido de micrita que presenta la facies. Dichos restos esqueletales provenientes de sectores costeros, pudieron haber sido transportados directamente como corrientes de fondo durante la declinación de la intensidad de una tormenta (Flügel, 2010). 


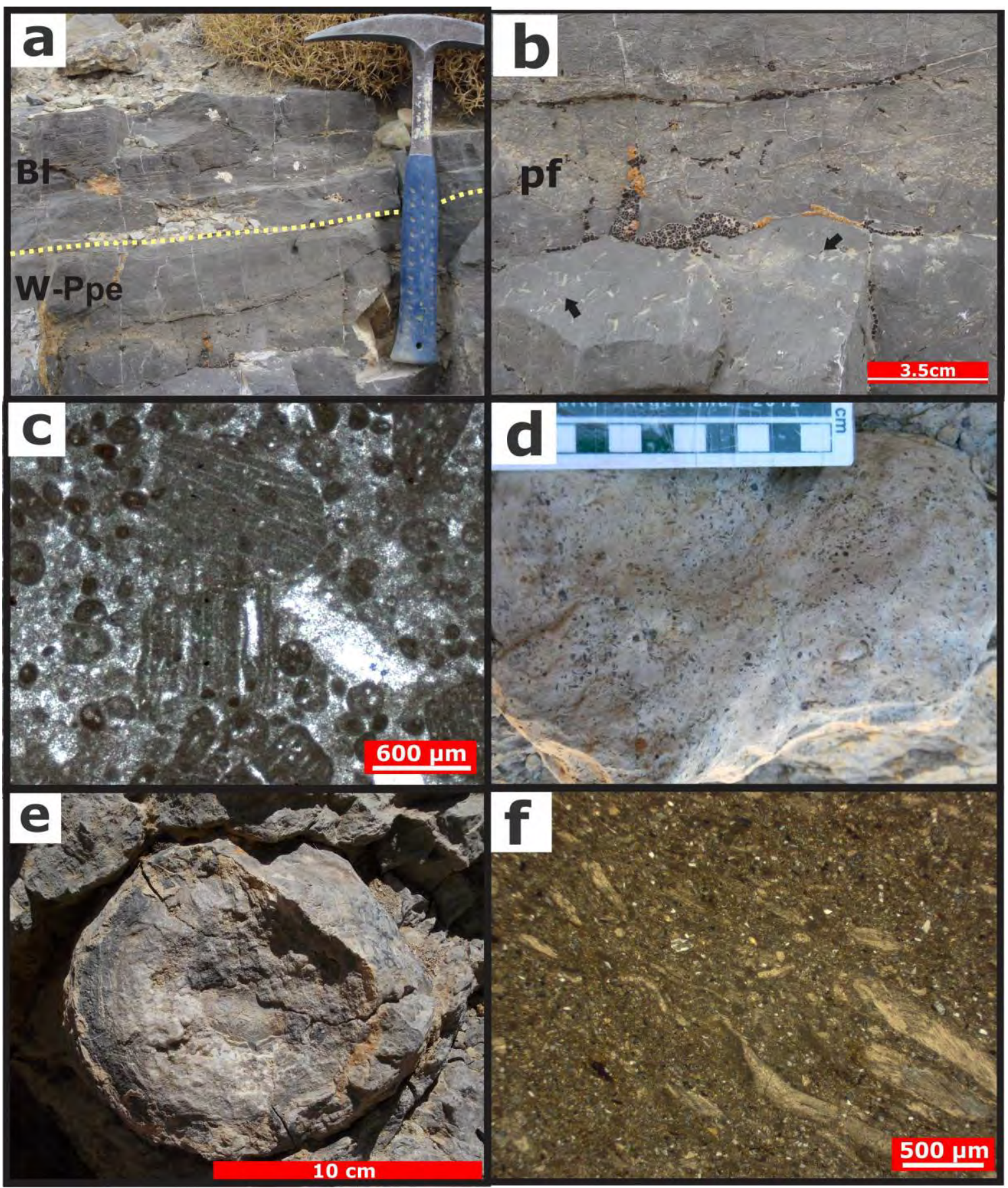

Figura 5.35: Litofacies de wackestone. a) Niveles poco potentes de wackestone a packstone con pellets (W-Ppe) en contacto con estromatolito planar (BI). La línea amarilla punteada marca el pasaje transicional entre ambas facies. Escala martillo de $35 \mathrm{~cm}$ de altura. b) Presencia de moldes de cristales de evaporitas (flechas negras) y de porosidad fenestral (pf) dentro de WPpe. c) $[N X, 2 X]$ : Litofacies W-Ppe. d) Restos desorientados de bioclastos en wackestone bioclástico (Wb). e). Ostra en la litofacies Wb. f) [NX, 4X]: Restos angulosos a subangulosos de ostras con bajo desarrollo de envoltura micrítica. Los ejemplos de las figuras a, b y c son del perfil Arroyo La Vaina, mientras que los de las figuras d, e y f se corresponden con la sección Río Potimalal. 


\section{Boundstone:}

\section{Estromatolito planar (BI)}

Se trata de estromatolito con laminación criptoalgal, en general con presencia de láminas planas en la base y crenuladas hacia el tope de la capa; resultan de menor importancia los niveles conformados solamente por laminación paralela (figura 5.36a). La laminación plana está evidenciada por la alternancia de láminas claras y oscuras, discontinuas, de tamaño milimétrico (1-4 mm). Hacia el techo de la capa aumentan su espesor $(2-8 \mathrm{~mm})$ y se vuelven irregulares pasando a una laminación crenulada. Las estructuras bird eyes si bien son comunes en todo el nivel, se encuentran mayormente representadas hacia el techo. En las sección Arroyo La Vaina (zona de Bardas Blancas), además se distinguen estructuras tepee en el techo de la facies. Los bancos son poco potentes ( 0.10 a $0.20 \mathrm{~m}$ de espesor), con geometrías tabulares a irregulares y contactos netos a transicionales con la facies subyacente. Se destaca la ausencia de fósiles en la facies. Esta facies conforma el tope de la sucesión carbonática en el noroeste de las zonas de Malargüe (perfiles ANE y ACS, ver Anexo Ia) y de Bardas Blancas (sección ALV, ver Anexo Ib).

Petrografía: estromatolito planar conformado por una alternancia de láminas claras de $10 \mathrm{~mm}$ de espesor, con otras oscuras que oscilan entre 1 a $5 \mathrm{~mm}$ de potencia (figura 5.36b). Las láminas claras, compuestas por microesparita y escasa micrita homogénea a grumosa, muestran un abundante contenido de cavidades irregulares rellenas con cemento microesparítico a esparítico, dispuestas de forma paralela a la laminación. Por otra parte, las láminas oscuras presentan un mayor contenido de micrita homogénea a grumosa, baja proporción de microesparita y escasas cavidades irregulares rellenas con cemento microesparítico a esparítico paralelas a la estratificación. 
Interpretación dinámica: comprende depósitos formados por la decantación de material fino y el entrampamiento y aglutinación de dicho sedimento por parte de las cianobacterias, bajo condiciones marinas someras de aguas tranquilas (Wright y Burchette, 1996). La fábrica planar-crenulada que presenta el estromatolito se debe a la actividad de cianobacterias y sus discontinuidades pueden estar relacionadas con la presencia de fenestras paralelas a la laminación. Dichas estructuras pudieron haber sido generadas por la descomposición de la materia orgánica o por contracción de las láminas algales debido a la alternancia de períodos húmedos y secos (Shinn, 1968). La presencia de estructuras tepee en el tope de la sección ALV denota la exposición subaérea hacia el techo de la facies.

\section{Framestone coralígeno (FRc)}

Dicha litofacies se distribuye en la zona de Malargüe dentro del tramo medio de la sucesión terrígena-mixta e inferior a medio de la sucesión carbonática (perfiles PLN y ATW, ver Anexo Ia). Se trata de framestone masivo con colonias de corales en posición de vida a parautóctonas con bajo grado de fragmentación y abrasión, ambos con frecuentes rasgos de bioerosión (figura 5.36c). Las mismas están representadas por corales de formas esféricas a dómicas y ramosas con alturas que varían entre 10 y $40 \mathrm{~cm}$ y extensión de 20 a $60 \mathrm{~cm}$, raramente se distinguen formas laminares (figuras $5.36 \mathrm{~d}$-f). En ocasiones se presentan sólo formas dómicas in situ dentro de la facies (subfacies 1 ). Las colonias se encuentran separadas por sedimento carbonático acompañado por bioclastos completos o restos de ostras grandes (100 a $150 \mathrm{~mm}$ de largo), serpúlidos y corales. Los niveles tienen potencias entre 0.60 y $1.7 \mathrm{~m}$, geometrías lenticulares a irregulares y contactos neto o transicional con las facies inferiores. Mientras que el contacto con las facies superiores es neto, de morfología plana o irregular. Lateralmente puede pasar hacia facies de packestone peloidal bioturbado (sección PLN, ver Anexo Ia). 
Petrografía: El sedimento entre las colonias está representado por abundantes peloides, acompañado por ooides micríticos superficiales y restos de ostras, equinoideos y colonias de corales, de bordes subredondeados a redondeados. Además, contiene subordinados clastos terrígenos (feldespatos, líticos volcánicos ácidos y cuarzo monocristalinos) de tamaño arena fina a limo, micrita homogénea en baja a moderada proporción y escasa microesparita a esparita.

Interpretación dinámica: a juzgar por la zonación de corales in situ (dómicos, ramosos y escasos laminares), la presencia de colonias removilizadas y la fauna que las acompaña, se interpreta un ambiente marino normal de moderada a alta energía de olas ubicado dentro de la zona fótica (James, 1984; Reolid et al., 2009). Sustentan esta interpretación la marcada abrasión de los restos esqueletales presentes, indicativa de una zona con retrabajo por la acción de las olas. Asimismo, la presencia de material terrígeno de grano fino entre las colonias denota que el crecimiento de las mismas se produjo durante períodos de bajo aporte clástico hacia el sistema (Wilson, 2005).

Dentro de esta facies, sobre la base de sus rasgos mega y microscópicos se diferenció una subfacies:

Subfacies 1 (FRc SF1): Está conformada por colonias de corales dómicas en posición de vida, con abundantes rasgos de bioerosión, y alturas promedio de 10 $\mathrm{cm}$, acompañados por ostras articuladas. En los sectores entre las colonias presentan sedimento carbonático con textura mudstone acompañado por braquiópodos rynchonellidos articulados y espinas de equinoideos, los cuales se concentran hacia el tope de la capa. Es poco común la presencia de lentes poco potentes (menos de $5 \mathrm{~cm}$ de espesor) de arenisca media con clastos de líticos volcánicos tamaño sábulo. El contacto con la facies inferior de areniscas masivas es neto y con la facies suprayacente es neto e irregular. Se presenta en la sección Arroyo Torrecillas Oeste (ATW, ver Anexo Ia). 
Petrografía: colonia de coral acompañada por abundante micrita homogénea con escasa presencia de cristales angulosos de cuarzo monocristalino (tamaño limo a arenisca fina) y fragmentos angulosos de bioclastos indeterminados. Las cavidades de la colonia están rellenas por el mismo sedimento que las rodea (figura $5.36 \mathrm{~g}$ ). Escasa presencia de cemento carbonático microesparítico.

Interpretación dinámica: considerando la presencia de colonias de corales dómicas in situ, el grado de articulación de la fauna que acompaña a las mismas y el contenido de micrita de la facies, se infiere un ambiente marino normal de moderada a baja energía de olas ubicado dentro de la zona fótica (James, 1984; Wilson, 2005). El fango carbonático decanta entre las colonias durante períodos de sedimentación tranquila, y su producción estaría relacionada con la destrucción biológica (bioerosión) de la colonia y de los organismos bentónicos que la acompañan (Wright y Burchette, 1996). Asimismo, el contenido de material silicoclástico dentro, de la facies sugiere que las colonias de corales se desarrollan durante períodos de bajo suministro clástico al sistema con aportes episódicos de material grueso desde la zona costera (Wilson, 2005). 


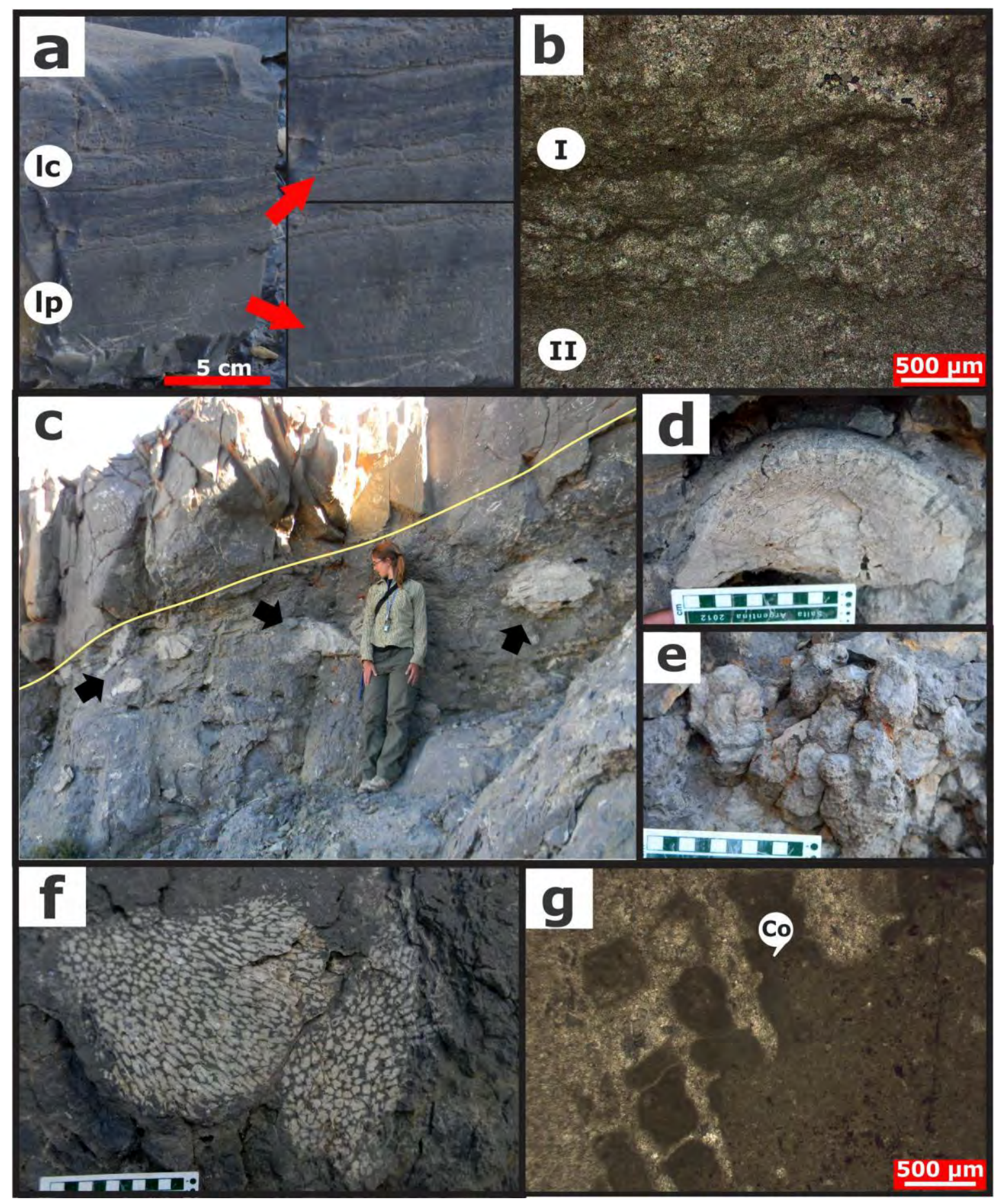

Figura 5.36: Litofacies de boundstone. a) Estromatolito planar (BI) con laminación plana (Ip) en la base y crenulada en el techo (Ic). Los recuadros a la derecha muestran un detalle de ambas laminaciones. Tope de la sección Arroyo Calabozo Sur. b) [NX,4X]: En Bl, alternancia de láminas claras (I) con abundantes cavidades irregulares rellenas de microesparíta, paralelas a la laminación, y oscuras (II) de micrita homogénea a grumosa. Tope de la sección Arroyo La Vaina. c): Framestone coralígeno con colonias de corales dómicas in situ a levemente movilizadas (flechas negras) separadas por sedimento carbonático. La línea amarilla marca el tope de la facies. Escala persona 1.68 metros. d) Colonia de coral dómica. e y f) Variedades de colonias de corales ramosas. g) Subfacies1 conformada por colonia de coral (Co) rodeada por abundante micrita homogénea. Las figuras c-g son de la sección Arroyo Plomo Norte. 


\subsection{2: Litofacies clásticas}

A pesar de que se realizó una caracterización composicional de las psamitas clásticas y mixtas mediante petrografía, para la definición de las facies clásticas solo se tuvieron en cuenta los caracteres macroscópicos. Los atributos considerados son la litología, las estructuras sedimentarias mecánicas, el contenido fosilífero y la bioturbación.

\subsection{2-I: Litofacies psefíticas}

Se reconocieron diferentes litofacies conglomerádicas de acuerdo a la cantidad de matriz que presentan y las estructuras mecánicas y sus escalas (figura 5.26b). Estas litofacies están dominadas por fragmentos terrígenos, con un contenido subordinado de fragmentos intracuencales. Se caracterizan por ser psefitas matriz soportada, menos frecuente clasto soportado, con matriz arenosa. Los clastos grandes alcanzan tamaños máximos de $40 \mathrm{~mm}$ y promedios de $10 \mathrm{~mm}$. Por lo general son redondeados a subredondeados, con predominio de fragmentos líticos volcánicos ácidos, cuarzo y feldespato. De forma subordinada presenta restos esqueletales conformados por valvas de ostras, fragmentos de colonias de corales, restos de ¿algas rojas? y bivalvos no ostreidos. De acuerdo con la clasificación propuesta por Limarino et al. (1996) se ubican dentro de matriz ortoconglomerados y clasto ortoconglomerados polimícticos. Dichas litofacies psefíticas se encuentran en la zona de Malargüe a lo largo de la sucesión terrígena-mixta. En este sector se distingue una manifiesta disminución en la importancia y espesor de dichas litofacies desde el suroeste hacia el noreste (ver Anexo Ia). 


\section{Conglomerado con estratificación entrecruzada en artesa (Gt)}

Psefita fina con clastos de 5 a $15 \mathrm{~mm}$ de tamaño (tamaño máximo $25 \mathrm{~mm}$ ), matriz a clasto soportada, con moderada selección. Muestran cruda estratificación entrecruzada en artesa de $20 \mathrm{~cm}$ de espesor por $200 \mathrm{~cm}$ máximo de extensión. Conforman capas aisladas poco espesas $(0.15$ a $0.40 \mathrm{~m})$, con geometría de cuña que puede pasar tanto lateral como verticalmente a facies de arenisca conglomerádica con similar estructura (SGt). Su contacto inferior es neto plano a levemente irregular. Se presenta en el tramo superior de la sucesión terrígenamixta, en el perfil Plomo Este (PLE, ver Anexo Ia).

Interpretación dinámica: dicha facies representa la migración de dunas tridimensionales gravo-arenosas generadas por corrientes inducidas por las olas de tormenta en un ambiente marino por encima de las olas de buen tiempo (Leithold y Bourgeois, 1984; Massari y Parea, 1988). Bajo estas condiciones de tormenta grandes volúmenes de sedimento, especialmente de material gravoso, son removidos desde la zona de playa y llevados hacia esta zona costera más profunda (Massari y Parea, 1988).

\section{Conglomerado con estratificación entrecruzada planar (Gp)}

Se trata de ortoconglomerado fino de 5 a 15 mm de tamaño (tamaño máximo 40 $\mathrm{mm}$ ), matriz a clasto soportado, con moderada a buena selección. Se presenta en sets gruesos a muy gruesos (40 a $110 \mathrm{~cm}$ ) de difusa a clara estratificación entrecruzada planar simple o tangencial, donde es común la presencia de fábricas imbricadas. En la base de las capas la estructura suele estar conformada por bandas oblicuas de conglomerado intercalados con bandas de arenisca-arenisca conglomerádica (figuras 5.37a y b). Las capas son tabulares de 0.4 a $2 \mathrm{~m}$ de potencia y $47 \mathrm{~m}$ de extensión, con bases netas planas a irregulares, poco erosivas y en algunos casos arreglos granodecrecientes (figuras $5.37 \mathrm{a}$ y $\mathrm{c}$ ). Esta facies se 
presenta solo en el tramo superior de la sucesión terrígena-mixta dentro de la sección Plomo Este (PLE en el Anexo Ia), donde suprayace a la facies de arenisca con estratificación entrecruzada en artesa (St).

Interpretación dinámica: facies generada por la migración unidireccional de dunas bidimensionales gravosas, que en algunos casos llegan a superar los $60 \mathrm{~cm}$ de altura, producto de corrientes intensas derivada de las olas de tormenta en un ambiente marino por encima de las olas de buen tiempo (Hart y Plint, 1995, 2003). Evidencian el retrabajo de las olas la moderada a buena selección que presenta el depósito, su geometría tabular y extensión lateral (Clifton, 1973; Reading y Collinson, 2006).

\section{Conglomerado con estratificación horizontal (Gh)}

Psefita fina con clastos de 10 a $15 \mathrm{~mm}$ de tamaño (tamaño máximo $30 \mathrm{~mm}$ ), matriz soportada, con moderada selección. Desarrolla láminas horizontales de conglomerado intercalados con láminas de arenisca conglomerádicas cuyos espesores oscilan entre 1 a $4 \mathrm{~cm}$ (figura 5.37d). Se distingue un escaso contenido de bioclastos dentro de la facies. El nivel es poco potente ( $0.60 \mathrm{~m}$ de espesor), con geometría tabular, su contacto basal no se encuentra expuesto y su tope es plano y neto. Esta litofacies solamente fue reconocida en el tramo medio de la sucesión terrígena-mixta dentro de la sección Arroyo Torrecillas Oeste (ATW en el Anexo Ia). Se ubica en la base del nivel, pasando hacia arriba a facies de arenisca con estratificación entrecruzada en artesa (St).

Interpretación dinámica: se infiere que el depósito se originó en condiciones ácueas por flujos de alta descarga y baja profundidad (alto régimen de flujo), que pueden corresponder a crecidas en manto o barras muy aplanadas en un ambiente marino por encima de las olas de buen tiempo (Collinson et al., 2006). A su vez la presencia de restos esqueletales y de estratificación horizontal marcada, 
acompañada por su geometría tabular, evidencian el dominio de olas de alta energía como proceso formador de estos conglomerados (Hart y Plint, 2003).

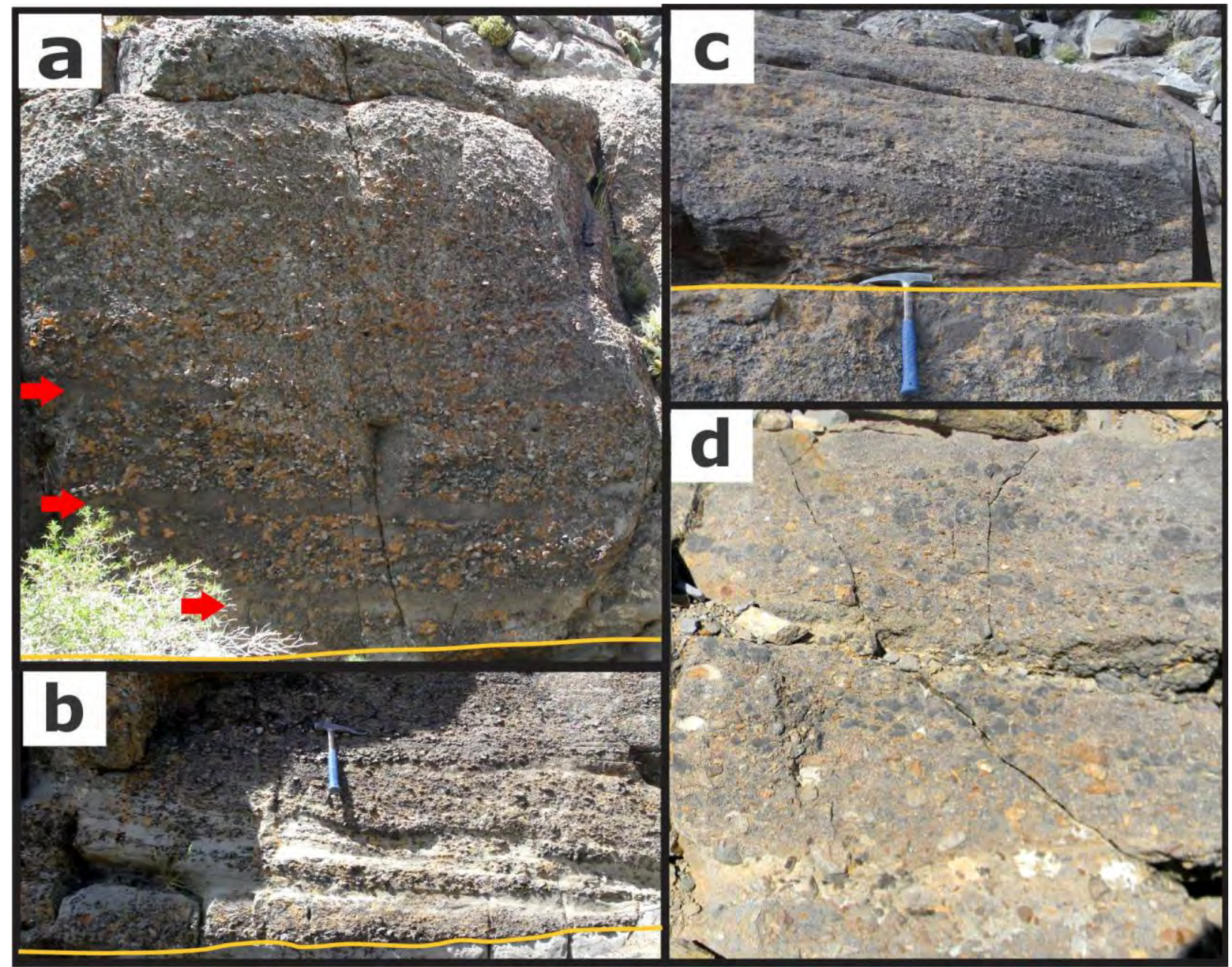

Figura 5.37: Litofacies psefíticas. a) Conglomerado con estratificación entrecruzada planar (Gp) conformando niveles de $2 \mathrm{~m}$ de potencia. En la base se distinguen bandas oblicuas de conglomerado intercalados con bandas de arenisca (flechas rojas). La línea amarilla indica la base del nivel en todas las imágenes. b) Detalle de la estratificación entrecruzada tangencial. La escala de la imagen está dada por la piqueta de $35 \mathrm{~cm}$ de alto. c): Gp conformando un nivel con arreglo granodecreciente. Tramo superior de la sucesión terrígena-mixta en la sección PLE. d): Facies de conglomerado con estratificación horizontal (Gh). Nótese la alternancia de láminas de conglomerado con láminas de areniscas conglomerádicas. El nivel mide $0.60 \mathrm{~m}$. Tramo medio de la sucesión terrígena-mixta en la sección ATW. 


\section{Conglomerado masivo clasto sostén (Gmc)}

Ortoconglomerado fino (fragmentos de 3 a $15 \mathrm{~mm}$; tamaño máximo $40 \mathrm{~mm}$ ), con alta densidad de clastos y moderadas selección (figura 5.38a). Conforma capas tabulares poco potentes y extensas lateralmente (50 a $70 \mathrm{~cm}$ de espesor; 30 a 50 $m$ de extensión), con contacto basal neto plano a irregular (levemente erosivo) y en ocasiones con arreglos granodecrecientes (figura 5.38b). Se presenta como bancos aislados que pasan hacia arriba a facies de arenisca masiva (Sm) o arenisca con estratificación entrecruzada planar (Sp; figura 5.38c). Esta facies se encuentra en el tramo superior de la sucesión terrígena-mixta en el sudoeste de la zona de Malargüe (perfiles APS y ATW, ver Anexo Ia).

Interpretación dinámica: comprenden cuerpos tabulares extensos originados por el retrabajo y redistribución del material gravoso costero por parte de olas de tormenta de períodos largos (swell) en un ambiente marino por encima de las olas de buen tiempo (Leithold y Bourgeois, 1984). Estos estratos evidencian la presencia de un agente que actúa de manera uniforme sobre un amplia área de la costa, lo cual favorece la segregación del material arenoso por sobre el gravoso y la conformación de texturas clasto sostén (Clifton, 1973; Leithold y Bourgeois, 1984; Massari y Parea, 1988; Hart y Plint, 1995; Pomar et al., 2002).

Figura 5.38: Litofacies de conglomerado masivo clasto sostén (Gmc). a) Textura clasto soportada con moderada selección. La barra de escala mide $3 \mathrm{~cm}$ de largo. b) Arreglo granodecreciente. La piqueta de escala mide $35 \mathrm{~cm}$ de alto. Tramo medio de la sucesión terrígena-mixta en la sección ATW. c): Facies Gmc conformando bancos aislados que subyacen a niveles de arenisca masiva ( $\mathbf{S m}$ ). El tope y la base de la unidad están marcados por líneas negras. Tramo medio de la sucesión terrígena-mixta en la sección APS. 


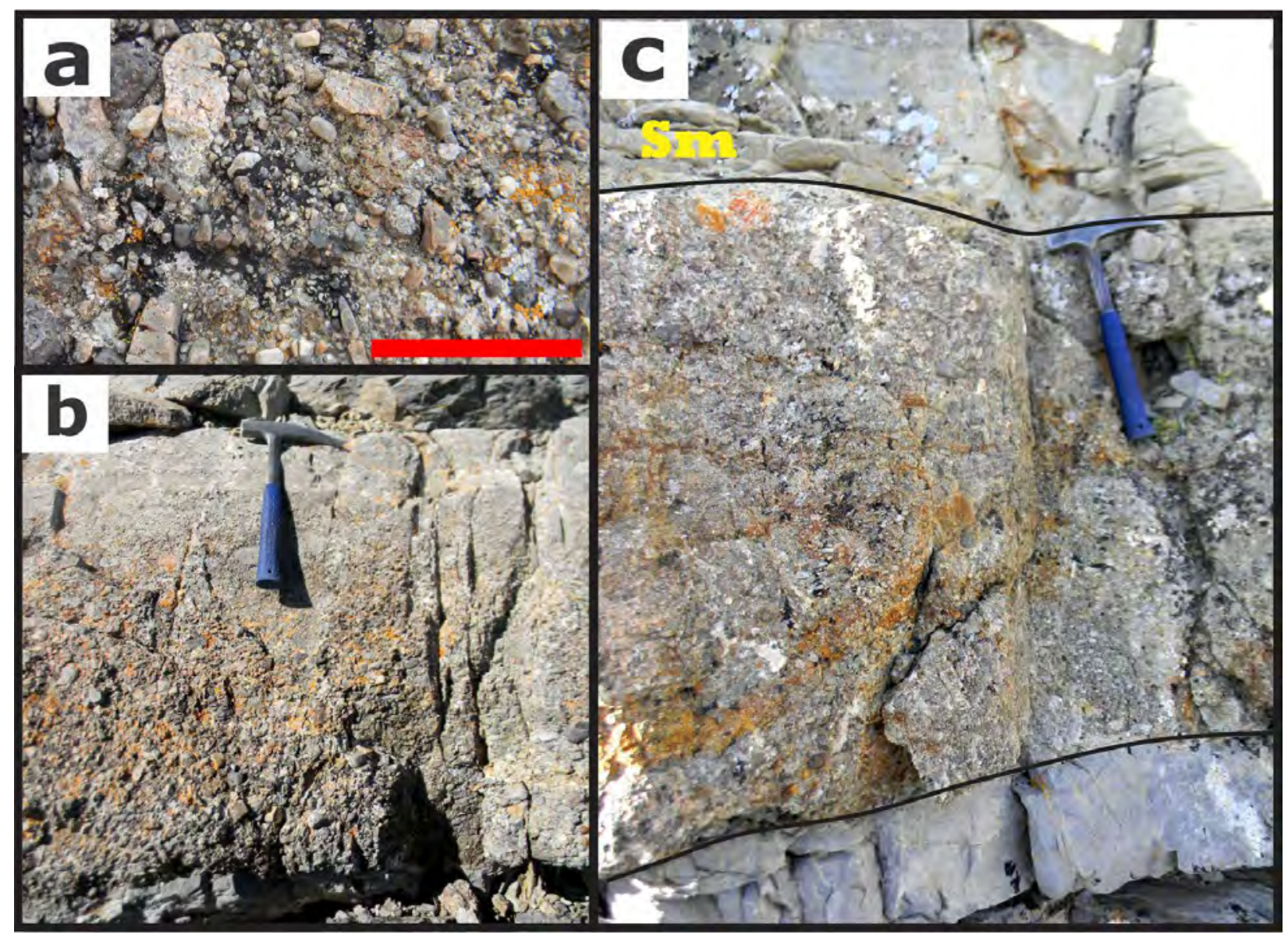

\section{Conglomerado masivo matriz sostén ( $\mathrm{Gmm})$}

Está conformada por psefitas finas a medianas (clastos de 3 a $30 \mathrm{~mm}$ ), matriz sostén, con variable densidad de clastos subredondeados a bien redondeados. Presenta una moderada a pobre selección, matriz arenosa (clástica a carbonática) y escasos restos de corales, bivalvos y calgas rojas? (figuras 5.39a-b). Los niveles tienen potencias que varían entre los 0.3 a $1.75 \mathrm{~m}$ (raramente de $10 \mathrm{~cm}$ de espesor), geometrías lenticulares a irregulares y contactos basales netos e irregulares. Hacia el noreste de la zona de Malargüe las capas portan en su base intraclastos arenosos de bordes subangulosos a subredondeados de 50 a $130 \mathrm{~mm}$ (tamaño máximo) y en ocasiones presentan flutes en su base (figuras 5.39c-d). Aparecen como capas aisladas o amalgamadas, en el tramo inferior a superior de la sucesión terrígena-mixta (secciones ASE a ATW, ver Anexo Ia). Hacia el noreste 
pasa tanto lateral como verticalmente a facies de floatstone intraclástico (Fi), mientras que hacia el sudoeste está relacionada a facies de arenisca masiva (Sm).

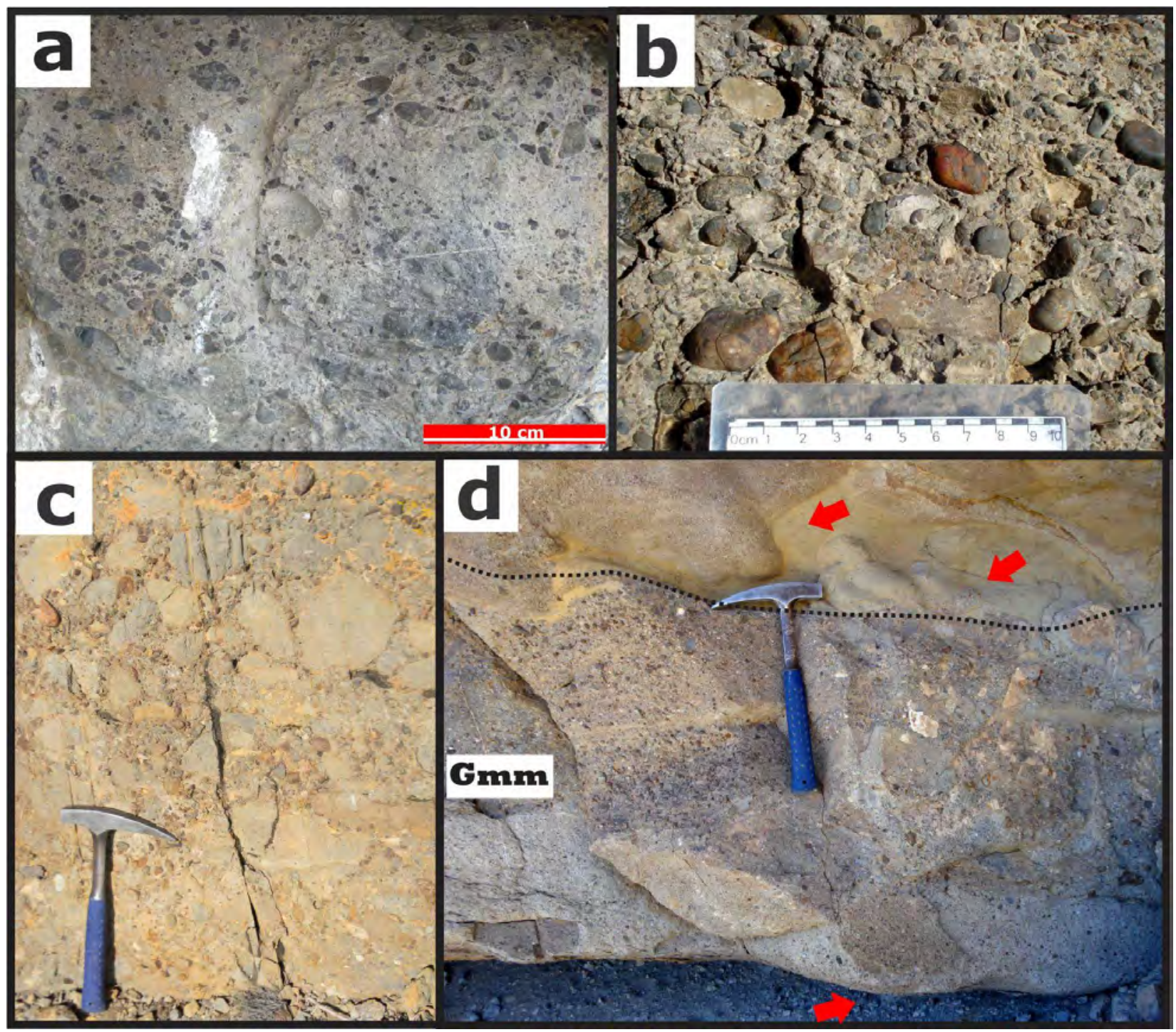

Figuras 5.39: Litofacies de conglomerado matriz sostén masivo ( $\mathbf{G m m}$ ). a) y b): Detalle de la textura matriz sostén donde se distingue la variable densidad de clastos que presenta. Nótese la moderada a pobre selección de $\mathbf{G m m}$ en las imágenes a y b, respectivamente. c): Intraclastos de areniscas en la base de la capa. La piqueta de escala mide $35 \mathrm{~cm}$ de altura. Niveles basales del perfil ASE. d): Niveles de geometría irregular con bases netas e irregulares con presencia de flutes (flecha roja). La línea punteada negra marca el contacto entre ambos niveles. Perfil ACN. 
Interpretación dinámica: a juzgar por la pobre a moderada selección de la facies y la ausencia de estructuras sedimentarias se infiere un flujo confinado que se deposita de forma súbita en una zona transicional fluvial-marina, acompañada por procesos de flujo gravitatorio relacionados con la inestabilidad de este ambiente (Kleinspehn y Steel, 1984; Hart y Plint, 1995; 2003). Sustentan la interacción de procesos fluviales y marinos en este sector costero la textura matriz soportada de la facies, su geometría lenticular a irregular y la presencia de restos esqueletales marinos (Hart y Plint, 2003). Asimismo, su contacto irregular basal junto con la presencia de flutes y relictos de acumulaciones arenosas previas cerca de su base, indicarían un período erosivo de forma anterior a su depositación en el noreste de la zona de Malargüe.

\subsection{2-II: Litofacies psamíticas}

En este grupo se incluye a las litofacies clásticas con mayor representación dentro de las sucesiones terrígena-mixta y carbonática y de amplia distribución areal en la zona de estudio (Anexo I). Están conformadas por fragmentos de 0.062 a $2 \mathrm{~mm}$ de tamaño, de composición terrígena y mixta (tablas 3a y b), asociados con un porcentaje de matriz menor al $15 \%$, aunque también se reconocieron areniscas con mayor proporción de matriz o vaques. Son psamitas finas a gruesas, terrígenas y mixtas, que pueden contener clastos de sábulo a conglomerado fino ( 2 a $15 \mathrm{~mm}$ de tamaño, hasta $20 \mathrm{~mm}$ ) distribuidos en proporciones variables. Siguiendo el esquema de facies propuesto, se reconocen litofacies de areniscas (S) y areniscas conglomerádicas (SG) con igual estructura sedimentaria, ya que a pesar de su textura diferente representan condiciones de sedimentación similares (figura 5.26b). Dichas litofacies psamíticas se encuentran a lo largo de la sucesión terrígena-mixta, menos comunes son en el tramo inferior a medio de la sucesión carbonática. En la zona de Malargüe se reconoce una clara disminución en importancia y espesor de estas litofacies desde el suroeste hacia el noreste (ver Anexo Ia), mientras que en la zona de Bardas Blancas se presentan como capas poco potentes (ver Anexo Ib). 


\section{Areniscas con estratificación entrecruzada en artesa (St)}

Esta litofacies se caracteriza por sets de estratificación entrecruzada en artesa de dimensiones variables, desde tamaños máximos de $20 \mathrm{~cm}$ de potencia por $220 \mathrm{~cm}$ de longitud, hasta mínimos de $2 \mathrm{~cm}$ de espesor por $20 \mathrm{~cm}$ de longitud (figuras 5.40a-b). Conforman cosets de 10 a $40 \mathrm{~cm}$ de espesor dentro de cuerpos tabulares a irregulares con base plana a levemente irregular. Las areniscas comprenden granulometrías finas a medias, de composición mayormente mixta y en menor cantidad terrígena con moderada selección, que en ocasiones pueden portar clastos de sábulo a conglomerado fino (tamaños hasta $10 \mathrm{~mm}$ ) en la base de los sets o en las caras frontales. Su proporción en volumen varía ampliamente dentro de la facies hasta conformar areniscas conglomerádicas (subfacies sGt, figura 5.40b). Esta facies se presenta dentro de la sucesión terrígena-mixta en el centro y sudoeste de la zona de Malargüe (perfiles PLN, PLE y ATW, ver Anexo Ia).

Interpretación dinámica: se infiere que esta facies fue generada por la migración unidireccional de ondulas a dunas tridimensional (dado el espesor variable de los sets entrecruzados) en un ambiente marino por encima de las olas de buen tiempo (Bourgeois y Leithold, 1984; Clifton, 2006). Dicha migración puede ocurrir como resultado de la acción de las olas, o de sus corrientes derivadas, activas durante períodos de buen tiempo o tormenta (Leithold y Bourgeois, 1984; Massari y Parea, 1988; Clifton, 2006). Alternativamente estos depósitos arenosos pueden formarse por debajo del nivel de olas de buen tiempo durante las tormentas, cuando el nivel de base de olas se profundiza (Leithold y Bourgeois, 1984).

\section{Subfacies de areniscas conglomerádicas con estratificación entrecruzada en artesa (SGt SF1)}

Se compone de areniscas mixtas y terrígenas medias con láminas de conglomerados finos ( 5 a $10 \mathrm{~mm}$ de tamaño, hasta $20 \mathrm{~mm}$ ) ubicados en la base y en las caras frontales de los sets (figura 5.40b). Los sets de artesas presentan 
dimensiones que varían desde los 10 a $20 \mathrm{~cm}$ de potencia por 150 a $250 \mathrm{~cm}$ de longitud. Conforman cosets de hasta $40 \mathrm{~cm}$ de espesor donde se distingue un pasaje lateral continuo desde facies de Gt hacia facies de st. Junto con estas facies forman cuerpos tabulares a irregulares con contactos basales netos planos a levemente erosivos y arreglos granodecrecientes (figura 5.40c). Se presenta en el tramo superior de la sucesión terrígena-mixta, en la sección Plomo Este.

Figura 5.40: Litofacies de arenisca con estratificación entrecruzada en artesa (St). a) Sets de 2 a $3 \mathrm{~cm}$ de potencia en el perfil ATW. La barra de escala mide $5 \mathrm{~cm}$. b) Facies de st y arenisca conglomerádica con estratificación entrecruzada en artesa (SGt) donde se distinguen láminas de conglomerados finos en la cara frontal de los sets. Los sets miden 5 a $20 \mathrm{~cm}$ de espesor (escala piqueta de35 cm de alto). Ejemplo sacado del perfil PLE. c) Facies sGt y St, en este caso aparecen por un pasaje lateral desde la facies de Gt. Conforman un cuerpo irregular con arreglo granodecreciente. Ejemplo tomado de la sección PLE.

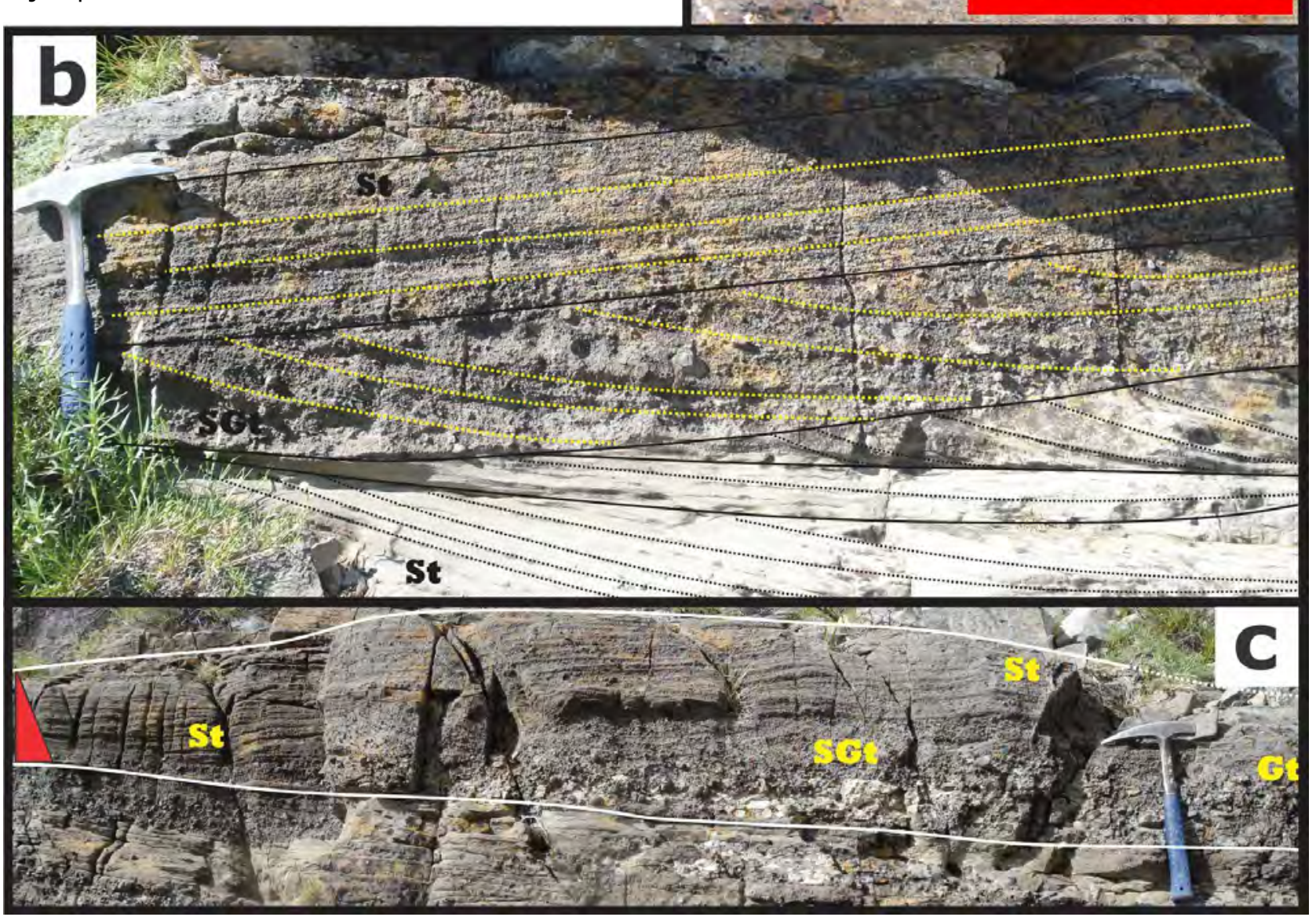


Interpretación dinámica: esta facies al igual que la facies Gt representa la migración de dunas tridimensionales gravo-arenosas generadas por corrientes inducidas por las olas de tormenta en un ambiente marino por encima de las olas de buen tiempo (Leithold y Bourgeois, 1984; Massari y Parea, 1988).

\section{Arenisca con estratificación entrecruzada monticular (Sx)}

Esta litofacies es poco frecuente dentro de la unidad, está caracterizada por areniscas finas a medias terrígenas y mixtas, con moderada selección y laminación fina de bajo ángulo hasta horizontal que desarrolla montículos y cubetas. Conforman cuerpos tabulares poco espesos ( 0.30 a $0.60 \mathrm{~m}$ de potencia), con contacto basal neto y plano, y presencia de montículos aislados de mayor escala (60 $\mathrm{cm}$ de potencia y $\lambda: 70 \mathrm{~cm}$ ) a amalgamados de menor escala (10 a $20 \mathrm{~cm}$ de potencia y $\lambda: 20$ a $80 \mathrm{~cm}$ ). Se presenta dentro del sector superior de la sucesión terrígena-mixta en las secciones Plomo Norte, Plomo Oeste y Arroyo Torrecillas Oeste (ver Anexo Ia). Aparece como capas aisladas por encima de facies de psamitas masivas $(\mathbf{S m})$ o de floatstone intraclástico $\left(\mathbf{F}_{\mathbf{i}}\right)$ y en general es cubierta por la facies Sm (figura 5.41a).

Interpretación dinámica: se infiere que los montículos de menor escala comprenden ondulas tridimensionales pequeñas y simétricas, mientras que la estructura de mayor escala se habría generado por ondulas similares de mayor tamaño (Myrow y Southard, 1991). De acuerdo con estos autores dichas estructuras se deben a la acción de flujos oscilatorios puros o combinados dominados por la oscilación; estos flujos se originan durante condiciones de tormenta en un ambiente marino abierto por debajo del nivel de base de olas de buen tiempo (Dott y Bourgeois, 1982; Reading y Collinson, 1996). 


\section{Arenisca con estratificación entrecruzada planar (Sp)}

Está conformada por areniscas de grano medio a grueso, de moderada selección, con ocasionales clastos tamaño sábulo a grava fina (2 a $10 \mathrm{~mm}$ ) distribuidos en las caras frontales de los sets. Presentan estratificación entrecruzada planar a tangencial, formada por sets de 15 a $60 \mathrm{~cm}$ de espesor. Conforman cuerpos tabulares a irregulares de 0.4 a $1.10 \mathrm{~m}$ de potencia, con contactos basales netos planos a levemente erosivos. Pueden contener fragmentos de colonias de corales, bivalvos no ostreidos y restos de bioclastos indiferenciados. En general suprayace a facies de conglomerado masivo clasto sostén (Gmc) o arenisca masiva (Sm) y es cubierta por facies de $\mathbf{S h}$ (arenisca con estratificación horizontal) y Sm (figura 5.41b). Se distribuyen dentro de la sucesión terrígena-mixta, en el sudoeste de la zona de Malargüe (secciones APS y ATW, ver Anexo Ia).

Interpretación dinámica: la estratificación entrecruzada plana a tangencial se interpreta como la migración de ondulas a dunas bidimensionales debido a la acción de olas o flujos unidireccionales. Estas estructuras se generan en un ambiente marino por encima de las olas de buen tiempo (Clifton, 1987).

\section{Arenisca con estratificación entrecruzada de bajo ángulo (S1)}

Es una facies poco frecuente dentro de la unidad, solo se encuentra en el tramo inferior de la sucesión carbonática en el noreste de la zona de Malargüe (perfil ACN, ver Anexo Ia). Se compone de areniscas muy gruesas a sabulitas, con moderada selección. Presenta estratificación entrecruzada plana de bajo ángulo difusa, conformada por sets de 40 a $60 \mathrm{~cm}$ de espesor. Forma un nivel irregular de $2.30 \mathrm{~m}$ de potencia, con base plana levemente erosiva con presencia de flutes (figuras 5.42a-b). Se presenta como una capa aislada ubicada entre facies de conglomerado masivo matriz sostén ( $\mathbf{G m m}$ ) y de floatstone intraclástico (Fi). 
Interpretación dinámica: esta facies se generó por una sedimentación episódica conformada por una fase temprana erosiva donde una corriente erosiona el material fino ubicado en el tope de los niveles subyacentes (Gmm, Fi), seguida inmediatamente por otra de depositación del material grueso cuando empieza a disminuir el régimen de flujo de dicha corriente. Asimismo, se infiere que la estratificación entrecruzada de bajo ángulo fue originada por condiciones de alto régimen de flujo.

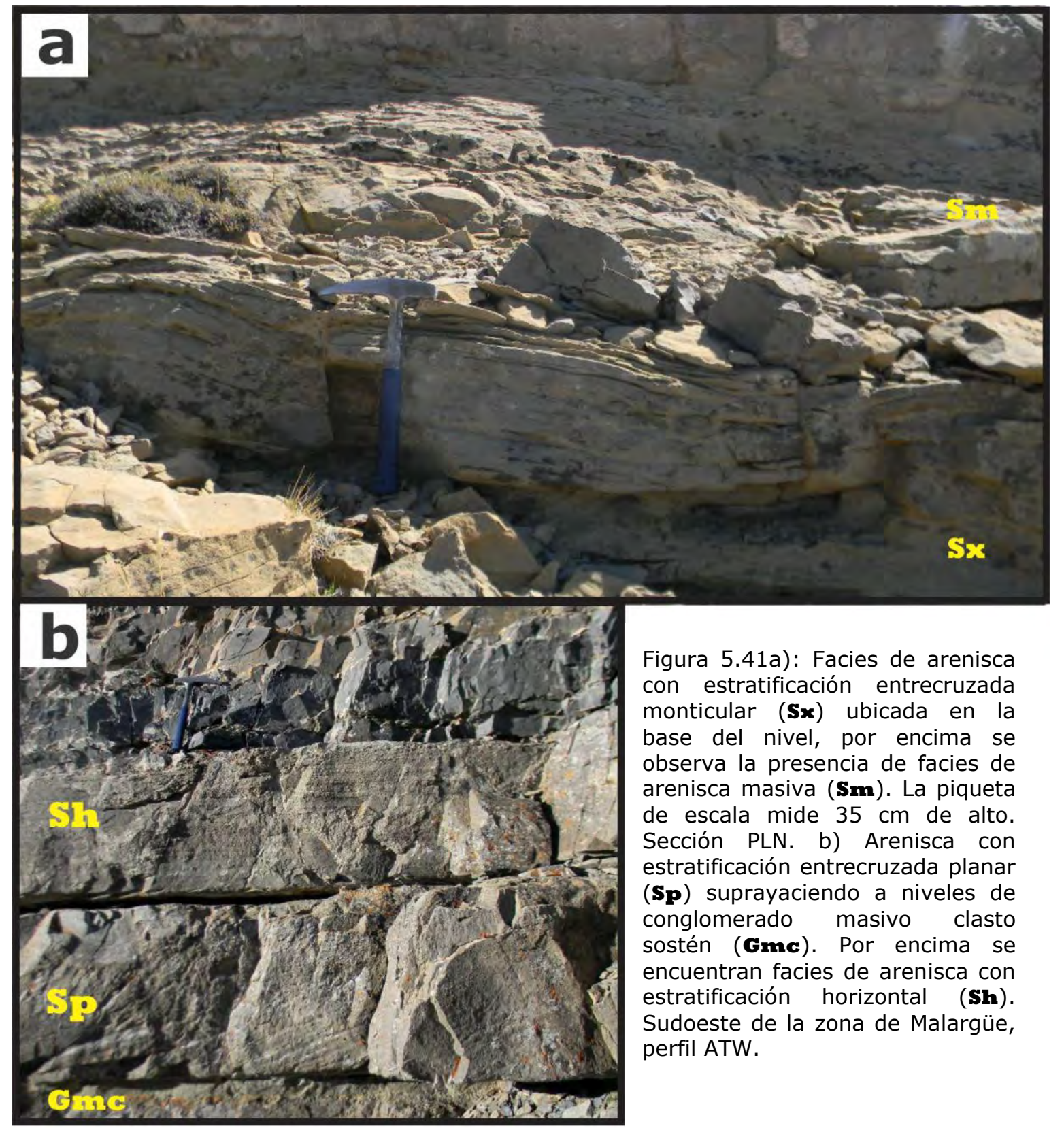




\section{Arenisca con estratificación horizontal (Sh)}

Está conformada por láminas paralelas (1 a $4 \mathrm{~cm}$ de espesor) de arenisca media que se intercalan con otras de arenisca gruesa a muy gruesa, a veces con clastos tamaño sábulo a grava fina dispersos (figura 5.42c). Cuando las láminas presentan espesores menores a $1 \mathrm{~cm}$ conforman la subfacies Shl. La composición resulta ser mixta a terrígena, con buena a moderada selección y pueden contener restos esqueletales (ostras, ¿algas rojas?, corales, equinoideos, braquiópodos y bivalvos no ostreidos). Constituye bancos tabulares a irregulares de 0.30 a $0.70 \mathrm{~m}$ de espesor, con base neta plana a irregular, que en ocasiones puede portar intraclastos de areniscas mixtas (hasta $3 \mathrm{~cm}$ de tamaño) paralelos a la estratificación (figuras 5.41d-e). Su tope es plano a irregular. Esta facies se distribuye en el tramo inferior a superior de la sucesión terrígena-mixta en el centro a sudoeste de la zona de Malargüe (PLN-ATW, ver Anexo Ia). Se presenta como bancos aislados asociados a la facies $\mathbf{S m}, \mathbf{S p}$ o $\mathbf{G m m}$, o en el tope de las capas suprayaciendo a facies de $\mathbf{S m}$.

Interpretación dinámica: comprende depósitos originados en condiciones ácueas de alto régimen de flujo, es decir producido por corrientes de alta descarga y baja profundidad, que podrían corresponder con flujos en manto dentro de un ambiente marino por encima de las olas de buen tiempo (Clifton, 1987, 2006; Collinson et al., 2006). A su vez, a juzgar por la ocasional presencia de intraclastos en la base de las facies, se infiere un período erosivo anterior a su depositación.

\section{Subfacies de arenisca con laminación horizontal (Shl SF)}

Arenisca terrígena a mixta de buena selección, conformada por láminas horizontales de 1 a $2 \mathrm{~mm}$ de espesor de granulometrías finas intercaladas con psamitas muy finas. Comprende niveles poco potentes $(0.15 \mathrm{~m})$, con geometría tabular y contactos netos y planos con la facies inferior y superior (figura $5.42 \mathrm{f}$ ). Se presenta como una capa aislada entre los niveles carbonáticos del tramo inferior 
a medio de la sucesión carbonática en la zona de Bardas Blancas (perfil ALV, ver Anexo Ib).

Interpretación dinámica: se establece que la facies fue originada por flujos de densidad inducidos por las tormentas, en un ambiente marino por debajo del nivel de olas de buen tiempo. Asimismo, el contacto neto y plano de la capa indicativo de un flujo no permanente, representa un aporte episódico de material terrígeno hacia esta área (Aurell y Bádenas, 2004).

\section{Arenisca y arenisca conglomerádica masiva (Sm, SGm)}

Es la litofacies clástica más representada en la zona de estudio. Aparece de base a techo dentro del intervalo estudiado tanto en la zona de Malargüe como en la de Bardas Blancas, con una clara disminución de su representatividad desde el sudoeste hacia el noreste en la zona de Malargüe, y escasa participación en la zona de Bardas Blancas (ver Anexos Ia-b). Incluye a las areniscas terrígenas y mixtas en las que no se observa estructuras sedimentarias mecánicas ni evidencias claras de bioturbación, junto con las areniscas terrígenas con clara homogenización por bioturbación (Smw SF). En general se corresponden con texturas finas a gruesas, de moderada selección y ocasional presencia de clastos terrígenos de 2.5 a $5 \mathrm{~mm}$ de largo (tamaños hasta $15 \mathrm{~mm}$ ) que pueden llegar a presentarse en proporciones significativas dentro de la roca (facies $\mathbf{S G m}$ ). Es común la presencia de restos esqueletales de ostras, corales, bivalvos no ostreidos, ¿algas rojas? y bioclastos indiferenciables dentro de la facies. Las capas son tabulares a irregulares, aunque también pueden ser lenticulares, con contactos basales netos planos a irregulares, raramente transicionales, y espesores entre 0.20 y $1.60 \mathrm{~m}$.

Interpretación dinámica: la ausencia de una estructura sedimentaria primaria se interpreta como resultado de una rápida depositación, probablemente por la súbita desaceleración de un flujo denso (Collinson et al., 2006). No obstante, no se descarta que la masividad pueda haber sido originada por una bioturbación intensa 
posterior a su depositación, sobre todo cuando la facies se encuentra asociada con depósitos arenosos similares con presencia de estructuras tractivas.

\section{Subfacies de arenisca masiva con ondulas simétricas ( $S m w$ SF)}

Comprende areniscas terrígenas de grano fino a medio con un grado total de homogeneización por bioturbación y ocasional presencia de ondulas simétricas y laminación paralela difusa. Dentro de la misma se distinguen traza fósiles representadas por tubos horizontales paralelos a la base y techo de la capa, que tentativamente se asignan a planolites isp. Es frecuente la presencia de briznas vegetales acompañada por fragmentos de fósiles marinos (bivalvos, amonites, equinoideos y braquiópodos). Los niveles tienen potencias de 0.10 a $1.20 \mathrm{~m}$, geometrías tabulares a irregulares y contactos netos y planos a irregulares con las facies subyacente y suprayacente. Se distribuye en el tramo superior de la sucesión terrígena-mixta en el noreste del área de Malargüe (secciones ANE-ACS, Anexo Ia).

Interpretación dinámica: de acuerdo con la presencia de laminación paralela y de ondulas simétricas se infiere un deposito generado por encima de la base de olas de buen tiempo, bajo condiciones de baja velocidad de olas y/o flujos bidireccionales (Wilson, 2005). Asimismo, se interpreta que la masividad de la facies se debe a una destrucción parcial de la estructura primaria original a través del intenso retrabajo de parte de los organismos (Collinson et al., 2006). El contenido de restos vegetales indica el suministro de material terrestre hacia estos depósitos. 


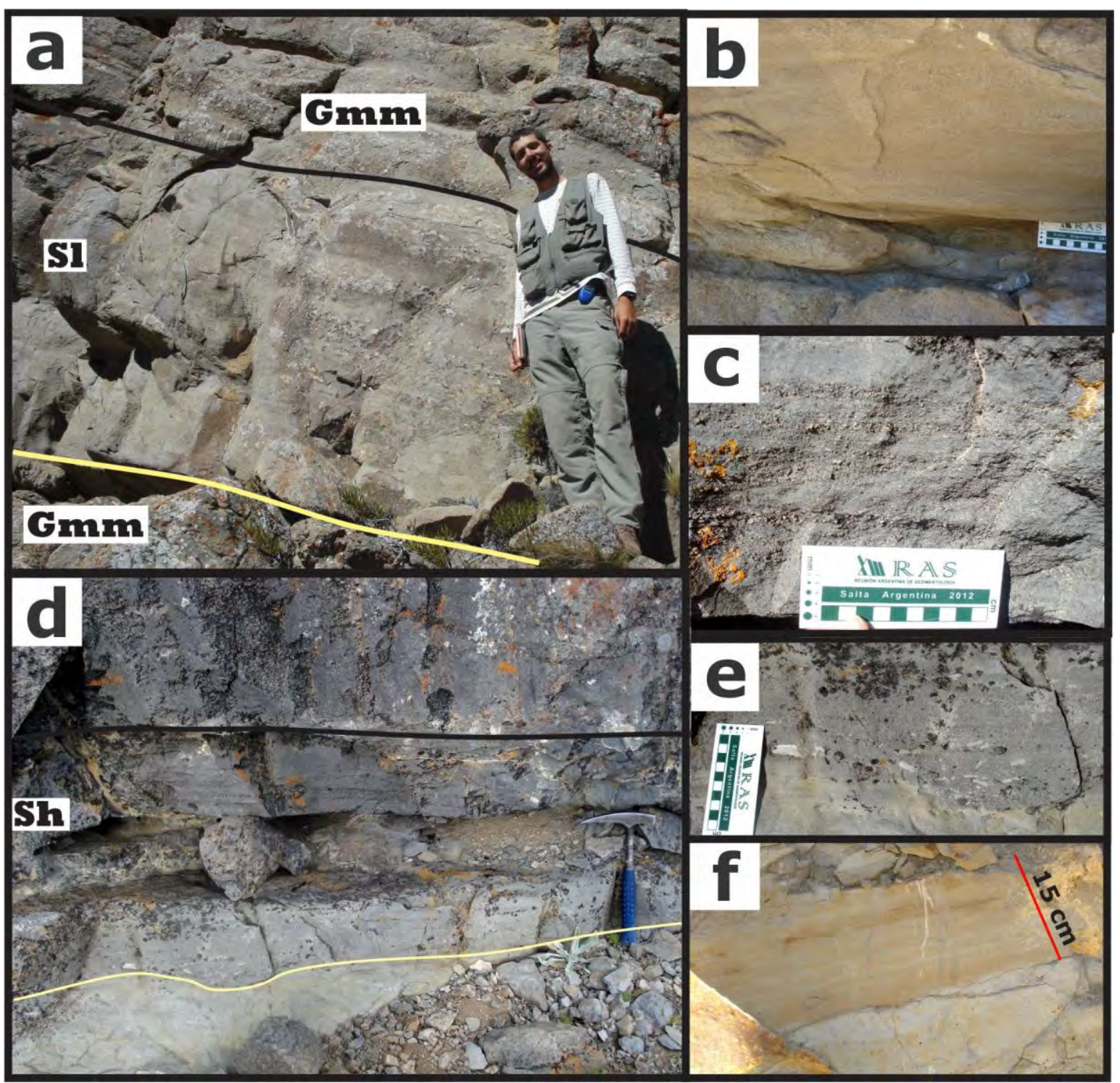

Figura 5.42: a) Litofacies de arenisca con estratificación entrecruzada de bajo ángulo (S1). La línea amarilla marca el contacto neto y plano con la facies subyacente $\mathbf{G m m}$ (conglomerado masivo), la línea negra marca el contacto con la facies suprayacente. Escala persona de 2 metros de alto. b) Detalle de la base del nivel donde se destaca la presencia de flutes. Perfil ACN. c) Facies de arenisca con estratificación horizontal (Sh). c) Láminas horizontales de arenisca gruesa intercaladas con láminas de arenisca media. d) Contacto basal plano a irregular con la facies subyacente (línea amarilla) y neto y plano con la facies suprayacente. e) Intraclastos de arenisca mixta paralelos a la estratificación. Sección PLE. f) Litofacies de arenisca con laminación paralela $(\mathbf{S})$. Sección ALV 


\section{CAPÍTULO 6: ASOCIACIONES DE FACIES}

\section{1: Introducción}

Para una correcta interpretación paleoambiental del intervalo estratigráfico estudiado, es esencial el conocimiento de las relaciones existentes entre las litofacies que lo conforman (Reading y Levell, 1996). Teniendo en cuenta esta información se puede agrupar a las litofacies en un número determinado de asociaciones de facies (AF), lo que permite conferirle una característica ambiental a cada asociación (Reading y Levell, 1996).

En este apartado se abordará la cuarta etapa del análisis de facies propuesto por Pirrie (1998), correspondiente al agrupamiento de las facies reconocidas para las sucesiones carbonática y terrígena-mixta en asociaciones de facies. Para luego interpretar los sistemas depositacionales que serán tratados en el capítulo 8.

Para establecer cada asociación se consideraron las relaciones entre facies, la geometría y escala de los litosomas intervinientes, definida en los afloramientos, y la composición en el caso del grupo de facies carbonáticas. En este sentido, las diferentes asociaciones de facies fueron descriptas en términos de la distribución espacial de las facies presentes, de la geometría externa (tabular, irregular, cuneiformes) y dimensiones (espesor y extensión lateral).

En el intervalo estratigráfico estudiado las asociaciones de facies se corresponden a un medio marino somero, dadas las características principales de las litofacies que las integran detalladas en el capítulo 5 (figuras $5.26 a$ y b) y su contenido fosilífero puntualizado en el Anexo IIIa-b. Se agruparon de acuerdo con su composición en un sistema de acumulación marino abierto carbonático (C), donde predominan las facies carbonáticas, y en otro clástico $(M)$ donde las litofacies terrígenas y mixtas resultan frecuentes. Dicho ordenamiento no coincide con su posición estratigráfica, puesto que aquellas asociaciones de facies clásticas, que representan condiciones de sedimentación proximal y texturas más gruesas, son las que se encuentran de preferencia en las porciones inferiores a medias del intervalo estratigráfico 
analizado; mientras que los grupos de facies carbonáticas son los que se ubican en general hacia el tope de este intervalo. Dentro de cada sistema de acumulación, las asociaciones de facies que lo conforman se organizaron respecto a su posición con la paleolínea de costa, desde las ubicadas en sectores más distales hasta los más proximales. La distribución lateral y vertical de dichas asociaciones de facies dentro de las zonas de Malargüe y Bardas Blancas puede consultarse en el Anexo IVa y b. Por otra parte, en las figuras $6.1 \mathrm{a}$ y $\mathrm{b}$ se muestran las características principales de las asociaciones de facies individuales desarrolladas de forma sintética. A esta información se le suman los datos de paleocorrientes de la figura 6.2, recolectadas solo en las asociaciones de facies de la sección Plomo Este (PLE) donde los afloramientos resultaron ser de fácil acceso y las estructuras sedimentarias se denotaron visibles y bien delimitadas. Por otra parte, en el Anexo IIIb se detallan los taxones presentes en las asociaciones de facies.

\section{2: Asociaciones de facies de sistema de acumulación marino abierto carbonático (C)}

Dicha asociación está conformada por litofacies carbonáticas y escasas facies terrígenas de naturaleza psamítica. Las mismas fueron agrupadas en seis asociaciones de facies que se incluyen dentro de los subambientes de rampa media e interna (figura 6.1a) según el modelo de rampa carbonática propuesto por Ahr (1973) y modificado por Burchette y Wright (1992). Dentro de este ambiente las subdivisiones se definen de acuerdo con los procesos depositacionales dominantes (Wright y Burchette, 1996). De esta forma se considera rampa media a la zona que yace entre el nivel de base de olas de buen tiempo y de tormenta, donde dominan los procesos de tormenta. Por su parte, el subambiente de rampa interna se interpreta como el sector de acumulación ubicado por encima del nivel de base de olas de buen tiempo donde la actividad de las olas y de las mareas resulta casi continua (Burchette y Wright, 1992; Wright y Burchette, 1996). 


\begin{tabular}{|c|c|c|c|c|c|c|c|}
\hline Asociación & Conformación interna & \multicolumn{2}{|c|}{ Facies } & $\begin{array}{l}\text { Fósiles/bioturbación } \\
\text { Otras características }\end{array}$ & Imágenes & \multicolumn{2}{|r|}{ Ambiente depositacional } \\
\hline \multirow[t]{2}{*}{ C1 } & $\frac{0_{0}}{1001}$ & \multirow{2}{*}{\multicolumn{2}{|c|}{\begin{tabular}{l|l}
$\mathrm{Pp}-\mathrm{b}(\mathrm{SF} 1) / \mathrm{Wb}$ \\
$\mathrm{Sm} / \mathrm{SF}$ Shl \\
$\mathrm{Pp}$ \\
$\mathrm{Pp}$ \\
$\mathrm{Wb}$ \\
$\mathrm{Pb} / \mathrm{Pp}-\mathrm{b}$ (SF1)
\end{tabular}}} & $\begin{array}{l}\text { 3-4: bivalvos y equinoideos. } 2: \\
\text { gasterópodos y corales. } \\
0\end{array}$ & 6.3 & \multirow{3}{*}{ 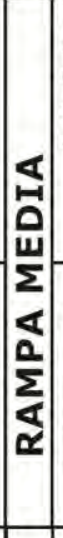 } & \multirow{2}{*}{$\begin{array}{l}\text { Foreshoal dominado por la acción de } \\
\text { corrientes tractivas en el sector } \\
\text { proximal y procesos de tracción- } \\
\text { decantación en la zona distal. }\end{array}$} \\
\hline & & & & $\begin{array}{l}\text { 3-4: bivalvos y equinoideos. 2: } \\
\text { gasterópodos y corales. }\end{array}$ & & & \\
\hline $\mathbf{C 2}$ & 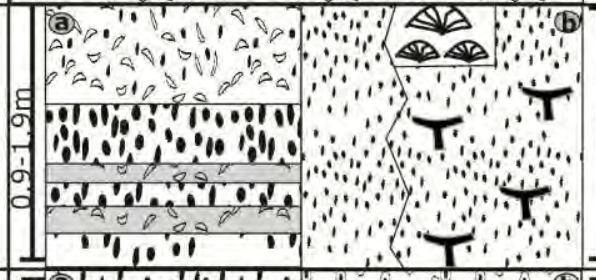 & 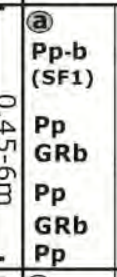 & FRc & $\begin{array}{l}\text { a) 3: equinodermos, bivalvos y } \\
\text { braquiópodos. } \\
\text { b) Colonias de corales in situ } \\
\text { con ostras, 2: restos de corales } \\
\text { ostras; 1:bivalvos no ostreidos, } \\
\text { gasterópodos, braquiópodos, } \\
\text { algas (Dasycladales). } \\
\text { Icnofacies de Glossifungites. }\end{array}$ & $\begin{array}{l}6.4,6.5 \\
6.6 \text { y } 6.7\end{array}$ & & $\begin{array}{l}\text { a-Foreshoal proximal con frecuentes } \\
\text { tormentas. } \\
\text { b-Foreshoal proximal con desarrollo } \\
\text { de un firmground e implantación de } \\
\text { arrecifes en parche discretos. }\end{array}$ \\
\hline C3 & 0000000000 & \begin{tabular}{|l|l|} 
\\
0 \\
$\vdots$ \\
$\vdots$
\end{tabular} & \begin{tabular}{l|} 
GRo \\
Grb
\end{tabular} & $\begin{array}{l}\text { a) 3: ostras y colonias de } \\
\text { corales. } \\
\text { b) 2:gasterópodos, bivalvos, } \\
\text { cianobacterias, equinoideos y } \\
\text { foraminíferos. }\end{array}$ & $\begin{array}{l}6.5 ; 6.6 a- \\
b ; 6.8\end{array}$ & & $\begin{array}{l}\text { a-Shoal peloidal. } \\
\text { b-Shoal oolítico. }\end{array}$ \\
\hline C4 & & Pp-b-i & $\begin{array}{l}\text { Pp-b-i } \\
\text { Pp }\end{array}$ & \begin{tabular}{|l|} 
2: corales, bivalvos, \\
cianobacterias, gasterópodos. \\
equinoideos.
\end{tabular} & $6.8 b ; 6.9$ & 虽 & \begin{tabular}{|l|} 
Intershoal dominado por las \\
corrientes tractivas con ocasionales \\
períodos de sedimentación tranquila.
\end{tabular} \\
\hline C5 & 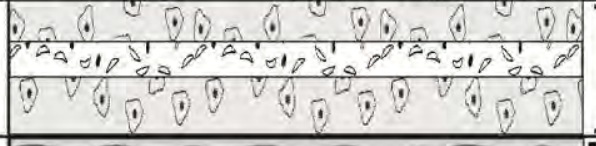 & $\begin{array}{l}\mathrm{Pp}-\mathrm{b}-\mathrm{i} \\
\mathrm{Fa}-\mathrm{O} / \mathrm{F} \\
\mathrm{Pp}-\mathrm{b} \text { (s }\end{array}$ & & $\begin{array}{l}\text { 2:cianobacterias, bivalvos, } \\
\text { gasterópodos, braquiópodos, } \\
\text { equinoideos, foraminíferos. }\end{array}$ & $6.8 \mathrm{a}$ & 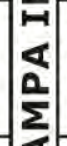 & $\begin{array}{l}\text { Albufera dominada por las } \\
\text { condiciones de sedimentación } \\
\text { tranquila. }\end{array}$ \\
\hline C6 & 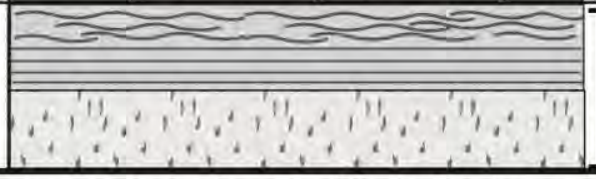 & 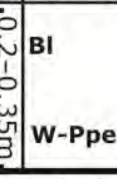 & & $\begin{array}{l}\text { 0. Estromatolitos laminares, } \\
\text { EES (comunes). } \\
\text { 2: bivalvos, gasterópodos, } \\
\text { equinoideos y foraminiferos. } \\
\text { EES (raras). }\end{array}$ & 6.10 & $\varangle$ & $\begin{array}{l}\text { Llanura de marea con condiciones } \\
\text { submareales a intermareales hacia } \\
\text { el tope. }\end{array}$ \\
\hline & 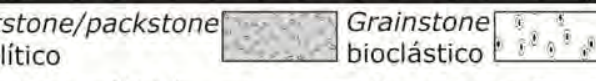 & & & 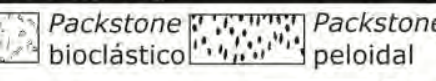 & W. & & rés \\
\hline
\end{tabular}

Figura 6.1a: Asociaciones de facies de ambiente marino abierto carbonáticas (C1-C6). Los números indican la abundancia relativa de los restos esqueletales dentro de cada AF: 0 ausente; 1: escaso, 2: bajo; 3: moderado; 4: abundante. EES: estructuras de exposición subaérea. 


\begin{tabular}{|c|c|c|c|c|c|}
\hline Asociación & Constitución interna/geometría & Facies & $\begin{array}{l}\text { Fósiles/bioturbación } \\
\text { Otras características }\end{array}$ & Imágenes & Ambiente depositacional \\
\hline M1 & 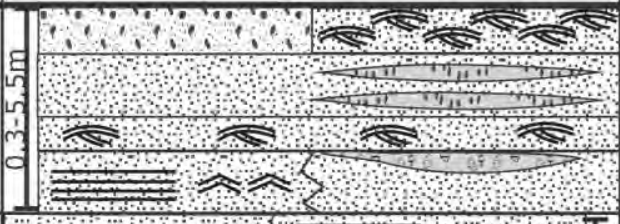 & \begin{tabular}{|l|}
$\mathbf{S G m} / \mathbf{S x}$ \\
$\mathrm{Sm} / \mathrm{Pp}-\mathrm{Sm}$ \\
$\mathrm{Sx}$ \\
$\mathbf{F i}$ \\
$\mathrm{SF} \mathbf{S m w} / \mathbf{S m}$ \\
\end{tabular} & $\begin{array}{l}\text { 2-3: briznas vegetales, } \\
\text { bivalvos, amonites, } \\
\text { equinodermos y braquiópodos. } \\
\text { 2-3:bivalvos, ?algas rojas?, } \\
\text { corales, braquiópodos. }\end{array}$ & 6.11 & $\begin{array}{l}\text { Shoreface inferior afectada } \\
\text { por flujos oscilatorios o } \\
\text { combinados durante } \\
\text { condiciones de buen tiempo } \\
\text { y de tormenta. }\end{array}$ \\
\hline M2 & 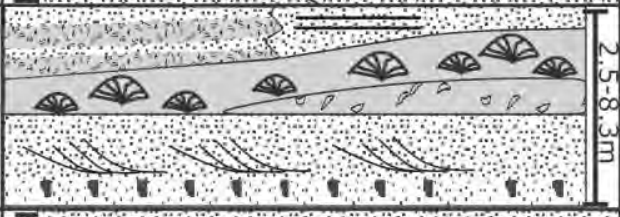 & $\begin{array}{l}\text { Pp-b(SF1)-Sh-Sn } \\
\text { FRc (SF1)/FRc } \\
\text { Fb } \\
\text { Sm } \\
\text { St } \\
\text { Gh }\end{array}$ & $\begin{array}{l}\text { 3-4:?algas rojas?, bivalvos, } \\
\text { corales, equinoideos. } \\
\text { Colonias de corales in situ. } 3 \text { : } \\
\text { ostras, braquiópodos, serpúlidos y } \\
\text { equinoideos. }\end{array}$ & 6.12 & $\begin{array}{l}\text { Shoreface inferior a } \\
\text { superior con arrecifes en } \\
\text { parche discretos. }\end{array}$ \\
\hline M3 & $\frac{1}{4+4}$ & $\begin{array}{l}\text { Sm } \\
\text { Sh } \\
\text { Sp } \\
\text { Gme }\end{array}$ & $\begin{array}{l}\text { 2:bivalvos y colonias de } \\
\text { corales. }\end{array}$ & 6.13 & Shoreface superior. \\
\hline M4 & 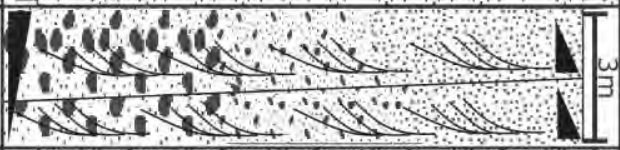 & Gt, SGt,St & $\begin{array}{l}\text { 3: bivalvos, ?algas rojas?, } \\
\text { equinodermos. }\end{array}$ & 6.14 & $\begin{array}{l}\text { Barra gravo-arenosa debido } \\
\text { a condiciones de tormenta } \\
\text { en el shoreface superior. }\end{array}$ \\
\hline M5 & l & \begin{tabular}{|l|} 
St \\
Sm \\
Sh \\
Gmm
\end{tabular} & $\begin{array}{l}\text { 3: bivalvos, ?algas rojas? y } \\
\text { restos de corales. }\end{array}$ & 6.15 & $\begin{array}{l}\text { Foreshore-shoreface } \\
\text { superior. }\end{array}$ \\
\hline M6 & 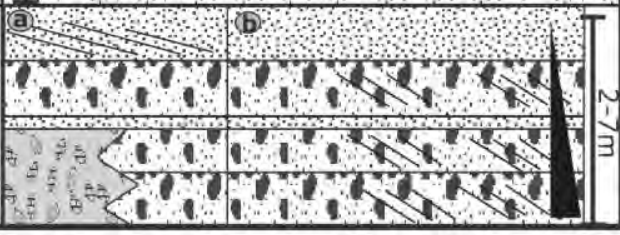 & $\begin{array}{ll}\mathrm{s} 1 / \mathrm{Sm} & \\
\mathrm{Gmm} & \\
\mathrm{Sm} & G_{P} \\
\mathrm{Fi} / \mathrm{Gmm}_{\mathrm{mm}} & G_{\mathbf{P}}\end{array}$ & $\begin{array}{l}\text { a) 3-2: colonias de corales, } \\
\text { serpúlidos, bivalvos y } \\
\text { amonites. } \\
\text { b) 3-2: colonias de corales, } \\
\text { ?algas rojas?, bivalvos. }\end{array}$ & 6.16 & $\begin{array}{l}\text { Barra de desembocadura en } \\
\text { un ambiente marino } \\
\text { somero. }\end{array}$ \\
\hline $\begin{array}{l}\text { Floa } \\
\text { bioc }\end{array}$ & 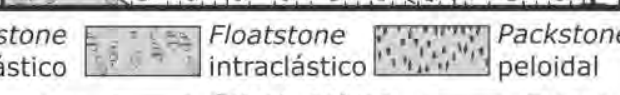 & e $\begin{array}{l}\text { Packst } \\
\text { peloida }\end{array}$ & $\begin{array}{l}\text { tone } \\
\text { al-bioclástico }\end{array}$ & 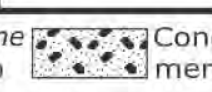 & 10 Sabulita \\
\hline $\begin{array}{l}\text { Estra } \\
\text { en at }\end{array}$ & $\begin{array}{l}\text { entrec. } \approx \begin{array}{l}\text { Estrat. entrec. } \\
\text { de bajo ángulo }\end{array} \approx \begin{array}{l}\text { Estrat } \\
\text { monti }\end{array}\end{array}$ & entrec. & $\begin{array}{l}\text { Estrat. entrec. } \begin{array}{c}\text { Estrat } \\
\text { horiz }\end{array} \\
\text { lana }\end{array}$ & ción & 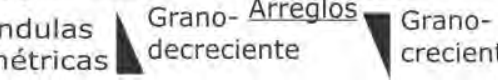 \\
\hline
\end{tabular}

Figura 6.1b: Asociaciones de facies clásticas de ambiente marino abierto (M1-M6). Los números indican la abundancia relativa de los restos esqueletales dentro de cada AF: 0 ausente; 1 : escaso, 2: bajo; 3: moderado; 4: abundante. Estrat: estratificación; entrec.: entrecruzada. 


\section{Asociación de facies M4 (facies St)}

Nivel superior

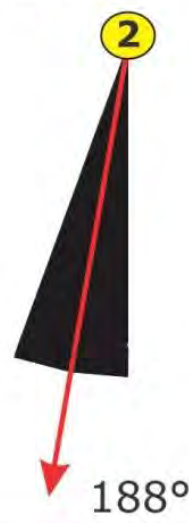

\section{Asociación de facies M5 (facies St)}

$303^{\circ}$

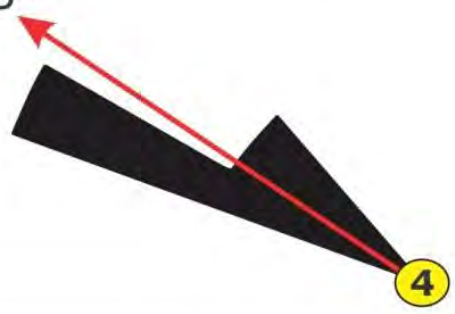

\section{Nivel inferior}

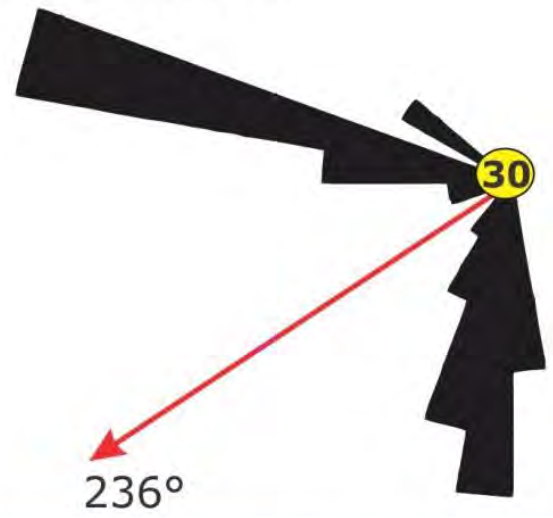

\section{REFERENCIAS}

frecuencia del intervalo: $10^{\circ}$

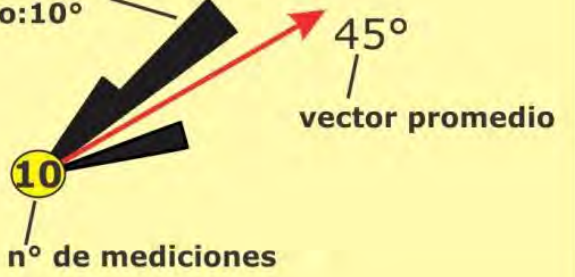

\section{Asociación de facies M6 (facies Gp)}

Nivel superior

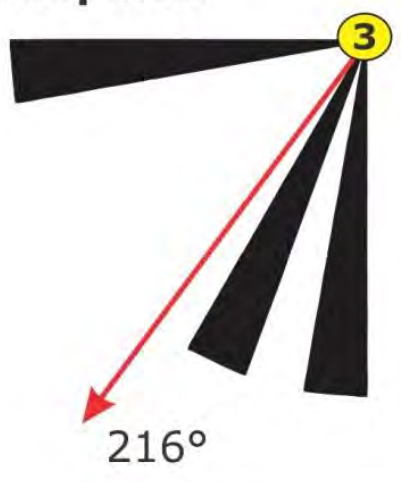

Nivel inferior

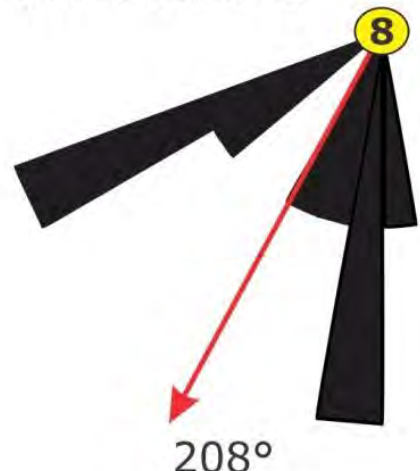

Figura 6.2: Detalle de las paleocorrientes de la sucesión terrígena-mixta en la sección PLE. 


\subsection{1: Subambiente de rampa media}

Este subambiente carbonático se presenta en el área de Malargüe y de Bardas Blancas con un mayor desarrollo hacia el centro de la primera zona citada. Comprende en su mayoría texturas packstone junto con wackestone, grainstone y boundstone que conforman litosomas de 3 a $6 \mathrm{~m}$ de espesor. Dentro del mismo se distinguen dos asociaciones de facies: foreshoal dominado por eventos de tormenta (C1) y foreshoal con bioconstrucción (C2; figura 6.1a).

\subsection{1-I: Foreshoal dominado por eventos de tormenta (C1)}

Esta asociación de facies se distribuye solamente en el área de Bardas Blancas, dentro del tramo inferior a medio de la sucesión carbonática (ver Anexo IVb). Está compuesta principalmente por wackestone y packstone masivos con contenidos $<15 \%$ de material terrígeno ( $\mathrm{Wb} ; \mathrm{Pb} ; \mathrm{Pp}-\mathrm{b}, \mathrm{SF} 1$ ), junto con escasas areniscas terrígenas finas masivas ( $\mathbf{S m}$ ) o laminadas (Shl SF). En la base de la asociación, se reconoce un arreglo de facies con un marcado incremento en la proporción de fango carbonático en la vertical (figura 6.3a). El mismo consta de packstone ( $\mathrm{Pb}$ ) que gradan hacia arriba a wackestone (Wb), ambos con abundantes formas completas y fragmentos de ostras y bivalvos no ostreidos, equinoideos y escasos restos de gasterópodos y corales (figura 6.1a, ver Anexo IIIb). Por encima se suceden capas discretas ( $<0.50 \mathrm{~m}$ de potencia) de packstone a wackestone peloidal ( $\mathrm{Pp}$ ) y de areniscas (Sm, Shl SF), a los que sobreyacen de forma neta niveles de wackestone similares a los de la base de la asociación (figuras 6.1a y 6.3b).

Patrones de apilamiento semejantes se reconocieron hacia el noroeste de la zona de Bardas Blancas (sección ALV), donde los niveles de la base y tope de la asociación son reemplazados por packstone con abundantes peloides, restos esqueletales y un bajo contenido de ooides normales tipo 1 (Strasser, 1986; Pp-b, SF1). 
Esta AF conforma litosomas tabulares a irregulares menores a los $4 \mathrm{~m}$ de potencia. Aparece de forma neta sobre las pelitas de la Formación Tres Esquinas y es cubierta a través de un contacto neto y plano a irregular por la AF C3 de shoal oolítico o por la AF C4 de intershoal (figura 6.3a).

Interpretación: dadas las características de esta asociación se infiere que su depositación tuvo lugar desde olas y corrientes costeras de alta energía, principalmente por corrientes tractivas y en menor medida por suspensión, en un ambiente marino somero ubicado en la base de un shoal oolítico. En este contexto, los packstone con abundantes peloides, restos esqueletales y ooides normales son interpretados como depósitos cercanos al shoal activo donde el retrabajo de las olas de buen tiempo y de tormenta resulta frecuente. Por otra parte, los arreglos matriz creciente de bioclastos con niveles discretos peloidales y clásticos, se asumen como depósitos distales dominados por olas y corrientes de tormentas.

En este ambiente se destaca el predominio de fauna de bivalvos, equinodermos, gasterópodos y corales que habitan áreas marinas abiertas (Aurell y Bádenas, 2004), posiblemente correspondientes a sectores proximales del foreshoal o de la rampa interna. De acuerdo con la presencia de esta biota en el foreshoal distal, como concentrados de formas completas y restos esqueletales, se infiere que reflejan los eventos de tormenta en este sector (Kreisa y Bambach, 1982; Benyoucef y Meister, 2015). Durante estos episodios de alta energía la fauna bentónica que habita el foreshoal proximal-rampa interna sería retrabajada y transportada junto con el fango carbonático a través de corrientes de retorno. Estos restos esqueletales se depositarían rápidamente desde las corrientes tractivas, mientras que a medida que la tormenta disminuye su intensidad, el fango carbonático decanta desde la suspensión de forma gradual en los concentrados bioclásticos, dando lugar a la formación de texturas wackestone (Kreisa y Bambach, 1982). Este último proceso también resulta común durante los períodos de buen tiempo que prosiguen a la tormenta en este ambiente (Kreisa y Bambach, 1982; Burchette y Wright, 1992; Bádenas et al., 1993). 


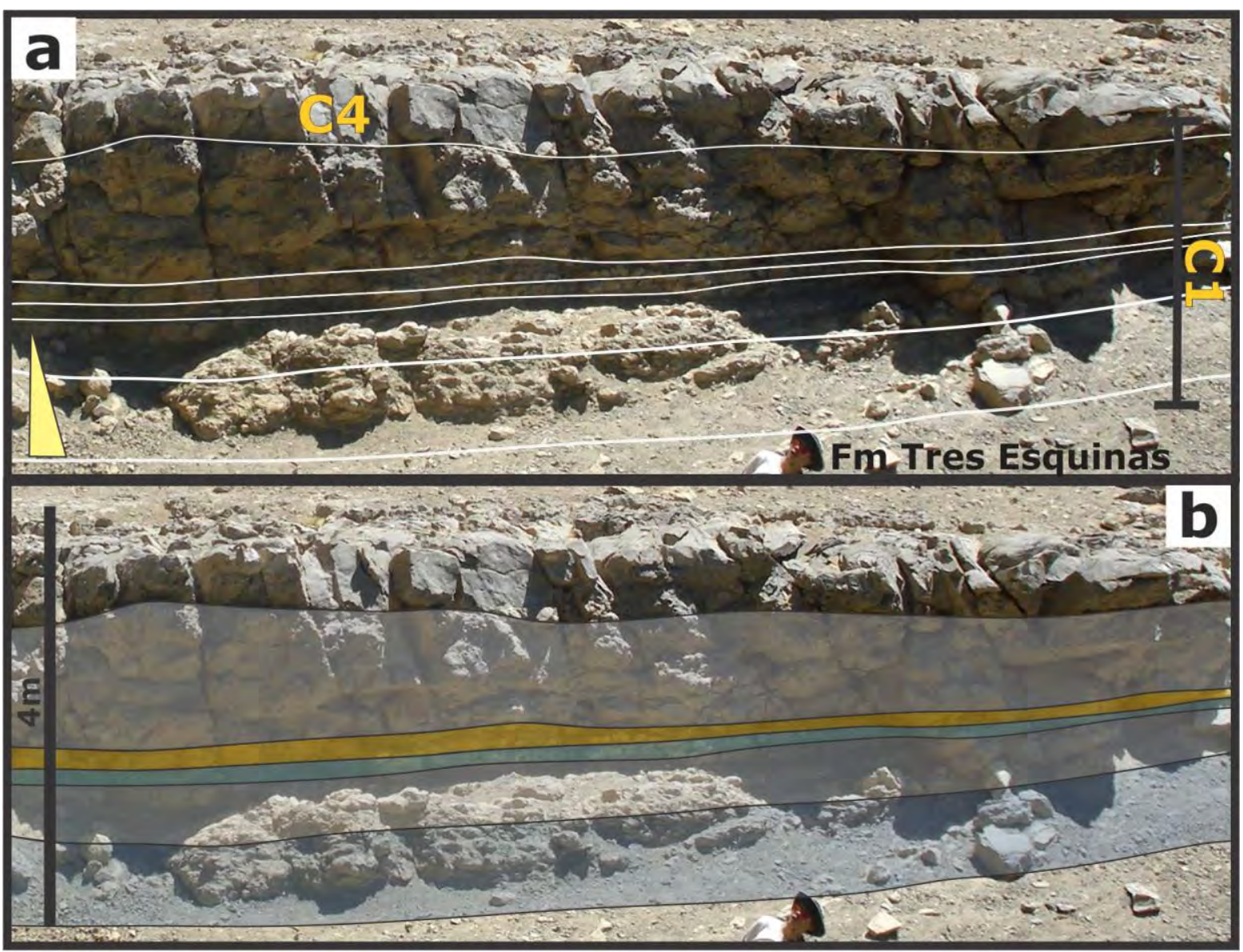

\section{Litofacies carbonáticas}

$\mathbf{P b}$
Pp

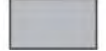

Wb

\section{Litofacies clásticas}

Sm

Figura 6.3: Asociación de facies de foreshoal dominado por eventos de tormenta (C1) en la sección Río Potimalal (PCH). a) Contacto basal neto con la Fm Tres Esquinas y con la AF de ambiente de intershoal (C4) que la cubre. Se destaca el arreglo granodecreciente en la base de la asociación. b) Litofacies carbonáticas (packstone bioclástico-Pb, packstone peloidal-Pp, wackestone bioclástico-Wb) y terrígenas (arenisca masiva-Sm) de la AF C1. Nótese el bajo espesor que presentan Sm y Pp. 
Por su parte, dado el bajo espesor de los depósitos peloidales en el foreshoal distal respecto a la zona proximal y a la relación que mantienen con los niveles clásticos, se infiere un origen similar a los concentrados esqueletales descriptos previamente. No obstante, no se descarta que parte de este material terrígeno y carbonático resedimentado pueda ser suministrado hacia esta zona a partir de corrientes costeras activas durante condiciones de buen tiempo y de tormenta. Esto estaría de acuerdo con el bajo contenido de material terrígeno reconocido en los depósitos carbonáticos ubicados a lo largo del foreshoal.

A partir de las observaciones mencionadas, se infiere que la falta de desarrollo de una fauna bentónica propia en este medio podría indicar condiciones ambientales limitantes como variaciones de la salinidad de las aguas o turbidez de las mismas relacionadas con el ingreso de material terrígeno a este medio.

Es de notar que el contacto neto basal que el foreshoal presenta con los niveles pelíticos de la Formación Tres Esquinas, muestra una tendencia marcada hacia un menor aporte clástico y una mayor productividad carbonática en este medio marino. El mismo indicaría el comienzo de la sedimentación carbonática en el área de Bardas Blancas.

\subsection{1-II: Foreshoal con bioconstrucción (C2)}

Esta asociación de facies tiene una amplia distribución en el área de Malargüe dentro del tramo inferior a medio de la sucesión carbonática (ver Anexo IVa). Consta de sucesiones monótonas sin un arreglo definido de packstone a wackestone peloidales con ooides superficiales (tipo 1; Strasser, 1986) y baja proporción de material terrígeno ( $<15 \%$ del total), masivo o con laminación paralela difusa ( $\mathrm{Pp}$, Pp-b SF1). En la misma los restos de equinodermos, bivalvos y braquiópodos resultan frecuentes, acompañados por escasos foraminíferos (ver Anexo IIIb). Se reconocen como niveles poco potentes menores a los $50 \mathrm{~cm}$ de espesor en la base y parte media de la asociación (GRb), o hacia el tope de la misma como concentraciones en láminas paralelas o distribuidos al azar (Pp-b SF1; figuras 6.1a; 
6.4a). Este grupo de sedimentitas se apilan conformando litosomas tabulares a cuneiformes que no superan los $2 \mathrm{~m}$ de espesor. En general estos cuerpos resultan incididos o cubiertos por lentes espesos de conglomerados ( $\mathbf{G m m}$ ) asociados con depósitos tabulares a irregulares de floatstone ( $\mathrm{Fi}$; figura 6.4b) correspondientes a la AF M6 de barra de desembocadura (secciones ASE y ACN, ver Anexo IVa). Estos últimos pueden contener intraclastos carbonáticos y de areniscas de las AF M2 y M1 del sistema marino clástico, en ocasiones junto a variedades carbonáticas del subambiente de rampa interna (AF C3 y C4, sección ACN figura 6.4c).

Sucesiones similares fueron encontradas hacia el centro y sudoeste de Malargüe (secciones ACS-ATW, ver Anexo IVa), dando lugar a una faja de afloramientos discontinua en sentido noreste-sudoeste de aproximadamente $10 \mathrm{~km}$ de extensión. Aquí se reconocen cuerpos cuneiformes a tabulares de packstone ( $\mathrm{Pp}, \mathrm{Pp}-\mathrm{bi})$, de hasta $6 \mathrm{~m}$ de espesor con clara disminución de su potencia hacia el sudoeste donde alcanzan espesores $<2 \mathrm{~m}$ (figuras $6.1 \mathrm{a} ; 6.5 \mathrm{a}-\mathrm{b} ; 6.6 \mathrm{a}$ ). En general se encuentran intensamente bioturbados ( $\mathrm{Pp}-\mathrm{bi}$ ) con asociaciones de trazas fósiles de la icnofacies de Glossifungites (Thalassinoides paradoxidus, Gastrochaenolites isp.). En los mismos niveles los restos de colonias de corales y ostras resultan comunes, acompañados por bivalvos no ostreidos, gasterópodos, equinoideos, braquiópodos rhynchonellidos y escasas algas (Dasycladales; ver Anexo IIIb). Especialmente en el perfil PLN del centro de Malargüe (ver Anexo IVa) estas sedimentitas se agrupan hacia el techo con lentes ( $<\operatorname{los} 2 \mathrm{~m}$ de espesor) de colonias de corales in situ y removidas, asociadas con ostras y separadas por sedimento carbonático (FRc; figuras $6.1 a, 6.6 a)$.

Es de notar que el tope de esta sucesión en el centro y sudoeste de Malargüe (secciones ACS-ATW, ver Anexo IVa) presenta una morfología plana a irregular con ocasional erosión de las trazas fósiles y ausencia de rasgos de exposición subaérea (figuras 6.6b-d).

Al noroeste de esta faja de afloramientos (sección complementaria PLW, ver apartado 4.5.2) se distinguen el pasaje lateral hacia un cuerpo irregular, menor a los $2 \mathrm{~m}$ de potencia, de floatstone portador de intraclastos ( $\mathrm{Fi}$ ) de packstone y en menor medida de areniscas. Los intraclastos carbonáticos pueden alcanzar los $2 \mathrm{~m}$ 
de longitud y derivan en su mayoría de las litofacies Pp-bi y Pp-b-i, esta última correspondiente a la AF C4 suprayacente (figura 6.7).

La asociación de facies de foreshoal suprayace de forma neta al sistema de acumulación marino abierto clástico (AF M6, figura 6.5b; AF M1 y M3) y es cubierta de forma neta a transicional por diferentes AF del subambiente de rampa interna (C3 de shoal peloidal, C4 de intershoal o C5 de albufera, figuras 6.5b; 6.6a).

Interpretación: de acuerdo a las características de este grupo de facies tales como su composición, textura grano soportada y la presencia de fauna marina abierta, se infiere que su depositación se produce por corrientes tractivas en un ambiente marino somero de moderada energía, ubicado costa afuera de un shoal peloidal activo (e.g. Bádenas y Aurell, 2010). Estos depósitos no solo incluyen granos carbonáticos derivados de la zona de shoal, como peloides y ooides superficiales, sino también restos esqueletales y un bajo contenido de material terrígeno, indicando sectores favorables para la actividad de organismos y un suministro de material extracuencal posiblemente de parte de corrientes costeras.

Dentro de este contexto, en el noreste de Malargüe los concentrados de equinodermos, bivalvos y braquiópodos presentes en este grupo de facies se asumen como generados por olas y corrientes de alta energía durante episodios de tormenta. En especial en esta zona, se infiere que la sedimentación carbonática se encuentra interrumpida por el aporte puntual de una fuente fluvial cercana a la costa que permite la formación de una barra de desembocadura sobre estos depósitos. Relacionado con este proceso se produce la entrada de material retrabajado de asociaciones de facies previas (M2 y M1), acompañado en ocasiones por variedades del subambiente de rampa interna ( $A F$ C3 y C4). La interpretación de dichos depósitos de barra de desembocadura será ampliada en el apartado 6.3.6. 


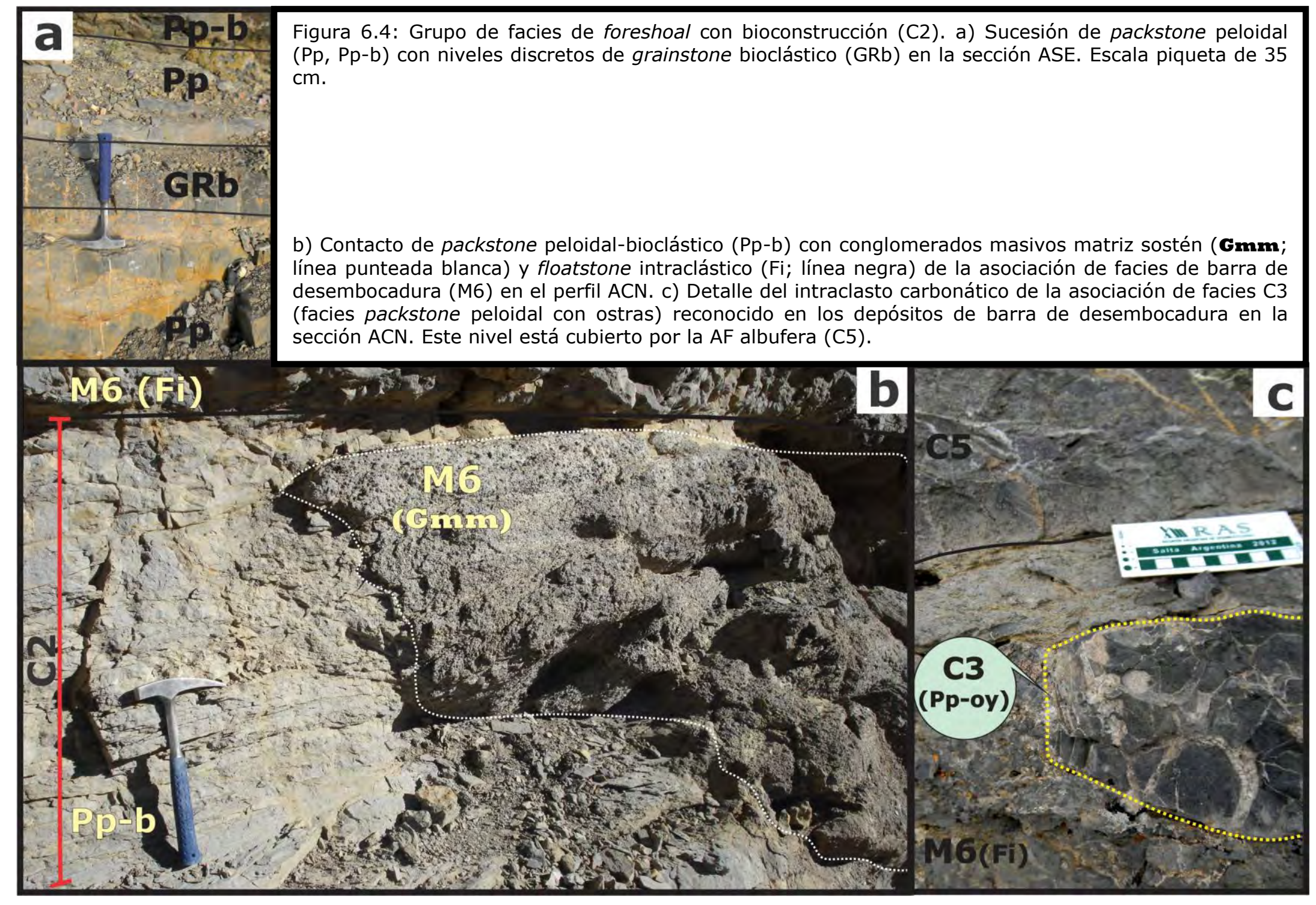


Por su parte, en el centro y sudeste de Malargüe el crecimiento de colonias de corales sugiere un medio marino con salinidad normal de las aguas y bajo contenido de nutrientes (condiciones oligotróficas), lo que resulta coherente con el bajo suministro de material terrígeno que recibe esta zona (e.g. Wilson, 2005; Bádenas y Aurell, 2010). A juzgar por la presencia de sedimento carbonático rodeando a dichas colonias, se infiere que las mismas desarrollan arrecifes en parche sin una estructura rígida, lo que las hace propensas a la destrucción física durante la erosión mecánica de las olas y las corrientes de alta energía. Esta característica contribuye a la generación de restos de colonias de corales y bioclastos asociados que se acumulan en este ambiente y dentro de la rampa interna (shoal peloidal-AFC3 e intershoal-AFC4).

Estas bioconstrucciones se establecen sobre un sustrato estable y cohesivo (firmground) desarrollado solamente en este sector, de acuerdo con la presencia de trazas fósiles de la icnofacies de Glossifungites que indican su endurecimiento de forma previa a la colonización de los organismos (Buatois y Mángano, 2011). La falta de rasgos típicos asociadas con la emersión y exposición subaérea en su superficie, como horizontes con raíces, superficies kársticas, paleosuelos u horizontes bauxíticos (e.g. Clari et al., 1995; Hillgärtner, 1998; Sattler et al., 2005) sugiere que su litificación se origina en un ambiente subacuático (e.g. Purser, 1969; Christ et al., 2012). Asimismo, el tope que presenta de plano a irregular acompañado por el truncamiento ocasional de las trazas fósiles evidenciarían que esta superficie fue sometida a una erosión mecánica significativa (e.g. Schwarz y Buatois, 2012) de forma previa o posterior a su litificación. Dadas estas características, se infiere que dicho firmground podría reflejar un período de no depositación o baja tasa de sedimentación carbonática dentro de este medio marino, el cual no se encuentra relacionado a un episodio de exposición subaérea.

En cuanto a los depósitos de floatstone intraclástico de corta distribución areal en este ambiente, dada la magnitud de los intraclastos y su relación genética con los niveles preservados de packstone (Pp-bi y $\mathrm{Pp}-\mathrm{b}-\mathrm{i}$ ), se sugiere que su depositación tuvo lugar a partir de flujo de detritos ocasionados por un cambio de pendiente dentro del foreshoal distal. No se descarta que dicho cambio pueda estar relacionado a la generación de fracturas de gran extensión vertical (decímetros a m 
de escala) que corten de forma perpendicular a los niveles de packstone, como describen Aurell et al. (2009) para depósitos carbonáticos similares del TriásicoJurásico de la Cuenca Ibérica, aunque en este caso no se cuenta con evidencia de fracturas.

Dentro de este contexto de acumulación del foreshoal, se destaca su contacto neto basal con los diferentes subambientes del sistema marino clástico subyacente. El mismo indicaría un cambio marcado hacia un menor aporte clástico y una mayor productividad carbonática en este medio marino.

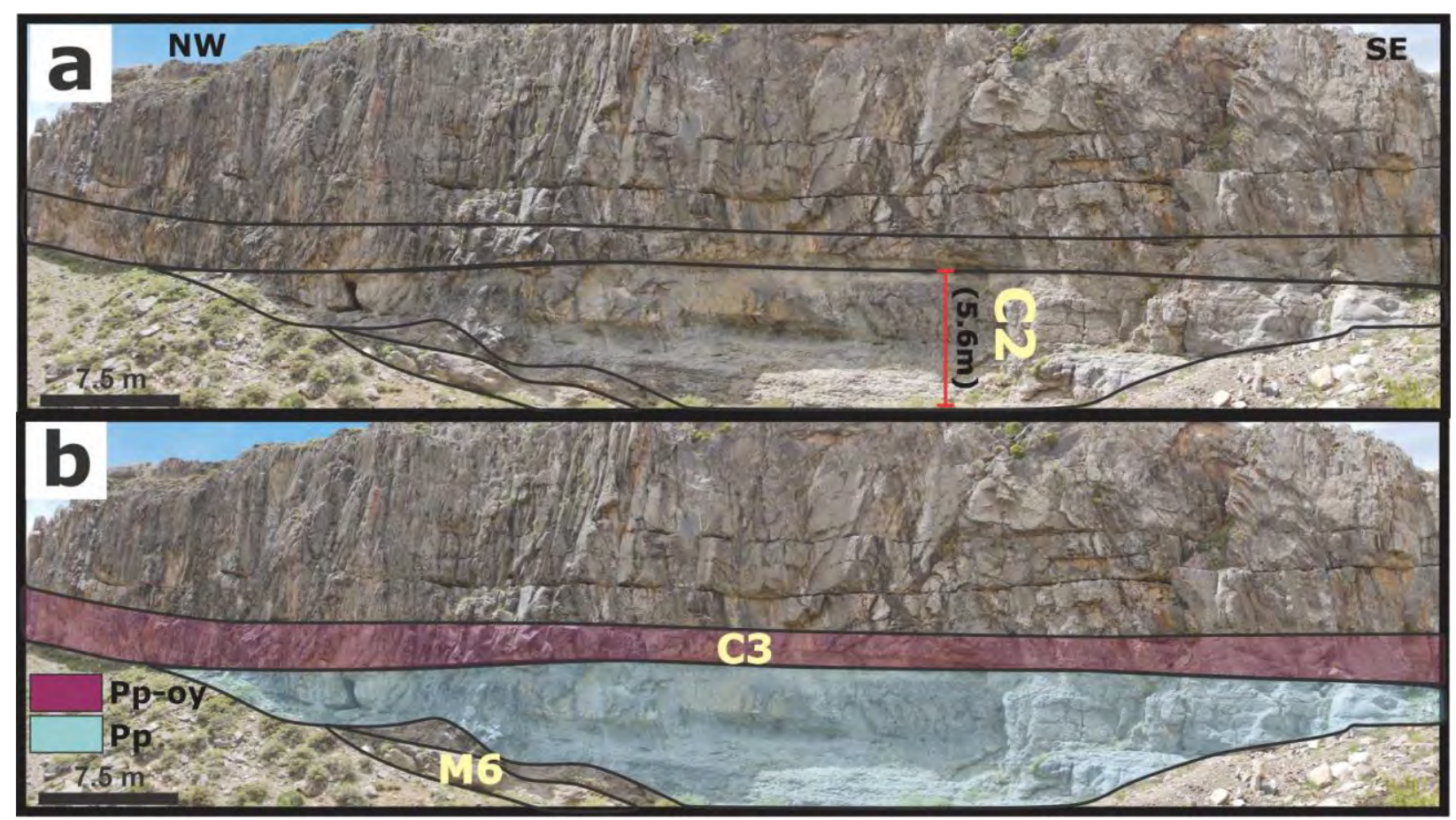

Figura 6.5: Asociación de facies de foreshoal con bioconstrucción (C2). a-b) Litosomas cuneiformes de packstone peloidal (Pp) en la sección ACS. Se destaca el contacto basal neto con la AF M6. Al tope es cubierto por la AF C3 de shoal peloidal (Pp-oy). 


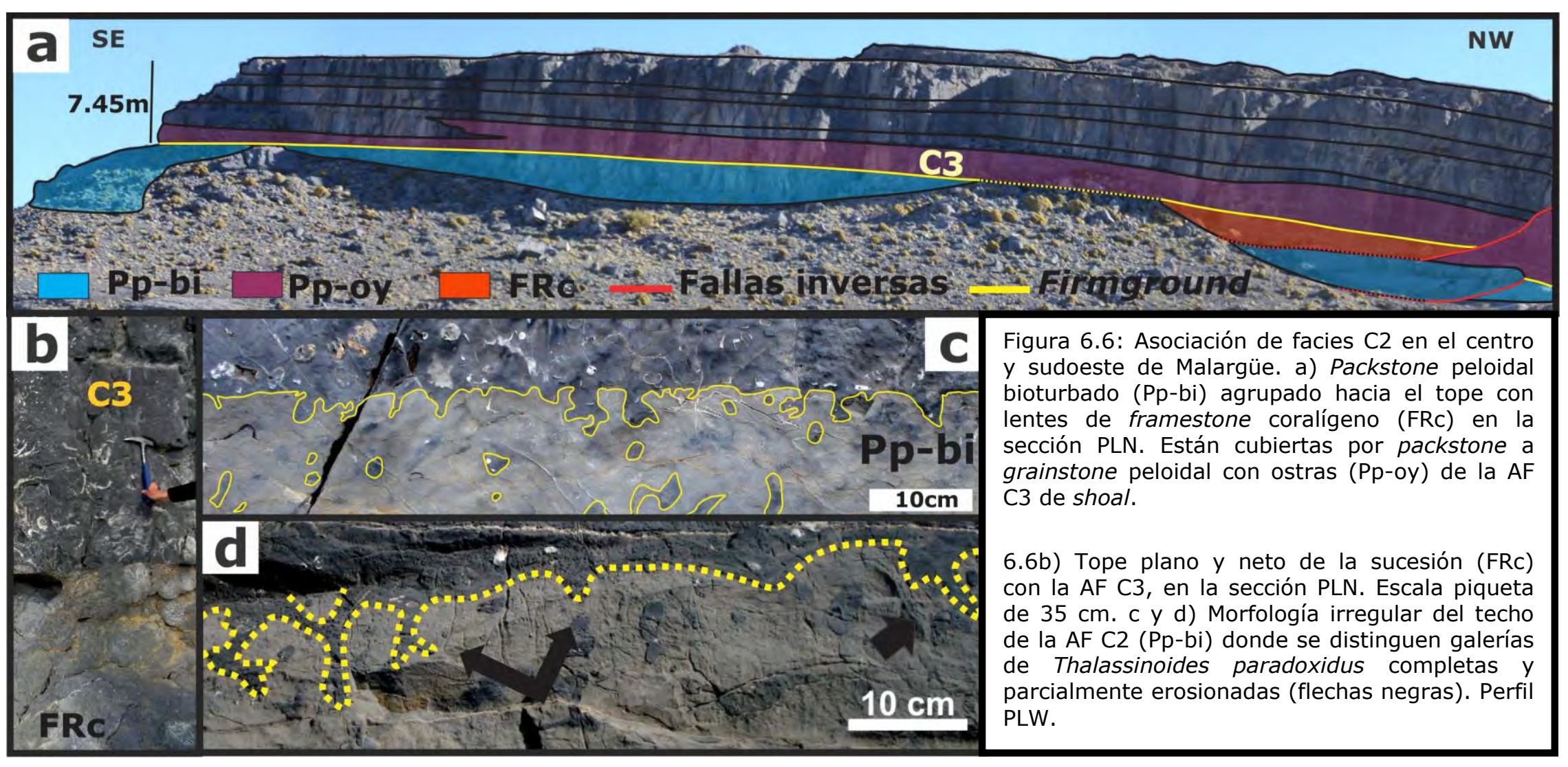




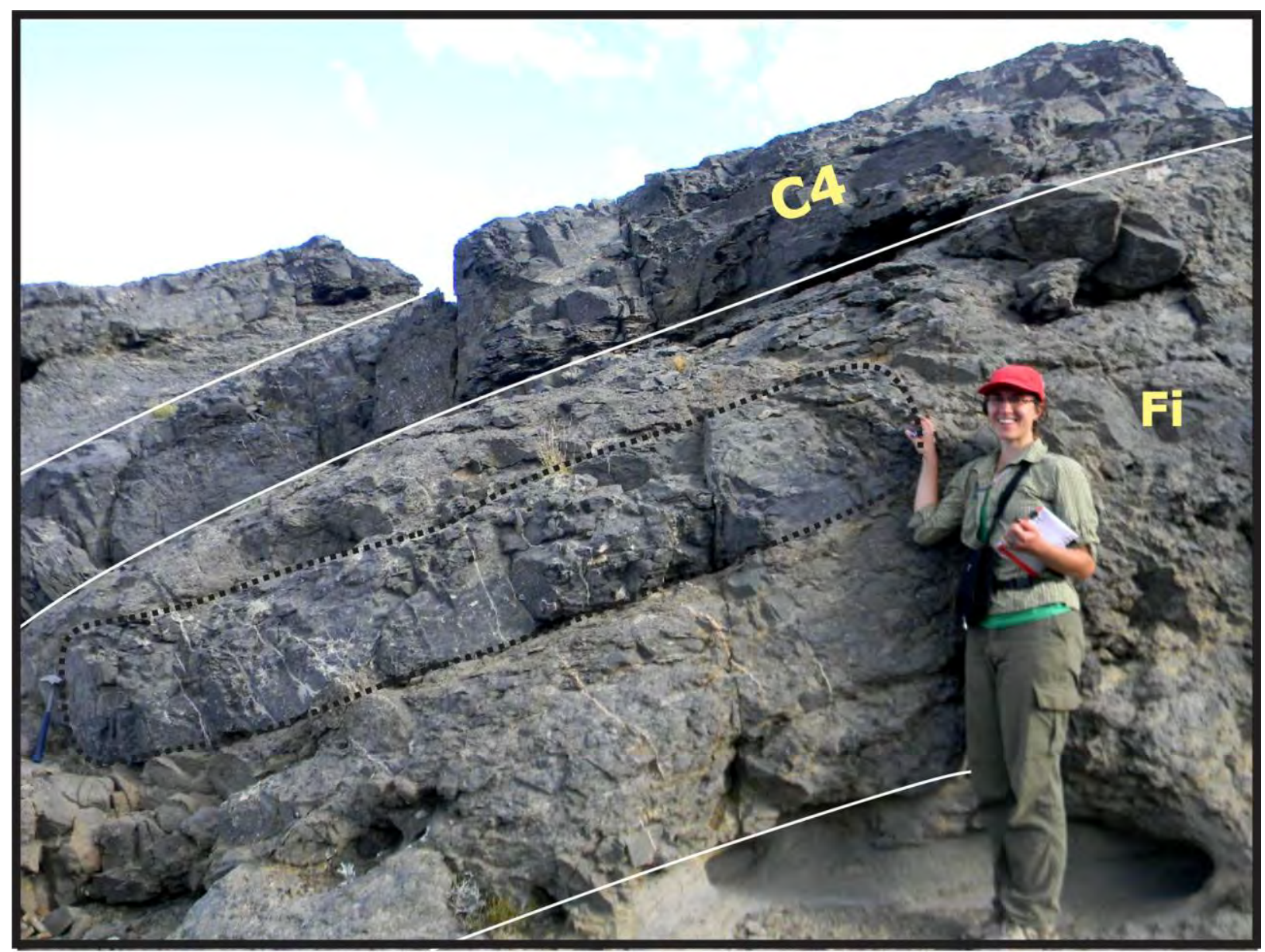

Figura 6.7: Grupo de facies C2 al noroeste de la sección PLW, sudeste de Malargüe. Consta de floatstone con intraclastos ( $\mathrm{Fi}$ ) de hasta $2 \mathrm{~m}$ de longitud (línea negra punteada). Nótese el contacto al tope con la AF C4 de intershoal. Escala persona de $1.68 \mathrm{~m}$ de alto.

\subsection{2: Subambiente de rampa interna}

Este subambiente carbonático es el mejor representado dentro de la sucesión carbonática, se encuentra tanto en el área de Malargüe como en la de Bardas Blancas con un mayor desarrollo hacia el centro de la primera zona. Está conformado en su mayoría por packstone y grainstone acompañadas por floatstone, wackestone y boundstone en forma secundaria, los cuales conforman litosomas de 3 a $12 \mathrm{~m}$ de potencia. Dentro de este subambiente se distinguen cuatro asociaciones de facies: shoal (C3), intershoal (C4) albufera (C5) y llanura de marea (C6; figura 6.1a). 


\subsection{2-I: Shoal (C3)}

Dicho grupo de facies resulta frecuente en el área de estudio dentro del tramo medio a superior de la sucesión carbonática (ver Anexo IVa y b). Comprende grainstone a packstone masivos con predominio de ooides tipo 1 (Strasser, 1986) o peloides (GRo, Pp-oy), raramente bioclastos (GRb). Los mismos conforman litosomas tabulares a irregulares, discontinuos que de acuerdo con su ubicación en la rampa interna fueron diferenciados en cuerpos externos e internos, separados entre sí por la zona de intershoal (AF C4) o de albufera (AF C5; figuras 6.8a y b).

En particular en la zona de Malargüe el shoal externo conforma un litosoma tabular de $2.20 \mathrm{~m}$ de espesor (figuras $6.5 \mathrm{~b}, 6.6 \mathrm{a}$ ) que se extiende por $2.3 \mathrm{~km}$ en el centro de esta zona (secciones ACS-PLN, ver Anexo IVa). En la base de este cuerpo se destaca su contacto neto y plano con la AF de foreshoal (C2; figura 6.5b). El mismo se compone de peloides, ooides superficiales y una baja proporción de material terrígeno ( $<15 \%$ del total), acompañados por concentrados de ostras y restos de corales ubicados en la parte inferior a media (Pp-oy; figuras 6.1a, ver Anexo IIIb).

En esta zona los shoal internos presentan una amplia distribución. Los mismos comprenden cuerpos tabulares a irregulares, con espesores variables de 1 a $5 \mathrm{~m}$ (figura 6.8a), raramente $<0.50 \mathrm{~m}$ (sección ASE, ver Anexo IVa), que son cubiertos por la AF de llanura de marea (C6). Predominan los ooides normales junto con un bajo contenido de gasterópodos, bivalvos, cianobacterias (Caulerpales), equinoideos y foraminíferos con enroscamiento polymorphinido (GRo; ver anexo IIIb).

Diferente es lo que ocurre en el área de Bardas Blancas donde el shoal externo e interno resultan tabulares, poco potentes ( $<1 \mathrm{~m}$ de potencia) y de composición similar al banco interno de Malargüe (Gro; figura 6.8b, ver Anexo IVb). Los cuerpos externos presentan una baja proporción de material terrígeno ( $<15 \%$ del total) y en ocasiones concentrados de ostras, equinoideos, gasterópodos y cianobacterias (Caulerpales) en su base (GRb; ver anexo IIIb). Los mismos cubren a través de un contacto neto e irregular a la AF de foreshoal (C1; figura 6.8c). 
Interpretación: dadas las características litofaciales descriptas se asume que las condiciones hidrodinámicas del ambiente controlaron en mayor medida la abundancia de los componentes no esqueletales y la preservación de los restos esqueletales dentro de estos depósitos carbonáticos (Bádenas y Aurell, 2010). En la rampa interna en la zona de Malargüe, donde imperan las olas de moderada energía se desarrolla un shoal peloidal con ooides superficiales (Amour et al., 2012; 2013); mientras que en los sectores donde las condiciones hidrodinámicas resultan de mayor importancia, la energía de las olas se disipa por fricción con el fondo marino dando lugar al movimiento de las partículas carbonáticas y a la remoción del material fino, con la subsecuente formación de un shoal con ooides normales (Strasser, 1986; Pomar et al., 2002). Estas condiciones hidrodinámicas favorecen la preservación de concentraciones esqueletales dentro del shoal peloidal y disminuyen su conservación dentro de los depósitos oolíticos.

En especial en los litosomas peloidales el marcado suministro de ostras y colonias de corales derivados de la erosión mecánica de arrecifes en parche (foreshoal AF C2) indicaría un shoal externo en contacto con el ambiente marino abierto (e.g. Colombié y Strasser, 2005). El aporte de dichos bioclastos podría incrementarse durante los episodios de tormenta, dando lugar a concentraciones esqueletales dentro de los mismos. En estos cuerpos se distingue además un bajo suministro de material terrígeno durante su formación.

Diferente es lo que ocurre en los depósitos oolíticos donde los restos esqueletales (gasterópodos, bivalvos, cianobacterias, equinoideos y foraminíferos) serían retrabajados en su mayoría desde sectores protegidos de la rampa interna, como el intershoal-AF C4 y la albufera-AF C5, lo que implica una posición interna de estos litosomas (e.g. Colombié y Strasser, 2005).

En particular en la zona de Bardas Blancas, se asume que dentro de la rampa interna prevalecen las condiciones de moderada a alta energía de olas evidenciado por la presencia de bancos externos e internos con ooides normales y bajo contenido de restos esqueletales. Se destaca que en los litosomas externos se distingue un bajo suministro de material terrígeno durante su formación, de forma semejante a lo que ocurre en la zona de Malargüe. 


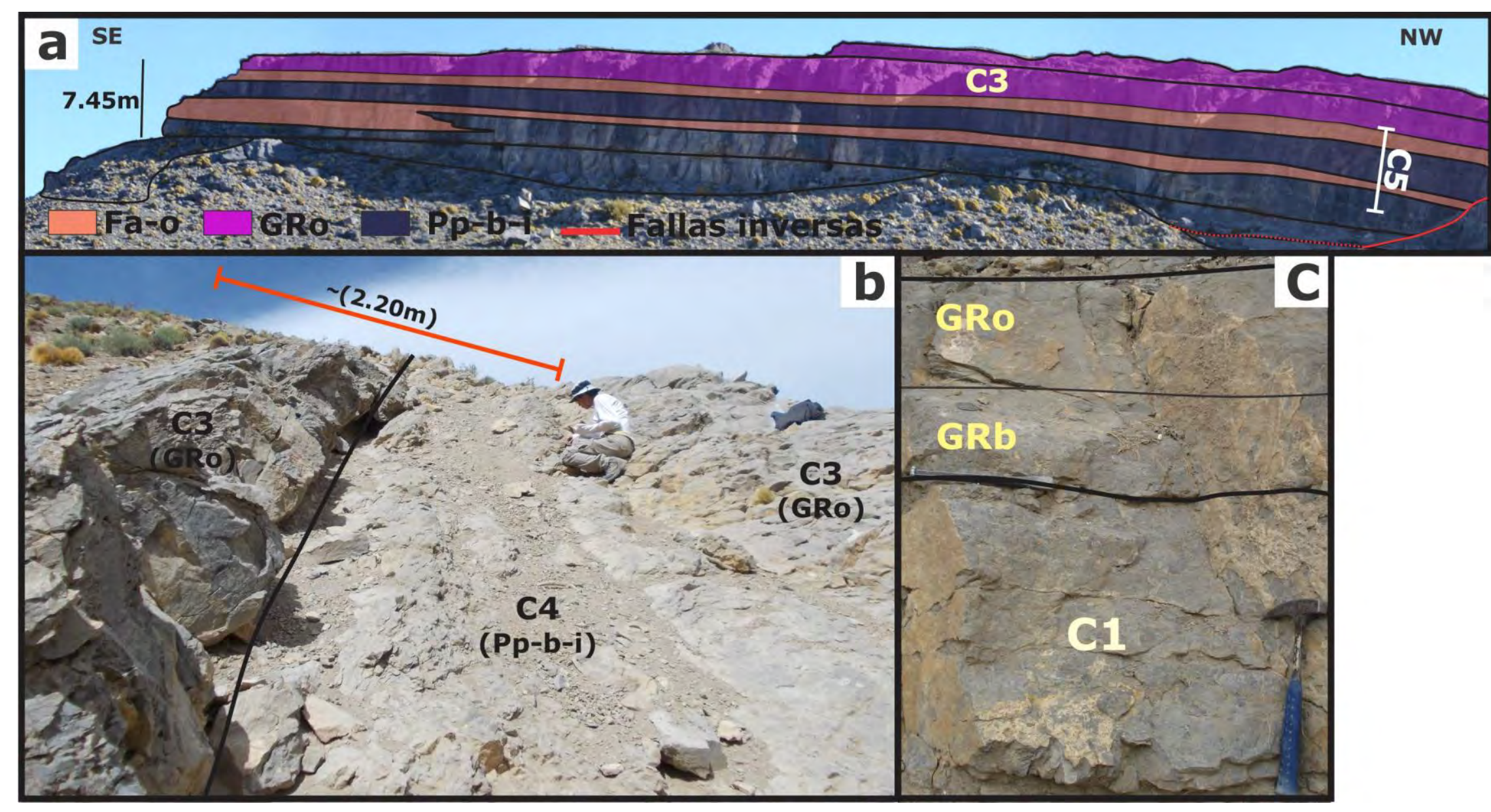

Figura 6.8: Asociación de facies de shoal (C3). a) Contacto basal neto con la AF de albufera (C5) en el perfil PLN. La AF C3 está conformada por grainstone a packstone ooidal (GRo), mientras que la AF C5 está compuesta por: floatstone algal-oncolítico (Fa-o) y packstone peloidalbioclástico-intraclástico (Pp-b-i). b) Vista hacia el noreste de shoals oolíticos (GRo) separados por depósitos de intershoal (AF C4, facies Pp-bi) en la zona de Bardas Blancas, perfil PCH. c) Shoal oolítico (GRo) con concentraciones esqueletales en la base (GRb) en la zona de Bardas Blancas, perfil ALV. Se destaca el contacto neto con la AF C1 de foreshoal. 


\subsection{2-II: Intershoal (C4)}

Se distribuye dentro del tramo medio a superior de la sucesión carbonática en el centro y sudoeste de la zona de Malargüe y de Bardas Blancas (ver Anexos IVa-b). Comprende packstone a wackestone, raramente floatstone, peloidales masivos con una marcada micritización de las partículas carbonáticas que la componen (Pp-b-i, $\mathrm{Pp}$ ). Dentro de estas litofacies es poco común la presencia de material terrígeno a excepción de lo que sucede con los niveles basales en la sección ACS (centro de Malargüe, ver Anexo IVa) y en la zona de Bardas Blancas.

En general se presenta como una sucesión sin arreglo definido de packstone a floatstone ( $\mathrm{Pp}-\mathrm{b}-\mathrm{i})$ con abundantes peloides, restos esqueletales e intraclastos de las litofacies FRc, Pp y Pp-bi, acompañado por un menor contenido de ooides normales. La misma conforma litosomas tabulares a irregulares $<2 \mathrm{~m}$ de potencia.

Una excepción es lo que sucede en el centro de Malargüe (sección ACS) donde niveles de $\mathrm{Pp}-\mathrm{b}-\mathrm{i}$ se intercalan con capas de packstone a wackestone peloidales (Pp; figuras 6.1a, 6.9a-b). Los mismos conforman pares de facies de 0.90 a $3.35 \mathrm{~m}$ de espesor que se agrupan en cuerpos tabulares a irregulares de $6 \mathrm{~m}$ de potencia con un claro arreglo estrato y granocreciente, donde el pasaje entre ambas litofacies resulta gradual (figura 6.9b). El contenido de fauna marina normal es bajo en la base del ciclo a moderado hacia el tope.

En esta asociación de facies la fauna presente se corresponde con fragmentos de colonias de corales, ostras, bivalvos no ostreidos, cianobacterias (Caulerpales), equinoideos y gasterópodos (ver anexo IIIb). Dicha AF se presenta entre los niveles de shoal peloidal u oolítico (AF C3; figuras 6.8b, 6.9a) o se apoya a través de un contacto neto a transicional sobre los niveles de foreshoal (AF C2 y C1) y es cubierta de forma neta por la AF de llanura de marea (C6). En el centro de Malargüe pasan lateralmente con la AF C5 de albufera (ver Anexo IVa). 
Interpretación: de acuerdo con la textura de este grupo de facies, su composición y la marcada micritización de sus componentes, se asume que su depositación ocurrió en un medio submareal ubicado entre depósitos de shoal, dominado por la acción de corrientes tractivas con ocasionales períodos de sedimentación tranquila, y bajo suministro de material terrígeno.

Dentro de este ambiente la entrada frecuente de olas de buen tiempo y de tormenta a través del shoal externo, daría lugar al retrabajo de las facies depositadas previamente con la subsecuente formación de intraclastos. Estas corrientes tractivas, además transportarían restos de corales y ostras, y granos no esqueletales (peloides, ooides e intraclastos) desde el foreshoal y el shoal activo generando acumulaciones con mezclas de aloquemes de varios ambientes ( $P p-b-i)$ (e.g. Bádenas y Aurell, 2010). Dichos depósitos de sobrelavado también resultan comunes durante las mareas altas (Pierre et al., 2010; Amour et al., 2013) donde se produciría la entrada de restos esqueletales desde la albufera (cianobacterias, equinoideos y gasterópodos).

En particular en el centro de Malargüe (sección ACS), el grupo de facies Pp-b-i, Pp se interpreta como depósitos de sobrelavado desde el shoal externo peloidal (Pp) hacia este ambiente (Pp-b-i) durante las tormentas o mareas altas (Amour et al., 2013). En este sentido su arreglo estrato y granocreciente indicaría una menor recurrencia de dicho proceso en la vertical.

Cabe señalar que a pesar de las condiciones hidrodinámicas que imperan en este medio, se encuentran interrumpidas por períodos de sedimentación tranquila donde se favorece la decantación de fango carbonático y la marcada micritización de las granos esqueletales y no esqueletales (Tucker y Bathurst, 1990). En este caso, se infiere además una baja tasa de sedimentación para esta zona ya que los granos carbonáticos de forma posterior a su depositación se encuentran expuestos por largos períodos de tiempo a la actividad microorganismos y de organismos incrustantes en el lecho marino (Tucker y Bathurst, 1990; Palma et al., 2007b). Estas condiciones de baja tasa de sedimentación favorecerían la micritización de ooides superficiales y normales derivados de los bancos peloidales y oolitos activos, y permitirían explicar la abundancia de los peloides respecto a estos aloquemes. 


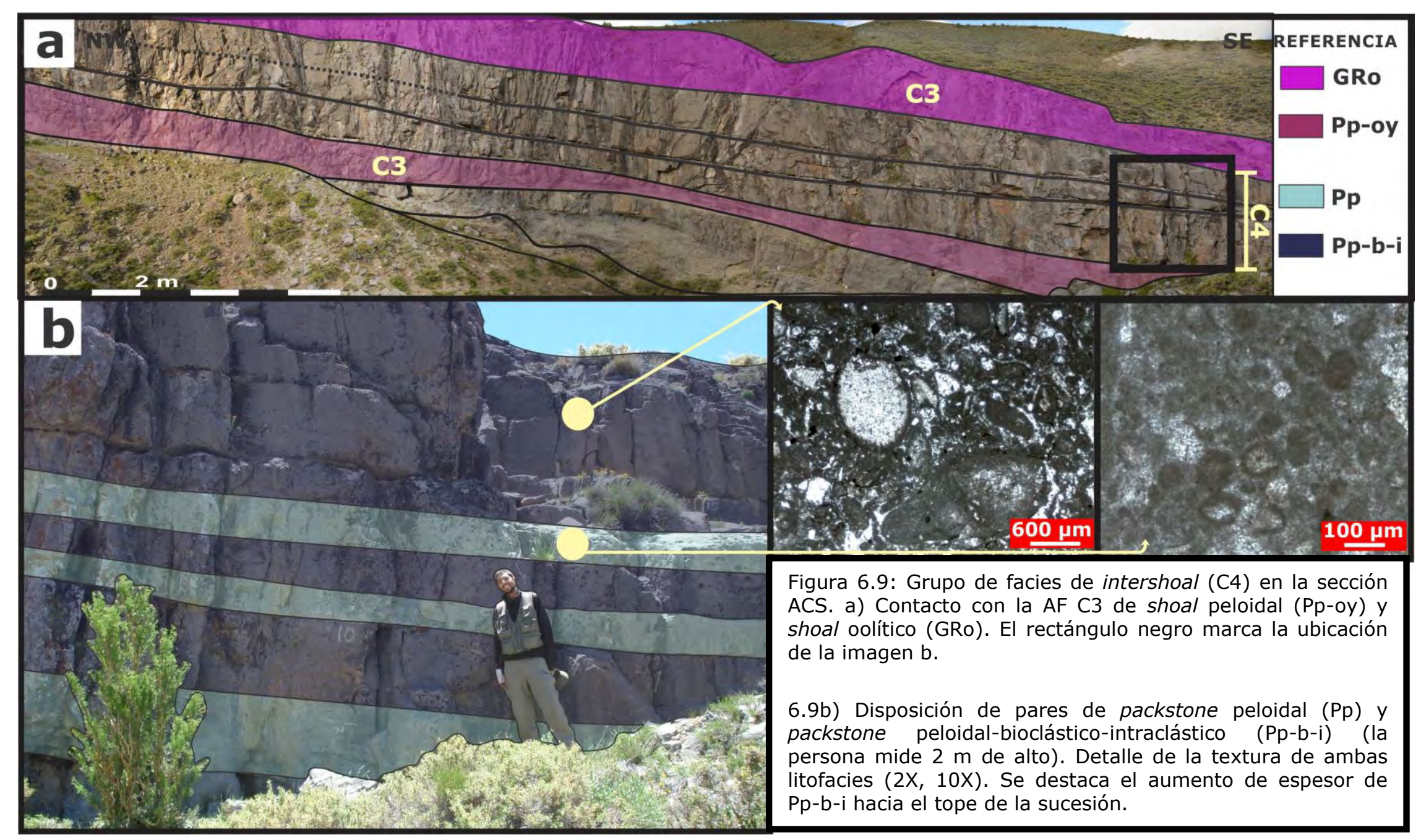




\subsection{2-III: Albufera (C5)}

Esta asociación de facies se ubica en el tramo medio a superior de la sucesión carbonática en el centro y noreste de la zona de Malargüe (ver Anexo IVa). Abarca floatstone $y$ wackestone masivos con abundantes oncoides ( $\mathrm{Fa}-\mathrm{On}$, Fon, Pp-b subfacies 2), acompañados por un menor contenido de packstone peloidales masivos (Pp-b-i). Se caracterizan por presentar una marcada micritización de las partículas carbonáticas que la componen y ausencia de material terrígeno.

Dicha sucesión en el noreste de Malargüe (perfiles ANE y ACN, ver Anexo IVa) comprende un litosoma tabular a irregular de $1.3 \mathrm{~km}$ de extensión de wackestone peloidal con oncoides de laminación difusa a nula (Pp-b subfacies 2), que pasa lateralmente a floatstone con oncoides tipo C (Fon). Su contenido de fauna marina normal es bajo, caracterizada por fragmentos de braquiópodos, equinoideos, gasterópodos, foraminíferos con enroscamiento polymorphinido y escasas colonias de corales (ver Anexo IIIb).

Diferente es lo que ocurre hacia el centro de Malargüe (perfil PLN, ver Anexo IVa) donde esta sucesión comprende cuerpos tabulares de floatstone con restos de cianobacterias (Caulerpales) y oncoides con laminación difusa (Fa-on), interrumpidos por un nivel de packstone peloidal ( $\mathrm{Pp}-\mathrm{b}-\mathrm{i}$ ) similar en su composición a los descriptos para el intershoal (figuras 6.1a y 6.8a). Conforma un cuerpo tabular de base neta y plana sobre Fa-on que resulta cubierto de forma transicional por esta facies. En esta asociación de facies la fauna marina es escasa y aumenta hacia los niveles de packstone. Está representada por restos de equinoideos, gasterópodos, ostras y escasas colonias de corales.

Estas litofacies se agrupan en cuerpos tabulares a irregulares con espesores que varían entre los $4.40 \mathrm{~m}$, en el centro de Malargüe, a $<2 \mathrm{~m}$ hacia el noreste de esta zona. Pasan lateralmente al grupo de facies de intershoal (C4, ver Anexo IVa). En el centro de Malargüe estos litosomas se distribuyen entre los niveles de shoals (AF C3, figura 6.8a), mientras que hacia el noreste se apoyan de forma neta en los depósitos de barra de desembocadura (AF M6) o transicional sobre el foreshoal (AF 
C2). En ambos casos son cubiertos a través de un contacto neto por la AF de llanura de marea (C6).

Interpretación: se asume que este grupo de facies se corresponde con un ambiente marino somero submareal de sedimentación tranquila y baja tasa de sedimentación de acuerdo con su textura matriz soportada, abundante contenido de oncoides y la marcada micritización de las partículas carbonáticas que lo conforman (Tucker y Bathurst, 1990; Bádenas et al., 1993; Gómez-Pérez et al., 1998; Palma et al., 2007; Beigi etal., 2017). Asimismo, la falta de material terrígeno en estas sedimentitas sugiere su acumulación en un medio de aguas claras sin aporte clástico. Estas condiciones favorecerían la proliferación de algas y cianobacterias y el crecimiento de oncoides, dado que los granos carbonáticos se encuentran expuestos por largos períodos de tiempo a la colonización de las algas y cianobacterias en el lecho marino (Bádenas et al., 1993; Védrine et al., 2007; Bádenas y Aurell, 2010). Además, habría permitido la colonización de equinoideos, gasterópodos y foraminíferos.

Dicho episodios de sedimentación tranquila alternan con períodos donde la acción de las mareas daría lugar al crecimiento de los oncoides. En este sentido, estas corrientes tendrían un efecto más marcado en los sectores donde se depositan los oncoides tipo C (Fon), característicos de aguas con constante movimiento, respecto a los sectores donde se generan los oncoides con laminación difusa a nula (Fa-on; Pp-b subfacies 2) que indicarían el movimiento intermitente de las aguas.

En general este ambiente se encuentra ubicado por detrás de un shoal peloidal a excepción de lo que ocurre en el noreste de Malargüe donde no se reconocen estos bancos. A pesar de esto, dado que en este sector imperan las mismas condiciones de sedimentación tranquila que en el resto de la albufera y que además los depósitos de barra de desembocadura evidencian la destrucción mecánica del shoal peloidal en esta zona (véase apartado 6.2.1-II), se infiere que estos depósitos no se encuentran preservados. Se considera que los mismos actúan como una barrera que evita la entrada frecuente de olas o flujos de alta energía a este medio. No obstante, la presencia de niveles grano soportados con aloquemes y restos 
esqueletales (ostras, corales y braquiópodos) de la zona de foreshoal-shoal, sugiere la conexión ocasional con el medio marino abierto durante episodios de tormenta (Brigaud et al., 2014).

\subsection{2-IV: Llanura de marea (C6)}

Se presenta tanto en la zona de Malargüe como de Bardas Blancas, dentro del tramo superior de la sucesión carbonática (ver Anexos IVa-b). Dicha asociación está compuesta por litofacies carbonáticas masivas (W-Ppe) y laminadas (BI) que constituyen sucesiones discretas menores a los $0.50 \mathrm{~m}$ de espesor, sin un arreglo definido (figura 6.1a).

La misma se inicia con wackestone a packstone con abundante pellets (W-Ppe) a los que cubren, en la mayoría de los casos, estromatolitos con laminación criptoalgal plana en la base y crenuladas hacia el tope de la capa ( $\mathrm{Bl}$; figura 6.10a). Se caracteriza por presentar en su base (W-Ppe) una baja proporción de restos esqueletales de ambiente marino abierto (bivalvos no ostreidos, gasterópodos, equinoideos; ver Anexo IIIb), acompañados por foraminíferos con enroscamiento polymorphinido, en raras ocasiones junto con porosidad fenestral y moldes de evaporitas. Mientras que, hacia el tope de la sucesión (BI) los bioclastos están ausentes y los rasgos de exposición subaérea como la porosidad fenestral, laminación crenulada y estructura tepee resultan frecuentes. Una excepción es lo que ocurre en la zona de Bardas Blancas donde dichos rasgos son comunes desde la base de esta asociación de facies.

Conforma litosomas tabulares a irregulares que cubren de forma neta a la AF de shoal (C3), intershoal (C4) o de albufera (C5; figura 6.10b, ver Anexos IVa y b). Sobre esta AF se apoyan de forma neta las evaporitas de la Formación Tábanos (secciones ACS, PLE y ALV, ver Anexos IVa y b; figura 6.10a). 
Interpretación: teniendo en cuenta las características de este grupo de facies como su textura y la presencia de rasgos de exposición subaérea (porosidad fenestral, laminación crenulada y estructura tepee) se asume un ambiente marino somero de aguas tranquilas, submareal a intermareal (Wright y Burchette, 1996). Asimismo, la falta de material clástico en estas sedimentitas sugiere que las mismas se depositaron en un medio de aguas claras.

En este contexto los niveles de wackestone (W-Ppe) son interpretados como depositados en una zona submareal debido a la ausencia de rasgos de exposición subaérea, a excepción de lo ocurre en la zona de Bardas Blancas donde la presencia de porosidad fenestral en estos niveles indicaría un medio con alternancia de períodos de emersión e inundación (Shinn, 1968). En estos depósitos se infiere que los restos esqueletales de bivalvos, gasterópodos y equinoideos se habrían acumulado durante eventos de tormenta en este medio. Por el contrario, se asume que los estromatolitos $(\mathrm{BI})$ se formaron en un sector intermareal, evidenciados por la presencia de porosidad fenestral, laminación crenulada y estructura tepee hacia el tope (Benyoucef y Meister, 2015).

Dentro de este ambiente el bajo a nulo contenido de fauna bentónica, representada por foraminíferos con enroscamiento polymorphinido, acompañado por los escasos registros de eventos de tormenta indicarían un medio restringido (Benyoucef $y$ Meister, 2015), donde la conexión con el ambiente marino abierto resulta poco frecuente. Estas condiciones podrían aumentar la salinidad de este medio lo que favorecería la producción primaria, con la proliferación de cianobacterias y la formación de estromatolitos laminares hacia el tope de la sucesión (Wright y Burchette, 1996; Beigi et al., 2017).

Este ambiente pasa de manera abrupta a los depósitos evaporíticos de la Formación Tábanos que representa condiciones de acumulación hipersalinalina del medio marino posiblemente debido a un efecto de umbral morfológico ejercido por el arco magmático situado en el margen oeste de la Cuenca Neuquina (Legarreta y Uliana, 1996; Armella et al., 2013). 


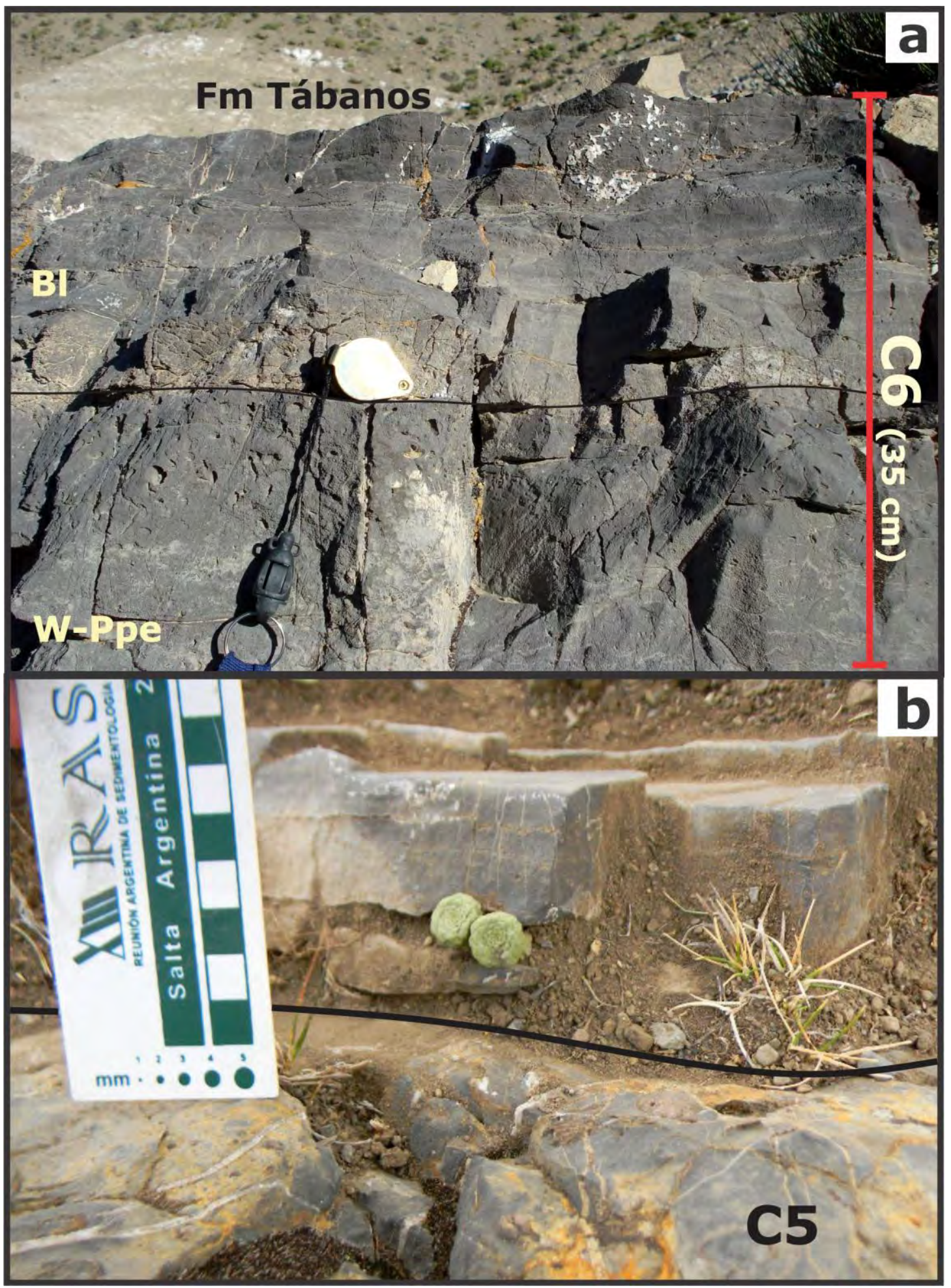

Figura 6.10a: Detalle de la asociación de facies de llanura de marea (C6) en la zona de Bardas Blancas. Se reconocen wackestone a packstone con pellets (W-Ppe) que pasan hacia arriba a estromatolitos laminares $(\mathrm{Bl})$. Nótese la presencia de la Formación Tábanos cubriendo a la sucesión. b) Contacto neto con la asociación de facies de albufera (C5) en el perfil ANE, zona de Malargüe. 


\section{3: Asociaciones de facies de sistema de acumulación marino abierto clástico (M)}

Dentro de este sistema de acumulación se incluye a todas las litofacies psefíticas, la mayor parte de las psamitas terrígenas y mixtas y un menor contenido de facies carbonáticas, agrupadas en seis asociaciones de facies. Se distinguen los subambientes de shoreface y foreshore, delimitados de acuerdo con la posición promedio del nivel de base de olas de tormenta, de buen tiempo y el nivel promedio de marea baja y alta. De esta manera, se considera shoreface a la zona que se extiende desde el nivel de base promedio de las olas de buen tiempo hasta el nivel de promedio de marea baja, el cual se diferencia del sector de foreshore ubicado entre el nivel promedio de marea baja y alta (Reading y Collinson, 1996). De forma secundaria dentro del shoreface se diferencia según la naturaleza de la transformación de las olas un tramo inferior de otro superior (Reading y Collinson, 1996). Acorde con esto, se diferencian los grupos de facies de shoreface inferior (M1), shoreface inferior a superior con bioconstrucción (M2), shoreface superior (M3), barra de tormenta (M4), foreshore-shoreface superior (M5) y barra de desembocadura (M6; figura 6.1b). 


\subsection{1: Subambiente de shoreface inferior (M1)}

Este grupo de facies se distribuye en la zona de Malargüe dentro del tramo superior de la sucesión terrígena-mixta (secciones ASE a ACS, PLN, PLW y ATW, ver Anexo IVa). Consta de psamitas finas a medias, raramente gruesas, en general masivas ( $\mathbf{S m}$, subfacies $\mathbf{S m w}, \mathbf{S G m}$ ), menos frecuente con estratificación en montículo (Sx). De forma subordinada presenta floatstone intraclástico (Fi) y packstone peloidal $(\mathrm{Pp})$ con bajo contenido de material terrígeno ( $<15 \%$ del total).

La base de la asociación comprende una sucesión monótona de psamitas sin estructura tractiva $(\mathbf{S m})$, en algunos casos homogeneizadas por bioturbación con ocasionales ondulas simétricas y estratificación paralela difusa (subfacies $\mathbf{S m w}$ ) (figura 6.1b). En el noreste y centro de Malargüe (secciones ACS-ACN-ANE, ver Anexo IVa) predominan las composiciones terrígenas con briznas vegetales y restos de bivalvos no ostreidos, amonites, equinoideos y braquiópodos rhynchonellidos (ver Anexo IIIb). Por su parte, hacia el centro y sudoeste (secciones PLN y ATW, ver Anexo IVa) dominan las areniscas mixtas con presencia de fósiles marinos (ostras, bivalvos no ostreidos, ¿algas rojas?, colonias de corales y braquiópodos rhynchonellidos). En este sector se distinguen niveles tabulares poco potentes de 30-60 cm, con micromontículos amalgamados o montículos aislados de mayor

escala (Sx) dentro de la sucesión (figuras 5.41a, 6.11a). En la base presentan lentes discretos, de $0.5 \mathrm{~m}$ de potencia, con concentraciones de intraclastos carbonáticos y bioclastos de la AF M2 (shoreface inferior-superior con bioconstrucción), junto con material terrígeno tamaño sábulo a grava fina ( $\mathrm{Fi}$; figura 6.1b). Hacia el tope pueden estar cubiertos por un interestratificado fino de packstone peloidal (Pp) y Sm (figuras 6.1 b y $6.11 a$ ).

Las porciones altas de esta asociación solo se presentan en las secciones PLN y PLW (ver Anexo IVa). Están caracterizadas por bancos aislados de areniscas conglomerádicas masivas ( $\mathbf{S G m}$ ) de composición terrígena o niveles amalgamados espesos ( $1 \mathrm{~m}$ de potencia) de areniscas mixtas con montículos amalgamados ( $\mathbf{S x}$ ) y presencia de granos tamaño sábulo a grava fina en la base de los montículos (figura $6.11 b)$. 
En general la sucesión se encuentra incompleta, faltando en algunos casos el tramo inferior o superior. La misma conforma litosomas tabulares a irregulares de 1 a 5.5 $\mathrm{m}$ de potencia, raramente menores a $1 \mathrm{~m}$ que se apoyan de forma neta e irregular sobre la AF M2 o su contacto basal no se encuentra expuesto (ver Anexo IVa). En particular en el noreste y centro de Malargüe (secciones ASE a ACS) este grupo de facies es cubierto a través de un contacto neto y erosivo por la AF M6 de barra de desembocadura. Mientras que hacia el centro y sudoeste de Malargüe (perfiles PLN, PLW y ATW) la AF de foreshoal con bioconstrucción (C2, figuras 6.6e y 6.11b) o de shoreface superior (M3) se apoyan de forma neta sobre esta sucesión.

Interpretación: dadas las características de este grupo de facies se asume un ambiente marino somero de moderada a baja energía, afectada por flujos oscilatorios durante condiciones de buen tiempo (Reading y Collinson, 1996) o combinados durante episodios de tormenta. Por su parte, la presencia de invertebrados marinos acompañados por restos vegetales hacia el noreste y centro de Malargüe sugiere un ambiente marino abierto con influencia continental, posiblemente de un sistema fluvial cercano a la costa. En este sentido, la relación entre este subambiente y los depósitos de barra de desembocadura suprayacentes sustentarían esta interpretación.

En la base de la sucesión, se infiere que el material arenoso es retrabajado durante los episodios de tormenta por flujos oscilatorios o combinados, dando lugar a capas aisladas o amalgamadas con estructura monticular (Sx) (Swift et al., 1983) o niveles con estratificación paralela (subfacies Smw) (Reading y Collinson, 1996). Durante la declinación de la tormenta dicho material decanta por la suspensión, y luego en los períodos posteriores de buen tiempo, es afectado por procesos relacionados con olas oscilatorias (subfacies Smw) (Reading y Collinson, 1996). En esta etapa, debido quizás a un ritmo de sedimentación bajo y al restablecimiento de la fauna bentónica de forma posterior a la tormenta, se produciría una fuerte homogeneización del sustrato dando lugar a capas sin estructuras tractivas ( $\mathbf{S m}$, subfacies Smw). No obstante, no se descarta que debido a la abundancia de los 
niveles masivos en la sucesión parte de ellos se podrían haber generado por una rápida depositación en los períodos de tormenta.

Dentro de este tramo de la asociación, los eventos de tormenta se desarrollan en ambientes someros por encima del nivel de base de olas de buen tiempo en la zona de shoreface inferior, como sugiere la presencia de niveles con laminación paralela (Reading y Collinson, 1996) o con estratificación monticular amalgamada y ausencia de niveles finos (Aigner y Reineck, 1982; Cheel y Leckie, 1993) los que están de acuerdo con la alta energía durante los eventos de tormenta. En este sentido, los concentrados con material carbonático y terrígeno (Fi) derivado de la zona de shoreface superior a inferior ubicados en la base de los niveles monticulares, sustentan las condiciones de alta energía. Dichos niveles lenticulares se interpretan como el relleno de canales o depresiones producidas por corrientes de retorno perpendiculares u oblicuas a la costa generadas durante las tormentas (e.g. Bressan et al., 2013).

Por su parte, las capas interestratificadas de packstone (Pp) con areniscas ( $\mathbf{S m}$ ) se asumen como el registro de corrientes de retorno durante una tormenta o de varias poco espaciadas en el tiempo. En este caso, dada la cercanía de este ambiente con los arrecifes en parche de la AF M2, se sugiere que el suministro de material carbonático hacia este sector proviene del retrabajo de dichas bioconstrucciones.

Hacia el tope de la sucesión los niveles amalgamados de areniscas Sx resultan más espesos, con material gravoso en la base de los montículos y además se reconocen niveles de arenisca conglomerádica ( $\mathbf{S G m}$ ), por lo que se infiere una ubicación dentro del shoreface inferior a superior. El notorio aumento de material grueso en este ambiente sugiere un mayor suministro de grava desde la zona de shoreface superior aledaña, posiblemente debido al aumento de la descarga de sistemas fluviales asociados con este ambiente. 


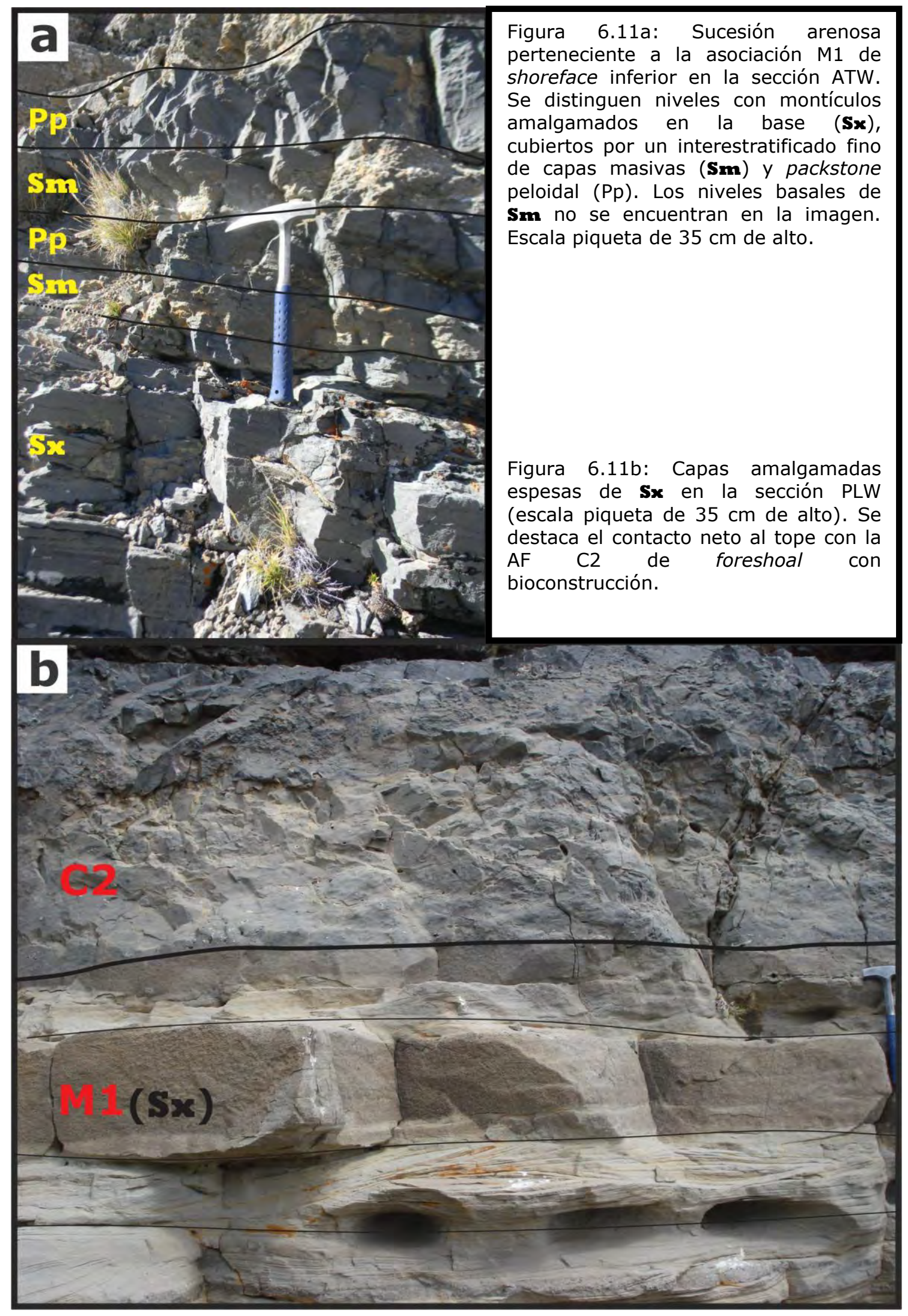




\subsection{2: Subambiente de shoreface inferior a superior con bioconstrucción (M2)}

Esta asociación de facies es poco usual, se distribuye en el centro y suroeste de la zona de Malargüe dentro del tramo medio de la sucesión terrígena-mixta (secciones PLN y ATW, ver Anexo IVa). Consta de areniscas mixtas estratificadas (St, Sh) o masivas ( $\mathbf{S m}$ ), junto con litofacies carbonáticas masivas con un bajo contenido de material terrígeno ( $<15 \%$ del total) y niveles de conglomerados estratificados (Gh) subordinados. Las litofacies carbonáticas están representadas por packstone peloidal-bioclástico (Pp-b SF1), floatstone bioclástico (Fb) y framestone coralígeno (FRc).

La sucesión completa se inicia con niveles de areniscas finas a media con estratificación entrecruzada en artesa (St) de hasta $5 \mathrm{~m}$ de espesor, discontinuos en algunos casos, seguidos por areniscas finas masivas Sm. Eventualmente pueden presentar en la base de la sucesión capas tabulares discretas ( $<1 \mathrm{~m}$ de potencia) de conglomerado con estratificación horizontal (Gh) dando lugar a arreglos granodecrecientes. Por encima de dichas sedimentitas se desarrollan arrecifes en parche (FRc) discretos de 0.6 a $1.70 \mathrm{~m}$ de espesor, en ocasiones mediante facies de asentamiento menores a los $2 \mathrm{~m}$ de potencia $(\mathrm{Fb})$. Las mismas comprenden concentrados esqueletales de ostras, braquiópodos rhynchonellidos, colonias de serpúlidos y equinoideos (centro de Malargüe, figura 6.12a-b). Estas bioconstrucciones están conformadas por colonias de corales in situ a removidas separadas por packstone peloidal (FRc) o mudstone (FRc subfacies 1) junto con formas completas y restos de ostras, colonias de corales, serpúlidos, braquiópodos rhynchonellidos y equinoideos; ver anexo IIIb).

Hacia el tope de la sucesión son comunes los litosomas de $1 \mathrm{~m}$ de espesor de areniscas gruesas masivas (Sm) y estratificadas (Sh) o la presencia de un interestratificado de packstone peloidal-bioclástico (Pp-b SF1) y Sm. En ambos casos su contacto basal es neto y erosivo sobre los arrecifes en parche (figura $5.36 \mathrm{~b})$ y abundan las calgas rojas?, ostras, restos de corales y equinoideos. 
Esta AF alcanza los 2.50 a $8.30 \mathrm{~m}$ de potencia. Es cubierta a través de un contacto neto por el grupo de facies de shoreface inferior (M1) en el centro de Malargüe y por la AF M5 de foreshore-shoreface superior hacia el sudoeste.

Interpretación: de acuerdo con las características de este grupo de facies, como su textura, estructuras tractivas y contenido de fósiles marinos se sugiere un ambiente marino somero ubicado por encima del nivel de base de olas de buen tiempo, donde la acción de las olas y corrientes costeras resultan frecuentes. En el mismo se distinguen diferentes etapas con variable suministro de material clástico desde las áreas costeras, el cual condiciona el desarrollo de los arrecifes en parche.

Durante los períodos de abundante aporte de material clástico a este medio, la acción de las olas y corrientes costeras generarían litosomas y barras arenosas (St) acompañadas en ocasiones por capas de grava en su base (Gh). Estas condiciones hidrodinámicas favorecerían la destrucción mecánica de la fauna bentónica que habita este ambiente dando lugar a barras arenosas de composiciones mixtas.

Hacia el tope de estos litosomas arenosos la disminución gradual del suministro clástico y la energía del medio se vería reflejada en su arreglo granodecreciente y en el desarrollo de arrecifes en parches sobre los mismos (e.g. García-García, 2004). En este sentido, el bajo aporte de material terrígeno generaría un medio de aguas claras y condiciones oligotróficas que propiciarían el asentamiento de las colonias de corales (e.g. Wilson, 2005) sobre litosomas arenosos o concentrados esqueletales $(\mathrm{Fb})$ producto de eventos de tormenta en este medio (véase capítulo 5, apartado 5.3.1, facies Fb). Una vez que las colonias se estabilizan conforman una estructura discreta rodeada por sedimento carbonático de textura packstone a mudstone, que indicarían condiciones variables de la energía de las olas. La falta de una estructura rígida y la abundante proporción de matriz inconsolidada que las rodea, aumenta su susceptibilidad al retrabajo temprano de la olas (Tudhope y Scoffin, 1994) afectando su potencial de preservación (Wilson, 2005).

En el techo de la sucesión los litosomas arenosos ( $\mathbf{S m}, \mathbf{S h}$ ) e interestratificados arena-packstone ( $\mathbf{S m}, \mathrm{Pp}-\mathrm{b})$ indicarían el cese de la producción carbonática, relacionado al ahogamiento físico de las colonias por el incremento del suministro 
clástico al sistema (Wilson, 2005). Asimismo, el aumento de partículas clásticas en suspensión asociada con la acción de las olas en este medio, generaría una mayor turbidez de las aguas que afecta el crecimiento de las colonias de corales (Bauch et al., 2011) y por lo tanto impide el restablecimiento de los arrecifes en parche.

A juzgar por el bajo espesor que presentan los arrecifes en parche y las condiciones ambientales bajo las que se forman (bajo suministro clástico y de nutrientes) se considera que los mismos no son frecuentes dentro de este subambiente. En este sentido, se sugiere que la presencia de dichas bioconstrucciones podría indicar períodos de baja tasa de sedimentación en este subambiente relacionados con variaciones del nivel del mar relativo de pequeña escala.

\subsection{3: Subambiente de shoreface superior (M3)}

Esta asociación se distribuye en el sudoeste de la zona de Malargüe dentro del tramo superior a medio de la sucesión terrígena-mixta (secciones APS y ATW, ver Anexo IVa). Abarca areniscas medias a gruesas, raramente finas, en general terrígenas con estratificación entrecruzada plana (Sp), paralela (Sh) o masivas ( $\mathbf{S m})$ junto con psefitas clasto sostén sin estructuras tractivas (Gmc). En la mayoría de estos casos se registra una sucesión de facies granodecreciente con niveles tabulares de conglomerados en la base que gradan a capas tabulares a irregulares de areniscas hacia el tope (figuras 6.1 b y 6.13 ). En la misma los niveles más finos representan cuerpos de mayor espesor ( $\left.\begin{array}{llll}1 & \text { a } & 2 & \mathrm{~m}\end{array}\right)$ respecto a los conglomerádicos de 0.50 a $0.70 \mathrm{~m}$ de potencia. Estos últimos se presentan como capas extensas lateralmente (30 a $50 \mathrm{~m}$ de extensión), con base neta plana a levemente erosiva. Las areniscas pueden presentar ocasionales clastos tamaño sábulo a grava fina ( 2 a $10 \mathrm{~mm}$ ) distribuidos en las caras frontales de los sets o entre las bandas paralelas. 
Este grupo de facies presenta un bajo contenido de restos esqueletales indiferenciados, bivalvos no ostreidos, colonias de corales y ostras (ver anexo IIIb). Conforman litosomas tabulares de 1.70 a $4.20 \mathrm{~m}$ de potencia. Se apoyan a través de un contacto neto sobre la AF de barra de desembocadura (M6) o de shoreface inferior (M1) y son cubiertos de forma transicional a neta por la AF M5 de foreshore o por la AF C2 de foreshoal con bioconstrucción, respectivamente (figura 6.13). Lateralmente pasa a la AF M4 de barra de tormenta o a la AF M2 de shoreface inferior a superior (ver Anexo IVa).

Interpretación: se infiere un ambiente marino somero de shoreface superior con suministro puntual de grava desde una barra de desembocadura o fuentes fluviales próximas a este ambiente (e.g.Hart y Plint, 1995; Pomar et al., 2002). En este sentido, se sugiere que dichas corrientes habrían afectado las aguas marinas normales de este medio a través de la fluctuación de su salinidad o incremento de su turbidez. Estas condiciones habrían inhibido la colonización del sustrato arenoso departe de organismos bentónicos (Veiga et al., 2013), dando lugar a un bajo contenido de restos esqueletales en este ambiente.

En este medio los procesos que imperan son las olas costeras y corrientes inducidas por las mismas con diferente orientación respecto a la línea de costa (Hart y Plint, 1995; Reading y Collinson, 1996). Estos agentes erosionan y transportan el material arenoso a lo largo de la costa y retrabajan el aporte puntual de grava que llega hacia este sector. El efecto neto de estos procesos costeros se refleja con la presencia de depósitos tabulares en el cual las gravas son segregadas en capas discretas, lateralmente extensas (Gmc) (Clifton, 2003). Además la acción de las olas propicia la conformación de estructuras clasto soportadas en los conglomerados (Hart y Plint, 1995; Pomar et al., 2002). El predominio de areniscas con estructuras tractivas generadas por la actividad de las olas en niveles extensos lateralmente (Sp, Sh) sustentarían esta interpretación. Asimismo, la falta de estructuras tractivas en algunos niveles psamíticos podría estar relacionada con una rápida depositación o con una intensa homogeneización por bioturbación. 


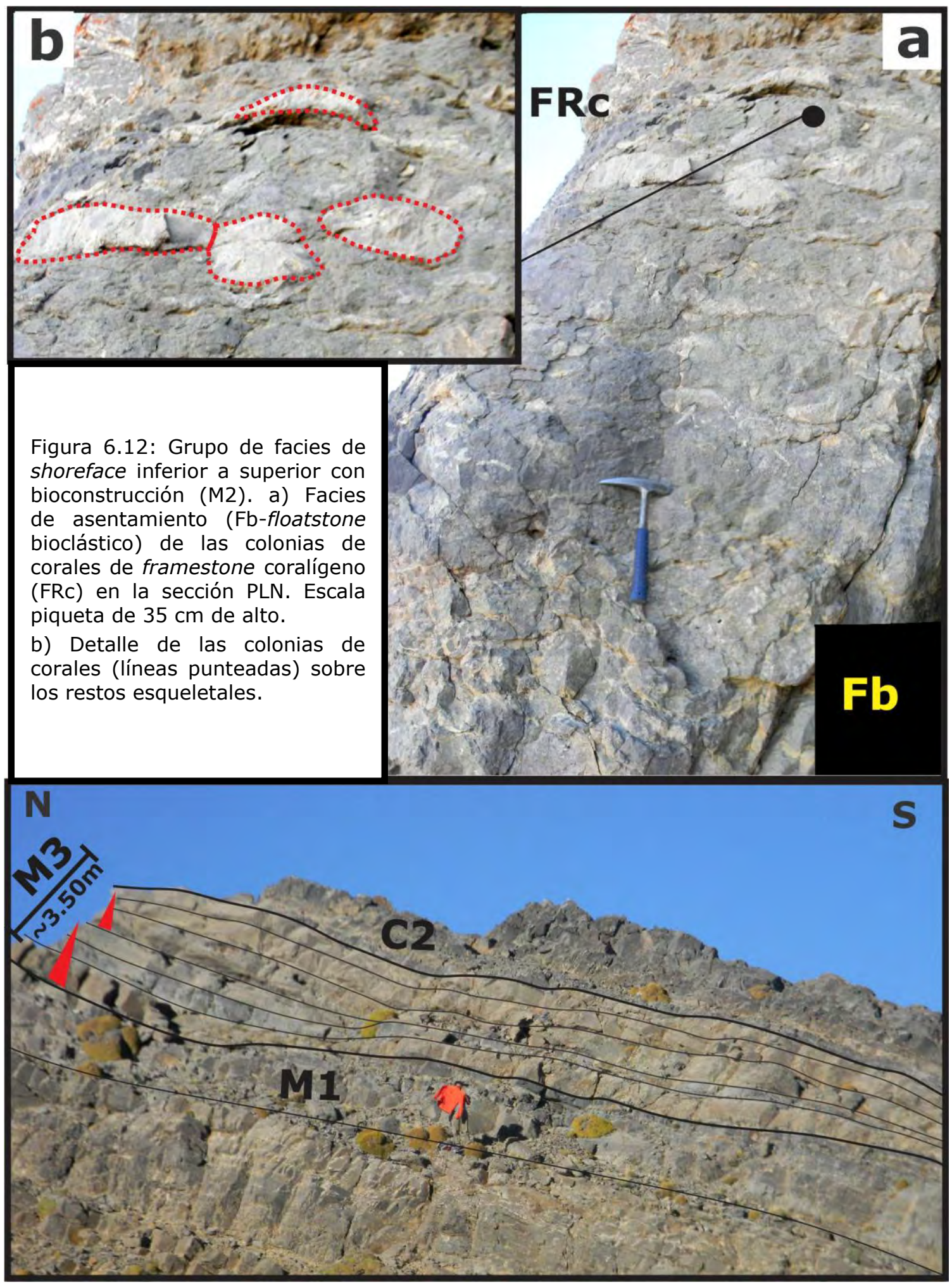

Figura 6.13: Niveles tabulares de la AF de shoreface superior (M3) con arreglo granodecreciente en la sección ATW. Se destaca el contacto neto al tope con la AF C2 de foreshoal con bioconstrucción y en la base con la AF M1 de shoreface inferior. 


\subsection{4: Barra de tormenta (M4)}

Este grupo de facies se presenta solo en el sudoeste de la zona de Malargüe dentro del tramo superior de la sucesión terrígena-mixta (sección PLE, ver Anexo IVa). Consta de conglomerados con estratificación entrecruzada en artesa (Gt) que pasan lateralmente hacia areniscas conglomerádica y areniscas, en general mixtas, con la misma estructura sedimentaria (SGt, St). Estos pares de grava-arena forman litosomas tabulares a irregulares de hasta $0.5 \mathrm{~m}$ de espesor con arreglos granodecrecientes, base neta plana a levemente erosiva y tope plano a levemente convexo (figura 6.14). Los cuerpos se encuentran separados por superficies netas planas a levemente inclinadas que en ocasiones pueden distinguirse dentro de los mismos. En estos cuerpos las modas principales de la cara de avalancha apuntan hacia el noroeste y hacia el sud-sudoeste (figura 6.2).

Esta asociación de facies se caracteriza por presentar un moderado contenido de restos de ostras, ¿algas rojas?, bivalvos no ostreidos y equinoideos (ver Anexo IIIb). Conforman una sucesión de aproximadamente $3 \mathrm{~m}$ de espesor grano y estratocreciente cuyo contacto basal no se encuentra expuesto (figuras $6.1 \mathrm{~b}$ y 6.14). Su techo es cubierto a través de un contacto erosivo por la AF M5 de foreshore-shoreface superior.

Interpretación: se considera que la depositación cíclica de dichos litosomas granodecreciente se corresponde con barras gravo-arenosas generadas en el shoreface superior por corrientes inducidas durante períodos de tormentas (e.g. Massari y Parea, 1988). Durante estos eventos se genera un régimen de circulación en esta zona donde se produce la remoción de material departe de corrientes longitudinales y de retorno inducidas por las tormentas, acompañadas por un fuerte movimiento oscilatorio de las olas costeras y de rompiente (Massari y Parea, 1988; Reading y Collinson, 1996). Grandes volúmenes de material arenoso y psefítico acumulados en condiciones de buen tiempo en el foreshore e incluso en la zona de shoreface son removidos y llevados hasta este sector (Einsele et al., 1996) dando lugar a estos depósitos de grava y arena. Se infiere que cada uno de estos pares de 
grava y arena podría representan el registro de una tormenta o de tormentas poco espaciadas en el tiempo (Massari y Parea, 1988) donde no se preserva el material acumulado durante condiciones de buen tiempo a juzgar por los contactos netos planos a levemente erosivos que presentan los sucesivos litosomas. De acuerdo con estas características y la geometría tabular que presentan estos litosomas se sugieren flujos de alta energía paralelos (orientación S-SW) a normales (orientación NW) respecto a la paleolínea de costa como procesos generadores.

\subsection{5: Subambiente de foreshore-shoreface superior (M5)}

Esta asociación se distribuye en el sudoeste de la zona de Malargüe dentro del tramo inferior a superior de la sucesión terrígena-mixta (secciones PLE, APS y ATW, ver Anexo IVa). Comprenden sucesiones de areniscas terrígenas y mixtas con estratificación paralela (Sh) o masivas $(\mathbf{S m})$, menos frecuente entrecruzada (St). En general se presentan arreglos granodecrecientes con granulometrías gruesas en la base, estratificadas y masivas (Sh, Sm), que gradan hacia el tope a granulometrías media a finas con estratificación paralela o entrecruzada (Sh, St; figura 6.15). Las areniscas con estratificación entrecruzada forman cuerpos tabulares a irregulares con base plana a levemente irregular que conforman cosets de 10 a $40 \mathrm{~cm}$ de espesor (St). En la sección PLE la cara de avalancha de los mismos indica paleocorrientes hacia el noroeste (figura 6.2). De forma subordinada pueden aparecer niveles aislados $<0.5 \mathrm{~m}$ de espesor de conglomerados masivos matriz sostén ( $\mathbf{G m m}$ ) en la base de la sucesión o intercalados en la misma (sección ATW).

Menos comunes son los arreglos granocrecientes dentro de la sucesión donde se distingue el pasaje de areniscas finas sin estructuras tractivas ( $\mathbf{S m}$ ) a psamitas medias con estratificación paralela (Sh).

En esta AF la presencia de ostras, bivalvos no ostreidos, ¿algas rojas?, restos de corales y braquiópodos rhynchonellidos es común (ver Anexo IIIb), de forma 
ocasional los mismos pueden presentarse como concentraciones. Conforman litosomas tabulares a irregulares de 1 a $3 \mathrm{~m}$ de potencia que se apoyan de forma transicional a neta sobre la AF M3 de shoreface superior o de barra de tormenta (M4), respectivamente. En este último caso es usual la presencia de intraclastos de hasta $3 \mathrm{~cm}$ de tamaño en la base de la sucesión. Asimismo, este grupo de facies es cubierto de forma neta y erosiva por la AF M6 de barra de desembocadura (figura $6.15)$.

Interpretación: de acuerdo con la abundancia de texturas gruesas, los arreglos granodecrecientes de este grupo de facies y la presencia común de fósiles marinos (bivalvos, ¿algas rojas?) se sugiere que se depositaron en un ambiente costero de alta energía dominado por las olas de buen tiempo y de tormenta (Walker y James, 1992). Se infiere que los depósitos de areniscas con estratificación paralela a entrecruzada se habrían formado como resultado de corrientes unidireccionales no canalizadas, las cuales redistribuyen el material extracuencal y los restos esqueletales bajo condiciones de alto o bajo régimen de flujo (e.g. Veiga et al., 2013). En este sentido, se sugieren flujos unidireccionales normales (orientación NW) respecto a la paleolínea de costa como procesos generadores de estos depósitos en la sección PLE. Dentro de este contexto, los niveles discretos de conglomerados masivos se interpretan como flujos hiperpicnales que ingresan a este medio, relacionados con un sistema fluvial cercano a la costa (Mulder et al., 2003; Veiga et al., 2013). 


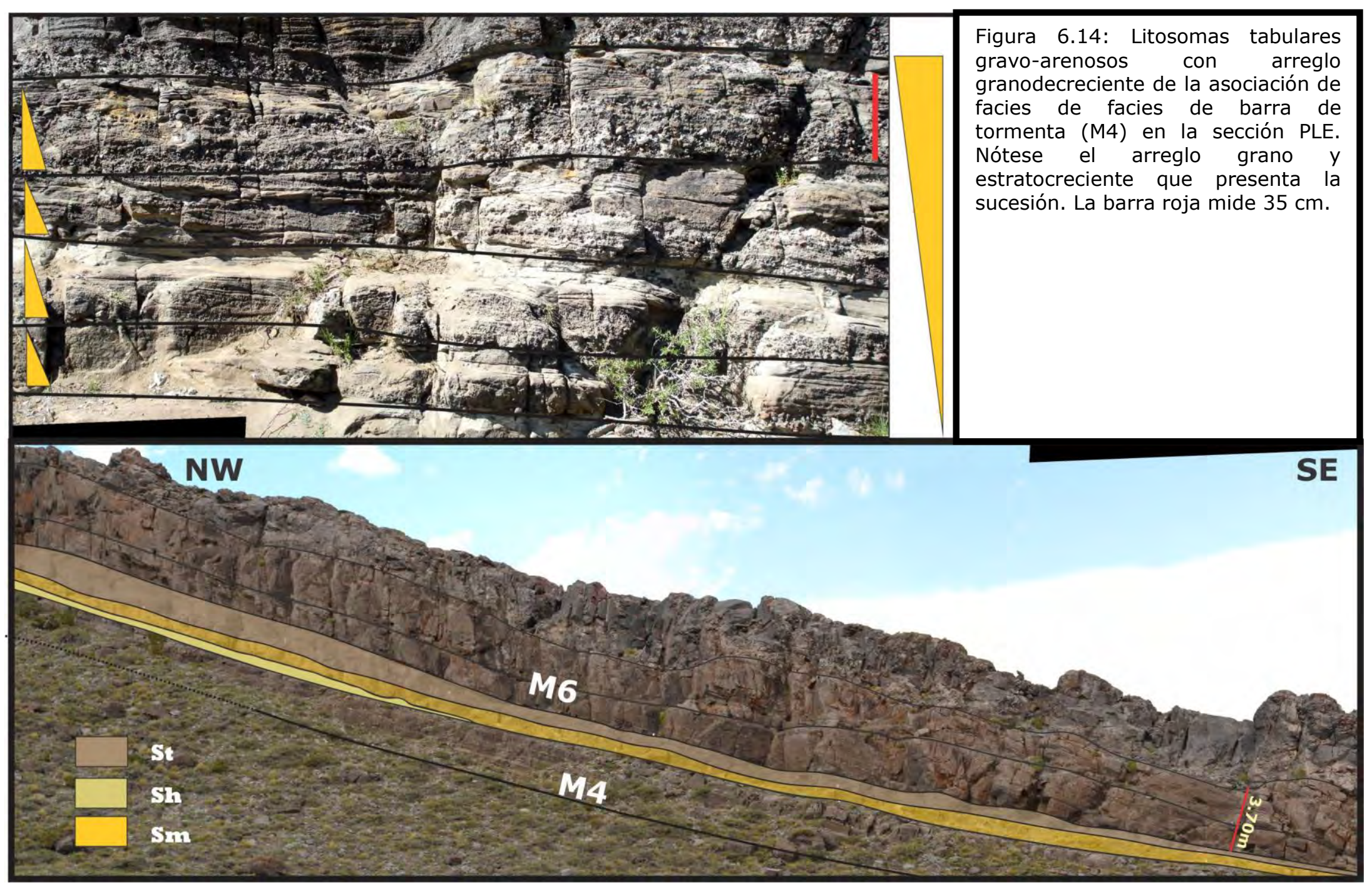

Figura 6.15: Grupo de facies de foreshore-shoreface superior (M5) conformada por niveles lenticulares en la base a tabulares en el tope de areniscas con estratificación paralela (Sh), masivas $(\mathbf{S m})$ o con estratificación entrecruzada en artesa (St). Ejemplo sacado de la sección PLE. 


\subsection{6: Barra de desembocadura (M6)}

Esta asociación se distribuye en la zona de Malargüe a lo largo de la sucesión terrígena-mixta (ver Anexo IVa). Abarca a la mayoría de los conglomerados identificados en este trabajo sin estructuras tractivas ( $\mathbf{G m m}$ ), en menor medida entrecruzados planos $(\mathbf{G} \mathbf{p})$, así como también floatstone masivos (Fi) y areniscas terrígenas masivas (Sm) o con estratificación entrecruzada (S1). Los niveles conglomerádicos en general están amalgamados y conforman litosomas de hasta 4 $\mathrm{m}$ de espesor. En algunos casos se encuentran separados por finos niveles de arenisca masiva (figuras 6.16a-b).

En particular en el noreste y centro de Malargüe (secciones ASE a ACS, ver Anexo IVa) resulta frecuente su agrupación tanto lateral como verticalmente con litosomas irregulares a lenticulares de floatstone intraclástico de hasta $3 \mathrm{~m}$ de potencia (figura 6.1b). Los mismos son portadores de intraclastos y bioclastos de tamaños variados derivados del retrabajo de facies carbonáticas (FRc, $\mathrm{Fb}$ ) y arenosas (subfacies Smw) previas correspondientes a la AF M2 y M1, respectivamente. Además pueden contener intraclastos carbonáticos de las AF C3 y C4 cuando se relacionan con depósitos de foreshoal (AF C2, figura 6.4c; véase apartado 6.2.1-II). En ambos casos acompaña un bajo contenido de material terrígeno $(<15 \%$ del total) tamaño sábulo a grava fina.

Las capas de conglomerados pueden formar arreglos granodecrecientes con areniscas finas a muy gruesas (hasta sábulo) masivas ( $\mathbf{S m}$ ) o con estratificación entrecruzada de bajo ángulo (S1), donde dichos niveles más finos representan una menor proporción (figura 6.1b). Estas últimas cubren a los conglomerados a través de un contacto neto y plano con presencia de flutes.

En esta sucesión es común la presencia de fósiles marinos a excepción de lo que ocurre en los niveles superiores de $\mathbf{G p}$. Dentro de esta fauna predominan los restos de colonias de corales, acompañados por fragmentos de colonia de serpúlidos, ostras, bivalvos no ostreidos y amonites en el noreste de Malargüe, mientras que 
hacia el sudoeste abundan las ¿algas rojas?, bivalvos y restos de corales (ver Anexo IIIb).

Dicha asociación de facies alcanza los $7 \mathrm{~m}$ de potencia. Se presenta rellenando cuerpos irregulares a lenticulares, con bases erosivas ( $\mathbf{G m m}$ ) y ocasional presencia de flutes e intraclastos. Menos común son los litosomas tabulares y extensos (de hasta $50 \mathrm{~m}$ de extensión), con bases netas planas a irregulares, poco erosivas y en algunos casos arreglos granodecrecientes (Gp, figura 6.16a). En estos cuerpos las paleocorrientes medidas en sus caras de avalancha indican flujos con una marcada moda hacia el sud-sudoeste (figura 6.2).

Su contacto basal es neto y erosivo sobre la AF de shoreface inferior (M1) en el noreste y centro de Malargüe, y sobre el grupo de facies de foreshore-shoreface superior (M5) hacia el sudoeste de esta zona (figura 6.16a). En la mayoría de los casos esta AF es cubierta de forma neta por el grupo de facies C2 de foreshoal con bioconstrucción (figuras 6.5b; 6.16a), menos frecuente por AF de shoreface superior (M3). En especial hacia el noreste de Malargüe niveles aislados de esta asociación cortan o cubren a las calizas de la AF C2 (figura 6.4b).

Interpretación: los litosomas espesos de conglomerados con areniscas subordinadas se consideran formados en un medio marino somero por la descarga de un sistema fluvial de carga de lecho gravo-arenosa que se encontraría relativamente próximo a la costa. Las características que presentan estos depósitos como la presencia de fósiles marinos, textura matriz a clasto soportada, depósitos estratificados o masivos indican la interacción de procesos de flujos en masa y tractivos en su formación como sucede en una barra de desembocadura (Kleinspehn y Steel, 1984; Hart y Plint, 2003). Cuando el sistema fluvial ingresa a este ambiente se generan flujos gravitatorio por un cambio de pendiente en el sistema que depositan su carga de lecho de forma súbita cuando pierden su capacidad de transporte (Kleinspehn y Steel, 1984; Hart y Plint, 1995; 2003). En este sentido, los conglomerados matriz sostén de geometrías irregulares a lenticulares se concentran en posiciones más cercanas al sistema fluvial ( $\mathbf{G m m}$ ) respecto a los niveles tabulares clasto sostén 
(Gp) donde la acción de las olas es más marcada (Clifton, 1973; Hart y Plint, 1995). En estos depósitos las paleocorrientes indican una moda marcada hacia el sud-sudoeste paralela a la paleolínea de costa inferida.

En ambos casos, los niveles amalgamados de conglomerados sugieren un suministro constante de grava al sistema marino dando lugar a episodios de sedimentación poco espaciados en el tiempo, separados en ocasiones por finos bancos de arena que podrían representar eventos de baja descarga fluvial. No obstante, el arreglo granodecreciente de estos litosomas gravo-arenosos indicaría una disminución gradual del suministro fluvial hacia este medio marino.

Además las olas y corrientes costeras aportan material intracuencal retrabajado desde la zona de foreshore-shoreface (restos de bivalvos, ¿algas rojas? y colonias de corales) que se mezcla con dicho material terrígeno. Como se puede observar la diversidad de fauna marina es baja, la cual refleja el número limitado de fauna bentónica que vive en estos ambientes de alta energía y sustrato inestable (Bourgeois y Leithold, 1984).

Hacia el noreste de Malargüe relacionados con un contacto neto erosivo en su base los litosomas conglomerádicos se asocian con espesas capas de floatstone intraclástico ( $\mathrm{Fi}$ ). Se considera que dada la marcada influencia que presentan dichos depósitos en su composición respecto a las asociaciones de facies M1 y M2 subyacentes, su origen podría estar relacionado con los flujos gravitatorios que depositan a los niveles conglomerádicos en este ambiente. Los intraclastos y parte de los bioclastos que conforman a los floatstone pueden ser erosionados y transportados por dichas corrientes cuando ingresan al ambiente marino dando como resultado concentraciones mixtas espesas derivadas de diferentes subambientes. Por su parte, cuando estos depósitos se encuentran relacionados con la zona de foreshoal ( $A F(C 2$ ) se sugiere que dichos litosomas erosionan parcialmente a estas calizas e interrumpen la sedimentación carbonática, de acuerdo con la relación de corte y el contacto erosivo que presentan. En este caso además se produce la entrada de material erosionado y retrabajado de asociaciones de facies de shoal externo e intershoal (AF C3 y C4, respectivamente). 


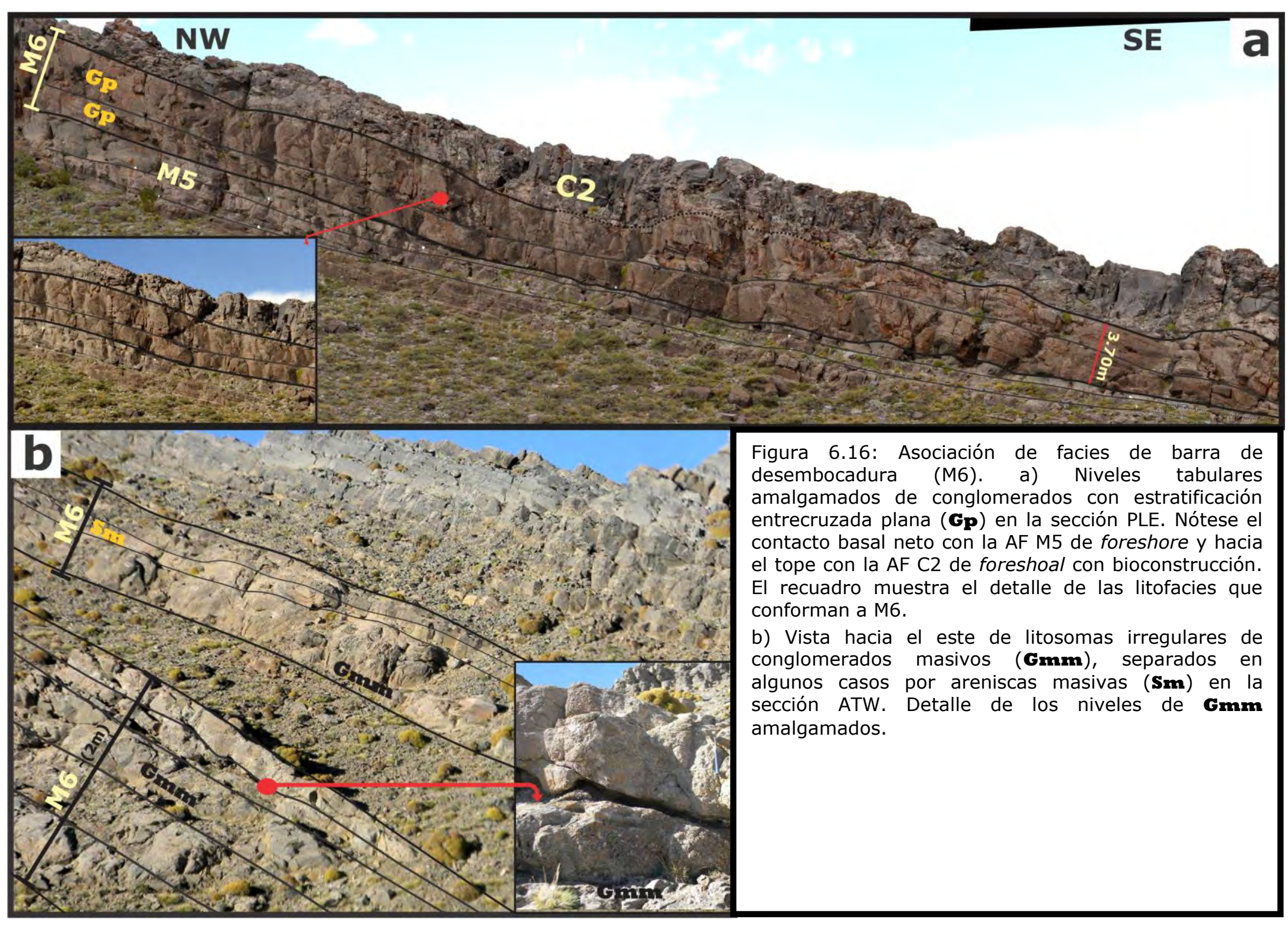




\section{4: Consideraciones finales}

A modo de síntesis puede indicarse que, la asociación de las 27 facies y 6 subfacies presentadas en el capítulo 5 (apartado 5.3) permitió el reconocimiento de diferentes grupos de facies, vinculadas genéticamente y con significado paleoambiental. De esta forma, dentro del intervalo estratigráfico de interés se identificaron y caracterizaron 12 asociaciones de facies marinas someras, de las cuales 6 asociaciones son atribuidas a acumulación en un sistema carbonático (C), y 6 asociaciones son interpretadas como acumuladas en un sistema clástico (M).

Las asociaciones de facies de sistema carbonático representan el tramo superior del intervalo de estudio (sucesión carbonática) que se distribuye en toda el área de trabajo (Anexo IVa-b). Según los procesos depositacionales dominantes pueden separarse en dos grupos. El primero de ellos se dispone dentro del tramo inferior a medio de la sucesión carbonática e incluye depósitos de foreshoal dominado por eventos de tormenta (C1) y foreshoal con bioconstrucción (C2), considerados afín con un subambiente de rampa media. Por su parte, el segundo grupo se distribuye en el tramo medio a superior de la sucesión carbonática y comprende depósitos de shoal (C3), intershoal (C4), albufera (C5) y llanura de marea (C6) interpretados como un subambiente de rampa interna.

Por su parte, las asociaciones de facies de sistema clástico abarcan el tramo inferior a medio del intervalo de estudio (sucesión terrígena-mixta) que se distribuye solo en el área norte de trabajo (Anexo IVa). Solo en el noreste de esta zona comprenden el tramo superior del intervalo en estudio junto al grupo de facies de sistema carbonático. Se incluyen los depósitos de shoreface inferior (M1), shoreface inferior a superior con bioconstrucción (M2), shoreface superior (M3), barra de tormenta (M4), foreshore-shoreface superior (M5) y barra de desembocadura (M6), interpretados como afines a los subambientes de shoreface (inferior a superior) a foreshore. 


\section{CAPÍTULO 7: DIAGÉNESIS DE LA SUCESIÓN CARBONÁTICA}

\section{1: Introducción}

La diagénesis involucra a todos los procesos que modifican las características y composición de las sedimentitas carbonáticas desde su depositación hasta que dichos materiales se sitúan en el campo del metamorfismo a presiones y temperaturas elevadas (Tucker y Bathurst, 1990). Su análisis comprende la descripción e interpretación de los diferentes estadios de cementación, el reemplazo de texturas y la generación y obliteración de la porosidad en calizas, según la composición original de la fase carbonática, el ambiente de formación y la composición química del agua poral (Tucker y Bathurst, 1990).

En este capítulo, a partir del análisis composicional y de asociaciones de facies realizado en los apartados 5 y 6 , se abordarán los procesos diagenéticos que modificaron a las sedimentitas de la sucesión carbonática, donde se pondrá especial énfasis en los diferentes estadios de cementación carbonática. Luego, a partir de la construcción de la historia diagenética, se explicará la evolución temporal de estos procesos junto con el ambiente diagenético donde tuvieron lugar. En este contexto, en el Anexo II puede consultarse el índice de las muestras obtenidas en el campo y de los distintos estudios realizados sobre cada una de ellas. Entre ellos se incluyen la descripción de secciones delgadas de calizas bajo petrografía de polarización y catodoluminiscencia en frío, cuyos principales resultados se expondrán a continuación. Por otra parte, en el Anexo IV se presenta la representación gráfica de las asociaciones de facies carbonáticas utilizadas en este análisis, cuyas características principales pueden consultarse en la figura 6.1a. 


\section{2: Diagénesis de las sedimentitas carbonáticas}

La diagénesis de las rocas carbonáticas depende de su mineralogía original, de la composición del fluido poral y de su ambiente de formación (Tucker y Bathurst, 1990). En este sentido, los carbonatos compuestos de aragonita resultan más susceptibles a la alteración diagenética respecto a los conformados por calcita con alto contenido en magnesio (HMC), y estos a su vez respecto a los de calcita con bajo contenido de magnesio (LMC).

En lo que respecta al ambiente de formación, se identifican tres medios principales donde se llevan a cabo las transformaciones diagenéticas: marino, meteórico y de soterramiento (Tucker, 2001). En el ambiente marino los cambios ocurren en el fondo marino o inmediatamente por debajo del mismo desde sectores someros (supramareales a intermareales) a profundos. En contraste, la diagénesis meteórica ocurre de forma posterior a la depositación de las sedimentitas carbonáticas si la línea de costa prograda o si se produce un descenso del nivel relativo del mar, o de forma tardía cuando dicho depósito previamente enterrado es llevado a la superficie. Por su parte, en el ambiente de soterramiento los cambios en los depósitos carbonáticos acontecen por debajo de la zona afectada por los procesos superficiales hasta las profundidades en las que comienzan las reacciones metamórficas (Tucker, 2001).

Por otra lado, Choquette y Pray (1970) proponen la denominación de los diferentes estadios diagenéticos como eogénesis, desde la sedimentación al enterramiento muy somero; mesogénesis, del enterramiento somero al profundo y telogénesis, posterior a un ascenso tectónico. En este trabajo se utilizó una combinación de las etapas previamente descriptas debido a que los cambios relativos en el nivel del mar generan que dichos estadios se desarrollen en más de un ambiente diagenético. Además, se le asignó una división interna a cada uno de estos estadios diagenéticos de acuerdo al orden de aparición de los diferentes procesos, a los fines de comprender mejor la evolución diagenética de la unidad en estudio. 


\section{3: Procesos diagenéticos}

Cada uno de los ambientes diagenéticos previamente descriptos se caracterizan por el tipo y magnitud de los procesos que modifican a los sedimentos y rocas carbonáticas. Dentro de ellos, los principales son la micritización, cementación, neomorfismo, reemplazo por dolomita o fases minerales no carbonáticas, disolución y compactación (Tucker, 2001; Flügel, 2010).

En este contexto, a partir del análisis de alta resolución de doscientas y tres láminas delgadas de calizas, y de escasas areniscas, mediante petrografía de polarización y catodoluminiscencia en frío (Anexo II) se identificaron los productos diagenéticos. Luego se definieron los procesos involucrados, según la metodología y condiciones operativas descriptas en el capítulo 2, apartado 2.5.1. En particular, para las fases cementantes carbonáticas y silíceas se consideró la textura descripta en el capítulo 5 (apartado 5.2.1-II), junto con su distribución dentro de la porosidad primaria (depositacional) o secundaria (por diagénesis o tectónica) de las sedimentitas. En este sentido, de acuerdo con Tucker (2001) se diferenció dentro la porosidad primaria, cavidades intergranulares (entre granos), intragranulares (interior de organismos esqueletales) y porosidad fenestral. Por su parte, dentro de las cavidades secundarias se distinguieron entre porosidades intercristalinas (entre cristales), móldicas (generado por la disolución parcial a total de granos esqueletales y no esqueletales) y en el interior de fracturas tensionales.

Además, en el caso de los precipitados carbonáticos el uso de la catodoluminiscencia permitió reconocer diferentes generaciones y estadios de cementación que rellenan las cavidades porales. De esta forma se identificaron cementos luminiscentes, de luminiscencia baja (dull) o no luminiscentes, de acuerdo a su contenido relativo en $\mathrm{Mn}^{+2}$ (elemento activador) y $\mathrm{Fe}^{+2}$ (elemento inhibidor) (Hiatt y Pufahl, 2014). Asimismo, dentro de los precipitados luminiscentes se identificaron patrones zonados y no zonados.

A continuación se describirán los procesos diagenéticos identificados dentro de la sucesión carbonática. En primer término se definirá el proceso y luego se realizará una breve descripción del producto que lo representa. Por último se determinará su 
abundancia relativa y distribución dentro de las asociaciones de facies descriptas en el capítulo 6, diferenciadas en el caso que sea necesario por zona de estudio (Malargüe y Bardas Blancas; figuras 7.1a-b). En este sentido las asociaciones de facies consideradas fueron: foreshoal dominado por eventos de tormenta (C1), foreshoal con bioconstrucción (C2), shoal externo e interno (C3), intershoal (C4), albúfera (C5) y llanura de marea (C6, ver figura 6.1a).

Figura 7.1a: Historia diagenética de la sucesión en estudio en el área de Malargüe, donde se muestra la frecuencia relativa de cada proceso diagenético dentro de las diferentes asociaciones de facies. Los rectángulos rojos indican la etapa donde el proceso diagenético resulta mejor representado y las líneas cortadas rojas donde se infiere que el mismo podría suceder. Por su parte, los rectángulos grises identifican la frecuencia de un proceso que ocurre solo en la sección PLE (Plomo Este). CIH: cemento isopáquico en halo; C. mec.: compactación mecánica; primera (CE1b), segunda (CE2) y tercera generación (CE3a-b) de cementación esparítica; CV: cementación en venas; CS: cementación silícea; C. feldespato autig.: cemento de feldespato autigénico; Dolomitiz.: dolomitización; R.: reemplazo; C. quim.: compactación química Dedolom: dedolomitización.

Figura 7.1b: Historia diagenética de la sucesión en estudio en el área de Bardas Blancas, donde se indica la frecuencia relativa de cada proceso diagenético dentro de las diferentes asociaciones de facies. Los rectángulos rojos indican la etapa donde el proceso diagenético resulta mejor representado y las líneas cortadas rojas donde se infiere que el mismo podría suceder. CIH: cemento isopáquico en halo; CFA: cementación fibrosa asimétrica; C.mec.: compactación mecánica; primera (CE1a-b), segunda (CE2) y tercera generación (CE3a-b) de cementación esparítica; CV: cementación en venas; CS: cementación silícea; C. feldespato autig.: cemento de feldespato autigénico; R.: reemplazo; C. quim.: compactación química. 


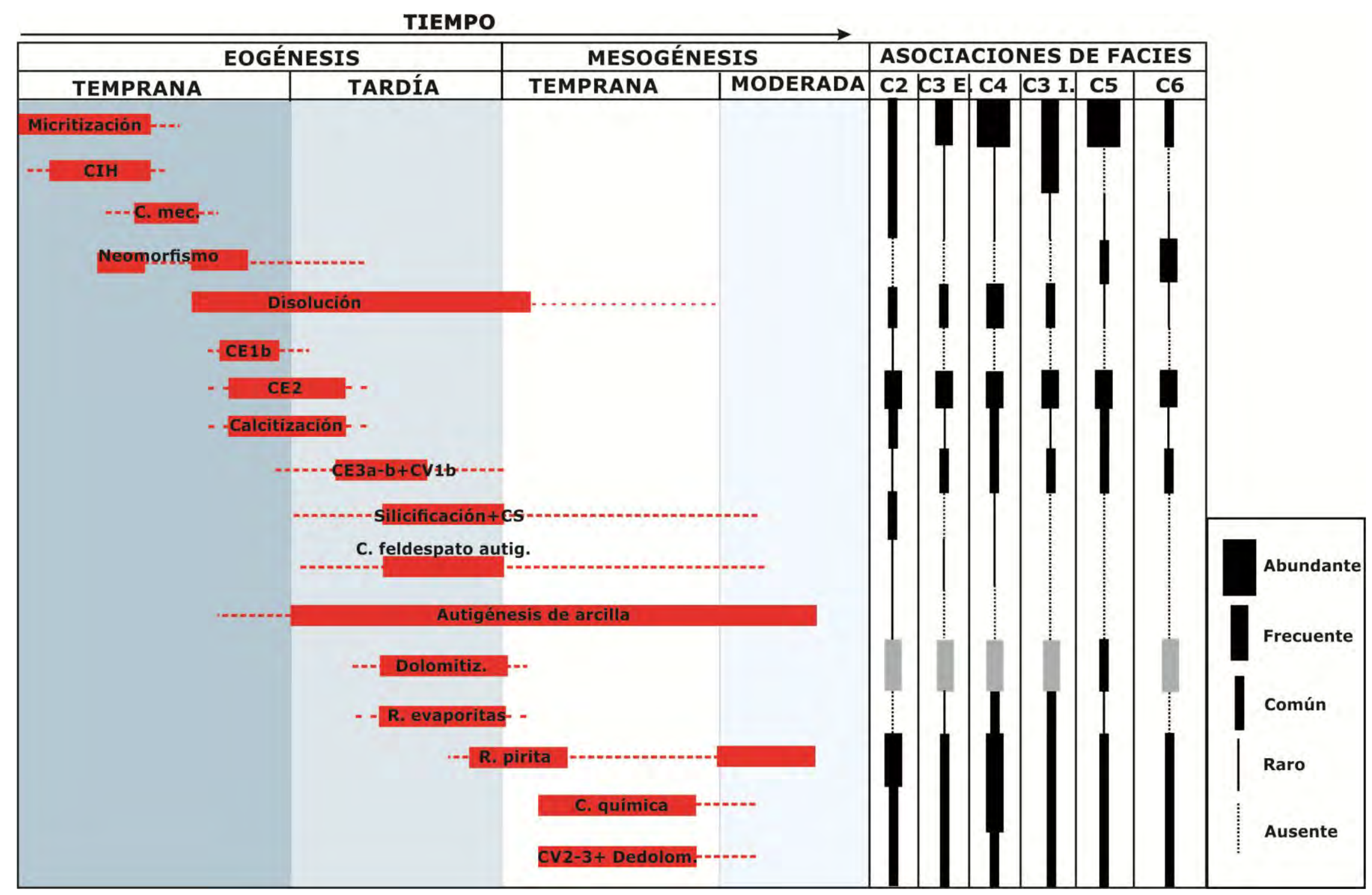




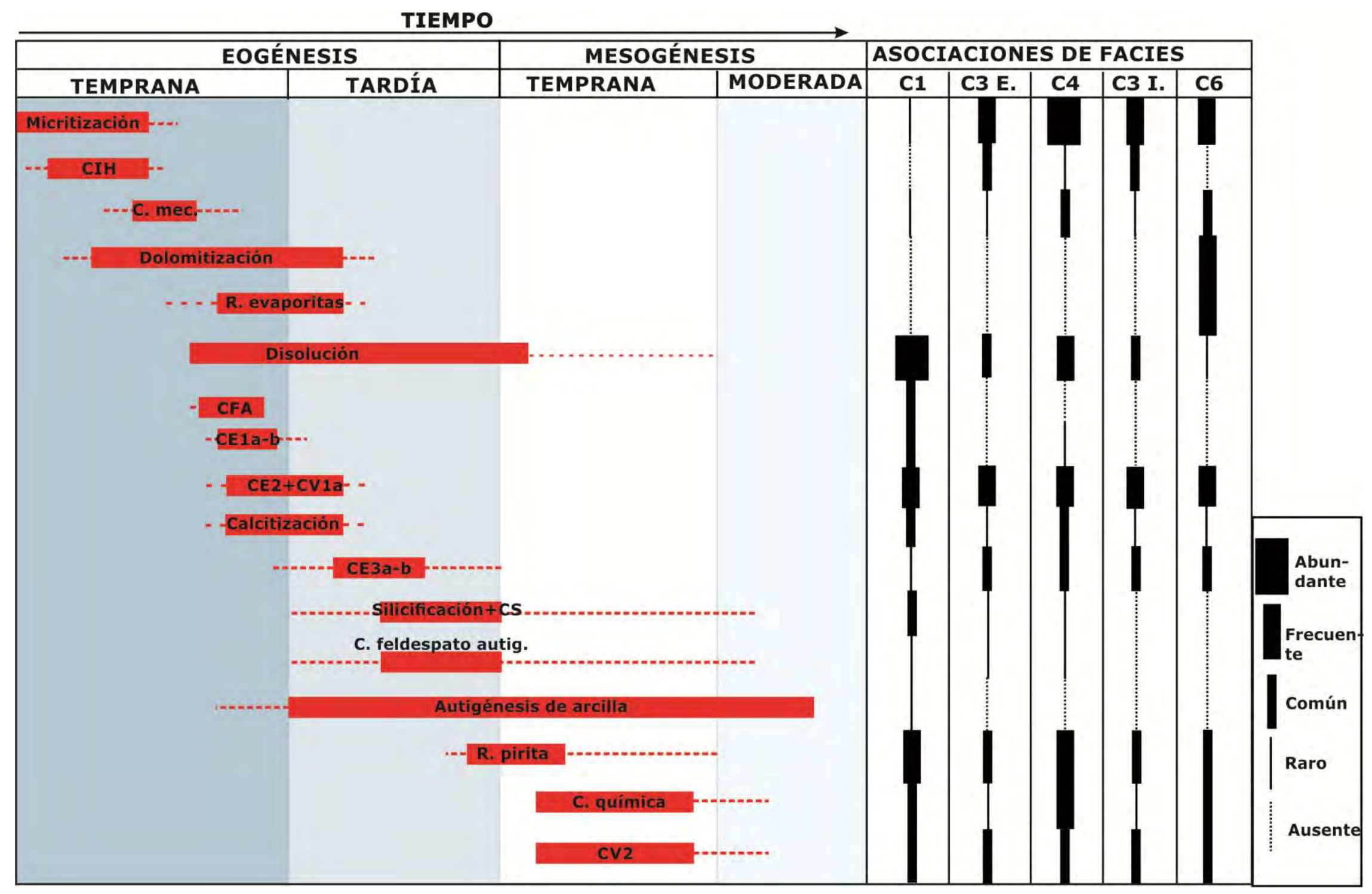




\subsection{1: Micritización}

Se define como la obliteración de la microestructura carbonática original a través de la alteración gradual a una textura criptocristalina (Reid y Macintyre, 2000). En el medio marino somero los granos carbonáticos son alterados en la interface aguasedimento, o inmediatamente por debajo, por las sucesivas perforaciones de algas, cianobacterias y microorganismos, y posterior relleno de las cavidades con micrita generada por su actividad (Tucker y Bathurst, 1990; Reid y Macintyre, 2000). Como resultado de este proceso se forman envolturas micríticas alrededor de los componentes esqueletales y no esqueletales que de forma eventual pueden evolucionar a una completa micritización del componente carbonático dando lugar a la pérdida de su estructura original (Tucker, 2001).

Se reconoce como una fina, moderada a espesa envoltura micrítica alrededor de los restos esqueletales (figuras $7.2 \mathrm{a}$ y $5.27 \mathrm{~b}$ ), que en el caso de los restos aragoníticos preserva la forma cuando resultan disueltos. En particular en los granos no esqueletales la micritización se identifica a través de la pérdida parcial a total de su estructura interna, evidenciado en especial en los ooides e intraclastos (figura 7.2b). Cuando la micritización resulta muy intensa en estos granos, pueden pasar a formar parte de la matriz dándole un aspecto grumoso a la misma.

En general dicho proceso es el primero que afecta a los granos carbonáticos en el ambiente marino en ambas zonas de estudio. Resulta abundante en el intershoal y la albúfera (C4, C5) donde la mayoría de los granos carbonáticos están micritizados, frecuente a común en la zona de shoal (C3) y llanura de marea (C6), y raro a común en el foreshoal $(\mathrm{C} 1, \mathrm{C} 2)$ donde la micritización de los aloquemes y bioclastos es baja a moderada (figuras 7.1a-b).

Interpretación: a pesar de que la micritización de los granos carbonáticos es común a lo largo de toda la sucesión carbonática, resulta abundante en el intershoal y albúfera donde las condiciones de sedimentación tranquila y baja tasa de sedimentación favorecieron la actividad de algas, cianobacterias y microorganismos en el fondo marino (véase capítulo 6, apartados 6.2.2-II y 6.2.2-III). Lo contrario 
sucede hacia el foreshoal donde los granos carbonáticos se depositaron rápidamente durante los períodos de buen tiempo y de tormentas inhibiendo su micritización (véase capítulo 6, apartados 6.2.1-I y II). Dicho lo anterior, se concluye que la abundancia de este proceso estaría relacionada con las condiciones del ambiente depositacional.

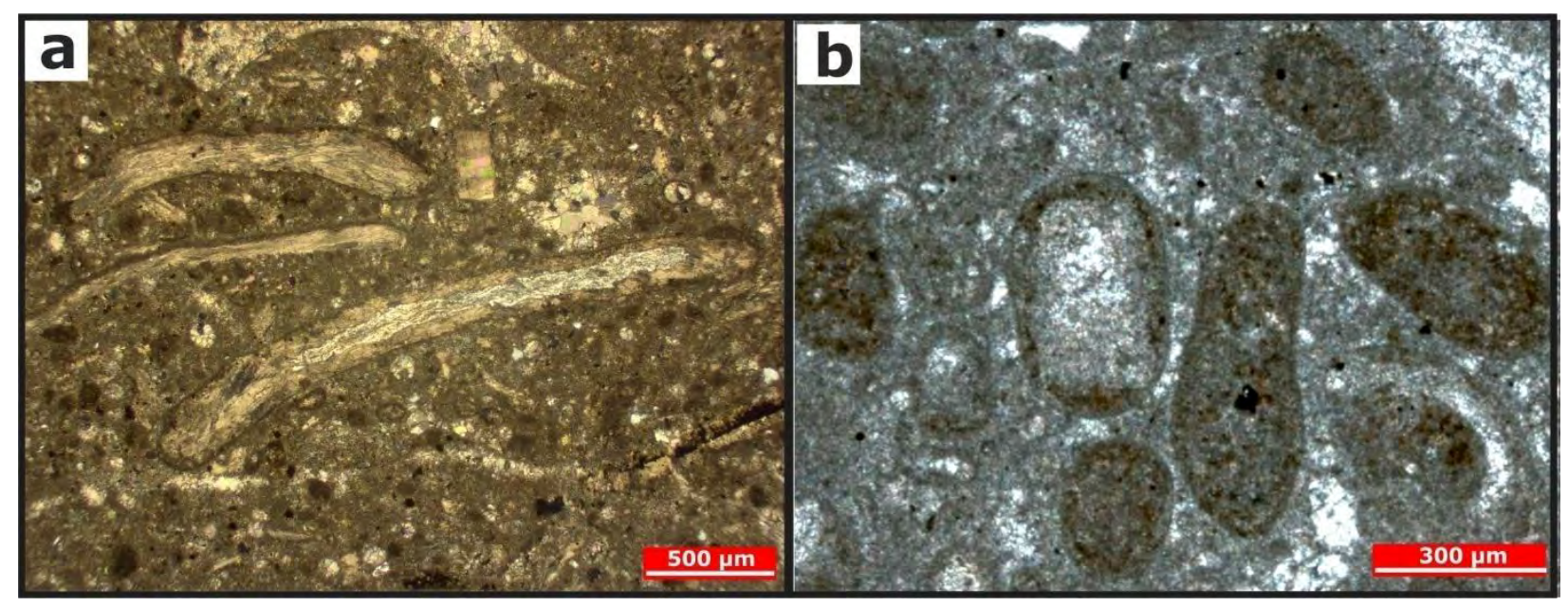

Figura 7.2a [NX,4X]: Fina envoltura micrítica que rodea a los restos esqueletales. b) [4X]: Abundante micritización de los ooides evidenciada por la pérdida parcial a total de su estructura interna.

\subsection{2: Cementación}

Es el proceso a través del cual las sedimentitas carbonáticas se litifican cuando los fluidos porales están sobresaturados con respecto a la fase cementante y no existen factores cinéticos que inhiban su precipitación (Tucker y Bathurst, 1990).

En el caso de la cementación carbonática, dicho proceso requiere de un importante suministro de la fase cementante y de un mecanismo eficiente del movimiento de los fluidos a través de los poros de las sedimentitas. En el medio marino la fuente de carbonato de calcio es el agua de mar. Ingresa en los sedimentos mediante la acción de las olas y las mareas, y de forma posterior es mezclada por los organismos durante la bioturbación. Por su parte, en los dominios meteóricos y de soterramiento la mayor parte del carbonato de calcio proviene de la disolución de granos calcáreos y del fango carbonático. En los mismos el movimiento de los 
fluidos depende del gradiente hidráulico y de las condiciones de confinamiento del fluido (Tucker y Bathurst, 1990).

A continuación, se abordarán los diferentes cementos presentes en la sucesión carbonática. En primera instancia se describirán los cementos carbonáticos fibrosos separados de los esparíticos, luego los precipitados carbonáticos en venas y por último se tratarán los cementos silíceos y de feldespato autigénico. Como se detalló en el capítulo 5 (apartado 5.2.1-II) los precipitados carbonáticos se presentan en escasa a baja proporción dentro de las texturas wackestone, packstone y floatstone (AF de foreshoal, intershoal, albúfera y llanura de marea), y en moderada a abundante proporción dentro de las texturas grainstone y boundstone (AF de shoal externo e interno). Por su parte, los cementos silíceos y de feldespato autigénico son escasos en las asociaciones de facies con bajo contenido de material terrígeno.

\subsection{2-I: Cementación fibrosa}

Comprende dos estadios de cementación, el primero de cemento isopáquico en halo (CIH) distribuido en las asociaciones de facies de ambas zonas de estudio y el segundo de cementación fibrosa asimétrica (CFA) presente solo en el área de Bardas Blancas.

En lo que respecta al cemento isopáquico en halo $(\mathrm{CIH})$, se reconoce una sola generación poco espesa ( 7 a $18 \mu \mathrm{m}$ de espesor) conformada por cristales fibrosos con abundantes inclusiones y no luminiscentes a luminiscencia dull (figuras 7.3a-b), con menor frecuencia luminiscencia naranja (figuras $7.3 c-d$ ). Se ubican en la periferia de los granos carbonáticos rodeándolos completamente (figuras $7.3 \mathrm{~b}$ y d) y además tapizan la porosidad intergranular e intragranular. Dicho precipitado que representa el primer estadio de cementación carbonática ocurre en menor proporción respecto a los cementos esparíticos, de forma posterior a la micritización de los granos carbonáticos pero anterior a la compactación mecánica (figuras 7.1ab). El mismo resulta frecuente a raro en el shoal (interno y externo, respectivamente), común en el foreshoal (C2) principalmente en los sectores con desarrollo de firmground y raro en el intershoal (C4) de la zona de Malargüe (figura 
7.1a). Por su parte, en la zona de Bardas Blancas es común en el shoal (externo e interno-C3) a raro en el intershoal (figura 7.1b).

Interpretación: se sugiere que dicho precipitado se formó en un medio marino de acuerdo con su textura, luminiscencia, disposición respecto a los granos carbonáticos y distribución dentro de la porosidad primaria de las sedimentitas carbonáticas (e.g. Moss y Tucker, 1995). En este contexto, su falta de luminiscencia reflejaría las condiciones oxidantes del fluido poral (agua de mar) del cual precipita donde tanto el $\mathrm{Mn}$ como el Fe se encuentran bajo la forma de $\mathrm{Mn}^{+4}$ y Fe ${ }^{+3}$ (Boggs y Krinsley, 2006). Por su parte la ocasional luminiscencia naranja de dicho cemento indicaría una recristalización posterior a su precipitación (e.g. Brigaud et al., 2014). Como se detalló previamente, este cemento se distribuyó en las zonas donde imperaron las condiciones de moderada a alta energía de las olas y corrientes asociadas de forma constante (shoal) a intermitente (foreshoal e intershoal, véase capítulo 6 apartados 6.2.1-II, 6.2.2-I y 6.2.2-II) que permitieron su precipitación (e.g. Barbier et al., 2015). En particular en el foreshoal con desarrollo de firmground la baja tasa de sedimentación o de no depositación en este sector, favorecería la cementación marina y la subsecuente consolidación de este sustrato (véase capítulo 6 apartado 6.2.1-II).

Por otra parte, el cemento fibroso asimétrico (CFA) está conformado por una generación de cristales aciculares orientados al azar, con variable contenido de inclusiones (cristales de aspecto turbio a límpido) y luminiscencia amarilla bajo catodoluminiscencia (figuras 7.3e-f). Se disponen de forma asimétrica, con estructura pendant o microestalactítica formando una fina envoltura $(<50 \mu \mathrm{m}$ de espesor) que tapiza de manera irregular la porosidad móldica e intergranular (figura 7.3f). Son comunes en baja proporción dentro del foreshoal (C1) de la zona de Bardas Blancas, asociados con la primera generación de cementación esparítica (CE1a; figura 7.1b). Ambos son cubiertos por la segunda generación de cementación esparítica (CE2; figuras 7.3e-f). 


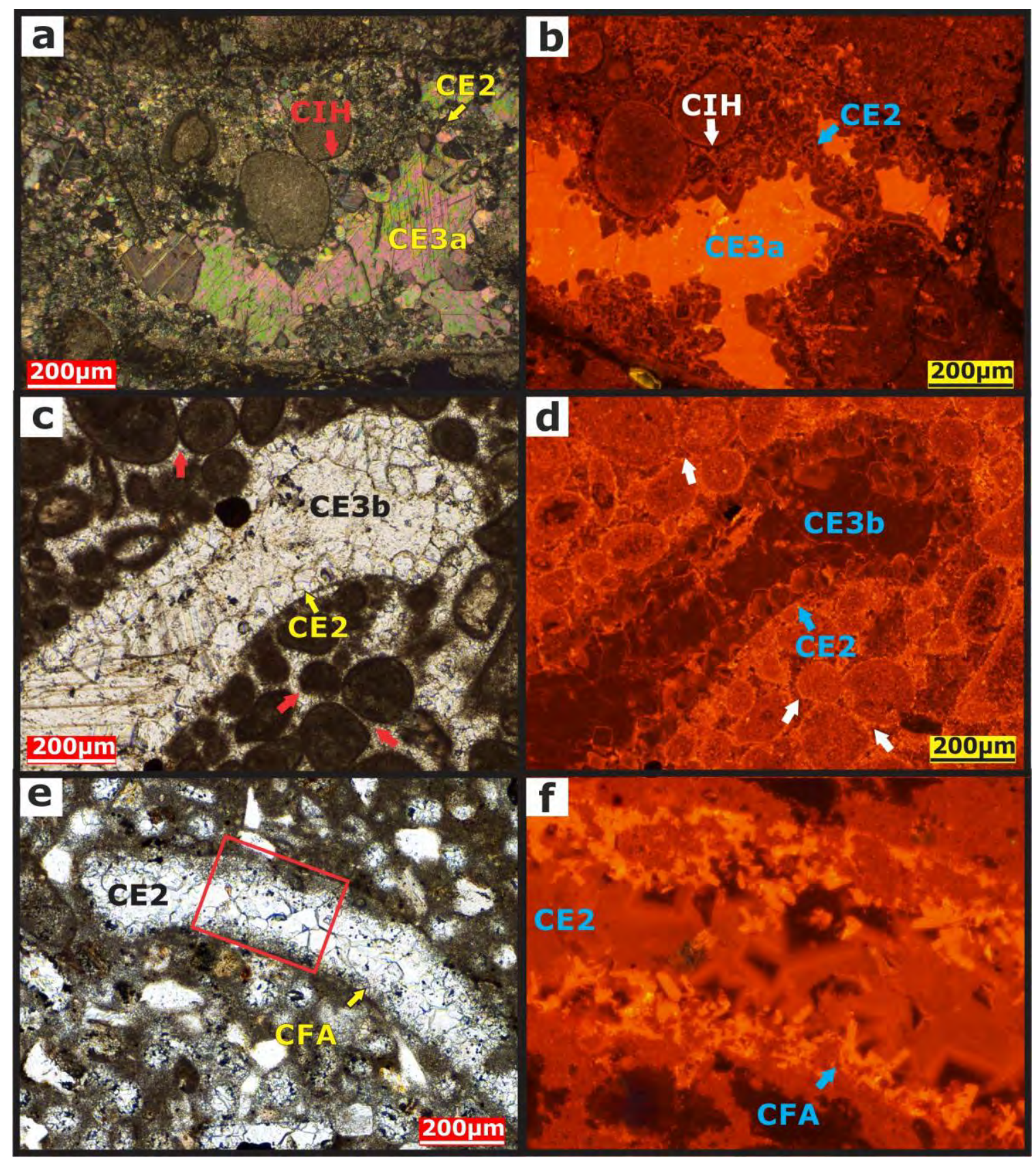

Figura 7.3a) [NX,10X]: Cemento isopáquico en halo (CIH) rodeando a los granos carbonáticos, sucedido por el segundo y tercer evento de cementación esparítica (CE2, CE3a) que obliteran la porosidad intergranular. b) $[\mathrm{CL}, 10 \mathrm{X}]$ : Vista bajo catodoluminiscencia de los precipitados de la imagen a. Nótese la falta de luminiscencia de CIH, el patrón zonado de CE2 y la luminiscencia naranja de CE3a. c) [NX,10X]: Cemento isopáquico en halo rodeando a los granos (flechas) y esparita como relleno de la porosidad intergranular y móldica (CE2 y CE3b). d) [CL,10X]: Vista bajo $\mathrm{CL}$ donde se destaca la luminiscencia naranja de CIH y la luminiscencia dull de CE3b. e) [10X]: Porosidad móldica tapizada por cemento fibroso asimétrico (CFA) y obliterada por esparita (CE2). El rectángulo indica la ubicación de la imagen f. f) Vista bajo catodoluminiscencia donde se distinguen cristales fibrosos con estructura pendant de luminiscencia amarilla (CFA), cubiertos por esparita zonada (CE2). 
Interpretación: de acuerdo con su textura fibrosa, estructura asimétrica y su disposición dentro de la porosidad móldica e intergranular, se sugiere que dicho cemento precipitó en un ambiente meteórico vadoso ( $\mathrm{Li}$ et al., 2016). Este precipitado ocurre de forma inmediatamente posterior a la generación de la porosidad móldica, posiblemente por la sobresaturación del fluido poral con carbonato de calcio producto de dicho evento de disolución. Por su parte, la luminiscencia que presenta este precipitado indicaría aguas porales moderadamente reductoras que incorporan abundantes cantidades de $\mathrm{Mn}^{+2}$ y bajas cantidades de $\mathrm{Fe}^{+2}$ (Boggs y Krinsley, 2006; Hiatt y Pufahl, 2014).

\subsection{2-II: Cementación ecuante o esparítica}

Se identifica como el segundo y tercer estadio de cementación carbonática en las asociaciones de facies de las zonas de Malargüe y Bardas Blancas, respectivamente. Comprende tres generaciones (CE1, CE2 y CE3) que en general se suceden entre sí como relleno de la porosidad primaria (inter e intragranular y fenestral) y secundaria (móldica, intercristalina) de las sedimentitas carbonáticas. De forma subordinada dichos cementos reemplazan parcialmente a los clastos terrígenos.

La primera generación (CE1) comprende microesparita a esparita granular a drusiforme, de cristales ecuantes límpidos a turbios, no zonados con luminiscencia amarilla (CE1a, figura 7.4a) a no luminiscentes bajo CL (CE1b, figuras 7.4b-c). Ambos precipitados se presentan en baja proporción, CE1a se identifica en el foreshoal de la zona de Bardas Blancas (C1) relacionado con el cemento fibroso asimétrico (CFA). Por su parte, CE1b resulta raro en el foreshoal de la zona de Malargüe (C2) y en el intershoal del área de Bardas Blancas (figuras 7.1a-b).

Por otro lado, la segunda generación (CE2) se corresponde con esparita granular a drusiforme (rara microesparita o macroesparita sintaxial), de cristales ecuantes con abundantes inclusiones cuando reemplazan al fango carbonático a límpidos (figuras 7.3a, c, e). Bajo catodoluminiscencia los mismos presentan dos a cinco zonas donde alternan bandas no luminiscentes o de luminiscencia dull (zonas 1, 3 y 5), con otras de luminiscencia naranja (zonas 2 y 4 ; figura 7.4d). Menos común resulta 
el patrón de luminiscencia donde alternan zonas no luminiscentes ( 1 y 4 ), dull ( 2 y 5) y naranjas a amarillas (3). Este precipitado es frecuente en todas las asociaciones de facies de ambas zonas de estudio donde representa la generación esparítica más abundante (figuras 7.1a-b). El mismo puede obliterar la porosidad primaria y secundaria de las sedimentitas carbonáticas y en ocasiones precipitar en el interior de fracturas dando lugar a la formación de venas (CV1a, figuras 7.4a-b).

Por último, la tercera generación comprende esparita (granular a drusiforme) a macroesparita (en mosaico, sintaxial o poiquilotópica) de cristales límpidos, con luminiscencia naranja a amarilla (CE3a, figuras 7.3a-b), o variedades dull a no luminiscente bajo $C L$ (CE3b, figuras 7.3c-d). Este cemento que se presenta en menor proporción respecto a CE2, resulta común en la mayoría de las asociaciones de facies de la zona de Malargüe y Bardas Blancas, siendo raro en el foreshoal (C1 y C2, figuras 7.1a-b). El mismo oblitera la porosidad primaria y secundaria de las sedimentitas carbonáticas y en ocasiones puede precipitar en el interior de fracturas dando lugar a la formación de venas (CV1b, véase apartado 7.3.2-III).

Interpretación: según los cambios de luminiscencia observados en esta sucesión de cementos sugieren variaciones en las condiciones de oxido-reducción de los fluidos porales de los cuales precipitaron, relacionados con su contenido relativo de $\mathrm{Mn}^{+2}$ (elemento activador) y $\mathrm{Fe}^{+2}$ (elemento inhibidor; Barnaby y Rimstidt, 1989). En este contexto, la primera generación de luminiscencia amarilla (CE1a) a no luminiscente (CE1b) habría precipitado desde aguas porales moderadamente reductoras a oxidantes, respectivamente (e.g. Li et al., 2016). La misma resulta cubierta por el segundo cemento esparítico que precipitaría desde fluidos porales donde alternan condiciones moderadamente reductoras (luminiscencia naranja) a reductoras (luminiscencia dull a no luminiscente) y evolucionan gradualmente a fluidos reductores. Esta sucesión culmina con CE3 que según su luminiscencia se formaría a partir de fluidos porales moderadamente reductores (CE3a) a reductores (CE3b). De esta forma, la sucesión de cementos descriptos estaría vinculada con un aumento gradual a condiciones reductoras de las aguas porales. 
En este sentido se considera que dada su textura, las condiciones de los fluidos porales de los cuales precipitan y su naturaleza obliterante de la porosidad primaria y secundaria, dichos cementos esparíticos se formarían en un ambiente meteórico freático de mezcla hasta una zona de enterramiento muy somero.

\subsection{2-III: Cementación en venas}

Se observan dos generaciones de venas no anastomosadas, escasas anastomosadas, de apertura variable y rellenas con esparita granular a drusiforme o microesparita (figuras 7.5a-f). En las asociaciones de facies de Malargüe las dos generaciones, raro tres, están rellenas con cristales ecuantes límpidos, de luminiscencia naranja que varía entre dull y amarilla bajo $\mathrm{CL}$, junto a escasos cristales y precipitados amorfos de pirita (figuras 7.5c-d). El primer evento (CV1b) en rara ocasión puede estar asociado con la tercera generación de esparita CE3a (figuras 7.5c-d; 7.1a). Por su parte, el segundo y tercer evento están relacionados con la formación de estilolitas y se asociarían con la dedolomitización (apartado 7.3.7-II, figura 7.1a).

En la zona de Bardas Blancas el relleno de la primera generación de venas se corresponde con el segundo evento de cementación esparítica CE2 (figuras 7.5a-b) al que comúnmente se encuentra asociado en el foreshoal e intershoal (C1 y C4, figura 7.1b). En lo que respecta a la segunda generación, está compuesta por cristales límpidos, no zonados con luminiscencia naranja bajo $\mathrm{CL}$. Es común en todas las asociaciones de facies donde está relacionada con la formación de estilolitas y sucede de forma posterior al reemplazo por pirita (figuras 7.5e-f; 7.1b).

Interpretación: según lo expuesto, la segunda y tercera generación de venas en ambas zonas de estudio precipitarían durante un estadio avanzado de la diagénesis, relacionado con procesos de compactación química (véase apartado 7.3.7-II). Dichos precipitados que representan el último evento de cementación carbonática se habría formado a partir de fluidos porales moderadamente reductores a reductores de acuerdo con su luminiscencia. 


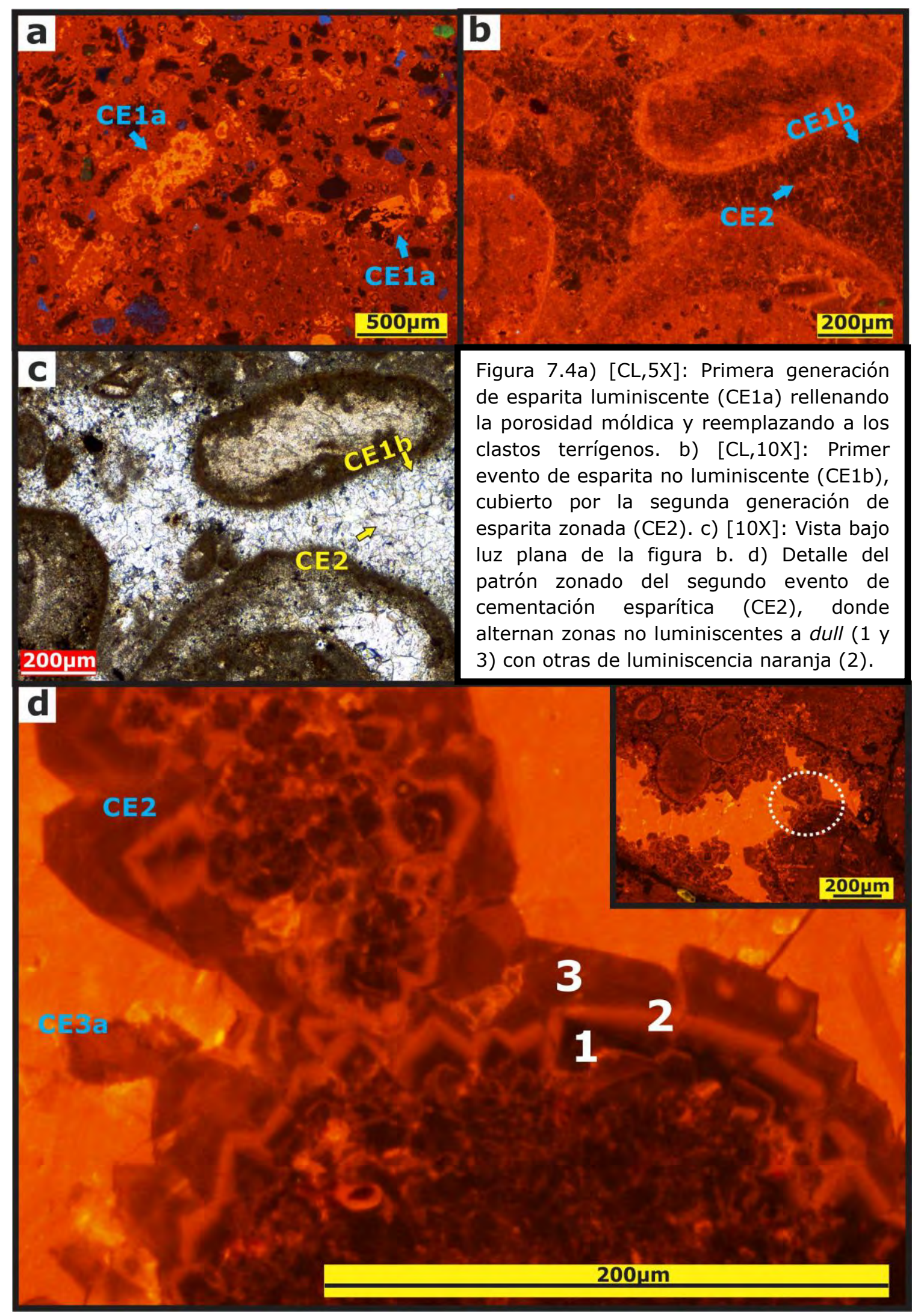

En el cuadro superior de la derecha, el círculo marca la ubicación de la imagen d. 


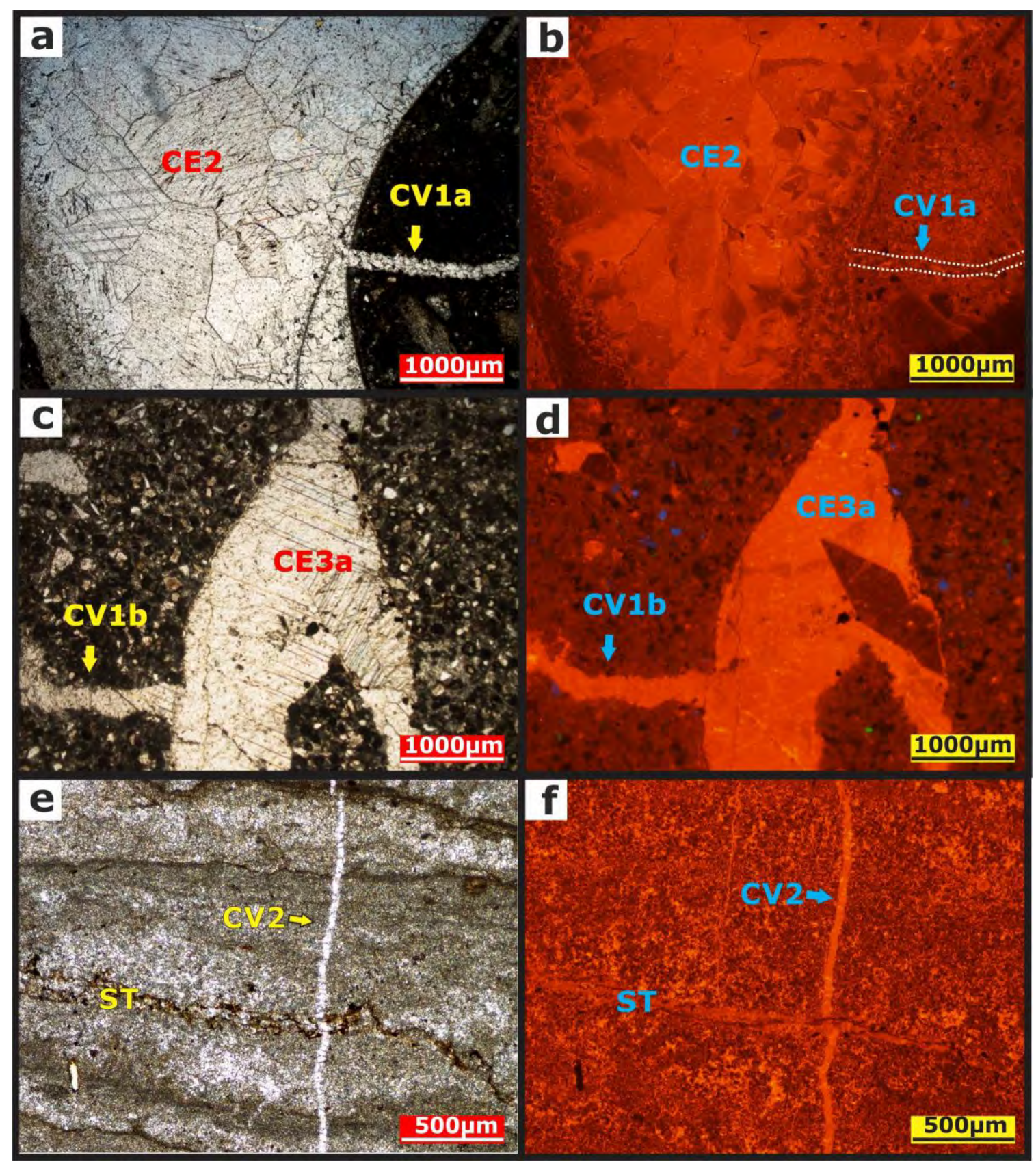

Figuras 7.5a [2.5X] y b [CL, 2.5X]: Primera generación de cementación en venas (CV1a) bajo luz plana y catodoluminiscencia, respectivamente. Se distingue su relación con la segunda generación de esparita (CE2). Figuras $7.5 c[2.5 \mathrm{X}]$ y d [CL, 2.5X]: Primer evento de cementación en venas (CV1b) bajo luz plana y catodoluminiscencia, respectivamente. Se observa su relación con la tercera generación de esparita (CE3a). Figuras 7.5e [5X] y $f$ [CL, 5X]: Segunda generación de cementación en venas (CV2) bajo luz plana y catodoluminiscencia, respectivamente, donde se distingue su luminiscencia naranja. Nótese la relación de corte con las estilolitas irregulares con concentrados de pirita (ST) que acompañan la fábrica de la sedimentita. 


\subsection{2-IV: Cementación silícea y de feldespato autigénico}

La cementación silícea (CS) se reconoce como cristales de calcedonia cebraica y megacuarzo que rellenan la porosidad intercristalina de forma posterior a la precipitación de la segunda y tercera generación de esparita (CE2, CE3a-b). Este proceso que está asociado con la silicificación que afecta a los bioclastos, es raro en las asociaciones de facies, solo se presenta en el foreshoal ( $C 2$, figura 7.1a) en Malargüe y en el intershoal (C4, figura 7.1b) en Bardas Blancas. La interpretación de este proceso será tratada en el apartado 7.3.5-II.

Por su parte, el cemento de feldespato autigénico se observa como un sobrecrecimiento límpido en continuidad óptica sobre feldespatos alterados a argilominerales, con bordes rectos que se encuentran encastrados con los granos que lo rodean (figura 5.14a). Su composición no pudo ser determinada mediante petrografía de polarización, no obstante se infiere que podría ser albítico, ya que según Molenaar y de Jong (1987) la albita es el feldespato autigénico más común en las calizas. Este tipo de cementación es rara en las asociaciones de facies de ambas zonas de estudio, solo se presenta en aquellas con bajo contenido de material terrígeno ( $\mathrm{C} 1, \mathrm{C} 2, \mathrm{C} 3$ externo y $\mathrm{C} 4$, figuras 7.1a-b). Bajo el análisis petrográfico realizado no fue posible reconocer su relación con los estadios de cementación carbonática.

Interpretación: dado que para que precipite el cemento de feldespato en calizas es necesario el suministro de iones $\mathrm{Na}^{+} \circ \mathrm{K}^{+}, \mathrm{Al}^{+3} \mathrm{y} \mathrm{Si}^{+4}$ hacia las aguas porales (Kastner y Siever, 1979; Álvaro y Bauluz, 2008) y que en general estos iones derivan de la hidrolisis y disolución de los granos terrígenos menos estables (Tucker, 2001), su precipitación estaría relacionada con la alteración de la fracción terrígena de la sucesión carbonática. Como se explicó en los apartados 5.2.1-I y 5.2.3 en estos depósitos tanto los feldespatos como los líticos volcánicos fueron alterados a argilominerales. En este contexto, cuando se produce la desvitrificación de los líticos volcánicos y su pasaje a esmectita y de forma posterior a illita se liberan iones de $\mathrm{Na}^{+}$y sílice hacia las aguas porales. De forma conjunta, cuando los 
feldespatos alcalinos o plagioclasas se alteran a caolinita se libera sílice en solución, $\mathrm{K}^{+}$y $\mathrm{Na}^{+}$o $\mathrm{Ca}^{+2}$ (Scasso y Limarino, 1997), no sucede lo mismo con la transformación de caolinita a illita.

\subsection{3: Autigénesis de arcillas}

En los poros de las sedimentitas carbonáticas no se observan cementos de arcillas mediante petrografía de polarización, no obstante a través del análisis por difractometría de rayos $X$ (capítulo 5; apartado 5.2.3) se determinó un contenido muy escaso a ausente en argilominerales, en general en el tramo inferior a medio, raramente hacia el superior de la sucesión carbonática (asociaciones C1, C2 y C5). Dentro de estos argilominerales, la illita y los interestratificados illita/esmectita (I/S) resultaron los más representativos, ambos interpretados como originados durante la diagénesis por la alteración de los líticos volcánicos y feldespatos. Alternativamente se propuso un origen detrítico para los interestratificados I/S.

En lo que respecta a su origen diagenético, producto de la desvitrificación en los líticos volcánicos se habría formado esmectita en condiciones superficiales a eogenéticas tempranas y de forma posterior, a medida que aumentaba el enterramiento (eogénesis tardía-mesogénesis moderada), se habría producido el pasaje a interestratificados I/S y luego a illita (Boggs, 2009). Además, se propuso que parte de la illita podría haberse generado por la alteración de los feldespatos a caolinita (eogénesis) y luego a illita durante la mesogénesis moderada (Boggs, 2009). Como se mencionó en el apartado 5.2.3 estas interpretaciones se sustentaron además con el grado de alteración de los clastos terrígenos (feldespatos y líticos volcánicos) a argilominerales y el escaso contenido de esmectita y caolinita dentro de la sucesión carbonática. 


\subsection{4: Neomorfismo}

Este término define a las transformaciones que suceden en un medio acuoso por la disolución-reprecipitación entre un mineral y su polimorfo o entre el mismo mineral (Folk, 1965; Flügel, 2010). Dentro de este proceso están la transformación de los componentes aragoníticos a calcita (calcitización) y la formación de microesparitapseudoesparita a partir de micrita (neomorfismo agradante).

\subsection{4-I: Calcitización}

Se reconoce esparita granular a drusiforme neoformada que reemplaza bioclastos aragoníticos (bivalvos, colonias de corales, gasterópodos, fragmentos indeterminados) parcialmente disueltos o micritizados (figura 7.6a). Los cristales ecuantes son castaños, de bordes irregulares, con relictos de la textura que reemplazan y luminiscencia dull a naranja bajo catodoluminiscencia (figuras 7.6ab). De forma eventual, resultan zonados donde alternan bandas dull a no luminiscentes (zonas 1 y 3 ) con otras de luminiscencia naranja (zona 2, figura 7.6b). Este proceso es común en el foreshoal, intershoal y albúfera a raro en el shoal y llanura de marea de ambas zonas de estudio (figuras 7.1a-b). El mismo resulta anterior a la tercera generación de esparita (CE3a-b).

\subsection{4-II: Neomorfismo agradante}

Se identifica pseudoesparita a esparita neoformada a expensas de la matriz micrítica. Está conformada por cristales con abundantes inclusiones a límpidos, con hasta 3 zonas bajo CL donde alternan bandas dull ( 1 y 3 ), con otras de luminiscencia naranja ( 2 , figuras $7.6 \mathrm{c}-\mathrm{d}$ ). Este proceso que resulta abundante en la llanura de marea (C6) y común en la albúfera (C5) de la zona de Malargüe, sucede de forma posterior a la compactación mecánica, pero anterior a la segunda y tercera generación de esparita (figura 7.1a). No obstante, en los estromatolitos laminares de llanura de marea puede considerarse como el primer proceso. 
Interpretación: según su patrón de luminiscencia este proceso habría ocurrido a partir de fluidos porales donde alternan condiciones moderadamente reductoras a reductoras, similares a las planteadas para CE2 (véase apartado7.3.2-II). De acuerdo a estas condiciones y su relación con la cementación esparítica, se sugiere que el mismo ocurrió en la albúfera y llanura de marea en un medio de mezcla de aguas porales marinas y meteóricas. No obstante, en los estromatolitos laminares de llanura de marea, donde alternaron períodos de emersión e inundación (véase capítulo 6, apartado 6.2.2-IV), sucedería desde un medio marino somero.

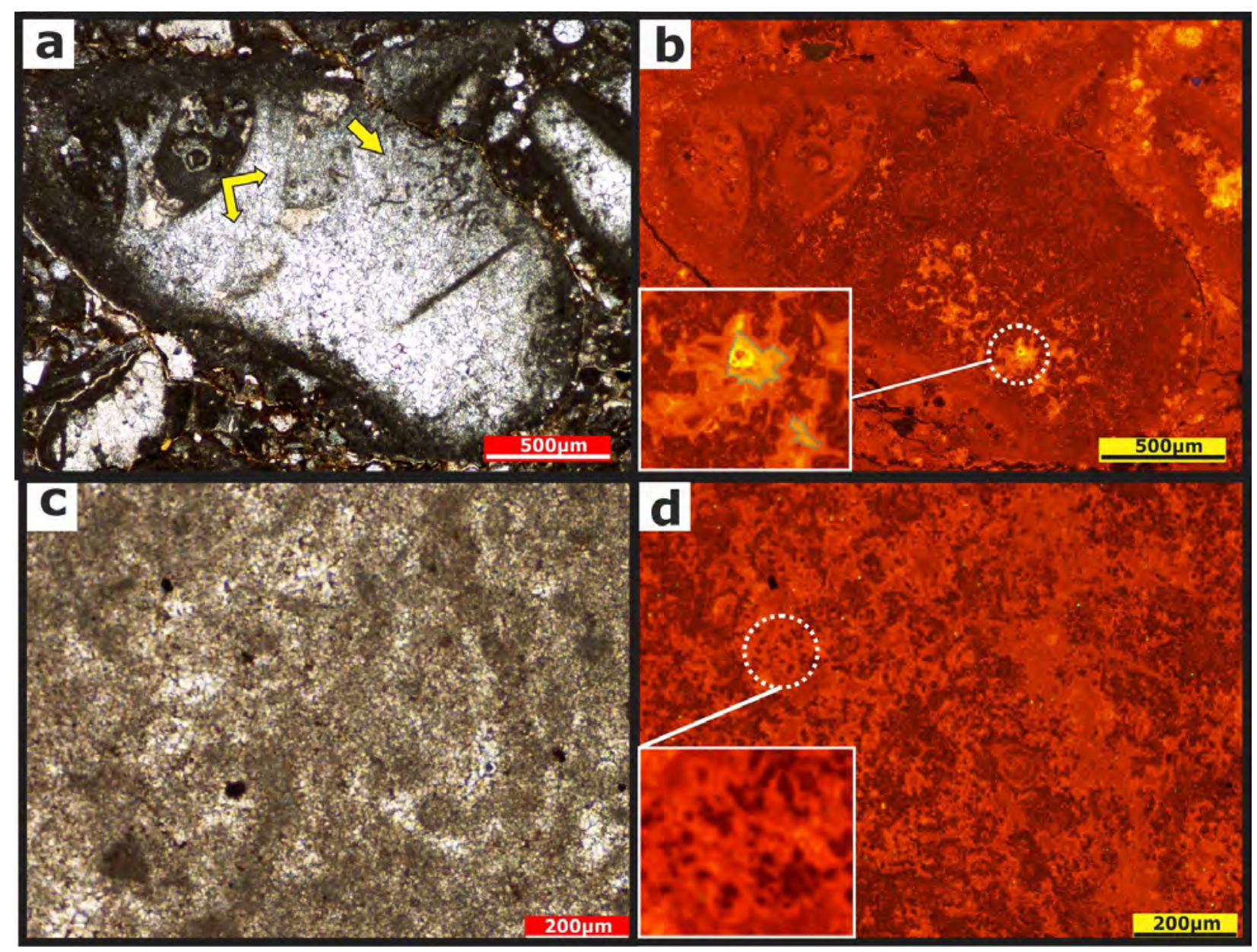

Figuras 7.6a $[5 X]$ y b $[C L, 5 X]$ : Calcitización de un fragmento esqueletal aragonítico parcialmente disuelto bajo luz plana y catodoluminiscencia, respectivamente. Nótese que en la esparita neoformada se distingue la estructura relictual del bioclasto (flechas amarillas). En el recuadro blanco de la figura b se muestra un detalle del patrón zonado de la esparita neoformada, sucedida por la tercera generación de esparita (línea punteada celeste). Figuras 7.6c [10X] y d [CL, 10X]: Pseudoesparita a esparita neoformada a expensas de la matriz micrítica bajo luz plana y catodoluminiscencia, respectivamente. En la figura d el recuadro muestra un detalle del patrón zonado de dicha esparita neoformada. 


\subsection{5: Reemplazos}

Se define como la transformación de un mineral a otro de diferente composición (Scholle y Ulmer-Scholle, 2003). Dentro de este proceso se identifican en la sucesión carbonática la dolomitización, cuando la calcita o aragonita se transforma en dolomita, la silicificación cuando la sílice es la fase que reemplaza, y el reemplazo por cristales de evaporita y pirita. Un tipo particular de reemplazo es la dedolomitización que ocurre cuando la dolomita pasa a calcita (Tucker, 2001).

\subsection{5-I: Dolomitización y dedolomitización}

Dichos procesos serán descriptos para cada zona de estudio de acuerdo a las características particulares que presentan los mismos en las asociaciones de facies.

En la zona de Malargüe se reconocen rombos y prismas euhedrales de hasta $4 \mathrm{~mm}$ de largo que reemplazan tanto a la matriz y granos carbonáticos, como a los precipitados esparíticos CE2 y CE3a-b (figura 7.7a). Se encuentran dedolomitizados, reemplazados por esparita granular de luminiscencia naranja a dull bajo catodoluminiscencia (figura 7.7b). En este sentido, se reconoce que la dolomitización ocurre de forma posterior a la tercera generación de cementación esparítica (CE3a-b), mientras que la dedolomitización estaría relacionada con la cementación en venas (CV2-3, figura 7.1a). Ambos procesos resultan frecuentes en todas las asociaciones de facies de la sección PLE (C2, C3, C4 y C6; figura 7.1a) y en particular en el foreshoal se desarrollan solo en el interior de las trazas fósiles que conforman el firmground (figuras 7.7a-b).

Interpretación: según su distribución y relación temporal con los precipitados esparíticos se interpreta a la dolomitización como un proceso local dentro de la zona de Malargüe, que ocurrió bajo condiciones de soterramiento somero. Por su parte, se infiere que la dedolomitización estaría relacionada con los efectos de la compactación química durante un estadio avanzado de la evolución diagenética (véase apartado 7.3.7-II). 
En la zona de Bardas Blancas se identifica un mosaico de rombos euhedrales con abundantes inclusiones a cristales límpidos, de hasta $50 \mu \mathrm{m}$ de largo, que reemplazan de forma mimética tanto las láminas claras como oscuras de los estromatolitos laminares de la llanura de marea y además tapizan su porosidad fenestral (figuras 7.7c-d). Bajo CL están conformados por tres a cinco zonas, donde alternan bandas no luminiscentes a dull (zonas 1 y 3 ) con otras de luminiscencia naranja (zonas 2 y 4) que finalizan con una última zona de luminiscencia amarilla (figura 7.7d). Este proceso resulta frecuente en la llanura de marea (C6, figura 7.1b) donde es el primero que afecta a los estromatolitos laminares. El mismo ocurre de forma anterior a la tercera generación de esparita (CE3a-b; figura 7.7d).

Interpretación: según la morfología de sus cristales, el reemplazo mimético que genera sobre los estromatolitos laminares y su relación con la cementación esparítica (CE3a-b), se sugiere un proceso temprano que sucedió de forma posterior a la depositación de los estromatolitos laminares. Asimismo, de acuerdo con su patrón de luminiscencia este reemplazo habría ocurrido a partir de fluidos porales que alternan condiciones oxidantes a moderadamente reductoras y que evolucionan a fluidos moderadamente reductores. Dado el ambiente depositacional intermareal de los mismos (véase capítulo 6, apartado 6.2.2-IV), dichas condiciones podrían corresponderse en primera instancia a un medio marino somero/de mezcla de aguas porales marinas y meteóricas, que evolucionaron a condiciones de soterramiento muy somero.

\subsection{5-II: Silicificación}

Se observa como un crecimiento selectivo de cristales de calcedonia cebraica que remplazan parcialmente las valvas de ostras, de braquiópodos y en menor medida espinas y placas de equinoideos (figura 7.7e). Dicho reemplazo, asociado con la cementación silícea, resulta común a raro en las asociaciones de facies con bajo contenido de material terrígeno ( $C 1, C 2, C 3$ externo y $C 4$, figuras $7.1 a-b)$. El mismo ocurre de forma posterior al segundo y tercer evento de esparita en ambas zonas de estudio, pero anterior al reemplazo por pirita (figuras 7.1a-b). 
Interpretación: según la distribución de estos reemplazos y la cementación silícea en las asociaciones de facies con material terrígeno, y la magnitud de ambos procesos, es posible relacionar el origen de la sílice con la alteración del material detrítico del entramado, tal como se mencionó en el apartado 7.3.2-IV para el feldespato autigénico. Este hecho se basa por una parte, en la alteración de los componentes volcánicos tanto por desvitrificación y disolución, como por alteración a esmectita y posteriormente a interestratificados illita-esmectita (Scasso y Limarino, 1997). En estas transformaciones se incrementa el $\mathrm{pH}$, aumenta la actividad de la sílice y de iones sodio y potasio (Huggett et al., 2005). De forma conjunta, la alteración de feldespatos detríticos en medio ácido con la subsecuente formación de caolinita, incorpora sílice en solución.

Según lo expuesto, se concluye que tanto los precipitados y reemplazos silíceos como la cementación de feldespato autigénico estarían relacionados con la alteración del material terrígeno del entramado, especialmente con la autigénesis de arcillas dentro de la sucesión carbonática. Por consiguiente, se infiere que ambos procesos sucederían durante una eogénesis temprana a mesogénesis (véase apartado 7.3.3). No obstante, dada la relación entre el cemento y reemplazo silíceo con su contraparte esparítica CE2 y CE3a-b, se sugiere un estadio eogenético tardío a mesogenético.

\subsection{5-III: Reemplazo por cristales de evaporitas}

En la zona de Malargüe se distinguen cristales prismáticos de yeso, de 60-800 $\mu \mathrm{m}$ de largo (excepcionales de 3,8 $\mathrm{mm}$ de longitud), no luminiscentes bajo $\mathrm{CL}$, con inclusiones de cemento carbonático y cristales de pirita en su interior. Los mismos reemplazan a los granos carbonáticos, la matriz y los precipitados esparíticos. En ocasiones dichos cristales pueden encontrarse total a parcialmente reemplazados por esparita y en ese caso presentan una luminiscencia naranja a amarilla bajo CL. Este proceso que ocurre de forma posterior a la cementación esparítica (CE2 y CE3a-b), pero anterior al reemplazo por pirita resulta común en la albúfera (C5), shoal interno (C3) e intershoal (C4), a raro en el shoal externo (C3, figura 7.1a). 
Por su parte, en la zona de Bardas Blancas se reconocen pseudomorfos de evaporitas prismáticos de yeso/anhidrita euhedrales a subhedrales, de hasta $8 \mathrm{~mm}$ de largo que reemplazan tanto a la matriz como los granos del esqueleto de las sedimentitas de llanura de marea (facies W-Ppe, figura 7.7f). Dichos cristales a su vez, están reemplazados por la segunda y tercera generación de esparita (CE2 y CE3a-b) y en algunos casos se encuentran parcialmente disueltos de forma posterior dando lugar a la generación de porosidad móldica (véase apartado 7.3.6). Este reemplazo ocurre de forma posterior a la compactación mecánica que afecta a las sedimentitas carbonáticas.

Interpretación: se sugiere que este proceso en la zona de Malargüe ocurrió durante un estadio de soterramiento somero de acuerdo a su relación con los eventos de cementación esparítica y el reemplazo por pirita. Por su parte, en la zona de Bardas Blancas se infiere que dicho proceso sucedió durante un estadio temprano de la diagénesis de las sedimentitas de llanura de marea según su relación temporal con la compactación mecánica y los eventos de cementación esparítica. De acuerdo con esta afirmación se sugiere que podría estar relacionado con la dolomitización que afecta a estas sedimentitas ya que a medida que avanza este proceso las aguas porales marinas se enriquecen en calcio y $\mathrm{SO}_{4}{ }^{-2}$ dando lugar a la sobresaturación en anhidrita/yeso (Al-qattan, 2014). La precipitación de dichas evaporitas disminuye la concentración de $\mathrm{SO}_{4}{ }^{-2}$ y a su vez favorece la precipitación de dolomita, dado que el sulfato resulta un inhibidor cinético de la precipitación de dolomita (Morrow y Abercrombie, 1994).

\subsection{5-IV: Reemplazo/cementación de pirita}

Se identifican cristales aislados (10 a $2000 \mu \mathrm{m}$ de largo) o en grupo, euhedrales a subhedrales, cúbicos a prismáticos de color castaño a negro que reemplazan de forma parcial a la matriz y granos carbonáticos de las sedimentitas (figura $7.7 \mathrm{~g}$ ). En menor medida se reconocen precipitados amorfos y cristales cúbicos que rellenan la porosidad intercristalina de los cementos esparíticos y silíceos y la 
porosidad intergranular residual (figura 7.7h). Este proceso sucede de forma posterior a la precipitación del cemento esparítico CE3a-b y silíceo, pero anterior a la formación de estilolitas (figuras 7.1a-b). El mismo resulta frecuente en el foreshoal e intershoal ( 1 , C2 y C4) a común en la zona de shoal, albúfera y llanura de marea (C3, C5 y C6) de ambas áreas de estudio (figuras 7.1a-b). En particular en las asociaciones de facies de Malargüe se registra un segundo estadio de precipitación de dichos cristales que rellenan la porosidad intercristalina de la cementación en venas (CV1b-CV3).

Interpretación: según la relación de este reemplazo con los precipitados carbonáticos y silíceos y la formación de estilolitas, se interpreta que sucedieron durante un enterramiento somero a moderado de la sucesión carbonática, de forma previa a la compactación química que las afecta. En este sentido, dada la tendencia de fluidos porales moderadamente reductores a reductores planteados para los precipitados esparíticos (véase apartado 7.3.2-II) se sugiere que los cristales que precipitaron se corresponden con pirita. Por su parte, se sugiere que el segundo evento de cristales de pirita es posterior a los efectos de la compactación química en la sucesión carbonática, de acuerdo a la relación temporal planteada con la cementación en venas.

Figuras 7.7a [2.5X] y b [CL, 2.5X]: Reemplazo por rombo de dolomita de los granos y la matriz de la sedimentita, bajo luz plana y catodoluminiscencia, respectivamente (flechas). Se presenta en el interior de las trazas fósiles que conforman un firmground en la zona de foreshoal. La línea punteada marca el contacto entre la roca hospedante $(\mathrm{RH})$ y el relleno de la traza. Nótese que el rombo de dolomita se encuentra dedolomitizado. Figuras 7.7c [5X] y d [CL]: Dolomitización mimética de estromatolitos laminares bajo luz plana y catodoluminiscencia, respectivamente. Nótese que además los rombos de dolomita rellenan su porosidad fenestral (línea punteada blanca). El círculo amarillo indica la ubicación de la imagen b donde se destaca la zonación del reemplazo y el tercer evento de esparita obliterando la porosidad intercristalina (línea celeste). e) [4X,NX]: Cristales de calcedonia cebraica que copian la textura de valvas de ostras (flechas). f) [10X,NX]: Pseudomorfo de evaporita que reemplazan tanto a la matriz como a los granos carbonáticos (flecha). Nótese que a su vez dicho cristal está reemplazo por esparita. g) [4X,NX]: Cristal subhedral de pirita que reemplazan parcialmente la matriz de la sedimentita. h) [10X]: Cristales cúbicos a prismáticos de pirita rellenando la porosidad intercristalina de los precipitados esparíticos (flechas). 


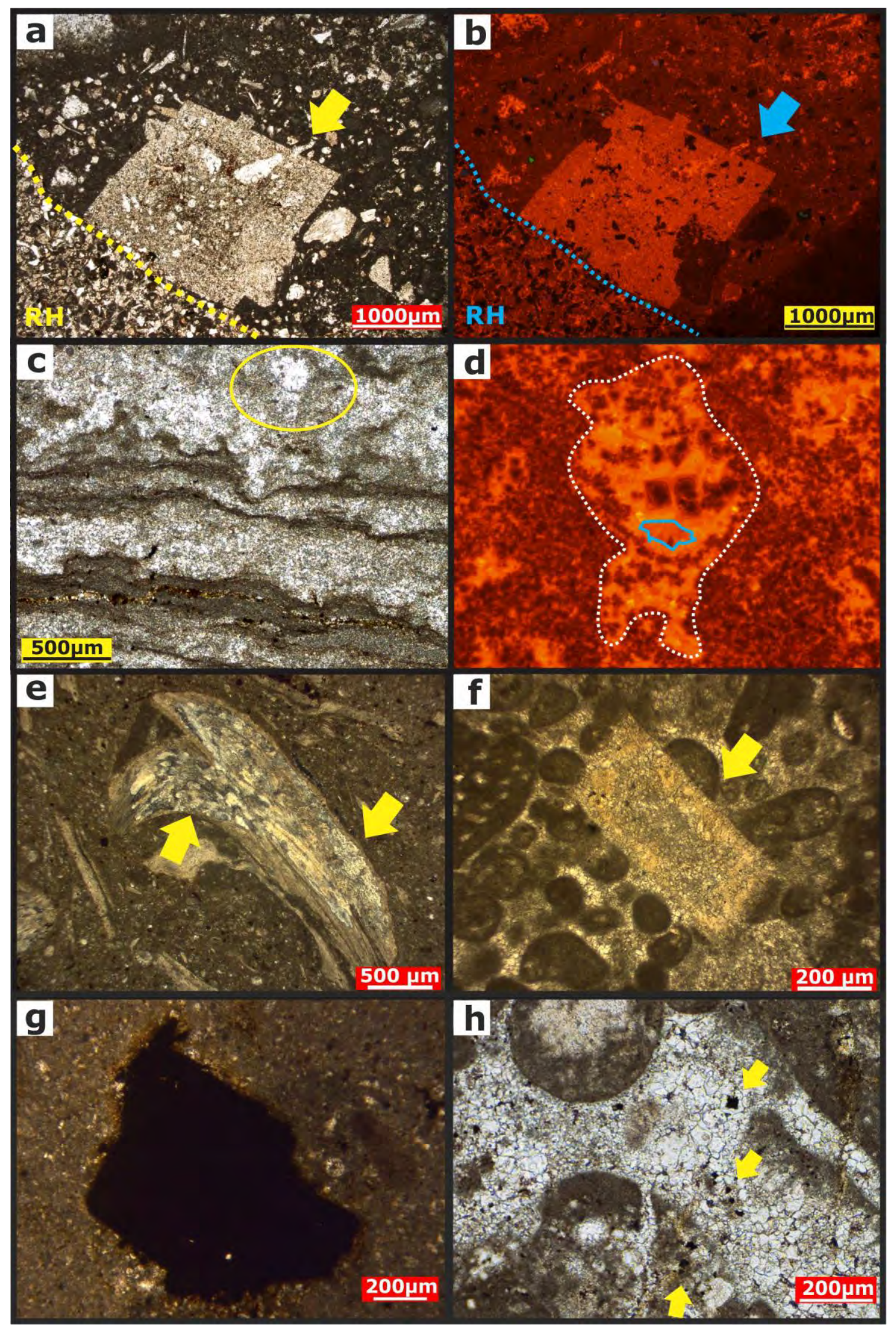




\subsection{6: Disolución}

Es el proceso por el cual un componente sólido dentro del sedimento se disuelve al estar en contacto con un fluido poral acuoso, dando lugar a la formación de una cavidad dentro del sedimento que lo aloja (Worden y Burley, 2003). Puede ocurrir a pequeña o gran escala cuando los fluidos porales están subsaturados respecto a calcita o aragonita. En este sentido, la disolución es un proceso importante en el ambiente meteórico debido a la infiltración de aguas ácidas provenientes de la atmósfera y de la iluviación edáfica, pero también puede ser efectivo durante el soterramiento (Tucker y Bathurst, 1990).

Este proceso se identifica a través de la generación de porosidad móldica en granos esqueletales y no esqueletales (aragoníticos y de HMC), de forma subordinada en pseudomorfos de evaporitas y clastos terrígenos, y por la formación de porosidad intercristalina en precipitados esparíticos. Dichas cavidades en general se observan obliteradas por cementos carbonáticos (fibrosos asimétricos y esparíticos), silíceos y precipitados de pirita, aunque en el caso de los pseudomorfos de evaporitas su porosidad puede preservarse (figura 7.8a). Este proceso está representado en una abundante a rara proporción dentro de las diferentes asociaciones de facies de ambas zonas de estudio (figuras 7.1a-b). Dicha proporción variable estaría relacionada con el contenido de granos aragoníticos y su grado de micritización, dado que en general el desarrollo de la envoltura micrítica contribuye a aumentar la estabilidad de los mismos ante la disolución (Beigi et al., 2017).

Interpretación: de acuerdo con la relación existente entre la generación de porosidad móldica y los diferentes estadios de cementación carbonática y silícea que la rellenan, se considera que la disolución comenzó en una etapa temprana de la diagénesis en el medio meteórico vadoso y se prolongó como eventos continuos hasta una etapa más avanzada de enterramiento muy somero. Asimismo, se asume que la generación de porosidad intercristalina en precipitados esparíticos sucedió durante una etapa más avanzada de enterramiento muy somero a somero, posiblemente producto de un cambio en las condiciones de $\mathrm{pH}$ del medio. 


\subsection{7: Compactación}

Se define como la disminución del espacio poral por presión de carga debido a efectos mecánicos y químicos. Durante el enterramiento somero, la compactación mecánica aumenta el empaquetamiento de las sedimentitas carbonáticas a través de la interpenetración, deformación y fractura de granos (Tucker y Bathurst, 1990; Lucia, 2007). A medida que el soterramiento aumenta, la compactación química ejerce una mayor influencia sobre estos depósitos mediante la disolución en el contacto entre granos (contactos suturados, cóncavos-convexos), la generación de estilolitas y la precipitación conjunta del material disuelto en el espacio poral remanente (Tucker y Bathurst, 1990; Lucia, 2007). En este sentido, de acuerdo con Flügel (2010) las estilolitas pueden generarse a partir de decenas a cientos de $\mathrm{m}$ de profundidad y en general se desarrollan de forma perpendicular a la dirección principal de esfuerzo. Las mismas, consideradas como superficies de disolución dentro del sedimento, concentran materiales menos solubles respecto a la sedimentita hospedante (Koehn et al., 2016).

\subsection{7-I: Compactación mecánica}

En general se identifica una compactación mecánica leve a través de contactos tangenciales, en menor medida rectos, entre los granos carbonáticos de sedimentitas clasto sostén con raro a ausente cemento isopáquico en halo (figura 7.8b). Este proceso que incrementa el empaquetamiento de las sedimentitas carbonáticas y disminuye su porosidad primaria, ocurre de forma posterior a la precipitación de cemento isopáquico en halo. El mismo en general resulta raro en las asociaciones de facies de Malargüe, con excepción de lo que sucede hacia el foreshoal donde es común (figura 7.1a). Por su parte, en la zona de Bardas Blancas este proceso varía de común ( $\mathrm{C} 4$ y C6) a raro (C3 y C1, figura 7.1b). 


\subsection{7-II: Compactación química}

Se distinguen estilolitas irregulares, en menor medida anastomosadas, con concentrados de pirita y en ocasiones clastos terrígenos, que se ubican de forma paralela a la base y techo de las sedimentitas (figuras $7.5 \mathrm{e} ; 7.8 \mathrm{c}$ ). Las mismas atraviesan a la matriz, granos del esqueleto y a los diferentes estadios de cementación que se registran en estas rocas carbonáticas. Además se identifican escasos contactos suturados entre los granos carbonáticos. Este proceso ocurre de forma posterior al reemplazo por pirita y de forma conjunta con la segunda $y$ tercera generación de venas (CV2 y CV3, figuras 7.5e-f). Solo de forma local en la zona de Malargüe este proceso estaría relacionado con la dedolomitización. El mismo resulta común en todas las asociaciones de facies de la zona de Malargüe (figura 7.1a), mientras que en la zona de Bardas Blancas resulta frecuente en el intershoal (C4), común en el foreshoal y llanura de marea (C1 y C6) a raro en la zona de shoal (C3, figura 7.1b).

Interpretación: dada la relación temporal existente entre la cementación en venas (CV2 y CV3) y la formación de estilolitas en la sucesión carbonática, se asume que el carbonato de calcio liberado durante la compactación química sería la fuente para su formación. Este hecho se basa por una parte, en la falta de relación de CV2-3 con los diferentes estadios de cementación esparítica y por otro lado en que este proceso ocurre de forma posterior al reemplazo por pirita a diferencia de lo que sucede con los precipitados esparíticos. No obstante lo mencionado, no se descarta un suministro externo al sistema de carbonato de calcio para la formación de dichas venas. 


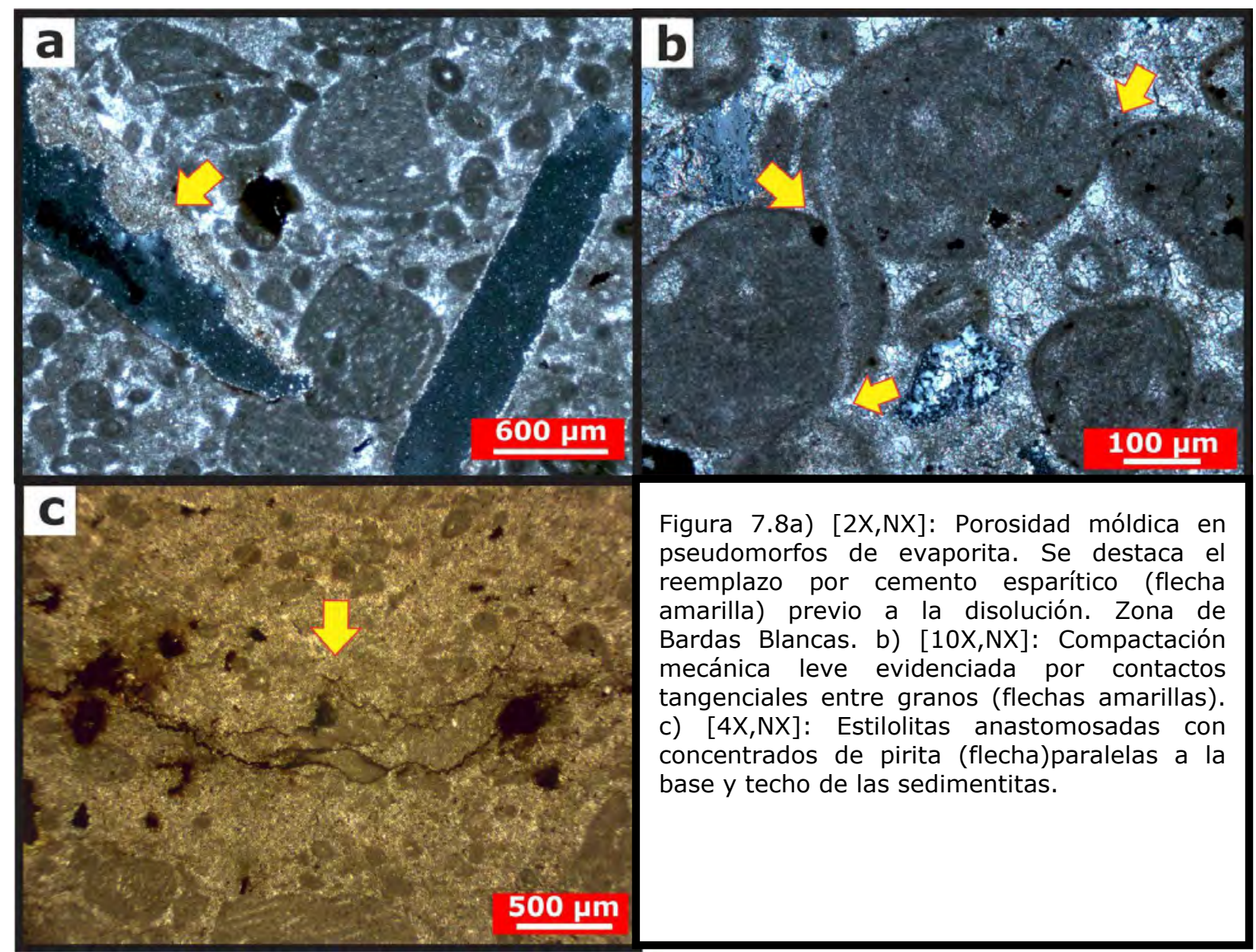

\section{4: Historia diagenética}

A continuación se describirá la evolución temporal de los procesos diagenéticos que modificaron a la sucesión carbonática en las zonas de Malargüe y Bardas Blancas. En general dichos procesos se registraron a lo largo de la sucesión, no obstante se destacan aquellos que son característicos de determinadas asociaciones de facies.

Durante la eogénesis temprana las sedimentitas carbonáticas se encontraban en el medio marino con sus poros rellenos con agua de mar. En este contexto, de forma inmediatamente posterior a su depositación, los granos carbonáticos resultarían micritizados, con una mayor intensidad hacia la albúfera e intershoal favorecida por las condiciones de baja energía y sedimentación tranquila (figuras 7.1a-b). De forma simultánea o bien a continuación, en los sectores con constante a 
intermitente acción de las olas (shoal, intershoal y foreshoal en Malargüe) precipitaría cemento marino ( $\mathrm{CIH}$ ) en baja proporción (figuras 7.1a-b). Asimismo, condiciones particulares de baja tasa de sedimentación o de no depositación en el foreshoal de la zona de Malargüe favorecerían dicha cementación y la subsecuente litificación de las sedimentitas (formación de firmground). A medida que la eogénesis temprana avanzaba estos depósitos resultarían afectados por una leve compactación mecánica que aumenta su empaquetamiento y disminuye su porosidad primaria (figuras 7.1a-b).

Por su parte, durante esta etapa en la llanura de marea la alternancia de períodos de emersión e inundación habría favorecido la mezcla de aguas porales marinas y meteóricas. En este sentido, se produciría el neomorfismo agradante (zona de Malargüe) y la dolomitización (zona de Bardas Blancas) de los estromatolitos laminares, asociado en el último caso con el reemplazo por cristales de evaporitas en los depósitos de wackstone a packstone (figuras 7.1a-b). Dichos procesos se prolongarían en la llanura de marea durante la eogénesis temprana a tardía y en el caso del neomorfismo agradante también modificaría a los depósitos de albúfera en este período más avanzado (figura 7.1a).

En una etapa posterior de la eogénesis temprana a tardía las sedimentitas carbonáticas se encontrarían en contacto con fluidos porales subsaturados respecto a carbonato de calcio. De esta forma, eventos de disolución continua afectaban a los granos carbonáticos (especialmente aragoníticos) dando lugar a la generación de porosidad secundaria y los subsecuentes eventos de cementación carbonática meteórica y de soterramiento muy somero, asociados con un aumento gradual a condiciones reductoras de las aguas porales (figuras 7.1a-b).

En la zona de Bardas Blancas el primer precipitado en rellenar la porosidad primaría remanente y secundaría generada sería el cemento vadoso (CFA), de forma local en el foreshoal (figura 7.1b). Luego, se sucede en este sector la primera generación de esparita freática de mezcla (CE1a) que también precipitaba hacia el intershoal y foreshoal de la zona de Malargüe (CE1b; figuras 7.1a-b). De forma posterior y generalizada en toda la sucesión carbonática, la segunda generación de esparita (CE2) rellenaba de forma parcial la porosidad de las sedimentitas y de forma local 
las fracturas (CV1a; figuras 7.1a-b). Relacionado con estos eventos se produciría la calcitización de los granos aragoníticos parcialmente disueltos o micritizados. Ya en una etapa de enterramiento muy somero (eogénesis tardía) el tercer evento de cementación esparítica (CE3a-b) obliteraría la porosidad de toda la sucesión carbonática y de forma local rellenaría fracturas (CV1b; figuras 7.1a-b).

Luego, cambios relacionados con las condiciones de $\mathrm{pH}$ del medio durante la eogénesis tardía a mesogénesis temprana, habrían disuelto parcialmente a la esparita, favoreciendo la escasa cementación silícea y de feldespato autigénico junto con la silicificación de bioclastos en el foreshoal, shoal externo e intershoal (figuras 7.1a-b). En este sentido, la sílice junto con los álcalis en solución llegarían a través de la alteración de la fracción terrígena en estos subambientes y de la autigénesis de illita e interestratificado illita/esmectita (eogénesis temprana a mesogénesis moderada, figuras 7.1a-b).

Durante este estadio de forma local en la zona de Malargüe, se produciría la dolomitización de las sedimentitas carbonáticas y el reemplazo por cristales de evaporitas en el shoal externo e interno, intershoal y albúfera (figura 7.1a).

Con el avance del soterramiento de la sucesión carbonática, cristales de pirita remplazarían parcialmente a las sedimentitas y precipitarían en la porosidad intercristalina remanente (eogénesis tardía a mesogénesis temprana). Por último, ya en un período de mesogénesis temprana a moderada los efectos de la compactación química afectarían a estos depósitos dando lugar a la formación de estilolitas y la liberación de carbonato de calcio en solución que precipitaba en el segundo y tercer estadio de venas (CV2-3) y de forma local se asociaría con la dedolomitización (figuras 7.1a-b). Solo en la zona de Malargüe un segundo evento de reemplazo por pirita ocurriría de forma posterior (figura 7.1a).

A partir de lo descripto se concluye que como resultado de la superposición de los diferentes procesos diagenéticos en la sucesión carbonática se obtuvo una roca completamente cementada, con ausencia de porosidad y en general sin relictos de las texturas originales de los componentes aragoníticos que la constituían. En este sentido, dichas sedimentitas se encontrarían totalmente cementadas de forma previa a su soterramiento, lo que inhibe los efectos de la compactación mecánica 
durante la etapa de mesogénesis. No obstante, dado que la evolución diagenética de la sucesión carbonática se realizó solo sobre muestras de afloramiento, no se descarta que en el subsuelo la misma pueda presentar diferentes características y un diferente comportamiento ante los efectos de la compactación mecánica.

\section{5: Consideraciones finales}

A modo de resumen, a partir del exhaustivo análisis de alta resolución bajo petrografía de polarización y por catodoluminiscencia en frío de seis asociaciones de facies del sistema carbonático desarrolladas en el capítulo 6, se determinaron los procesos diagenéticos y se delineó su evolución temporal en la sucesión bajo estudio. Además, para la identificación de los procesos diagenéticos se consideró la caracterización composicional de estas sedimentitas carbonáticas (capítulo 5, apartado 5.2.1). De esta manera, en la sucesión carbonática se reconocieron y caracterizaron procesos de micritización, cementación, neomorfismo, reemplazo por dolomita o fases minerales no carbonáticas, disolución y compactación.

En lo que respecta a la cementación, el contenido de cemento resulta escaso a abundante dentro de los diferentes subambientes, siendo los precipitados carbonáticos los mejor representados respecto a los silíceos y de feldespato autigénico. En este sentido, mediante el análisis bajo catodoluminiscencia en frío se identificaron tres estadios de cementación carbonática dentro de la sucesión. El primero de ellos marino ( $\mathrm{CIH})$, distribuido en escasa proporción dentro de shoal, intershoal y foreshoal con desarrollo de firmground, seguido por un segundo evento meteórico vadoso (CFA) localizado solo en el foreshoal de Bardas Blancas. Por último y de forma generalizada en toda la sucesión carbonática, se registró un tercer estadio meteórico freático-de soterramiento muy somero, en donde se distingue un aumento gradual a condiciones reductoras de los fluidos porales (CE1a-b, CE2, CE3a-b).

Asimismo, de acuerdo con la historia diagenética planteada para la sucesión carbonática se concluye que luego de su depositación en el medio marino y de una 
leve compactación mecánica (eogénesis temprana), la misma fue afectada de forma local por un evento meteórico vadoso, seguido por un período generalizado de diagénesis freática de mezcla de aguas porales marinas y meteóricas (eogénesis temprana a tardía). Estas condiciones se prolongarían hasta un soterramiento muy somero de la sucesión carbonática (eogénesis tardía), donde de forma posterior (mesogénesis temprana a moderada) dichas sedimentitas serían soterradas y afectadas por una moderada compactación química. 


\section{CAPÍTULO 8: PALEOAMBIENTE DE SEDIMENTACIÓN}

\section{1: Introducción}

En este apartado se presentarán los diferentes sistemas de acumulación reconocidos dentro las unidades en estudio en esta tesis. Dichos sistemas fueron definidos sobre la base de las relaciones verticales y laterales que guardan las asociaciones de facies y su comparación con modelos de acumulación existente. En particular, en el caso de las asociaciones de facies carbonáticas también fueron considerados los principales aspectos diagenéticos de estas sedimentitas. Seguidamente, se definirá el paleoambiente de sedimentación para el intervalo estratigráfico estudiado elaborado a partir de los vínculos laterales y verticales entre los sistemas depositacionales identificados.

De esta manera se reconocieron dos sistemas de acumulación marinos abiertos contrastantes dentro del intervalo estratigráfico estudiado. El primer sistema se corresponde con un ambiente marino somero clástico, el cual se reconoce en el tramo inferior del intervalo y abarca a toda la sucesión terrígena-mixta. Por su parte, en el tramo superior del intervalo se interpreta la presencia de un sistema de rampa carbonática, el cual comprende a toda la sucesión carbonática. A continuación se tratarán los dos sistemas de acumulación reconocidos. En primera instancia se planteará la distribución espacial y estratigráfica de las asociaciones de facies que los componen y luego se realizará la caracterización general del sistema de acumulación y su dinámica de sedimentación. De forma posterior, se expondrá la distribución espacial y estratigráfica de los dos sistemas de acumulación definidos y por último se llevará a cabo la caracterización general del paleoambiente de sedimentación. 


\section{2: Sistema de rampa carbonática}

\subsection{1: Distribución espacial de las asociaciones de facies}

Como se describiera en el capítulo 3, la sucesión carbonática se inicia con los primeros niveles de calizas que se apoyan de forma neta sobre las sedimentitas clásticas de la sucesión terrígena-mixta en el área de Malargüe, y de la Formación Tres Esquinas en la zona de Bardas Blancas, indicando un aumento de la productividad carbonática y una disminución del aporte clástico dentro del medio marino (véase capítulo 6, apartados 6.2.1-I y II). Su mayor potencia se registra en el centro de la zona de Malargüe (secciones ACS y PLN), con una clara disminución hacia el nor-noreste y sudeste-sudoeste de esta área y hacia la zona de Bardas Blancas (figuras 8.1a-a' y mapas adjuntos). Dentro de la misma, se reconoce un ordenamiento vertical somerizante de las asociaciones de facies en toda la zona de estudio, con excepción de lo que sucede en el noreste de Malargüe (figuras 8.1a-a'), sector que será tratado de forma particular en el apartado 8.2.1-I.

En este contexto, la sucesión comienza con depósitos peloidales de rampa media del foreshoal ( $\mathrm{AFC} 1$ y $\mathrm{C} 2$, figuras $8.1 \mathrm{~b}$ y c) dominados por la acción de olas de buen tiempo y de tormenta en el sector proximal, y por procesos de tracción y decantación en su contraparte distal. En particular en el foreshoal proximal del centro y sudoeste de Malargüe (AFC2) las aguas claras, de salinidad normal y bajo contenido de terrígenos y nutrientes, favorecerían el desarrollo de arrecifes en parche discretos (e.g. Wilson, 2005; Bádenas y Aurell, 2010; figura 8.1b). Estas bioconstrucciones se asientan sobre un firmground que registra un período de no depositación o baja tasa de sedimentación dentro de la rampa media, sin relación con un episodio de exposición subaérea (hiato, figura $8.1 \mathrm{~b}$; véase capítulo 6 apartado 6.2.1-II). Dichos depósitos proximales gradan hacia la zona distal a sedimentitas generadas por flujos de detritos ( $\mathrm{Fi}$ ) producto de cambios locales en la pendiente de la rampa carbonática (véase capítulo 6 apartado 6.2.1-II).

Por su parte, en el foreshoal de Bardas Blancas (AFC1) no se desarrolla una fauna bentónica propia, solo se reconocen concentrados esqueletales derivados del sector proximal-rampa interna. En esta zona la falta de un sustrato firme y quizás la 
variación de la salinidad o turbidez de las aguas (véase capítulo 6 apartado 6.2.1I), inhibirían el asentamiento de arrecifes en parche en el tramo proximal, dado que las colonias de corales son muy sensibles a los cambios de salinidad, nutrientes, iluminación y temperatura del medio marino (Bauch et al., 2011).

Luego del hiato registrado en el área de Malargüe, los depósitos de foreshoal son cubiertos en ambas zonas de estudio por sedimentitas de rampa interna del shoal externo (AFC3) e intershoal (AFC4, figuras 8.1a-a'). Los depósitos de shoal externo, dominados por la acción de olas, se disponen de forma discontinua en la rampa interna permitiendo la conexión entre el foreshoal e intershoal, raramente con la albúfera (figuras $8.1 \mathrm{~b}$ y $\mathrm{c}$ ). En estos bancos acumulados en un medio somero con bajo suministro de material terrígeno, las condiciones de moderada a alta energía de olas registradas en las zonas de Malargüe y Bardas Blancas (variedades peloidales y oolíticas, respectivamente) favorecerían la precipitación de cemento marino descripto en el capítulo 7 (apartado 7.3.2-I). Tanto lateralmente como en sentido vertical, dichas sedimentitas pasan al intershoal (AFC4) en el sudoeste y centro de Malargüe (sección ACS) y en la zona de Bardas Blancas, mientras que en el centro de Malargüe (sección PLN) son cubiertas por depósitos de albúfera (AFC5, figuras $\left.8.1 a-a^{\prime}\right)$.

En el intershoal (AFC4) las sedimentitas se forman en un medio submareal con bajo suministro de material terrígeno, dominado por la acción de olas y en menor medida por mareas, durante condiciones de buen tiempo y de tormenta. Dentro de este sector se registran períodos de menor frecuencia, de sedimentación tranquila y baja tasa de sedimentación donde decanta el fango carbonático y se produce la intensa micritización de estos depósitos como se detalla en el capítulo 7 (apartado 7.3.1). La entrada frecuente de las corrientes tractivas a este medio y su ubicación entre depósitos de shoal (figuras 8.1b y c) determinaría la composición de estas sedimentitas, las cuales presentan una mezcla de aloquemes (peloides, ooides, intraclastos y restos esqueletales) derivados del foreshoal, los bancos externos e internos y la albúfera (véase capítulo 6 apartado 6.2.2-II).

Lateralmente en el centro de Malargüe, el intershoal grada a depósitos oncolíticos de albúfera (AFC5) donde dominan los procesos de decantación y en menor medida 
de tracción de mareas, con ocasional acción de olas de tormenta (figuras 8.1a-a', 8.1b). En este medio submareal protegido de aguas claras, sin aporte de material terrígeno, las condiciones de sedimentación tranquila y baja tasa de acumulación permiten la proliferación de algas y cianobacterias, junto con el crecimiento de oncoides y la marcada micritización de estos depósitos (véase capítulo 6 apartado 6.2.2-III; capítulo 7 apartado 7.3.1). Además, habría propiciado la colonización de este medio por parte de equinoideos, gasterópodos y foraminíferos a diferencia de lo que sucede en el intershoal donde no se desarrolla una fauna bentónica propia (véase capítulo 6 apartado 6.2.2-II y III).

Por su parte, dichas sedimentitas de intershoal y albúfera pasan verticalmente a depósitos de shoal interno dispuestos en la rampa interna como una barrera efectiva para la entrada de corrientes tractivas hacia la llanura de marea (AFC6; figuras 8.1a-a', b y c). Estos bancos oolíticos se acumulan en un medio somero sin aporte de material terrígeno donde domina la acción de olas de moderada a alta energía que propicia la cementación marina (véase capítulo 7 apartado 7.3.2-I). Los mismos resultan cubiertos por sedimentitas con pellets y estromatolitos de llanura de marea (AFC6) formadas por la decantación debida a la actividad de mareas, con ocasional acción de olas. La restricción de este medio submareal a intermareal de aguas claras, incrementa la salinidad de sus aguas y disminuye el contenido de fauna marina bentónica (foraminíferos con enroscamiento polymorphinido), condiciones que favorecen la proliferación de cianobacterias, junto con el desarrollo de estromatolitos laminares hacia el tope (véase capítulo 6 apartado 6.2.2-IV). Asimismo, la alternancia de períodos de emersión e inundación en este sector propiciarían el neomorfismo y la dolomitización de los estromatolitos laminares (zona de Malargüe y Bardas Blancas, respectivamente), junto con el reemplazo por evaporitas de los depósitos con pellets (véase capítulo 7, apartado 7.4).

La sucesión carbonática culmina en ambas zonas de estudio con los depósitos de llanura de marea, los cuales resultan cubiertos de forma neta por las evaporitas de la Formación Tábanos (figuras 8.1a-a'). Las mismas representan condiciones de acumulación hipersalina del medio marino en la Cuenca Neuquina, posiblemente 
debido a un efecto de umbral morfológico ejercido por el arco magmático situado al oeste (Legarreta y Uliana, 1996; Armella et al., 2013).

\subsection{1-I: Consideraciones sobre la distribución espacial}

De acuerdo con lo expuesto, la distribución espacial de los depósitos reconocidos muestra que desde el subambiente de rampa media hacia el de rampa interna el pasaje resulta gradual sin evidencias significativas de resedimentación inducida por la gravedad o cambios de pendiente marcados. Este arreglo sugiere que la depositación se produjo en una rampa carbonática levemente inclinada u homoclinal (figuras 8.1b-c) de acuerdo con los modelos propuestos por Ahr (1973) y Burchette y Wright (1992). No obstante, cambios locales de su paleopendiente se registrarían en el área de Malargüe dentro de la rampa media donde se reconocen depósitos dominados por flujos de detritos dentro del foreshoal distal (e.g. Azerêdo 1998). En este contexto, de acuerdo a lo graficado en las figuras 8.1a-a', se identifica una zona profunda de la rampa carbonática ubicada hacia el nor-noroeste en ambas zonas de estudio, donde la rampa media alcanza su mayor potencia, respecto a otra somera ubicada hacia el sud-sudeste donde prevalece el subambiente de rampa interna.

Este sistema está integrado por una zona de foreshoal (AFC1 y C2) ubicada costa afuera de un shoal externo discontinuo (AFC3) que permite la conexión frecuente entre este sector y el intershoal (AFC4), menos común con la albúfera (AFC5). Atrás de ambos se establece un shoal interno (AFC3) cuya distribución dentro de la rampa permite el desarrollo de un medio protegido de llanura de marea (AFC6) por detrás (figuras $8.1 \mathrm{~b}-\mathrm{c}$ ). Una excepción a dicha configuración de rampa homoclinal propuesta se reconoce hacia el noreste de la zona de Malargüe. En este sector los depósitos peloidales de foreshoal proximal (AFC2, rampa media) resultan incididos o cubiertos por sedimentitas clásticas de barra de desembocadura (AFM6) dominadas por procesos fluviales y flujos gravitatorios relacionados, junto con la acción de olas (figura 8.1a). Dichas barras de desembocadura que interrumpen la sedimentación carbonática en la rampa, representan la descarga de corrientes 
fluviales cercanas a la costa relacionadas con el sistema marino clástico subyacente (véase capítulo 6, apartado 6.3.6). Vinculado con el ingreso de estas corrientes se produce la erosión parcial del foreshoal y el retrabajo de subambientes clásticos previos (AFM1y M2) y carbonáticos coetáneos (shoal externo e intershoal, véase capítulo 6, apartado 6.3.6). De forma posterior, la sedimentación carbonática se restablece y los depósitos de barra de desembocadura son cubiertos por sedimentitas de rampa interna de la albúfera y luego de llanura de marea, similares a las descriptas en el apartado 8.2.1 (figura 8.1a).

Teniendo en cuenta lo expuesto, se concluye que en el noreste de Malargüe el sistema de rampa homoclinal resulta modificado por el establecimiento de las barras de desembocadura a través de la interrupción de la producción carbonática, la erosión parcial de los depósitos de foreshoal y la destrucción mecánica de las sedimentitas de shoal externo e intershoal. Esto permitiría explicar el bajo espesor que la sucesión carbonática presenta en este sector y especialmente el bajo desarrollo del subambiente de rampa media en esta zona respecto al centro de Malargüe, ubicado ambos hacia el sector profundo de la rampa carbonática (véase apartado 8.2.1).

Figura 8.1a-a': Secciones columnares en el área de Malargüe (a) y de Bardas Blancas (a') graficadas según sus asociaciones de facies. Están acompañados por un mapa con la ubicación de las secciones, donde la flecha amarilla indica el sentido de profundización en cada sector. Fm Tb: Fm Tábanos; F: firmground. Figuras $8.1 \mathrm{~b}-\mathrm{c}$ : Esquema que representa el modelo de rampa carbonática homoclinal propuesto para el área de Malargüe (b) y de Bardas Blancas (c) (Modificado de Amour et al., 2012). BOBT: base de olas de buen tiempo; BOT: base de olas de tormenta, NDM: nivel del mar. 


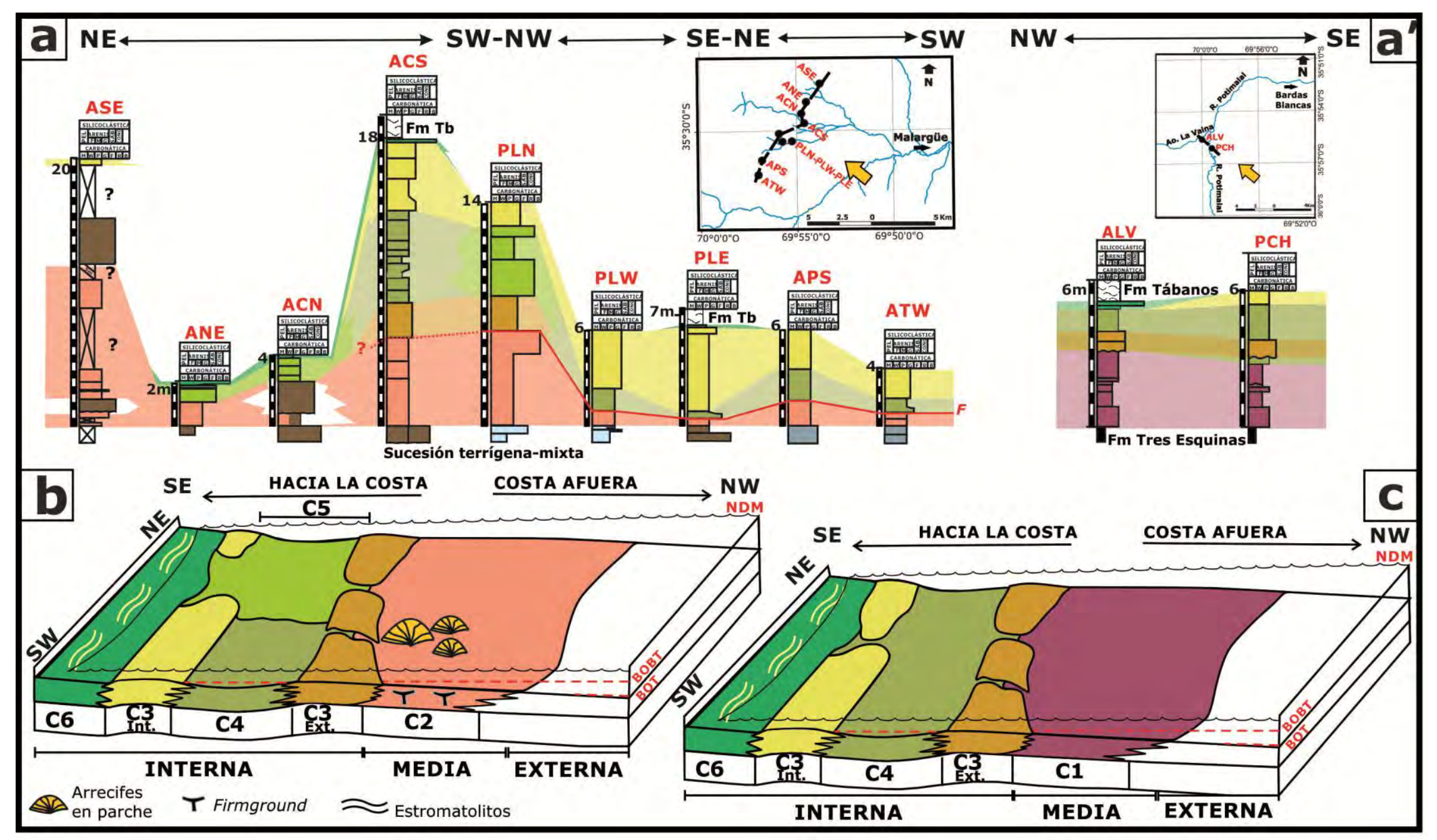




\subsection{2: Composición del sistema de rampa carbonática}

A lo largo de este sistema de acumulación carbonático se distingue en sus depósitos el predominio de los granos no esqueletales respecto a los esqueletales, con una mayor participación de estos último en la zona de Bardas Blancas (figuras 8.2a-b y 8.3). Dentro de los granos no esqueletales presentes, los peloides son los que abundan en ambas zonas de estudio. En particular en la zona de Malargüe los peloides predominan en el foreshoal, shoal externo e intershoal junto con un menor contenido de ooides superficiales, bioclastos, intraclastos y material terrígeno (feldespatos y líticos volcánicos> cuarzo monocristalino, véase capítulo 5, apartado 5.2.2.I). Su abundancia disminuye de forma abrupta hacia la albúfera hasta estar ausentes en el shoal interno y la llanura de marea (figuras 8.2a-b). En estos sectores dominan los oncoides en la albúfera, los ooides normales en el shoal interno, mientras que hacia la llanura de marea predominan los pellets y los estromatolitos hacia el tope. En este sentido, se observa una disminución del contenido de los restos esqueletales desde la albúfera hacia la llanura de marea y la ausencia de material terrígeno en todas estas zonas (figuras 8.2a-b). En especial, en el foreshoal proximal del noreste de Malargüe se reconocen acumulaciones de material terrígeno e intraclastos (AFM6, figura 8.2a), mientras que hacia el centro de esta zona se desarrollan colonias de corales in situ junto con acumulaciones de intraclastos hacia el foreshoal distal (figura 8.2b).

En esta zona los bioclastos que predominan son las ostras, gasterópodos, equinoideos, otros bivalvos no ostreidos, acompañados por corales, braquiópodos rhynchonellidos y telebratúlidos, cianobacterias y foraminíferos con enroscamiento polymorphinido. En menor proporción se reconocen crinoideos, poríferos, algas (Dasycladales), otros foraminíferos (uniseriados, con enroscamiento planoespiral) y algas unicelulares calcáreas (Coccolithophyacea; figuras 8.2a'-b'). En general, los corales junto con las ostras abundan desde el foreshoal hasta el intershoal en el centro y sudoeste de Malargüe (figura $8.2 b^{\prime}$ ), mientras que hacia el noreste dominan los braquiópodos, equinoideos, ostras, otros bivalvos no ostreidos y crinoideos desde el foreshoal hasta la albúfera (figura 8.2a'). Por su parte, los 
gasterópodos y equinoideos en general dominan en la rampa interna junto con cianobacterias y foraminíferos con enroscamiento polymorphinido. Estos últimos dos grupos se reconocen solo en este sector, desde el intershoal al shoal interno las cianobacterias, mientras que los foraminíferos aparecen desde la albúfera hasta la llanura de marea (figuras $8.2 a^{\prime}-b^{\prime}$ ).

En cuanto a la zona de Bardas Blancas los peloides y bioclastos predominan desde el foreshoal hasta el shoal interno, acompañados por un menor contenido de ooides normales, intraclastos y material terrígeno (feldespatos y líticos volcánicos> cuarzo monocristalino) (figura 8.3a). En general, disminuyen su contenido dentro de los depósitos de shoal externo e interno donde dominan los ooides normales, y hacia la zona de llanura de marea donde están ausentes y son reemplazados por pellets y estromatolitos (figura 8.3a). Como en la zona de Malargüe, el material terrígeno se reconoce hasta el intershoal, con sectores del foreshoal donde se presenta como depósitos de areniscas (figura 8.3a).

En este sector los bioclastos dominantes son las ostras, otros bivalvos no ostreidos, equinoideos y gasterópodos, acompañados por corales, cianobacterias y foraminíferos con enroscamiento polymorphinido. Como sucede en el área de Malargüe, estos últimos dos grupos se reconocen solo en la rampa interna, las cianobacterias desde el shoal externo al interno, mientras que los foraminíferos desde el shoal interno a la llanura de marea (figura 8.3b).

\subsection{2-I: Consideraciones sobre la composición del sistema}

Teniendo en cuenta el modelo de rampa homoclinal expuesto y la abundancia de componentes no esqueletales en sus depósitos, especialmente de peloides, este sistema se asemeja al de rampa peloidal de moderada a baja energía propuesto por Bádenas y Aurell (2010) para calizas del Jurásico tardío de España, tal como lo muestran las figuras $8.2 a-b$ y 8.3. En estos sistemas los peloides abundan desde el foreshoal hasta la albúfera, con una clara disminución en esta última zona donde 
dominan los oncoides. Además, pueden desarrollarse bioconstrucciones en el foreshoal.

No obstante, variaciones puntuales dentro de la rampa interna de la sucesión carbonática generan condiciones de moderada a alta energía en este subambiente que se reflejan en su composición y lo diferencian del modelo propuesto por Bádenas y Aurell (2010). En el mismo, la presencia de un shoal externo discontinuo favorece la entrada de corrientes tractivas hacia el intershoal, y en menor medida a la albúfera, dando lugar a la formación de un shoal oolítico interno de moderada a alta energía por detrás (véase apartado 8.2.1-I, figuras 8.2a-b, 8.3). En particular en la zona de Bardas Blancas estas condiciones hidrodinámicas imperan tanto en el shoal externo e interno de la rampa interna, como se refleja en la abundancia de ooides en estos depósitos (figura 8.3).

En este sistema de rampa peloidal la distribución del material terrígeno en baja proporción dentro del foreshoal, shoal externo e intershoal y su ausencia en los sectores más someros de la rampa interna como la albúfera, shoal interno y llanura de marea (figuras $8.2 a-b$ y 8.3 ) permite considerar que dicho material no proviene de la zona costera. En este sentido se infiere que en la zona de Malargüe el material extracuencal deriva de los depósitos de barra de desembocadura que interrumpen la sedimentación carbonática del foreshoal en el noreste de esta área (AFM6, véase apartado 8.2.1-I). Mientras que en la zona de Bardas Blancas la falta de un sistema clástico asociado no permite identificar el área fuente de dicho material. Dado que no se observan en afloramiento las paleocorrientes de los depósitos de la sucesión carbonática, no se puede determinar con exactitud la distribución del material terrígeno dentro de la misma. Sin embargo, de acuerdo a la disposición de este material se sugiere que podría haber ingresado a través de la zona de foreshoal-shoal externo y de forma posterior sería redistribuido por corrientes costeras activas (longitudinales u oblicuas) a lo largo de estas zonas. Luego, las olas y en menor medida las mareas, lo transportarían desde el foreshoalshoal externo hacia el intershoal. 


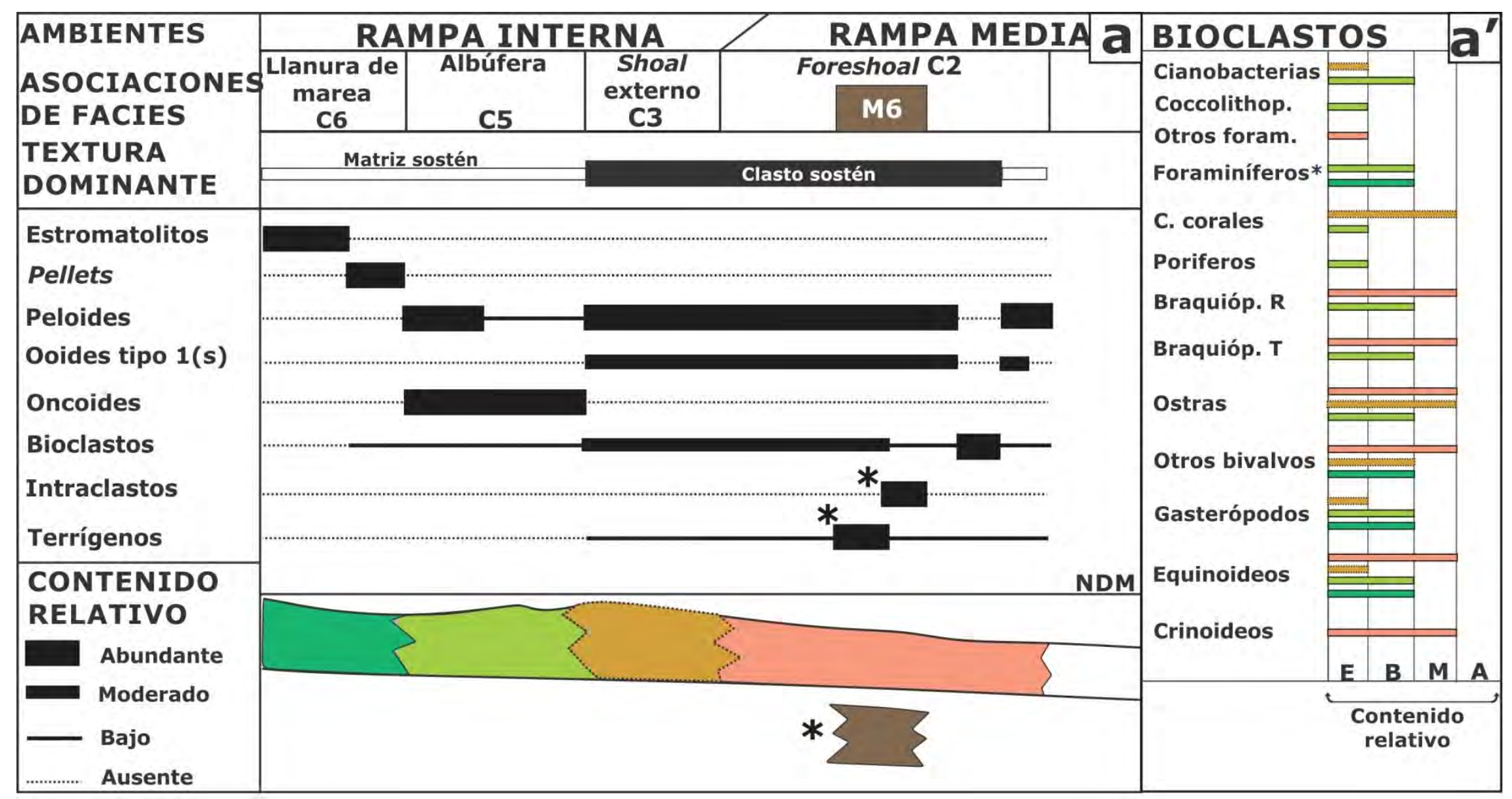

Figura 8.2a: Distribución de las asociaciones de facies y componente intracuencales y extracuencales dentro del modelo de rampa carbonática homoclinal en el noreste del área de Malargüe (modificado de Bádenas y Aurell, 2010). La línea punteada indica que la AF no está preservada. M6: asociación de facies de barra de desembocadura; NDM: nivel del mar. a': Contenido relativo y distribución de los diferentes bioclastos dentro del sistema de rampa carbonática. Coccolithop.: Coccolithophycae; foram.: foraminíferos; foraminíferos*: con enroscamiento polymorphinido; Braquióp. R., T.: braquiópodos rhynchonellidos y telebratúlidos. 


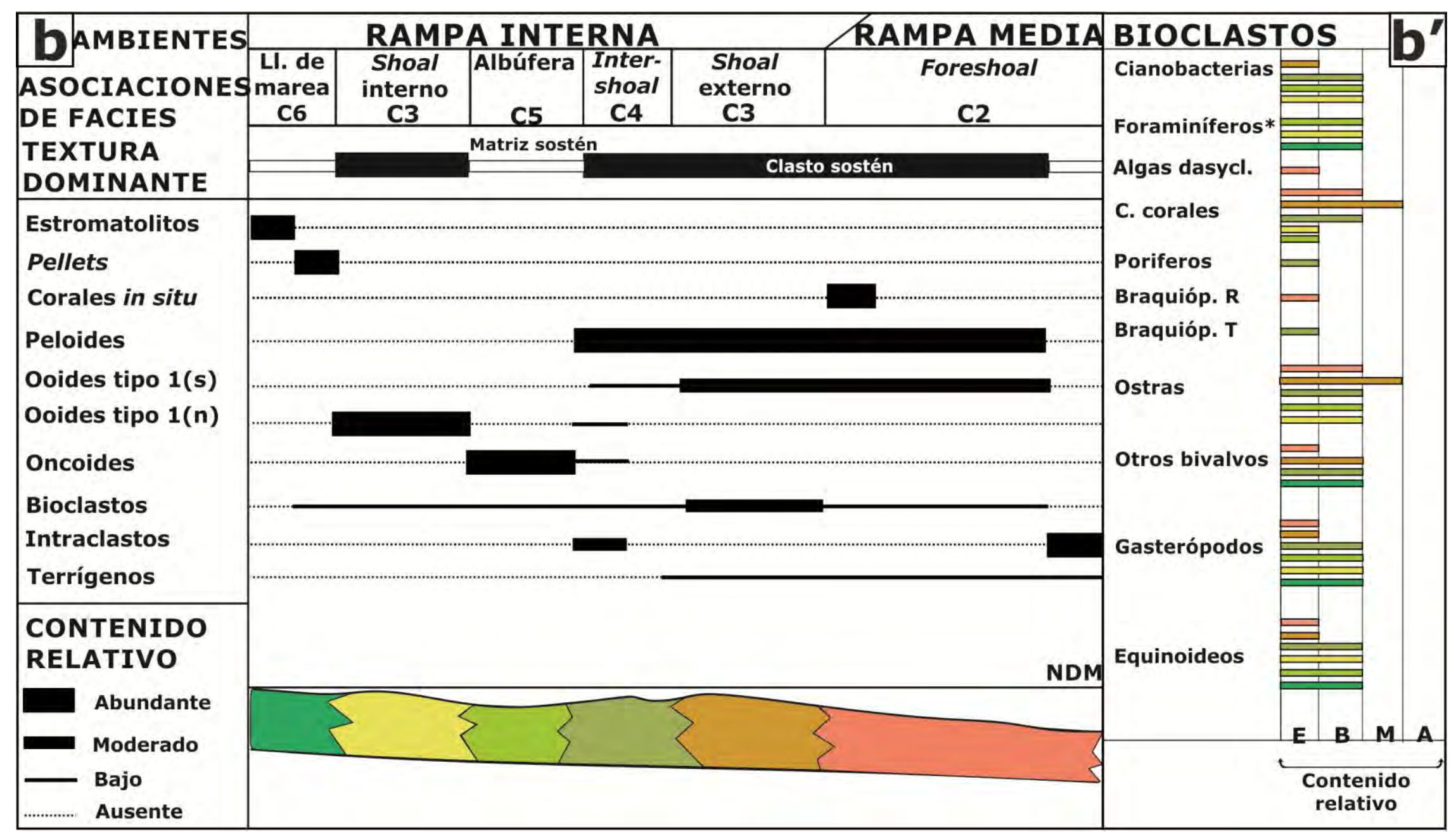

Figura 8.2b: Distribución de las asociaciones de facies y componente intracuencales y extracuencales dentro del modelo de rampa carbonática homoclinal en el centro y sudoeste del área de Malargüe (modificado de Bádenas y Aurell, 2010). NDM: nivel del mar. b': Contenido relativo y distribución de los diferentes bioclastos dentro del sistema de rampa carbonática. Foram.: foraminíferos; foraminíferos*: con enroscamiento polymorphinido; dasycl.: dasycladales; C. corales: colonias de corales; Braquióp. R., T.: braquiópodos rhynchonellidos y telebratúlidos. 


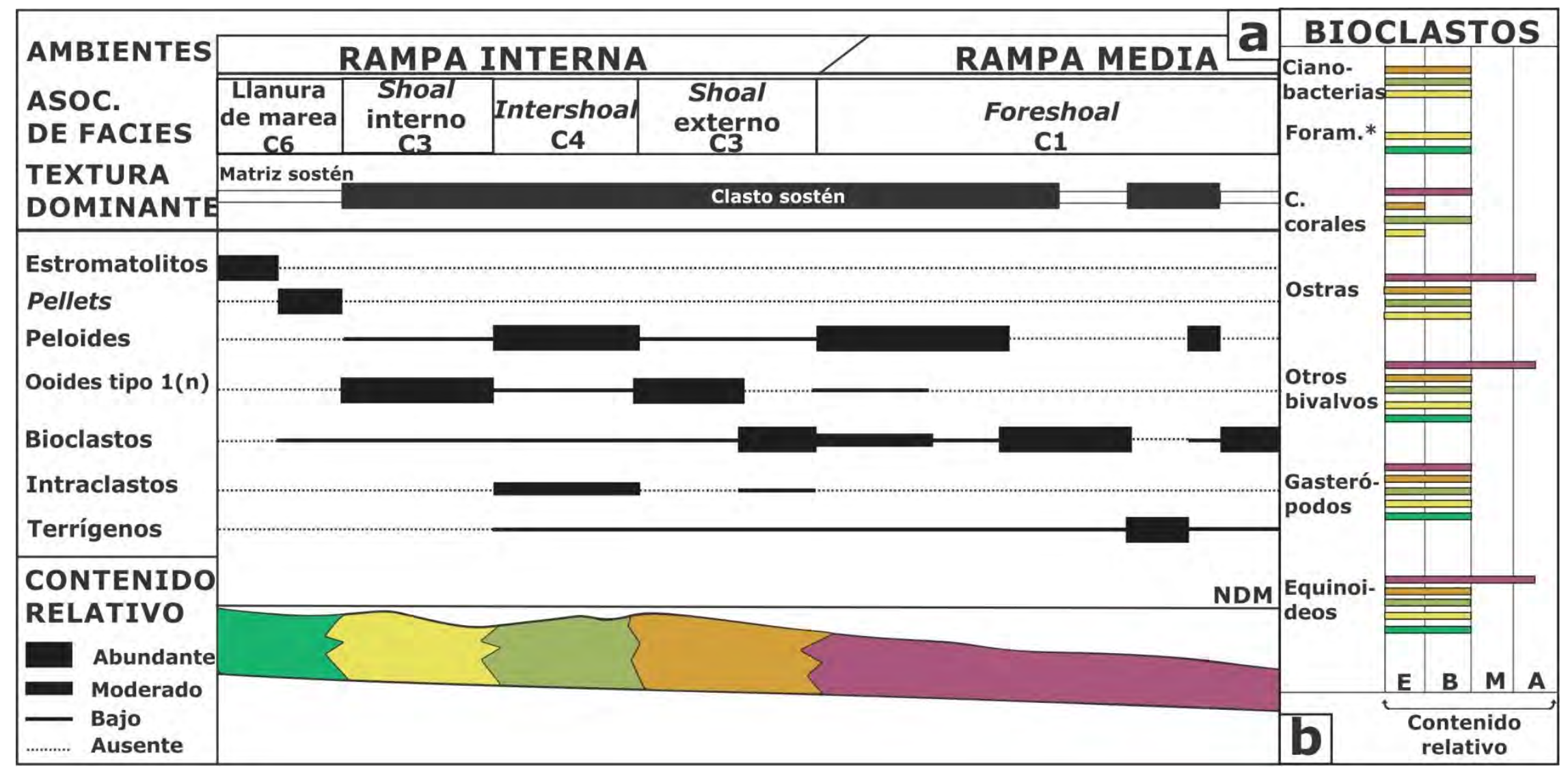

Figura 8.3a: Distribución de las asociaciones de facies y componente intracuencales y extracuencales dentro del modelo de rampa carbonática homoclinal en el área de Bardas Blancas (modificado de Bádenas y Aurell, 2010). NDM: nivel del mar. b: Contenido relativo y distribución de los diferentes bioclastos dentro del sistema de rampa carbonática. Foram.*: foraminíferos con enroscamiento polymorphinido; C. corales: colonias de corales. 


\subsection{3: Dinámica del sistema de rampa carbonática}

Sobre la base de la identificación de las zonas de producción carbonática dentro de la rampa y la distribución y abundancia de los componentes intra y extracuencales, se propone la dinámica de transporte del sedimento dentro de la misma. En este sistema, la distribución espacial de las asociaciones de facies muestra que durante la acumulación de la rampa media los procesos de las olas habrían dominado en este subambiente. Durante la generación del foreshoal (AFC1 y C2), la zona proximal y distal se conformaban a partir del material intracuencal (peloides, ooides superficiales y normales) que era transportado desde el shoal externo activo (AFC3) por corrientes de retorno durante condiciones de tormenta (véase apartados 6.2.1-I y II; figura 8.4a). Junto con este material, el fango carbonático era llevado en suspensión mediante corrientes de retorno desde la rampa interna, siendo acumulado de preferencia en el sector distal. Con frecuencia, se infiere que también llegaría material arenoso a partir de corrientes costeras activas durante condiciones de buen tiempo y de tormenta, proveniente del noreste de Malargüe o un área fuente que no se encuentra dentro del área de estudio, en el caso de la zona de Bardas Blancas (véase apartado 8.2.2-I y figura 8.4a'). Por su parte, los restos esqueletales eran transportados hacia el foreshoal proximal por las olas desde los arrecifes en parche o la rampa interna (figura 8.4a) y durante las tormenta llevados por corrientes de retorno hasta el sector distal. En particular en esta zona del área de Malargüe, intraclastos carbonáticos y arenosos eran transportados por flujos de detritos desde el foreshoal proximal y el intershoal.

En lo que respecta a la rampa interna durante su acumulación los procesos de las olas y las mareas habrían sido activos y su dinámica habría caracterizado a este subambiente. En el mismo los shoal externo e interno (AFC3) se conformaban por ooides superficiales o normales generados in situ por la acción de olas, junto con restos esqueletales transportados por estos flujos desde la rampa media o desde la albúfera-intershoal (figura 8.4b). Por su parte, al intershoal (AFC4) llegaba fango carbonático, granos no esqueletales (peloides, ooides e intraclastos) y esqueletales desde la rampa media, shoal externo y la albúfera mediante las olas y en menor 
medida las mareas (figura 8.4b). Con frecuencia estos flujos transportaban material terrígeno desde la rampa media hacia el shoal externo y el intershoal (véase apartado 8.2.2-I y figura 8.4b'). Por otro lado, en la albúfera (AFC5) los oncoides se generaban in situ por la acción de mareas, junto con el fango carbonático debido a la actividad de algas y cianobacterias. Además, llegaban escasos restos esqueletales y no esqueletales mediante ocasionales olas de tormenta desde la rampa media y el shoal externo (figura 8.4b). De la misma forma, la llanura de marea (AFC6) se construía por pellets, fango carbonático y estromatolitos formados in situ, acompañados por escasos bioclastos transportados por esporádicas olas de tormenta desde el intershoal-albúfera (figura 8.4b).

En el contexto de las características mencionadas, el sistema de acumulación estudiado podría ser clasificado como una rampa homoclinal dominada por las olas donde los procesos de las mareas tendrían una influencia minoritaria y localizada en la albúfera, en la llanura de marea y en menor medida en el intershoal. Dentro del mismo las tormentas controlarían el transporte y la resedimentación de los componentes no esqueletales, esqueletales y fango carbonático costa afuera de la zona de producción carbonáticas, ubicadas en su mayoría dentro de la rampa interna. De forma subordinada estos flujos habrían transportado restos esqueletales desde los arrecifes en parche hacia la rampa interna, y material intracuencal dentro de este último subambiente. Esta dinámica de movimiento del sedimento se asemeja a la propuesta por Bádenas y Aurell $(2001,2010)$ para rampas carbonáticas del Jurásico tardío de España.

\subsection{4: Consideraciones finales}

De esta forma, la sucesión carbonática es interpretada como un sistema de rampa peloidal homoclinal con bioconstrucciones discretas y cambios locales de su paleopendiente en la rampa media proximal y distal, respectivamente, de la zona de Malargüe. En este contexto, los arrecifes en parche habrían colonizado este medio de aguas claras, oligotróficas, de salinidad normal y bajo contenido de terrígenos durante un hiato depositacional registrado en el mismo. Por el contrario, 
la falta de este evento en la rampa media proximal de Bardas Blancas, junto con cambios en la salinidad y turbidez de sus aguas habrían impedido el desarrollo de dichas bioconstrucciones.

Por su parte, en la rampa interna el desarrollo de la fauna bentónica estaría condicionado por la distribución y continuidad de los shoals en este subambiente y la turbidez y contenido de material terrígeno de sus aguas. En este sentido, las algas y cianobacterias proliferan en la albúfera y llanura de marea, sectores protegidos, de aguas claras y sin terrígenos, encontrándose ausentes en el intershoal donde no se propician dichas condiciones. En particular, en la llanura de marea la restricción del medio produce un incremento de la salinidad, el cual favorecería el crecimiento de estromatolitos.

Este sistema de rampa está dominado por olas con una influencia menor y localizada de las mareas en la rampa interna, registrada en la albúfera, llanura de marea y en menor medida el intershoal. A lo largo del mismo, las tormentas controlarían el transporte y la redepositación del material intracuencal, en especial desde la rampa interna a media. En particular, este subambiente habría recibido un bajo aporte de material extracuencal desde el sistema clástico subyacente, en el noreste de Malargüe, y de un área fuente no identificada en Bardas Blancas, el cual sería transportado hasta el intershoal en la rampa interna.

Como consecuencia del establecimiento de este sistema clástico, modificaciones locales en la rampa carbonática habrían ocurrido en el noreste de Malargüe. En este contexto, se interrumpe la producción carbonática, se genera la erosión parcial de los depósitos de rampa media y la destrucción mecánica de las sedimentitas de shoal externo e intershoal de rampa interna, dando lugar a una disminución del registro de la rampa carbonática en esta zona. 


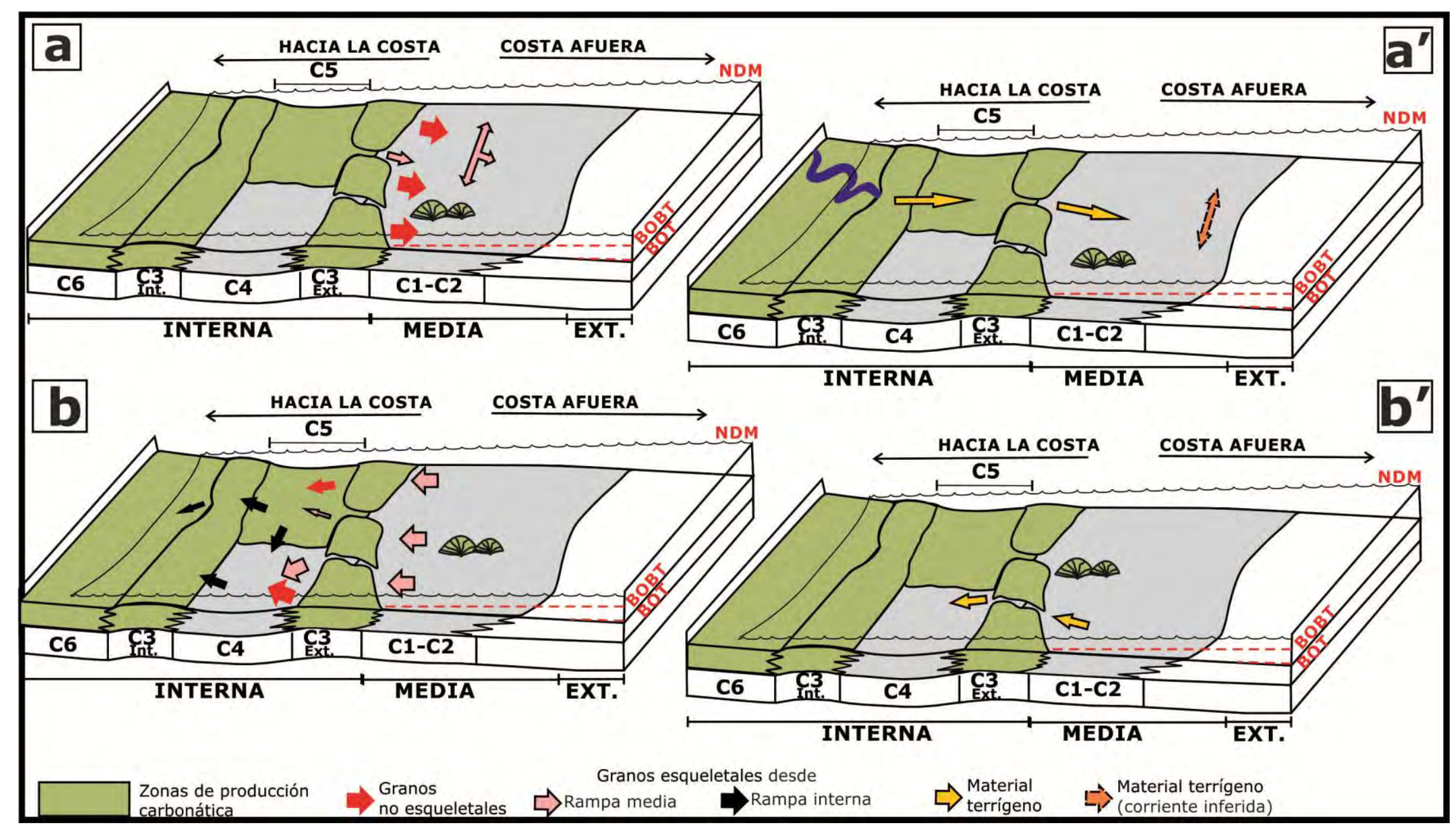

Figura 8.4: Transporte de los componentes intracuencales y extracuencales dentro de la rampa media ( $a$, $\left.a^{\prime}\right)$ e interna (b, $b^{\prime}$ ), respectivamente, junto con la ubicación de las zonas de producción carbonática. El ancho de la flecha indica la cantidad de material transportado de una zona hacia la otra. BOBT: base de olas de buen tiempo; BOT: base de olas de tormenta; NDM: nivel del mar. 


\section{3: Sistema marino clástico}

\subsection{1: Distribución espacial de las asociaciones de facies}

La sucesión terrígena-mixta comienza en la sección ATW, ubicada en el sudoeste de Malargüe, donde se reconoce el mayor espesor y registro más completo de la misma, no obstante su base no se encuentra expuesta (véase capítulo 4, apartado 4.5.3). Su potencia disminuye hacia el noreste de Malargüe donde se registra solo el tramo superior de la sucesión (figura 8.5a). Dentro de la misma, las asociaciones de facies (AF) se organizan en sucesiones, en general con arreglo somerizante, que varían su espesor entre $<1$ hasta 15 metros, indicadas como tramos I y II desde la base al tope de la unidad terrígena-mixta (figura 8.5a). Asimismo, en cada uno de ellos se distingue un sector I' y II' los cuales serán explicados de forma separada.

El tramo I se reconoce en el centro (sección PLN) y sudoeste de Malargüe (figura 8.5a). En general, este sector se inicia en el sudoeste de Malargüe con litosomas arenosos de shoreface superior (AFM3) acumulados en un medio dominado por la acción de olas y corrientes costeras inducidas por las mismas (véase capítulo 6, apartado 6.3.3). Estos depósitos resultan cubiertos por cuerpos arenosos de foreshore-shoreface superior (AFM5), colonizados por bivalvos y ¿algas rojas?, donde predomina la acción de olas y flujos unidireccionales no canalizados (véase capítulo 6, apartado 6.3.5; figura 8.5a). Dichas sedimentitas durante los períodos de bajo suministro clástico al sistema pasan lateralmente a arrecifes en parche discretos de shoreface superior a inferior (AFM2) hacia el sudoeste y centro de Malargüe (figuras $8.5 a$ y b1). Estas bioconstrucciones se desarrollan en un medio dominado por la acción de olas, con aguas claras, salinidad normal y condiciones oligotróficas (véase capítulo 6, apartado 6.3.2). Por el contrario, cuando el aporte de material terrígeno se restablece en el sistema, la producción carbonática cesa por ahogamiento físico de las colonias (véase capítulo 6, apartado 6.3.2). De esta forma se construyen barras arenosas en el shoreface inferior a superior (AFM2) del centro de Malargüe y litosomas arenosos en el foreshore-shoreface superior (AFM5) en el sudoeste de esta área (figura 8.5a). 


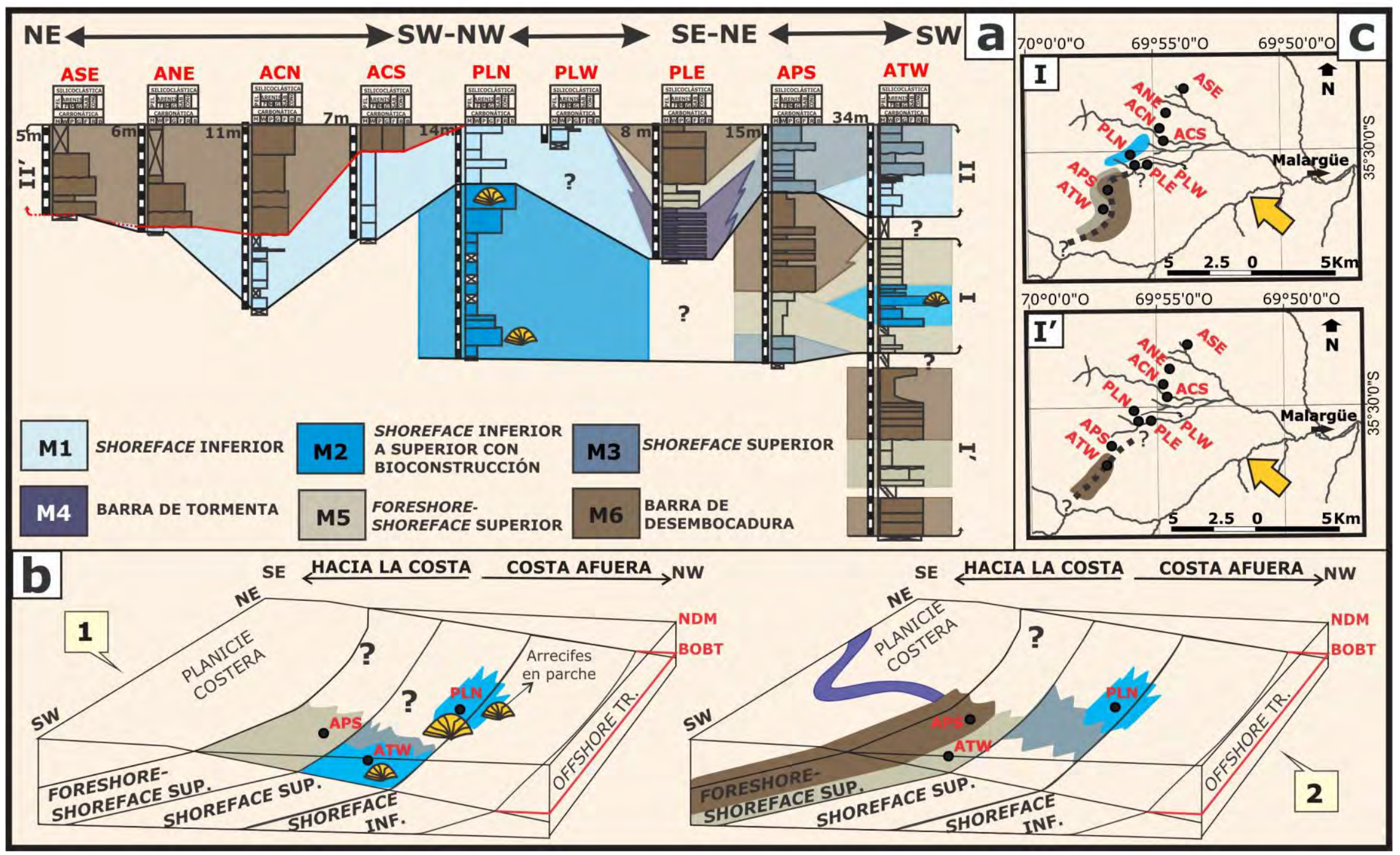


Figura 8.5a: Perfiles sedimentológicos que comprenden la sucesión terrígena-mixta graficados según sus asociaciones de facies, donde se distinguen los tramos I, I', II y II' que conforman a dicha sucesión. b: Esquema que representa el modelo marino somero propuesto para el tramo I, donde se diferencia un período con bajo aporte clástico y desarrollo de arrecifes en parche (1), de otro con descarga de sistemas fluviales y ausencia de bioconstrucciones (2). BOBT: base de olas de buen tiempo. NDM: nivel del mar. c: mapas que muestran la distribución de los subambientes hacia el tope del tramo I y I', respectivamente. La flecha amarilla indica hacia el sector donde se profundiza el ambiente marino somero. La línea punteada negra marca la posición de la paleo línea de costa inferida.

En particular en la sección APS (sudoeste de Malargüe), por encima de estos depósitos se acumulan barras gravosas en el foreshore-shoreface superior (AFM6) durante períodos de mayor descarga de los sistemas fluviales que desembocan en este sector (figuras $8.5 \mathrm{a}, \mathrm{b} 2$ ). Se construyen en un medio donde los procesos fluviales y la acción las olas actúan de forma conjunta. En este sector, durante los períodos de baja descarga fluvial se registraría un escaso aporte de sedimentos hacia el shoreface superior a inferior (AFM2) que favorecería nuevamente el asentamiento de arrecifes en parche en el centro de Malargüe (figuras 8.5a, 8.5cI).

Con una distribución similar de los depósitos de foreshore a shoreface superior, en la sección ATW se reconoce el tramo I' subyaciendo al anterior (figura 8.5a). En este contexto, durante los episodios de mayor descarga fluvial se acumulan barras gravosas de desembocadura (AFM6), las cuales son cubiertas por litosomas arenosos y de grava discretos en los períodos de baja descarga fluvial (AFM5). Por encima, la sucesión de litosomas de grava y arena vuelve a repetirse (figuras $8.5 a$, $\left.8.5 c I^{\prime}\right)$.

En cuanto al tramo II, se distribuye en toda el área de Malargüe por encima del tramo I (figura 8.5a). El mismo comienza en el sudoeste con depósitos de shoreface superior (AFM3, M4), aunque en ocasiones se reconocen por debajo de estos depósitos, sedimentitas de shoreface inferior dominadas por flujos oscilatorios y combinados (AFM1; figuras $8.6 a, b$ ).

En el shoreface superior los litosomas arenosos se acumulan en un medio dominado por olas y corrientes costeras bajo condiciones de buen tiempo y de tormenta. En este sector, la colonización de organismos bentónicos sería afectada por la frecuente descarga de sistemas fluviales donde se construyen litosomas gravosos, la turbidez de las aguas aumenta y su salinidad fluctúa (véase capítulo 6, apartado 
6.3.3). Por su parte, durante las tormentas se construyen barras gravo-arenosas (AFM4, figuras $8.6 a-b$ ) donde imperan las corrientes longitudinales a perpendiculares respecto a la paleolínea de costa inferida (orientación sud-sudoeste y orientación nor-noroeste, respectivamente; véase capítulo 6, apartado 6.3.4).

Por encima del shoreface superior en la sección PLE se acumulan psamitas de foreshore-shoreface superior (AFM5, figuras 8.6a-b) dominadas por olas y corrientes unidireccionales no confinadas, que se orientan perpendicular a la paleolínea de costa inferida (sentido nor-noroeste, véase capítulo 6, apartado 6.3.5). Al igual que en el tramo I, este sector es colonizado por bivalvos y calgas rojas? y durante los episodios de mayor descarga fluvial se construyen barras gravosas de desembocadura (AFM6, figuras $8.6 a-b$ ) con paleocorrientes paralelas a la paleolínea de costa (sentido sud-sudoeste, véase capítulo 6, apartado 6.3.5).

Dichas sedimentitas pasan lateralmente hacia el centro y noreste de Malargüe a cuerpos arenosos de shoreface inferior (AFM1) dominados por flujos oscilatorios y combinados durante condiciones de buen tiempo y de tormenta (figuras 8.6a-b). En general este sustrato se encuentra colonizado por biota marina, no obstante la influencia fluvial se refleja con la presencia de restos vegetales en el centro (sección ACS) y noreste de Malargüe (véase capítulo 6, apartado 6.3.1). En este sentido se infiere que el suministro constante de material terrígeno desde estos sistemas generaría condiciones ambientales desfavorables (turbidez de las aguas, incremento del contenido de nutrientes) que inhibirían el asentamiento de arrecifes en parche en este sector (Dupraz y Strasser, 2002).

El tramo II es cubierto por los depósitos de rampa carbonática homoclinal, mientras que hacia el centro (sección ACS) y noreste de Malargüe mediante un cambio abrupto se apoyan sedimentitas de foreshore-shoreface superior del tramo 'II' (figuras 8.6a, cII'). Comprenden barras gravosas de desembocadura y litosomas de material resedimentado de los ambientes subyacentes de shoreface inferior a superior (AFM1 y M2; ver capítulo 6, apartado 6.3.6). Los mismos representan el tope de la sucesión terrígena-mixta en este sector de Malargüe, cubiertos por el sistema de rampa carbonática homoclinal (figura 8.6a). 


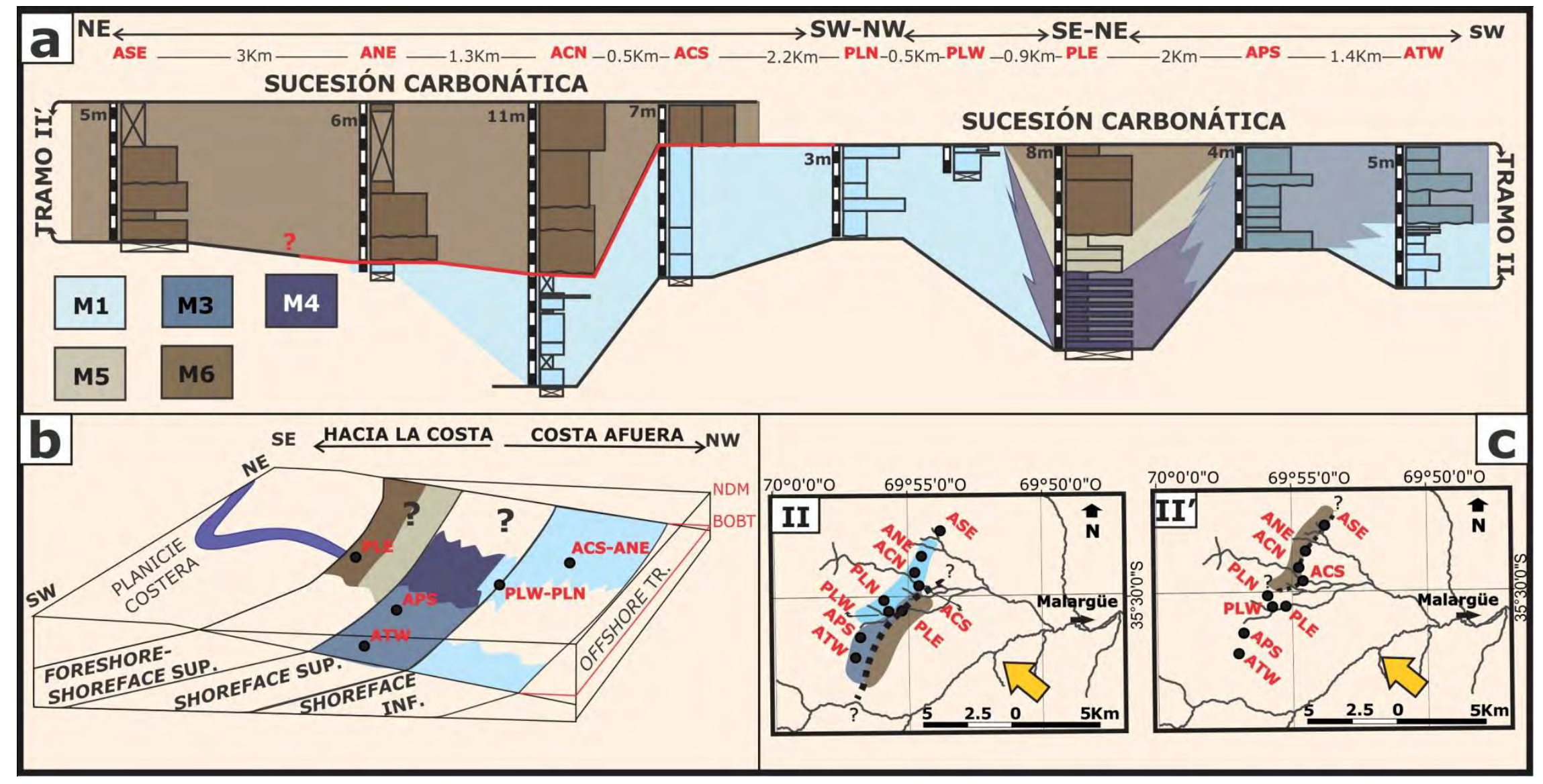

Figura 8.6a: Secciones columnares que abarcan el tramo II y II', respectivamente de la sucesión terrígena-mixta. La línea roja marca el contacto entre ambos tramos. b: Esquema que representa el modelo de sistema marino somero propuesto para el tramo II. BOBT: base de olas de buen tiempo. NDM: nivel del mar. c: Distribución de los subambientes del sistema marino somero hacia el tope del tramo II y II', respectivamente. La flecha amarilla indica el sector hacia donde se profundiza el sistema y la línea punteada negra la posición de la paleo línea de costa inferida. 


\subsection{1-I: Consideraciones sobre la distribución espacial}

De acuerdo con la distribución espacial de los depósitos expuestos, se interpreta un sistema marino somero con influencia de sistemas fluviales de carga de lecho gravo-arenosa ubicados en las cercanías de la costa, fuera del área de estudio (e.g. actual Costa Mediterránea de España, cf. Clifton, 2003). No obstante, se sugiere que este sistema con espesos niveles de grava también podría encontrarse asociado, o ser parte, de un sistema de fan delta que le aporta un abundante contenido de material arenoso y psefítico (Massari y Parea, 1988; Hart y Plint, 1995). Dentro de este medio marino el sistema fluvial o deltaico que lo alimenta se ubicaría hacia el sud-sudeste y habría migrado a través del tiempo desde el sudoeste hacia el noreste de Malargüe, evidenciado por la distribución de los depósitos de barra de desembocadura y su desplazamiento (figura 8.5a).

En este contexto, el sistema se divide en tramos donde se reconocen variaciones del mismo a través de la distribución de los subambientes y el desarrollo de la fauna bentónica (figuras $8.5 \mathrm{~b}$ y 8.6b). En particular en el caso del sector I' se asume una distribución similar al tramo I de los subambientes, no obstante la falta de registro del shoreface inferior a superior impide determinar la presencia de arrecifes en parche en este sector. En todos los tramos de este sistema según lo representado en las figuras $8.5 \mathrm{cI}-\mathrm{I}^{\prime}$ y $8.6 \mathrm{cII}-\mathrm{II}^{\prime}$, se reconoce una zona profunda hacia el nor-noroeste de Malargüe donde dominan los subambientes de shoreface superior a inferior (AFM1 y M2), de otra somera hacia el sud-sudeste donde predominan el foreshore a shoreface superior (AFM6, M5, M3, M4). Esta polaridad coincide con la descripta para el sistema de rampa carbonática homoclinal que lo suprayace (figuras $8.1 a-a^{\prime}$ y mapas adjuntos).

En este medio marino somero se reconoce que los depósitos de foreshore-shoreface superior del tramo I resultan cubiertos por sedimentitas de shoreface inferior y superior del tramo II (figura 8.5a). Dicha relación vertical marca una retrogradación de los subambientes de acumulación y podría ser interpretada como una superficie transgresiva que separa sucesiones somerizantes. No obstante, la falta de registro dentro de las sucesiones somerizantes del tramo I y II (figura 8.5a) no permite aseverar esta afirmación. Por otra parte, hacia el tope del tramo II los depósitos de 
shoreface inferior resultan cubiertos mediante un contacto erosivo, con evidencias de resedimentación, por depósitos de foreshore a shoreface superior del tramo II' (figura 8.5a). Este contacto involucra un desplazamiento marcado y rápido de los subambientes de acumulación que indicaría una significativa progradación de los mismos y podría ser interpretado como una caída del nivel del mar relativo (regresión forzada cf. Posamentier et al., 1992; Clifton, 2006). Esta superficie tendría su contraparte hacia el centro y sudoeste de Malargüe con la exposición subaérea del foreshore a shoreface superior (tramo II), seguido por un período de erosión o no depositación. Se interpreta que dicha somerización abrupta de los subambientes de acumulación podría estar inducida por efectos de una tectónica local en el noreste de la zona de Malargüe, que produjo un relieve irregular dentro de este sector junto con la exposición parcial de los subambientes acumulados previamente (AFM1y M2). Estos sectores elevados serían una de las áreas fuente de material para los depósitos que rellenan el espacio de acomodación generado por estas fallas.

\subsection{2: Dinámica del sistema marino clástico}

Según la distribución espacial de las asociaciones de facies, durante la acumulación de este sistema los procesos de las olas y de forma localizada los fluviales actuaron de manera contemporánea y su interacción habría caracterizado al mismo. En este sentido, los tramos I y I' se conformaban a partir del material arenoso y en menor medida psefítico que llegaba al foreshore-shoreface superior (AFM5) desde sistemas fluviales cercanos a la costa que no se encuentran aflorando en el área de estudio. En particular durante los períodos de mayor descarga fluvial se construían barras gravosas de desembocadura (AFM6).

El material arenoso en condiciones de buen tiempo y tormenta era transportado a lo largo de este sistema por olas y corrientes costeras. No obstante, se registraban períodos con bajo aporte de sedimentos al sistema donde se asentaban arrecifes en parche discretos en el shoreface superior a inferior (AFM2). En este contexto, cuando el suministro de material se restablecía la producción carbonática era 
interrumpida y se construían litosomas y barras arenosas desde el foreshore al shoreface inferior.

Al igual que en el tramo I, en el tramo II las descargas fluviales alimentaban al foreshore-shoreface superior (AFM5) con material arenoso. Junto con este material la grava era transportada durante períodos de mayor descarga fluvial dando lugar a la construcción de barras de desembocadura (AFM6) en el foreshore-shoreface superior y litosomas conglomerádicos en el shoreface superior (AFM3). Con menor frecuencia la grava llegaría durante estos episodios hasta el shoreface inferior proximal (AFM1; véase capítulo 6 , apartado 6.3.1). Dicho material arenoso y psefítico acumulado durante condiciones de buen tiempo era llevado por olas y corrientes costeras a lo largo de este sistema, y en particular durante las tormentas grandes volúmenes eran removidos y transportados. En estos episodios las corrientes longitudinales y de retorno inducidas por olas de tormenta construían barras gravo-arenosas en el shoreface superior (AFM4) y concentrados de material intracuencal (intraclastos, peloides) con grava subordinada en el shoreface inferior (AFM1, véase capítulo 6 apartado 6.3.1). Cabe señalar, que tanto en este tramo como en los anteriores los restos esqueletales eran transportados por las olas junto con el material arenoso desde el foreshore-shoreface superior (AFM5, véase apartado 8.3.1 este capítulo) y desde los arrecifes en parche (AFM2) durante condiciones de buen tiempo y tormenta. En particular en el shoreface inferior (AFM1) del noreste y centro (ACS) de Malargüe, con este material eran llevados en suspensión restos vegetales desde sistemas fluviales cercanos a la costa.

Eventualmente por encima de este sector se construían barras gravosas de foreshore-shoreface superior (AFM6) acompañadas por el material intracuencal carbonático y arenoso erosionado por estas corrientes desde los tramos subyacentes (tramo II', véase apartado 8.3.1). 


\subsection{2-I: Consideraciones sobre la dinámica del sistema}

De lo expuesto se concluye que en este sistema dominaban las olas y las tormentas con una influencia mayor de estos procesos hacia el tramo II del mismo. Dichas corrientes redistribuían a lo largo de este ambiente el material extracuencal que llegaba de los sistemas fluviales ubicados hacia el sud-sudeste (ver apartado 8.3.1I), e intracuencal desde las zonas de producción carbonática, correspondientes a los arrecifes en parche y la biota que habitaba en este ambiente. En particular el material extracuencal está representado por líticos volcánicos ácidos a intermedios, feldespatos (plagioclasa>feldespato potásico) y cuarzo (monocristalino>>policristalino) según la composición de las areniscas y psefitas que conforman este sistema (véase capítulo 5, apartados 5.2.2-I y 5.3.2-I). De acuerdo a la procedencia de las areniscas, este material deriva de un arco magmático de composición ácida a intermedia, disectado a transicional, anterior a la acumulación del sistema marino clástico (véase capítulo 5, apartado 5.2.2-III). En este contexto, se sugiere que dichos sistemas fluviales retrabajan vulcanitas ácidas a intermedias que podrían corresponderse con el Grupo Choiyoy y/o el Ciclo Precuyano que afloran hacia el sud-sudeste del área de Malargüe (zona del Arroyo Loncoche, margen norte del río Malargüe; Zona de Bardas Blancas al norte del río Grande, cf. Hojas Geológicas del SEGEMAR 1:250.000 y 1:200.000; Gulisano y Gutiérrez Pleimling, 1994; Arcila Gallego, 2010).

\subsection{3: Consideraciones finales}

Como resultado del análisis de facies realizado, la sucesión terrígena-mixta se interpreta como un sistema marino somero dominado por olas y tormentas con influencia fluvial o de fan deltas cercanos a la costa, que no se acumularon o no se encuentran preservados en el área de estudio. Durante las mayores descargas de estos sistemas se formaban espesos litosomas de conglomerados cercanos a la costa, mientras que durante los períodos de menor descarga se construían litosomas arenosos. Dichos sistemas no solo aportaron grandes cantidades de arena 
y grava a este medio, si no también controlaron la colonización de la fauna bentónica. En este sentido, las variaciones de salinidad del agua de mar, el aumento de su turbidez y del contenido de nutrientes y terrígenos habrían inhibido el desarrollo de arrecifes en parche y disminuido la colonización de bivalvos y calgas rojas? en este medio marino, especialmente durante los períodos de mayor descarga fluvial. De esta forma, los arrecifes en parche colonizaban el shoreface inferior a superior en estadios intermedios de este sistema, solo durante períodos de baja descarga fluvial, aguas claras, oligotróficas y de salinidad normal, encontrándose ausentes hacia el tramo superior donde no se registran dichas condiciones.

Dentro de este sistema, las variaciones del nivel relativo del mar y los efectos de una tectónica local en el noreste de Malargüe habrían controlado el pasaje entre sus diferentes estadios. En este sentido, se sugiere una superficie transgresiva como límite entre su tramo medio y superior (sectores I y II, respectivamente), y un episodio de caída del nivel relativo del mar hacia el tope del sistema (sectores II y II'). En este último caso, la tectónica local habría generado un relieve irregular con la exposición y destrucción parcial de los subambientes depositados previamente, acompañado por la somerización abrupta de los subambientes de acumulación. Dada la falta de información previa respecto a la tectónica local que afectó a este sistema en la zona de Malargüe, se requeriría un estudio estructural detallado acompañado por el análisis secuencial de esta sucesión terrígena-mixta para aceptar o descartar la hipótesis planteada. No obstante, tales estudios escapan a los objetivos de esta tesis. 


\section{4: Paleoambiente de sedimentación del intervalo estratigráfico en estudio}

Durante el intervalo Bathoniano a Calloviano temprano la sucesión sedimentaria analizada se deposita en una cuenca de retroarco-trasarco con subsidencia termal lenta, combinada por fenómenos localizados de inversión tectónica (Spalletti et al., 2012). En primera instancia, durante un período de regresión general del mar en la Cuenca Neuquina (véase capítulo 3, apartado 3.4.2) se acumula en la zona de Malargüe un sistema marino clástico con influencia fluvial o de fan delta ubicado hacia el sud-sudeste de esta zona, fuera del área de estudio. Durante su evolución, las descargas del sistema fluvial/deltaico en la costa y su desplazamiento en el tiempo desde el sudoeste hacia el noreste, aportan grandes volúmenes de material a este medio marino. No obstante, se registran períodos de bajo suministro clástico en sus estadios intermedios donde los arrecifes en parche colonizaban este sistema. Asimismo, estructuraciones locales en el noreste y centro de Malargüe habrían modificado la acumulación de los últimos estadios de este sistema, a través de la caída del nivel relativo del mar junto con la exposición y destrucción parcial de los subambientes depositados previamente. Se destaca que este sistema marino clástico tal como fue descripto no está preservado o no se depositó en el área de Bardas Blancas.

De forma posterior, durante el Calloviano temprano la tendencia decreciente del espacio de acomodación se revierte momentáneamente en el noroeste de la Cuenca Neuquina durante un episodio de inundación (véase capítulo 3, apartado 3.4.2) que da lugar a la acumulación de la rampa carbonática homoclinal en este medio marino. Hacia la zona de Malargüe, el subambiente de rampa media cubre al shoreface inferior a foreshore del sistema marino clástico subyacente, mientras que en el área de Bardas Blancas se apoya sobre el sistema marino profundo correspondiente a la Formación Tres Esquinas (figuras 8.1b, 8.5). En ambas situaciones, la relación vertical entre estos sistemas de acumulación refleja la profundización relativa del paleoambiente de sedimentación, acompañado por un aumento de la producción carbonática y la disminución del suministro clástico al medio marino. 
Conforme con el avance del mar y el desarrollo de la rampa carbonática en este medio, en la zona de Malargüe se produce la migración del sistema marino clástico y del medio fluvial/deltaico que lo alimenta hacia sectores proximales, fuera del área de estudio. En este contexto, la tasa de sedimentación disminuye de forma gradual en el medio marino, es decir que el sedimento se deposita de preferencia en la rampa interna y hacia la rampa media llega poco material dando lugar a la formación de un sustrato endurecido y a la colonización de los arrecifes en parche en el centro y sudoeste de Malargüe (ver apartado 8.2.1). Este hiato depositacional, sin evidencias de exposición subaérea, registraría un período de máxima inundación del medio marino hacia el continente. El mismo no se habría desarrollado o preservado hacia el noreste de esta zona.

Luego de este período, se registra la progradación del subambiente de rampa interna en toda el área de estudio incluyendo la zona de Bardas Blancas, donde no se reconoce un hiato depositacional ni tampoco el desarrollo de bioconstrucciones en la rampa media. A partir de esta instancia la producción carbonática es continua en este medio marino, no obstante el restablecimiento del sistema marino clástico en el noreste de Malargüe genera la destrucción mecánica parcial y erosión de los subambientes de rampa media e interna (ver apartado 8.2.1-I). Cuando el aporte clástico cesa hacia este medio, nuevamente se restablece la rampa carbonática.

Temporalmente este ambiente evolucionó hacia condiciones de desecación casi total que se registran en el noroeste de la Cuenca Neuquina, donde se acumulan las evaporitas de la Formación Tábanos de forma neta sobre la rampa carbonática. Se sugiere que este período de exposición del sistema carbonático estaría vinculado con la etapa de diagénesis meteórica planteada en el capítulo 7, apartado 7.5, posterior a la depositación de esta sucesión (eogénesis temprana a tardía). En este sentido en primer instancia y de forma local sería afectada por un evento meteórico vadoso, seguido por un período generalizado de diagénesis freática donde se produce la mezcla de aguas porales marinas y meteóricas.

De lo expuesto se concluye que las variaciones relativas del nivel del mar, junto con los efectos de estructuraciones locales habrían controlado la sedimentación en este medio marino. En este sentido, se reconocen dos eventos de estructuración local en 
el noreste del área de Malargüe. El primer episodio se registra hacia el tope del sistema marino clástico, de forma previa a la ingresión marina que da lugar a la depositación de la rampa carbonática. Por su parte, un segundo evento habría afectado a este sistema, como sugiere la destrucción mecánica parcial de los subambientes de rampa media e interna, acompañado por el pasaje abrupto con el sistema marino clástico.

Dado que no se cuenta con información de fracturas ni fallas relacionadas con estos episodios, ni tampoco con datos previos de estructuraciones locales para este intervalo estratigráfico dentro de la zona de trabajo y alrededores, se proponen estudios futuros focalizados en el análisis estructural del intervalo estratigráfico, integrados con un análisis secuencial detallado. Si bien este tipo de estudios permitirían aceptar o descartar la hipótesis planteada, dicho análisis escapa a los objetivos de esta tesis.

\section{5: Definición de la base de la Formación Calabozo}

Dentro del intervalo Bathoniano-Calloviano fueron identificados dos sistemas depositacionales contrastantes por sus características litológicas y ambientales. La Formación Calabozo fue reconocida por varios autores (Palma et al., 2000a, 2005, 2007a; Cabaleri et al., 2001, 2003; Valencio et al., 2003; Armella et al., 2005a, 2005b, 2013; Cagnoni et al., 2006) como un sistema predominantemente carbonático de rampa carbonática homoclinal con tendencia regresiva (véase capítulo 3, apartado 3.5.7). En la zona de Malargüe esta unidad se inicia con una delgada capa de conglomerados poligénicos o rudstones arenosos asociados a fenómenos de incisión y redepositación de la Formación Lajas subyacente, cubiertos de forma abrupta por niveles de calizas (véase capítulo 3, apartado 3.5.3-I y figura 8.7a). En esta zona la Formación Lajas está conformada por areniscas clásticas y calcáreas, conglomerados y pelitas subordinadas de ambiente marino a marino marginal (delta a estuario) (Gulisano y Gutiérrez Pleimling, 1994; Legarreta et al., 1993). 
Por su parte, hacia la zona de Bardas Blancas la Formación Calabozo, de composición netamente carbonática, yace mediante un contacto erosivo sobre las facies arenosas marinas de la Formación Bardas Blancas o bien sobre las lutitas marino profundas de la Formación Tres Esquinas o de las areniscas de ambiente marino marginal de la Formación Lajas (Cabaleri et al., 2001, 2003; Nullo et al., 2005; Armella et al., 2013)(figura 8.7b). En este último caso, Cabaleri et al. (2001) sugieren un contacto erosivo con evidencias de re sedimentación, mientras que Armella et al. (2005a) indican el pasaje gradual con la Formación Lajas (véase capítulo 3, apartado 3.5.3-I). En ambas zonas de estudio Gulisano y Gutiérrez Pleimling (1994) indican que el contacto basal entre las formaciones Lajas y Calabozo se corresponde con un límite de secuencia (véase capítulo 3, apartado 3.5.3-I).

Sin embargo, a partir de este estudio se reconoció dentro del intervalo estratigráfico analizado un sistema de rampa carbonática homoclinal netamente carbonático, que a través de un cambio marcado en las condiciones ambientales, cubre a un sistema marino terrígeno-mixto en el área de Malargüe, y se apoya sobre la Formación Tres Esquinas en la zona de Bardas Blancas (véase apartado 8.4). Dentro de este contexto, en la zona de Malargüe el contacto entre ambos sistemas resultaría neto en el centro y sudoeste, no obstante entre dichos sistemas media un período de erosión o no depositación (véase apartado 8.3.1-I). Por su parte, hacia el noreste de Malargüe la interacción entre dichos sistemas (véase apartado 8.4) sugiere un contacto transicional entre el sistema clástico y el carbonático. A diferencia de lo planteado por otros autores, en este trabajo se excluye del sistema de rampa a los niveles clásticos de su base, identificados en este estudio como correspondientes al tope del sistema marino clástico por una mayor afinidad con este sistema. Se distribuyen solo en el noreste y centro de Malargüe y son similares en cuanto a su composición, características de facies y ambientales a los que se presentan a lo largo del sistema terrígeno-mixto en el subambiente de foreshore-shoreface superior. De esta forma, el contacto erosivo y con evidencias de resedimentación propuesto entre la rampa carbonática y el sistema marino marginal, relacionado con un límite de secuencia por Gulisano y Gutiérrez Pleimling (1994), se corresponde en este trabajo con la somerización 
abrupta de los subambientes de acumulación ocurrida hacia el tope del sistema clástico (véase apartado 8.4).

Por otro lado hacia la zona de Bardas Blancas, la rampa carbonática se apoya de forma neta sobre las sedimentitas marino profundas de la Formación Tres Esquinas, dado que el sistema marino terrígeno-mixto no está preservado o no se acumuló en este sector (véase apartado 8.4), ni tampoco se reconoció el sistema marino marginal arenoso descripto por Cabaleri et al. (2001) y Armella et al. (2005a). En contraste con lo descripto por otros autores, el contacto entre la rampa carbonática y la Formación Tres Esquinas no es erosivo, ni presenta evidencias de resedimentación de la unidad subyacente. Por lo tanto, a diferencia de lo planteado por Gulisano y Gutiérrez Pleimling (1994), este contacto no se considera como un límite de secuencia.

De esta manera, a partir del análisis paleoambiental realizado en este trabajo, se propone denominar como Formación Calabozo al sistema de rampa carbonática homoclinal, netamente carbonático, que se apoya a través de un contacto neto a transicional en el sudoeste-centro y noreste de Malargüe, respectivamente, sobre el sistema marino terrígeno-mixto propuesto para este sector como Formación Lajas. Asimismo, dentro de esta unidad se incluyen los depósitos de conglomerados poligénicos o rudstones arenosos previamente identificados como la base de la Formación Calabozo (figura 8.7a). Por su parte, hacia la zona de Bardas Blancas dado que la Formación Lajas tal como fue definida en esta tesis no se encuentra preservada o no fue acumulada en este sector, la Formación Calabozo se apoya sobre la Formación Tres Esquinas mediante un contacto neto (figura 8.7b). 


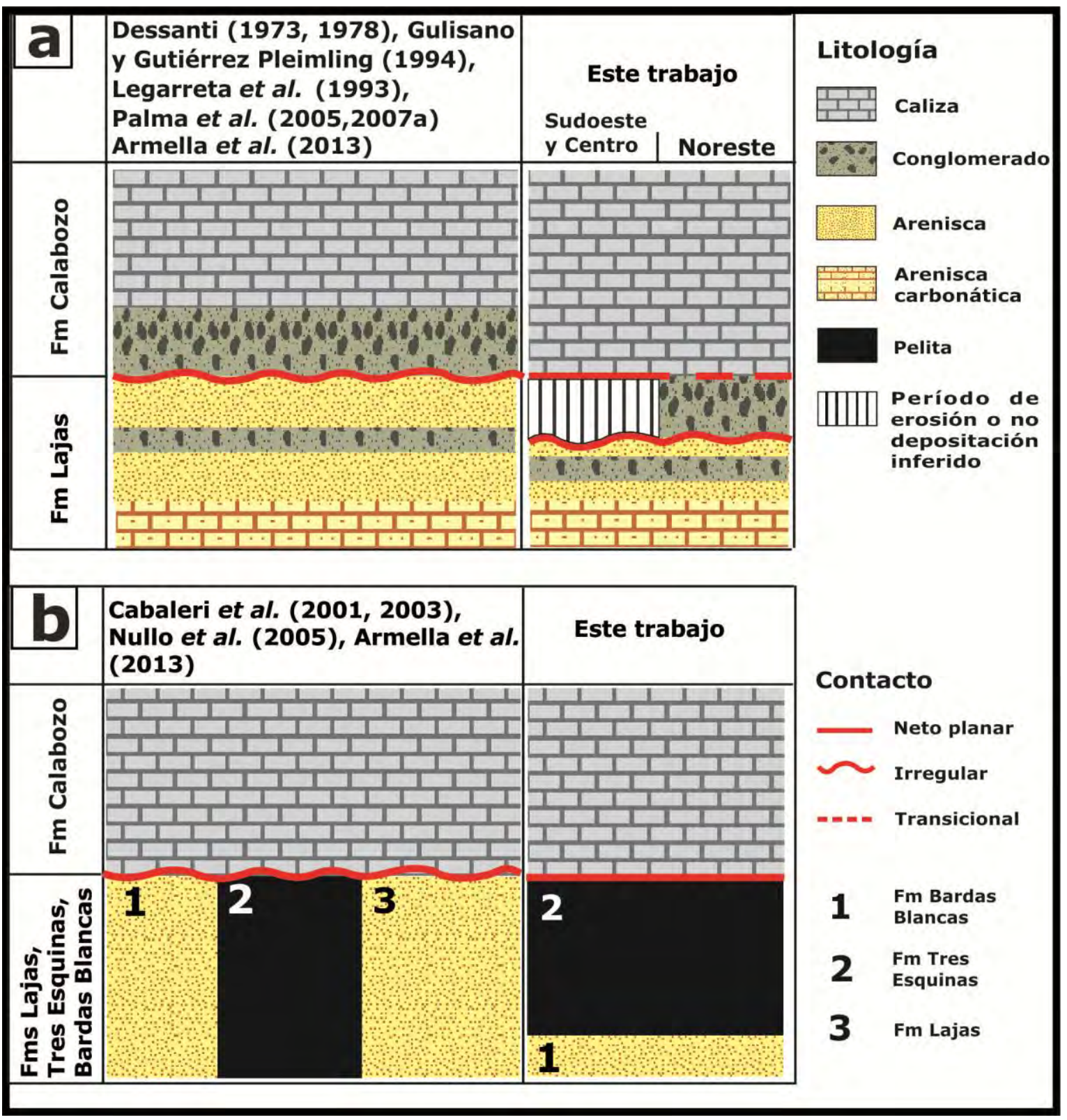

Figura 8.7: Relaciones estratigráficas de la Formación Calabozo con las unidades subyacentes en el área de Malargüe (a) y de Bardas Blancas (b). 


\section{CONCLUSIONES}

A partir de los objetivos y la hipótesis inicial planteada, en este trabajo de tesis doctoral se analizó el intervalo estratigráfico que abarca a las formaciones Calabozo y Lajas en el sudoeste de la provincia de Mendoza (localidades de Malargüe y Bardas Blancas). Acorde con el análisis bibliográfico realizado dicho intervalo estratigráfico se dividió en una sucesión inferior terrígena-mixta que abarca a la Formación Lajas y los depósitos clásticos basales de la Formación Calabozo, cubierta por una sucesión carbonática que incluye a las calizas de la Formación Calabozo. A continuación se enumeran los resultados más sobresalientes de este estudio:

1. Las sucesiones carbonática y terrígena-mixta del Jurásico medio a superior analizadas muestran una distribución dispar e importantes cambios de espesor dentro del área de estudio (zona de Malargüe y Bardas Blancas), los cuales fueron reconocidos mediante la construcción de mapas de detalle y el relevamiento de once perfiles sedimentológicos. La sucesión terrígenamixta fue identificada solo en el área de Malargüe, con una marcada disminución de su potencia desde el sudeste hacia el noreste de esta zona (34 a 4 metros, respectivamente), mientras que la sucesión carbonática se reconoció en ambos sectores. Su mayor potencia se registró en el centro de la zona de Malargüe (14 a 18 metros), con un claro detrimento de su espesor hacia el nor-noreste y sudeste-sudoeste de esta área y hacia la zona de Bardas Blancas (3 a 6 metros).

2. Litológicamente, en la sucesión carbonática dominan los packstone, grainstone y floatstone, junto con subordinadas areniscas ubicadas en su tramo inferior a medio. Por otro lado, su contraparte terrígena-mixta está compuesta de areniscas, subordinadas psefitas y escasos floatstone, packstone y framestone.

3. En primera instancia, a partir del análisis composicional se pudo observar que las calizas de ambas unidades resultaron en su mayoría no 
esqueletales. Sus modas detríticas, menores al 15\% del total, se componen de manera principal por fragmentos líticos volcánicos de composiciones ácidas a intermedias y plagioclasas, ambos parcialmente alterados. En particular se distinguió que:

a. Dentro de la sucesión carbonática los peloides y ooides tipo 1 superficiales dominan en el tramo inferior a medio, mientras que los ooides tipo 1 normales y oncoides abundan hacia el sector medio a superior, acompañado por intraclastos carbonáticos, pellets y agregado de partículas. En este contexto, los bivalvos, gasterópodos, equinodermos y braquiópodos resultaron los bioclastos dominantes de la sucesión, siendo los corales característicos del tramo inferior a medio, y las cianobacterias y foraminíferos del sector medio a superior. Por su parte, los terrígenos solo se presentan en el sector inferior a medio de la sucesión.

b. En las calizas de la sucesión terrígena-mixta dominan los peloides y los intraclastos carbonáticos hacia el tramo superior. De forma subordinada se presentan bivalvos, serpúlidos, corales, equinodermos y terrígenos, siendo las ¿algas rojas? características del tramo medio.

c. La matriz de estas sedimentitas carbonáticas, presente en escasa a abundante proporción, está compuesta por micrita homogénea a grumosa. Dentro de los cementos, en escaso a abundante contenido, dominan las variedades carbonáticas micro a macroesparíticas granulares, drusiformes y sintaxial, junto con subordinados precipitados fibrosos isopáquicos y asimétricos. Solo en el tramo inferior a medio de la sucesión carbonática se reconocieron escasos precipitados silíceos y de feldespato autigénico.

4. Luego, mediante el análisis composicional de las areniscas se distinguieron variedades terrígenas en la sucesión carbonática, y terrígenas y mixtas (granos intracuencales > al 15\% del total) en la sucesión terrígena-mixta. En particular se observó que:

a. Las modas detríticas de ambas psamitas se componen de manera principal por fragmentos líticos volcánicos de composiciones ácidas a intermedias y aspecto paleovolcánico, plagioclasas y subordinado cuarzo monocristalino. 
Se destaca que los líticos volcánicos y plagioclasas se encuentran parcialmente alterados. Por su parte, los componentes intracuencales principales comprenden bivalvos, ¿algas rojas? y peloides, con subordinados equinodermos, intraclastos carbonáticos y ooides.

b. En general la matriz representa menos del 15\% del total. Dentro de los cementos, en baja a moderada proporción, dominaron las variedades carbonáticas de micro a macroesparita granular, drusiforme y sintaxial, en menor medida los precipitados de feldespato autigénico.

c. De acuerdo con el contenido de cuarzo, feldespato y líticos (QFL) dichas areniscas terrígenas y mixtas fueron clasificadas en su mayoría como litoarenitas feldespáticas $\left(\mathrm{Q}_{17-30 \%} ; \mathrm{F}_{26-40 \%} ; \mathrm{L}_{38-52 \%}\right)$ y en menor medida como feldearenitas líticas $\left(\mathrm{Q}_{15-34 \%} ; \mathrm{F}_{35-60 \%} ; \mathrm{L}_{20-35 \%}\right)$. Se destaca que en la sucesión terrígena-mixta las feldearenitas líticas se distribuyeron en el tramo inferior a superior y las litoarenitas feldespáticas hacia el sector medio a superior. Estas últimas también se ubicaron en el tramo inferior a medio de la sucesión carbonática.

d. La principal área de aporte del material extracuencal para las areniscas de la sucesión terrígena-mixta habría sido un arco magmático ácido a intermedio, anterior a la sedimentación de esta sucesión. El mismo habría evolucionado desde un arco transicional (tramo inferior a medio) a un arco disectado (sector medio a superior).

5. De forma posterior, a partir del análisis mineralógico y del contenido de argilominerales de las sucesiones analizadas, se pudo interpreta que:

a. En las calizas de la sucesión carbonática domina la calcita con valores mayores al 50\% del total. Sólo de forma localizada, el cuarzo resulta abundante (25-50\% del total) en las calizas del tramo inferior a medio, atribuido de forma principal a su contenido de líticos volcánicos. En este tramo, además se reconocieron escasas plagioclasas ( $<15 \%$ del total).

b. Por su parte, en las arenitas de la sucesión terrígena-mixta dominan la calcita y el cuarzo, cuya suma siempre supera el 75\% del total, junto con subordinadas plagioclasas (25-5\% del total). Estas proporciones anómalas 
de calcita y cuarzo reflejarían el contenido de componentes intracuencales, cemento carbonático, líticos volcánicos y cuarzo de dichas psamitas.

c. En ambas sucesiones los argilominerales resultaron escasos $(<5 \%$ del total), no obstante, se definieron según las variedades dominantes tres (3) argilofacies (A1, A2, A3), la primera de ellas dividida en las subargilofacies S1, S2 y S3. La argilofacies A1 predomina en ambas sucesiones, con illita (I) dominante respecto a interestratificados illitaesmectita (I/S), caolinita (K) o esmectita (S), mientras que las argilofacies $\mathrm{A} 2(\mathrm{I}=\mathrm{I} / \mathrm{S})$ y $\mathrm{A} 3(\mathrm{I}<\mathrm{I} / \mathrm{S})$ resultan raras en el tramo inferior a medio de la sucesión carbonática. Se pudo apreciar que las subargilofacies S1 (I>I/S) y S3 (I>S), con contenidos de illita del 85-50\%, se relacionan con la sucesión terrígena-mixta y el tramo inferior a medio de la sucesión carbonática. Por otro lado, S2 (I>K) con menores contenidos de illita (40\%) y valores significativos de caolinita (28\%), se asocia al tramo medio a superior de esta sucesión.

d. Según la distribución de las argilofacies y su relación con el contenido de terrígenos en las arenitas y calizas analizadas, se propone un origen diagenético para la illita y el interestratificado illita/esmectita como producto de alteración de líticos volcánicos y plagioclasas durante la eogénesis temprana a mesogénesis. Este supuesto estaría avalado por el grado de alteración de los terrígenos mencionados y la disminución del contenido de illita hacia el tope de la sucesión carbonática, sector con ausencia de detritos.

6. Considerando el estudio composicional realizado, en el intervalo estratigráfico analizado se definieron veintisiete litofacies y seis subfacies, dieciséis facies carbonáticas y once clásticas. Las litofacies carbonáticas incluyen facies de floatstone (F), grainstone (GR), packstone (P), wackestone (W) y boundstone (Bl, FRc), mientras que las facies clásticas agrupan a conglomerados (G), areniscas terrígenas y mixtas finas a gruesas (S) y areno-gravosas (SG). Dentro del intervalo estratigráfico estudiado se observó que: 
a. Las facies de packstone peloidal caracterizaron al sector inferior a medio de la sucesión carbonática. De forma localizada, las litofacies de framestone coralígeno y floatstone intraclástico se reconocieron en la zona de Malargüe y las facies de packstone a wackestone bioclásticos y psamitas masivas o laminadas se identificaron en Bardas Blancas.

b. Los grainstone oolíticos y packstone peloidales-bioclásticos-intraclásticos resultaron dominantes en el tramo medio a superior de la sucesión carbonática, siendo frecuentes las facies de wackestone con pellets y estromatolitos laminares hacia el tope. Solo en la zona de Malargüe se reconocieron floatstone oncolíticos y algales en este sector.

c. Las litofacies de conglomerados masivos junto con subordinadas facies de areniscas estratificadas y masivas dominaron en el tramo inferior de la sucesión terrígena-mixta. Hacia el sector medio esta situación se invierte hasta llegar al tramo superior con un contenido similar en ambas facies. De forma localizada se distinguieron floatstone bioclástico y framestone coralígeno en el tramo medio y facies de floatstone intraclástico hacia el sector superior (noreste de Malargüe).

d. Cabe destacar que las facies de psefitas en general resultaron matriz soportada, subordinadas clasto soportadas, con matriz arenosa. Sus modas detríticas se componen de manera principal por fragmentos líticos volcánicos ácidos, cuarzo y feldespato, junto con subordinados restos esqueletales. Según su composición y contenido de matriz se clasificaron como matriz ortoconglomerados y clasto ortoconglomerados polimícticos.

7. Luego de definir las litofacies dentro del intervalo estratigráfico de interés se procedió al agrupamiento de las facies individuales en doce asociaciones de facies marinas someras. Dentro de este grupo se diferenciaron por un lado asociaciones de facies de sistema carbonático (AFC), y por otro lado aquellas atribuidas a un sistema clástico (AFM).

a. Las AFC permitieron inferir que el sector inferior a medio de la sucesión carbonática comprendió una rampa media ubicada costa afuera de un shoal externo discontinuo (foreshoal), y el tramo medio a superior una 
rampa interna. En este subambiente, el shoal externo permitió la conexión frecuente entre la rampa media y el intershoal, sector con acción intermitente de olas, menos común resultó su vínculo con la albúfera caracterizada por condiciones de sedimentación tranquila. Por detrás de ambos se estableció un shoal interno cuya amplia distribución generó un medio protegido de llanura de marea por detrás, donde alternan períodos de emersión e inundación.

b. En particular en la rampa media proximal de Malargüe (centro y sudoeste), se desarrollaron arrecifes en parche sobre un firmground que registró un período de no depositación o baja tasa de sedimentación, sin evidencias de exposición subaérea. Hacia el noreste, este sector resultó incidido por barras de desembocadura (AFM), mientras que hacia el tramo distal, cambios locales de la pendiente de la rampa se habrían registrado.

c. Las AFM sugieren que el tramo inferior de la sucesión terrígena-mixta, ubicado solo en el sudoeste de Malargüe, abarcaron los subambientes de foreshore-shoreface superior, mientras que los sectores medio y superior comprendieron desde el foreshore al shoreface inferior.

8. Sobre la base de las asociaciones de facies de sistema carbonático (AFC) definidas, se reconocieron y caracterizaron los procesos diagenéticos de micritización, cementación, neomorfismo, reemplazo, disolución y compactación, considerando el ambiente y el estadio diagenético en el cual tuvieron lugar. A partir de esto, se delineó la evolución diagenética de la sucesión carbonática. De este análisis se desprende que:

a. De forma inmediatamente posterior a su depositación en el medio marino (eogénesis temprana), las AFC fueron micritizadas, con una mayor intensidad hacia la albúfera e intershoal (rampa interna). Simultáneamente o a continuación, precipitó cemento marino en baja proporción en los sectores con constante a intermitente acción de olas (shoal, intershoal y foreshoal de Malargüe). En particular, en el foreshoal de Malargüe (centro y sudoeste) este precipitado habría dado lugar a la formación de un firmground. Por otro lado, en la llanura de marea, la 
mezcla de aguas porales marinas y meteóricas en esta etapa habría dado lugar al neomorfismo agradante (zona de Malargüe) y a la dolomitización (zona de Bardas Blancas), asociada con el reemplazo por evaporitas. Dichos procesos se habrían prolongado hasta la eogénesis tardía, y en el caso del neomorfismo agradante también ocurriría en la albúfera en este período.

b. Luego de la diagénesis marina de las AFC y de una leve compactación mecánica (eogénesis temprana), las mismas fueron afectadas de forma local por un evento meteórico vadoso, seguido por un período generalizado de diagénesis freática de mezcla de aguas porales marinas y meteóricas (eogénesis temprana a tardía). Estas condiciones se prolongarían hasta un soterramiento muy somero de las AFC (eogénesis tardía), donde de forma posterior se registrarían cambios locales en el pH del medio (eogénesis tardía a mesogénesis temprana). Por último (mesogénesis temprana a moderada), dichas sedimentitas serían soterradas y afectadas por una moderada compactación química.

c. Como resultado de la evolución diagenética planteada, las AFC quedaron totalmente cementadas, con ausencia de porosidad y en general sin relictos de las texturas originales de sus componentes aragoníticos. En este sentido, dichas sedimentitas se encontraban cementadas antes de su soterramiento, lo que inhibe los efectos de la compactación mecánica durante la mesogénesis. No obstante, dado que este análisis se realizó sólo sobre muestras de afloramiento, no se descarta que en subsuelo el comportamiento de las AFC haya resultado diferente ante los efectos de la compactación mecánica.

9. Luego, se establecieron los sistemas de acumulación carbonático y clástico a partir de las relaciones espaciales de los subambientes definidos y los principales aspectos diagenéticos de los subambientes carbonáticos. De esta manera, se interpretó:

a. Un sistema carbonático de rampa peloidal homoclinal, con bioconstrucciones discretas y cambios locales de su paleopendiente en la rampa media proximal y distal, respectivamente, de la zona de 
Malargüe. En el sector proximal, caracterizado por aguas claras, oligotróficas, de salinidad normal y bajo contenido de terrígenos, los arrecifes en parche se habrían asentado durante un hiato depositacional. La falta de este evento hacia el área de Bardas Blancas, junto con los cambios en la salinidad y turbidez de sus aguas habrían impedido la colonización de dichos arrecifes en este subambiente.

Por otro lado, hacia la rampa interna el desarrollo de la fauna bentónica estaría condicionado por la distribución y continuidad de los shoals en este subambiente, la turbidez de sus aguas y el contenido de terrígenos. Las algas y cianobacterias proliferaron en la albúfera y llanura de marea, sectores protegidos, de aguas claras y sin detritos, encontrándose ausentes hacia el intershoal donde no se propician dichas condiciones. Por su parte, los estromatolitos se desarrollaron en la llanura de marea, sector protegido y con una mayor salinidad de sus aguas.

En este sistema habrían dominado las olas con una influencia menor y localizada de las mareas (rampa interna). Las tormentas habrían controlado el transporte y re depositación del material intracuencal, en especial desde la rampa interna a media. En particular, la rampa media habría recibido un bajo aporte de material extracuencal desde el sistema clástico subyacente, en el noreste de Malargüe, y de un área fuente no identificada en Bardas Blancas, el cual sería transportado hasta el intershoal en la rampa interna.

b. Un sistema clástico correspondiente a un ambiente marino somero dominado por las olas y las tormentas, con influencia fluvial o de fan deltas cercanos a la costa que no se acumularon o preservaron en el área de estudio. Durante las mayores descargas de estos sistemas se formaron espesos litosomas de conglomerados cercanos a la costa, mientras que en los períodos de menor descarga se construían litosomas arenosos. Las áreas fuente de estos depósitos se constituían de vulcanitas ácidas a intermedias, posiblemente del Grupo Choiyoi y/o el del Ciclo Precuyano, aflorantes en el sud-sudeste de Malargüe y en Bardas Blancas. 
Esta influencia fluvial o deltaica habría inhibido el desarrollo de arrecifes en parche y disminuido la colonización de bivalvos y ¿algas rojas? en el medio marino, mediante las variaciones de salinidad del agua de mar, el aumento de su turbidez y del contenido de nutrientes y terrígenos, especialmente en los períodos de mayores descargas. De esta manera, las bioconstrucciones de corales colonizaron el shoreface inferior a superior en estadios intermedios de este sistema, durante períodos de baja descarga fluvial, de aguas claras, oligotróficas y de salinidad normal, encontrándose ausentes hacia el tramo superior donde no se registraron dichas condiciones.

Dentro de este sistema, las variaciones del nivel relativo del mar y los efectos de una tectónica local en el noreste de Malargüe habrían controlado el pasaje entre sus diferentes estadios. En este sentido, se sugiere una superficie transgresiva como límite entre su tramo medio y superior, y un episodio de caída del nivel relativo del mar hacia el tope del sistema.

10.Por último, a partir de las relaciones espaciales de los sistemas de acumulación definidos se caracterizó al paleoambiente de sedimentación, junto con los controles que tuvieron lugar durante su depositación:

a. Durante el intervalo Bathoniano a Calloviano temprano la sucesión sedimentaria analizada se depositaba en una cuenca de retroarcotrasarco con subsidencia termal lenta, combinada por fenómenos localizados de inversión tectónica. En primera instancia, durante un período de regresión general del mar en la Cuenca Neuquina se acumulaba en la zona de Malargüe un sistema marino clástico con influencia fluvial o de fan delta ubicado hacia el sud-sudeste de esta zona, fuera del área de estudio. Durante su evolución, las descargas del sistema fluvial/deltaico en la costa y su desplazamiento en el tiempo desde el sudoeste hacia el noreste, aportaron grandes volúmenes de material a este medio marino. No obstante, se registraron períodos de bajo suministro clástico donde los arrecifes en 
parche colonizaban este sistema. Asimismo, estructuraciones locales en el noreste y centro de Malargüe habrían modificado la acumulación de los últimos estadios de este sistema, mediante la caída del nivel relativo del mar junto con la exposición y destrucción parcial de los subambientes depositados previamente. Se destaca que este sistema marino clástico tal como fue descripto no está preservado o no se depositó en el área de Bardas Blancas.

b. De forma posterior, en el Calloviano temprano la tendencia decreciente del espacio de acomodación se revirtió en el noroeste de la Cuenca Neuquina durante un episodio de inundación donde se acumuló la rampa carbonática homoclinal. Hacia la zona de Malargüe, el subambiente de rampa media cubre al shoreface inferior a foreshore del sistema marino clástico subyacente, mientras que en el área de Bardas Blancas se apoya sobre el sistema marino profundo correspondiente a la Formación Tres Esquinas. En ambas situaciones, la relación vertical entre estos sistemas de acumulación reflejaba la profundización relativa del paleoambiente de sedimentación, acompañado por un aumento de la producción carbonática y la disminución del suministro clástico al medio marino.

c. Conforme con el avance del mar y el desarrollo de la rampa carbonática en este medio, en la zona de Malargüe se produjo la migración del sistema marino clástico y del medio fluvial/deltaico que lo alimenta a sectores proximales, fuera del área de estudio. En este contexto, la tasa de sedimentación disminuyó de forma gradual en el medio marino dando lugar a la formación de un sustrato endurecido y a la colonización de los arrecifes en parche en el centro y sudoeste de Malargüe. Este hiato depositacional, sin evidencias de exposición subaérea, registraría un período de máxima inundación del medio marino hacia el continente. El mismo no se habría desarrollado o preservado en el noreste de esta zona.

d. Luego de este período, el subambiente de rampa interna progradó en toda el área de estudio incluyendo la zona de Bardas Blancas, donde 
no se reconoció un hiato depositacional ni tampoco el desarrollo de bioconstrucciones en la rampa media. A partir de esta instancia la producción carbonática resultó continua en este medio, no obstante el restablecimiento del sistema marino clástico en el noreste de Malargüe genera la destrucción mecánica parcial y erosión de los subambientes de rampa media e interna. Cuando el aporte clástico cesó, nuevamente se restableció la rampa carbonática.

e. Temporalmente este ambiente evolucionó hacia condiciones de desecación casi total que se registran en el noroeste de la Cuenca Neuquina, donde se acumularon las evaporitas de la Formación Tábanos de forma neta sobre la rampa carbonática. Se sugiere que este período de exposición del sistema carbonático estaría vinculado con la etapa de diagénesis meteórica (eogénesis temprana a tardía) posterior a la depositación de esta sucesión.

f. De lo expuesto, se concluye que las variaciones relativas del nivel del mar, junto con los efectos de estructuraciones locales habrían controlado la sedimentación en este medio marino. En este sentido, se reconocieron dos eventos de estructuración local en el noreste del área de Malargüe. El primer episodio se registró hacia el tope del sistema marino clástico, de forma previa a la ingresión marina que da lugar a la depositación de la rampa carbonática. Por su parte, un segundo evento habría afectado a este sistema, como sugiere la destrucción mecánica parcial de los subambientes de rampa media e interna, acompañado por el pasaje abrupto con el sistema marino clástico. Dado que no se cuenta con información de fracturas ni fallas relacionadas con estos episodios, ni tampoco con datos previos de estructuraciones locales para este intervalo estratigráfico dentro de la zona de Mendoza, se proponen estudios futuros focalizados en el análisis estructural del intervalo estratigráfico, integrados con un análisis secuencial detallado. Si bien este tipo de estudios permitirían aceptar o descartar la hipótesis planteada, dicho análisis escapa a los objetivos de esta tesis. 
11.De esta manera, a partir del análisis paleoambiental realizado en este trabajo, se propone denominar como Formación Calabozo al sistema de rampa carbonática homoclinal, netamente carbonático, que se apoya mediante un contacto neto a transicional en el sudoeste-centro y noreste de Malargüe, respectivamente, sobre el sistema marino terrígeno-mixto propuesto para este sector como Formación Lajas. Asimismo, dentro de esta unidad se incluyen los depósitos de conglomerados poligénicos 0 rudstones arenosos previamente identificados como la base de la Formación Calabozo. Por su parte, hacia la zona de Bardas Blancas dado que la Formación Lajas tal como se definió en esta tesis no se preservó o acumuló, la Formación Calabozo se apoya directamente sobre la Formación Tres Esquinas mediante un contacto neto. 


\section{REFERENCIAS}

Afşar, F., Duda, J.-P., Zeller, M., Verwer, K., Westphal, H., Eberli, G.P., 2014. First report of sponge rhaxes in the Picún Leufú Formation (Tithonian-Berriasian), Neuquen Basin, Argentina. Spongy, slimy, cosy \& more...Commemorative volume in celebration of the 60th birthday of Joachim Reitner. Göttingen Contributions to Geosciences 77, 49-56.

Ahr, W.M., 1973. The carbonate ramp: an alternative to the shelf model. Gulf Coast Association of Geological Societies Transactions 23, 221-225.

Aigner, T., Reineck, H.E., 1982. Proximality trends in modern storm sands from the Helgoland Bight (North Sea) and their implications for basin analysis. Senckenbergiana maritima 14, 183-215.

Al-qattan, M.A., 2014. Microfacies, Diagenesis , Stable Isotope Geochemistry, and Reservoir Characterization of the Late Permian Khuff-C Reservoir, Southern Ghawar Field, Saudi Arabia. University of Colorado Boulder.

Álvaro, J.J., Bauluz, B., 2008. Feldspar concentrations in lower Cambrian limestones of the Moroccan Atlas: Pyroclastic vs authigenic processes. Journal of African Earth Sciences 50, 79-87.

Amour, F., Mutti, M., Christ, N., Immenhauser, A., Agar, S.M., Benson, G.S., Tomás, S., Alway, R., Kabiri, L., 2012. Capturing and modelling metre-scale spatial facies heterogeneity in a Jurassic ramp setting (Central High Atlas, Morocco). Sedimentology 59, 1158-1189.

Amour, F., Mutti, M., Christ, N., Immenhauser, A., Benson, G.S., Agar, S.M., TomÁs, S., Kabiri, L., 2013. Outcrop analog for an oolitic carbonate ramp reservoir: A scale-dependent geologic modeling approach based on stratigraphic hierarchy. AAPG Bulletin 97, 845-871.

Arcila Gallego, P.A., 2010. Los depósitos sinorogénicos del sur de Mendoza y su

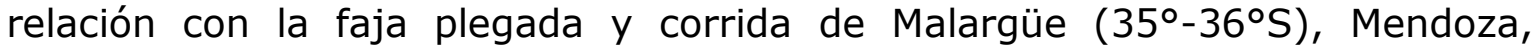
Argentina. Universidad de Buenos Aires.

Armella, C., Cabaleri, N. G., Cagnoni, M. C., Ramos, A. M., Valencio S. A., 2005a. Paleoambientes de la Formación Calabozo (Calloviano Inferior), en el río Potimalal, Mendoza, Argentina, en: $16^{\circ}$ Congreso Geológico Argentino. La Plata, pp. 117-124.

Armella, C., Cabaleri, N. G., Cagnoni, M. C., Ramos, A. M., Valencio S. A., Panarello, H.O. 2005b. Caracterización paleoambiental de la Formación Calabozo, Cuenca Neuquina, provincia de Mendoza, en: II Simposio Argentino del Jurásico. Buenos Aires, pp. 1-2.

Armella, C., Cabaleri, N.G., Cagnoni, M.C., Panarello, H.O., 2013. Early Callovian ingression in southwestern Gondwana. Palaeoenvironmental evolution of the carbonate ramp (Calabozo Formation) in southwestern Mendoza, Neuquen basin, Argentina. Journal of South American Earth Sciences 45, 293-315. 
Arregui, C., Carbone, O., Leanza, H.A., 2011. Contexto tectosedimentario, en: Relatorio del XVIII Congreso Geológico Argentino, Geología y Recursos Naturales de la provincia del Neuquén. Neuquén, pp. 29-36.

Astini, R.A., 1996. Las fases diastróficas del Paleozoico medio en la Precordillera del oeste argentino: evidencias estratigráficas, en: XIII Congreso Geológico Argentino y III Congreso de Exploración de Hidrocarburos. Buenos Aires, pp. 509-526.

Aurell, M., Bádenas, B., 2004. Facies and depositional sequence evolution controlled by high-frequency sea-level changes in a shallow-water carbonate ramp (late Kimmeridgian, NE Spain). Geological Magazine 141, 717-733.

Aurell, M., Bádenas, B., Casas, A.M., Salas, R., 2009. Peritidal carbonate-evaporite sedimentation coeval to normal fault segmentation during the Triassic-Jurassic transition, Iberian Chain, en: Sedimentary Processes, Environments and Basins: A Tribute to Peter Friend (Special Publication 38 of the IAS). John Wiley \& Sons, p. 219.

Azerêdo, A.C., 1998. Geometry and facies dynamics of Middle Jurassic carbonate ramp sandbodies, West-Central Portugal. Geological Society, London, Special Publications 149, 281-314.

Bádenas, B., Aurell, M., Melendez, A., 1993. Características sedimentológicas, zonación y evolución de una rampa carbonatada dominada por tormentas (Kimeridgiense, Cordilles Ibérica Septentrional). Revista Sociedad Geológica España 6, 57-75.

Bádenas, B., Aurell, M., 2001. Proximal-distal facies relationships and sedimentary processes in a storm dominated carbonate ramp (Kimmeridgian, Northwest of the Iberian Ranges, Spain. Sedimentary Geology 139, 319-340.

Bádenas, B., Aurell, M., 2010. Facies models of a shallow-water carbonate ramp based on distribution of non-skeletal grains (Kimmeridgian, Spain). Facies 56, 89-110.

Ballent, S.C., 1987. Foraminíferos y ostrácodos del Jurásico Inferior de la Argentina. Revista Museo La Plata (n.s.) Paleontología 9 (53), 43-130.

Ballent, S.C., 2004. A micropalaeontological study of two Jurassic sequences in the Neuquén Basin, central-west Argentina. Ameghiniana (Revista Asociación Paleontológica Argentina) 41, 331-345.

Bastida-Zavala, R.J., Salazar-Vallejo, S.I., 2000. Serpúlidos ( Polychaeta: Serpulidae ) del Caribe noroccidental con claves para la región del Gran Caribe : Salmacina , Ficopomatus , Pomatoceros ,Protula, Pseudovermilia, Spirobranchus y Vermiliopsis. Revista de Biología Tropical 48, 807-840.

Barbier, M., Floquet, M., Hamon, Y., Callot, J.P., 2015. Nature and distribution of diagenetic phases and petrophysical properties of carbonates: The Mississippian Madison Formation (Bighorn Basin, Wyoming, USA). Mar. Pet. Geol. 67, 230248.

Bauch, T., Reijmer, J.J.G., McNeill, D.F., Schäfer, P., 2011. Development of a Pliocene mixed-carbonate siliciclastic reef (Limon, Costa Rica). Sedimentary 
Geology 239, 37-47.

Beigi, M., Jafarian, A., Javanbakht, M., Wanas, H.A., Mattern, F., Tabatabaei, A., 2017. Facies analysis, diagenesis and sequence stratigraphy of the carbonateevaporite succession of the Upper Jurassic Surmeh Formation: Impacts on reservoir quality (Salman Oil Field, Persian Gulf, Iran). Journal of African Earth Sciences 129, 179-194.

Benyoucef, M., Meister, C., 2015. Lithostratigraphic evolution, facies analysis and depositional environment of the Cenomanian-lower Turonian in the Guir area, Southwestern Algeria. Cretaceous Research 53, 68-88.

Biscaye, P.E., 1965. Mineralogy and sedimentation of recent deep-sea clay in the Atlantic Ocean and adjacent seas and oceans. Geological Society of America Bulletin 76, 803-832.

Bodenbender, G., 1892. Sobre el terreno jurásico y cretáceo en los Andes argentinos entre el rio Diamante y rio Limay. Boletín Academia Nacional de Ciencias 13, 5-44.

Boggs, S., 2009. Petrology of Sedimentary Rocks, Second ed. ed, Journal of Chemical Information and Modeling. Cambridge.

Boggs, S., Krinsley, D., 2006. Application of Cathodoluminescence Imaging to the Study of Sedimentary Rocks, First. ed. Cambridge University Press.

Borya, A., Siccardi, A., Richiano, S., Matheos, S.D., Raigemborn, M.S., 2015. Caracterización icnológica de la transición entre las formaciones Lajas (Bathoniano-Calloviano ) y Calabozo (Calloviano), norte de Cuenca Neuquina, Argentina, in: Tercer Simposio Latinoamericano de Icnología. Colonia, Uruguay.

Bourgeois, J., Leithold, E.L., 1984. Wave-worked conglomerates-Depositional processes and criteria for recognition. En: Koster, E.H. y Steel, R.J. (Eds.), Sedimentology of Gravels and Conglomerates. Canadian Society of Petroleum Geologists Memoir 10, 331-343.

Brandano, M., Ronca, S., 2014. Depositional processes of the mixed carbonatesiliciclastic rhodolith beds of the Miocene Saint-Florent Basin, northern Corsica. Facies 60, 73-90.

Bressan, G.S., Kietzmann, D.A., Palma, R.M., 2013. Facies analysis of a ToarcianBajocian shallow marine/coastal succession (Bardas Blancas Formation) in northern Neuquén Basin, Mendoza province, Argentina. Journal of South American Earth Sciences 43, 112-126.

Brigaud, B., Benoit, V., Carpentier, C., Robin, C., Guillocheau, F., Yven, B., Huret, E., 2014. Growth and demise of the Jurassic carbonate platform in the intracratonic Paris Basin (France): Interplay of climate change, eustasy and tectonics. Marine and Petroleum Geology 53, 3-29.

Brigaud, B., Durlet, C., Deconinck, J.F., Vincent, B., Pucéat, E., Thierry, J., Trouiller, A., 2009a. Facies and climate/environmental changes recorded on a carbonate ramp: A sedimentological and geochemical approach on Middle Jurassic carbonates (Paris Basin, France). Sedimentary Geology 222, 181-206. 
Brigaud, B., Durlet, C., Deconinck, J.F., Vincent, B., Thierry, J., Trouiller, A., 2009b. The origin and timing of multiphase cementation in carbonates: Impact of regional scale geodynamic events on the Middle Jurassic Limestones diagenesis (Paris Basin, France). Sedimentary Geology 222, 161-180.

Brown, G., Brindley, G.W., 1980. Crystal structures of clay minerals and their X-ray identification. Mineralogical Society London, London.

Buatois, L.A., Mángano, M.G., 2011. Ichnology: Organism-substrate interactions in space and time. Cambridge University Press, New York.

Burchette, T., Wright, V., 1992. Carbonate ramp depositional systems. Sedimentary Geology 79, 3-57.

Burckhardt, C. 1900. Profils géologiques transversaux de la Cordillère ArgentinoChilienne. Stratigraphie et tectonique. Anales del Museo de La Plata, Sección Geología y Mineralogía 2, 1-136.

Burckhardt, C. 1903. Beiträge zur Kenntniss der Jura-und Kreideformation der Cordillere. Paleontographica 50, 1-144.

Cabaleri, N.G., Valencio, S.A., Cagnoni, M.C., Ramos, A.M., Armella, C., Panarello, H.O., Riccardi, C.A., 2001. Facies and carbon/oxygen isotopes of the Calabozo Formation (Middle Jurassic), Arroyo La Vaina, Mendoza, Argentina, en: III South American Symposium on Isotope Geology. Chile, pp. 367-370.

Cabaleri, N.G., Armella, C., Cagnoni, M., Ramos, A.M., Valencio, S.A., 2003. Carbonate Ramp Facies at the Calabozo Formation (Middle Jurassic), Mendoza, Argentina. Revista Geológica de Chile 30 (2), 205-221.

Cabaleri, N.G.., Ramos, A., Cagnoni, M., Armella, C., Panarello, H., 2007. Paleoambiente de baja energía de la rampa carbonática caloviana en el morro del arroyo Calabozo, Malargüe, provincia de Mendoza, en: III Simposio Argentino del Jurásico. Mendoza, p. 52.

Cagnoni, M. C., Ramos, A. M., Valencio, S. A., Panarello, H. O., Armella, C., Cabaleri, N. G., 2006. $\delta^{13} \mathrm{C}, \delta^{18} \mathrm{O}$ and ${ }^{87} \mathrm{Sr} /{ }^{86} \mathrm{Sr}$ of Early Callovian limestones from Cuenca Neuquina, Argentina, en: V South American Simposium on Isotope Geology, pp. 230-234.

Cant, D.J., Walker, R.G., 1976. Development of a braided-fluvial facies model for the Devonian Battery Point Sandstone, Quebec. Canadian Journal of Earth Science 13, 102-119.

Chamley, H., 1989. Clay Sedimentology. Springer, Berlin, p. 623.

Cheel, R.J., Leckie, D.A., 1993. Hummocky cross-stratification. Sedimentology review $1,103-122$.

Christ, N., Immenhauser, A., Amour, F., Mutti, M., Tomás, S., Agar, S.M., Alway, R., Kabiri, L., 2012. Characterization and interpretation of discontinuity surfaces in a Jurassic ramp setting (High Atlas, Morocco). Sedimentology 59, 249-290.

Choquette, P.W., Pray, L.C., 1970. Geologic nomenclature and classification of porosity in sedimentary carbonates. AAPG bulletin 54, 207-250. 
Cingolani, C. A., Zanettini, J.C.M., Leanza, H. A., 2011. El basamento ígneo y metamórfico, en: Relatorio XVIII Congreso Geológico, Geología y Recursos Naturales de la provincia del Neuquén. Neuquén, pp. 37-47.

Clari, P.A., Dela Pierre, F., Martire, L., 1995. Discontinuities in carbonate successions: identification, interpretation and classification of some Italian examples. Sedimentary Geology 100, 97-121.

Clifton, H.E., 1973. Pebble segregation and bed lenticularity in wave-worked versus alluvial gravel. Sedimentology 20, 173-187.

Clifton, E., 1987. Wave-formed sedimentary structures-A conceptual model, en: Beach and Nearshore Sedimentation (SP24). The Society of Economic Paleontologists and Mineralogists (SEPM), pp. 127-148.

Clifton, H.E., 2003. Supply, segregation, successions, and significance of shallow marine conglomeratic deposits. Bulletin of Canadian Petroleum Geology 51, 370-388.

Clifton, H.E., 2006. A reexamination of facies models for clastic shorelines, en: Posamentier, H.W., Walker, R.G. (Eds.), Facies Models Revisited. SEPM (Society for Sedimentary Geology), p. 293.

Collinson, J., Mountney, N., Thompson, D., 2006. Sedimentary structures, Third ed. Terra Publishing, England.

Colombié, C., Strasser, A., 2005. Facies, cycles, and controls on the evolution of a keep-up carbonate platform (Kimmeridgian, Swiss Jura). Sedimentology 52, 1207-1227.

Craig, H., 1957. Isotopic standards for carbon and oxygen and correction factors for mass-spectrometric analysis of carbon dioxide. Geochimica et cosmochimica acta 12, 133-149.

Critelli S., Ingersoll, R., 1995. Interpretation of neovolcanic versus palaeovolcanic sand grains: an example from Miocene deep-marine sandstone of the Topanga Group (Southern California). Sedimentology 42, 783-804.

De Ros, L.F., Sgarbi, G.N.C., Morad, S., 1994. Multiple authigenesis of K-feldspar in sandstone: evidence from the Cretaceous Areado Formation, Sao Francisco Basin, Central Brazil. Journal of Sedimentary Research. A64, 778-787.

Dellape, D, Mombrú, A.C., Pando, G.A., Riccardi, A.C., Uliana, M.A., Westermann, G. 1978. Edad y correlación de la Fm Tábanos en Chacay Melehue y otras localidades de Neuquén y Mendoza. Consideraciones sobre la distribución y significado de las sedimentitas Lotenianas. Obra Centenario Museo de La Plata, Paleontología 5, 81-105.

Dessanti, R.N. 1978. Descripción geológica de la Hoja 28b. Malargüe, provincia de Mendoza. Boletín del Servicio Nacional Minero 149, Buenos Aires, Argentina.

Dessanti, R.N. 1973. Descripción geológica de la Hoja 29b. Bardas Blancas, provincia de Mendoza. Boletín del Servicio Nacional Minero 139, Buenos Aires, Argentina.

Dickinson, W.R., 1970. Interpreting detrital modes of graywacke and arkose. 
Journal of Sedimentary Research 40, 695-707.

Dickinson, W.R., Suczek, C.A., 1979. Plate tectonics and sandstone compositions. AAPG Bulletin 63, 2164-2182.

Dickinson W., Breard L., Brakenridge G., Erjavec J., Ferguson R., Inman K., Knepp R., Lindberg, F., Ryberg P., 1983. Provenance of North American Phanerozoic sandstones in relation to tectonic setting. Geological Society of America Bulletin 94, 222-235.

Digregorio, J.H., 1972. Neuquén, en: Leanza, A.F. (Ed.), Geología Regional Argentina. Academia Nacional de Ciencias de Cordoba, Cordoba, pp. 439-506.

Digregorio, J. H., Uliana, M. A., 1979. Cuenca Neuquina. En: J.C.M. Turner (Coord.). Segundo Simposio Geológico Regional Argentino, Academia Nacional de Ciencias de Córdoba, 439-506.

Digregorio, J. H., Uliana, M. A., 1980. Cuenca Neuquina. Geología Regional Argentina 2, 985-1032.

Dimieri, L., 1992. Evolución estructural de la Cordillera Principal, a lo largo del arroyo La Vaina, entre el arroyo Potimalal y el arroyo Pehuenche, al oeste de Bardas Blancas, Mendoza. Universidad Nacional del Sur, p.151.

Dimieri, L., 1997. Tectonic wedge geometry at Bardas Blancas, southern Andes (3605), Argentina. Journal of Structural Geology 19 (11), 1419-1422.

Dott, R.H., 1964. Wacke, greywacke and matrix-what approach to immature sandstone classification?. Journal of Sedimentary Petrology 34, 625-632.

Dott, R. h., Bourgeois, J., 1982. Hummocky stratification: Significance of its variable bedding sequences. Geological Society of America Bulletin 93, 663680.

Dunham, R.J., 1962. Classification of carbonate rocks according to depositional textures, en: Ham, W.E. (Ed.), Classification of Carbonte Rocks. AAPG Special Volumes, pp. 108-121.

Dupraz, C., Strasser, A., 2002. Nutritional Modes in Coral-Microbialite Reefs (Jurassic, Oxfordian, Switzerland): Evolution of Trophic Structure. Palaios 17, 449-471.

Egger, H., Homayoun, M., Schnabel, W., 2002. Tectonic and climatic control of Paleogene sedimentation in the Rhenodanubian Flysch basin (Eastern Alps, Austria). Sedimentary Geology 152, 247-262.

Einsele, G., Chough, S.K., Shiki, T., 1996. Depositional events and their records-an introduction. Sedimentary Geology 104, 1-9.

Embry, A.F., Klovan, J.E., 1971. A late Devonian reef tract on northeastern Banks Island, NWT. Bulletin of Canadian Petroleum Geology 19, 730-781.

Flügel, E., 1982. Microfacies analysis of limestones, First. ed. Springer.

Flügel, E., 2004. Microfacies of carbonate rocks: Analysis, Interpretation and Application. Springer Berlin Heidelberg. 
Flügel, E., 2010. Microfacies of carbonate rocks: Analysis, Interpretation and Application, Second ed. Springer Berlin Heidelberg.

Folk, R.L., 1959. Practical petrographic classification of limestones. AAPG Bulletin 43, $1-38$.

Folk, R.L., 1962. Spectral subdivision of limestone types, en: HAM, W.. (Ed.), Classification of Carbonate Rocks. AAPG Special Volumes, pp. 62-84.

Folk, R.L., 1965. Some aspects of recrystallization in ancient limestones, in: Pray, L. C., Murray, R.C. (Eds.), Dolomitization and Limestone Diagenesis. Special Publications of SEPM, pp. 14-48.

Folk, R., Andrews P., Lewis D., 1970. Detrital sedimentary rock classification and nomenclature for use in New Zeland. New Zeland Journal of Geology and Geophysics 13, 937-968.

Folk, R.L., Pittman, J.S., 1971. Length-slow chalcedony: a new testament for vanished evaporites. Journal of Sedimentary Research 41, 1045-1058.

Fortunatti, N., Dimieri, L., 2005. La geometría del basamento en el arroyo Malo, valle del río Atuel, Mendoza, Argentina, en: $16^{\circ}$ Congreso Geológico Argentino. La Plata, pp. 313-318.

Franzese, J.R., Spalletti, L.A., 2001. Late triassic-Early jurassic continental extension in Southwestern Gondwana: Tectonic segmentation and pre-breakup rifting. Journal of South American Earth Sciences 14, 257-270.

Franzese, J., Spalletti, L., Pérez, I.G., Macdonald, D., 2003. Tectonic and paleoenvironmental evolution of Mesozoic sedimentary basins along the Andean foothills of Argentina ( $\left.32^{\circ}-54^{\circ} \mathrm{S}\right)$. Journal of South American Earth Sciences 16, 81-90.

Friedman, I., O'Neil, J.R., 1977. Data of geochemistry: Compilation of stable isotope fractionation factors of geochemical interest. US Government Printing Office.

Fürsich, F.T., Oschmann, W., 1993. Shell beds as tools in basin analysis: the Jurassic of Kachchh, western India. Journal of Geological Society 150, 169-185.

Garzanti, E., 2017. The Maturity Myth In Sedimentology and Provenance Analysis. Journal of Sedimentary Research 87, 353-365.

Gerth, E., 1925. Estratigrafía y distribución de los sedimentos mesozoicos en los Andes Argentinos. Academia Nacional de Ciencias, Actas 9 (1), 11-55, Córdoba.

Gerth, H., 1931. La estructura geológica de la Cordillera Argentina entre el río Grande y el río Diamante en el sud de la provincia de Mendoza. Academia Nacional de Ciencias, Actas IX (2), 125-172, Córdoba.

Giambiagi, L. B., Álvarez, P. P., Tunik, M., 2005a. Relación entre las estructuras de rift triásicas-jurásicas y el estilo de deformación en las fajas plegadas y corridas Aconcagua y Malargüe, en: $16^{\circ}$ Congreso Geológico Argentino. La Plata, pp. 8186. 
Giambiagi, L., Bechis, F., García, V., Clark, A., 2005b. Temporal and spatial relationship between thick-and thin-skinned deformation in the thrust front of the Malargüe fold and thrust belt, southern Central Andes, en: VI International Symposium on Andean Geodynamics. Barcelona, pp. 315-318.

Giambiagi, L., Bechis, F., García V., Clark, A., 2008a. Temporal and spatial relationship between thick-and thin-skinned deformation in the Malargüe fold and thrust belt, southern Central Andes. Tectonophysics 459, 123-139.

Giambiagi, L., Bechis, F., Lanés, S., Tunik, M., García, V., Suriano, J., Mescua, J., 2008b. Formación y evolución triásico-jurásica del depocentro Atuel, Cuenca Neuquina, provincia de Mendoza. Revista de la Asociación Geológica Argentina 63(4), 520-533.

Giambiagi, L., Ghiglione, M., Cristallini, E., Bottesi, G., 2009a. Características estructurales del sector sur de la faja plegada y corrida de Malargüe (35-36 S): distribución del acortamiento e influencia de estructuras previas. Revista de la Asociación Geológica Argentina 65(1), 140-153.

Giambiagi, L., Ghiglione, M., Cristallini, E., Bottesi, G., 2009b, Kinematic models of basement/cover interaction: Insights from the Malargüe fold and thrust belt, Mendoza, Argentina. Journal of Structural Geology 31, 1443-1457.

Giampaoli, P., Ramirez, J.L., Gait, M.A., 2005. Estilo de entrampamiento en la Faja Plegada y Fallada de Malargüe, en: 60 Congreso de Exploración y Desarrollo de Hidrocarburos. Simposio Las Trampas de Hidrocarburos en las Cuencas Productivas de Argentina. Mar del Plata, pp. 121-140.

Gómez-Pérez, I., Fernández-Mendiola, P.A., Garcíia-Mondéjar, J., 1998. Constructional dynamics for a Lower Cretaceous carbonate ramp (Gorbea Massif, north Iberia). Geological Society, London, Special Publications 149, 229-252.

Gomez Omil, R., Schmithalter, J., Cangini, A., Albariño, L., Corsi, A., 2002. El Grupo Cuyo en la dorsal de Huincul, consideraciones estratigráficas,tectónicas y petroleras. Cuenca Neuquina, en: $V^{0}$ Congreso de Exploración de Hidrocarburos.

Groeber, P. 1918. Estratigrafía del Dogger en la República Argentina. Estudio sintético comparativo. Dirección General de Minas, Geología e Hidrogeología, Boletín 18, Serie B (Geología), 1-81, Buenos Aires.

Groeber, P., 1929. Líneas fundamentales de la geología del Neuquén, sur de Mendoza y regiones adyacentes. Dirección Nacional de Geología y Minería, Publicación 58, 1-110. Buenos Aires.

Groeber, P., 1933. Confluencia de los ríos Grande y Barrancas (Mendoza y Neuquén): Descripción de la Hoja 31c del mapa geológico general de la República Argentina. Dirección Nacional de Geología y Minería, Boletín 38, 1-72, Buenos Aires.

Groeber, P., 1946. Observaciones geológicas a lo largo del meridiano $70^{\circ}$. 1. Hoja Chos Malal. Revista de la Sociedad Geológica Argentina I (3), 177-208. 
Groeber, P., 1947a. Observaciones geológicas a lo largo del meridiano $70^{\circ}$. 2. Hojas Sosneado y Maipo. Revista de la Sociedad Geológica Argentina II (2), 141-176.

Groeber, P., 1947b. Observaciones geológicas a lo largo del meridiano $70^{\circ}$. 1. Hojas Bardas Blancas y Los Molles. Revista de la Sociedad Geológica Argentina II (4), 409-433.

Groeber, P. 1947c. Observaciones geológicas a lo largo del meridiano $70^{\circ}$. 3. Hojas Domuyo, Mari Mahuida, Huar-huar Co y parte de Epu Lauken. Revista de la Sociedad Geológica Argentina II (3), 347-408.

Groeber, P. 1951. La Alta Cordillera entre las latitudes $34^{\circ}$ y $29^{\circ} 30^{\prime}$. Instituto de Investigaciones de las Ciencias Naturales. Museo Argentino de Ciencias Naturales Bernardino Rivadavia, Revista (Ciencias Geológicas) 1(5), 1-352.

Groeber, P., Stipanicic, P.N., Mingramm, A.G., 1953. Mesozoico. Geografía de la República Argentina. Sociedad Argentina de Estudios Geográficos 2 (1), 1-541.

Gulisano, C.A., 1981. El ciclo Cuyano en el norte de Neuquén y sur de Mendoza, en: $8^{\circ}$ Congreso Geológico Argentino. Buenos Aires, pp. 579-592.

Gulisano, C.A. 1993., Calabozo. En Riccardi, A. C. y Damborenea, S. E. (eds.) Léxico Estratigráfico de la Argentina, Volumen 9, Jurásico: 87. Asociación Geológica Argentina, Serie - $B^{\prime \prime}$ (Didáctica y Complementaria) 21, Buenos Aires.

Gulisano, C.A., Gutiérrez Pleimling, A.R., Digregorio, R.E., 1984. Esquema estratigráfico de la secuencia jurásica al oeste de la provincia del Neuquén, en: $9^{\circ}$ Congreso Geológico Argentino. Buenos Aires, pp. 236-259.

Gulisano, C.A., Gutiérrez Pleimling, A.R., 1994. Field Guide the Jurassic of the Neuquén Basin: B, Mendoza Province, Serie E ed. Asociación Geológica Argentina y Secretaría de Minería de la Nación, Buenos Aires.

Haq, B.U., Hardenbol, J., Vail, P.R., 1987. Chronology of fluctuating sea levels since the Triassic. Science 235, 1156-1167.

Harbaugh, J.W., Demirmen, F., 1964. Application of factor analysis to petrologic variations of Americus Limestone (Lower Permian), Kansas and Oklahoma. State Geological Survey, University of Kansas.

Harbaugh, J.W., Merriam, D.F., 1968. Computer applications in stratigraphic analysis. Wiley New York.

Hardie, L. A., 1987. Dolomitization: A critical view of some current views. Journal of Sedimentary Petrology 57, 166-183.

Hart, S.B., Plint, A.G., 1995. Gravelly shoreface and beachface deposits. Special Publication of the International Association of Sedimentologists 22, 75-99.

Hart, B.S., Plint, A.G., 2003. Stratigraphy and sedimentology of shoreface and fluvial conglomerates: Insights from the Cardium Formation in NW Alberta and adjacent British Columbia. Bulletin of Canadian Petroleum Geology 51, 437464.

Hart, B.S., Plint, A.G., 2003. Stratigraphy and sedimentology of shoreface and fluvial conglomerates: Insights from the Cardium Formation in NW Alberta and 
adjacent British Columbia. Bulletin of Canadian Petroleum Geology 51, 437464.

Hein, J.R., School, D.W., Gutmacher, C.E., 1976. Neogene clay minerals of the far northwest Pacific and southern Bering Sea: sedimentation and diagenesis, en: Proceedings of the International Clay Conference. Mexico, pp. 71-80.

Hiatt, E.E., Pufahl, P.K., 2014. Cathodoluminescence petrography of carbonate rocks: a review of appilcations for understanding diagenesis, reservoir quality, and pore system evolution, en: CL PETROGRAPHY OF CARBONATE ROCKS. Mineralogical Association of Canada, pp. 75-96.

Hillgärtner, H., 1998. Discontinuity surfaces on a shallow-marine carbonate platform (Berriasian, Valanginian, France and Switzerland). Journal of Sedimentary Research 68, 1093-1108.

Horowitz, A.S., Potter, P.E., 1971. Introductory Petrography of Fossils. SpringerVerlag, Berlin.

Howell, J.A., Schwarz, E., Spalletti, L.A., Veiga, G.D., 2005. The Neuquén Basin: an overview. Geological Society, London, Special Publications 252, 1-14.

Huggett, J.M., Gale, A.S., Wray, D.S., 2005. Diagenetic clinoptilolite and opal-CT from the middle Eocene Wittering Formation, Isle of Wight, UK. J. Sediment. Res. 75, 585-595.

Imbrie, J., Purdy, E.G., 1962. Classification of modern Bahamian carbonate sediments. AAPG Memoir 1, 253-272.

Ingersoll, R.V., Bullard, T.F., Ford, R.L., Grimm, J.P., Pickle, J.D., y Sares, S.W., 1984. The effect of grain size on detrital modes: A test of the Gazzi-Dickinson point-counting method. Journal of Sedimentary Petrology 54, 103-116.

James, D.M.D., 1984. The geology and hydrocarbon resources of Negara Brunei Darussalam. Muzium Brunei.

James, N. P., Ginsburg, R. N., 2009. The Seaward Margin of the Belize Barrier and Atoll Reefs. Special Publication of the International Association of Sedimentologists 3, 161.

Jaworski, E., 1926. La Fauna del Lias y Dogger de la Cordillera Argentina en la parte meridional de la Provincia de Mendoza. Actas Academia Nacional de Ciencias de Cordoba 9, p. 4.

Johnson HD, Baldwin C.T., 1996. Shallow clastic seas. En: Reading HG (ed) Sedimentary environment and facies III. Blackwell, Oxford, pp 232-282.

Kastner, M., Siever, R., 1979. Low temperature feldespars in sedimentary rocks. American Journal of Sciences 279, 435-479.

Kidwell, S.M., Bosence, D.W.J., 1991. Taphonomy and time-averaging of marine shelly faunas, en: Taphonomy: releasing the data locked in the fossil record. Plenum, New York, pp. 115-209.

Kim, H.J., Scaricabarozzi, N., Ramos, V.A., 2005. La estructura al sur del río Diamante y su relación con la falla de Malargüe, cuenca Neuquina, centro-oeste 
de Mendoza, en: $16^{\circ}$ Congreso Geológico Argentino. La Plata), pp. 63-70.

Kleinspehn, K.L., Steel, R.J., 1984. Conglomeratic fan-delta sequences, late Carboniferous-early Permian, western Spitsbergen, en: Koster, E.H., Steel, R.J. (Eds.), Sedimentology of Gravels and Conglomerates. Canadian Society of Petroleum Geologists, pp. 279-294.

Kley, J., Monaldi, C.R., Saltify, J.A., 1999. Along-strike segmentation of the Andean

foreland: causes and consequences. Tectonophysics 301, 75-94.

Klovan, E.J., 1964. Facies analysis of the Redwater reef complex, Alberta, Canada. Bulletin of Canadian Petroleum Geology 12, 1-100.

Koehn, D., Rood, M.P., Beaudoin, N., Chung, P., Bons, P.D., Gomez-Rivas, E., 2016. A new stylolite classification scheme to estimate compaction and local permeability variations. Sedimentary Geology 346, 60-71.

Kozlowski, E., 1984. Interpretación estructural de la Cuchilla de la Tristeza, Provincia de Mendoza, en: $9^{\circ}$ Congreso Geológico Argentino. Bariloche, pp. 381-395.

Kozlowski, E., Cruz, C., Condat, P. y Manceda, R., 1989. Informe geológico zona Malargüe Occidental. YPF (inédito), Buenos Aires.

Kozlowski, E., Cruz, C., Condat, P. y Manceda, R., 1990. Modelo estructural para el zócalo de la cuenca Neuquina, Mendoza, Argentina, en: $11^{\circ}$ Congreso Geológico Argentino. San Juan, 27-30.

Kozlowski, E., Manceda, R., Ramos, V.A. 1993. Estructura. En: Ramos, V.A. (ed.): Geología y recursos naturales de Mendoza. 120 Congreso Geológico Argentino y 20 Congreso Exploración de Hidrocarburos. Mendoza, pp. 235-256.

Kreisa, R.D., Bambach, R.K., 1982. The role of storm processes in generating shell beds in Paleozoic shelf environments, en: Einsele, G., Seilacher, A. (Eds.), Cyclic and event stratification. Springer Berlin Heidelberg, pp. 200-207.

Lahee, F.H., 1927. The Petroliferous Belt of Central-Western Mendoza Province, Argentina. AAPG Bulletin 11, 261-278.

Leanza, A.F., 1945. Ammonites del Jurásico superior y del Cretácico inferior de la Sierra Azul, en la parte meridional de la provincia de Mendoza, en: Anales del Museo de La Plata. na, La Plata, pp. 1-99.

Legarreta, L., Gulisano, A., 1989. Análisis estratigráfico secuencial de la Cuenca Neuquina (Triásico superior-Terciario inferior), en: Chebli, G., Spalletti, L.A. (Eds.), Cuencas sedimentarias argentinas. Instituto Superior de Correlación Geológica, Universidad Nacional de Tucumán, pp. 221-243.

Legarreta, L., Gulisano, C.A. y Uliana, M.A. 1993. Las secuencias sedimentarias jurásico-cretácicas. En Ramos, V.A. (ed.) Geología y Recursos Naturales de Mendoza. $12^{\circ}$ Congreso Geológico Argentino y $2^{\circ}$ Congreso de Exploración de Hidrocarburos. Buenos Aires, pp. 87-114.

Legarreta, L., Uliana, M. A., 1996. The Jurassic succession in west-central Argentina: stratal patterns, sequences and paleogeographic evolution. 
Palaeogeography, Palaeoclimatology, Palaeoecology 120, 303-330.

Legarreta, L., Uliana, M.A., 1999. El Jurásico y Cretácico de la Cordillera Principal y la Cuenca Neuquina, en: Caminos, R. (Ed.), Geología Argentina. Servicio Geológico Minero Argentino, pp. 399-416.

Leithold, E.L., Bourgeois, J., 1984. Characteristics of coarse grained sequences deposited in nearshore, wave-dominated environments-examples from the Miocene of south-west Oregon. Sedimentology 31, 749-775.

Li, Z., Goldstein, R.H., Franseen, E.K., 2016. Meteoric Calcite Cementation: Diagenetic Response to Relative Fall in Sea-Level and Effect on Porosity and Permeability, Las Negras area, southeastern Spain. Sedimentary Geology 348, $1-18$.

Limeres, M., 1996. Sequence Stratigraphy of the Lower-Middle Jurassic in Southern Neuquén: Implicance for Unraveling Synsedimentary Tectonics along the Huincul Wrench System. GeoResearch Forum 1-2, 275-284.

Llambias, E., 2001. Complejos Magmaticos triasicos al norte de los $40^{\circ} \mathrm{S}$, en: Artabe, A., Morel, E., Zamuner, A.B. (Eds.), El Sistema Triásico de la Argentina. Fundación Museo de La Plata. La Plata, pp. 55-68.

Llambías, E.J., Leanza, H.A., Carbone, O., 2007. Evolución tectono-magmática durante el Pérmico al Jurásico Temprano en la cordillera del Viento (37 05 S-37 $15 \mathrm{~S})$ : nuevas evidencias geológicas y geoquímicas del inicio de la cuenca Neuquina. Revista de la Asociación Geológica Argentina 62, 217-235.

Llambías, J.E., Sato, A.M., 2011. Ciclo Gondwánico: La Provincia Magmática Choiyoi En Neuquén, en: relatorio XVIII Congreso Geologico Geología y Recursos Naturales de la provincia del Neuquén. Neuquén, pp. 53-62.

Logan, B.W., Rezak, R., Ginsburg, R.N., 1964. Classification and environmental significance of algal stromatolites. The Journal of Geology 72, 68-83.

Lucia, F.J., 2007. Carbonate Reservoir Characterization, Second. ed. Springer.

Manceda, R. y Figueroa, D., 1995. Inversion of the Mesozoic Neuquén rift in the Malargüe fold-thrust belt, Mendoza, Argentina. En Tankard, A.J., Suárez, R., Welsink, H.J. (eds): Petroleum Basins of South America. American Association of Petroleum Geologists, Memoir 62, 369-382.

Massari, F., Parea, G.C., 1988. Progradational gravel beach sequences in a moderate-to high-energy, microtidal marine environment. Sedimentology 35, 881-913.

Marshall, D. J., Giles, J. H., Marino, A., 1988. Combined instrumentation for EDS elemental analysis and cathodoluminescence studies of geological materials. In Hagni, R. D. (ed.), Process Mineralogy VI, Warrendale, PA, The Metallurgical Society Inc.,117-35.

McCrea, J.M., 1950. On the isotopic chemistry of carbonates and a paleotemperature scale. The Journal of Chemical Physics 18, 849-857.

McKee, E.D., Gutschick, R.C., 1969. History of the Redwall Limestone of northern Arizona. Geological Society of America Memoirs 114, 1-700. 
McIlroy, D., Flint, S., Howell, J. a., Timms, N., 2005. Sedimentology of the tidedominated Jurassic Lajas Formation, Neuquen Basin, Argentina. Geological Society, London, Special Publications 252, 83-107.

Mescua, J.F., Giambiagi, L.B., 2012. Fault inversion vs. new thrust generation: A case study in the Malargüe fold-and-thrust belt, Andes of Argentina. Journal of Structural Geology 35, 51-63.

Miall, A., 1977. A review of the braided river depositional environment. Earth Science Reviews 13, 1-62.

Miall, A.D., 1996. The Geology of Fluvial Deposits: Sedimentary Facies, Basin Analysis and Petroleum Geology. Springer-Verlag, New York.

Molenaar, N., de Jong, A.F.M., 1987. Authigenic quartz and albite in Devonian limestones: origin and significance. Sedimentology 34, 623-640.

Moore, D.M., Reynolds, R.C., 1989. X-ray Diffraction and the Identification and Analysis of Clay Minerals. Oxford university press Oxford.

Morad, D., Paganoni, M., Harthi, A.A.L., Morad, S., Ceriani, A., Mansurbeg, H., Suwaidi, A.A.L., Al-aasm, I.S., Ehrenberg, S.N., 2016. Origin and evolution of microporosity in packstones and grainstones in a Lower Cretaceous carbonate reservoir , United Arab Emirates. Geological Society of London, Special Publication 435, 47-66.

Morrow, D.W., Abercrombie, H.J., 1994. Rates of dolomitization: the influence of dissolved sulphate, in: Purser, B., Tucker, M.E., Zenger, D. (Eds.), Dolomites: A Volume in Honour of Dolomieu. International Association of Sedimentologists, pp. 377-386.

Moss, S., Tucker, M.E., 1995. Diagenesis of Barremian-Aptian platform carbonates (the Urgonian Limestone Formation of SE France): near-surface and shallowburial diagenesis. Sedimentology 42, 853-874.

Mulder, T., Syvitski, J.P.M., Sebátien, M., Jean-Claude, F., Savoye, B., 2003. Marine hyperpycnal flows: initiation, behavior and related deposits. A review. Marine and Petroleum Geology 20, 861-882.

Myrow, P.M.., Southard, J.B., 1991. Combined-flow model for vertical stratificaction sequences in shallow marine storm-deposited beds. Journal of Sedimentary Petrology 61, 202-210.

Narciso, V., Zanettini, J.C., Santamaría, G., Mallimacci, H.S. 2007. Hoja Geológica 3769-11, Agua Escondida, Provincias de Mendoza y La Pampa. Instituto de Geología y Recursos Minerales. Servicio Geológico Minero Argentino ( $2^{\circ}$ ed. Revisada), Boletín 300, p. 54.

Nullo, F.E., Stephens, G., Combina, A., Dimieri, L., Baldauf, P., Bouza, P., Zanettini, J.C.M., 2005. Hoja geológica 3569-III/3572-IV Malargüe, provincia de Mendoza, Servicio Geológico Minero Argentino. Instituto de Geología y Recursos Minerales. 
Olivo, M.S., 2016. Análisis sedimentológico y estratigráfico secuencial de los sistemas fluviales y eólicos del Valanginiano en el sector central de la provincia de Neuquén, cuenca Neuquina, Argentina.

Palma, R.M., Lo Forte, G.L., Lanés, S., 2000a. Ciclos depositacionales en la Formación Calabozo (Calloviano), Cuenca Neuquina, Mendoza, Argentina, en: $2^{\circ}$ Congreso Latinoamericano de Sedimentología y $8^{\circ}$ Reunión Argentina de Sedimentología. Mar del Plata, p.138.

Palma, R.M., Lo Forte, G.L., Lanés, S., 2000b. Preservación y diagénesis de corales escleractínidos en la Formación Calabozo (Calloviano), Cuenca Neuquina, Mendoza, Argentina, en: $2^{\circ}$ Congreso Latinoamericano de Sedimentología y $8^{\circ}$ Reunión Argentina de Sedimentología. Mar del Plata, p.139.

Palma, R.M., Lo Forte, G.L., Medhli, M., Piethé, R.D., 2005. High frequency subtidal-peritidal cycles of the Callovian Calabozo Formation (Neuquén Basin, Western Argentina): Preliminary approach. Geologica Acta 3, 119-132.

Palma, R.M., Mehdli, M., Bressan, G.S., Kietzmann, D.A., 2007a. Carbonatos subtropicales de la Formación Calabozo (Caloviano) y su diagénesis, cuenca Neuquina, Mendoza. Revista de la Asociacion Geologica Argentina 62, 163-174.

Palma, R.M., Bressan, G.S., Kietzmann, D.A., 2007b. Oncoides tipo Osagia en la Formación La Manga (Oxfordiano) y su significado paleoecológico , Arroyo La Vaina , Mendoza. Revista de la Asociacion Geologica Argentina 62, 116-123.

Pereira, D.M., Broens, S., 2005. La deformación andina a la latitud del río Diamante, provincia de Mendoza, en: $16^{\circ}$ Congreso Geológico Argentino. La Plata, pp. 101-106.

Pettijhon, F.J., Potter, P.E., Siever, R., 1972. Sand and Sandstones. SpringerVerlag, New York, p. 618.

Pettijohn, F.J., Potter, P.E., Siever, R., 1987. Sand and sandstone. Segunda edición, Springer-Verlag, pp.553.

Pierre, A., Durlet, C., Razin, P., Chellai, E.H., 2010. Spatial and temporal distribution of ooids along a Jurassic carbonate ramp: Amellago outcrop transect, High-Atlas, Morocco. Geological Society, London, Special Publications $329,65-88$.

Pirrie, D., 1998. Interpreting the record: facies analysis. Lyell: the past is the key to the present: Geological Society of London, Special Publication 143, 395-420.

Pomar, L., Obrador, A., Westphal, H., 2002. Sub-wavebase cross-bedded grainstones on a distally steepened carbonate ramp, Upper Miocene, Menorca, Spain. Sedimentology 49, 139-169.

Posamentier, H.W., Allen, G.P., James, D.P., Tesson, M., 1992. Forced regressions in a sequence stratigraphic framework: concepts, examples, and exploration significance (1). AAPG bulletin 76, 1687-1709.

Pose, F.A., Spagnuolo, M. y Folguera, A., 2005, Modelo para la variación del volumen orogénico andino y acortamientos en el sector $20^{\circ}-46^{\circ} \mathrm{S}$. Revista de la Asociación Geológica Argentina 60, 724-730. 
Purser, B.H., 1969. Syn-sedimentary marine lithification of Middle Jurassic limestones in the Paris Basin. Sedimentology 12, 205-230.

Raigemborn, M.S., Gómez-Peral, L.E., Krause, J.M., Matheos, S.D., 2014. Controls on clay minerals assemblages in an early paleogene nonmarine succession: Implications for the volcanic and paleoclimatic record of extra-andean patagonia, argentina. Journal of South American Earth Sciences 52, 1-23.

Ramos, V.A., 1984. Patagonia: un continente paleozoico a la deriva?, en: 9० Congreso Geologico Argentino. Bariloche, pp. 311-325.

Ramos, V. A., 1985. El Mesozoico de la Alta Cordillera de Mendoza: Reconstrucción tectónica de sus facies, Argentina, en: Congreso Geológico Chileno. Antofagasta, pp. 104-118.

Ramos, V.A., Allmendinger, R.W., Kay, S.M., Cortés, J.M., Allmendinger, R.W., Kay, S.M., Cortes, J.M., 1986. Paleozoic Terranes of the Central Argentine-Chilean Andes. Tectonics 5, 855-880.

Ramos, V. A., 1988. The tectonics of the Central Andes, 30 to $33 \mathrm{~S}$ latitude. Geological Society of America Special Papers 218, 31-54.

Ramos, V.A., 2002. La transición entre las fajas plegadas y corridas de Aconcagua y Malargüe: influencia del basamento de la Cordillera Frontal, en: $15^{\circ}$ Congreso Geológico Argentino. El Calafate, pp. 166-167.

Rapalini, A.E., López de Luchi, M., Martínez Dopico, C., Lince Klinger, F., Giménez, M., Martínez, P., 2010. Did Patagonia collide with Gondwana in the late Paleozoic? Some insights from a multidisciplinary study of magmatic units of the North Patagonian Massif. Geologica Acta 8, 349-371.

Reading, H.G., 1996. Sedimentary Environments: Processes, facies and stratigraphy, Tercera. ed. Blackwell Science Oxford.

Reading, H.G., Collinson, J.D., 1996. Clastic coasts, en: Reading, H.G. (Ed.), Sedimentary environments: processes, facies and stratigraphy. Blackwell Science Oxford, pp. 154-231.

Reading, H.G., Levell, B.K., 1996. Controls on the sedimentary rock record, en: Reading, H.G. (Ed.), Sedimentary environments: processes, facies and stratigraphy. Blackwell Science Oxford, pp. 5-36.

Reid, R.P., Macintyre, I.G., 2000. Microboring Versus Recrystallization: Further Insight into the Micritization Process. J. Sediment. Res. 70, 24-28.

Reolid, M., Molina, J.M., Löser, H., Navarro, V., Ruiz-Ortiz, P.A., 2009. Coral biostromes of the Middle Jurassic from the Subbetic (Betic Cordillera, southern Spain): Facies, coral taxonomy, taphonomy, and palaeoecology. Facies 55, 575-593.

Riccardi, A.C., 1983. The Jurassic of Argentina and Chile. En Moullade, M., Nairn, A.E.M. (eds.) The Phanerozoic Geology of the Word 2, Mesozoic B, pp. 201-263, Amsterdam, Elsevier.

Riccardi, A.C., 1984. Las asociaciones de amonitas del Jurásico y Cretácico de la Argentina, en: $9^{\circ}$ Congreso Geológico Argentino. Bariloche, pp. 559-595. 
Riccardi, A.C., 1985. Identificación paleontológica correspondiente al perfil del arroyo Calabozo. Informe YPF, Buenos Aires (inédito).

Riccardi, A.C., Westermann, G.E.G., Elmi, S., 1989. The Bathonian Callovian Ammonite Zones of the Argentine Chilean Andes. Geobios 22, 553-597.

Riccardi, A.C., Westermann, G.E.G., 1991. Middle Jurassic Ammonoid Fauna and Biochronology of the Argentine-Chilean Andes. Part 3: Bajocian-Callovian Eurycephalitinae, Stephanocerataceae. Part 4: Bathonian-Callovian Reineckeiidae. Revista Palaeontographica A216 (1-6), 1-145.

Riccardi, A.C., C.A Gulisano, 1990. Unidades limitadas por discontinuidades. Su aplicación al Jurásico Andino. Revista Asociación Geológica Argentina 45 (3-4), 346-364.

Riccardi, A.C., 1992. Biostratigraphy of west-central Argentina. En: Westermann, G.E.G. (ed.) The Jurassic of the Circum-Pacific, pp. 139-141, Cambridge University.

Riccardi, A.C., 1994. Biostratigraphy of the marine Jurassic of Argentina, en: $4^{\text {th }}$ International Congress on Jurassic Stratigraphy and Geology. Mendoza, p. 5.

Riccardi, A.C., Leanza, H., Damborenea, S., Manceñido, M., Ballent, S., Zeiss, A., 2000. Marine Mesozoic Biostratigraphy of the Neuquén Basin. En: Miller, H., Hervé, F. (eds.) Zeitschrift für Angewandte Geologie, Hannover, 31st International Geological Congress. Hannover, pp. 103-108.

Riccardi, A.C., 2008. El Jurásico de la Argentina y sus Amonites. Revista de la Asociación Geológica Argentina 63(4), 625-643.

Rojas, L., Radic, J.P., 2002. Estilos de deformación del basamento y de la cobertura sedimentaria en la faja plegada y fallada de Malargüe en el área de Puesto Rojas, Mendoza, Argentina, en: $15^{\circ}$ Congreso Geológico Argentino. El Calafate, pp. 224-229.

Rossi, C., Kälin, O., Arribas, J., Tortosa, A., 2002. Diagenesis, provenance and reservoir quality of Triassic TAGI sandstones from Ourhoud field, Berkine (Ghadames ) Basin, Algeria. Marine and Petroleum Geology. 19, 117-142.

Ruggiero, M.A., Gordon, D.P., Orrell, T.M., Bailly, N., Bourgoin, T., Brusca, R.C., Cavalier-Smith, T., Guiry, M.D., Kirk, P.M., 2015. A higher level classification of all living organisms. PLoS ONE 10, 1-60.

Sattler, U., Immenhauser, A., Hillgärtner, H., Esteban, M., 2005. Characterization, lateral variability and lateral extent of discontinuity surfaces on a Carbonate Platform (Barremian to Lower Aptian, Oman). Sedimentology 52, 339-361

Scasso, R. A. y Limarino, C. O., 1997. Petrología y diagénesis de rocas clásticas. Asociación Argentina de Sedimentología, Publicación Especial 1, p.258.

Schiller, W., 1912. La alta Cordillera de San Juan y Mendoza y parte de la Provincia de San Juan. Ministerio de Agricultura de la Nación, Sección Geología, Mineralogía y Minería, Buenos Aires.

Scholle, P., 1979. Constituents, Textures, Cements, and Porosities of Sandstones and Associated Rock. AAPG Memoir 82. 
Scholle, P.A., Ulmer-Scholle, D.S., 2003. A Color Guide to the Petrography of Carbonate Rocks: Grains, textures, porosity, diagenesis. AAPG Memoir 77, Tulsa, Oklahoma.

Schwarz, E., 2003. Análisis paleoambiental y estratigrafía secuencial de la Formación Mulichinco (Valanginiano), en el sector septentrional de la Provincia del Neuquén, Cuenca Neuquina, Argentina. Universidad Nacional de La Plata

Schwarz, E., Buatois, L.A., 2012. Substrate-controlled ichnofacies along a marine sequence boundary: The Intra-Valanginian Discontinuity in central Neuquén Basin (Argentina). Sedimentary Geology 277-278, 72-87.

Shinn, E.A., 1968. Practical significance of birdseye structures in carbonate rocks. Journal of Sedimentary Research 38, 215-223.

Silvestre, J. y Kraemer, P. 2005. Evolución tectosedimentaria de la Cordillera Principal en el sector surmendocino a los 35030'S. Faja Plegada de Malargüe. República Argentina, en: $6^{\circ}$ Congreso de Exploración y desarrollo de hidrocarburos. Mar del Plata.

Spalletti, L.A., 1995. Depósitos de tormenta en un frente deltaico. Jurásico medio de la cuenca neuquina, República Argentina. Revista Sociedad Geológica España 8, 261-272.

Spalletti, L.A., Parent, H., Veiga, G.D., Schwarz, E., 2012. Amonites y bioestratigrafía del Grupo Cuyo en la Sierra de Reyes (cuenca Neuquina central, Argentina) y su significado secuencial. Andean Geology 39, 464-481.

Stipanicic, P.N., 1951. Sobre la presencia del Oxfordense Superior en el Arroyo de la Manga (Provincia de Mendoza). Revista de la Asociación Geológica Argentina 6, 213-239.

Stipanicic, P.N., 1966. El Jurásico en Vega de La Veranada (Neuquén), el Oxfordense y el diastrofismo Divesiano (Agassiz-Yaila) en Argentina. Revista de la Asociación Geológica Argentina 20(4), 403-478.

Stipanicic, P.N., 1969 El avance en los conocimientos del Jurásico argentino a partir del esquema de Groeber. Revista de la Asociación Geológica Argentina 24 (4), 367-388.

Stipanicic, P.N., Rodrigo, F., 1970. El diastrofismo jurásico en Argentina y Chile, en: IV Jornadas Geológicas Argentinas, pp. 353-368.

Strasser, A., 1986. Ooids in Purbeck limestones (lowermost Cretaceous) of the Swiss and French Jura. Sedimentology 33, 711-727.

Suresh, N., Ghosh, S.K., Kumar, R., Sangode, S.J., 2004. Clay-mineral distribution patterns in late Neogene fluvial sediments of the Subathu sub-basin, central sector of Himalayan foreland basin: implications for provenance and climate. Sedimentary Geology 163, 265-278.

Swart, P.K., Burns, S.J., Leder J.J., 1991. Fractionation of the stable isotopes of oxygen and carbon in carbon-dioxide during reaction of calcite with phosphoric acid as a function of temperature and technique. Chemical Geology 52, 365374. 
Swift, D.J.P., Figueiredo Jr, A.G., Freeland, G.L., Oertel, G.F., 1983. Hummocky cross-stratification and megaripples: a geological double standard?. Journal of Sedimentary Research 53, 1295-1317.

Tarashchan, A.N., Waychunas, G., 1995. Interpretation of luminescence spectra in terms of band theory and crystal field theory. Sensitization and quenching, photoluminescence, radioluminescence, and cathodoluminescence, en: Marfunmin, A.S. (Ed.), Advanced Mineralogy 2, Methods and Instrumentations: Results and Recent Development. Springer-Verlag, Berlin, pp. 35-124.

Terry, R. D., Chlllngar, G. V., 1955: Summary of "Concerning some additional aids in studying sedimentary formations" by M S. Shvetsov. Journal Sedimentary Petrology 25 (3), 229-34.

Tomita, K., 1993. Synthesis of smectite from volcanic glass at low temperature. Clays and clay mineral 41, 655-661.

Tucker, M.E., Bathurst, R.G.C., 1990. Carbonate Diagenesis. Reprint series Volumen I of the International Association of Sedimentologists. Blackwell Science, Oxford.

Tucker, M.E., 1991. Sedimentary petrology. An introduction to the origin of sedimentary rocks, Second. ed. Blackwell Sci. Publ., London.

Tucker, M.E., 2001. Sedimentary Petrology, $3^{\circ}$ Edición. ed. Blackwell Science Oxford.

Tudhope, A.W., Scoffin, T.P., 1994. Growth and Structure of Fringing Reefs in a Muddy Environment, South Thailand. Journal of Sedimentary Research 64A, 752-764.

Turienzo, M. Dimieri, L., Ponce, F., 2005. Descripción e interpretación de las estructuras asociadas al alto de basamento del río Blanco, perfil Arroyo TordilloLos Toscales, Mendoza, en: $16^{\circ}$ Congreso Geológico Argentino. La Plata, pp. 47-52.

Turienzo, M. M., 2010. Structural style of the Malargüe fold-and-thrust belt at the Diamante River area $\left(34^{\circ} 30^{\prime}-34^{\circ} 50^{\prime} \mathrm{S}\right.$ ) and its linkage with the Cordillera Frontal, Andes of central Argentina. Journal of South American Earth Sciences 29(3), 537-556.

Uliana, M. a., Legarreta, L., 1993. Hydrocarbons habitat in a Triassic-Cretaceous sub-andean setting: Neuquén Basin, Argentina. Journal of Paleontology 16, 397-420.

Uliana, M. A., Arteaga, M. E., Legarreta, L., Cerdán, J. J., Peroni, G. O., 1995. Inversion structures and hydrocarbon occurrence in Argentina. Geological Society, London, Special Publications 88(1), 211-233.

Valencio, S.A., Ramos, A.M., Cagnoni, M.C., Panarello, H.O., Cabaleri, N.G., Armella, C., 2003. Isotope signal of the middle Jurassic carbonate ramp of Calabozo Formation, at Arroyo El Plomo, Mendoza, Argentina, en: IV South American Symposium on Isotope Geology. Salvador, Bahia, Brasil, pp. 409412. 
Varela, A.N., Gomez-Peral, L.E., Richiano, S., Poire, D.G., 2013. Distinguishing Similar Volcanic Source Areas From An Integrated Provenance Analysis: Implications for Foreland Andean Basins. Journal of Sedimentary Research 83, 258-276.

Védrine S., Strasser A., Hug W., 2007. Oncoid growth and distribution controlled by sea-level fluctuations and climate (Late Oxfordian, Swiss Jura Mountains). Facies 53, 535-552.

Veiga, G.D., 1998. Estratigrafia Secuencial en series continentales: aplicación a los depósitos de la Formación Challacó, Jurásico de la Cuenca Neuquina Austral (República Argentina). Revista Sociedad Geológica de España 11 (1-2), 95-109.

Veiga, G.D., Schwarz, E., Spalletti, L.A., Massaferro, J.L., 2013. Anatomy And Sequence Architecture of the Early Post-Rift In the Neuquen Basin (Argentina): A Response To Physiography and Relative Sea-Level Changes. Journal of Sedimentary Research 83, 746-765.

Vergani, G.D., 2005. Control estructural de la sedimentación Jurásica (Grupo Cuyo) en la Dorsal de Huincul, Cuenca Neuquina, Argentina. Modelo de falla lístrica rampa-plano, invertida. Boletín de Informaciones Petroleras 1, 32-44.

Vicente, J.C., 2005. Dynamic paleogeography of the Jurassic Andean Basin: pattern of transgression and localisation of main straits through the magmatic arc. Revista de la Asociación Geológica Argentina 60, 221-250.

Volkheimer, W., 1978. Descripción geológica de la hoja 27b, Cerro Sosneado, Provincia de Mendoza. Boletín del Servicio Geológico Nacional 151, 1-85.

Walker, R.G., 1983. Cardium Formation 3. Sedimentology and stratigraphy in the Garrington-Caroline area. Bulletin of Canadian Petroleum Geology 31, 213-230.

Walker, R.G., James, N.P., 1992. Facies models: response to sea level change. St. John's, Nfld. Geological Association of Canada.

Weaver, V., 1931. Paleotology of the Juraassic and Cretaceosu central Argentina. University of Washington. Memoir, pp. 469, Seattle.

Wilson, M.D., Pittman, E.D., 1977. Authigenic clays in sandstones: recognition and influence on reservoir properties and paleoenvironmental analysis. Journal of Sedimentary Research 47, 3-31.

Wilson, M.E.J., 2005. Development of equatorial delta-front patch reefs during the Neogene, Borneo. Journal of Sedimentary Research 75, 114-133.

Williams, P.F., Rust, B.R., 1969. The sedimentology of a braided river: Journal of Sedimentary Petrology 39, 646-679.

Wilson, J.E., 1975, Carbonate Facies in Geologic History: New York, SpringerVerlag, p.471.

Worden, R.H., Burley, S.D., 2003. Sandstone Diagenesis: The Evolution of Sand to Stone, Sandstone Diagenesis.

Wright, V.P., Burchette, T.P., 1996. Shallow-water carbonate environments, en: Reading, H.G. (Ed.), Sedimentary environments: processes, facies and 
stratigraphy. Blackwell Science, pp. 325-392.

Yrigoyen, M.R., 1972. Cordillera Principal. En: Leanza, A., ed., Geología Regional

Argentina. Academia Nacional de Ciencias. Córdoba, pp. 345-364.

Yrigoyen, M.R., 1991. Hydrocarbon resources from Argentina. En: World Petroleum Congress, Buenos Aires. Petrotecnia 13 Special Issue, 38-54.

Zapata, T., Brissón, I., Dzelalija, F., 1999. The role of the basement in the Andean fold and thrust belt of the Neuquén basin. En: McClay, K. (ed.): Thrust Tectonics 99, 122-124.

Zavala, C.A., 1993. Estratigrafía y análisis de facies de la Formación Lajas (Jurásico medio) en el sector suroccidental de la Cuenca Neuquina, provincia del Neuquén. República Argentina. Universidad Nacional del Sur. Bahía Blanca.

Zeller, M., Verwer, K., Eberli, G.P., Massaferro, J.L., Schwarz, E., Spalletti, L.A., 2015. Depositional controls on mixed carbonate-siliciclastic cycles and sequences on gently inclined shelf profiles. Sedimentology 62, pp. 2009-2037.

Zuffa, G.G., 1980. Hybrid arenites: their composition and classification. Journal of Sedimentary Petrology 50, 21-29.

Zuffa, G.G., 1985. Optical analyses of arenites: Influence of methodology on compositional results. En: Provenance of arenites: North Atlantic (Ed: Zuffa G.). Tretay Organization, Advanced Study Institute Series 148, 165-189. 


\section{AGRADECIMIENTOS}

- A mis viejos, Cecilia Ferrario y Juan Carlos Borya, por el apoyo y el amor incondicional, por enseñarme que nada es imposible que solo cuesta un poco más.

- A mi segunda mamá Silvia Ferrario, a mis hermanos del corazón Gerónimo Figueron, María José Figueron y María Belén Figueron, a mis abuelos y tíos, especialmente a Fernando Ferrario, por aportar su apoyo incondicional.

- A Ambar Peñalva mi princesa y sol de todos los días.

- A Santiago Barbero por compartir conmigo estos últimos años, por alentarme a seguir en este camino y a no bajar los brazos nunca.

- A mis amigas y hermanas del alma: Cecilia Arana, Daniela Arrastia, Victoria Bosc, Guillermina Prioretti, Florencia Rapacini, Luciana Monsalve y a los peques del grupo Joaco, Juana y Agustín, por su amor y cariño constante, por acompañarme en todo momento.

- A la Universidad Nacional de La Plata y a la Facultad de Ciencias Naturales y Museo por haberme formado como geóloga, por permitirme seguir creciendo día a día como profesional y docente.

- Al CONICET por haber financiado este proyecto de tesis doctoral.

- A Sergio Matheos y a Sol Raigemborn por haberme permitido desde estudiante iniciarme en el mundo de la ciencia, por las charlas, los debates y las buenas horas de trabajo juntos.

- A los directivos y personal del Centro de Investigaciones Geológicas (CIG) por haberme dado el lugar de trabajo.

- Al personal de los Laboratorios de Cortes Delgados, Geoquímica, Geomática y Molienda del CIG: Pablo, Daniel, las Claudias, Jorge, Marcos, Alfredo, Víctor por la ayuda que me brindaron durante estos años.

- A Nely, Mabel, Rita, Mercedes, Andrea y Oscar por los buenos momentos de mates y charlas.

- Al grupo de becarios del CIG, especialmente a mis amigos y compañeros de oficina: Nicolás Scivetti, Agustín Argüello, Luciano Zapata y Numa Sosa por 
todos los buenos momentos vividos, por hacer más amenas las horas de trabajo y escritura, por las charlas, los debates y la buena onda.

- A Daniela Cuccaro, Nicolás Scivetti, Mauro Mingo, Alejandro Gómez Dacal, Damián Gutiérrez y Aron Siccardi con los que tuve oportunidad de compartir largas horas de trabajo de campo en Malargüe, de reflexión, discusión y sobre todo de aprendizaje.

- A Leandro M. Pérez y Arón Siccardi por la ayuda brindada con la identificación de los macrofósiles y por los buenos momentos de debates.

- A Juan Pérez Panera, Diana Ronchi y Luciana Hiriart de Y-TEC por la ayuda brindada con la identificación de los micro y nanofósiles en este trabajo.

- A Sebastián Richiano y Arón Siccardi por la ayuda y el trabajo conjunto en la descripción e interpretación de las trazas fósiles en esta tesis.

- A la Cátedra de Geología Histórica: Carlos Cingolani, Héctor Leanza, Norberto Uriz, Andrea Bidone, Aron Siccardi, Leandro M. Pérez, Maximiliano Escalona, Jesica Omar, Micaela Chaumeil Rodríguez, Sofía Apcarián, Jonatán Arnold y Natalia Portillo por permitirme crecer como docente y por el aguante de todos estos años.

- A Jim Marshall y Steve Crowley de la University of Liverpool por transmitirme su pasión por la ciencia, por sus enseñanzas y su ayuda.

- A David S. Wray de la University of Greenwich por la ayuda brindada durante mi estadía.

- A mi familia de Liverpool: Ivan Scivetti, Covi Gonzalez, Waltraud Boxall, Alberto Elena de Leonardo y Jorge Rodríguez por hacerme sentir como en casa a miles de kilómetros de distancia, por las charlas interminables y las cenas entre amigos. Especialmente a Ivan Scivetti por los debates y consejos desde el otro lado del Atlántico.

- A LCV s.r.I por permitirme utilizar su equipamiento para mejorar la calidad de las microfotografías de esta tesis.

- A Elisa Gianatti por darme las herramientas para emprender con felicidad este largo viaje que es la vida.

- A mi abuela Chela y a mi hermano Gero que me cuidan y guían desde arriba, sea donde sea que estén lo logramos!!!!. 


\section{ANEXO I}

En este anexo se muestran todos los perfiles sedimentológicos relevados en las localidades seleccionadas dentro del área de estudio. Los mismos se presentan en dos paneles denominados ANEXO Ia y ANEXO Ib de $90 \times 100 \mathrm{~cm}$ el primero, y $29 \mathrm{x}$ $42 \mathrm{~cm}$ el segundo en formato papel. En formato digital ambos paneles se presentan en un archivo de extensión pdf separados de este documento.

EI ANEXO Ia contiene todas las secciones columnares relevadas en la zona norte del área de estudio distribuidas de NE a SW, mientras que el ANEXO Ib abarca los perfiles relevados en la zona sur ubicados de NW a SE (ver mapa de ubicación adjunto en el anexo). Los mismos fueron dibujados a escala 1:50, nivelados al techo de la sucesión terrígena-mixta en la zona de Malargüe y al tope de la Formación Tres Esquinas en la zona de Bardas Blancas. En la columna principal de cada uno de estos perfiles se representa la información litológica, acompañada por otra secundaria donde se registran las estructuras sedimentarias y el contenido fosilífero. Además, a la derecha de cada sección, en dos columnas adicionales, se exponen las muestras recolectadas en cada nivel y las facies reconocidas en este estudio, designadas por su código respectivo (ver referencias adjuntas en el anexo). 


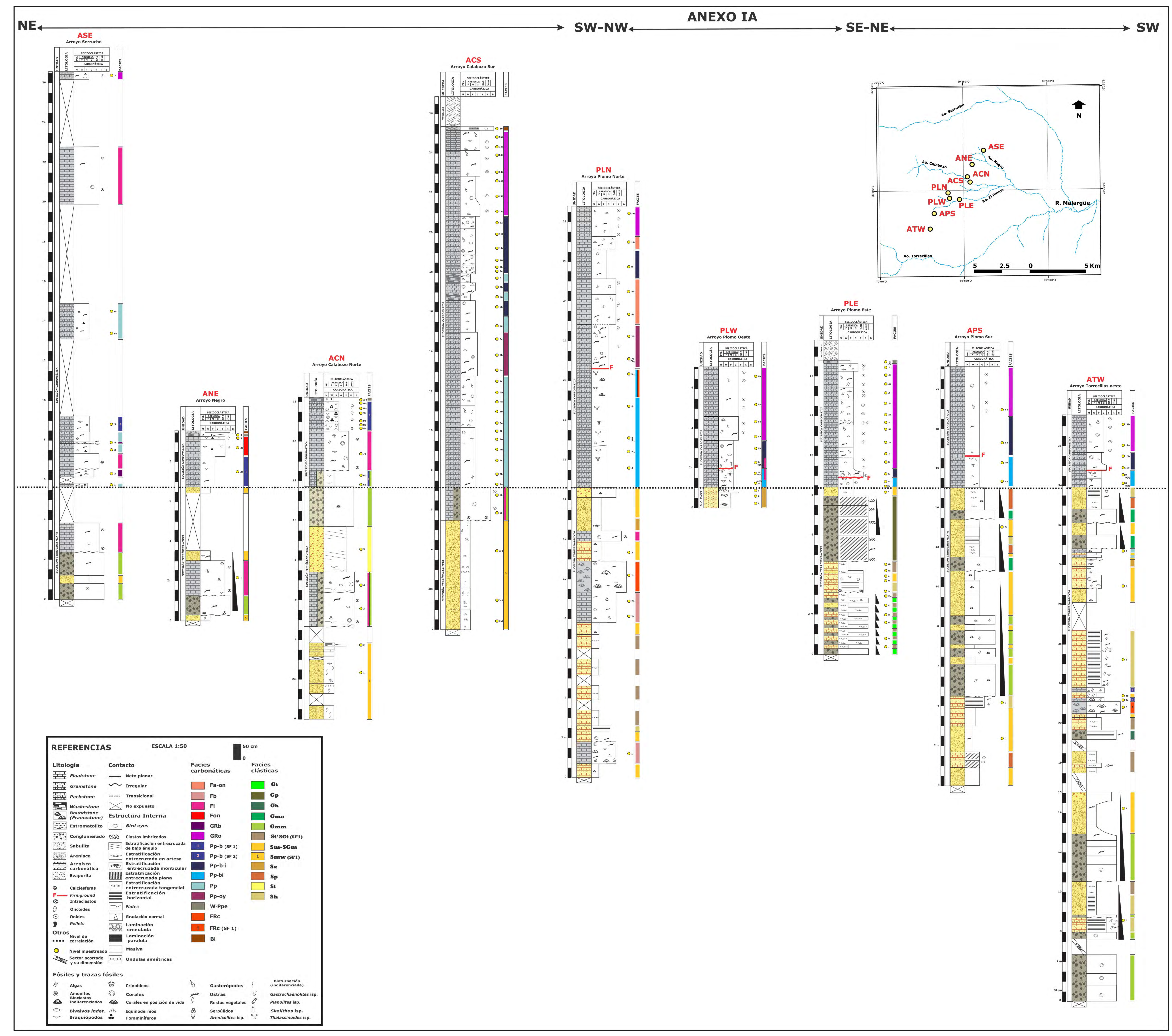




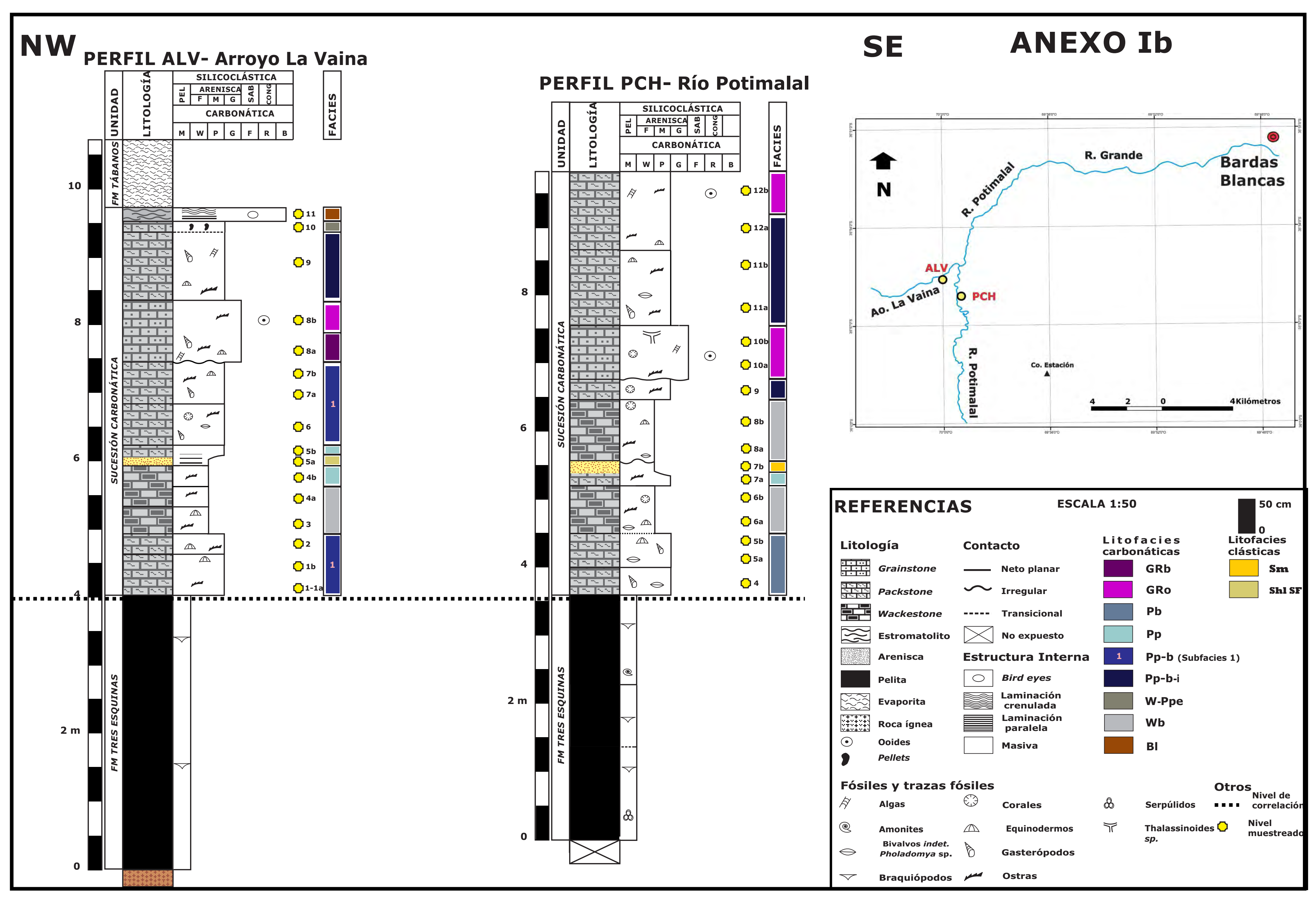




\section{ANEXO II}

En este anexo se incluye la información que constituye la base de datos de los resultados e interpretaciones que se encuentran en el texto. En el mismo se presenta una lista completa de las muestras recolectadas durante las actividades de campo y los análisis que se realizaron sobre ellas.

$\mathbf{N}^{\circ} \mathbf{M}$ : número de muestra. Las muestras están ordenadas de base a techo en cada uno de los perfiles. Existen casos en que la numeración de las muestras no es continua debido a que las mismas han sido recolectadas en diferentes campañas.

Descripción: caracterización básica del material recolectado. En el caso de las rocas se realiza una descripción elemental de la textura. Para la descripción del material fósil se describe el taxón (clase) presente.

Estudios realizados: P: corte delgado para petrografía óptica de polarización; D: determinaciones por conteo de puntos; C: corte delgado para petrografía de catodoluminiscencia; $\mathbf{M}$ : reconocimiento del contenido de microfósiles y nanofósiles; F: determinaciones taxónomicas; $\mathbf{T}$ : determinaciones icnotáxonomicas; $\mathbf{R}$ : análisis por difracción de rayos $\mathrm{X}$.

Otras abreviaturas: $\mathbf{i}$ :muestras tratadas que resultaron infertiles, $\mathbf{n}$ : muestras con contenido de nanofósiles; $\mathbf{r}$ : diagrama de roca total; a:diagrama de arcilla.

Muestras de la sucesión terrígena-mixta. Muestras de la sucesión carbonática

\begin{tabular}{|r|l|c|c|c|c|c|c|}
\hline $\mathbf{N}^{\circ} \mathbf{M}$ & Descripción & $\mathbf{P}$ & $\mathbf{C}$ & $\mathbf{M}$ & $\mathbf{F}$ & $\mathbf{T}$ & $\mathbf{R}$ \\
\hline ASE1 & Wackestone & $\mathrm{X}$ & & & & & $\mathrm{r}$ a \\
\hline ASE2 & Floatstone & $\mathrm{X}$ & $\mathrm{X}$ & & & & \\
\hline ASE3 & Packstone & $\mathrm{X}$ & $\mathrm{X}$ & $\mathrm{i}$ & & & $\mathrm{r}$ \\
\hline ASE4 & Floatstone & $\mathrm{X}$ & $\mathrm{X}$ & & & & \\
\hline ASE5 & Packstone & $\mathrm{X}$ & & & & & \\
\hline ASE6A & Packstone & $\mathrm{X}$ & $\mathrm{X}$ & $\mathrm{i}$ & & & \\
\hline ASE6B & Packstone & $\mathrm{X}$ & & & & & \\
\hline ASE7 & Grainstone & $\mathrm{X}$ & & $\mathrm{i}$ & & & \\
\hline
\end{tabular}

\begin{tabular}{|r|l|c|c|c|c|c|c|}
\hline N$^{\circ} \mathbf{M}$ & Descripción & P & C & M & F & T & R \\
\hline ANE1 & Floatstone & X & & & & & \\
\hline ANE1(f) & Bivalvo(ostra) & & & & X & & \\
\hline ANE2A & Packstone & $\mathrm{X}$ & $\mathrm{X}$ & & & & $\mathrm{r}$ \\
\hline ANE2B & Floatstone & $\mathrm{X}$ & & $\mathrm{i}$ & $\mathrm{X}$ & & \\
\hline ANE2B(f) & Braquiópodo & & & & $\mathrm{X}$ & & \\
\hline ANE3 & Floatstone & $\mathrm{X}$ & $\mathrm{X}$ & $\mathrm{n}$ & & & $\mathrm{r}$ \\
\hline ANE3(f) & Braquiópodo & & & & $\mathrm{X}$ & & \\
\hline ANE4 & Wack-Bound & $\mathrm{X}$ & & $\mathrm{i}$ & & & \\
\hline
\end{tabular}

\begin{tabular}{|l|l|c|c|c|c|c|c|}
\hline $\mathbf{N}^{\circ} \mathbf{M}$ & Descripción & $\mathbf{P}$ & $\mathbf{C}$ & $\mathbf{M}$ & $\mathbf{F}$ & $\mathbf{T}$ & $\mathbf{R}$ \\
\hline ACN1 & Arenisca & $\mathrm{X}$ & & & & & \\
\hline ACN2 & Arenisca & $\mathrm{X}$ & & & & & \\
\hline ACN4 & Floatstone & $\mathrm{X}$ & & & & & \\
\hline
\end{tabular}

\begin{tabular}{|l|l|l|l|l|l|l|l|}
\hline ACN5 & Arenisca & $\mathrm{D}$ & & & & & \\
\hline ACN6a & Packstone & $\mathrm{X}$ & & & & & $\mathrm{r}$ a \\
\hline ACN6(f) & Braquiópodo & & & & $\mathrm{X}$ & & \\
\hline ACN6B & Packstone & $\mathrm{X}$ & & & & & \\
\hline ACN7(f) & Bivalvo(ostra) & & & & $\mathrm{X}$ & & \\
\hline ACN7B & Floatstone & $\mathrm{X}$ & & & & & \\
\hline ACN8A & Packstone & $\mathrm{X}$ & $\mathrm{X}$ & & & & \\
\hline ACN8B & Packstone & $\mathrm{X}$ & $\mathrm{X}$ & & & & \\
\hline ACN9(f) & Braquiópodo & & & & $\mathrm{X}$ & & \\
\hline ACN9A & Packstone & $\mathrm{X}$ & & $\mathrm{I}$ & & & \\
\hline ACN9B & Packstone & $\mathrm{X}$ & & & & & $\mathrm{r}$ \\
\hline ACN9B(f) & Braquiópodo & & & & $\mathrm{X}$ & & \\
\hline ACN10A(f) & Braquiópodo & & & & $\mathrm{X}$ & & \\
\hline ACN10B & Packstone & $\mathrm{X}$ & & $\mathrm{i}$ & & & \\
\hline ACN10B(f) & Braquiópodo & & & & $\mathrm{X}$ & & \\
\hline ACN10C & Packstone & $\mathrm{X}$ & $\mathrm{X}$ & & & & \\
\hline ACN10D & Wackestone & $\mathrm{X}$ & & & & & \\
\hline
\end{tabular}




\begin{tabular}{|l|l|l|l|l|l|l|l|}
\hline ACS2(f) & Bivalvo(ostra) & & & & $\mathrm{X}$ & & \\
\hline ACS2A & Packstone & $\mathrm{X}$ & $\mathrm{X}$ & & & & \\
\hline ACS2B & Packstone & $\mathrm{X}$ & & & & & \\
\hline ACS2C & Packstone & $\mathrm{X}$ & $\mathrm{X}$ & & & & \\
\hline ACS2D & Packstone & $\mathrm{X}$ & & & & & \\
\hline ACS2E & Packstone & $\mathrm{X}$ & & & & & \\
\hline ACS2F & Packstone & $\mathrm{X}$ & & & & $\mathrm{r}$ \\
\hline ACS2G & Packstone & $\mathrm{X}$ & & & & & \\
\hline ACS2G(f) & Bivalvo(ostra) & & & & $\mathrm{X}$ & & \\
\hline ACS3A & Packstone & $\mathrm{X}$ & $\mathrm{X}$ & & & & \\
\hline ACS3B & Packstone & $\mathrm{X}$ & & & & & \\
\hline ACS4A & Packstone & $\mathrm{X}$ & & & & & \\
\hline ACS4B & Packstone & $\mathrm{X}$ & & & & & \\
\hline ACS4C & Packstone & $\mathrm{X}$ & & & & & $\mathrm{r}$ \\
\hline ACS4D(f) & Bivalvo(ostra) & & & & $\mathrm{X}$ & & \\
\hline ACS5(f) & Bivalvo(ostra) & & & & $\mathrm{X}$ & & \\
\hline ACS5A & Packstone & $\mathrm{X}$ & & & & & \\
\hline ACS5A(f) & Bivalvo(ostra) & & & & $\mathrm{X}$ & & \\
\hline ACS5B & Packstone & $\mathrm{X}$ & $\mathrm{X}$ & & & & \\
\hline ACS5C & Packstone & $\mathrm{X}$ & $\mathrm{X}$ & & & & \\
\hline ACS6A & Packstone & $\mathrm{X}$ & & & & & \\
\hline ACS6B & Packstone & $\mathrm{X}$ & $\mathrm{X}$ & & & \\
\hline ACS7A & Wackestone & $\mathrm{X}$ & & & & \\
\hline ACS7B & Packstone & $\mathrm{X}$ & $\mathrm{X}$ & & & \\
\hline ACS8 & Wackestone & $\mathrm{X}$ & $\mathrm{X}$ & $\mathrm{i}$ & & & $\mathrm{r}$ \\
\hline ACS9(f) & Bivalvo(ostra) & & & & $\mathrm{X}$ & & \\
\hline ACS9A & Packstone & $\mathrm{X}$ & & & & \\
\hline ACS9B & Packstone & $\mathrm{X}$ & & & & & \\
\hline ACS10 & Packstone & $\mathrm{X}$ & $\mathrm{X}$ & & & & \\
\hline ACS11A & Packstone & $\mathrm{X}$ & $\mathrm{X}$ & $\mathrm{i}$ & & & \\
\hline ACS11B & Packstone & $\mathrm{X}$ & & & & & \\
\hline ACS12 & Packstone & $\mathrm{X}$ & $\mathrm{X}$ & & & & \\
\hline ACS13A & Grainstone & $\mathrm{X}$ & & $\mathrm{i}$ & & & \\
\hline ACS13B & Packstone & $\mathrm{X}$ & $\mathrm{X}$ & & & & \\
\hline ACS13C & Packstone & $\mathrm{X}$ & & & & & \\
\hline ACS14A & Grainstone & $\mathrm{X}$ & $\mathrm{X}$ & & & & \\
\hline ACS14B & Grainstone & $\mathrm{X}$ & $\mathrm{X}$ & & & & \\
\hline ACS15A & Grainstone & $\mathrm{X}$ & $\mathrm{X}$ & & & & \\
\hline ACS15B & Grainstone & $\mathrm{X}$ & $\mathrm{X}$ & & & & \\
\hline ACS16 & Boundstone & $\mathrm{X}$ & & & & & \\
\hline
\end{tabular}

\begin{tabular}{|l|l|l|l|l|l|l|l|}
\hline PLN4(f) & Thalassinoides & & & & & $\mathrm{X}$ & \\
\hline PLN5 & Packstone & $\mathrm{X}$ & & & & & \\
\hline PLN5(f) & Thalassinoides & & & & & $\mathrm{X}$ & \\
\hline PLN6 & Packstone & $\mathrm{X}$ & & & & & \\
\hline PLN6(f) & Thalassinoides & & & & & $\mathrm{X}$ & \\
\hline PLN7A & Packstone & $\mathrm{X}$ & $\mathrm{X}$ & & & & \\
\hline PLN7A(f) & Bivalvo(ostra) & & & & $\mathrm{X}$ & & \\
\hline PLN7B & Packstone & $\mathrm{X}$ & $\mathrm{X}$ & & & & \\
\hline PLN8A & Floatstone & $\mathrm{X}$ & & & & & \\
\hline PLN8B & Floatstone & $\mathrm{X}$ & & & & & \\
\hline PLN9 & Packstone & $\mathrm{X}$ & $\mathrm{X}$ & & & & \\
\hline PLN10A & Floatstone & $\mathrm{X}$ & & & & & \\
\hline PLN10B & Grainstone & $\mathrm{X}$ & & & & & \\
\hline
\end{tabular}

\begin{tabular}{|l|l|c|c|c|c|c|c|}
\hline \multicolumn{1}{|c|}{$\mathbf{N}^{\circ} \mathbf{M}$} & Descripción & $\mathbf{P}$ & $\mathbf{C}$ & $\mathbf{M}$ & $\mathbf{F}$ & $\mathbf{T}$ & $\mathbf{R}$ \\
\hline PLW1 & Arenisca & $\mathrm{X}$ & & & & & $\mathrm{r}$ a \\
\hline PLW2 & Arenisca & $\mathrm{X}$ & & & & & \\
\hline PLW3 & Arenisca & $\mathrm{D}$ & & & & & \\
\hline PLW4A & Packstone & $\mathrm{X}$ & & & & & $\mathrm{r}$ a \\
\hline PLW4B(f) & Thalassinoides & $\mathrm{X}$ & & & & $\mathrm{X}$ & \\
\hline PLW4C & Packstone & $\mathrm{X}$ & & & & & \\
\hline PLW4C(f) & Thalassinoides & & & & & $\mathrm{X}$ & \\
\hline PLW5(f) & Thalassinoides & & & & & $\mathrm{X}$ & \\
\hline PLW5A & Packstone & $\mathrm{X}$ & $\mathrm{X}$ & & & & \\
\hline PLW5B & Packstone & $\mathrm{X}$ & & & & & \\
\hline PLW6A & Grainstone & $\mathrm{X}$ & & & & & \\
\hline PLW6B & Grainstone & $\mathrm{X}$ & $\mathrm{X}$ & & & & \\
\hline PLW7A & Grainstone & $\mathrm{X}$ & & & & & $\mathrm{r}$ \\
\hline PLW7B & Grainstone & $\mathrm{X}$ & $\mathrm{X}$ & & & & \\
\hline
\end{tabular}

\begin{tabular}{|l|l|c|c|c|c|c|c|}
\hline \multicolumn{1}{|c|}{$\mathbf{N}^{\circ} \mathbf{M}$} & Descripción & $\mathbf{P}$ & $\mathbf{C}$ & $\mathbf{M}$ & $\mathbf{F}$ & $\mathbf{T}$ & $\mathbf{R}$ \\
\hline PLE1A & Arenisca & $\mathrm{X}$ & & & & & \\
\hline PLE2A & Arenisca & $\mathrm{D}$ & & & & & \\
\hline PLE2B & Arenisca & $\mathrm{X}$ & & & & & \\
\hline PLE2C & Arenisca & $\mathrm{D}$ & & & & & \\
\hline PLE2D & Arenisca & $\mathrm{D}$ & & & & & $\mathrm{r}$ a \\
\hline PLE2F & Arenisca & $\mathrm{D}$ & & & & & \\
\hline PLE2G & Arenisca & $\mathrm{X}$ & & & & & \\
\hline PLE3A & Arenisca & $\mathrm{X}$ & & & & & \\
\hline PLE3B & Arenisca & $\mathrm{D}$ & & & & & \\
\hline PLE3C & Arenisca & $\mathrm{X}$ & & & & & \\
\hline PLE4A & Arenisca & $\mathrm{D}$ & & & & & \\
\hline PLE4B & Arenisca & $\mathrm{X}$ & & & & & $\mathrm{r}$ a \\
\hline PLE7 & Vaque & $\mathrm{X}$ & & & & & \\
\hline PLE8(f) & Thalassinoides & $\mathrm{X}$ & & & & & \\
\hline PLE8A & Packstone & $\mathrm{X}$ & $\mathrm{X}$ & & & & \\
\hline PLE8B & Packstone & $\mathrm{X}$ & $\mathrm{X}$ & & & & $\mathrm{r}$ \\
\hline PLE9A & Packstone & $\mathrm{X}$ & $\mathrm{X}$ & & & & \\
\hline PLE9B & Grainstone & $\mathrm{X}$ & & & & & \\
\hline PLE10 & Packstone & $\mathrm{X}$ & $\mathrm{X}$ & & & & \\
\hline
\end{tabular}

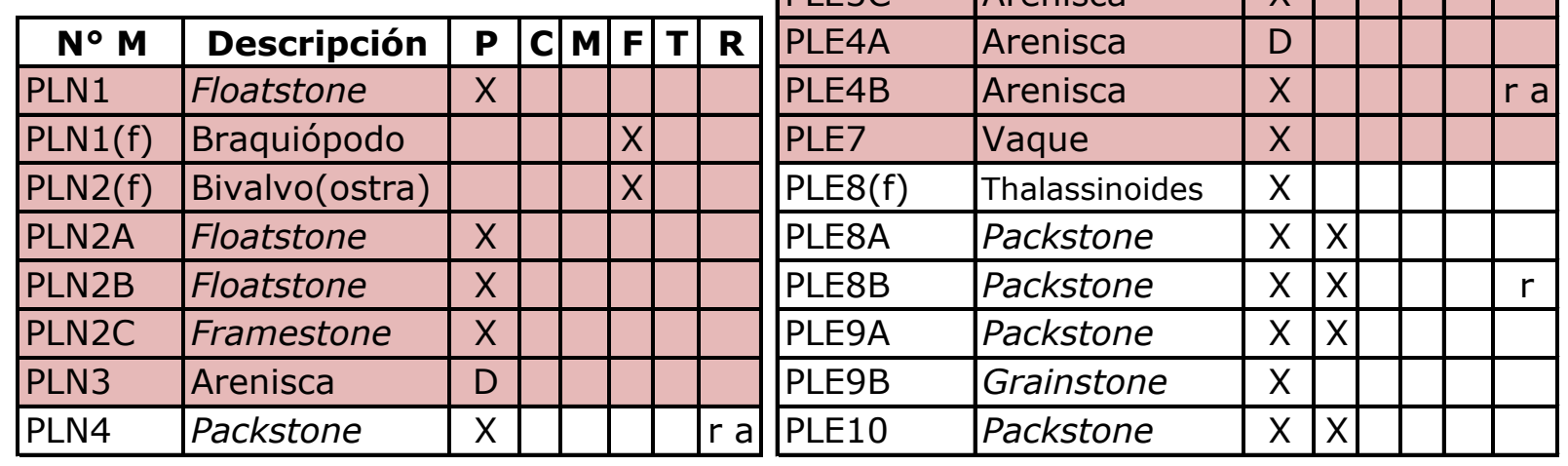




\begin{tabular}{|l|l|c|c|c|c|c|c|}
\hline PLE11A & Packstone & $\mathrm{X}$ & $\mathrm{X}$ & & & & \\
\hline PLE11B & Packstone & $\mathrm{X}$ & & & & & \\
\hline PLE12 & Packstone & $\mathrm{X}$ & & & & & \\
\hline PLE13A & Packstone & $\mathrm{X}$ & $\mathrm{X}$ & & & & \\
\hline PLE13B & Packstone & $\mathrm{X}$ & & & & & \\
\hline PLE14 & Packstone & $\mathrm{X}$ & & & & & $\mathrm{r}$ \\
\hline PLE15A & Packstone & $\mathrm{X}$ & $\mathrm{X}$ & & & & \\
\hline PLE15B & Packstone & $\mathrm{X}$ & & & & & \\
\hline PLE16 & Grainstone & $\mathrm{X}$ & $\mathrm{X}$ & & & & \\
\hline PLE17B & Packstone & $\mathrm{X}$ & & & & & \\
\hline PLE17B & Wackstone & $\mathrm{X}$ & $\mathrm{X}$ & $\mathrm{i}$ & & & \\
\hline
\end{tabular}

\begin{tabular}{|l|l|l|l|l|l|l|l|}
\hline \multicolumn{1}{|c|}{$\mathbf{N}^{\circ} \mathbf{M}$} & Descripción & $\mathbf{P}$ & $\mathbf{C}$ & $\mathbf{M}$ & $\mathbf{F}$ & $\mathbf{T}$ & $\mathbf{R}$ \\
\hline $\mathrm{PCH} 4$ & Packstone & $\mathrm{X}$ & $\mathrm{X}$ & & & & \\
\hline $\mathrm{PCH} 4(\mathrm{f})$ & Bivalvo & & & & $\mathrm{X}$ & & \\
\hline $\mathrm{PCH} 5 \mathrm{~A}$ & Wackestone & $\mathrm{X}$ & & & & & \\
\hline $\mathrm{PCH} 5 \mathrm{~B}$ & Packstone & $\mathrm{X}$ & & & & & \\
\hline $\mathrm{PCH} 6(\mathrm{f})$ & Bivalvo(ostra) & & & & $\mathrm{X}$ & & \\
\hline $\mathrm{PCH} 6 \mathrm{~A}$ & Wackestone & $\mathrm{X}$ & & & & & $\mathrm{r}$ \\
\hline $\mathrm{PCH} 6 \mathrm{~B}$ & Wackestone & $\mathrm{X}$ & & & & & \\
\hline $\mathrm{PCH7A}$ & Packstone & $\mathrm{X}$ & & & & & \\
\hline $\mathrm{PCH} 7 \mathrm{~B}$ & Arenisca & $\mathrm{X}$ & & & & & \\
\hline $\mathrm{PCH} 8(\mathrm{f})$ & Bivalvo(ostra) & & & & $\mathrm{X}$ & & \\
\hline $\mathrm{PCH} 8 \mathrm{~A}$ & Wackestone & $\mathrm{X}$ & & & & & \\
\hline $\mathrm{PCH} 8 \mathrm{~B}$ & Wackestone & $\mathrm{X}$ & & & & & \\
\hline $\mathrm{PCH} 9$ & Packstone & $\mathrm{X}$ & & & & & \\
\hline $\mathrm{PCH} 10(\mathrm{f})$ & Bivalvo(ostra) & & & & $\mathrm{X}$ & & \\
\hline $\mathrm{PCH} 10(\mathrm{f})$ & Thalassinoides & $\mathrm{X}$ & & & & & \\
\hline $\mathrm{PCH} 10 \mathrm{~A}$ & Grainstone & $\mathrm{X}$ & & & & & \\
\hline $\mathrm{PCH} 10 \mathrm{~B}$ & Grainstone & $\mathrm{X}$ & $\mathrm{X}$ & & & & \\
\hline $\mathrm{PCH} 11 \mathrm{~A}$ & Packstone & $\mathrm{X}$ & & & & & \\
\hline $\mathrm{PCH} 11 \mathrm{~B}$ & Grainstone & $\mathrm{X}$ & $\mathrm{X}$ & & & & \\
\hline $\mathrm{PCH} 12 \mathrm{~A}$ & Packstone & $\mathrm{X}$ & & & & & $\mathrm{r}$ \\
\hline $\mathrm{PCH} 12 \mathrm{~B}$ & Packstone & $\mathrm{X}$ & & & & & \\
\hline
\end{tabular}

\begin{tabular}{|l|l|c|c|c|c|c|c|}
\hline \multicolumn{1}{|c|}{$\mathbf{N}^{\circ} \mathbf{M}$} & Descripción & $\mathbf{P}$ & $\mathbf{C}$ & $\mathbf{M}$ & $\mathbf{F}$ & $\mathbf{T}$ & $\mathbf{R}$ \\
\hline ATW1 & Arenisca & $\mathrm{D}$ & & & & & \\
\hline ATW2 & Arenisca & $\mathrm{X}$ & & & & & $\mathrm{r}$ a \\
\hline ATW3 & Framestone & $\mathrm{X}$ & & & & & \\
\hline ATW3(f) & Braquiópodo & & & & & $\mathrm{X}$ & \\
\hline ATW4A & Packstone & $\mathrm{X}$ & & & & & \\
\hline ATW4B & Arenisca & $\mathrm{X}$ & & & & & \\
\hline ATW5 & Arenisca & $\mathrm{X}$ & & & & & \\
\hline ATW6 & Arenisca & $\mathrm{D}$ & & & & & \\
\hline ATW7 & Packstone & $\mathrm{X}$ & & & & & \\
\hline ATW8 & Packstone & $\mathrm{X}$ & & & & & $\mathrm{r}$ \\
\hline ATW8(f) & Thalassinoides & $\mathrm{X}$ & & & & $\mathrm{X}$ & \\
\hline ATW9 & Packstone & $\mathrm{X}$ & $\mathrm{X}$ & & & & \\
\hline ATW9(f) & Thalassinoides & & & & & $\mathrm{X}$ & \\
\hline ATW10A & Packstone & $\mathrm{X}$ & & & & & \\
\hline ATW10B & Packstone & $\mathrm{X}$ & $\mathrm{X}$ & & & & \\
\hline ATW11A & Packstone & $\mathrm{X}$ & & & & & \\
\hline ATW11B & Packstone & $\mathrm{X}$ & $\mathrm{X}$ & & & & \\
\hline
\end{tabular}

\begin{tabular}{|l|l|c|c|c|c|c|c|}
\hline \multicolumn{1}{|c|}{$\mathbf{N}^{\circ} \mathbf{M}$} & Descripción & $\mathbf{P}$ & $\mathbf{C}$ & $\mathbf{M}$ & $\mathbf{F}$ & $\mathbf{T}$ & $\mathbf{R}$ \\
\hline ALV1 & Wackstone & $\mathrm{X}$ & & $\mathrm{i}$ & & & $\mathrm{r}$ \\
\hline ALV1A & Packstone & $\mathrm{X}$ & & & & & \\
\hline ALV1B & Packstone & $\mathrm{X}$ & & & & & \\
\hline ALV2 & Packstone & $\mathrm{X}$ & & $\mathrm{i}$ & & & \\
\hline ALV3 & Wackstone & $\mathrm{X}$ & & & & & \\
\hline ALV4A & Wackstone & $\mathrm{X}$ & & & & & \\
\hline ALV4B & Wackstone & $\mathrm{X}$ & & & & & $\mathrm{r}$ a \\
\hline ALV5A & Arenisca & $\mathrm{D}$ & & & & & \\
\hline ALV5B & Packstone & $\mathrm{X}$ & & & & & \\
\hline ALV6 & Packstone & $\mathrm{X}$ & & & & & \\
\hline ALV6(f) & Bivalvo(ostra) & & & & $\mathrm{X}$ & & \\
\hline ALV7A & Wackstone & $\mathrm{X}$ & & $\mathrm{i}$ & & & \\
\hline ALV7B & Wackstone & $\mathrm{X}$ & & & & & \\
\hline ALV8A & Grainstone & $\mathrm{X}$ & $\mathrm{X}$ & & & & \\
\hline ALV8B & Grainstone & $\mathrm{X}$ & & & & & \\
\hline ALV9 & Packstone & $\mathrm{X}$ & $\mathrm{X}$ & & & & \\
\hline ALV10 & Packstone & $\mathrm{X}$ & & & & & $\mathrm{r}$ \\
\hline ALV11 & Boundstone & $\mathrm{X}$ & $\mathrm{X}$ & & & & \\
\hline
\end{tabular}




\section{ANEXO III}

En el anexo III se muestran todos los taxones identificados dentro de este trabajo de tesis doctoral, tanto en la sucesión carbonática como en su contraparte terrígena-mixta. Los mismos fueron clasificados de acuerdo a los criterios utilizados en los volúmenes del Treatise on Invertebrate Paleontology publicados por la Geological Society of America y la University of Kansas, y la clasificación taxonómica propuesta por Ruggiero et al.(2015). Además, se consideró el International Code of Zoological Nomenclature (ICZN) (ver, http://iczn.org/code).

Dentro del apartado IIIa se distinguen los taxones identificados dentro de las facies definidas en este trabajo y su forma de preservación. En las primeras cuatro columnas se muestran las categorías reino, phyllum, clase y subclase/orden/familia en las que fueron agrupados las taxones, representados en la quinta columna. En el mismo los reinos reconocidos se exponen a través de un patrón cromático donde el color azul se corresponde con Eubacteria, amarillo con Chromistas, verde con Plantae y rojo con Animalia. Por su parte, los phyllum se exponen en negrita y las ${ }^{1}$ subclase $/{ }^{2}$ orden $/{ }^{3}$ familia con un superíndice según su categoría. Por otra parte, a la derecha de cada taxa, se muestra en dos columnas contiguas la escala de reconocimiento macroscópica (R-Ma) y/o microscópica (R-Mi) de los organismos. En un apartado colindante, se identifican los taxones presentes dentro de las facies definidas en este trabajo según su forma de preservación, como individuos completos (IC) y/o fragmentos $(F)$ y/o moldes $(M)$.

Por su parte, en el apartado IIIb se exponen los taxones identificados dentro de cada una de las asociaciones de facies marinas carbonáticas y clásticas reconocidas en esta trabajo. En las primeras dos columnas se muestran las categorías reino y phyllum (expuestas según el patrón cromático del ANEXO IIIa) en las que fueron agrupados las taxones, representados en la tercera columna. Por otro lado, a la derecha de cada taxa se muestra su frecuencia relativa de aparición dentro de las sucesiones carbonáticas (Frec. SC) y terrígena mixta (Frec. ST-M), respectivamente. En este caso se identifica de 
forma semicuantitativa una frecuencia relativa de aparición de los taxones baja $(x)$, moderada ( $x x)$ y abundante ( $x x x)$. Para ello se considera en cuantas secciones columnares se presenta el taxón y en cuantas asociaciones de facies se encuentra. 

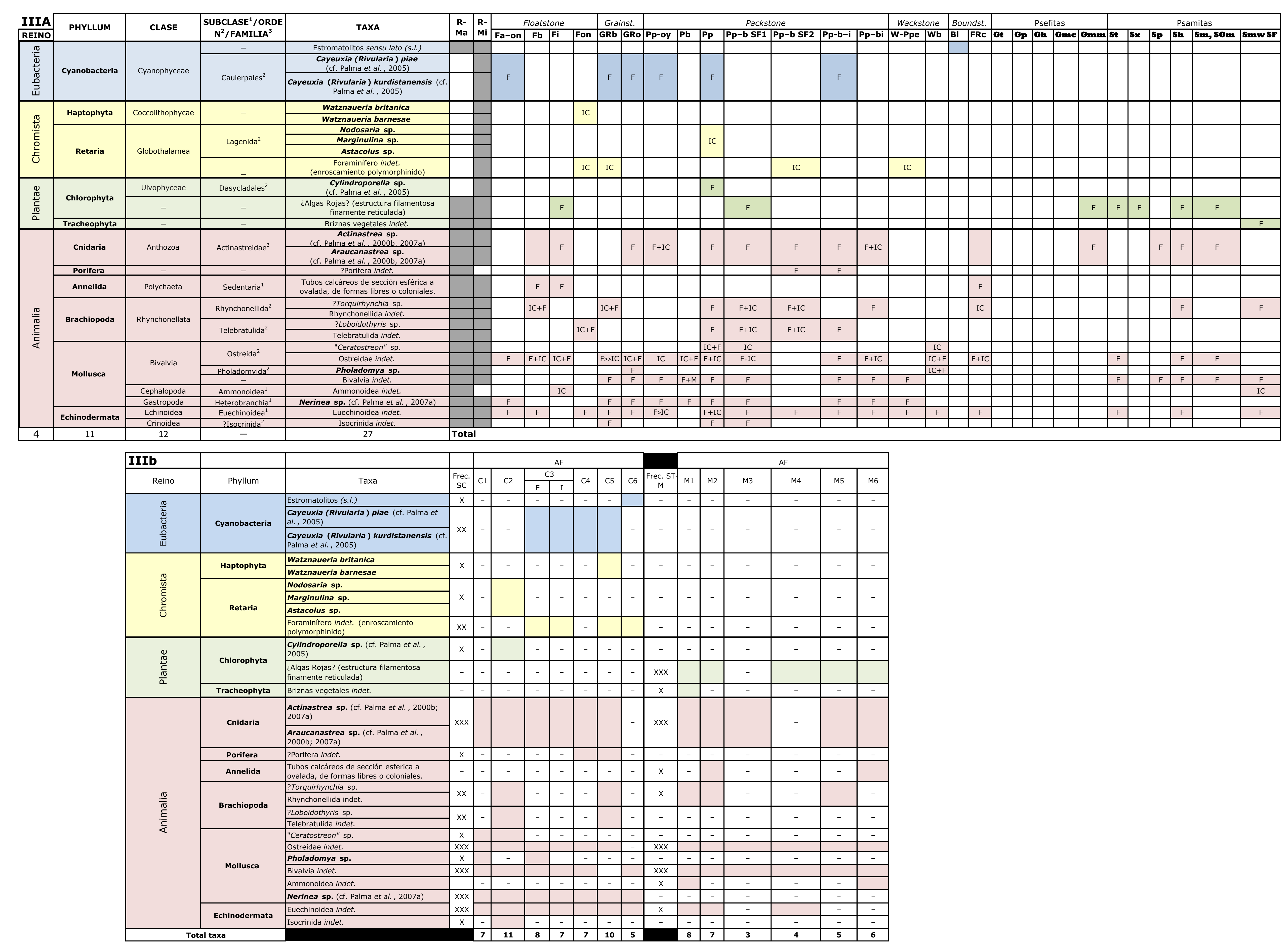


\section{ANEXO IV}

En este anexo se presentan todos los perfiles sedimentológicos relevados en las localidades seleccionadas dentro del área de estudio, graficados de acuerdo a las litofacies presentes en cada uno de ellos. Los mismos se muestran en un panel denominado ANEXO IV de alrededor de $59 \times 42 \mathrm{~cm}$ en formato papel, dividido en un sector $a$ y $b$. No obstante, en formato digital este panel se presenta en un archivo de extensión pdf separado de este documento.

EI ANEXO IVa contiene todas las secciones columnares relevadas en la zona norte del área de estudio distribuidas de NE a SW, mientras que el ANEXO IVb presenta los perfiles sedimentológicos relevados en la zona sur ubicados de NW a SE (ver mapa de ubicación adjunto en el anexo). Los mismos fueron dibujados a escala $1: 100$, nivelados al techo de la sucesión mixta-terrígena en la zona de Malargüe y al tope de la Formación Tres Esquinas en la zona de Bardas Blancas. En la columna principal de cada perfil sedimentológicos se representan las facies reconocidas en este estudio designadas con su código respectivo (ver referencias adjuntas en el anexo). Además, agrupando a las facies se presentan bandas de diferentes coloraciones que representan las asociaciones de facies identificadas en este trabajo, designadas con su código respectivo (ver referencias adjuntas en el anexo). 


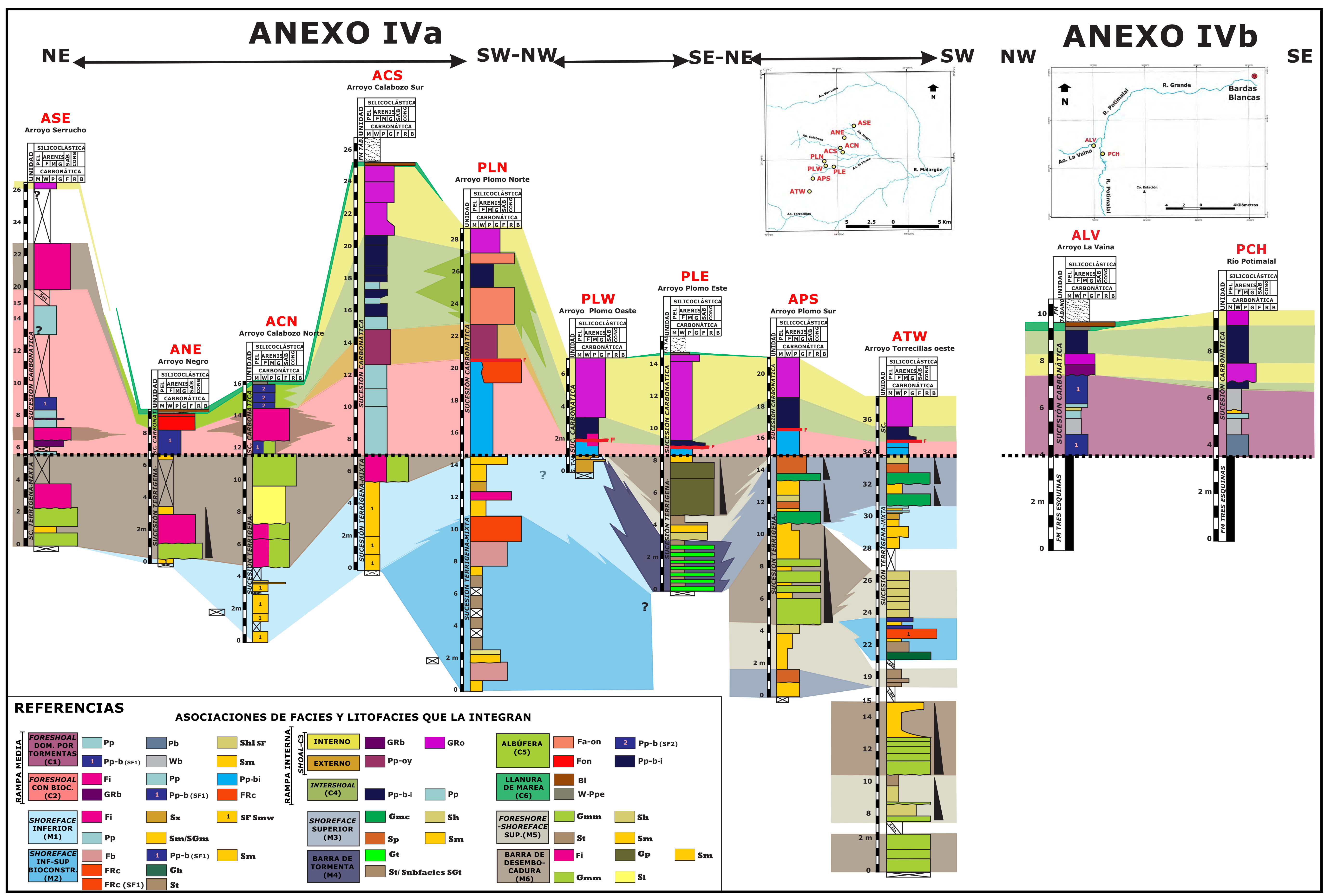

